\title{
The Characteristics of the Waiwhetu Artesian Aquifer beneath Wellington Harbour including the Spatial Distribution and Causes of Submarine Spring Discharge
}

\author{
By \\ Steven James Harding
}

A thesis

submitted to Victoria University of Wellington as partial fulfillment of the requirements for the degree of Master of Science (Honours) in Physical Geography

August 2000

VICTORIA UNIVERSITY OF WELLINGTON

Te Whare Wananga o te Upoko o te Ika a Maui

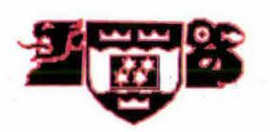


VICTORIA UNIVERSITY OF WELLINGTON 


\section{Frontispiece}

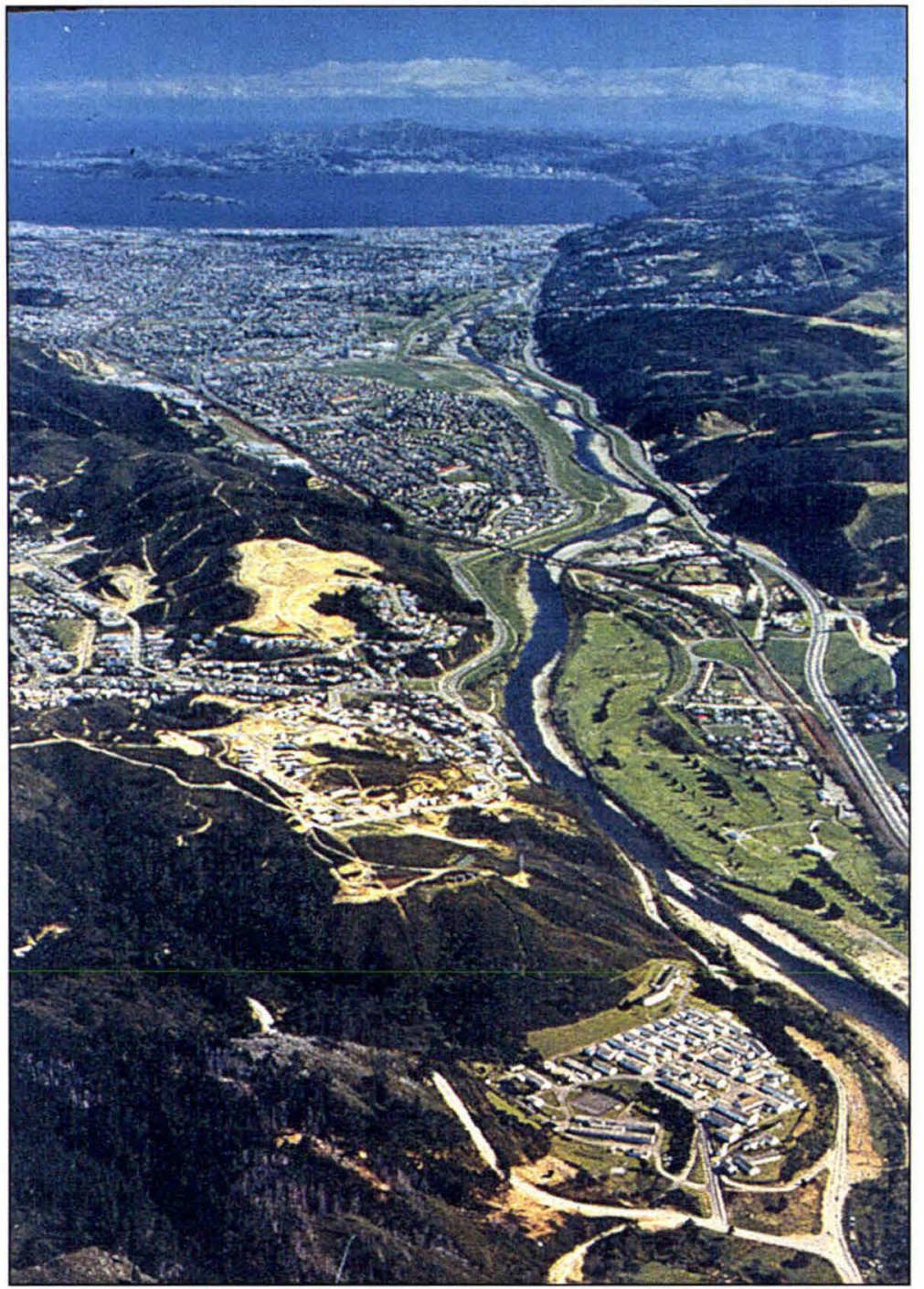

Looking south down the Lower Hutt Valley from Taita Gorge with Wellington Harbour in the distance.

“...But some rivers so hate the sea that they actually flow underneath the bottom of it..." (Quote from "Natural History" by Pliny the elder, AD 77) 


\begin{abstract}
This thesis is a study of the sub-harbour Waiwhetu Artesian Aquifer, and in particular the nature and characteristics of artesian leakage from submarine springs. This aquifer is a sheet of gravel and other coarse sediments which continues from the Lower Hutt Valley and extends beneath Wellington Harbour where it varies in thickness from approximately $70 \mathrm{~m}$ against the Wellington Fault scarp to just over $20 \mathrm{~m}$ thick against the eastern harbour margin. The water it contains is a valuable resource - supplying approximately one third of Wellington's municipal water consumption.
\end{abstract}

At present, there are plans to utilise this artesian water source to a greater extent in the future, to support a greater burden of the region's water requirements. However concerns over possible salt-water intrusion and contamination of the aquifer led to an interest in developing a better understanding of the characteristics of this artesian system, particularly beneath the harbour floor.

Harbour floor depressions were selected as likely sources of artesian water leakage based on the presumption that they had been formed by the action of leaking artesian water from beneath. Eleven depression 'zones' were investigated by recording the salinity of the water within the depressions using a portable conductivity/temperature meter. SCUBA diver's observations and bathymetric mapping revealed that depressions ranged in width from $53 \mathrm{~m}$ to $369 \mathrm{~m}$ (at the harbour floor) and $12 \mathrm{~m}$ to $69 \mathrm{~m}$ (at the depression base), with depths ranging from $13.3 \mathrm{~m}$ to $31.3 \mathrm{~m}$ below sea level.

Only a few depressions were found to be actively discharging significant amounts of artesian water. SCUBA diver investigations found this leakage to be typically concentrated at a number of small and discrete spring 'vents' located on the base of the active depression. Typical salinities recorded ranged from $28-33$ ppt within a few centimetres of the discharge vents. Deployment of an S4 current meter in two depressions showed that spring vent discharges vary with the pattern of abstraction from the pumping stations in the Lower Hutt Valley and as a consequence of the tidal cycle. High tides generate a greater load on the underlying aquifer, which in turn compresses the aquifer structure to a greater extent than at low tides, thus 'squeezing' out more water.

Almost all of the recorded leakage was found to occur from a cluster of submarine springs within one of the depression zones, roughly 1100 metres from the Hutt River mouth. One other notable area of leakage was found close to Seaview Wharf. No significant leakage was observed or recorded from the two deep depressions south of Somes Island, which had previously been considered to be the major outlet of artesian leakage in the harbour. 
Lower than normal salinity values were also recorded in the harbour entrance. In this region the aquiclude is hypothesised to peter out, allowing artesian water to escape from the aquifer through a large area of the seabed in the form of widespread leakage as opposed to the concentrated, or discrete, form associated with spring vent discharge.

Seismic profiles were used to map the extent of the sub-harbour Waiwhetu Artesian Aquifer and its upper confining aquiclude, the Petone Marine Beds. This work showed that the aquifer gravels extend across the entire harbour area. However, the water-bearing capacity of these deposits was found to be inconsistent. Preferential pathways, present as paleochannels (relic river channels), can be mapped within the aquifer. They concentrate the flow of groundwater through the aquifer and as such supply the submarine spring regions with much higher rates of water flow than the inter-paleochannel areas.

The harbour floor depressions are thought to have formed as a consequence of the deformation of aquifer and aquiclude deposits during intense shaking associated with earthquakes leading to the removal of portions of the confining aquiclude. This typically occurs from a combination of raised piezometric pressures as a result of consolidation of the aquifer material during shaking, and from failure of the aquiclude by liquefaction. This rupture of the aquiclude results in the release of large volumes of artesian water through the aquiclude and to the sea. As this flow of water moves upward through the aquiclude, it erodes and transports away the fine sediment that forms this member. The features left behind are the characteristic harbour floor depressions we associate with submarine spring discharge.

The abstraction of water from the Waiwhetu Artesian Aquifer (for the Wellington municipal water supply) lowers the piezometric pressure within the aquifer close to the abstraction zone. As such, the relocation of the abstraction focus (during 1980) to three kilometres inland from Petone Foreshore has greatly improved the 'health' of the subharbour aquifer and has similarly reduced the threat of salt-water intrusion.

Data gathered during this study implies that while the two deep depressions south of Somes Island are unlikely to be a threat with regard to salt-water intrusion, the cluster of depressions off the Hutt River mouth could be a site of salt-water entry if piezometric pressures in the aquifer beneath them dropped low enough. Spring discharge velocities collected over one spring vent indicate that the presently set minimum piezometric Petone Foreshore level (below which abstraction must cease) needs to be revised. 


\section{Acknowledgements}

I have a lot of people to thank for helping me with this research. I apologise to those whom I may have inadvertently forgotten.

Firstly I would like to thank the Frances Henrietta Muter Charitable Trust for financial assistance at the onset of my research. Similarly, a big thanks goes out to the Wellington Regional Council (WRC) and in particular to Murray Kennedy and Andrew Samuel of the Water Resources Group, for arranging financial assistance during the latter stages of the research. Without their assistance, this thesis would not have been completed. Also appreciated was the access I was allowed to the WRC hydrological database - thanks to Mike Ede (formerly of the WRC) for promptly supplying me with piezometric data when requested. Thanks also to Brydon Hughes (former groundwater hydrologist at the WRC) for the discussions of various problems I encountered. I would like to make a special mention of Andrew Samuel, who provided much useful information along the way as well as doing a great job in checking my facts and figures in Chapter One, and putting me right on a number of points.

My supervisors - Prof. Peter Barrett and James Goff both deserve my thanks, particularly for keeping me motivated when $I$ had run out of energy and for the much appreciated words of encouragement (thanks Peter). Thanks also to Rodney Grapes for stepping in while Peter was overseas.

A big thanks goes out to the staff at the Island Bay Marine Lab, especially Robert Williamson for his unparalleled enthusiasm and willingness to take to the water with me, both as boat master and as diving buddy (mostly in absolutely hideous diving conditions). You're a good keen man Robert!

Grant Norder and Ian Patience, boat masters with the Wellington Regional Council, also deserve many thanks for time spent taking me out to various parts of the harbour in the council boat (but hey - it got them out of the office!). Thanks also to my various one-off diving buddies (Nick, Hamish, Bronwyn, Mike, Tim etc) who came out once and then vowed never to go again (I don't blame them). Cheers guys. Thanks also to Alan for letting me use his boat when the WRC or Marine Lab boats were not available.

Thanks to all the staff and post-grad students of the Earth Sciences Department for making the last few years' loads of fun (mostly). Special mention goes to my good mate Paul Soldera who spent endless hours with me testing one methodology after another in the freezing cold at the Overseas Passenger Terminal. Thanks also for putting up with me in our shared office in the Geography Department for a couple of years, as well as letting me win at pool now and again. Thanks to Dennis and Mike of the (now defunct) Mechanical Workshop at VUW for helping me out with construction of my various wacky ideas for field equipment, and for always pretending to be happy to see me. Thanks also to the interloan team at the VUW library for somehow finding me all of my ludicrously obscure interloan requests.

Mark Greaves deserves a word of thanks for gladly ridiculing himself at the Kilbirnie Aquatic Centre helping me record the flow from the jets at the bottom of the pool for current meter calibration tests and for generally being a good mate. Jarrod and Laurilee, apart from being great friends, housed me for many weeks when I was in-between places. Thank you so much...

Lastly, but most importantly, thanks to my family (Ann, Vernon, Caroline, James and Olivia) and the many good friends I made during the time I spent at VUW for their support over the years of my life that this thesis consumed. 


\section{Contents}

Frontispiece ___ ii

Abstract ___ iii

Acknowledgements ______________

Table of Contents___ vi

List of Figures ___ ix

List of Tables ___ $x i$

Chapter One _______________

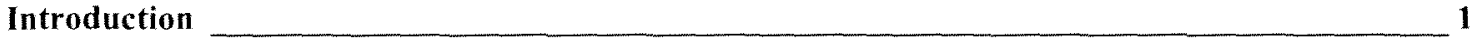

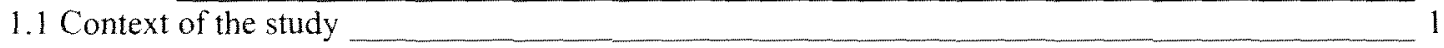

1.2 Groundwater use in the Wellington area 2

$1.3 \mathrm{Aims}$

Chapter Two ___ 6

Basic Groundwater Concepts ___ 6

2.1 Introduction ___ 6

2.2 Unconfined aquifers ________ 7

2.3 Confined aquifers _________ 7

$\begin{array}{lr}\text { Chapter Three } & 10\end{array}$

Groundwater Discharge to the Marine Environment $\quad 10$

3.1 Introduction 10

3.2 Types of submarine groundwater discharge ___ 11

3.2.1 Discharge from unconfined aquifers _ 11

3.2.2 Discharge from confined aquifers 11

3.3 Submarine springs and their recognition ______ 12

Chapter Four $\quad 16$

Nature of the Study Area___ 16

4.1 Location and physiography___ 16

4.2 Tidal flow patterns ___ 17

4.3 Tidal flow rates___ 17

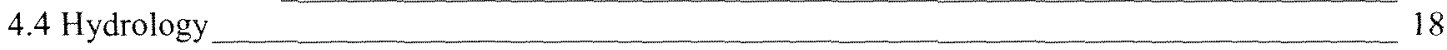

Chapter Five _ـ_ 20

Geological Setting _ 20

5.1 Introduction 20

$\begin{array}{ll}5.2 \text { Tectonic setting } & 20\end{array}$

5.3 Stratigraphy __ 24

5.4 Sedimentation history ______ 28

5.5 Present-day sedimentation regime ___ 31 

33

Methodology and Techniques ___ 33

6.1 Introduction $\quad 33$

6.2 Research assumptions $\quad 33$

6.3 Results from reconnaissance fieldwork 36

6.4 Main data collection 38

6.5 Field Instrumentation ____ 40

The S4 Current Meter $\quad 40$

The conductivity/temperature meter $\quad 41$

The echosounder 441

The GPS unit 42

Bathymetric data___ 42

6.6 Recording the spring flow______________ 43

6.7 Mapping the bathymetry of selected sites within Wellington Harbour___ 44

6.7.1 Introduction _ 44

6.7.2 Data collection__ 46

6.7.3 Data transformation to chart datum ___ 46

Chapter Seven __ 48

Hydraulic Characteristics of Aquifers __ 48

7.1 Introduction $\quad 48$

7.2 Hydraulic characteristics of unconsolidated rock aquifers _ 49

7.2.1 Introduction _- 49

7.2.2 Porosity, specific yield and storativity ___ 51

$\begin{array}{ll}7.2 .3 \text { Permeability, hydraulic conductivity and transmissivity } & 52\end{array}$

7.3 Hydraulic characteristics of the Waiwhetu Artesian Aquifer 53

7.3.1 Introduction _ 53

7.3.2 Transmissivity and storativity values___ 54

7.4 Groundwater balance ___ 56

7.4.1 Introduction ___ 56

7.4.2 River recharge 56

$\begin{array}{ll}7.4 .3 \text { Rainfall recharge } & 60\end{array}$

7.4.4 Recharge via leakage through the Wilford Shell Beds_ 61

7.4.5 Recharge via leakage through the Petone Marine Beds/Melling Peats___ 61

7.4.6 Overall recharge to the Waiwhetu Artesian Aquifer $\quad 62$

7.4.7 Response of the Waiwhetu Artesian Aquifer to recharge and abstraction 64

7.4.8 Direct evidence for preferential pathways in the Waiwhetu Artesian Aquifer___ 65

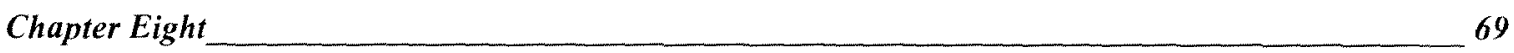

Extent and Character of the Sub Harbour Waiwhetu Artesian Aquifer ___ 69

8.1 Introduction __ 69

8.2 Seismic surveys undertaken in Wellington Harbour _ 70

8.3 Characteristics of the sub harbour Waiwhetu Artesian Aquifer based on seismic information 72

8.4 Characteristics of the Petone Marine Beds (upper aquiclude) based on seismic information _ 77

8.5 The interference region $\quad 79$

8.6 The southerly extent of the aquifer 86

8.6.1 Introduction _ 86

$\begin{array}{ll}\text { 8.6.2 The Harbour Entrance } & 87\end{array}$

8.6.3 The Rongotai Isthmus (Evans Bay - Lyall Bay corridor)__ 92 


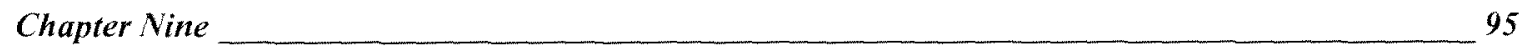

Submarine Springs in Wellington Harbour ___ 95

9.1 Introduction $\quad 95$

9.2 Background information 95

9.3 The causes of submarine spring inception in Wellington Harbour 99

$\begin{array}{ll}9.3 .1 \text { Tidal scour } & 100\end{array}$

$\begin{array}{ll}9.3 .2 \text { Gas blowout } & 101\end{array}$

$\begin{array}{ll}9.3 .3 \text { Tectonism } & 101\end{array}$

$\begin{array}{ll}9.4 \text { Sites of active leakage } & 105\end{array}$

9.4.1 Introduction 105

9.4.2 Zone 1 (Petone Foreshore/Hutt River mouth springs)_ 109

9.4.3 Zone 2 (south of Somes Island)

9.4.4 Zone 3 (southwest of Somes Island, near Somes Rock)_ 114

9.4.5 Zone 4 (near Seaview Wharf) 115

$\begin{array}{ll}\text { 9.4.6 Zone } 5 \text { (north of Somes Island) } & 116\end{array}$

9.4.7 Zone 6 (Pt Jerningham) 117

9.4.8 Zone 7 (Falcon Shoals) and Zone 8 (Harbour Entrance)___ 118

$\begin{array}{ll}9.4 .9 \text { Other sites } & 119\end{array}$

Chapter Ten 121

Salt-Water Intrusion at Submarine Spring Sites ___ 121

$\begin{array}{ll}10.1 \text { Introduction } & 121 \\ \end{array}$

10.2 Piezometric pressures within the sub-harbour Waiwhetu Artesian Aquifer 121

10.3 Effect of changing the abstraction focus 123

10.4 Present day potential for salt-water incursion at the deep depressions south of Somes Island _ 124

10.5 Recorded submarine spring discharges in Zone 1__ 126

\begin{tabular}{ll} 
10.5.1 Introduction & 126 \\
\hline & 126
\end{tabular}

10.5.2 Results from Depression 1, Zone 1__ 126

10.5.3 Results from Depression 6, Zone 1—127

10.6 Minimum Petone Foreshore level based on spring discharge ___ 128

Chapter Eleven _ 130

Conclusions _ـ 130

References

135

Appendix One:

Historic notes; unpublished reports and other information

Appendix Two:

DGPS locations and line of sight positioning of the sites investigated

Appendix Three: Salinity values recorded at sites during July, August and October 1997

Appendix Four:

Psim routines

Appendix Five:

Bathymetric survey data plots

Appendix Six:

Pump test data

Appendix Seven:

Probability distributions for Hutt River, McEwan Park and PCM 


\section{List of Figures}

1.2.1 Location map of the study area f2

2.1.1 The Hydrological Cycle 6

2.1.2 Generalised Groundwater System ___ 7

3.3.1 3D artistic impression of a 'typical' submarine spring ___ f14

4.1.1 Main features of Wellington Harbour____ fl6

4.1.2 Aerial view of Greater Wellington Area __ 16

4.2.1 Brodie's tidal currents in Wellington Harbour__ $\mathrm{f17}$

4.2.2 Johnson's tidal currents in Wellington Harbour $\quad \mathrm{fl7}$

$\begin{array}{ll}\text { 5.1.1 Spatial extent of the Waiwhetu Artesian Aquifer } & \text { f20 }\end{array}$

5.2.1 Location of major active faults in the Wellington Region ___ 21

5.2.2a Location of basins adjacent to the Wellington Fault $\quad \mathrm{f} 22$

5.2.2b Diagram showing basin formation __ $\mathrm{f} 22$

5.2.3a Basement contour map of Wellington Harbour ___ f23

5.2.3b Major active faults in Wellington Harbour _ $\quad \mathrm{f} 23$

5.3.1 Cross-section of Lower Hutt Valley along Petone Foreshore _ 24

5.3.2 Cross section down the Lower Hutt Valley ___ 25

5.3.3 Interpreted bore log from the Great Meat Company production well __ 126

6.3.1 Graph showing artesian leakage in submarine spring cluster, near Petone Foreshore $\quad 37$

6.5.1 The S4 Current Meter__ 40

6.5.2 Bathymetry of Wellington Harbour __ 142

6.6.1 Artistic representation of the $\mathrm{S} 4$ set up__ f43

6.6.2 Artistic close-up view of S4 over a submarine spring vent __ f44

7.4.2.1 Recharge zone of the Waiwhetu Artesian Aquifer _ $\quad f 56$

7.4.2.2 Concurrent gaugings on Hutt River at KGB and Taita Gorge _

7.4.2.3 Concurrent gaugings on Hutt River at KGB and Boulcott $\quad$ f58

7.4.6.1 Hydraulic gradients in the Waiwhetu Artesian Aquifer $\quad 62$

7.4.6.2 Location of wells used to derive the hydraulic gradients ___ f63

7.4.7.1 Response of the Waiwhetu Artesian Aquifer to rainfall/river charge_f64

7.4.7.2 Response of the Waiwhetu Artesian Aquifer to abstractions from the main pumping stations f64

8.2.1 Extent of the 'interference' region

8.3.1 Isopach image of the sub-harbour Waiwhetu Artesian Aquifer___ 774

8.3.2a Location of seismic survey lines (1991 survey) ___ f75

8.3.2b Seismic Line MC3 175

8.4.1 Isopach image of the Petone Marine Beds (the confining aquiclude) ___ f78

8.5.1 Extent of the 'interference' region (same as Figure 8.2.1)

8.6.2.1 Bathymetry of Harbour Entrance (from Chart NZ 23) _ 187

8.6.2.2a Basement contour map of Wellington Harbour (same as Figure 5.2.3a)_ 189

8.6.2.2b Major active faults in Wellington Harbour (same as Figure 5.2.3b) __ 189

8.6.3.1 Basement contour map of Rongotai Isthmus ___ 193

Note: ' $\mathrm{f}$ ' = facing page 


\section{List of Figures (continued)}

9.3.3.1 Correlation between tides and piezometric pressure $\quad \mathrm{f104}$

9.4.1.1 Location Map of Study Sites _ f105

9.4.1.2 Seepage of groundwater through the harbour floor __ f107

9.4.2.1 Bathymetry of Zone 1 f 109

9.4.2.2 Dredging Plan for Petone Foreshore during 1920's_ f111

9.4.2.3 Bathymetry of northeast quadrant of Wellington Harbour as surveyed in 1849 and $1904 \quad$ f1 12

9.4.3.1 Bathymetry of Zone $2 \ldots \mathrm{f} 113$

9.4.4.1 Bathymetry of Zone $3 \quad$ f114

9.4.5.1 Bathymetry of Zone 4_f115

9.4.6.1 Bathymetry of Zone 5_f116

9.4.7.1 Bathymetry of Zone $6 \_$f1 117

9.4.8.1 Salinity variations at Falcon Shoals __ f118

10.2.1 Relationship of Piezometric Head levels between Somes Island and McEwan Park__ f122

10.3.1 Piezometric Head Level record at McEwan Park ad Somes Island (1971 - 1998)___ f123

10.4.1 Relationship between Groundwater abstractions and Piezometric head___ f124

10.5.2.1 Submarine Spring Discharge Data (Zone 1, Depression 1) ___ f126 _ _ _ _ _ _ _ _ _ _ _ _

10.5.2.2 Piezometric conditions within Waiwhetu Artesian Aquifer $\quad$ f126

10.5.3.1 Submarine Spring Discharge Data (Zone 1, Depression 6) _ f127

10.5.3.2 Tidal effect and piezometric condition within Waiwhetu Artesian Aquifer__ f127

10.5.3.3 Current Speed v Piezometric head _ f128

10.5.3.4 Current Speed v Piezometric head (lagged)___ f128

10.6.1 Relationship of Submarine Spring Discharge to McEwan Park Piezometric Head f129

Note: ' $\mathrm{f}$ ' = facing page 


\section{List of Tables}

7.3.2.1 Summary of two main pump tests carried out on the Waiwhetu Artesian Aquifer

7.4.2.1 Gaugings recorded on the Hutt River (Taita Gorge and Kennedy Good Bridge)

7.4.2.2 Gaugings recorded on the Hutt River (KGB - Boulcott)

9.4.1.1 Dimensions and locations of depressions exhibiting artesian leakage ___ 106

9.4.2.1 Average salinity values for Zone 1 depressions __ 109

9.4.3.1 Average salinity values for Zone 2 depressions 113

9.4.4.1 Average salinity values for Zone 3 depressions____ 114

9.4.5.1 Average salinity values for Zone 4 depressions ___ 115

9.4.6.1 Average salinity values for Zone 5 depressions ___ 116

9.4.7.1 Average salinity values for Zone 6 depressions ___ 117

9.4.8.1 Average salinity values for Zones 7 and $8 \quad 118$

Note: ' $\mathrm{f}$ ' = facing page 


\section{Chapter One}

\section{INTRODUCTION}

\subsection{Context of the study}

Water is fast becoming one of the World's most valued commodities. This is true not only in water deficient areas such as the Middle East where water has replaced oil as the major cause of confrontation, but also in water abundant countries, where the pressures of an expanding population have placed a great strain on the available resources.

New Zealand is blessed by having an abundance of water, and being an island nation, does not have the difficulties associated with disputes over water rights with neighbouring countries that many nations have to contend with. However, given this enviable position, we still encounter difficulties concerning the management of the water resources we have at our disposal. While our country as a whole has an abundance of water, there exists a huge contrast in the spatial and temporal distribution of this valuable resource.

As a result, each region must be prepared to deal with issues such as floods and droughts when too much, or too little water is a problem. In catchments containing large urban areas where a proportion of the water must be of a high enough quality to supply municipal needs, the management of the available water resources is of the utmost importance and must be carefully planned.

As in the rest of the world, groundwater is becoming the most preferred source of municipal water supply in areas where it can be found in abundance. The reasons for this are clear - it is usually of extremely high quality - needing little, if any, treatment before use, and it is not as prone to contamination as surface water sources are. In addition, the extraction of groundwater does not come with the complications associated with the many competing users that surface waters have. What is meant here is that while there may be competition over the extraction of the water itself, there are not the issues of recreational use, loss of habitat and the detrimental effects on aquatic life that surface water allocation has to deal with.

Groundwater is also not detrimentally affected during floods, when surface water sources often become too silt-laden to be used in water treatment plants. 


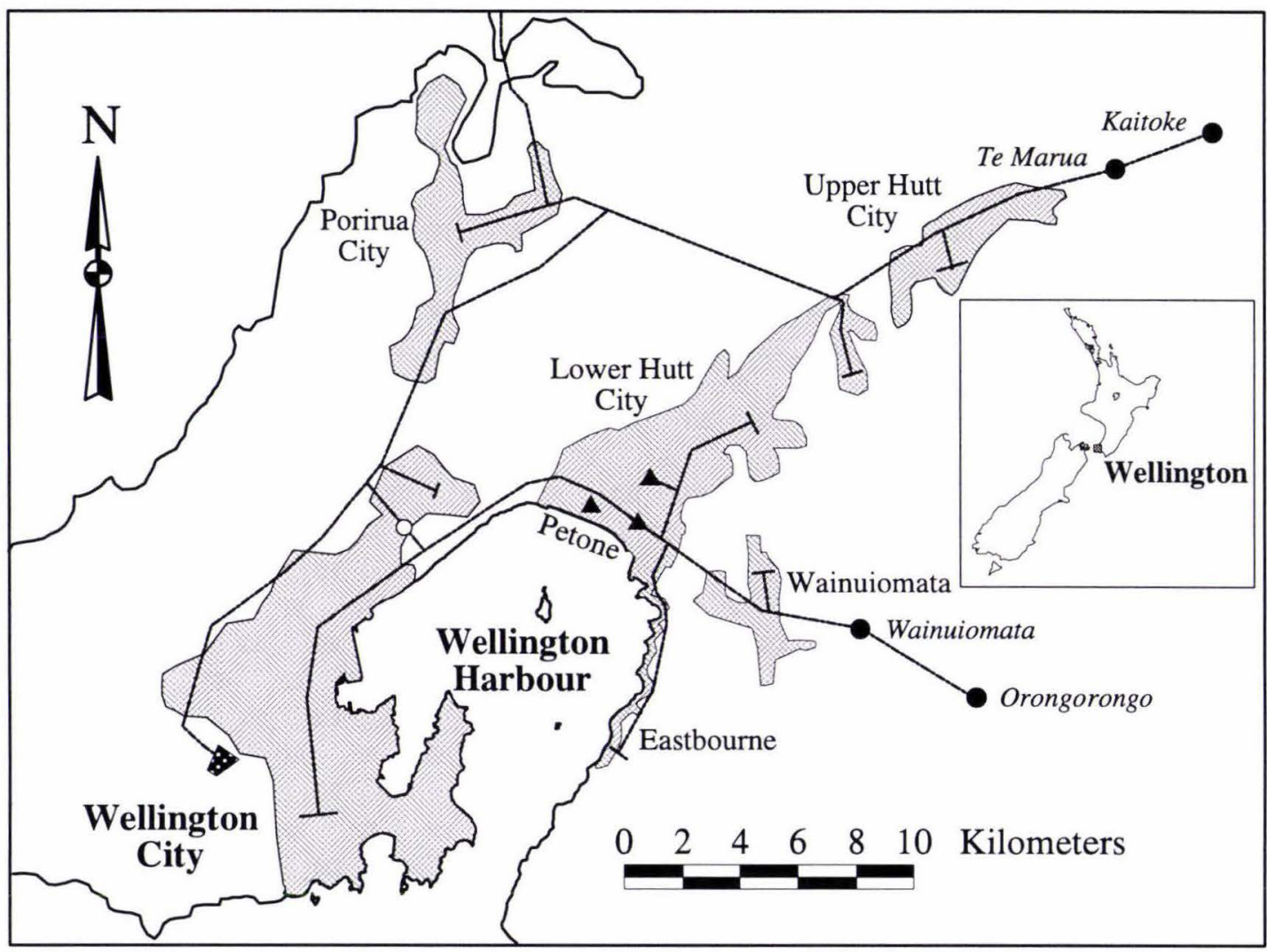

Figure 1.2.1 Location map of the study area showing the major urban areas (shaded regions) within the Wellington metropolitan area. The main water supply network is plotted as a dashed line. The surface water collection and treatment plants (solid circles) and the artesian water pumping stations of Waterloo, Gear Island and Buick Street (triangles) are shown. Note that the western-most triangle (Buick Street Pumping Station) is not in operation any more (closed in October 1999). Of the other two pumping stations, Gear Island, the southern-most one, is presently used only as a standby facility when demands cannot be met by the Waterloo Pumping Station alone. 


\subsection{Groundwater Use in the Wellington area}

Both surface water and groundwater are used in the supply of water to the four cities of the Wellington metropolitan region (Upper Hutt, Lower Hutt, Wellington City and Porirua City). Figure 1.2.1 shows the water supply network for this region. Surface water is collected at the Kaitoke, Wainuiomata and Orongorongo schemes and passed to Te Marua and Wainuiomata treatment plants respectively. Water is stored at the Te Marua treatment plant, but fed directly into the water supply network at the Wainuiomata treatment plant.

Groundwater is abstracted near the Waterloo pumping station (the northern-most triangle) along Knights Road in Lower Hutt and passed to the pumping station where it is treated with lime before being added to the main water supply network. Wells near the Gear Island pumping station were, until recently, used regularly by the Water Group to abstract water for the municipal supply. However, this scheme is now a standby facility, used only in the event of a shortfall of supply from the WRC's main treatment plants. The Buick Street pumping station (the western-most triangle in Figure 1.2.1) was built by the Petone Borough Council in 1964 and supplied the local community only, until its closure in October 1999. Petone residents are now supplied by the regional water supply network. Other abstractions take place at localised industries such as Lever Rexona Ltd in Petone. However, these are minor in comparison and do not place a great strain on the aquifer.

The entire groundwater component is abstracted from the Waiwhetu Artesian Aquifer (also referred to as the 'Waiwhetu Aquifer' and the 'Waiwhetu Gravels Aquifer') in the Lower Hutt Valley. This aquifer forms part of the Lower Hutt Groundwater Zone, which contains three aquifers - a surface 'unconfined' aquifer (the Taita Alluvium), and two confined aquifers - the Waiwhetu Artesian Aquifer, and the relatively unexploited deeper Moera Gravels Aquifer.

Water from the Waiwhetu Artesian Aquifer presently supports about 35\% of Wellington's water requirements. The Wellington Regional Council (WRC) is responsible for issuing consents which allow the abstraction of artesian water within the Wellington region. By far the largest consent is for the Council's Water Group to supply the municipal region.

Over the last 30 years, the amount of artesian water extracted from the Waiwhetu Artesian Aquifer has been in the order of around $60,000 \mathrm{~m}^{3} /$ day. This figure is well under the calculated safe yield of $90,000 \mathrm{~m}^{3} /$ day (WRC, 1995). However, it is the Water Group's intent to utilise the artesian water to a greater extent in the future to support a greater burden of Wellington's water requirements. The reason for this is due to resource allocation. Under the WRC's Fresh Water Plan, the Water Group expects to receive a smaller allocation from surface waters than is currently available (pers. comm. Andrew Samuel, Water Group, WRC, April 2000). 
This was not really an option in the past due to the fact that the pumping capacity of Waterloo and Gear Island was not that great. However, the Waterloo pumping station was recently upgraded (during 1998) with the amount of water able to be abstracted increasing from $60,000 \mathrm{~m}^{3} /$ day to $110,000 \mathrm{~m}^{3} /$ day.

In August 1998, the Water Group was granted new consent conditions regarding the abstraction of water from the Waiwhetu Artesian Aquifer. The consent is such that it will allow a maximum abstraction of $115,000 \mathrm{~m}^{3} /$ day during the three summer months (DecFeb), but stipulates that the average abstraction by the Water Group for the year must not exceed an average of $80,500 \mathrm{~m}^{3} /$ day. When all users are taken into account (e.g. industrial as well as municipal), the average abstraction for the year must not exceed $90,000 \mathrm{~m}^{3} /$ day the calculated safe yield for the Waiwhetu Artesian Aquifer (WRC, 1995). Thus the potential exists for the safe yield to be exceeded by a substantial amount during the summer months.

The reasoning behind allowing such a high abstraction during this summer period is because it is believed that the greater river recharge during the winter months, combined with a lower abstraction rate will replenish any deficit in the aquifer brought about by the high summer withdrawals.

Whether or not the $115,000 \mathrm{~m}^{3} /$ day summer abstraction maximum will ever be realised is uncertain at present and perhaps a little unlikely given the demands on the water resource that stands at present. For example, the summer of 1998/9 (Dec - Feb) was the most severe (with regards to time between rainfall events) since 1971 (pers. comm. Andrew Samuel, Water Group, WRC, April 2000), and yet the maximum abstracted for any given 24hour period during this summer was only $98,000 \mathrm{~m}^{3} /$ day.

Regardless of this, the potential exists for sustained periods of high abstraction under the new consent conditions. The need to abstract such large volumes as is allowable may be necessary if the Fresh Water Plan is again revised making it harder to utilise river water for municipal supply. Similarly, if one of the surface water sources became contaminated, the Waiwhetu Artesian Aquifer may be exploited to its maximum limit for extended periods to cover the loss of surface water to the city's municipal water supply.

What effect will an increase in abstraction have on the aquifer? There is one very major concern to the safe management of any coastal aquifer - that being the risk of contamination of the aquifer with sea water. Once inside an aquifer system, salt water can be difficult to remove. It does not necessarily get flushed out during periods of high recharge as it is denser than fresh water, and can sit as a deeper layer within the aquifer. It can then be drawn closer to the withdrawal zone next time the aquifer is under stress and when piezometric levels fall low enough to permit its movement landward. 
The Wellington Regional Council are aware of this threat and an over-riding condition on the abstraction of water from the Waiwhetu Artesian Aquifer is that abstraction from the aquifer must cease when the piezometric level in observation wells along Petone Foreshore fall below 1.4 masl (metres above sea level).

This level was calculated by Donaldson and Campbell (1977) to be the foreshore piezometric level below which artesian leakage would cease, and the flow path reverse to allow salt water to enter the aquifer at the 32 metre deep depressions south of Somes Island. Part of this calculation required knowing the piezometric head at the site of saltwater incursion i.e. the depressions south of Somes Island. In lieu of 'real' data at these sites, Donaldson and Campbell (1977) used the piezometric head as recorded at Somes Island as a close approximation to the piezometric head in the aquifer beneath the deep depressions.

However, the accuracy of this value, and the validity of the method and data used to calculate it, has been questioned in the 1995 WRC report "Hydrology of the Hutt catchment; Volume 2: Groundwater" (hereafter referred to as WRC, 1995). Furthermore, unbeknown to neither Donaldson and Campbell at the time of their study, nor the WRC at the time of their report, there exists a cluster of harbour floor depressions exhibiting artesian leakage just off the Hutt River mouth, much closer to Petone Foreshore. Given the location of these submarine springs, this minimum foreshore value needs to be revised with these sites in mind as points of possible salt-water intrusion.

Unfortunately, there are no artesian bores penetrating the aquifer in the vicinity of these springs that can reveal the hydrodynamics of the sub harbour aquifer at these sites. As such, an understanding of the nature of discharge from these submarine springs can be useful as a tool to determine the minimum piezometric level at Petone Foreshore before salt-water incursion occurs at these sites.

Indeed, while it can be said that the existence of fresh-water submarine springs implies that the landward segment of an aquifer is underdeveloped in terms of its water-yielding potential, the cessation of flow from submarine springs immediately suggests that the safe yield of part of the aquifer has been exceeded. Kohout (1966) recognises this and states that "finding, and then periodically observing the discharge and salinity of submarine springs could be used as a tool to monitor hydrologic changes brought about by future exploitation of an aquifer."

In this sense, the submarine spring discharges are an indicator of the 'health' of the aquifer i.e. the greater the discharge, the greater the excess of water and thus the 'healthier' the aquifer is. 


\subsection{Aims}

This research aims to improve the understanding of the sub-harbour portion of the Waiwhetu Artesian Aquifer, with particular regard given to the location and discharge of fresh water submarine springs.

As such, the objectives of this thesis are to;

- Locate and investigate areas where aquifer leakage (via submarine spring discharge) into Wellington Harbour is presently occurring. Provide reasoning as to how the springs formed and why there may be variations between the prolificness of the various spring discharges.

- Develop a better understanding of the hydrodynamics of the sub-harbour portion of the Waiwhetu Artesian Aquifer. Part of this will involve proving the existence of 'preferential pathways' within the aquifer beneath the Lower Hutt Valley where piezometric and groundwater flow data is plentiful. Offshore seismic survey data will then be used to map these areas of higher than 'normal' transmissivity (a measure of the ease of flow through aquifer deposits) within the aquifer gravels beneath the harbour floor. These pathways are important as they are likely to represent regions where artesian water will exist in greater quantities and with possibly higher piezometric pressures than elsewhere within the aquifer.

- Define the boundaries of the Waiwhetu Artesian Aquifer, with particular detail given to its southern extent. This will be accomplished through the interpretation of seismic line data and bore-hole data.

- Calculate the minimum piezometric level at Petone Foreshore below which salt-water incursion may occur at the depressions off the Hutt River mouth. 


\section{Chapter Two}

\section{BASIC GROUNDWATER CONCEPTS}

\subsection{Introduction}

The flow path of all liquid fresh water on land is ultimately to the sea - this being an integral part of the hydrologic cycle (see Figure 2.1.1). In the simplest of scenarios, fresh water (provided by precipitation) falls on the land surface and is either evapourated, transpired, forms rivers or streams via runoff, or makes its way underground whereupon it is classified as groundwater. Defined as all water contained within spaces in bedrock and regolith, groundwater constitutes roughly $96 \%$ of all the non-frozen fresh water on Earth.

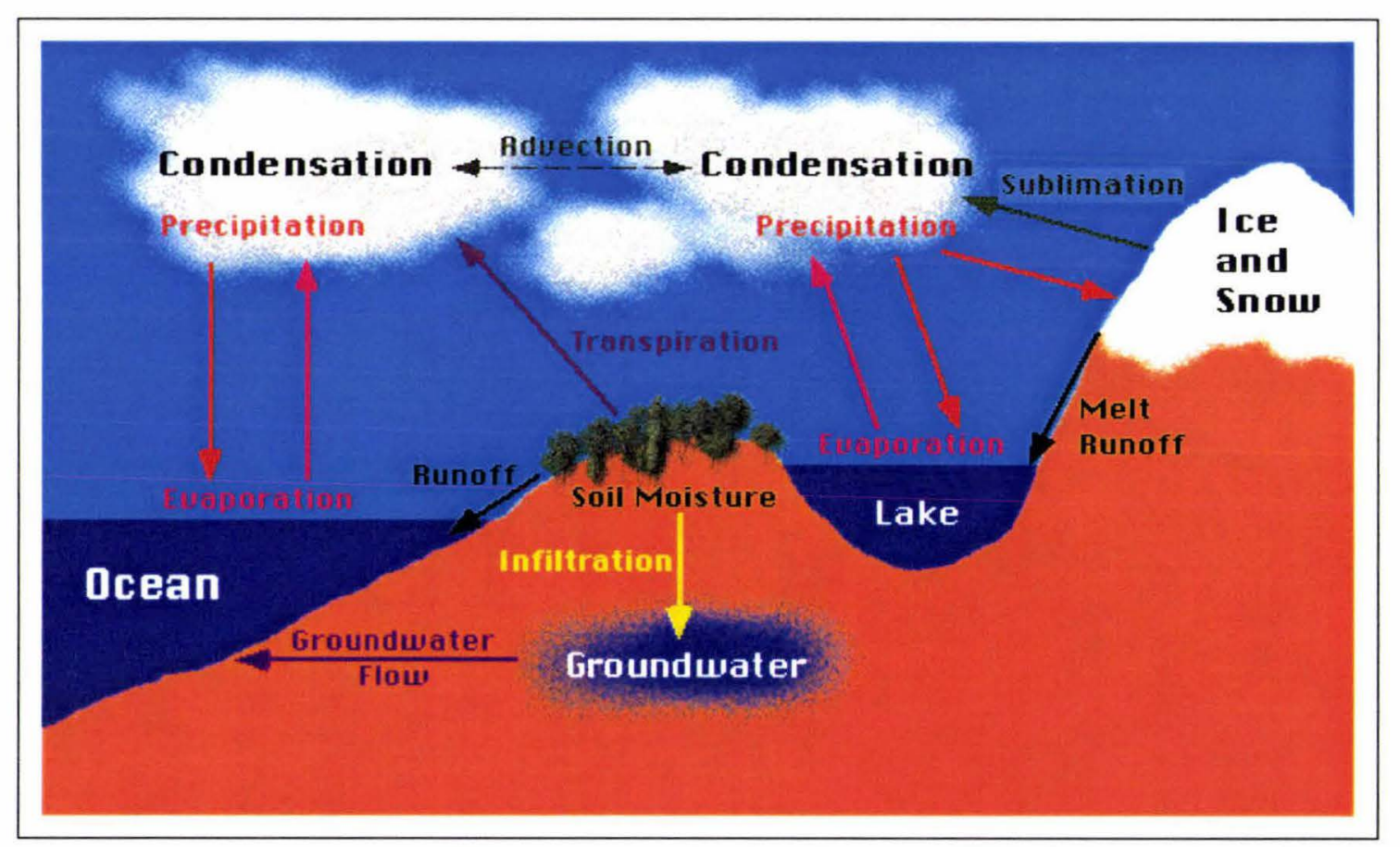

Figure 2.1.1 The Hydrologic Cycle (from http://hydroc.evsc.virginia.edu/eph/CHAP6B.HTM\#6.4)

Virtually every type of geologic material, both consolidated and unconsolidated, contains water to some degree (albeit some in minute quantities). While the ultimate goal of all this groundwater is to reach the sea, some water is held so tightly within its geologic host (due to the very low permeability e.g. unfractured metamorphic rocks) that to suggest it is moving is nonsense.

However, some formations do store significant quantities of water and are permeable enough to allow the water to flow through at an appreciable rate. We call these formations 
'aquifers' (see Figure 2.1.2). Aquifers are defined as "a saturated permeable geologic unit that can transmit significant quantities of water under ordinary hydraulic gradients" (Freeze and Cherry, 1979).

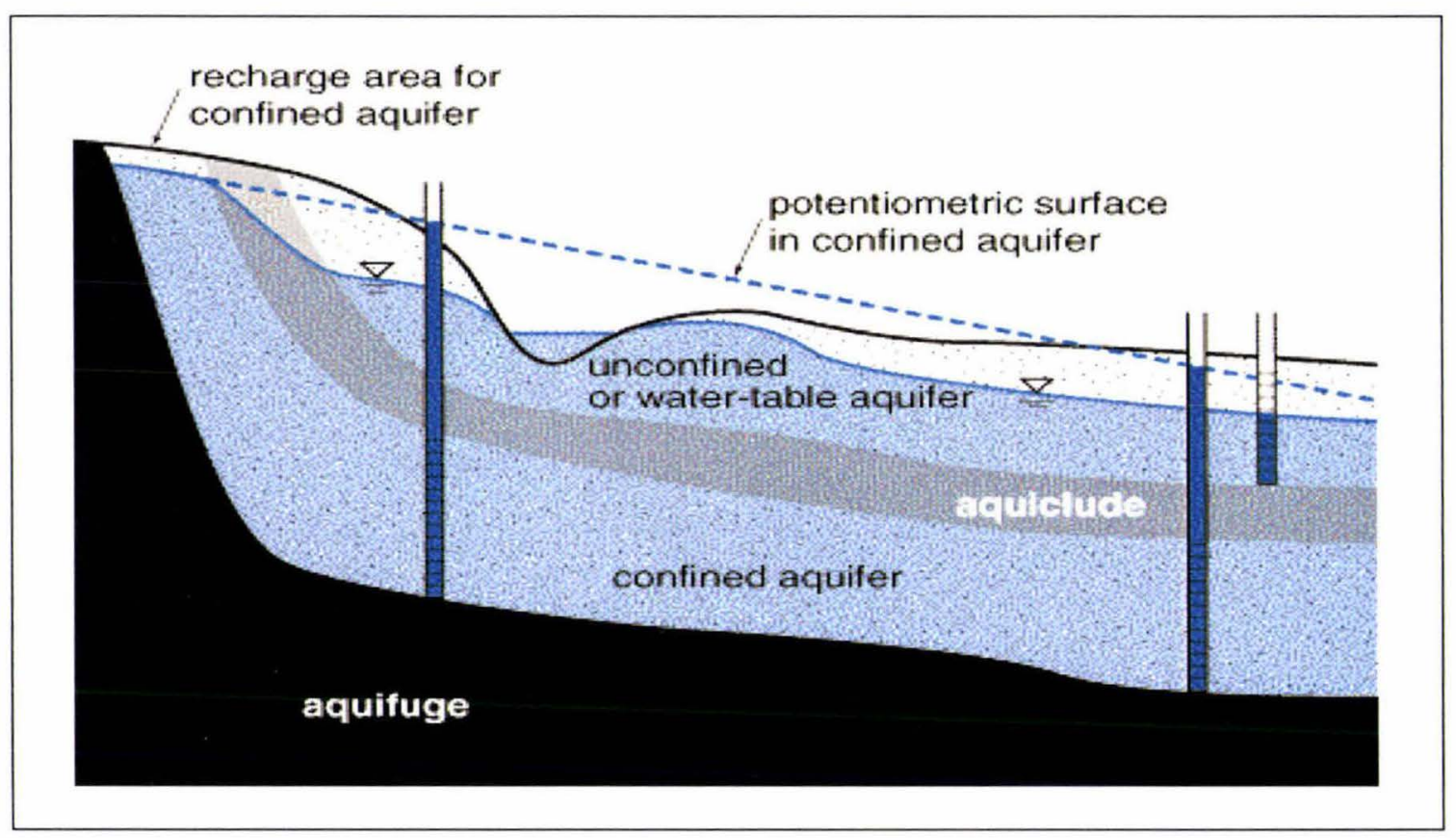

Figure 2.1.2 Generalised Groundwater System and some commonly used terminology (taken from http://hydroc.evsc.virginia.edu/eph/CHAP7B.HTM\#7.4.2). The well on the left is a flowing artesian well due to the fact that the potentiometric surface is above the surface of the land. The middle well is not a flowing artesian well as the water can only rise up to the potentiometric level, which at this location is below the ground surface. The shallow well on the right only penetrates the upper, unconfined aquifer and thus rises only to the level of the water table.

\subsection{Unconfined aquifers}

An unconfined aquifer is one in which a water table varies in undulating form and slope, depending on areas of recharge and discharge, pumpage from wells, and permeability. Rises and falls in the water table correspond to changes in the volume of water stored within an aquifer (Todd, 1959).

\subsection{Confined aquifers}

Confined aquifers, also known as artesian or pressure aquifers, occur where groundwater is confined under pressure greater than atmospheric by overlying relatively impermeable strata (Todd, 1959). Basically, there are three types of confining bed which are distinguished by differences in their permeability - aquitard, aquiclude and aquifuge. 
- 'Aquitard' is used to describe the "less permeable beds in a stratigraphic sequence" (Freeze and Cherry, 1979). Many overbank deposits within the Waiwhetu Artesian Aquifer member would fit this description. They can store and transmit water, but not in sufficient amounts to be considered an aquifer in its proper sense.

- 'Aquiclude' is defined as "a saturated geologic unit that is incapable of transmitting significant quantities of water under ordinary hydraulic gradients" (Freeze and Cherry, 1979).

- 'Aquifuge' is a rarely used term and is defined as being "an absolutely impermeable unit that will neither store nor transmit water" (Fetter, 1980).

In reality, none of the above terms are used well. Hydrogeologists differ in their interpretation of them, and as a result, many texts are confusing and misleading. The trend nowadays is to use the more generic terms 'confining bed' and 'leaky confining bed' to classify the units that confine artesian aquifers. However, with respect to the confining beds found both above and below the Waiwhetu Artesian Aquifer member (the Petone Marine Beds above, and the Wilford Shell Beds below), I believe the term 'aquiclude' best describes their characteristics (see Chapter Five).

Confined aquifers are recharged via river flow or rainfall on an unconfined portion of the aquifer. This is known as the recharge area (see Figure 2.1.2). Recharge may also occur via seepage through a leaky confining bed from a deeper or shallower aquifer.

Natural discharges from confined aquifers are manifested as 'springs'. Two factors are necessary for springs to form;

- the absence, or weakening, of a portion of the upper confining material, and

- when the potentiometric (or piezometric) surface of the aquifer has a greater elevation than the level of the land.

The potentiometric surface is an imaginary surface coinciding with the hydrostatic pressure of water within the aquifer. Thus it is the level, or elevation, to which water would rise in a well penetrating a confined aquifer (see Figure 2.1.2). Should the pontentiometric surface lie above the ground surface, a flowing artesian well will result (as is the case with the well on the left side of Figure 2.1.2). The other well penetrating the confined aquifer in Figure 2.1.2 is a non-flowing artesian well due to the fact that the potentiometric surface has a lower elevation that the land surface.

The potentiometric surface is affected by the amount of recharge into the aquifer and the losses from it. For instance, floods or intense rainfall events that pass over the recharge area of an artesian aquifer will cause the potentiometric surface to rise in elevation, causing spring flows to increase. 
Abstraction of water from an aquifer lowers the elevation of the potentiometric surface, causing spring flows to reduce. A characteristic shape called a 'cone of depression' is often apparent in the potentiometric surface around the wells drawing water. This 'cone of depression' becomes more prominent during times of low recharge (i.e. during extended periods of low river flows, or droughts), or when abstractions are high. 


\section{Chapter Three}

\section{GROUNDWATER DISCHARGE TO THE MARINE ENVIRONMENT}

\subsection{Introduction}

Where an aquifer meets the sea, an interaction between two hydrological regimes takes place, and a mixing occurs. Groundwater flowing through the aquifer discharges to the ocean environment, while seawater infiltrates the extremities of the aquifer as a wedge. These two processes can be considered to be in equilibrium, but do vary in response to changes in the hydrological properties of the aquifer.

This leakage of groundwater to the ocean environment is a very common occurrence and takes place largely unnoticed. Submarine spring discharge, on the other hand, is an unusual and relatively uncommon feature of coastal geography whereby leakage from a confined artesian aquifer takes place from an isolated area and produces a noticeable upwelling of fresh water through the sea floor.

Kohout (1966) did the first major work looking at submarine springs as a phenomenon. His paper "Submarine Springs: A neglected phenomenon of coastal hydrology" summarised all of the previous research and investigations of submarine springs from around the world (of which there were less than ten) and made a few observations of their general character. His definition of submarine springs is simple: "A submarine spring is merely an unusual form of the commonplace spring and may be defined as an issue of water from the earth beneath the sea".

However, "an issue of water from beneath the sea" is rather vague, especially given that this is only one of the many ways in which groundwater can discharge into the ocean. Thus, Kohout's definition needs some clarification. Certainly, the discharge of groundwater to the ocean can be considered a very common occurrence, and in some circumstances quite prolific. In fact, Moore (1996) concluded from his research into the coastal waters of the South Atlantic Bight (USA) that Submarine Groundwater Discharge (SGWD) was equivalent to about $40 \%$ of the river-water flux for the coastal waters in that region. Moore's groundwater input to the ocean included no concentrated discharge in the form of submarine springs and thus this estimate of groundwater entering the sea was from what we can call 'normal groundwater discharge'. 
Despite the fact that no two coastal areas will have exactly the same hydrological or geological properties, and given that the coastal region of the South Atlantic Bight is notoriously rich in groundwater, this figure of $40 \%$ is perhaps rather high when compared to the 'average' coast. However, it is still useful as an estimate of the proportion of the total influx of fresh water into the coastal zone that can come from a groundwater source.

Two important points have been raised here that require attention. Firstly, it has been identified that submarine spring discharge is just one form in which groundwater can escape to the marine environment. Secondly, it is clear that the amount of leakage of groundwater to the marine environment is dependent on the hydrological and geological properties of water bearing formations from which it issues. Thus, to fully understand the forms in which groundwater discharges to the ocean, we must also have knowledge of the type of aquifer (and its hydrological properties) from which the leakage is occurring.

\subsection{Types of Submarine Groundwater Discharge}

There are many different types of aquifer, both confined and unconfined. To identify and discuss all the forms in which groundwater may discharge to the ocean would be impractical. Thus, the following section is written with unconsolidated rock aquifers in mind - such as the type found beneath Wellington Harbour.

\subsubsection{Discharge from unconfined aquifers}

Where unconfined aquifers meet the sea, seawater mixes with groundwater within the aquifer and the resultant mixture seeps out through the seabed virtually undetectable. The discharge of this water from the aquifer is dependent on the height of the water table in the aquifer, and the power of the waves striking the beach. This latter process is often referred to as 'tidal pumping'. This type of groundwater leakage is typical of the near shore environment and usually extends no further than the inter-tidal range.

\subsubsection{Discharge from confined aquifers}

Where confined aquifers meet the sea at their extremities, the resulting leakage is manifested as evenly distributed discharge over a large area which is quickly dispersed by the overlying sea water. The amount of water discharged is proportional to the piezometric head driving the aquifer system.

If the confining bed has very low permeability, the water may be forced far offshore to points where the confining layer terminates. In theory, if the confining layer were completely competent and entirely impermeable, this would be the only type of natural discharge from a confined aquifer. 
However, in reality, it is very rare to find a confining bed that is totally impermeable. As such, leakage from a confined artesian aquifer through its confining bed is quite common. This leakage may not necessarily be via obvious pathways such as a fault trace that has offset the confining bed through which a flow path may initiate - rather it may be manifested as widespread, but slow, seepage through a large proportion of the confining bed. The volume of water leaking through the confining bed in this way is dependent on a number of factors. The main ones being the thickness, permeability and homogeneity of the confining bed, and the piezometric head within the underlying aquifer (which itself is dependent on many factors - see Chapter Seven).

It is important to note that the amount leaking through a confining bed from a discreet area (for example a square metre) is extremely small - virtually undetectable. However when we consider the total area of the confining bed through which seepage could be occurring, the amount of water lost may be quite significant.

\subsection{Submarine Springs and their recognition}

Submarine springs on the other hand are more concentrated areas of leakage from the aquifer to the sea. They can be likened to terrestrial 'springs' in that the amount of discharge is dependent on the absence of, or at least severely weakened, confining beds, and the level of the potentiometric surface. However, in the case of a submarine spring, the potentiometric surface must be above sea level to counter the opposing pressure of the overlying sea water. To be precise, the potentiometric surface must be greater than 1.025 times the depth of sea, due to the fact that 'normal' sea water is 1.025 times denser than fresh water, and thus has a greater opposing force for a corresponding head of fresh water. Where these factors allow, submarine springs form.

As Kohout (1966) states, submarine springs can be considered unique features of coastal hydrology. However, instead of being defined as 'an issue of water from beneath the sea', they are perhaps better defined as 'an area of concentrated leakage, significantly greater than that from the surrounding sea floor'. They emerge at the sea floor as upwelling currents and the discharge may be prolific enough to form a boil or slick at the sea surface (Kohout 1966). The amount of water expelled, and the degree of force of the upwelling water is once again dependent on the pressure (or piezometric head) within the aquifer. It follows that if the piezometric head within the aquifer drops below 1.025 times the depth of sea water then the flow path at a submarine spring site may reverse and salt-water incursion may occur. This scenario will be discussed in Chapter Ten.

The presence of submarine springs, both hot and cold, have been recognised for many centuries. Pausanius, who lived in the second century AD describes two locations where there was "water boiling in the sea" which was "unmistakingly fresh". One of these 
springs was a hot spring around which a man made structure was constructed to allow bathing to take place (Kohout, 1966).

Strabo, a Roman geographer who lived from 63BC to $21 \mathrm{AD}$ talks about a submarine spring outcropping close to the rocky coastline of Arvad, an island about $4 \mathrm{~km}$ from the city of Latakia, Syria from which water could be collected during war-times. Here, people could collect potable water by lowering an inverted wide mouth funnel made of lead with a 'leathern tube' attached to the top over the spring. Strabo states that "... the first water that is forced up is seawater, but the boatmen wait for the flow of pure and potable water and catch all that is needed..." (Kohout, 1966).

Thus for at least the last two millennia, submarine spring discharge has been a recorded and utilised feature of coastal hydrology. They were identified because of a temperature anomaly (in the case of hot springs) or by their surface expression - that is, as a boil of water on a calm sea surface, or as a slick or smooth area in an otherwise choppy sea. The factors that determine the degree of surface expression are;

1) The force driving the artesian water through the sea floor (the piezometric pressure):

- The greater the velocity of the artesian water from the aquifer, the stronger the vertical flow of water. If the flow is strong enough, a 'water boil' may be seen at the sea surface.

2) The differences in density between fresh and salt water,

- Fresh water is less dense than saltwater water and thus the water issuing from a submarine spring is encouraged to rise to the surface. Furthermore, waters of different density do not mix readily. The result is the formation of a prominent vertical plume of less saline (and thus less dense) water rising from the submarine spring vent. The plume will retain its identity until full mixing has occurred with the ambient sea water. In addition to this, temperature also affects the density of the waters - the cooler the water, the more dense it is (maximum density for fresh water is $4^{\circ} \mathrm{C}$ ). For most of the year, the harbour water is cooler than the artesian water. Only during summer months does this trend reverse (see Chapter Four, section 4.4). Thus, for much of the year, the leaking fresh water is more buoyant than the surrounding sea water, not only because of its lower salinity but also because of its relative 'warmth' compared to the sea water. These factors encourage the 'freshened' water plume to form a sea surface expression.

3) The physics behind wave propagation in the marine environment:

- A vertically rising column of water prevents the propagation of wave energy. The result is a smooth area on an otherwise choppy sea surface. 


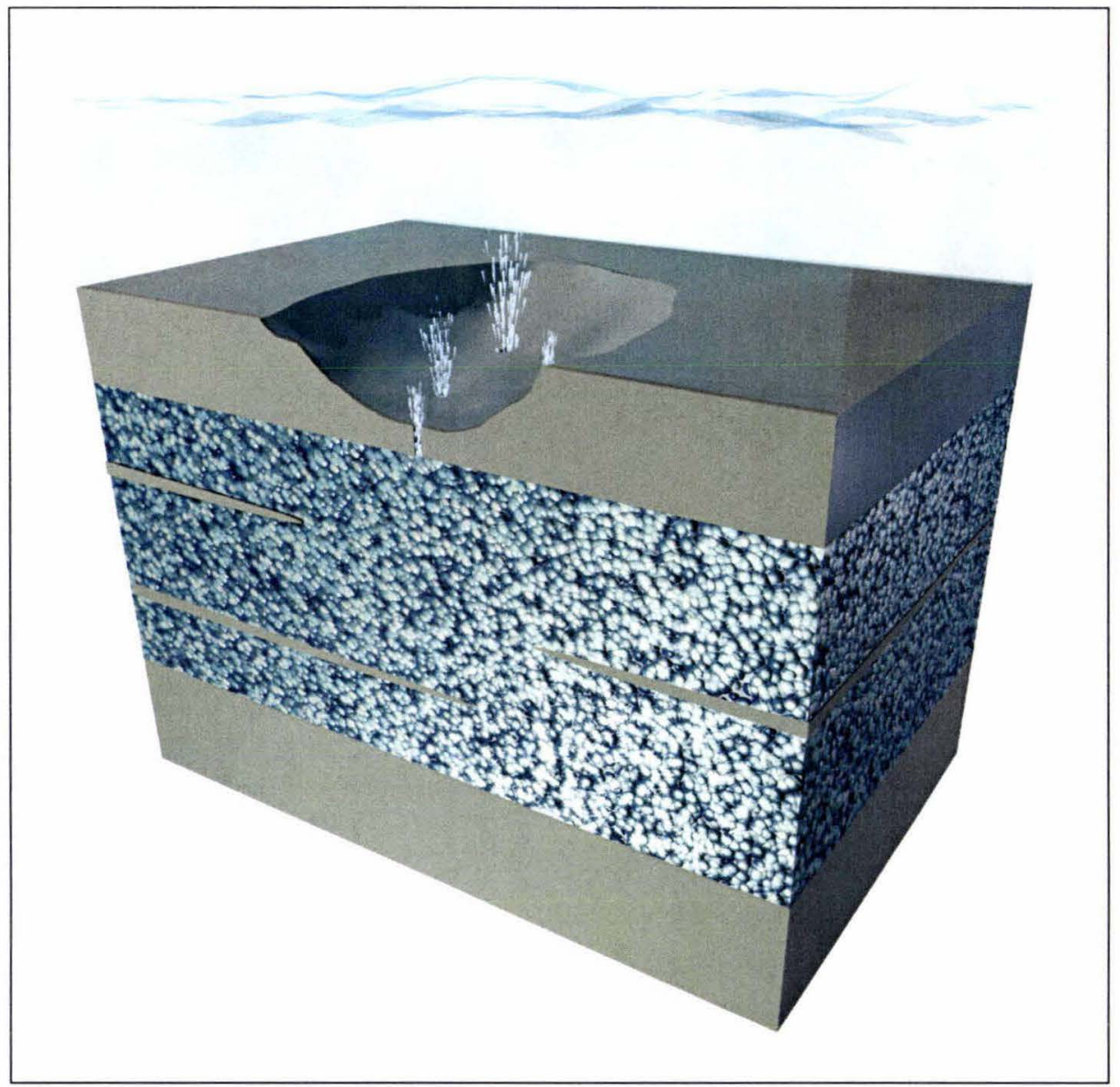

Figure 3.3.1 Schematic diagram of a 'typical' submarine spring found in Wellington Harbour. Due to the extremely poor visibility of the harbour water, photography is not a realistic option in capturing either the geomorphic form of a sea floor depression, or the leakage of water from the springs. Hence, the above diagram is an artistic impression of a sea floor depression showing artesian leakage. The depression image has been sliced in half to reveal the sedimentary units beneath. The grey, coarse unit represents the Waiwhetu aquifer, the thin brown lenses within it represent overbank deposits. The thick units above and below the aquifer gravels represent the confining aquicludes, - the Wilford Shell Beds (below) and the Petone Marine Beds (above).

The basal sedimentary unit - the Moera Gravels Aquifer (which lie beneath the Wilford Shell Beds) are not shown due to its great thickness and the subsequent reduction in vertical resolution that would accompany its inclusion.

Note that the leakage of artesian water occurs at discreet vents rather than from the entire depression floor. The depression form, plus the size of the submarine vents were recreated from divers' observations. The relatives thickness' of the various units are all to scale, having been calculated via the interpretation of seismic line data. This diagram was created in the software package $3 D$ Artworks. 
4) The depth at which the submarine spring occurs.

- The less distance the leaking artesian water has to travel before it reaches the surface, the less mixing will take place and thus the less characteristics it will have of 'normal' seawater. As such, the shallower the water depth, the more likely a surface expression will be exhibited.

In arctic areas, a unique sea (or lake) surface expression can also be found. If the sea ice is not very thick and the groundwater leaking up is relatively 'warm', interesting phenomenon known as polynas can be formed. Polynas are circular areas where sea ice has not formed due a heat source from beneath. One such polyna in Cambridge Fjord, Baffin Island has been identified and described in Sadler and Serson (1980). Such features are easily identified as an open hole formed in the sea ice. This is possible as groundwater usually remains at a constant temperature all year round. In this case, the water leaking was warmer than the environment it was discharging into. In warmer climates, the leaking groundwater is normally cooler.

Regardless of the environment in which a spring may be found, if the discharge is small, or the water depth is large, an identifiable sea surface expression may not necessarily be exhibited. This is the case in Wellington Harbour. The typical leakage rates are not prolific enough to cause a sea surface disturbance. Information gathered on the world-wide occurrence and characteristics of submarine springs, found that the springs investigated were almost always initially identified because of a strong sea surface expression. They are almost all found in karstic or volcanic areas - and typically the springs themselves were found to be emitting prolific amounts of water through the entire depression floor.

In contrast, the springs in Wellington Harbour issue from an unconsolidated gravel aquifer. Leakage occurs from depressions in the harbour floor where the confining aquiclude has been removed or weakened, but is concentrated at a number of small vents in the floor of the depression through which leakage occurs. These vents are irregularly spaced and are occasionally on the sides of the depressions rather than on the base. Figure 3.3.1 is an artistic impression of what this research has discovered in terms of the nature of a submarine spring issuing from an unconsolidated gravel aquifer. The data used to compile this diagram were taken from seismic line data collected by Davy and Wood (1993).

There are many ways of recognising submarine spring discharge in areas where the sea surface expression may be too subtle for human eyes such as is the case in Wellington Harbour. They include;

1) Differences in water temperature

- Unlike sea temperatures that fluctuate throughout the year in reflection to the seasons, groundwater in confined aquifers usually has the same temperature 
throughout the entire year with very little deviation. In Wellington's case, the groundwater is around $13.9^{\circ} \mathrm{C}$ all year long and is thus cooler than the harbour water during summer, but warmer during winter (given the fluctuation in harbour water temperature throughout the year - see Chapter Four, section 4.4). These differences can be recorded via thermometers, or even distinguished by a temperature difference in the sea when diving. Obviously, the closer to the spring site, the more noticeable the difference.

- If the water above the vented artesian water is deep, the 'freshened' water is generally well mixed and displays little variation from the ambient sea temperature at the sea surface. However, temperature differences as little as $0.2^{\circ} \mathrm{C}$ can be sensed by infrared scanning radiometers. Such instruments were used by Fischer et al (1964) to show the existence of both warm and cool submarine spring discharges around parts of the Hawaiian Islands.

\section{2) Differences in water salinity}

- Salinity and conductivity measurements can be made throughout the water column to distinguish water of lesser salinity than 'normal' seawater. The conductivity of water is a function of salinity and temperature - conductivity increases with increasing salinity and temperature. The discharge of groundwater at a spring site reduces the salinity and thus conductivity of the water column above the issuing vent. The amount of reduction in salinity (and thus conductivity) is dependent on the amount of fresh water discharged and the degree of mixing it has undergone before being recorded (i.e. the proximity to the spring vent).

3) Direct subsurface observations

- The different in light refractive indices between fresh and saline water (due to their contrasting densities) means that the water becomes 'blurred' where the two mix. This 'bluriness' of the water can be observed (by SCUBA divers) in the water column adjacent to an issuing spring.

4) Sea floor topography.

- Depending on the sea floor substrate, and the discharge from the spring, a depression in the sea floor may be present. This is most likely caused by the initial removal of material from the leakage site upon submarine spring inception (possibly as a catastrophic event) and the subsequent prevention of any further sediment from being deposited once the depression form has stabilised. Thus as the rest of the sea floor is built up through sedimentation, the depressions 'grow' in size (relative to the surrounding sea floor) and become more pronounced with time. This may be a useful indicator of the relative age of springs (if sedimentation rates are constant and known). 


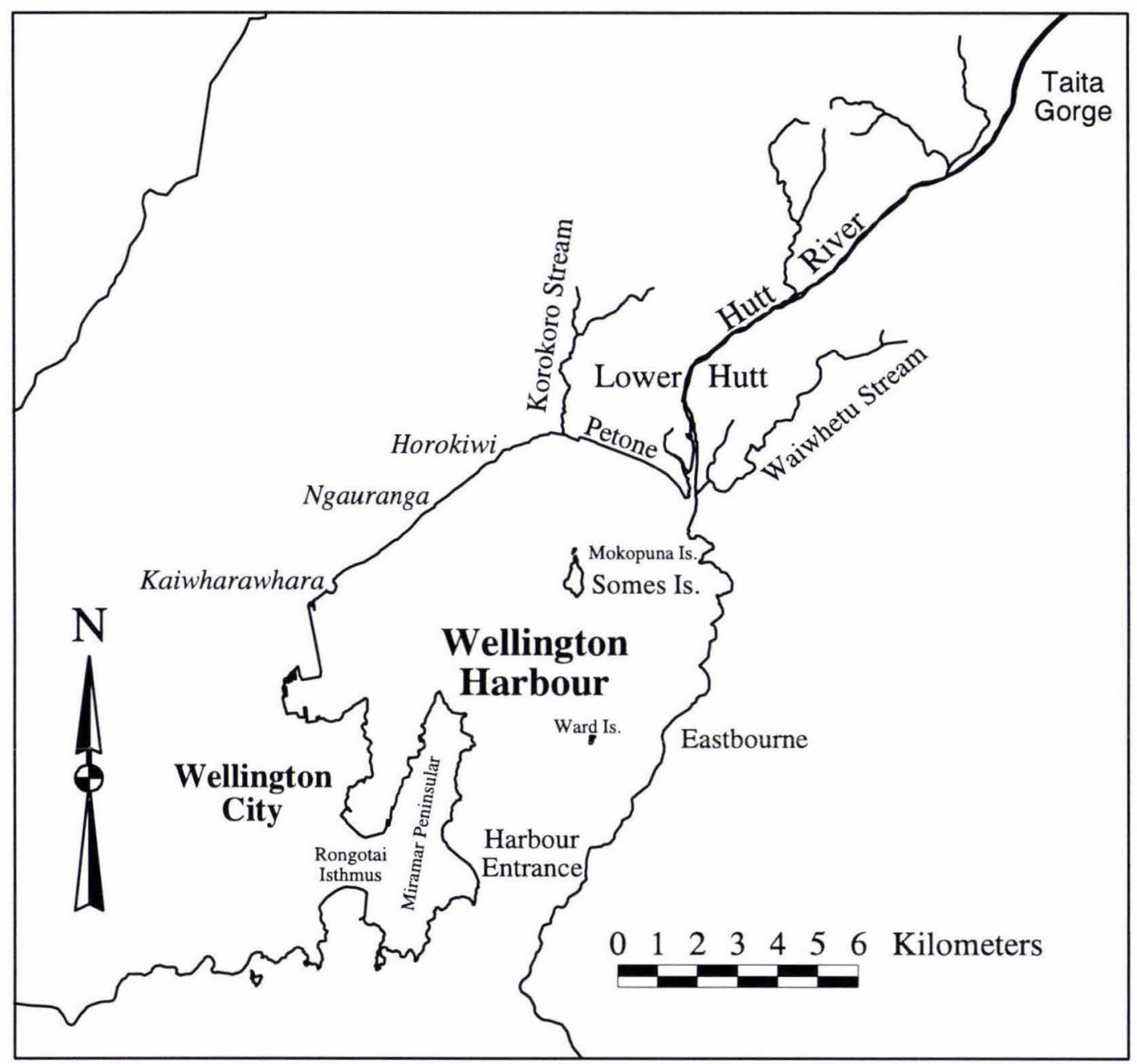

Figure 4.1.1 Wellington Harbour (Port Nicholson) as seen here, occupies part of a large basin extending from Taita Gorge in the north to the harbour entrance in the south. The Hutt River is the main provider of fine sediment to both the Hutt Valley floodplain and the harbour. Several small rivers, plus the mouths of three others (in italics) are also indicated. 


\section{Chapter Four \\ NATURE OF THE STUDY AREA}

\subsection{Location and Physiography}

Wellington Harbour, at the southern tip of the North Island of New Zealand, fills part of the Port Nicholson - Lower Hutt Valley basin, which extends from Taita Gorge in the north to the harbour entrance in the south. The harbour itself is roughly $80 \mathrm{~km}^{2}$ in area, has a single entrance to the south and contains three islands - Somes, in the middle of the harbour, Mokopuna, a very small island to the north of Somes, and Ward, a small island towards the harbour entrance near Eastbourne (Figure 4.1.1).

A number of rivers discharge into the harbour, but only the Hutt River has any significant flow with an average discharge of around $25 \mathrm{~m}^{3} / \mathrm{s}$, although the median is much lower at 15 $\mathrm{m}^{3} / \mathrm{s}$ (over the period of record from March 1979 to August 1999 - see Appendix Seven). Two other minor rivers - the Waiwhetu Stream which enters the harbour at the mouth of the Hutt River and the Korokoro Stream which enters the harbour at the other side of the valley have average discharges of $0.24 \mathrm{~m}^{3} / \mathrm{s}$ and $0.23 \mathrm{~m}^{3} / \mathrm{s}$ respectively.

The total catchment area of the harbour is $725 \mathrm{~km}^{2}$, with the Hutt River catchment occupying the majority of this area with $630 \mathrm{~km}^{2}$ (Johannesson, 1958). Several small streams on the western side of the harbour at Horokiwi, Ngauranga, and Kaiwharawhara also contribute minor amounts of water into the harbour. During flooding these inputs can be quite significant. (Booth, 1974).

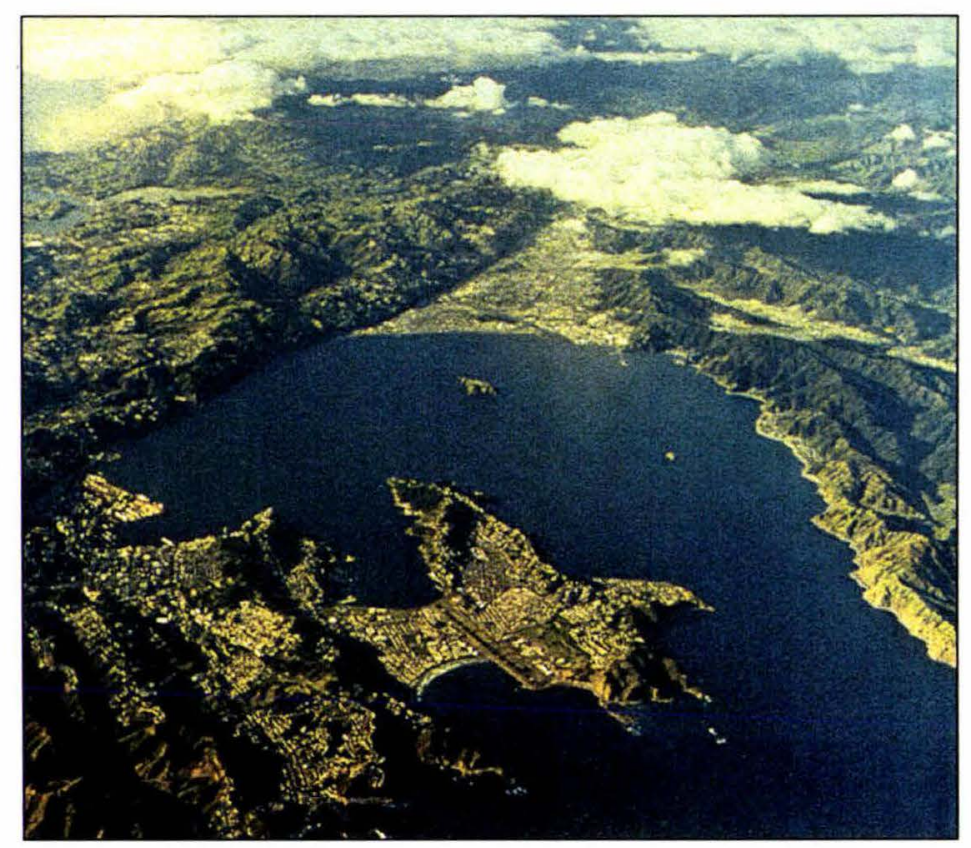

Figure 4.1.2 Aerial view of the greater Wellington City area (looking north). 

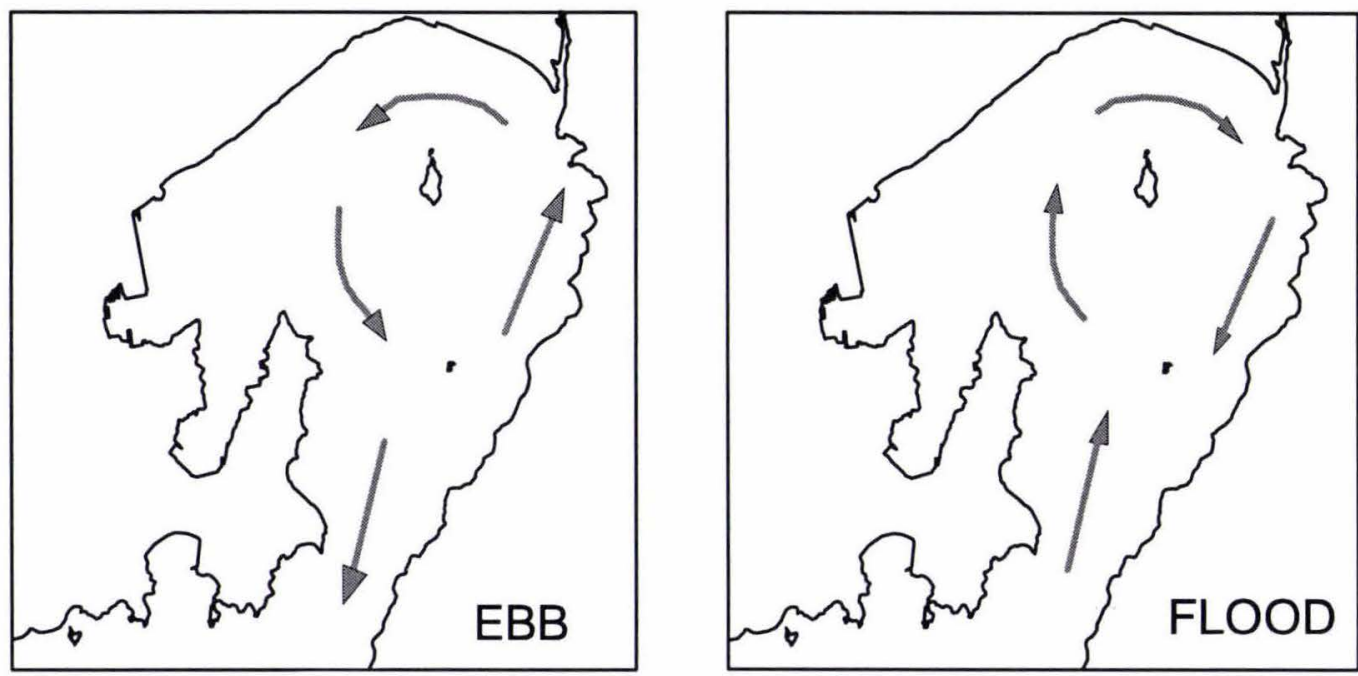

Figure 4.2.1 Brodie's model of ebb and flood tidal flows in Wellington Harbour (after Brodie, 1958). Note the rather simplistic trend of anticlockwise flow during the ebb tide and a clockwise flow during the flood tide.
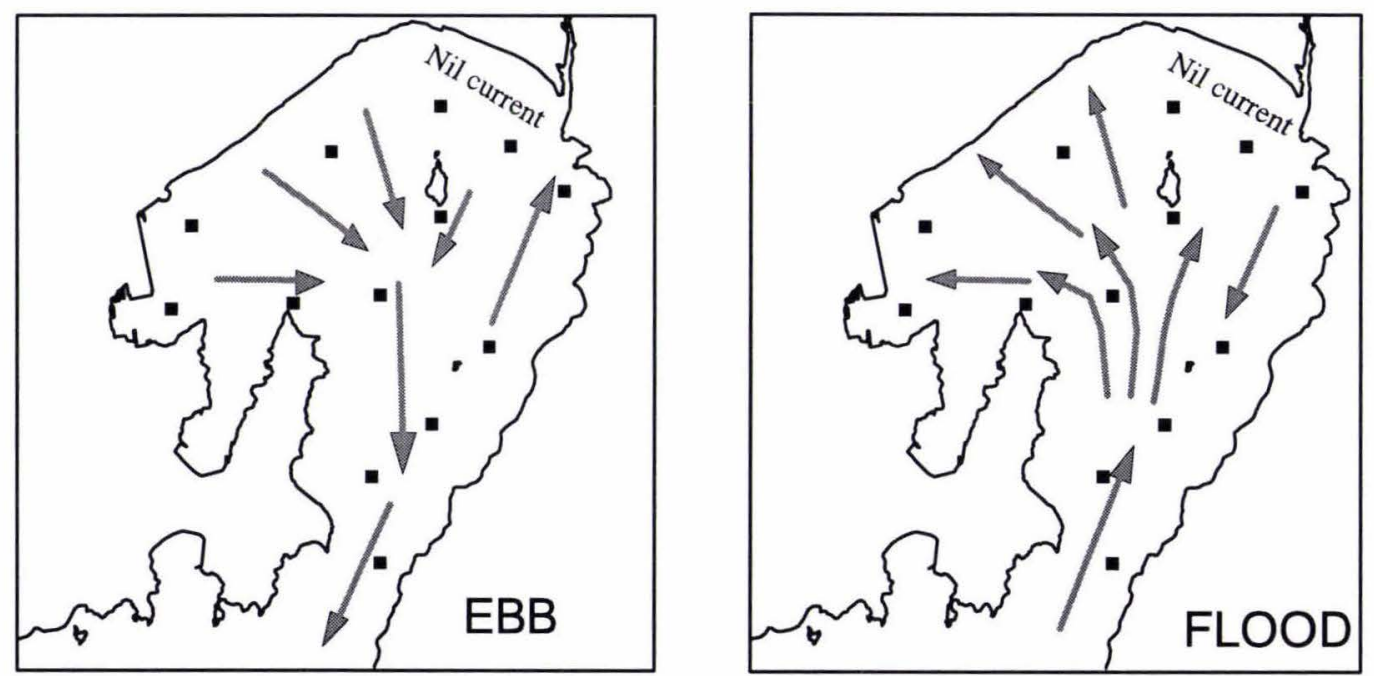

Figure 4.2.2 A model of the tidal flows in Wellington Harbour based on Johnson (1988). The black squares mark the sites where tidal flows were recorded every hour in both ebb and flood conditions tides and over a range of meteorological conditions. Note that Johnson found that the currents between Petone Foreshore and Somes Island were so small that they were below the threshold of the current meters he used (0.02 knots). 


\subsection{Tidal Flow Patterns}

Tides in Wellington Harbour are semi-diurnal (twice a day) with a maximum range of $1.5 \mathrm{~m}$ (Maxwell, 1956). Brodie (1958) showed with fluorescent dyes and floats that the flood (incoming) tidal stream moves in a clockwise direction around the harbour while the ebb (outgoing) tide flows anti-clockwise. Brodie's model has since been generally accepted as the undisputed model for tidal flow in Wellington Harbour (Figure 4.2.1).

However, a more recent study carried out by Commander G.W.D.Johnson of the Wellington Harbour Board (now part of the WRC) in 1988 proposed a slightly different scenario with less circular movement in the harbour. Johnson's study suggests that in an incoming (flood) tide, water flows through the harbour entrance and towards all areas of the harbour, with the opposite occurring during flood tides. However, an anomaly down the eastern side of the harbour exists with the tidal flows in the opposite directions to the rest of the harbour water for both the ebb and flood tides (Figure 4.2.2). This is likely to be an eddy type feature.

\subsection{Tidal flow rates}

Of particular interest to this study are the velocity of tidal flows around basement outcrops on the harbour floor and the flows through the harbour entrance. This would help to explain the present-day sedimentation within the harbour. Assuming tidal flow rates and patterns have changed little during the deposition of the Petone Marine Beds (last 6.500 years) a knowledge of today's tidal regime will help in identifying areas where deposition of aquiclude material would have been restricted in the past (discussed in greater detail in Chapter Seven).

Johnson's comprehensive study used current meter observations to measure the tidal flow under varying meteorological conditions at 13 sites within the harbour (see Figure 4.2.2). He measured tidal flows on an hourly basis for twelve continuous hours at each site obtaining a picture of the complete tidal cycle. Johnson also varied the depths at which he recorded current flow so that a picture of water movement at various depths throughout the entire water column could be obtained. Measurements were performed during both spring and neap tides.

The maximum flow through the harbour entrance was recorded by Johnson at 0.75 Knots $(39 \mathrm{~cm} / \mathrm{s})$ near the sea floor and at 0.80 Knots $(41 \mathrm{~cm} / \mathrm{s})$ halfway through the water column. This can be compared to the previous studies of Brodie(1958) and Heath (1976a cited by Heath (1977)) who noted velocities through the harbour entrance of up to $26 \mathrm{~cm} / \mathrm{s}$ and $50 \mathrm{~cm} / \mathrm{s}$ respectively. 
Heath (1977) used the volume change of the harbour from low to high tide and the cross sectional area of the harbour entrance to calculate flow rates through the harbour entrance. This method gave a maximum flow (assuming typical sinusoidal tidal flow) of $45 \mathrm{~cm} / \mathrm{s}$. Although crude in its design, this method does give a value extremely close to the aforementioned recorded flows of Johnson and Heath (1976).

Typical velocities in the inner harbour were shown by Johnson (1988) to seldom exceed $0.10 \mathrm{Knotts}(5 \mathrm{~cm} / \mathrm{s})$ with the area between the Petone Foreshore and Somes Island usually in the order of 0.04 knots $(2 \mathrm{~cm} / \mathrm{s})$ or less. Brodie's study gave much higher tidal flows in both the inner harbour and along the Petone Foreshore - up to $13 \mathrm{~cm} / \mathrm{s}$.

Heath (1977) used his area/volume relationship to derive a figure for tidally induced currents in the inner harbour. His results showed that current velocities would need to be in the order of $3 \mathrm{~cm} / \mathrm{s}$ in this region of the harbour - a velocity that compares very favourably to Johnson's findings. Johnson's work also showed that tidal flows were not greatly influenced by basement outcrops or headlands. Observations made at Pt Halswell showed a maximum flow of $6 \mathrm{~cm} / \mathrm{s}$.

These findings do not fit with Brodie's flow rates or his circular model of tidal flow, especially along the northern end of the harbour. Given the good correlation of Heath's area/volume relationship with Johnson's findings, it is likely that Johnson's tidal velocities and flow model are more accurate than the currently accepted model of Brodie's.

\subsection{Hydrology}

Booth (1975) found that surface temperature of inner harbour water ranges from $10^{\circ} \mathrm{C}$ in winter (July/August) rising to about $19^{\circ} \mathrm{C}$ in the peak of summer (January/February). A slight thermocline (a change in temperature gradient through the water column) develops in the summer months from December to March, with warmer water overlying slightly cooler water. The thermocline becomes more pronounced during an incoming tide when a wedge of colder Cook Strait water $\left(\sim 4^{\circ} \mathrm{C}\right.$ cooler during the summer months) forces under the warmer harbour water. During, winter, minimum surface temperatures within the harbour are about $1^{\circ} \mathrm{C}$ cooler than in Cook Strait (Heath 1977).

A picnocline (change in density) is observed near the Hutt River mouth with lower density 'freshened' water sitting as a thin layer on top of the denser 'normal' sea water (Heath, 1977). Sea surface salinity variations were also noted by Brodie (1958). Many of his readings were seemingly not related to any river outflow due to their isolated locations in the harbour entrance (north of the Falcon Shoals area) and in both the western and eastern harbour margins. The lowest salinity values recorded were $22 \%$ (parts per thousand) to 
the east of the top of Miramar Peninsular at the northern end of the harbour entrance ('normal' seawater has a salinity of $\sim 34.5 \%$ ). These were recorded at high tide. Brodie also states that low salinity water $(30 \%)$ was detected along the eastern harbour margin at both low and high water. However, given that the close proximity of the eastern harbour margin with the Hutt River outlet, we cannot preclude the possibility that this water may have been 'freshened' by the discharge from the Hutt River, rather than by SGWD.

Due to the density differences between salt and fresh water, mixing does not occur readily and during periods of flooding, tongues of brown, sediment laden, less saline water can often be seen emanating from the Hutt River mouth into the harbour. Brodie (1958) found that the distribution of this water once it left the Hutt River mouth was almost entirely dependent on the wind. Under a northerly or north-westerly wind, the river outflow is confined to a narrow zone down the eastern shore of the harbour, while during a southerly it gets pushed against the northern end of the harbour, along the Petone Foreshore.

Booth (1975) showed that the lower salinity surface water could be found to a depth of $5 \mathrm{~m}$, but work done as part of this research showed that while this is true close to the Hutt River mouth, this layer actually thins to a fine wedge at its extremities. Booth (1975) also states that the lower salinity surface water can be traced as far south as Somes Island. This study found that Hutt River surface water could be detected even further south under a combination of elevated river discharge and strong northerly winds, and across the entire harbour width adjacent to Petone foreshore during a southerly.

As such, care must be taken when measuring and interpreting the salinity of the harbour water. 


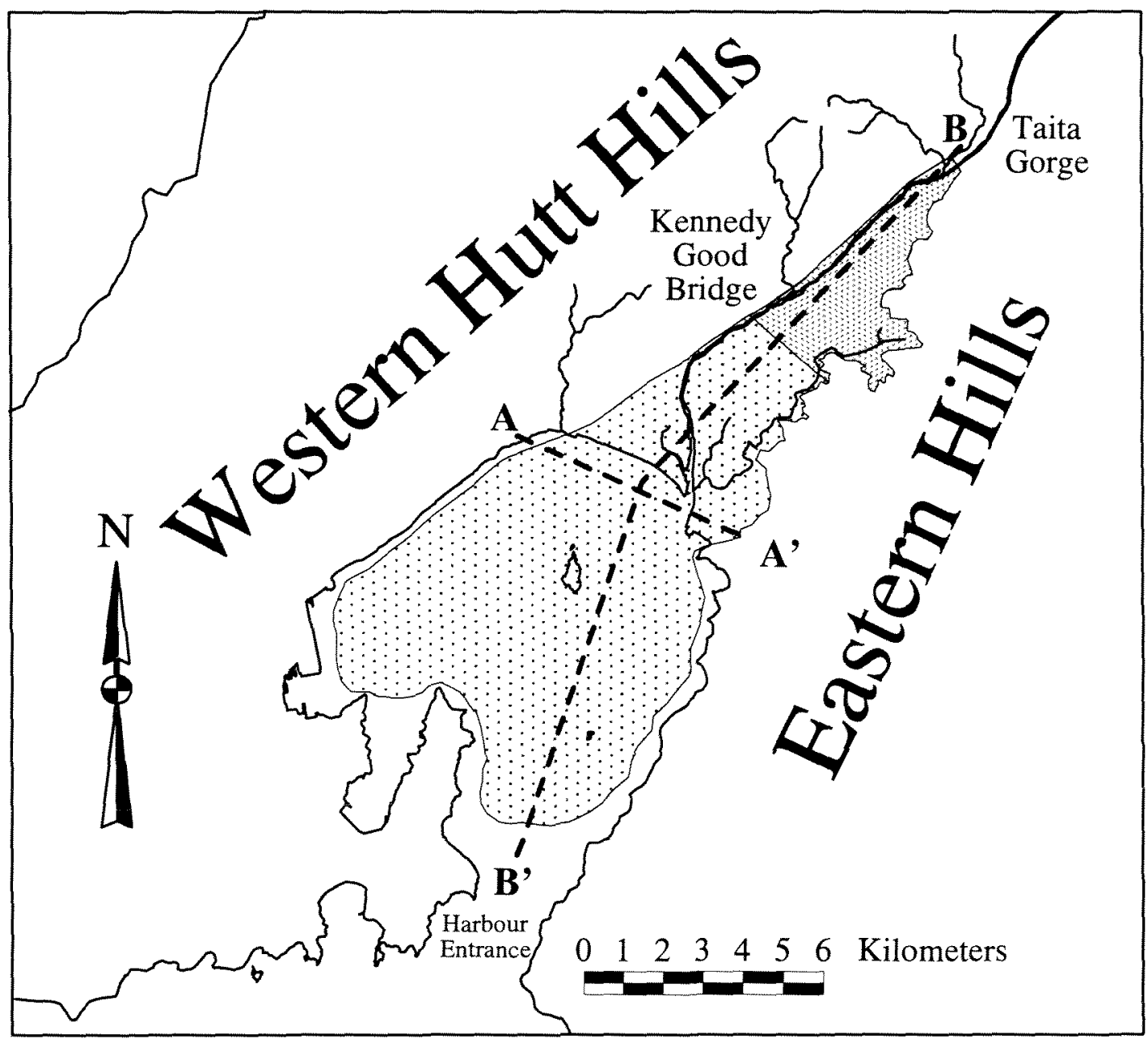

Figure 5.1.1 Diagram showing the spatial extent of the Waiwhetu Artesian Aquifer based borehole data in the landward portion, and on seismic information in the sub-harbour portion (see Chapter Eight). The aquifer is unconfined in the northern part of the Lower Hutt Valley from Taita Gorge to the Kennedy Good Bridge (fine stipple). The aquifer is then confined, first by the Melling Peats formation, and then by the Petone Marine Beds formation to the harbour entrance region (coarse stipple). A more detailed examination of the southern extent is discussed in Chapter Eight. The dashed lines $A-A^{\prime}$ and $B-B$ ' mark the cross-sections in Figures 5.3.2 and 5.3.3 respectively. 


\section{Chapter Five}

\section{GEOLOGICAL SETTING}

\subsection{Introduction}

The Waiwhetu Artesian Aquifer is contained within an alluvial basin comprising the Lower Hutt area and Wellington Harbour (Figure 5.1.1). The basin is defined by Taita Gorge in the north, the Eastern Hills to the east, and the Western Hills to the west. The bounding structure to the south is poorly defined, but is considered to be between Somes Island and the entrance to Wellington Harbour (Stevens 1955, 1956b, 1974; Davy and Wood, 1993; amongst others). Chapter Eight discusses the southern extent of the aquifer in great detail.

The Waiwhetu Artesian Aquifer is one of the most studied and actively monitored aquifer systems in New Zealand (pers. comm. Tony Cussins, WRC, 1996). This is a reflection of its importance of supplying water to a large population in the Wellington metropolitan area. Its importance as a water supplier is compounded by the fact that it has also been identified as the foremost aquifer in New Zealand that requires more research (pers. comm. Brydon Hughes, WRC, 1997).

To fully understand the relationship between the groundwater within the basin and the submarine springs that are present on the harbour floor, we must first look at the structure of the basin in which the sediments sit. We must also consider the processes that formed, and are continuing to modify the structure of the basin (the tectonics), and the sediments themselves (the stratigraphic record).

\subsection{Tectonic Setting}

The present day tectonic setting of the North Island, New Zealand is dominated by the oblique subduction of the oceanic Pacific Plate beneath the continental Indo-Australian Plate (Van Dissen and Berryman, 1996). The oblique component of subduction is accommodated by a transcurrent fault belt which trends NE-SW, roughly parallel to the subduction zone (Dunbar, 1994). In the Wellington region, this belt contains four major faults - the Shepherd's Gully Fault, the Ohariu Valley Fault, the Wellington Fault and the Wairarapa Fault (Figure 5.2.1). These four primary faults were once considered to represent the North Island continuations of major South Island faults, but recent seismic evidence does not support this view. It is now believed that the faults of the North and 
South Islands (with the possible exception of the Wairau Fault) terminate in the central Cook Strait along an apparent dextral offset (Carter et al, 1988).

The relative movement of the two plates at the latitude of Wellington varies between estimations of $\sim 40 \mathrm{~mm} / \mathrm{year}$ (Van Dissen and Berryman, 1996) to $\sim 50 \mathrm{~mm} / \mathrm{yr}$ (Berryman, 1990). Based on a relative movement of $50 \mathrm{~mm} / \mathrm{yr}$, Berryman suggests that because of the angle of collision, this results in about $38 \mathrm{~mm} / \mathrm{yr}$ of shortening and $32 \mathrm{~mm} / \mathrm{yr}$ of strike-slip (transcurrent) motion. The four major Wellington region faults account for as much as 80 $100 \%$ of this strike slip component of the relative plate motion with a ratio of horizontal slip to vertical slip of around 10:1 (Ota et al, 1981).

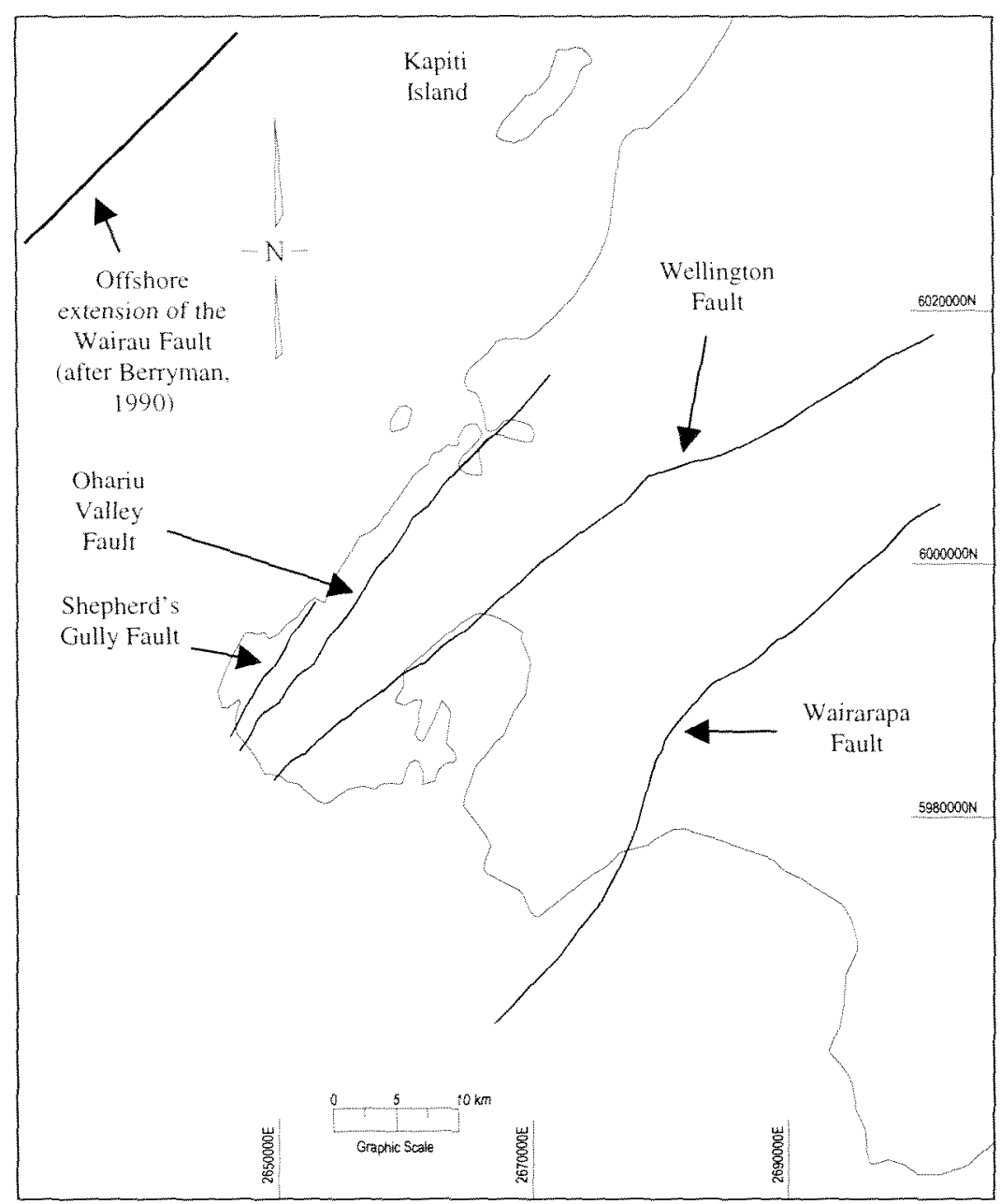

Figure 5.2.1 Location of the major active faults in the Wellington Region (after Dunbar, 1994). The co-ordinate system shown is the New Zealand Map Grid.

Stevens (1974) suggests that during the Pliocene, the various Wellington region faults started to move in a new phase of earth movements. The old peneplain rocks were pushed up, folded and tilted as a series of fault angle blocks. 


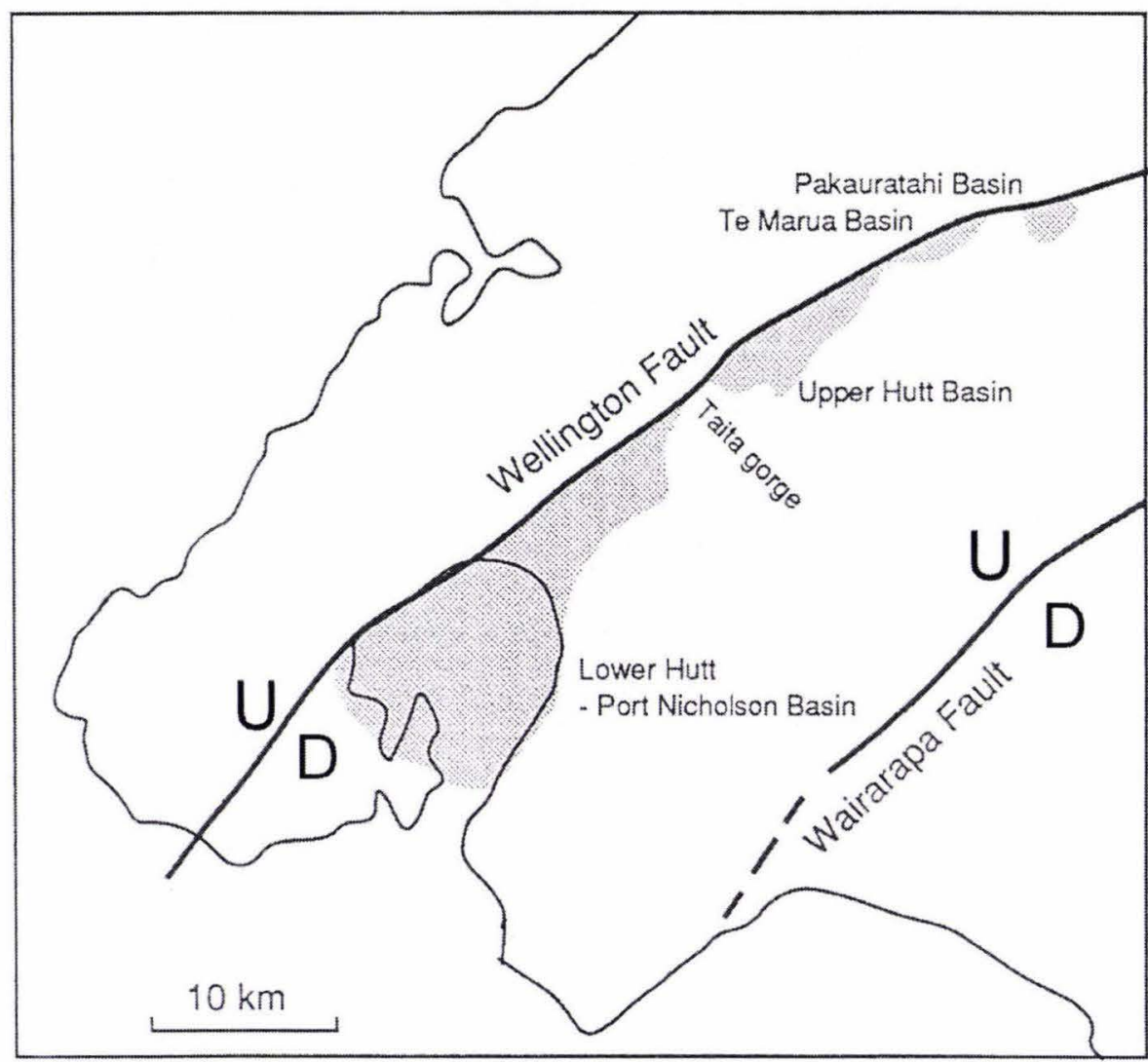

Figure 5.2.2a Compression of the fault block adjacent to the Wellington Fault has caused a number of basins to form on the downwarped side. The Lower Hutt

- Port Nicholson Basin is the largest (after Dunbar, 1994).

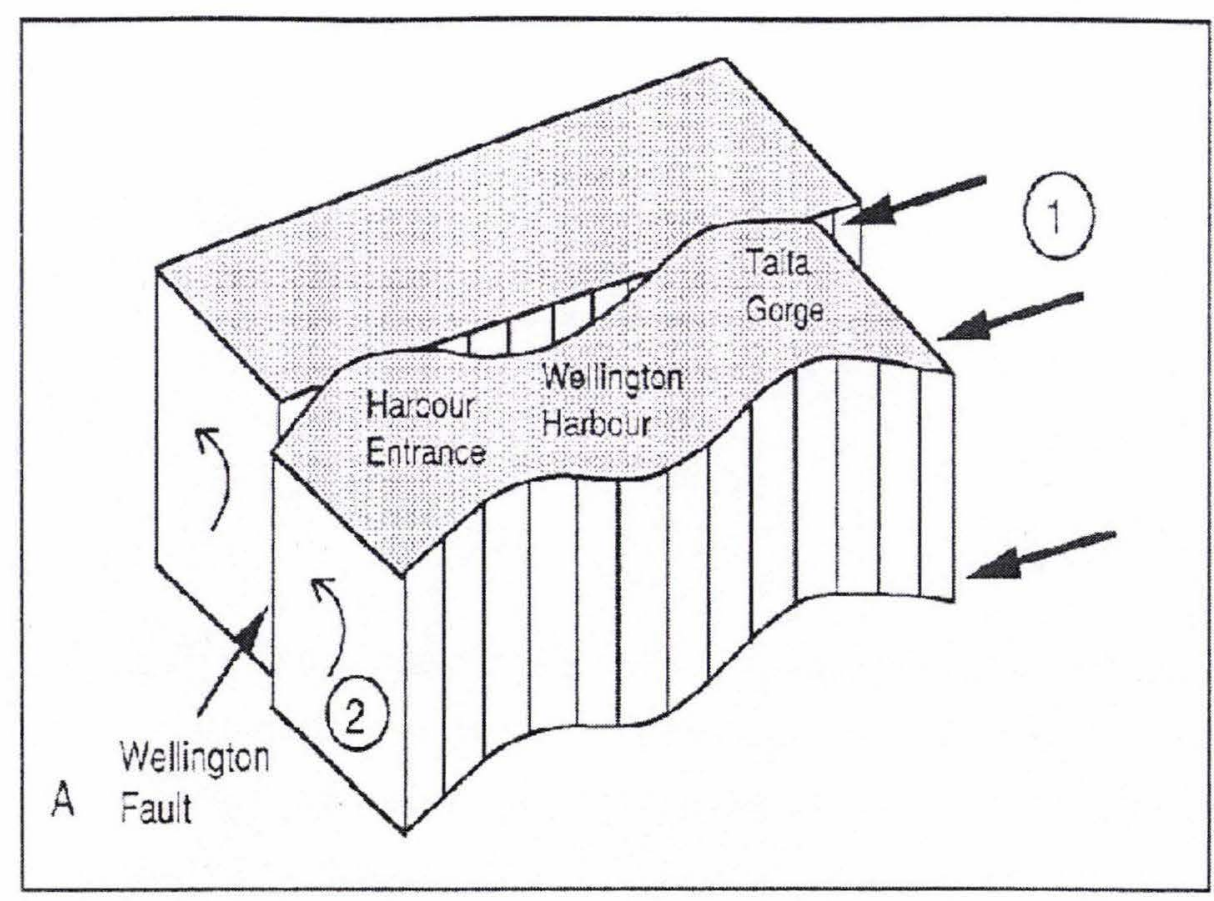

Figure 5.2.2b Block diagram showing the shortening and consequent folding (1) of the Hutt Valley block during the Tertiary. Subsequent tilting (2) has rotated the fault blocks towards the west (after Dunbar, 1994). 
However Suggate et al (1978) suggests that it was not until the mid-Quaternary that basin development proceeded at a significant rate, when movement on the Wellington Fault was "newly initiated". Movement on the Wellington Fault is accompanied by a compression of the fault block. This has caused a series of basins to form on the eastern (downwarped) side, adjacent to the fault (Figure 5.2.2a).

This idea of basin formation through compression was first recognised by Cotton (1956) who proposed that compression was manifested as a form of transcurrent buckling. He argued that evidence of this process and its consequences could be observed in many places in New Zealand where horizontal compression was taking place. Lauder (1962) developed this idea further and applied it to the Wellington region, with the idea of a 'plough' mechanism (essentially compression) on the Wellington Fault as the means of basin formation. Four recognisable basins were formed alongside the Wellington Fault as a result of this transcurrent buckling. They are the Lower Hutt - Port Nicholson, Upper Hutt, Kaitoke and Pakuratahi basins. These basins decrease in size as you move northwards along the fault. It is the southernmost and largest one, the Lower Hutt - Port Nicholson basin that this study is primarily interested in.

Much work has been carried out to determine the dimensions and structure of the Lower Hutt - Port Nicholson basin and in doing so, establish the thickness of the sediments within it. Cowan and Hatherton (1968) used gravity measurements to obtain a good idea of the basement rock morphology beneath Wellington Harbour. The residual gravity anomaly map they produced of the harbour provides a good impression of the warped nature of this greywacke basin. They estimated that the maximum sediment thickness in the harbour was between 3000 to 4000 feet (roughly 900 - 1200 metres) offshore from Ngauranga Gorge. Their work also led them to propose that the Wellington Fault is nearly vertical, lying about $300 \mathrm{~m}$ east of the present-day fault scarp.

Seismic surveys have also been used to determine the morphology of the harbour basin. Hochstein and Davey (1974) used seismic data to obtain a sub-harbour basement structure that was very similar to that produced by Cowan and Hatherton (1968). Both surveys acknowledged the presence of a basement ridge running roughly in line with the Miramar Peninsular, through Somes Island, and up through the Hutt Valley. This ridge separates two sub-basins - a deeper one to the west (deepening closer to the Wellington Fault) and a shallower one on the east. However, Hochstein and Davey (1974) concluded that the basin reaches a maximum depth of just over $400 \mathrm{~m}$ to the east of Ngauranga Gorge, as opposed to the $900-1200 \mathrm{~m}$ thickness hypothesised by Cowan and Hatherton (1968). The discrepancy between the results was reasoned by Hochstein and Davey (1974) to be "a systematic error" with regards to the earlier gravity measurements. 


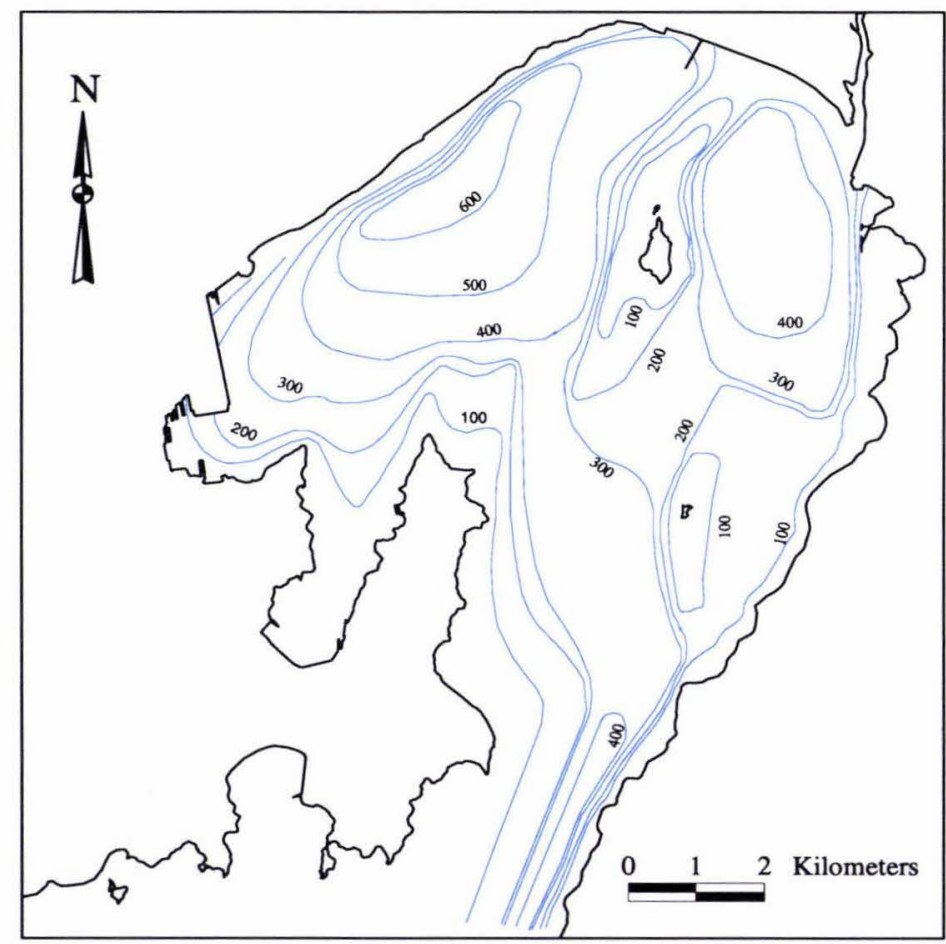

Figure 5.2.3a Map showing contours of depth to basement (metres below sea level) for Wellington Harbour, based largely on Wood and Davy (1992). Note the two deep basins separated by the Somes Island ridge and the deep channel running through the harbour entrance.

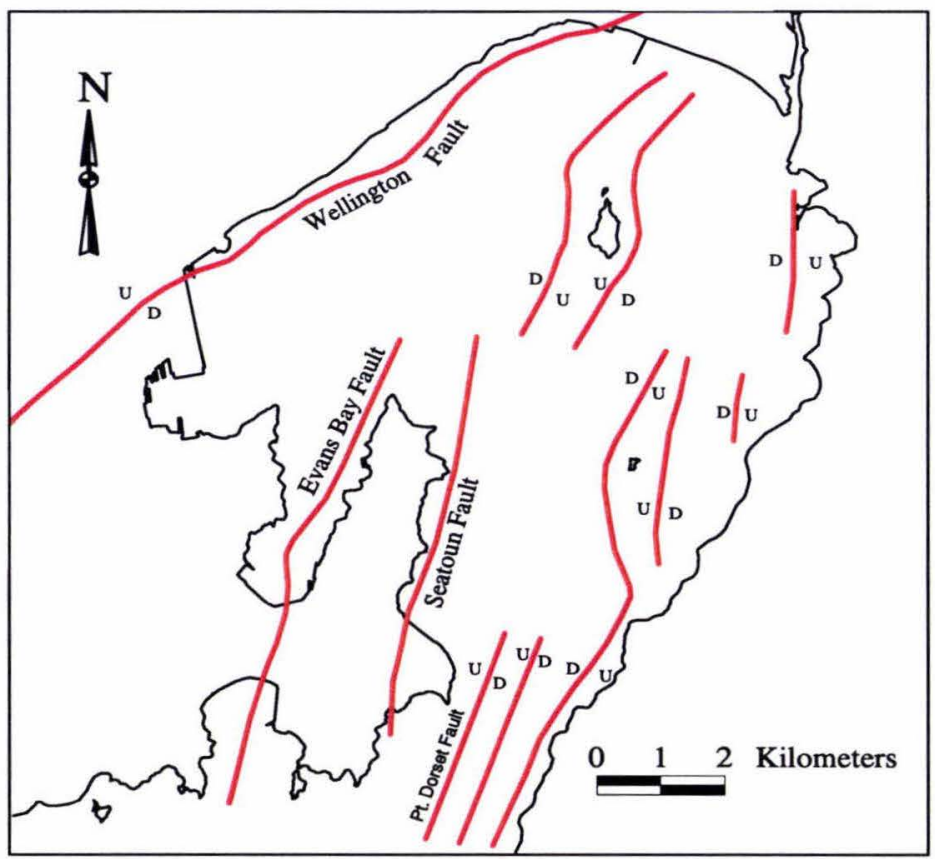

Figure 5.2.3b The major active faults in Wellington Harbour as identified by Wood and Davy (1992), Davy and Wood (1987), and Huber (1992), amongst others. 
More recently, Wood and Davy (1992) used geophysical data collected in 1991 to produce a basement structure map similar, but not identical, to that generated by Hochstein and Davey (1974). The main difference between their work and that of Hochstein and Davey (1974) concerns the depth of the two sub-basins. The maximum depth of the western subbasin was found to be close to 700 metres deep offshore from Ngauranga Gorge adjacent to the Wellington Fault. The maximum depth of the basin to the east of the Somes Island ridge was interpreted to be just over 400 metres deep.

Figure 5.2.3a shows the basement contours of the harbour (in metres below sea level) as used in this study. It is contoured at $100 \mathrm{~m}$ intervals and is based largely on the map generated by Wood and Davy (1992). The seismic lines interpreted by Wood and Davy (1992) were re-examined in detail and the basement picks were checked on all lines. At one location (near Eastbourne) the basement picks were found to not correlate on intersecting lines. These lines were then re-interpreted and the subsequent changes were made to the basement picks. Other changes made to the original basement contour map of Wood and Davy (1992) include a deepening of the area between the uplifted Ward and Somes Island basement blocks, plus a more detailed structure around both islands. The basement map shown in Figure 5.2.3a incorporates these changes.

One interesting feature is the extremely deep channel running through the eastern side of the Harbour Entrance. The depth to basement through the Harbour Entrance was determined from geophysical investigations carried out by Davy and Wood (1987). Although their findings were far from conclusive, the evidence they collected suggests that an extremely deep channel runs through the Harbour Entrance adjacent to its eastern margin. The model that Davy and Wood (1987) propose is a faulted graben, as it is very improbable that the channel could have been formed in any other way. It is certainly too deep for the ancient Hutt River to have cut given that sea level was lowered by a maximum of around $120 \mathrm{~m}$ during the last glaciation.

With regards to this fault-controlled graben, the vertical offset on the fault through the centre of the harbour entrance (see Figure 5.2.3b) is over 300 metres. The eastern most fault shown in the diagram was not found during their investigations (probably because their survey felt short), but is assumed to be present due to the offset necessary to raise the basement back up above sea level. This fault would have a vertical offset of over 400 metres. In figure 5.2.3b this missing fault has been linked with the fault that uplifts the Ward Island block However, this is not based on any actual evidence and as such is speculation. The faulting structure through the harbour entrance will be discussed in greater detail in Chapter Eight.

The faults shown in the main part of the harbour are taken from Wood and Davy (1992). These fault traces are by no means the only ones present within the harbour, but they do 
represent the most significant faults that appear to have been active in the recent past. The entire harbour basin is heavily faulted according to the seismic interpretations of Wood and Davy (1992). Faulting is particularly common along the western side of the harbour associated with the Wellington Fault, the eastern basin and along the eastern harbour margins, and the areas around the uplifted Somes and Ward island blocks. There is some dispute over the faulting structure around Somes Island, but the model proposed by Wood and Davy (1992) has been accepted for the purposes of this research.

\subsection{Stratigraphy}

Due to the numerous bores drilled throughout the Lower Hutt Valley for water supply purposes, much sub-surface information is available upon which we can use to describe the various stratigraphic units within the basin.

A cross section through the valley from Horokiwi to Seaview (see A-A', Figure 5.1.1) is shown in Figure 5.3.1. This cross section was compiled from bore hole interpretations and seismic line information collected and interpreted by Wood and Davy (1992).

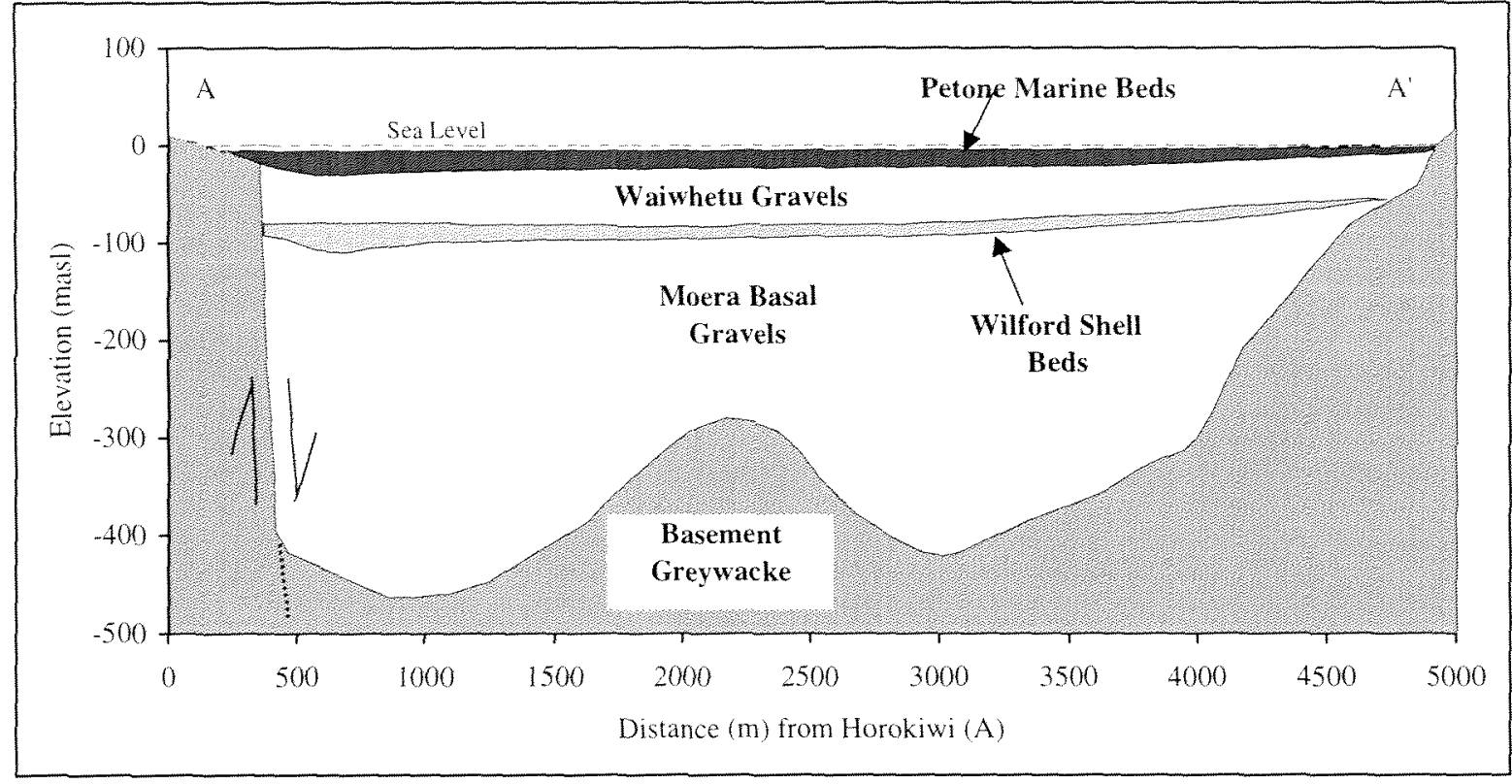

Figure 5.3.1 Cross-section across the Lower Hutt Valley along Petone Foreshore (see Figure 5.1.1 for location). Note that the upper units dip to the west, highlighting the post-deposition movement of the region. The basement greywacke ridge represents the northern extension of the Somes Island horst block and divides the basin into two sub-basins, aligned north-south.

Figure 5.3.1 shows a basement ridge just over $2 \mathrm{~km}$ from the western side of the harbour (A). This ridge is an extension of the block of uplifted greywacke that Somes Island is a part of. This basement ridge divides the basin into two smaller sub-basins trending northsouth. The basin to the west of the ridge is the deeper of the two and this is demonstrated quite clearly by the basement contour map (Figure 5.2.3a). 
As demonstrated in Figure 5.3.1, all units deposited after the Moera Basal Gravels (or Moera Gravel Aquifer) thin towards the east and dip towards the west. This is a result of the tilting of this Wellington block via tectonic movements on the Wairarapa Fault coeval to the deposition of the post Moera Gravels Aquifer member. Given that confined artesian water will flow to areas of lowest pressure, we could expect to find the highest waterbearing gravels towards the eastern side of the basin i.e. up dip.

The north-south longitudinal cross-section from Taita Gorge to the harbour entrance (see B - B' in Figure 5.1.1 for location) is shown in figure 5.3.2. This cross section was compiled from seismic line information collected by Wood and Davy (1992).

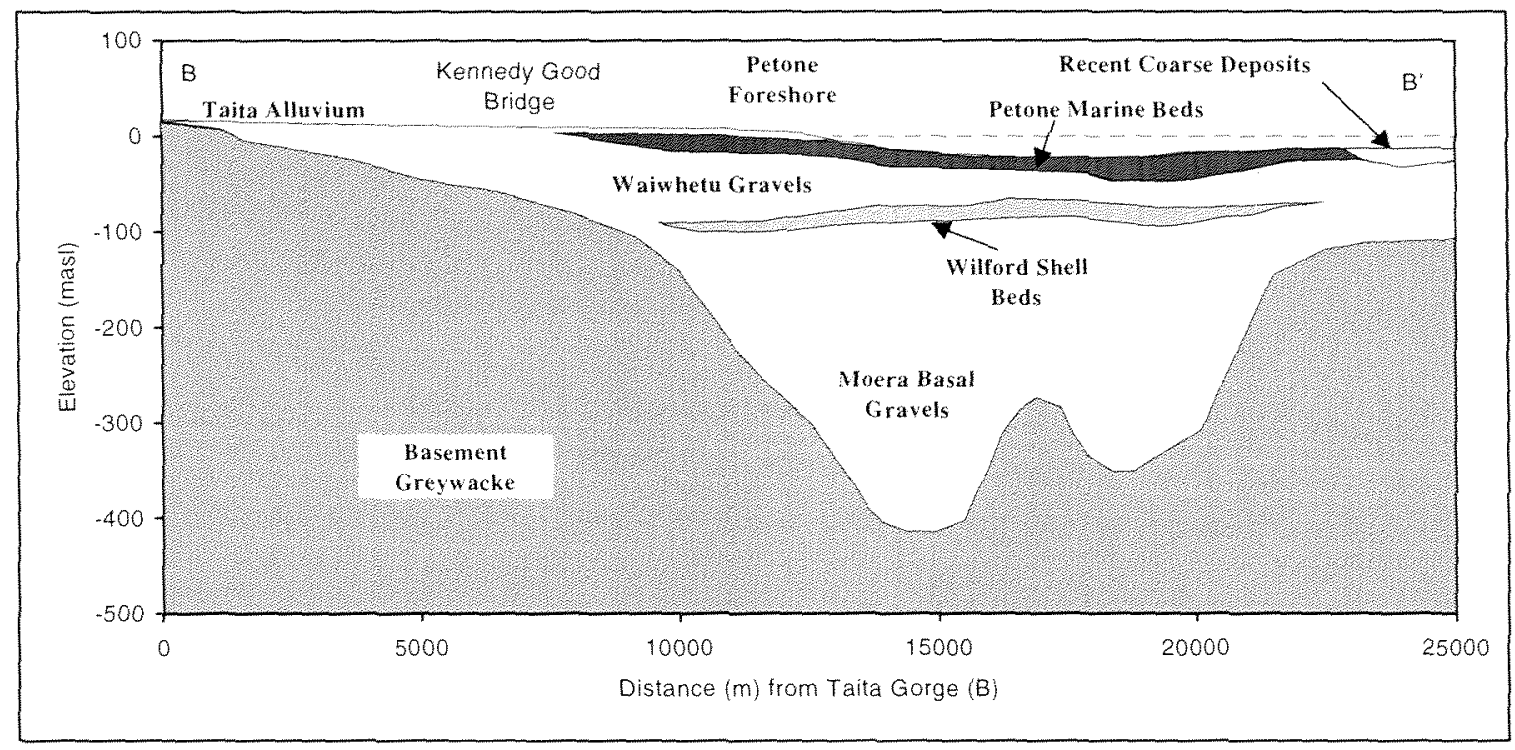

Figure 5.3.2 Longitudinal cross-section down the valley (orientated north-south) from Taita Gorge (B) to the harbour entrance (B). Note the connection of the confined and unconfined aquifers north of Kennedy Good Bridge. The small rise in basement at around $17 \mathrm{~km}$ from Taita Gorge represents a shallowing of the basement between Somes Island and Ward Island.

As can be seen in Figure 5.3.2, the Waiwhetu Artesian Aquifer is unconfined in the northern section from Taita Gorge (B) to the Kennedy Good Bridge. From the Kennedy Good Bridge south the aquifer is confined first by the Melling Peats and then by the Petone Marine Beds (shown as one unit due to the fact that they were deposited concurrently). The Petone Marine Beds peter out towards the harbour entrance whereupon the aquifer becomes unconfined once more (this is discussed in greater detail in Chapter Eight). Coarser deposits transported from the south coast then overlie the aquifer gravels. The Taita Alluvium overlies the Waiwhetu Aquifer deposits in the unconfined section, and then forms a thin veneer over the Petone Marine Beds, extending to the foreshore region. According to Stevens (1955), greywacke basement rock is only $18 \mathrm{ft}$ (6metres) deep across Taita Gorge. 


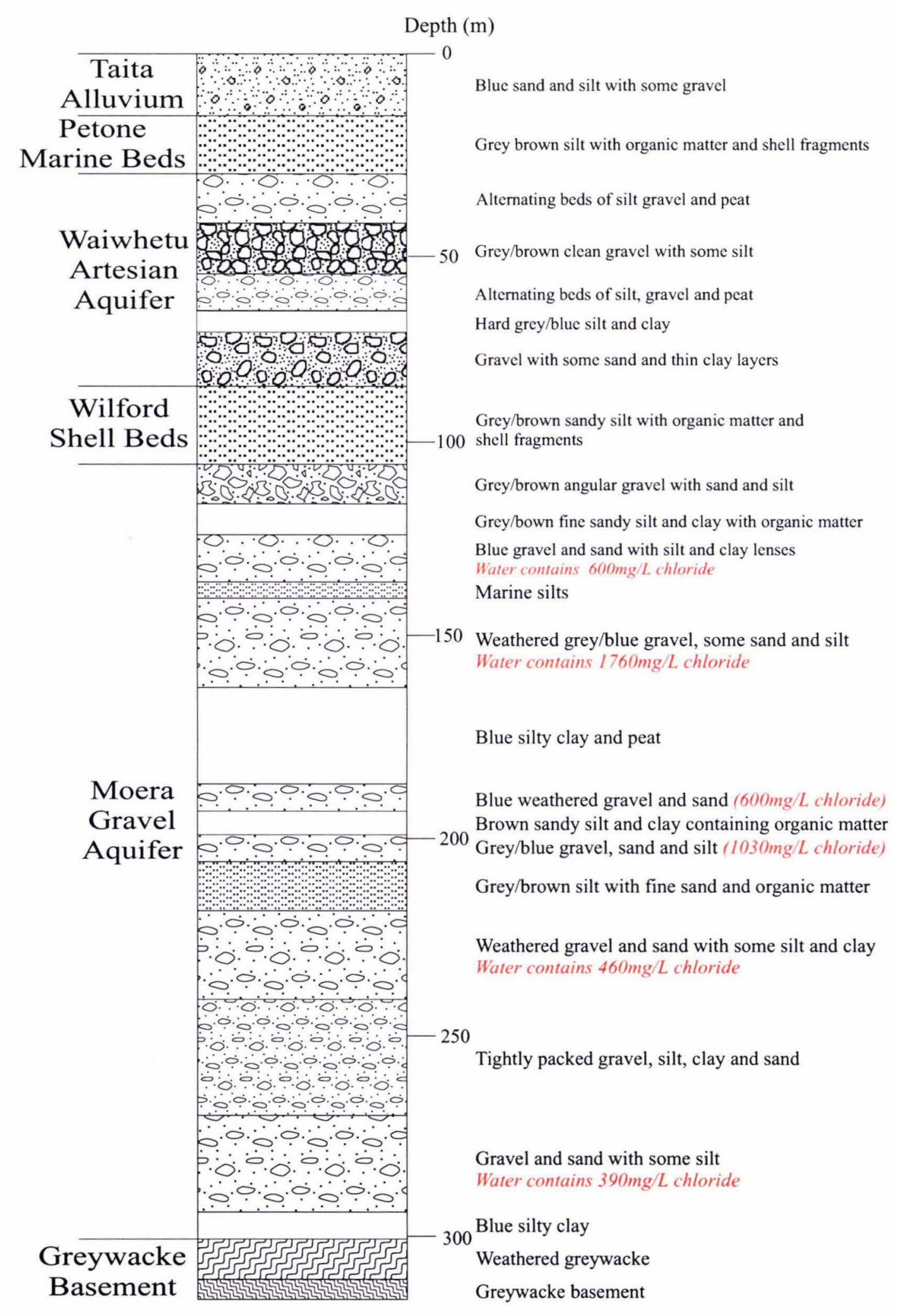

Figure 5.3.3 Interpreted bore log from the Gear Meat Company production well (after WRC, 1995). The location of this bore is on the western side of Petone, about 100 metres from the foreshore, just west of the Petone Pier. It is the deepest well drilled in the Lower Hutt Valley, and as such has been used by previous researchers as the Type Section for the sediments within the Lower Hutt - Port Nicholson Basin. 
The following description of units is based on material in the previously mentioned Wellington Regional Council report on the Hydrology of the Hutt Catchment (referenced as WRC, 1995). Much of the material within this report is based on work done by Stevens (1955, 1956b, and 1974), Hutton (1965), research carried out by Donaldson and Campbell (1977), and seismic information collected by Davy and Wood (1993).

To aid the description of the units, an interpreted bore log, from the Gear Meat Company (near the Petone Foreshore, just to the west of the Petone Pier), is shown in figure 5.3.3.

Moera Gravel Aquifer: Only eight boreholes penetrate the Moera Gravel Aquifer thus making it difficult to confidently describe this unit in great detail. However, from these eight bores, four distinct lithological units can be identified.

- An upper succession of weathered gravels

- A section of marine sands and silts

- A thin layer of silt and peat beds, and

- A thick succession of tightly packed gravel, sand and silts above basement (WRC, 1995)

This unit extends over 200 metres in thickness and forms a single hydrogeological unit known as the Moera Gravel Aquifer (also referred to as the Moera Basal Gravels).

Two groundwater units have been identified by Hutton (1965) within the Moera Gravel Aquifer; a lower unit of saline water with highly variable concentrations of salt, and an upper unit of freshwater, between 16 and 60 metres thick. It is not clear whether the saline water is connate water (trapped during sedimentation), or present because of salt-water incursion subsequent to deposition. However, due to the sedimentation history of these layers, it is more likely that the salt-water present is connate.

The various units within this member have comparable artesian pressures indicating complete hydraulic connection. The permeability of the Moera Gravel Aquifer is low due to a high clay content resulting from the weathering of aquifer materials. The piezometric head in this aquifer is between one and two metres higher than that of the Waiwhetu Artesian Aquifer (Hutton, 1965).

Wilford Shell Beds: The Wilford Shell Beds are an aquiclude between 17 and 22 metres thick, occuring at depths ranging from 70 to 83 metres at the Petone Foreshore. This unit thins and becomes shallower toward the eastern side of the valley reflecting the concurrent tectonic movements along the major faults in the Wellington region during the deposition of this member. 
The upper section of this unit is comprised of 12 metres of silt, while the lower 7 metres is comprised of alternating beds of gravel and silt which contain shell fragments (Stevens, 1956b).

By analysing the difference in hydrological parameters measured in the aquifers above and below this unit, we can assume that this aquiclude is continuous and of low permeability. It probably extends inland at least as far as the Waterloo Wellfield, and as far south as the harbour entrance vicinity.

Waiwhetu Artesian Aquifer: This is the major artesian aquifer in the Lower Hutt Groundwater Zone. The materials comprising this unit are highly heterogeneous, ranging in size from coarse gravel to clay. The aquifer is comprised of channelised alluvial gravels as well as irregular overbank silt, clay and swamp deposits. The highly permeable gravels which form the best water bearing layers are separated by discontinous lenses of peat, silt and clay. Analyses of bores drilled throughout the Lower Hutt Valley testify to the limited lateral extent of these lenses. This is not unusual given the nature of formation of alluvial gravel aquifers.

Bore hole data shows that this member can be mapped to the northern extent of the Lower Hutt - Port Nicholson basin at Taita Gorge where it sits on top of the Moera Gravel Aquifer deposits and beneath the Taita Alluvium as an unconfined aquifer. From the Kennedy Good Bridge south, the aquifer deposits are confined above by the Melling Peats and the Petone Marine Beds. Seismic line data collected by Davy and Wood (1993) indicates that the Waiwhetu Artesian Aquifer is widespread across the entire width and length of the harbour to the harbour entrance (and possibly through it). Chapter Eight discusses the extent of the sub-harbour aquifer deposits in detail.

The thickness of the Waiwhetu Artesian Aquifer beneath the Lower Hutt Valley varies between 47 and 56 metres. Due to the regional westerly dip of the basin deposits, the thickest deposits are close to the Wellington Fault, with a general thinning towards the eastern hills. In general, the water bearing capacity decreases with depth, and increases towards the east (up-dip). The piezometric head in this aquifer is between one and two metres lower than that of the Moera Gravel Aquifer.

Petone Marine Beds: Along with the Melling Peats formation, the Petone Marine Beds form the upper aquiclude to the Waiwhetu Artesian Aquifer. They are comprised of silts and clays of marine origin. They form the present day harbour floor and the unit can be mapped from bores as extending about $2.5 \mathrm{~km}$ inland from Petone Foreshore. At their northern extremity, they become less defined and interdigitate with the Melling Peats. Their southern extent and the characteristics of the sub-harbour Petone Marine Beds are discussed in greater detail in Chapter Eight. 
Melling Peats: Continuing on from the Petone Marine Beds, the Melling Peats (which are in fact interbedded lenses of terrestrial silty sand, silt-packed gravels, clay and peat), extend the aquiclude for a further 1500 metres inland. Thus the northern extent of the upper aquiclude is about $4 \mathrm{~km}$ from the Petone Foreshore - to roughly the Kennedy Good Bridge vicinity. It is likely that the Melling Peats and the lower members of the Petone Marine Beds were deposited concurrently, at the time of the Post-Glacial Climatic Optimum $\sim 6,500$ years ago.

Taita Alluvium: The Taita Alluvium represents a thin (less than 10 metres thick) veneer of alluvial gravels deposited in recent times by the Hutt River. It extends north of the unconfined/confined artesian boundary and overlies the Waiwhetu Gravels forming the unconfined aquifer. South of the unconfined/confined boundary, a thin layer of Taita Alluvium overlies the Melling Peats/Petone Marine Beds aquiclude forming a shallow unconfined aquifer extending to the Petone Foreshore region.

\subsection{Sedimentation History}

The initial stages of sedimentation within the Port Nicholson basin are fairly complex given the few bore logs from which information can be obtained on the lower units. As described previously, Suggate (1978) proposes that basin development (formed by movement on the Wellington Fault) didn't really progress at any significant rate until the mid Quaternary Period (around 1 million years ago). Prior to this time the ancient Hutt River flowed northwest towards Porirua Harbour. It was during the mid-Quaternary that Suggate (1978) suggests that the drainage of the region was then reorganised by the "newly initiated Wellington Fault". As such, the basal layer within the Moera Gravel Aquifer comprising of "tightly packed gravels, sand and silts" (WRC, 1995), is likely to be midQuaternary in age. Given that the Quaternary Period is characterised by a number of glacial events separated by warmer interglacials, the coarse sediment characteristic of the lower Moera Gravel Aquifer is likely to have been generated via freeze/thaw weathering during a glaciation.

It is unclear how extensive these lower deposits of the Moera Gravel aquifer are across the harbour as only one bore penetrates this deep, and this is located at the western end of Petone Foreshore, close to the Wellington Fault. However, the presence of silts in the "tightly packed gravels, sands and silts" probably represent fluvial overbank deposits. Given that overbank deposits are something we associate with flooding, we can assume that the river may have been able to transport and deposit this coarse material across much of the Lower Hutt - Port Nicholson Basin in a braided river type scenario. It must have remained this way for some time given the great thickness of these deposits. 
The presence of silts and peat on top of this initial deposition of coarse sediment indicates that the climate was continuing to warm, and was now certainly warm enough to support extensive vegetation. The climate after this deposition of silt and peats is unclear, but the thick deposit of "marine sands and silts" (WRC, 1995) indicates that relative sea level had risen enough to flood the present Lower Hutt Valley. This could either have been due to tectonic activity lowering the land to a level that allowed the sea to flood much of the basin, but is more likely attributable to melting polar ice as a result of a warming climate.

Following this phase, another glaciation took hold, causing temperatures and sea level to drop. Once again, large amounts of material were made available for deposition within the basins during this colder regime due to intensive physical weathering. However, the lack of water in its liquid state meant that much of this material remained close to its source. Basin formation due to compression on the Wellington Fault was probably still a very prominent process and the fault angle depression alongside the Wellington Fault received much of this weathered greywacke of this glacial phase. This is shown by the extremely thick deposits alongside the Wellington Fault we now associate with the upper gravel layer of the Moera Gravel Aquifer. The ancient Hutt River is probably responsible for the deposition of these coarse sediments within this fault angle depression.

As this glacial period ended and the interglacial followed, temperatures warmed, sea level rose, and the valley was flooded by the Flandrian sea incursion. It was during this time that the Wilford Shell Beds were deposited.

Immediately following the deposition of the Wilford Shell Beds, temperatures dropped once again with sea level following suit. The present day harbour once again became a dry river valley. Coarse sand and gravels, were once again transported down the valley and deposited. The analysis of bore logs that show that these deposits of the Waiwhetu Artesian Aquifer sit conformably on top of the Wilford Shell Beds. As such, the deposition of the Waiwhetu Artesian Aquifer must have begun immediately following the drop in sea level.

Stevens (1956b) proposes that the sediments of the Waiwhetu Artesian Aquifer were deposited as deltaic deposits in a prograding river scenario. Bore logs show a fining down sequence of sediments - indicative of deltaic progression, thus providing supporting evidence to this hypothesis. Given that the climate was warming following the end of the glaciation, sedimentation must have been very rapid to keep up with the Flandrian sea incursion. Indeed, Stevens (1956b) states that some $200 \mathrm{ft}(61 \mathrm{~m})$ of gravels and sands were deposited in this prograding river scenario.

Stevens (1956b) noted that no marine foraminifera are found within this section, also providing evidence for its fluvial origin. 
The migrating nature of the Hutt River at this time is evident by the many lenses of fine sands and silts common throughout the Waiwhetu Artesian Aquifer member. These are present as a result of overbank deposits that occurred during times of flooding. These lenses are not continuous across the entire width of the valley as shown by the consistent overall piezometric pressures that exist laterally throughout the entire Waiwhetu Artesian Aquifer member (indicating hydraulic connection of the artesian water). However, localised aquifer transmissivities and permeabilities can vary quite remarkably from place to place as a result of the variation in material that is encountered within the Waiwhetu Artesian Aquifer. It is also likely that preferential flow paths exist within these deposits where the main river channel was stable for long periods. Preferential pathways represent zones where groundwater flow rates are higher than in adjacent areas. The deposition of the sub-harbour Waiwhetu Artesian Aquifer gravels and the development of preferential pathways will be discussed in greater detail in Chapter Eight.

After this period of intensive deposition of material within the Lower Hutt - Port Nicholson Basin, the Flandrian sea finally overwhelmed and halted the deltaic progression. This was due possibly as a result of a waning of material available for transportation from the upper catchment, but more likely as a result of a combination of downthrow of the basin on the Wellington Fault and a final rise of global temperature causing sea level to rise.

The thermal maximum was reached about 6,500 years ago. At that stage, relative sea level was approximately $6 \mathrm{~m}$ higher than what it is at present in the Hut Valley. Tectonic movements and sedimentation within the valley since that time have raised the land to its present level, thus lowering the relative sea level.

In the period following the thermal maximum, the Petone Marine Beds were deposited. This layer of fine silt now forms the aquiclude to the Waiwhetu Artesian Aquifer. It extends from $2.5 \mathrm{~km}$ inland from Petone Foreshore and thins out towards the harbour entrance. At their northern extremity, the Petone Marine Beds become less defined and interdigitate with the Melling Peats which extend the aquiclude a further $1.5 \mathrm{~km}$ inland. The present day harbour floor is essentially the upper surface of the Petone Marine Beds and thus material is still being added to it today via fine sediment transported into the harbour by the Hutt River.

It is likely that the Melling Peats and the Petone Marine Beds were deposited concurrently. Evidence for this is provided by Stevens (1956b), who carbon-dated some of the wood fragments found within the peat. He stated that "the peat is comprised of the remains of a fossil forest, samples of which have yielded carbon dates of approximately 4,400 years BP. Trunks of the former forest remain in life position, broken off a metre above their base. The roots of the fossil forest penetrate a brown clay layer which represents the former forest floor". 
The Taita Alluvium are the present day deposits of the Hutt River, and extend over the full width of the floodplain. North of the unconfined/confined artesian boundary they overly the unconfined portion of the Waiwhetu Aquifer. South of the artesian margin, a thin layer of Taita Alluvium overlies the main aquiclude forming a shallow unconfined aquifer extending to the Petone foreshore region.

\subsection{Present-day sedimentation regime}

As mentioned earlier, the Petone Marine Beds form the present day harbour floor. The thickness and homogeneity of this unit are crucial in maintaining a 'seal' on the underlying artesian water. Any weaknesses or breaches in the aquiclude can result in SGWD submarine spring leakage and more importantly, possible points of salt-water intrusion. As such, an understanding of the present day tectonics and sedimentation within the harbour is crucial if we are to reveal the likely locations of SGWD, and in particular, submarine springs.

There are two main sources of sediment to the harbour - the Hutt River entering the harbour at the northern end, which introduces fine silts and muds, and the south coast beaches which provide the coarse sediment transported through the harbour entrance during southerly storms.

There is a progressive decrease in bed material size down the Hutt River. In the lower reaches of the river, the median grain diameter of bedload decreases from $10 \mathrm{~mm}$ at Whites line $(\sim 1 \mathrm{~km}$ upstream from river mouth) to about $0.2 \mathrm{~mm}$ at the river mouth (Clarke, 1988).

The amount of fine material entering the harbour each year is hard to determine given that suspended sediment sampling has not been done on a regular basis. The best data from the Hutt River in recent times is a six year period of monitoring between 1983 and 1988 at Taita Gorge. This data showed an average annual amount of $50,000 \mathrm{~m}^{3}$ (Williams Consultants Ltd., 1991; cited by Dunbar, 1994). Mean annual transport of bedload sediment to the harbour via the Hutt River has been calculated as $>10,000 \mathrm{~m}^{3} \mathrm{yr}^{-1}$ (Clarke, 1988).

Irwin (1993) showed that the mud $(<0.064 \mathrm{~mm}$ grain size) content of seafloor samples taken in 10 metres depth of water off the Petone Foreshore were as high as 97.5\%. Dunbar (1994) showed from cores taken in the middle of the harbour that mud content was also very high - averaging $98 \%$. This extremely fine grain size would be expected, given that most of the inner harbour is deep enough to be below the storm wave base (Dunbar, 1994).

However, the settling velocities for clay and silt are so low that even the extremely small tidal flows observed in the central harbour and Petone Foreshore regions are strong enough 
to keep mud already in the water column in suspension. This is why the visibility of the inner harbour water is so poor. Also, the shallower the water (i.e. the closer to Petone Foreshore), the more likelihood of a greater concentration of suspended sediment due to the effect of wave energy interacting with the shallow harbour floor.

Strong tidal currents through the harbour entrance (see section 4.3) preclude the idea of fine sediment being deposited here, and any such material previously deposited would have been removed (Van der Linden, 1967). Indeed, the strong southerly swells that Wellington's south coast regularly receives, generate large storm waves in the constricted harbour entrance. Matthews (1980), states that waves of up to $3 \mathrm{~m}$ high have been observed at Barretts Reef, with the average around $1.5 \mathrm{~m}$. The power of these storm waves is evident by the large 'pulses' of gravel moving north through the harbour entrance along the eastern coast (Matthews, 1980; Carter and Mitchell, 1988).

Beaches as far north as Eastbourne have aggraded significantly over the last 100 years with coarse river gravels that have been pushed northwards through the harbour entrance during these strong southerly storms. Haddon and Wear (1993) carried out sediment analysis on the harbour entrance material and found that the typical grain size in the middle of the channel coarsened from a well sorted fine sand around Falcon Shoals to a less well sorted coarse sand in the deep channel east of Barrett's Reef. 


\section{Chapter Six}

\section{METHODOLOGY AND TECHNIQUES}

\subsection{Introduction}

To achieve the aims of this research, two main components of fieldwork had to be undertaken. These were to locate and map the areas of submarine groundwater discharge (SGWD), and to then measure the flow from selected submarine spring sites to gain an understanding of the hydrodynamics of these features. In achieving these fieldwork objectives, not only would the areas of artesian leakage be identified and mapped, but the relationship of spring discharge to piezometric head on land could be obtained.

Locating the areas of SGWD in a piece of water $80 \mathrm{~km}^{2}$ in area is a daunting prospect, and before any fieldwork was undertaken, an intensive literature search was performed to gain an idea of how the fieldwork program should develop. This was performed on both a local and international scale. Searching through the international literature involved the extensive use of the Internet and electronic library databases. The Internet was particularly useful in obtaining email addresses of other scientists around the world who had dealt with the discharge of groundwater to the marine environment. While these contacts were of some use, it was soon realised that in every case, previous research on submarine springs concerned the discharge of groundwater from karstic or volcanic aquifers. It appeared that very little research had been performed on the discharge of water from unconsolidated gravel aquifers into the marine environment.

However, a lengthy search through the archived records of the Wellington Regional Council and the now defunct Wellington Harbour Board (see Appendix 1) revealed a variety of unpublished reports that provided a great deal of background information. This information was used to make a number of assumptions on which to base the fieldwork program. This reduced the area of the harbour that needed to be investigated to a manageable size. Thus, before detailing the methodology behind finding and recording the discharge from submarine springs in Wellington Harbour, I believe it would be useful to give some background to the assumptions on which this research was based.

\subsection{Research Assumptions}

The literature review indicated that the discharge of artesian water can often lead to the formation of sea floor depressions (e.g. Kohout, 1966; Hovland and Judd, 1988; Stringfield and Cooper, 1951). This is due to the fact that where the sea floor sediment is fine enough, 
it can be eroded and transported away by the upwelling currents, thus forming depressions in the vicinity of the leaking water. We can assume that the size, and indeed the presence, of these depression features are dependent on the force of the upwelling water, the grain size and density of the sea floor substrate, and the rate of sedimentation.

Data from the two main bathymetric surveys of Wellington Harbour surveyed in 1949/50 and 1981/82, show that many sea floor depressions are present at various locations. These depressions are all located in areas of mud deposition and had been explained in the past as being possible areas of artesian leakage (Reyners and Christoffel, 1973; Stevens, 1974; Donaldson and Campbell, 1977; Davey and Wood, 1993). However, it is possible that sea floor depressions can be formed by other mechanisms such as tidal scour, escaping gas, meteor impact, biologic activity, dredging (in shallow environments), plus a whole range of glaciation related features such as collapsed pingo's and studel scour (Hovland and Judd, 1988). In the case of Wellington Harbour, the significant size of the depressions (depths from harbour floor to depression floor range up to 8 metres), as well as the fact that the confining aquiclude was deposited since the last glaciation, renders many of the aforementioned alternative hypotheses redundant.

The various processes that erode the confining aquiclude creating harbour depressions are discussed in chapter Nine. At this stage it is important to note that regardless of how a significant depression was formed, it was assumed that these areas would be the most likely to exhibit artesian leakage due to the significantly reduced confining beds at these locations. As such, it was decided that all significantly deep conically shaped depressions in Wellington Harbour would be investigated.

However, one concern with regards to this hypothesis was that there may exist other areas of the harbour where aquifer leakage was occurring but that may not have a sea floor expression associated with it. One could expect to find such a phenomenon in areas where the substrate is too coarse or too heavy to erode, where the sedimentation rates are very high, or where the leakage may not have enough force to remove the material through which it passes. Aquifer leakage had previously been hypothesised in two regions of the harbour where no known sea floor depressions existed. These were in the harbour entrance (Stevens, 1955, 1956b and 1974) and along the sea floor trace of the Wellington Fault (Lewis, 1989).

With regards to the harbour entrance, leakage was hypothesised by Stevens (1955, 1956b and 1974) to be significant here following his premise that the confining beds covering the aquifer gravels peter out somewhere through the entrance corridor. Indeed, it has previously been shown, in Chapter Five, that the tidal currents are presently too strong through the harbour entrance to allow the deposition of the Petone Marine Beds member 
(e.g. van der Linden, 1966, 1967; Carter, 1977; and Matthews, 1980). As such, this hypothesis of thinning confining beds towards the harbour entrance has some merit.

In addition, there is some limited evidence for artesian leakage in this vicinity as proposed by Brodie (1958). Given that the extent of the artesian aquifer was one of the objectives of this research, the harbour entrance region became an important site. It was also the one site where investigations were undertaken despite there being no sea floor features to aid in the location of any leakage areas.

With regards to the hypothesis of aquifer leakage up though the Wellington Fault trace, there is certainly a good deal of evidence to support this as shown in previous research by Lewis (1989), and Truebridge et al (1978). Even the Hydrographic Chart NZ4633 shows spring symbols along the Wellington fault trace and around the Thorndon Container Terminal area. Two ex-Wellington Harbour Board personnel, Roger Carter (now retired, living in Plimmerton, Wellington) and Commander GBW Johnson (now retired, living in Christchurch), were the boat masters involved in the bathymetric survey of Wellington Harbour from which chart NZ4633 was complied. These men were contacted regarding the submarine spring symbols shown on this chart.

According to Roger Carter, vertically rising disturbance plumes were observed on the echosounder trace which were hypothesised to be caused by either rising fresh water or gas. Divers were sent down to investigate and observed visible signs of artesian leakage from parts of the sea floor. Samples of water were taken and later 'tested' to reveal it being brackish. Upon asking Roger how the water was tested for its salinity, he replied "We tasted it". Although not particularly useful in terms of its scientific basis, tasting the water is certainly good enough to determine the relative salinity, and in this case it was deemed to be certainly not as salty as 'normal' sea water.

While this reported occurrence of artesian leakage along the Wellington Fault trace was perhaps the most 'concrete' evidence at hand, the visibility of the harbour waters is so poor that if you don't get right on top of a leakage vent, you have little chance of finding it when diving. This was realised during the initial stages of the fieldwork programme and after much deliberation, it was decided to omit the leakage associated with the Wellington Fault from the fieldwork programme. This was mostly due to financial constraints (which determined how much boat time was available).

With regards to the harbour floor depressions, two further assumptions made in the initial stages of this research, around which the fieldwork programme was based, were found during the course of the fieldwork programme, to be largely incorrect. These assumptions were; 
- If a depression was in fact exhibiting artesian leakage, it would be from the deepest part of the depression that the majority of discharge would occur (as the aquiclude would be thinnest here), and

- Despite knowing that the visibility of the harbour waters was poor, if calm periods were chosen, the visibility should be good enough to allow for the easy recognition of artesian leakage while diving.

Interestingly, the pattern of groundwater discharge from a harbour floor depression did not necessarily follow the first assumption above. As stated, it was assumed before the fieldwork programme began, that the entire floor of a depression would exhibit significant quantities of fresh water leakage. Thus once a depression had been located, recording the discharge would simply be a case of descending to the depression floor and setting up the S4 current meter to record the flow. This hypothesis was based largely on Kohout's work who described artesian leakage in this fashion. However, Kohout's work concentrated on submarine spring discharge from karstic aquifer systems whose hydrodynamics are very different from gravel aquifers, not to mention the mechanisms for spring formation which also influence the subsequent leakage patterns.

The actual pattern of submarine spring discharge in Wellington Harbour only became apparent after much fieldwork had been undertaken. The following section details the salient reconnaissance fieldwork from which the ultimate methodology was devised.

\subsection{Results from Reconnaissance Fieldwork}

Results obtained from the early part of the fieldwork programme showed quite clearly that the initial assumptions were quite incorrect (particularly regarding the visibility of the harbour waters!). The original methodology (which was based on these initial assumptions) had to be re-evaluated and altered significantly. Thus the first few months of field data can be considered reconnaissance fieldwork on which the main methodology was based.

Figure 6.3.1 shows the data of the fieldwork undertaken in May 1997 after which time the original methodology for this research was scrapped and a new one adopted. The data depicted above was obtained by randomly raising and lowering an S4 current meter over a region of the harbour floor containing many sea floor depressions (the 'Petone Foreshore submarine springs cluster' off the Hutt River mouth). The fluctuating nature of the depth data is due to the poor resolution of the S4's pressure transducer in measuring shallow depths. The salinity is zero at the beginning and end of the graph reflects the S4 out of the water before and after deployment. 


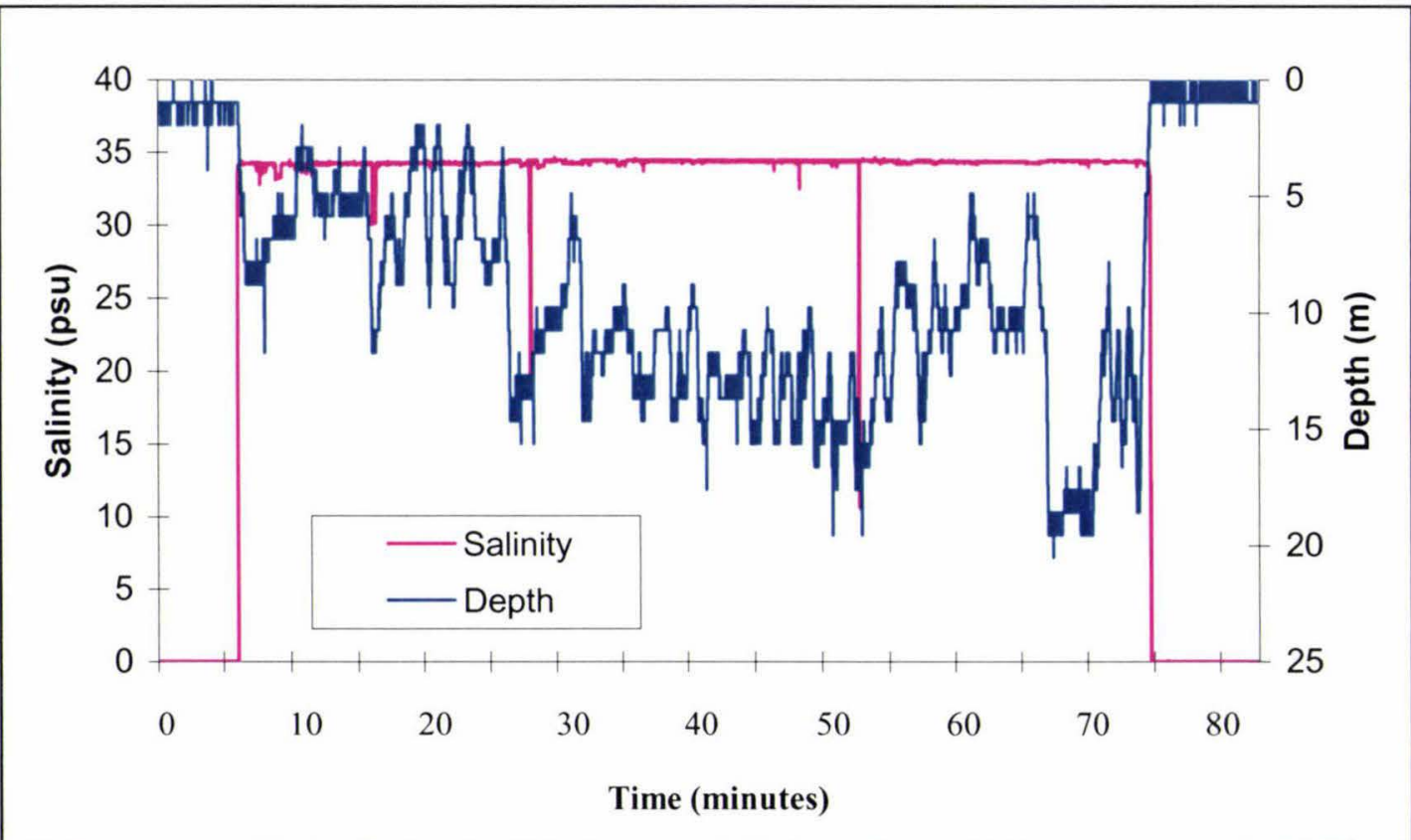

Figure 6.3.1 Detection of discrete artesian leakage in the Petone Foreshore depressions cluster

As can be seen, little evidence of SGWD was detected. However, it became obvious from this work that leakage from a given harbour floor depression was not as widespread as it had been hypothesised, but occurred at discrete locations which only affected the salinity of the water in close proximity to the 'vents'. This was confirmed upon diving when depression floors were found to be essentially void of any leakage activity except for small circular areas of extremely soft sediment which offered little resistance (even a two metre long PVC pipe could be pushed in with little force). These submarine spring discharge 'vents' are between one and two metres in diameter and represent the areas where the present day artesian discharge is issuing from under 'normal' piezometric conditions.

Later, this 'find' was confirmed by an unpublished report found in the Wellington Harbour Board archives. A group of divers surveying the sea bed between Somes Island and the Petone Foreshore in 1969 found "three deep depressions" which varied in depth, but had similar sizes with a "top diameter of approximately 60 yards (55 metres) and the flat saucer-like floor is about 20 yards (18 metres) across". As with this research, they found the depression floors to be "composed of the normal harbour floor mud but contain a number of extremely soft patches, some of which display visible evidence of artesian leakage" (see Historic Notes in Appendix 1).

As described previously, the other piece of useful information regarded the ability to use echosounders to find areas of artesian leakage. It was found that when the boat passed over a depression, the echosounder displayed a very disturbed sea floor signal in certain locations. This disturbed signal was manifested as a vertical plume of 'noise' in the signal, 
the size probably being in proportion to the amount of leakage. This is similar to the effect that had been noted by previous researchers (eg Truebridge et al, 1978). This effect is likely due to the sound absorption that is characteristic of a thermocline, halocline or picnocline (change in water temperature, salinity or density) as shown by Schneider et al (1985). The plumes were anything between 2 metres and 12 metres in height from the sea floor, similar to those described by Truebridge et al (1978).

Thus after the initial fieldwork, the original methodologies disintegrated, and data gathering expeditions became focused on the realisation that the areas of greatest discharge coincided with the greatest amount of sea floor disturbance as exhibited on the echosounder image, and not necessarily the deepest part of the depression.

\subsection{Main Data collection}

This difficulty in finding the submarine spring sites is reflected in the length of time it took to record some useful data. The environment of this particular study area combined with the relative uniqueness of this type of research, resulted in a constant abandonment and revision of a series of methodologies till one was formulated that not only worked well, but was suited to the Wellington Harbour environment.

Furthermore, it was initially proposed to use an S4 current meter to record all the data obtained during this research. However, due to the fact that the S4 was not available to be used for four months every year when it was taken to Antarctica, an alternative piece of equipment and methodology was employed during these periods. This alternative method involved using an older style conductivity/temperature meter which measured the conductivity and temperature of the water via a sensing probe which could be lowered through the water column.

However, the results obtained from these two methods are different. The S4 records conductivity, temperature, depth current direction and current speed (see section 6.5). It can be set to record data at a maximum rate of twice a second. It logs the data internally and keeps recording until it is told to stop (either by the user making the necessary settings before deployment, or by downloading the recorded data after it is retrieved which interrupts the recording pattern). The only other reason for data to stop being recorded is if the batteries run out of power, or when the S4 memory is full.

In contrast to this, the old style conductivity/temperature meter does not log any data and thus salinity values must be recorded manually. The obvious disadvantage to this method is the fact that a continuous stream of data is not recorded and only spot values can be obtained. However, there is an advantage of this equipment over the S4 and this is that real-time data is output. With the $\mathrm{S} 4$, the data recorded could not be viewed until retrieval. 
The old style conductivity/temperature meter allowed for instantaneous recognition of lower salinity areas within the depressions, which meant that divers could investigate the exact locations of low salinity water by descending down the cable attached to the conductivity meter probe once low salinity water had been detected.

Although this sounds straightforward, it was still essentially by chance that a submarine vent would be located from the surface using the conductivity meter. Much time was spent searching the harbour floor depressions both remotely from the surface using the conductivity meter and by diving down and looking for visible sign of leakage. It was also discovered that extremely low erroneous salinity values would be returned by the conductivity meter if the probe penetrated the soft harbour floor muds. As a result, it was decided to tie a weight with a metre length of rope onto the probe so that it hung down a meter lower than the probe. Subsequently, the weight would be dragged along the depression floor with the probe moving above the depression floor surface at an elevation of about $1 \mathrm{~m}$ (as long as the rope to the boat remained taut). While this worked well, it meant that the vents were harder to find, as the leaking water had had more time to mix with the sea water.

More frustrating was that once found, submarine vents could effectively not be marked, as buoys left out in the harbour would soon be 'lost', either through the deeds of unscrupulous fishermen, or possibly by 'yachties' not looking where they were going, getting tangled up, and then cutting them free.

When a boat with DGPS on-board became available and sites could be re-located more accurately, the absence of rope leading down to the discharge vent meant that hours, if not days of dive time, were wasted in trying to re-find the vent sites in the near-zero visibility harbour floor conditions. Even plastic milk bottles used as buoys went missing occasionally. This was a major concern to the future of this study as it was proposed to leave the valuable S4 current meter on the harbour floor for lengthy periods. Slightly submerged plastic milk bottles with floating lines were found to be the key to keeping these sites marked. Thus, the basic series of events involved in the data gathering became;

- Select sites deemed worthy of investigation on the basis that a significant depression in the harbour floor, of a conical form, probably represents a past or present submarine spring discharge zone.

- Determine the position of this site in relation to at least three easily identifiable objects on land (line of sight positioning), so that the rough area could be reached by boat. Later, when DGPS was available, co-ordinates for sites (read off the Hydrographic Chart NZ4633 and then adjusted for satellite positioning) were entered into the GPS unit and the boat was manoeuvred to this spot. 
- Using an echosounder, map the site until the areas of most prolific disturbance (as recorded by the echosounder) were located, upon which time a weight with a rope attached would be lowered over the side of the boat to mark the site (a buoy would then be attached).

- Lower the conductivity/temperature meter (with weighted end) to the depression floor and take conductivity readings within the depression, targeting any areas of disturbance (as shown by the echosounder). At least 10, but quite often 20 readings were taken at each depression (see Appendix 3).

- If the depression warranted further investigation (i.e. low salinities detected), divers would descend to the harbour floor with a weight (attached to a buoy at the surface), and search around the depression. The objectives of this were to look for visible signs of artesian leakage, and to feel the substrate for unusually soft patches of mud. If vents were found, the weight would be left beside the vent, the divers would ascend to the surface, and the exact location would be noted (either by DGPS, or by line of sight in the early stages of the research).

\subsection{Field Instrumentation}

This section outlines the equipment used and developed in the course of this study. The fact that submarine springs are hard to find meant that we had to be extremely precise in not only the recording of the leakage's, but also in recording the position of the areas of interest. As a result, many pieces of equipment were used in this study.

\section{The S4 Current Meter}

The S4 current meter is a state-of-the-art electromagnet current meter. It is spherical in shape with a $25 \mathrm{~cm}$ diameter and weighs $11 \mathrm{~kg}$ in air, $1.5 \mathrm{~kg}$ in water (see Figure 6.5.1).

The following is taken from the "S4 Current Meter User's Manual":

"The S4 Current Meter measures current by creating a magnetic field and sensing the voltage induced by the movement of water through the field. A microprocessor acquires instrument orientation from a flux-gate compass and computes Earth referenced current components in North and East co-ordinates. These current vectors are then recorded immediately (burst sample mode) or integrated over time and recorded (vector averaged mode)".

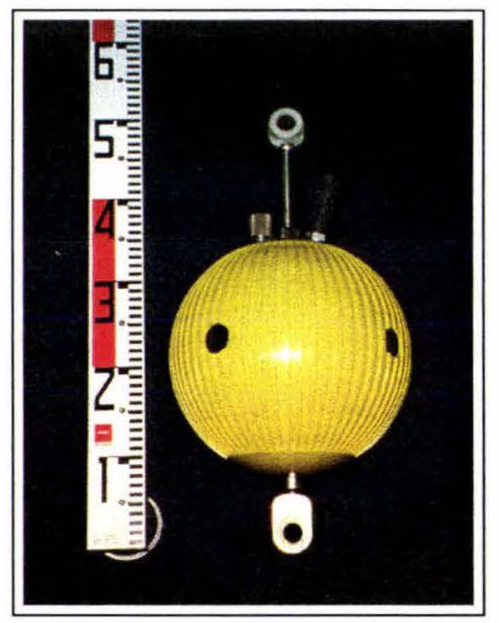

Figure 6.5.1 The S4 Current Meter. The scale on the left is in $\mathrm{cm}$ (the large numbers are in decimetres). 
Data is logged internally, and other available options are conductivity, temperature and depth. All sensors are interior or surface mounted to avoid any projection on the sphere. Once the S4 is retrieved, the data can be downloaded and viewed or exported into other software packages.

This unit was most useful in recording the spring flow once the vent had been located. Although used initially to randomly sample areas suspected of having artesian leakage, the results obtained were not particularly useful in accurately locating submarine spring vents as the data was not real-time and had to be downloaded upon retrieval of the S4. This meant that while lower salinity areas were recorded by the $\mathrm{S} 4$, it was difficult to determine exactly where these locations were. However, this information was useful in isolating which depressions warranted further investigation.

\section{The Conductivity/Temperature meter}

The conductivity and temperature meter was useful in locating areas where the salinity of the sea water was lower than 'normal' sea water. The meter is a portable hand-held unit that has a transducer at the end of a 42 metre length of water-resistant cable. It works by measuring the electrical resistance of the water and then converting it into a conductivity. Salinity, a function of conductivity and temperature (water is more conductive when it is warmer), is calculated internally. The unit could be set to display temperature or conductivity and it was calibrated before each use to ensure that the data being collected was correct. The advantage of this type of data over the data recorded by the S4 current meter was that it was 'real-time' as opposed to the S4's requirement to retrieve the equipment and then download the data before it could be analysed.

Having initially found a harbour floor depression, it was particularly useful in finding those areas of the depression that were actively leaking as often only small localised areas of depressions would exhibit any active leakage. Unfortunately, this unit was lost in the latter stages of the fieldwork program when the cable was cut by the boat propellers. As a result, an image of this unit cannot be included here.

\section{The Echosounder}

The echosounder proved to be very valuable, not only in mapping the dimensions of the depression, but also as a means of identifying the individual sites where spring flow was occurring, as described in section 6.3 .

Echosounders work by sending a sonic signal from a transducer at the waters surface vertically down to the sea floor. The signal bounces back off the sea floor and the depth 


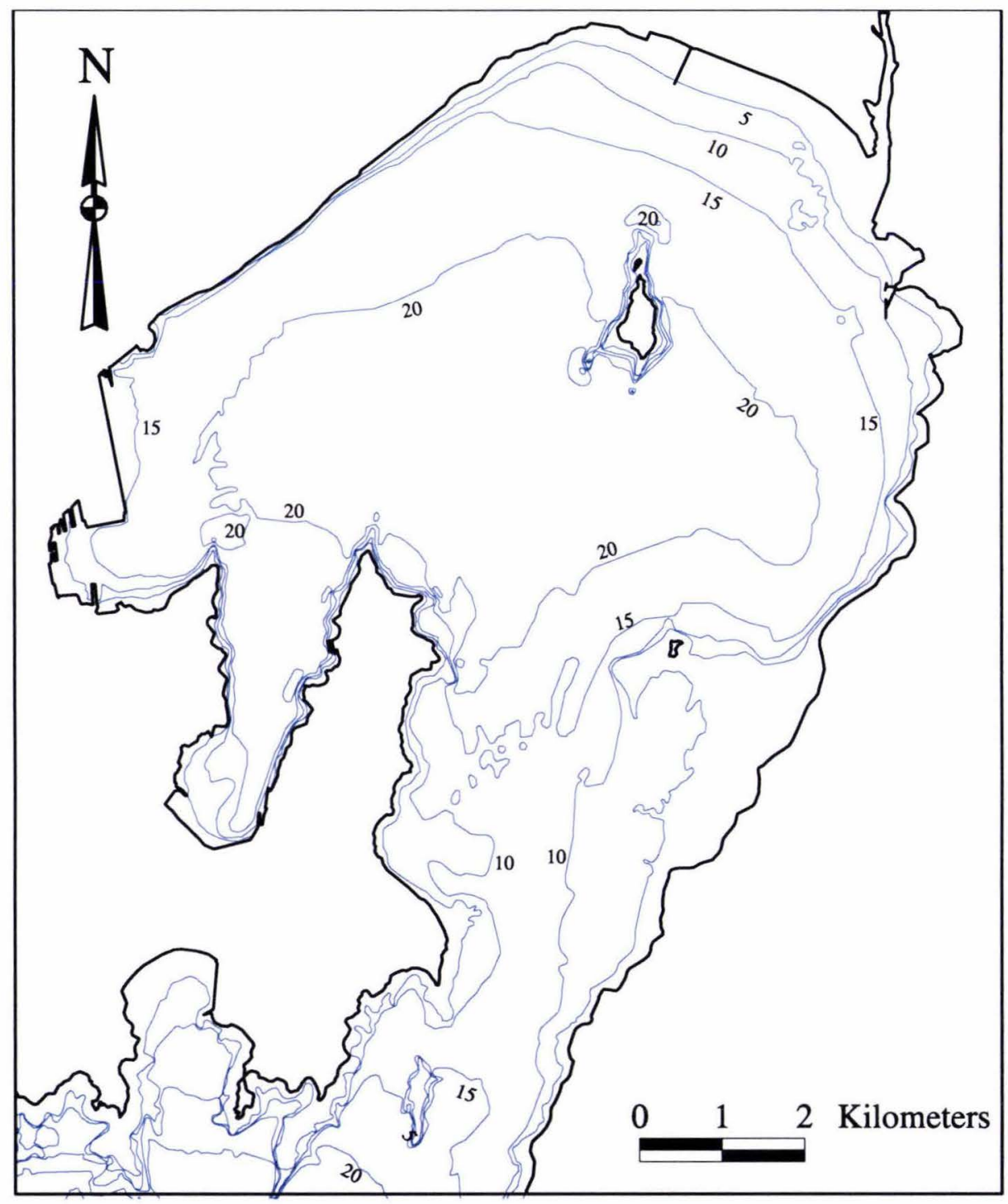

Figure 6.5.2 The salient bathymetry for Wellington Harbour taken from Hydrographic Chart NZ4633, as digitised in ArcInfo. Many sea floor depressions can be seen on this map, particularly around Somes Island, Miramar Peninsula, and near the Hutt River mouth. The small features in the harbour entrance vicinity (near Falcon Shoals) are actually slightly raised mounds and not depressions. Depths are in metres below sea level. 
calculated by halving the two way travel time and then multiplying by the speed of sound in sea-water (roughly $1500 \mathrm{~m} / \mathrm{s}$ ).

As described previously, the echosounder signal was an excellent means of locating areas of prominent artesian leakage as it could distinguish between the different densities of freshened water and 'normal' salt-water

\section{The GPS unit}

GPS or Global Positioning System, is fast becoming the preferred (and most accurate) way to map areas. Satellite information is received and processed which is then translated into a position on the Earth's surface. Portable GPS systems work directly with the satellite information and need at least three different satellite readings to get a fix. The accuracy of these units is roughly $+/-100$ metres. As most of the submarine spring sites are much smaller in size than this error, it was obvious that a portable GPS unit was not going to be of much use. At the initial stages of this research, a hand-held unit was used, but as expected was only helpful in finding the vicinity of the spring site and line of sight positioning was employed to obtain more accurate positioning.

Towards the latter stages of the research, a boat became available that had DGPS capabilities. DGPS (Differential GPS) uses an on-land base relay station with which it derives its position. There are huge advantages with this method as the relay station enables extremely accurate positioning (deci-metre). DGPS was used to map all the submarine spring sites and to assist in the deployment and retrieval of the S4 current meter.

\section{Bathymetric Data}

A comprehensive bathymetric survey of Wellington Harbour was carried out during the early 1980's, from which the widely used Hydrographic chart NZ4633 was compiled. Figure 6.5.2 shows the salient bathymetry as digitised from NZ4633. Depths were recorded about every 80 metres, and were accurate to about 0.1 metres depth. After an extensive search through the Wellington Harbour Board archives, the original soundings charts of these surveys were located. These original charts showed many more individual depressions in the area off the Hutt River and thus offered a more accurate picture of the bathymetry in this region of the harbour than the more general NZ4633 chart provided.

Further searching of archived material of the Wellington Harbour Board and the various predecessors of the Wellington Regional Council (esp. Hutt Valley Under Water Authority) revealed a surprising amount of material concerning interest in the sub-harbour leakage from the aquifer. The age of this material varies considerably, ranging from the early 1920 's to the early 1970's. This material is Jaid out in Appendix One. 


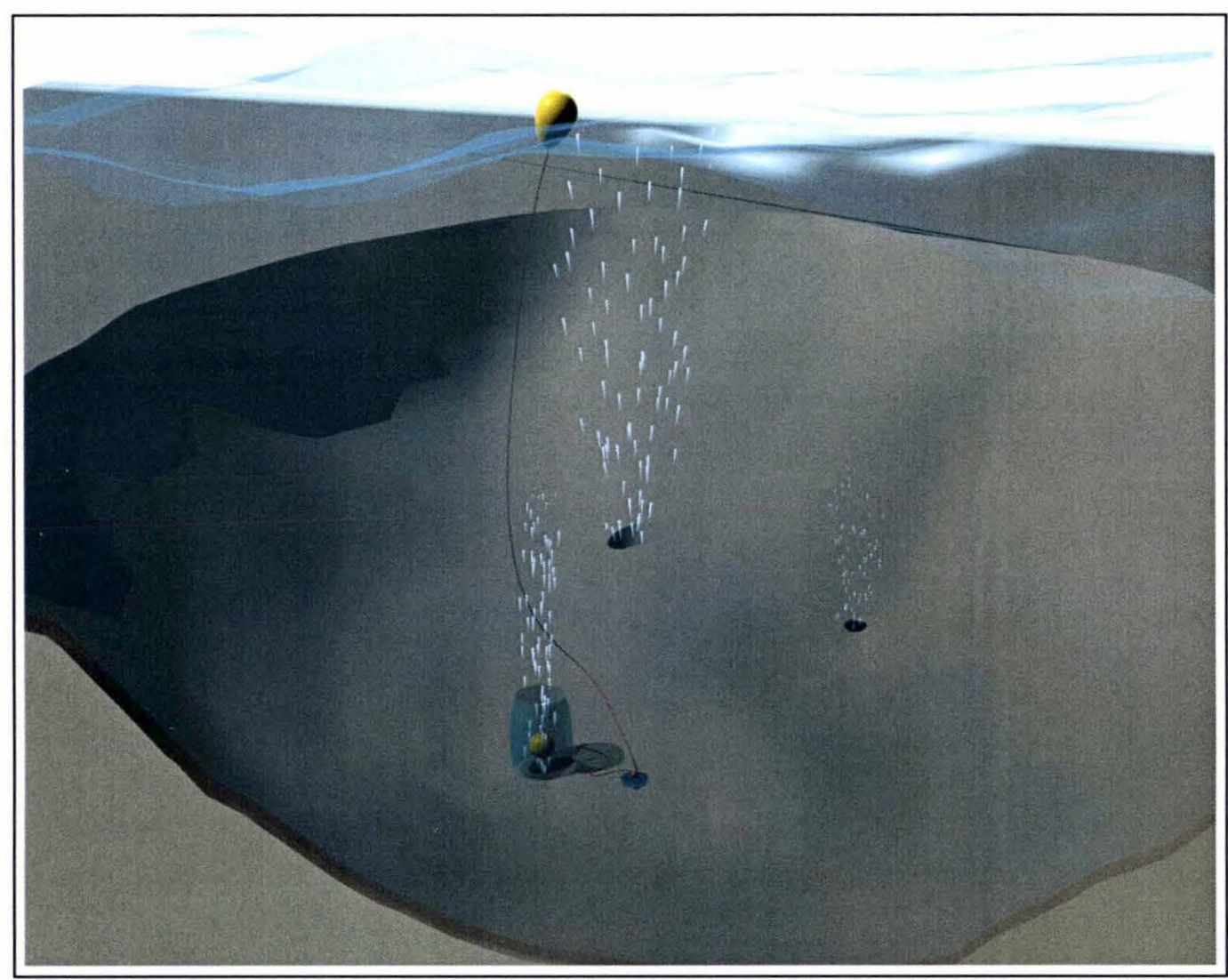

Figure 6.6.1 An artistic representation of how the S4 current meter was set up to record discharging aquifer water from a harbour floor depression. Note that the entire depression floor is not exhibiting artesian leakage, rather it is occurring at discrete vents, of varying intensity (as recorded by divers' observations). A buoy attached to a heavy weight, in turn attached to the S4 set-up, was used to mark the site. This diagram was created in the computer software package $3 D$ Artworks. 


\subsection{Recording the spring flow}

One of the objectives of this research was to derive the relationship that exists between submarine spring discharge and piezometric head within the Waiwhetu Artesian Aquifer. The S4 current meter was the equipment used to measure and record the spring flow from selected depressions within the harbour.

Before using the S4 to record the vertically rising currents at the depression sites, the unit was tested to determine its usefulness in measuring such currents. While the S4 is "intended primarily for taut-line mooring or mounted to fixed structures" so as to measure currents in the horizontal plane, this study required the measurement of vertically rising currents upwelling from the sea floor.

It was unsure at first whether the S4 had the ability to do this. After much searching of literature on the S4, talking to various organisations (NIWA, CSIRO in Australia, Inter Ocean - the S4 manufacturers in San Diego, and searching on the internet), it was discovered that the $\mathrm{S} 4$ had probably never been used in the proposed way before.

It became necessary to test the $\mathrm{S} 4$ to see whether it could record vertically rising currents. As the $\mathrm{S} 4$ can't distinguish between its own movement in the water from the water's movement around it (i.e. it records the relative current), moving the $\$ 4$ through a stationary water body would simulate the effect of water passing around a stationary S4. This was done in a series of vertical drag tests in the 5 metre deep pool at the Kilbirnie Aquatic Centre in Kilbirnie and off the Overseas Passenger Terminal in calm conditions.

The idea here was to mount the S4 horizontally inside its purpose built housing unit (44 gallon drum with the ends cut off - see figure 6.6.2), and raise the set up from the bottom of the pool (the harbour floor in the case of the Overseas Passenger Terminal) to the water surface. The exact depths at both sites were measured, and the time of travel was recorded by stopwatch. This was done a number of times at a number of speeds. The same tests were also tried by lowering the $\mathrm{S} 4$ from surface to base, but it was found that the set-up did not always descend completely perpendicular to the surface, especially at higher velocities, which gave erroneous results. The S4 performed well during these tests and clearly showed it could record currents in the vertical plane if mounted horizontally.

Having successfully tested the $\mathrm{S} 4$, the equipment was set up as shown in figure 6.6.1, at pre-selected sea floor depressions. A close-up view of the set-up is shown in figure 6.6.2.

Due to the fact that the amount discharged at each spring site will be directly related to the piezometric head within the aquifer, a range of piezometric head values and their corresponding spring discharge must be recorded to obtain a good relationship. 


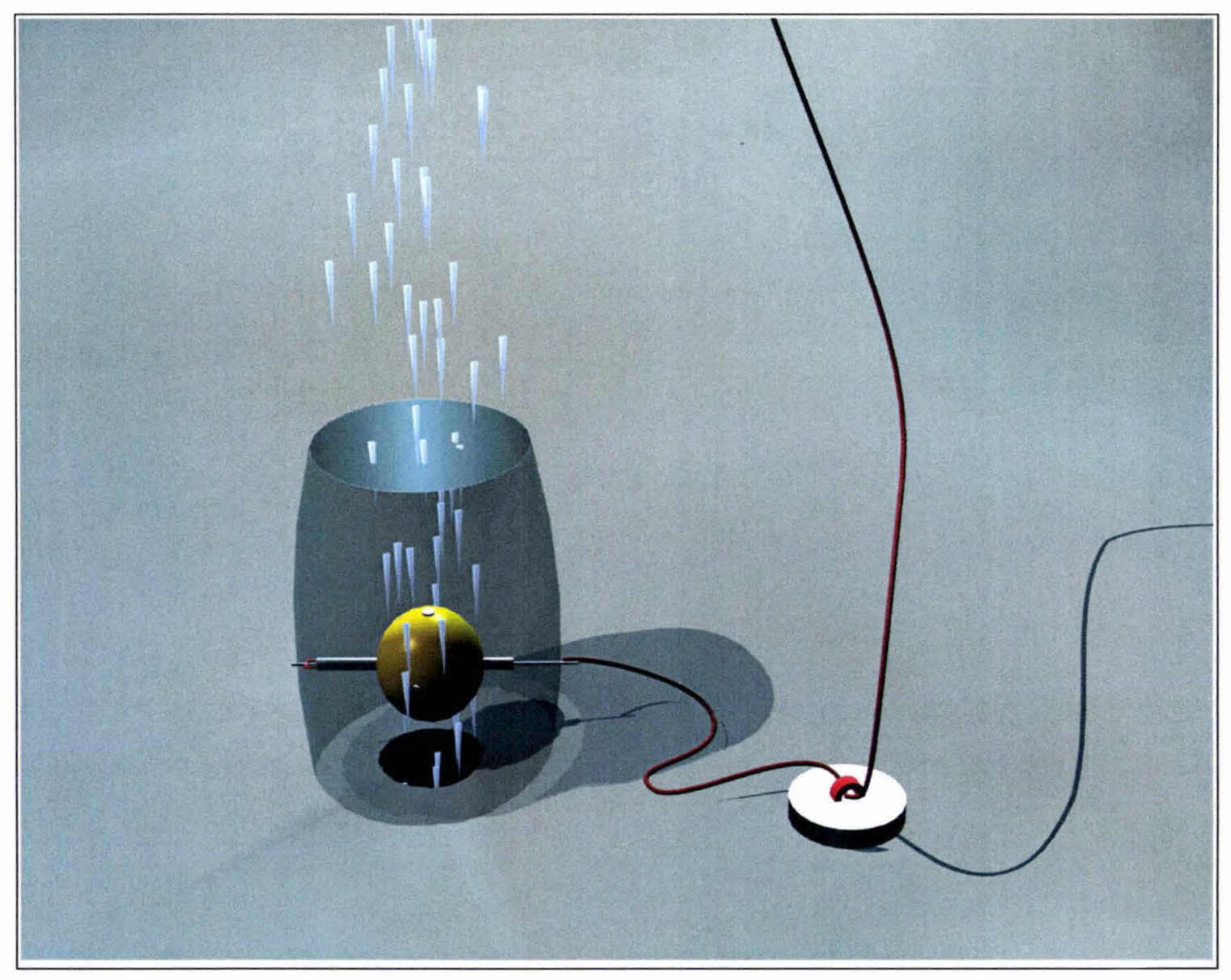

Figure 6.6.2 Set up of the S4 over a submarine spring vent. The S4 is mounted horizontally across the inside of a plastic 44 Gallon drum (shown translucent here for descriptive purposes) by bolting the ends of the S4 to eye bolts attached to the inside of the drum. The north facing velocity sensor is anchored facing down, so that the north-south plane is perpendicular to the vent. The drum is pushed a little way into the soft mud to ensure stability. The drum, with S4 anchored inside, is attached, by a 5 metre rope, to a $30 \mathrm{~kg}$ weight which in turn is attached by rope to a buoy at the sea surface (see Figure 6.6.1).

The S4 works by generating an electromagnetic field around itself which is subsequently distorted by the movement of water around it. The current speed and direction is then calculated by the S4 via measuring the distortion of the magnetic field. The absence of any moving parts allows for the detection of extremely low current velocities. Care must be taken in using the S4 as any non-stainless steel metal close to the S4 unit can distort the magnetic field and thus the current recorded. This is why a plastic drum was used to house the S4. The bolts used to attach the S4 to the drum are stainless steel. This diagram was created in the computer software package $3 D$ Artworks. 
Piezometric head within an aquifer changes under the influence of many factors such as;

- the amount of recharge the aquifer receives (seasonal variations i.e. summer/winter)

- amount of abstraction (causing a reduction in head)

- tidal changes (loading)

- atmospheric pressure (loading)

- $\quad$ earthquakes (causing an increase in head due to the consolidation of the aquifer structure)

There are a number of factors affecting the piezometric head and thus spring discharge, such as rainfall, river flow, abstraction totals and the load on the aquifer, in this case as produced by the fluctuating tides.

To make sure spring flow was recorded over a wide range of piezometric levels, it was decided to leave the S4 out to record for a week long period. It was hoped that during this period, the $\mathrm{S} 4$ would record not only the diurnal fluctuations caused by the changing tide, but also some longer period fluctuations such as those associated with a reduction in abstractions at weekends, and if possible, to record the effect that a flood has on the piezometric level and thus spring discharge.

This was done at two sites in total as this is all that time could permit. Both of these sites are within the cluster of depressions off the Hutt River mouth. This region was selected not only because of their close proximity to the abstraction zone and thus of the greatest concern with regards to salt-water intrusion into the Waiwhetu Artesian Aquifer, but also because it was at these sites where the greatest leakage was occurring.

\subsection{Mapping the bathymetry of selected sites within Wellington Harbour}

\subsubsection{Introduction}

Although the currently used Hydrographic Chart (NZ4633) was accurate enough in locating the rough area of the sea floor depressions from which spring discharge could be collected, the data used to compile this chart was collected during 1981 and 1982 and thus were over 15 years out of date. While this immediately raises concerns about the present-day depths of the depressions, it was unlikely that the harbour floor, as shown in NZ4633, was absolutely accurate around the harbour depressions, given the small size of the sea floor depressions.

By accurately re-mapping the present day bathymetry of the sites of interest with a greater resolution, the depression's form and depth could be accurately represented and used as a benchmark to correlate future bathymetric surveys with. Thus correlations can be made 
with any surveys performed in the future to determine whether the depressions remain static in form, or alter in response to changes in the hydrological or sedimentological regime.

Initially, it was proposed to use a grid type survey with a set of buoys (positioned by line of site) laid out in a grid between which the boat would travel while depths recorded by the echosounder were noted. This method, although the most practical with the equipment available at the time (no DGPS or charting package), was never going to be easy or that accurate, and thus was put on hold until the last stages of the fieldwork in case a more precise method became viable.

Late in 1998, funding was made available by the Wellington Regional Council from which the Kiwitech software package "Commercial Fishing Suite" was jointly purchased with the School of Biological Sciences in January 1999. This package included a scanned map of Hydrographic Chart NZ4633 (among others) on which the real-time position of the boat could be shown by linking with the signal from the DGPS (also recently available).

The signal from the echosounder could also be linked as an extra channel, thus enabling concurrent DGPS (decimetre accuracy) positioning and depth recording (also decimetre accurate). The Kiwitech program with electronic chart was installed on a laptop computer, and the DGPS and echosounder signals (which also recorded sea surface temperature) were fed into the computer which the program then incorporated on its chart display for realtime display, while also saving this data to a file for later analysis.

This allowed for an extremely accurate, if not the most accurate, method of mapping the harbour floor. The possibility of using side-scan sonar as an alternative method of mapping was investigated, but this was deemed to be too expensive and not particularly well-suited to picking up detail in a mud substrate (the finer/softer the sediment, the whiter the returned image).

The Commercial Fishing Suite was considered to be the best option of the all the packages available as it contained the most relevant features, including the option of recording the sea surface temperature.

This software could be set to record the data at a maximum rate of twice a second. However, this proved to be a little excessive at the speeds we were travelling, so a sampling rate of once every second was selected. 


\subsubsection{Data Collection}

After an initial testing of the charting software in mid January 1999, the sites were mapped according to a combination of good (calm) weather, boat availability and as time permitted. Two days in January $\left(28^{\text {th }}\right.$ and $30^{\text {th }}$ ) plus the $5^{\text {th }}$ of March were the days when all the bathymetric mapping was performed.

\subsubsection{Data transformation to Chart Datum}

It was decided that while the data obtained from these mapping surveys could be used independently of any other data to produce bathymetric maps, it would make sense to conform these data to the datum's and format of the Hydrographic Chart NZ4633 to enable compatibility. Thus, before the data obtained in these surveys could be used, the depths recorded needed to be reduced to the NZ4633 chart datum (Lowest Astronomical Tide). This was done within the hydrological program TIDEDA.

To this end, the data was first transformed into TIDEDA format - that is, relative to the date and time of recording. This was performed in Excel with the Date converted to yymmdd (year, month, day), and time converted to the 24 hour clock as used in TIDEDA, with the format hhmmss (hours, minutes, seconds). TIDEDA cannot use decimal points, therefore all data had to be in whole numbers. Thus, depths were converted to millimetres, temperature to deci-degrees, and positioning to Decimal Degrees * 10000. Note that decimal degrees were used in preference to the Degrees/decimal minutes format as used in chart NZ4633 to enable easier reference with future satellite derived positioning.

One interesting piece of information on Chart NZ4633 (strangely in small print) concerned the correlation with satellite derived positions. It states that "Positions obtained from satellite navigation systems referred to the World Geodetic System (WGS) must be moved 0.10 minutes SOUTHWARD and 0.00 minutes EASTWARD to agree with this chart". It is not clear why Chart NZ4633 is offset by 0.10 minutes Southward in the latitude with respect to satellite positioning, but obviously a transformation of the data was necessary to make it compatible to this chart.

As the DGPS unit records data in Decimal Degrees, 0.16666 Decimal Degrees was required to be added on to all of the Latitude values $(0.10$ minutes $=0.16666$ Decimal Degrees) to correct for this discrepancy. Of course, this became $16666\left(0.16666^{*} 10000\right)$ as the positioning had to be in whole numbers to conform to TIDEDA format. This was performed in Excel before listing the data into a TIDEDA ' $m$ td' file.

Reducing the data to NZ4633 Chart Datum (the Lowest Astronomical Tide), was performed in TIDEDA using three PSim routines 'Tide28.sim', 'Tide30.sim' and 'Tide5.sim'. These short programs were constructed to correct for the height of the tide 
and reduce the recorded depths to the Lowest Astronomical Tide (the datum used in the hydrographic Chart NZ4633). All bathymetric data collected during these surveys was transformed in this way. The programs are listed in Appendix Four, with an example and description of their function using Tide 28 .sim as an example.

The results of the bathymetric mapping of the selected areas of the harbour are incorporated into the discussion of sites in Chapter Nine. 


\section{Chapter Seven}

\section{HYDRAULIC CHARACTERISTICS OF AQUIFERS}

\subsection{Introduction}

To fully understand the hydrodynamics behind submarine spring discharge, we must first understand the conditions within aquifers that can lead to the inception of the springs in the first instance.

Kohout's investigations into a number of submarine spring sites around the world led him to surmise that; "the occurrence of a recognisable submarine spring implies the existence of a large permeability contrast in the aquifer or in the low permeability beds that overlie and confine the aquifer water under artesian pressure" (Kohout, 1966). With regards to the hydrodynamics of the above statement, Kohout probably means that concentrated leakage in the form of a submarine spring is attributable to one of two factors. Either the aquifer contains areas where the permeability changes from low to high, or the "low permeability beds that confine the aquifer water' contains areas where the permeability is much greater than normal, thus allowing a greater amount of water to escape.

The second of these premises is easy to understand - the confining layer is weakened or compromised for some reason, and the water within the aquifer exploits this weakness and develops a flow path to the sea.

However, the first premise, regarding a change in permeability within the aquifer, does not easily explain why leakage should increase. An increase in permeability does not necessarily cause a corresponding increase in piezometric pressure, which is the only factor that could initiate leakage, assuming all other factors (such as those associated with the confining bed) remain constant. However, we can explain Kohout's reasoning when we look at the types of aquifers from which he gathered his information.

Most of the scientific studies that Kohout used in his study of submarine springs concerned groundwater discharge from karstic or volcanic areas - both of which are notoriously heterogeneous rock types. In fact, so heterogeneous are these formations that they are extremely permeable in some places, but almost totally impermeable in others. 
In karstic (limestone) aquifers, slightly acidic rainwater percolates through the calcium carbonate rich rock and enlarges joints or fractures via solution to form underground channels. Water in volcanic aquifers finds its way to the path of least resistance, which will ultimately be any relic lava tunnels that exist. Thus both types of aquifer will develop, over time, preferential pathways for the artesian water. By permitting the movement of water in segregated channels while confining it everywhere else, they act not only as the water bearing aquifer, but also as a confining aquiclude as well.

Water will continue to flow through these subterranean channels to the limits of the aquifer, unless an alternative leakage point is encountered first which offers an easier flowpath. While leakage can occur at many places from an aquifer, a submarine spring of significant discharge would only occur when linked with an area of high permeability (i.e. a subterranean channel). In these areas, the rate of water available to the spring site - the transmissivity of the aquifer, is higher than normal. In this sense, we can explain Kohout's description of the aquifer conditions (i.e. 'the existence of a large permeability contrast in the aquifer') that must be met to give rise to a 'recognisable' submarine spring discharge.

Can the same set of rules be applied to unconsolidated artesian aquifers like those found beneath Wellington Harbour? That is, do areas of differing permeability and transmissivity exist within these types of aquifers? We can answer this by looking at the hydraulic characteristics of unconsolidated rock aquifers.

\subsection{Hydraulic characteristics of unconsolidated rock aquifers}

\subsubsection{Introduction}

Models dealing with aquifers often assume that the aquifer material is homogenous and that the aquifer is of uniform thickness. This in turn allows constant permeabilities and transmissivities to be applied to the entire aquifer. This is done because a model incorporating all the variations in aquifer parameters would be extremely difficult to build and interpret. As a result, much of the real-life hydrodynamics of an aquifer are lost.

In reality, unconsolidated alluvially deposited aquifers like those found beneath Wellington Harbour are heterogeneous in nature and do contain areas of higher permeability than elsewhere. Although there is not the option of preferential pathways being developed via the solution of any material, or the presence of caverns or tunnels like we find in karstic or volcanic aquifers, the way in which unconsolidated aquifers are deposited can explain how preferential pathways in these aquifers already exist upon deposition.

Using the Waiwhetu Artesian Aquifer as an example, we already know that it was deposited in the Lower Hutt Valley - Port Nicholson basin as a prograding deltaic 
formation that kept pace with the Flandrian sea incursion (Stevens, 1955). To be able to keep pace with a rising sea level, the amount of material being brought down from the upper reaches of the Hutt River and from the sides of the Hutt Valley must have been immense. It is thus reasonable to assume that the Hutt River would have been an aggrading, braided type river system that contained perhaps one or two stable main channels with a number of smaller channels.

Given the nature of an aggrading braided river system, the river channels would have migrated, over time, across the entire width of the basin as a course of natural channel progression. It would also have occasionally changed very rapidly as a result of catastrophic events such as after major flooding periods or as a response to tectonic events. Consequently, any core taken through the Waiwhetu Artesian Aquifer member can be expected to exhibit the same sorts of depositional sequence. Although the thickness and character of each member is unlikely to be identical from place to place, the basic trend would be the same - layers of coarse gravel and sand separated by layers of fine silt. The coarser layers representing channel deposits and the silt layers representing overbank deposits as a result of flooding.

These coarser layers will naturally have a high permeability while the overbank deposit material will have a much lower permeability and act as semi-impermeable layers in relation to the coarser channel deposit layers. Thus, within the Waiwhetu Artesian Aquifer itself, or indeed most alluvially deposited aquifers, there would exist pathways (relic river channels) of high permeability where water would preferentially flow, and other areas where permeability would be much lower and the movement of water restrained (fine sediment overbank deposits).

So what does this mean in relation to transmissivity and storativity values? Before we answer this question, a brief description of these terms is necessary.

There are two main parameters associated with aquifers that are used to classify them from one another, or indeed to distinguish certain portions of an aquifer from the rest. These parameters concern the ability of the aquifer to store water (the porosity) and the ability of the aquifer to transmit the water it possesses (the permeability).

The following section is not meant to be a comprehensive report of all the properties of an aquifer system - this can be obtained from the many readily available texts, such as Freeze and Cherry (1979), Fetter (1994), and Todd (1959). Rather, this chapter is a brief rundown on the basic hydraulic properties and parameters that we use to describe and characterise aquifers. 


\subsubsection{Porosity, specific yield and storativity}

If a cubic metre of saturated material could be taken undisturbed from an aquifer, water would drain from it under the force of gravity. The volume of drained water, expressed as a percentage of the bulk volume ( 1 cubic metre) is called the specific yield of the material. Not all the water will drain from the material, - some is held within the pores by capillary forces - this percentage is the specific retention. The sum of the specific yield and the specific retention is equal to the porosity (Thorpe, in Waters of New Zealand, 1992).

Any water recharged to, or discharged from, an aquifer represents a change in the storage volume within the aquifer. For unconfined aquifers, this is simply expressed by the product of the volume of aquifer lying between the water table at the beginning and at the end of a period of time, and the average specific yield of the formation.

For example, when water enters an unconfined aquifer, the water table rises as the pore spaces are filled. Depending on the specific yield of the medium, the amount that the water table rises will correspond to the total amount of water that has gone into storage. If the specific yield of the medium is $35 \%$ (typical for a uniform -sized sand or gravel medium), and the water table rises one metre over an area of $10^{6}$ square metres, then 350,000 cubic metres of water has gone into storage.

However, if an aquifer is confined, it is already full of water and has little capacity to store more. Extra water can only enter a confined aquifer if the water pressure increases. This inflates the aquifer very slightly and compresses the water by a minute percentage, as water is virtually non-compressible. These are elastic changes (i.e. reversible). Thus the hydrostatic pressure (in the water) within an aquifer partially supports the weight of the overburden, while the solid structure of the aquifer provides the remaining support.

Data detailing the amount of water released from a known drop of hydrostatic pressure are known as values of storativity or the storage coefficient of an aquifer. This is defined by Todd (1959) as being "the volume of water that an aquifer releases from or takes into storage per unit surface area of aquifer per unit change in the component of head normal to that surface." It is basically the sum of the amount of water lost through aquifer compaction (dependent on aquifer compressibility) and the amount of water lost through water expansion (fluid compressibility).

Essentially, values of storativity differ within and between confined aquifers as a result of the porosity of the aquifer material plus the factors that determine how much water is 'squeezed' into the aquifer medium. Measurements of storativity can be made by looking at the response of the aquifer to changes in a known amount of hydrostatic pressure. 
For instance, when the hydrostatic pressure is reduced, such as by pumping water from a well, two processes occur. Firstly, the load on the aquifer medium (i.e. sand/gravels etc) increases as some of the water partially supporting the overburden has been removed. The extra load causes the aquifer material to compact a little, thus compression of the aquifer occurs, which subsequently leads to the squeezing out of some more water. The second process that results from reducing the hydrostatic pressure is that a small expansion of the remaining water occurs. This results in a further release of water. Pump tests, where a known amount of hydrostatic drawdown takes place, is the standard method for determining the storativity of an aquifer. Typical values of storativity for confined aquifers fall in the range $5 \mathrm{E}^{-5}$ to $5 \mathrm{E}^{-3}$ (Todd, 1959).

\subsubsection{Permeability, hydraulic conductivity and transmissivity}

The ease at which water can pass through the aquifer material is known as the constant of proportionality or the hydraulic conductivity. It recognises the fact that different types of media will affect the velocity of the water flow through it i.e. the larger and less-sinuous the conduits, the easier the water will pass through it. Essentially it is a measure of the permeability of the media, thus values of hydraulic conductivity are high for coarse material such as gravel and sand, but low for the low permeable clays and silts. Units are distance/time, usually metres/day.

Transmissivity $(\mathrm{T})$ is directly proportional to hydraulic conductivity $(\mathrm{K})$ and is expressed in the formula $\mathrm{T}=\mathrm{Kb}$, where $\mathrm{b}$ is the saturated thickness of the confined aquifer. Like hydraulic conductivity, transmissivity is a measure of flow of water through the aquifer media, but introduces the aquifer thickness into the equation, and thus incorporates another dimension to the equation. Thus, the formal definition of transmissivity is the rate of flow of water through a unit width of aquifer under unit hydraulic gradient (Thorpe, in Waters of New Zealand, 1992). The flow is assumed to occur through the full thickness of the aquifer. Thus an aquifer (or an isolated portion of it) will only have high values of transmissivity where both the hydraulic conductivity (permeability) and thickness of the aquifer are large. Alternatively, if the thickness of the aquifer is known, or constant throughout a large portion, variations in values of transmissivity as derived from pump tests can be a useful way of determining those areas where permeabilities are either high or low. This sort of information can then be useful in mapping relic river channels that might offer preferential pathways for the artesian water.

In general, values of transmissivity vary with particle size - clayey materials exhibit low values of hydraulic conductivity, whereas sand and gravels display high values (Todd, 1959). Transmissivity values, range over 13 orders of magnitude, with unfractured metamorphic rocks representing the rock type having lowest transmissivity, and unconsolidated gravels having the highest. 
Values of both transmissivity and storativity can be obtained by looking at the response of an aquifers potentiometric surface to the abstraction of artesian water from a known position. Once again, pump tests are the primary test used to calculate these aquifer characteristics.

\subsection{Hydraulic Characteristics of the Waiwhetu Artesian Aquifer}

\subsubsection{Introduction}

The purpose of determining the hydraulic characteristics of an aquifer is to illustrate groundwater flow patterns and to estimate safe yields for the aquifer system (WRC, 1995). For the purposes of this study, the values of transmissivity and storativity obtained for the Waiwhetu Artesian Aquifer are being used to determine how much variation there is within the aquifer that can be translated to the presence of any preferential pathways that may be present.

The presence of preferential pathways are important as it is the hypothesis of this study that they may determine the location of submarine spring discharges, or at least influence the prolificness of the discharge from submarine springs. If preferential pathways do exist, it is these areas of high permeability and transmissivity within an aquifer that are likely to be the most significantly affected by extreme events. What is meant here is that during floods, or periods when the aquifer has high piezometric pressures, preferential pathways are able to transmit large volumes of water away from areas of high piezometric head (close to the recharge zone) and transport it to areas of low piezometric head (i.e. the aquifer extremities or exit points - submarine springs).

During droughts or periods of heavy abstraction, these pathways become conduits for water to replenish the affected areas. If the hydraulic gradient becomes reversed as could be possible during extended droughts, water from under the harbour will flow towards the affected area, using the preferential pathways as the quickest route. If depressions in the harbour floor are linked to these preferential pathways, then the chance of salt-water incursion occurring at these locations is greatly enhanced.

Little is known of the sub-harbour portion of the Waiwhetu Artesian Aquifer, which is the focus of this study. However, a reasonably large amount is known about the aquifer beneath the Lower Hutt Valley and thus by extrapolating these properties offshore, we can gain a relatively good understanding of the aquifer south of Petone Foreshore. 


\subsubsection{Transmissivity and Storativity values}

A very comprehensive summary of the hydraulic characteristics of the Waiwhetu Artesian Aquifer can be found in the technical report "Hydrology of the Hutt Catchment; Volume 2, Groundwater" by the Wellington Regional Council (1995). This report details each of the major pump tests carried out over the years on the Waiwhetu Artesian Aquifer, and provides listings of the storativities and transmissivities determined from these tests. It also highlights the deficiencies and problems encountered during each of the pump tests and the effect that these may have had on the values obtained.

Appendix 4 details the values of transmissivity and storativity that have been determined from pump tests carried out on the Waiwhetu Artesian Aquifer over the years. Table 7.3.2.1 is a summary of the results of the two major pump tests carried out in the early 1990's, detailing the ranges of transmissivity and storativity found within the Waiwhetu Artesian Aquifer.

\begin{tabular}{|l|c|c|c|c|}
\hline Pump Test name & $\begin{array}{c}\text { Pumping } \\
\text { rate }\end{array}$ & Year & $\begin{array}{c}\text { Transmissvity Range } \\
\left(\mathrm{m}^{2} / \mathrm{day}\right)\end{array}$ & Storativity Range \\
\hline Gear Island & $309 \mathrm{~L} / \mathrm{s}$ & 1991 & $10,900-33,700$ & $9.1 \times 10^{-4}-3.0 \times 10^{-2}$ \\
\hline Waterloo & $405 \mathrm{~L} / \mathrm{s}$ & 1993 & $14,400-69,450$ & $8.6 \times 10^{-4}-3.3 \times 10^{-2}$ \\
\hline
\end{tabular}

Table 7.3.2.1 Summary of two main pump tests carried out on the Waiwhetu Artesian Aquifer. Note that the extremely high values of storativity recorded during the two tests are outside the range set by Todd (1959). However the consistency of the values over the two pump tests implies that they are valid, indicating extremely high storativities in some areas of the Waiwhetu Artesian Aquifer.

The values obtained from these various pump tests highlights the fact that both the transmissivity and storativity values for the Waiwhetu Artesian Aquifer varies widely. This demonstrates quite clearly that the Waiwhetu Artesian Aquifer is neither homogenous nor isotropic in its composition. In fact, it highlights the opposite, - that the Waiwhetu Artesian Aquifer is very much a heterogeneous and anisotropic (having different properties in all directions) aquifer. We must keep in mind that the data collected from these pump tests was recorded at various wells and bores throughout the Lower Hutt Valley that were all considered to be highly productive wells. Thus the above values show how the aquifer material lying between the pumped well and any given observation well may contain lenses of less permeable strata that the groundwater has problems moving through or around.

This is typical of alluvially deposited, unconsolidated aquifers, due to the large range of sediment size that rivers can transport and deposit, and the nature of their deposition (i.e. overbank deposits during flooding). Furthermore, the Waiwhetu Artesian Aquifer was deposited immediately after the last glaciation - events that are notorious for generating not only vast amounts of material, but material of extreme size, ranging from coarse gravel down to fine silt. Due to this geologic heterogeneity, an extremely wide range of 
transmissivity and storativity values are likely. Previous research has found that glaciofluvial aquifers exhibit great spatial variability, with this reflected in porosity values varying within one order of magnitude, while permeability can vary over several orders of magnitude (http://www.uc.edu/geology/geologylistabstract.html). Thus it is no surprise to find such a wide range of values.

We must be careful when using average values of transmissivity and storativity to describe an aquifer or apply it to a model, as it is obvious that the characteristics of the aquifer change quite markedly from place to place. We can also show this effect in a simpler, 'true-life' situation without having to wrestle with the idea of varying transmissivity values. On the $12^{\text {th }}$ January, 1937, a large piezometric pressure drop (of approximately $50 \mathrm{~cm}$ ) was experienced at the Gear Island pumping station as well as some nearby users. Consequently, there was much debate as to whether this drop was caused by a breach of the aquiclude (a dredge was operating in the Hutt River mouth at the time) or through a combination of high abstraction and low recharge (it had been very dry for a few months). However, regardless of what caused the drop in pressure, it still only affected a localised area (near Gear Island). Interestingly, the $50 \mathrm{~cm}$ drop in piezometric level was $38 \mathrm{~cm}$ lower than what the estimated level would have reached under drought conditions (see Historic Notes, Appendix One).

Another example is provided by an unusual, but highly effective pump test that was conducted in July 1936 at Gear Island. Instead of recording the drawdown of the piezometric head at observation wells, this test involved pumping the Waiwhetu Artesian Aquifer at 3.5 Million gallons per day $(182 \mathrm{l} / \mathrm{s})$, and waiting for a complaint to arise. The following is from a correspondence between a Mr. G.I.B Thomas to the Deputy City Engineer;

"After five days continuous running, a complaint was received from Mr. Batland, Poultry Farmer. The flow from his well had practically stopped at half tide. [However], Messrs. Oppeneimer and Company had noticed no difference in flow and were not aware that our wells had been operating."

Unfortunately, neither the position of Mr. Batland's bore or the Oppenheimer bore is detailed in this correspondence, and has been unable to determine from other sources. However, we can assume that Mr. Batland's bore was reasonably close as it was the first bore affected. We can also assume that the Oppenheimer bore was also nearby due to the fact that it was unusual that their water supply had not been affected. Thus, while this test was not 'scientific' in the true sense of the word, it did produce some useful data to suggest that in the Gear Island vicinity, the Waiwhetu Artesian Aquifer is certainly neither homogeneous nor isotropic. 


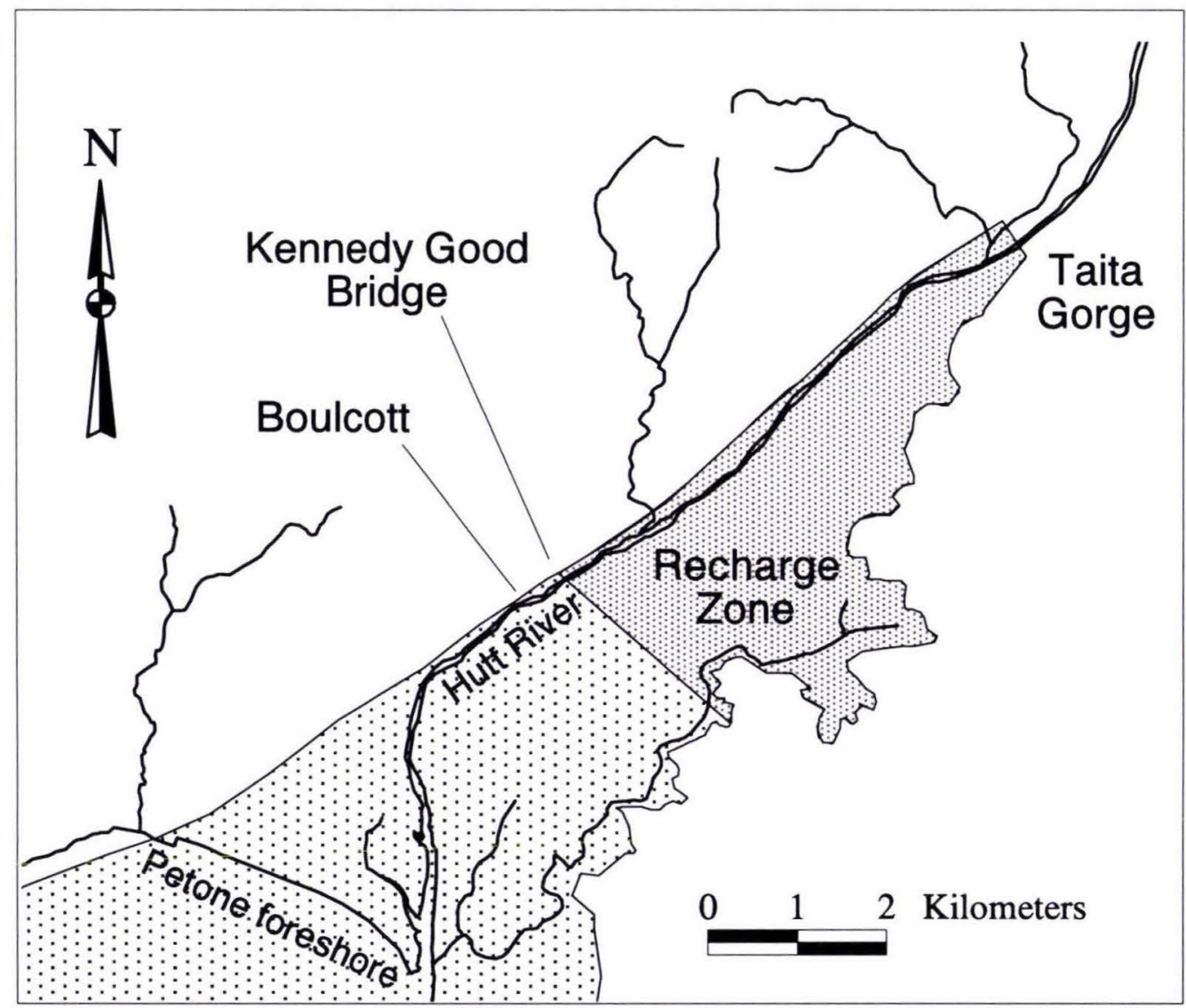

Figure 7.4.2.1 The recharge zone of the Lower Hutt Groundwater System. The unconfined portion of the groundwater system (fine stipple) is where recharge of water into the confined aquifers takes place. It extends from Taita Gorge to the Kennedy Good Bridge vicinity. However, a small amount of water does return to the river in the stretch between the Kennedy Good Bridge and the Boulcott area. 


\subsection{Groundwater Balance}

\subsubsection{Introduction}

The purposes of calculating a groundwater balance for the Waiwhetu Artesian Aquifer is to determine the safe yield of the aquifer. Without a knowledge of the safe yield, an aquifer may remain under-utilised or be over-exploited, possibly leading to contamination from salt-water incursion. For the purposes of this research, a groundwater balance is useful as it determines exactly how much water passes under the harbour portion of the aquifer and thus how much could theoretically be lost via submarine spring discharge. This amount is simply determined by balancing the equation Inflows = Outflows.

With regards to the Waiwhetu Artesian Aquifer, the "inflows" are essentially made up of the recharge to the aquifer in the unconfined zone, plus the leakage across the aquicludes confining the Waiwhetu Artesian Aquifer. The outflows consist of the abstractions from wells on land plus the leakage from the Waiwhetu Artesian Aquifer to the Moera Gravel Aquifer below and the Taita Alluvium above. The natural discharge of water from the aquifer in the marine environment i.e. submarine groundwater discharge is the difference between these variables.

Thus, in summary, the amount that could possibly be escaping through the harbour floor (SGWD) is;

$\begin{aligned} \text { SGWD }= & \text { (Recharge }+ \text { leakage to the Waiwhetu Artesian Aquifer })-(\text { Abstractions }+ \\ & \text { leakage from the Waw }\end{aligned}$

The leakages to and from the Waiwhetu Artesian Aquifer are likely to be very minor factors in the above equation and thus the amount of water available for SGWD will be controlled primarily by the difference between the Recharge and Abstractions.

A comprehensive groundwater balance for the Waiwhetu Artesian Aquifer has already been detailed in the report "Hydrology of The Hutt Catchment, Volume 2: Groundwater" by the Hydrology section of the Wellington Regional Council (1995). Thus the following section is a summary of their findings with some critiquing and elaboration where necessary.

\subsubsection{River Recharge}

Where a river or stream channel is in direct contact with an unconfined aquifer, potential exists for the river to either recharge the groundwater system or receive discharge from groundwater depending on the relative head difference (WRC, 1995). 


\begin{tabular}{|lccc|}
\hline Gauging Date Taita Gorge (29809) & $\begin{array}{c}\text { Kennedy-Good Bridge } \\
\text { Flow (L/s) }\end{array}$ & $\begin{array}{c}\text { Difference } \\
\text { (29824) Flow (L/s) }\end{array}$ & 637 \\
\hline $21 / 02 / 39$ & 5714 & 5077 & 892 \\
$22 / 02 / 39$ & 4668 & 3776 & 1377 \\
$2 / 03 / 39$ & 3724 & 2347 & 1505 \\
$9 / 03 / 39$ & 3597 & 2092 & 1581 \\
$4 / 04 / 39$ & 3061 & 1480 & 1632 \\
$13 / 04 / 39$ & 2959 & 1327 & 1214 \\
$14 / 04 / 43$ & 5204 & 3990 & 204 \\
$15 / 02 / 61$ & 3936 & 3732 & 891 \\
$23 / 03 / 69$ & 4191 & 3300 & 1050 \\
$29 / 03 / 69$ & 3000 & 1950 & 149 \\
$30 / 03 / 69$ & 2141 & 1992 & 769 \\
$22 / 02 / 70$ & 2334 & 1565 & 794 \\
$7 / 02 / 73$ & 2662 & 1868 & 984 \\
$15 / 02 / 73$ & 2494 & 1510 & 507 \\
$18 / 02 / 73$ & 2336 & 1829 & 988 \\
$27 / 02 / 73$ & 1868 & 880 & 770 \\
$16 / 02 / 93$ & 5560 & 4790 & \\
\hline
\end{tabular}

Table 7.4.2.1 Hutt River flows recorded at Taita Gorge and the Kennedy Good Bridge for the dates shown. The difference between the values obtained at these sites demonstrates the rate of recharge to the Lower Hutt Groundwater Zone.

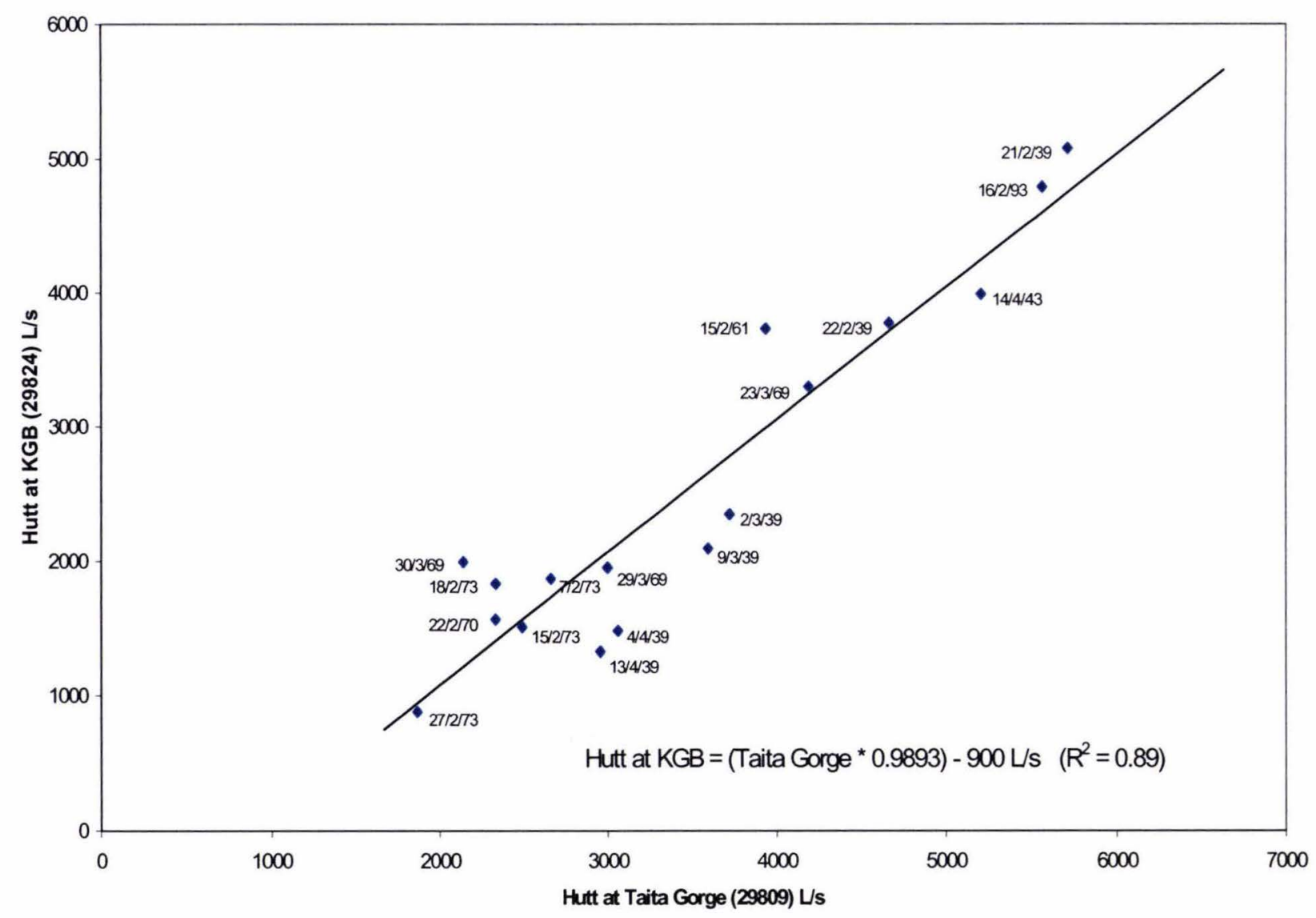

Figure 7.4.2.2 Relationship between concurrent gaugings completed at Taita Gorge (site 29809) and Kennedy Good Bridge (KGB) (site 29824) from 1939 to 1993 (after WRC, 1995). Dates of gauging are shown. 
The groundwater zone in the Lower Hutt Valley is unconfined between Taita Gorge and the Kennedy Good Bridge region (see Figure 7.4.2.1). By recording concurrent gaugings (on the same day) at these sites over time, we can derive a relationship that describes the recharge into the Lower Hutt Groundwater Zone. It is very difficult to ascertain exactly what the 'typical' recharge rate is as many factors influence the recharge such as the groundwater conditions, the river flow and the characteristics of the recharge zone itself. Low flow conditions are used as these are easier to measure accurately and thus form a good dataset on which to base the relationship of flow loss. However, the relationships derived must be used with caution as low river flows often coincide with low groundwater levels and thus the river losses are sometimes affected by a steepened hydraulic gradient.

Table 7.4.2.1 is a list of the low flow gaugings taken at Taita Gorge, and Kennedy Good Bridge over a 54 year period between 1939 and 1993. As can be seen in the table, a varying proportion of the river flow is lost between Taita Gorge and Kennedy Good Bridge. By graphing these gaugings, a relationship can be derived that gives an average rate of recharge to the groundwater. This is shown in Figure 7.4.2.2. From this relationship, the rate of recharge is given as;

The flow at Kennedy Good Bridge = (Taita Gorge flow * 0.9893) - 900. The units are litres per second, and the regression coefficient is 0.89 .

This relationship tells us that for the median flow of about 15,000 litres/second at Taita Gorge, the flow at the Kennedy Good Bridge is about 13,939 L/s. Thus roughly 1060 litres/second (or $91,584 \mathrm{~m}^{3} /$ day) enters the aquifer between Taita Gorge and Kennedy Good Bridge. We can be reasonably confident with this figure due to the high correlation coefficient figure of 0.89 . However, between the Kennedy Good Bridge and Boulcott, a small amount of water is returned to the river thus effectively decreasing this recharge rate. Table 7.4.2.2 and Figure 7.4.2.3 highlights this relationship.

The equation relating this data is;

The flow at Boulcott $=(K G B$ flow $* 1.015)+155$. The units are in litres per second, and the regression coefficient is 0.99 .

Thus for the median flow of $15,000 \mathrm{l} / \mathrm{s}$ at Taita Gorge, the flow at KGB is $13.939 \mathrm{l} / \mathrm{s}$, and is $14,303 \mathrm{l} / \mathrm{s}$ at Boulcott. Therefore, based on these gaugings, the overall recharge rate to the groundwater system is about $697 \mathrm{Litres} / \mathrm{second}$, or $60,221 \mathrm{~m}^{3} /$ day.

However, as mentioned previously, if drought conditions develop, the hydraulic gradient may steepen and water may essentially be 'sucked' into the groundwater system. This may artificially increase the rate of recharge to the groundwater. 


\begin{tabular}{|lccc|}
\hline $\begin{array}{l}\text { Gauging } \\
\text { Date }\end{array}$ & $\begin{array}{c}\text { Kennedy-Good Bridge } \\
(29824) \text { Flow (L/s) }\end{array}$ & $\begin{array}{c}\text { Boulcott (29811) } \\
\text { Flow (L/s) }\end{array}$ & $\begin{array}{c}\text { Difference (Loss to } \\
\text { River) (L/s) }\end{array}$ \\
\hline $21 / 02 / 39$ & 5077 & 5265 & 188 \\
$22 / 02 / 39$ & 3776 & 3980 & 204 \\
$2 / 03 / 39$ & 2347 & 2526 & 179 \\
$9 / 03 / 39$ & 2092 & 2219 & 127 \\
$4 / 04 / 39$ & 1480 & 1530 & 50 \\
$13 / 04 / 39$ & 1327 & 1355 & 28 \\
$14 / 04 / 43$ & 3990 & 4490 & 500 \\
$23 / 03 / 69$ & 3300 & 3571 & 271 \\
$29 / 03 / 69$ & 1950 & 2102 & 152 \\
$22 / 02 / 70$ & 1565 & 1582 & 17 \\
$7 / 02 / 73$ & 1868 & 2182 & 314 \\
$15 / 02 / 73$ & 1510 & 2023 & 513 \\
$18 / 02 / 73$ & 1829 & 1850 & 21 \\
$27 / 02 / 73$ & 880 & 1153 & 273 \\
$16 / 02 / 93$ & 4790 & 4854 & 64 \\
\hline
\end{tabular}

Table 7.4.2.2 Hutt River flows recorded at the Kennedy Good Bridge and Boulcott. The difference between these values demonstrates the rate of loss from the Lower Hutt Groundwater Zone back to the river.

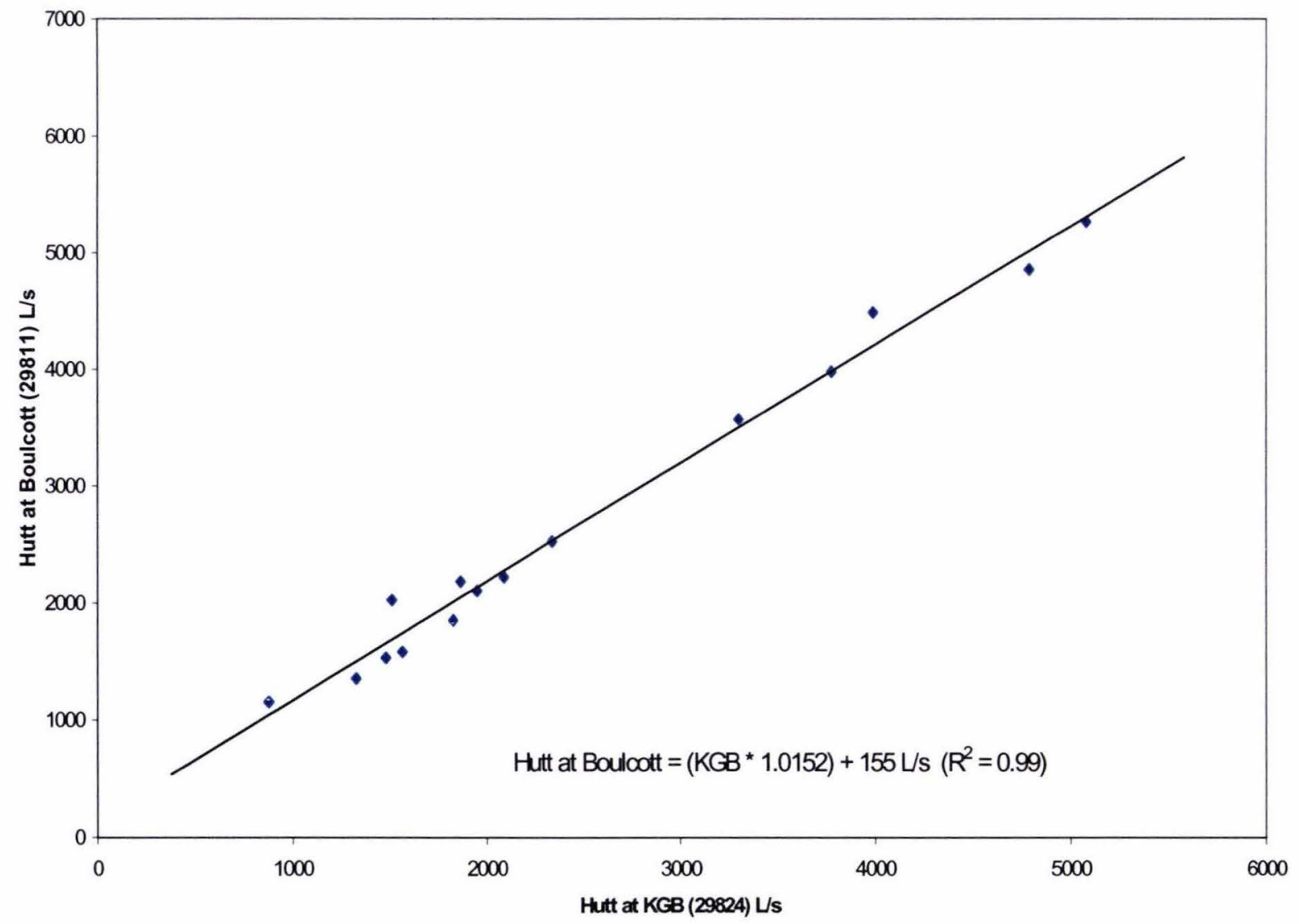

Figure 7.4.2.3 Relationship between concurrent gaugings completed at Kennedy Good Bridge (29824) and Boulcott (29811) from 1939 to 1993. 
One such drought occurred during February to April 1939, and we see from the gaugings taken over this period that the recharge rate gradually increased to give a maximum 1632 $\mathrm{L} / \mathrm{s}$ on the 13/4/39. The loss of water back to the river on this day was only $28 \mathrm{~L} / \mathrm{s}$, thus giving an overall recharge of $1604 \mathrm{~L} / \mathrm{s}$, or $138,600 \mathrm{~m}^{3} /$ day.

Another notable drought occurred in February 1973, with gaugings showing the recharge rate reaching a maximum of $984 \mathrm{~L} / \mathrm{s}$, with the minimum return during the drought being 21 $\mathrm{L} / \mathrm{s}$. This gives an overall recharge of $963 \mathrm{~L} / \mathrm{s}$, or $83,200 \mathrm{~m}^{3} /$ day.

This event saw the Hutt River flows reaching almost half of what was experienced during the 1939 drought. However, as we can see from the gaugings data, the losses to the groundwater were not as great as that experienced during the 1939. More intriguing is that groundwater abstractions in the early 1970's were higher than they had ever been in the past, and significantly higher than the amount abstracted during 1939.

With regards to the groundwater levels during this drought, the Taita Intermediate groundwater monitoring site in the unconfined zone declined by 0.50 metres during January and February 1973, or $8.5 \mathrm{~mm} /$ day. The Waiwhetu Artesian Aquifer, measured at McEwan Park, showed a decline of $1.56 \mathrm{~m}$ or $25.5 \mathrm{~mm} /$ day over the same period. These levels indicate that daily abstraction during this period exceeded daily recharge to the system (WRC, 1995). It is interesting to note that the recharge rate during the 1939 drought was greater than during the 1973 event, despite the fact that the 1973 drought was worse and the aquifer under greater stress due to the larger daily abstractions that took place in 1973. Furthermore, the returns to the Hutt River in the 1939 event were lower than in 1973. This can be explained by the changes to the Hutt River bed level over time.

It must be remembered that the river gaugings were taken over a considerable length of time (1939 - 1993). This period witnessed many changes to the Hutt River such as river straightening and a massive decline in the bed level brought about by gravel extraction. Indeed, Easther (1991), states that "by 1931 there were at least 12 gravel extraction plants operating on the river", with "extraction peaking in the 1960's." Gravel extraction appears to have been concentrated in the lower reaches of the Hutt River early on when "substantial lowering of the Hutt riverbed occurred between 1944 and 1964" (Easther, 1991). During this period, in the vicinity of the Melling Bridge ( $4.4 \mathrm{~km}$ upstream from Petone Foreshore in the confined zone), a decline of $2.8 \mathrm{~m}$ was recorded.

However, the largest declines in the Hutt riverbed levels occurred in the unconfined (recharge) zone between the Kennedy Good Bridge and Pomare Bridge (near Taita Gorge) in the period 1950 to 1977 . The average decline over this reach was about 4.8 metres! This reduction in river bed level means a lower elevation of the river bed. This in turn reduces the hydraulic gradient of the recharge zone, which reduces the aquifer throughflow. 
As a steeper hydraulic gradient will generate greater aquifer throughflow due to the effective weight of the water (gravity * elevation), it follows that a lower elevation will result in a lower hydraulic gradient and thus less aquifer throughflow due to less force pushing the water. This results in less water entering the groundwater system. Furthermore, gravel extraction is often accompanied by the redistribution of large amounts of fine bank material. This tends to 'clog up' the river bed and further reduce its ability to transmit water to the groundwater system beneath. Easther (1991) notes that during the period of gravel extraction, the river was "heavily silt laden for extended periods."

By removing the early gauging data from the relationship, the equation using gaugings taken during the period 1961 to 1973 becomes:

\section{The flow at Boulcott $=($ Taita Gorge flow $* 0.9963)-618($ litres/second $)$}

Thus during this period, the overall flow loss to the groundwater system for the median flow of $15,000 \mathrm{l} / \mathrm{s}$ is roughly $674 \mathrm{l} / \mathrm{s}$. The regression coefficient of this relationship is higher than for the full record with a value of 0.96 . This gives a daily recharge rate of $58,234 \mathrm{~m}^{3} /$ day.

This is probably a more realistic figure of recharge during this period as the river bed would have probably had a lower transmittance due to it being silted up as a result of the extraction works. It is possible that this recharge rate increased during drought periods (when the groundwater resource is stressed), and also during flood and high rainfall events (when more water passes over the recharge area). However, we can assume that the above relationship represents the average recharge that can be expected under 'normal' surface water and groundwater hydrological conditions during this period 1961 to 1973.

Of interest, is that during drought periods in this regime, the maximum recharge rate reached is not nearly as much as it has been in the past, such as during the 1939 drought when the recharge rate rose to a very high level. This difference in recharge rates during drought periods is most likely attributable to the reduction in riverbed level (and thus hydraulic gradient) and a reduction in the permeability of the gravels in the recharge zone (from siltation) during this period. This low recharge rate during periods when the aquifer is under stress can result in the recharge rate being less than the abstraction rate, thus placing an even greater stress on the confined Waiwhetu Artesian Aquifer. In such scenarios, water from elsewhere in the aquifer system will be drawn towards the zone of abstraction during periods of aquifer stress.

Water from within the aquifer beneath the harbour is one source from which this replenishment may occur. This could have been the case during the drought of 1973 when it was observed that the hydraulic gradient reversed between Somes Island and the Petone 
Foreshore indicating a movement of water from the Somes Island vicinity towards the Petone area (Donaldson and Campbell, 1977). If submarine spring vents issuing from the artesian aquifer are present in the region replenishing the abstraction zone, it is possible that the spring flow may cease and seawater may enter the artesian aquifer. This would be particularly relevant if the submarine spring sites are indeed linked to areas of higher transmissivity, or preferential flowpaths, as is one of the hypotheses of this research. This will be discussed in greater detail in Chapter Ten.

There is limited evidence to suggest that the recharge rate has improved slightly in the period since 1973. Gaugings taken during the Waterloo pump test (1993) indicate a net loss (between Taita Gorge and Boulcott) of $1,088 \mathrm{~L} / \mathrm{s}\left(94,000 \mathrm{~m}^{3} /\right.$ day) to the groundwater system. While this figure may be raised due to the effects of the pump test $\left(43,000 \mathrm{~m}^{3} /\right.$ day was pumped from the Waiwhetu Artesian Aquifer), it is possible that the reduction in gravel extraction plants operating on the Hutt River since the late 1970's has improved the situation a little.

\subsubsection{Rainfall Recharge}

In the most basic sense, the rainfall recharge can be described as;

Rainfall Recharge $=$ Rainfall - Actual evapotranspiration - Soil moisture deficit

Thus rainfall recharge is calculated by using a soil moisture budget model which assumes that the ground surface is completely permeable wherever the surface is not paved or covered. The various components to the above equation are described in detail in WRC (1995).

Total mean annual rainfall recharge for the Lower Hutt Groundwater Zone was calculated by WRC (1995) as being $804 \mathrm{~mm}$, or $58 \%$ of the mean annual rainfall (1383mm). Given that the surface area of the unconfined area is roughly $9.2 * 10^{6} \mathrm{~m}^{2}$, and the non-urbanised surface area open to rainfall is approximately $40 \%$ of this total, the area available for rainfall recharge is assumed to be $3.68 * 10^{6} \mathrm{~m}^{2}$. This equates to a mean annual rainfall recharge of around $3^{*} 10^{6} \mathrm{~m}^{3} /$ year, or $8,100 \mathrm{~m}^{3} /$ day $(941 / \mathrm{s})$.

It must be noted that this figure is perceived as being on the high side (pers comm. Brydon Hughes, WRC, 1998). Regardless of this, we must remember that rainfall recharge only takes place intermittently and not as a constant recharge as is the case with river recharge. This is an important concept as it leads to the conclusion that during heavy rainstorms on the Lower Hutt Valley, the amount of recharge to the groundwater system is significantly increased (for a brief period). Thus the amount of throughflow through the aquifers within the groundwater system can be much higher than 'normal' during these rainstorm events 
and consequently the amount available to be lost via SGWD during these events may also increase significantly.

\subsubsection{Recharge via Leakage through the Wilford Shell Bed}

The Wilford Shell Beds is the confining unit that separates the Moera Gravel Aquifer from the Waiwhetu Artesian Aquifer. Piezometric head data shows that the Moera Gravel Aquifer has a head about 1.1 metres higher than that of the Waiwhetu Artesian Aquifer (Hutton, 1965; WRC, 1995). It is thus possible that leakage across the Wilford Shell Beds could occur, with water from the higher pressure Moera Gravel Aquifer moving across the aquiclude and into the Waiwhetu Artesian Aquifer (e.g. WRC, 1995). This was assumed to be the case by Hutton (1965), WRC (1995) and Reynolds (1993).

However, data gathered from a pump test conducted in 1998 on the Moera Gravel Aquifer does not fit this hypothesis. The observed response in observation wells in the Waiwhetu Artesian Aquifer during the 1998 pump test showed that the leakage across the Wilford Shell Beds is in the order of $3.5 \times 10^{-19} \mathrm{~m} /$ day (WRC, 1998). This extremely low seepage value is consistent with the results of the 1995 Waterloo pump test, which pumped from the Waiwhetu Artesian Aquifer. During this test, the IBM \#1 bore (formerly known as the UWA 1 bore, see figure 7.4.6.2) showed no response in the Moera Gravel Aquifer to the reduced piezometric head in the Waiwhetu Artesian Aquifer (Hughes, 1998). These findings differ greatly from Reynolds (1993) who assumed a high degree of leakage through the Wilford Shell Bed $\left(1 \times 10^{-4} \mathrm{~m} /\right.$ day $)$, but this assumption was based on no actual data though.

It would thus seem that the amount of recharge from the Moera Gravel Aquifer to the Waiwhetu Artesian Aquifer is virtually nil. Even under extreme stress (drought) or prolonged pumping at a high rate it is unlikely that much additional water be sucked through the Wilford Shell Bed confining layer.

\subsubsection{Recharge via Leakage through the Petone Marine Beds/Melling Peats}

Given that the piezometric head of the Waiwhetu Artesian Aquifer is about 1.8 metres higher than the Taita Alluvium aquifer, it is hard to envisage any movement of water from the lower pressure Taita Alluvium to the higher pressure Waiwhetu Artesian Aquifer, especially with a confining bed to pass through. Indeed, the hydraulic conductivity of the Petone Marine Beds is low, ranging from $10^{-7}$ to $10^{-9} \mathrm{~m} / \mathrm{s}$ (WRC, 1995). If any recharge to the Waiwhetu Artesian Aquifer does occur, it would most likely do so where the confining layer is thinnest, which is close to the unconfined/confined boundary. If leakage in this vicinity does occur, it possibly only occurs during periods when the Waiwhetu Artesian Aquifer is under stress i.e. when the water would be encouraged to flow across the confining beds. 


\subsubsection{Overall Recharge to the Waiwhetu Artesian Aquifer}

It will have become apparent in the previous sections that the values for rainfall and river recharge have been in terms of recharge to the 'groundwater system' and not just the Waiwhetu Artesian Aquifer. This is because there is an absence of continuous impermeable strata in the recharge zone, which means that the amount lost from the river will recharge the two confined aquifers (the Waiwhetu Artesian Aquifer and the Moera Gravel Aquifer), plus the unconfined Taita Alluvium (see figure 5.3.2 for schematic diagram).

It is extremely difficult to measure exactly what proportion of the recharge water enters the various aquifers due to varying hydraulic gradients between the aquifers. However, we can assume that a major proportion of this water does enter the Waiwhetu Artesian Aquifer as demonstrated by the high hydraulic gradient in the initial stages of the confined aquifer (see Figure 7.4.6.1).

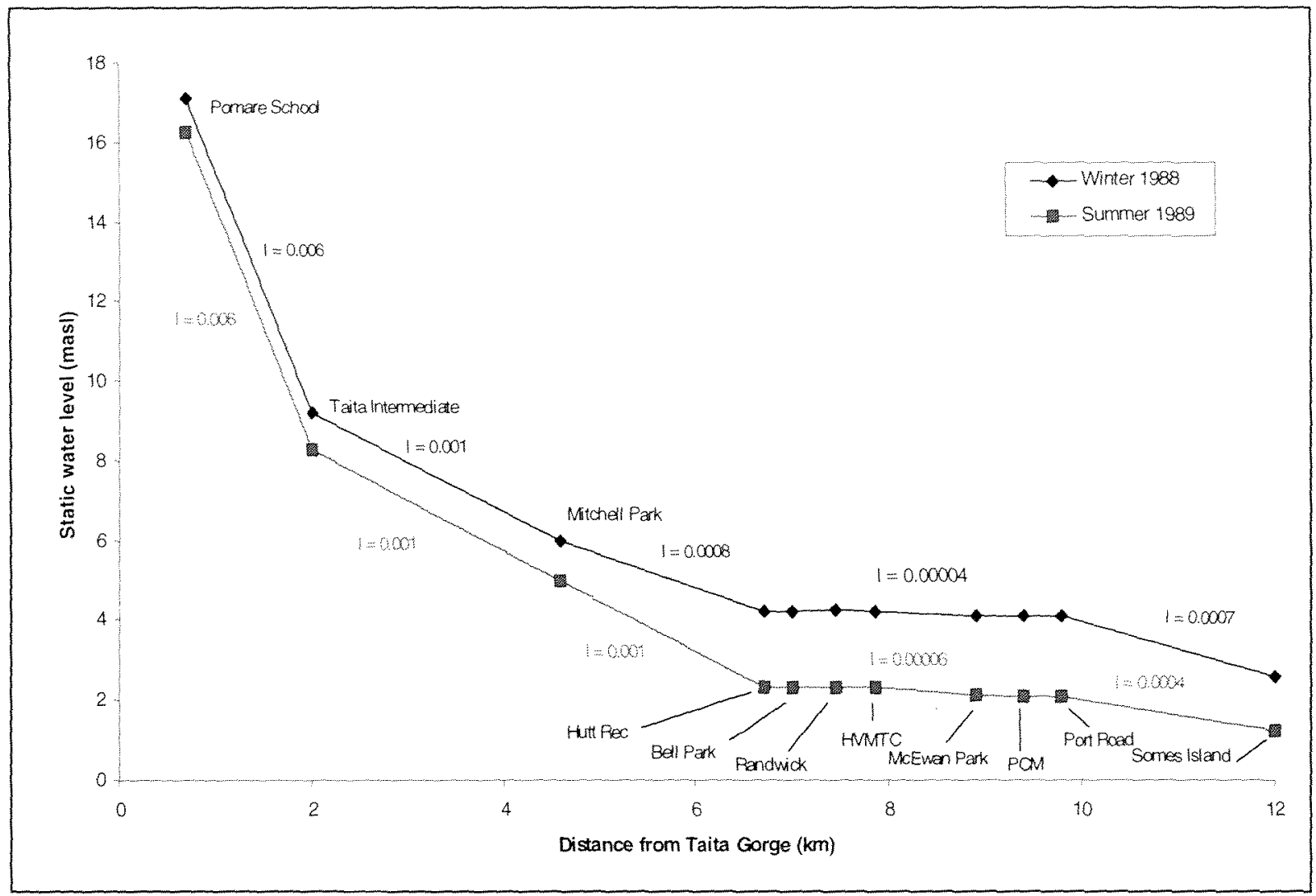

Figure 7.4.6.1 Calculated hydraulic gradients based on measured piezometric levels in the unconfined and confined sections of the Waiwhetu Artesian Aquifer.

Figure 7.4.6.1 shows the seasonal differences between the hydraulic gradients as measured in the Waiwhetu Artesian Aquifer during winter 1988 and Summer 1989 (after WRC, 1995). The unconfined/confined boundary passes very close to the Mitchell Park site. 


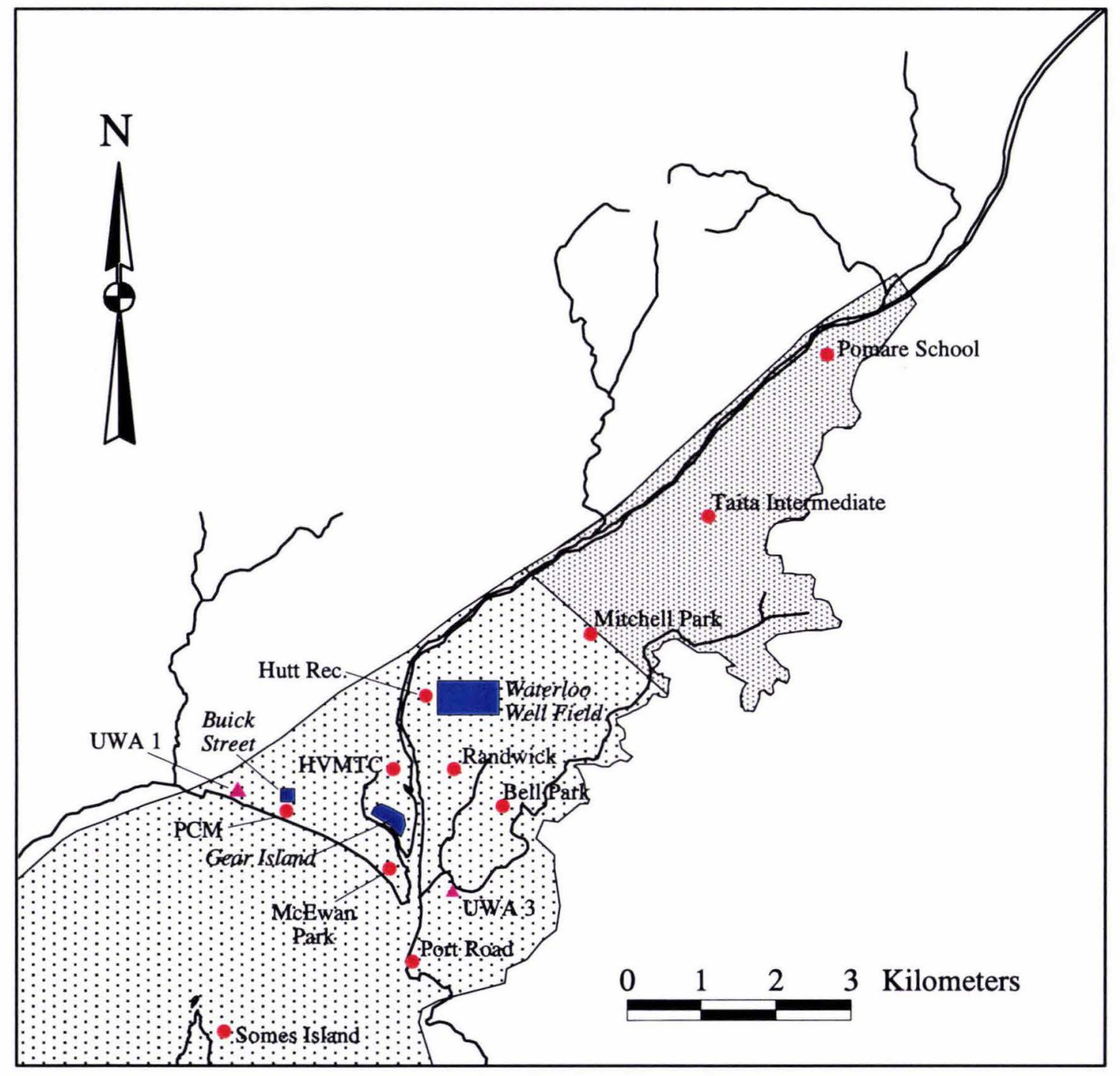

Figure 7.4.6.2 Location of the wells used to derive the hydraulic gradient of the Waiwhetu Artesian Aquifer. The unconfined section of the aquifer is shown as a fine stipple. The abstraction wellfields are also shown (in blue). The two pink triangles show the locations of two of the wells penetrating the Moera Gravels Aquifer. Well UWA 1 is also known as IBM \#1, PCM = Petone Centennial Memorial, and HVMTC $=$ Hutt Valley Memorial Technical College. 
Figure 7.4.6.2 shows the locations of the wells used to derive these hydraulic gradients. The data shows a clear divergence of the two lines at Mitchell Park, at the onset of the confined portion. As can be seen, the hydraulic gradient in the northernmost section of the confined aquifer between Mitchell Park and the Hutt Recreation Ground is steeper in summer than it is in winter. This is due to the demand placed on the Waiwhetu Artesian Aquifer during the summer periods.

The low hydraulic gradient apparent between the Petone Foreshore and Somes Island during summer is a concern to the future management of this aquifer. However, it must be noted that the Somes Island record in the WRC hydrological database shows that there is a gap in the data during winter 1988. It is unclear where WRC (1995) obtained the piezometric data at this site for this winter period. Furthermore, the data for summer 1989 is known to be erroneous due to a leaking bore at the Somes Island observation well (discovered in 1993). As such, the hydraulic gradient between the Petone Foreshore and Somes Island cannot be used with any degree of confidence. Recent data suggests that the hydraulic gradient between the foreshore and Somes Island is very flat.

We can use these hydraulic gradients to obtain better idea of the throughflow of the aquifer at various locations. Throughflows of aquifers are often used to estimate the potential recharge to any given groundwater unit. It describes the flow of water through any given groundwater system. It is controlled by the head of water driving the flow, the pressures existing down-gradient of the recharge area, and the resistance of the matrix making up the aquifer (WRC, 1995).

The daily throughflow of an aquifer can thus be estimated using the equation below.

$Q=$ TiW where $\quad \begin{array}{ll}\text { Q } & \text { is the discharge }\left(\mathrm{m}^{3} / \text { day }\right) \\ \mathrm{T} & \text { is the transmissivity }\left(\mathrm{m}^{2} / \text { day }\right) \\ \mathrm{i} & \text { is the hydraulic gradient, and } \\ \mathrm{W} & \text { is the width of the aquifer }\end{array}$

Because all three of the above parameters $(T, i$, and $W$ ) all vary significantly within the aquifers in the Lower Hutt Groundwater Zone, the above equation becomes fairly redundant when applying it to the entire aquifer member.

Regardless of this, WRC (1995) estimated an average throughflow for the Waiwhetu Artesian Aquifer based on an average transmissivity (T) of $35,000 \mathrm{~m}^{2} /$ day, an average hydraulic gradient (i) of 0.0004 , and a width (W) of $3 \mathrm{~km}$. Their calculated figure of throughflow came to $42,000 \mathrm{~m}^{3} / \mathrm{day}$. However, it is unclear how they came to use an average hydraulic gradient of 0.0004 for the Waiwhetu Artesian Aquifer. If we use the summer hydraulic gradient data of the confined zone between the Petone Foreshore and 


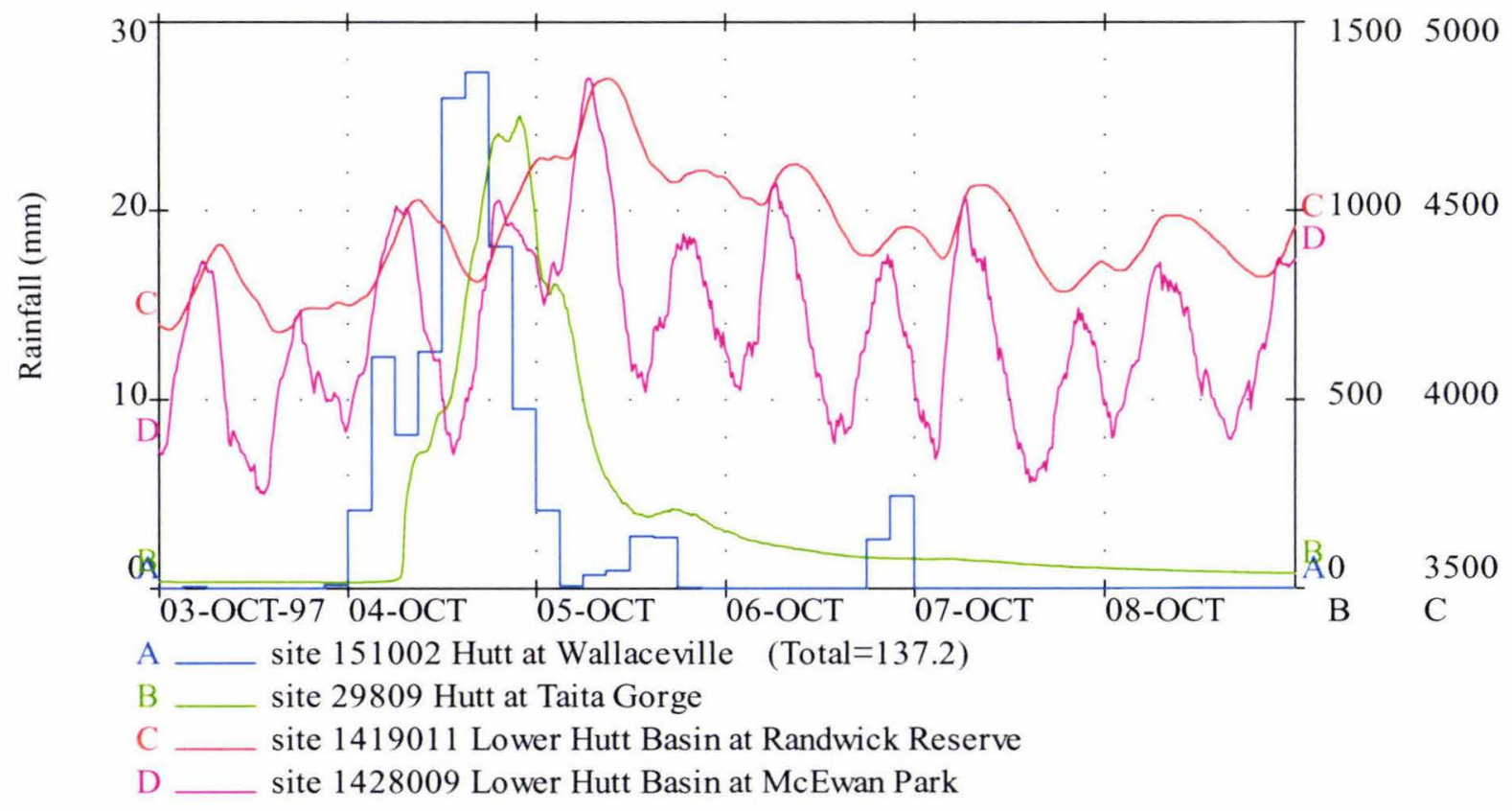

Figure 7.4.7.1 The response of the Waiwhetu Artesian Aquifer to rainfall/river recharge. Line A (blue) is the 3 hourly rainfall recorded in the Hutt Valley at Wallaceville (corresponds to the left axis). Line B (green) is the river flow recorded at Taita Gorge (corresponds to axis B, in $\mathrm{m}^{3} / \mathrm{s}$ ). Line $\mathrm{C}$ (red) is the piezometric head recorded at Randwick, and Line D (pink) is the piezometric head recorded on the Petone Foreshore at McEwan Park (both correspond to axis $\mathrm{C}$, in $\mathrm{mm}$ above sea level).

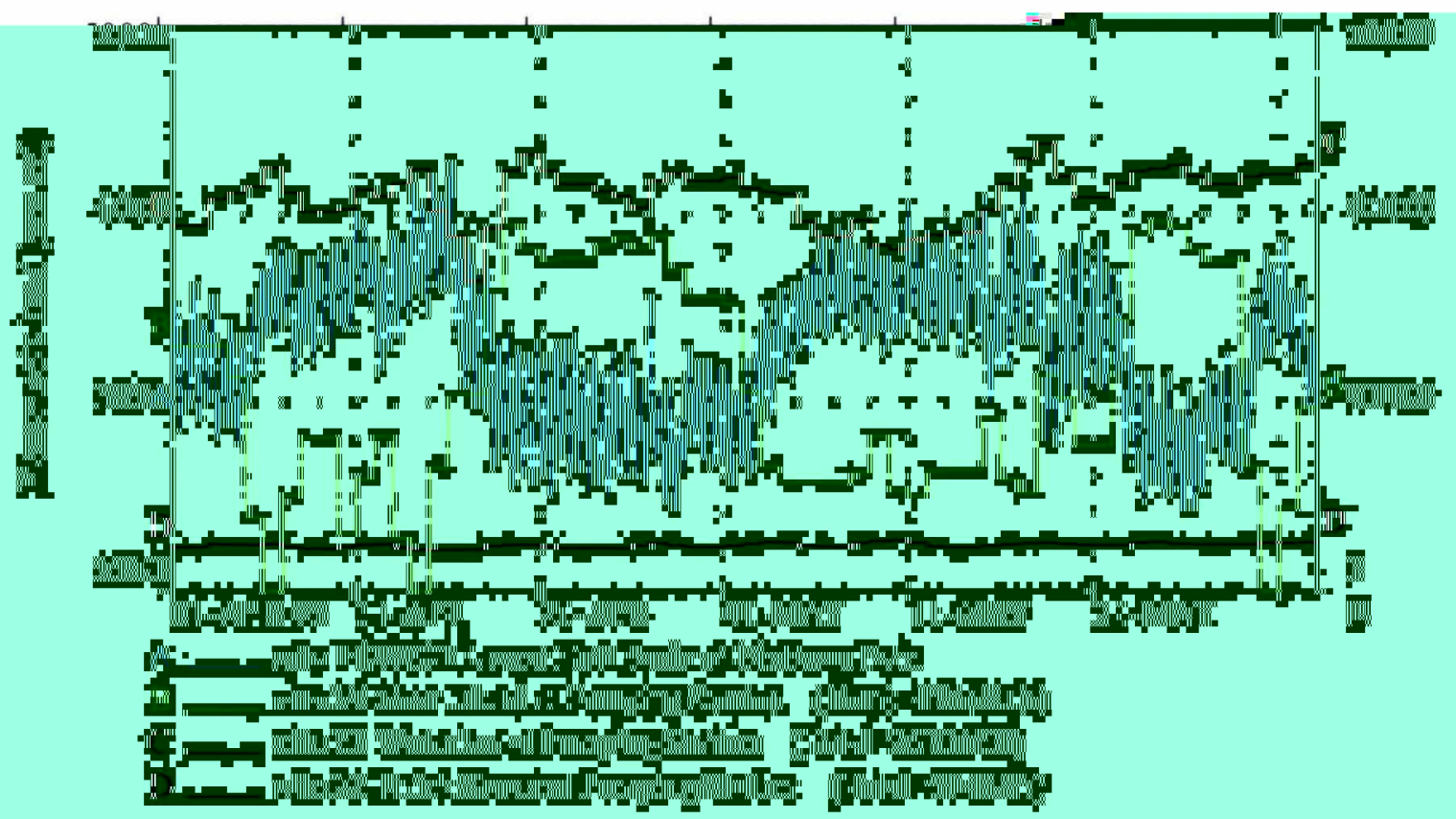

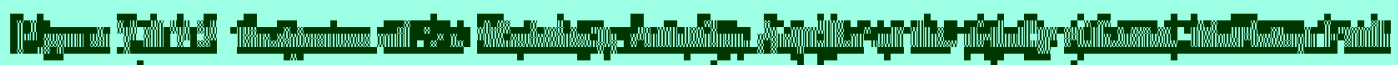

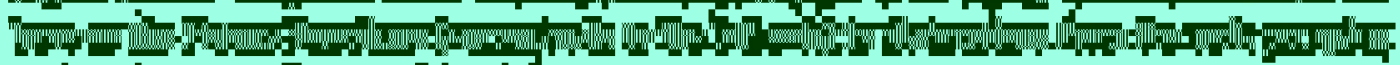
Mand|and a 
Mitchell Park, an average hydraulic gradient of 0.0006 is obtained. Also, the average width throughout this entire zone is roughly $3.5 \mathrm{~km}$. This gives a throughflow of 73,700 $\mathrm{m}^{3} /$ day. This would imply that most of the water entering the recharge zone makes its way into the Waiwhetu Artesian Aquifer. This is not that surprising given the high demand placed on the Waiwhetu Artesian Aquifer during summer, not to mention the low transmissivities found in the Moera Gravel Aquifer (around $1200 \mathrm{~m}^{2} /$ day) (Hughes, 1998) and the low water table in the Taita Alluvium during summer periods.

Furthermore, we can see from the transmissivities obtained from pump tests carried out in 1991 and 1993 (Table 7.3.2.1; page 54) that a wide range of throughflow can be expected in the Waiwhetu Artesian Aquifer. By using the highest recorded transmissivity of 69,450 $\mathrm{m}^{2} /$ day, an average hydraulic gradient of 0.0006 , and a more realistic aquifer width of $3.5 \mathrm{~km}$, a throughflow of $145,845 \mathrm{~m}^{3} /$ day is obtained. While the aquifer, as a total, clearly does not have such a high throughflow as this, it shows that there are likely to be areas within the Waiwhetu Artesian Aquifer that can transmit much larger quantities of water than the 'average' aquifer. This provides more support to the preferential pathway theory, which suggests that conduit pathways exist within the aquifer that could be responsible for supplying the most prolific submarine spring discharges in Wellington Harbour.

\subsubsection{Response of Waiwhetu Artesian Aquifer to Recharge and Abstraction}

The response of piezometric head variations in both recharge and abstractions can be demonstrated graphically. Figure 7.4.7.1 shows the response of the Waiwhetu Artesian Aquifer at two locations to a rainfall/flood event. The rainstorm event of $4 / 10 / 97$, produced $120 \mathrm{~mm}$ in a 24 hour period and generated a river flow of just over $1200 \mathrm{~m}^{3} / \mathrm{s}$. The lag time between the rainfall peak and river flow peak is about 4 hours. The groundwater peak occurs about 10 hours after the river flow peak. This doesn't mean that the water from this event only takes ten hours to reach these sites, rather it is the response of the aquifer to the increased pressure resulting from this abnormally high recharge event.

The response of the Waiwhetu Artesian Aquifer at McEwan Park (Petone Foreshore) to abstractions from the three main pumping stations is shown in Figure 7.4.7.2. As shown in this plot, Buick Street was pumping at constant rate of around $7000 \mathrm{~m}^{3} /$ day. This amount varies little and thus the effect of it pumping on wells along the Petone Foreshore is hard to determine. In contrast, the abstraction from both Waterloo and Gear island fluctuates markedly, with Gear Island in particular having an extremely varied pumping regime. As can be seen, the pumps at Gear Island get 'switched' on and off quite regularly to provide additional water to the municipal supply when required.

The effect of pumping fluctuations at both Waterloo and Gear Island have an affect on the piezometric levels at McEwan Park, as well as most other wells in the Lower Hutt Valley. 
However, as can be seen in Figure 7.4.7.2, the effect of the Gear Island Well Field abstractions is much more pronounced than that of the Waterloo Well Field abstractions on the aquifer beneath the foreshore region,. Extremely rapid changes in piezometric head can be observed when pumping at Gear Island is either increased or shut down. The period after the $21^{\text {st }}$ of May 1995 on Figure 7.4.7.2 highlights this response to good effect. This rapid and marked response is not surprising given the close proximity of Gear Island to the foreshore and to the McEwan Park water level recorder.

This of course means that extended periods of abstraction from Gear Island would provide the greatest chance of salt-water incursion at the submarine spring sites close to the Petone Foreshore. The closest of these spring sites is only about $1500 \mathrm{~m}$ away from the Gear Island pumping station. Thus care must be taken when using the Gear Island Well Field for periods of prolonged abstraction.

Unfortunately, although not surprisingly, it is not possible to find a rainfall event without a correlating rise in river flow. As such, the effects of rainfall recharge on the aquifer cannot be distinguished from the overall recharge, which is dominated by the river recharge.

\subsubsection{Direct evidence for preferential pathways in the Waiwhetu Artesian Aquifer}

We have already hypothesised the presence of preferential pathways existing in the Waiwhetu Artesian Aquifer based on its depositional history and on pump test data. However, there is a lot more evidence for these pathways that has been gathered over the years.

Looking back at Figure 7.4.7.1, we can see that the response at McEwan Park is slightly faster than that of Randwick Reserve. Given that Randwick Reserve is about $2 \mathrm{~km}$ closer to the recharge zone than McEwan Park, this rapid response at McEwan Park is something of an anomaly. However, this could possibly indicate that a pathway of higher transmissivity links the recharge zone with the McEwan Park area. If this is the case, it is likely be a paleochannel, and one that we could expect to continue beneath Wellington Harbour.

The idea of preferential pathways within the Waiwhetu Artesian Aquifer has been raised previously to explain the differences in the velocity of aquifer seepage rates derived from tracer tests compared with those calculated using the widely used equation below:

$\mathrm{Q}=-\mathrm{K} . \mathrm{i} / \mathrm{n}$

$$
\begin{aligned}
& \text { where } Q \quad \text { is the seepage velocity in } \mathrm{m} / \text { day } \\
& \mathrm{K} \text { is the hydraulic conductivity in } \mathrm{m} / \text { day } \\
& i \quad \text { is the hydraulic gradient } \\
& \mathrm{n} \quad \text { is the porosity of the porous medium }
\end{aligned}
$$


In general, the above equation is used with average values of $\mathrm{K}, \mathrm{i}$ and $\mathrm{n}$ and thus the result generated is an average figure for the entire aquifer.

Tracer tests sample a portion of the aquifer by releasing the trace liquid at one point and observing its movement through the aquifer at observation wells 'downstream'. The different values generated using these methods are vast. For instance, a seepage velocity for the Taita Alluvium Aquifer was calculated using the above equation to be $3.8 \mathrm{~m} /$ day. Groundwater tracer tests carried out at Fraser Park produced seepage velocity estimates of $111 \mathrm{~m} /$ day (WRC, 1995).

This difference clearly shows that the Taita alluvium material is not homogenous, and contains regions of higher permeability than elsewhere - these regions most likely being paleochannels. Indeed, WRC (1995) supports this by stating "the seepage velocities in paleochannels (relic river channels) will be one to two orders of magnitude higher due to significantly higher permeability of these material... They go on to state "... in addition, the degree of sorting in general increases with distance down the valley, producing higher permeability values, and hence greater seepage velocities" (WRC, 1995). The calculation of seepage velocities assumes a (homogeneous) vertical distribution of hydraulic conductivity, whereas in reality the variation of hydraulic conductivity in natural aquifer materials may vary by up to 2-3 orders of magnitude (WRC, 1995). The same would most certainly apply to the Waiwhetu Artesian Aquifer.

Age-dating the groundwater is another method of determining the seepage rates within an aquifer. 'Dating' the water has been carried out on a number of occasions in the past, with varied results. Tritium analysis of groundwater from the Waiwhetu Artesian Aquifer reported by Grant-Taylor and Taylor (1967) (cited by WRC, 1995) indicate a travel time of approximately 40 months from the recharge zone to the Hutt Park Pumping Station (in the eastern side of the valley near the present day UWA 3 bore (see figure 7.4.6.2). This is an average figure as the water was sampled from the entire thickness of the water-bearing gravels. The calculated travel time equates to a seepage velocity in the range of 4 to 7.5 $\mathrm{m} /$ day (depending on whereabouts in the recharge zone the water entered the aquifer).

Recently, tritium dating was again used to 'date' the groundwaters within the Lower Hutt Groundwater Zone. According to Uwe Morgenstern, a physicist at GNS in Lower Hutt who undertook this work, the relationships on which these figures were derived was extremely accurate and thus can be assumed to have a good degree of certainty.

The results reveal that it takes about 3.5 years (42 months) for water to travel from the recharge zone to the (now retired) Hutt Park pumping station (pers comm. Uwe Morgenstern, GNS, 1998). These results are extremely similar to those calculated by Grant-Taylor and Taylor (1967). 
However, while this correlation of results allows them to be used with confidence, we must remember that they are still average values. The apparent heterogeneity of the Waiwhetu Artesian Aquifer would give it a wide range of seepage velocities. Indeed, tracer tests undertaken by McKillop (1935) at Gear Island indicated a seepage velocity of between 18 $26 \mathrm{~m} /$ day in the Waiwhetu Artesian Aquifer in the Gear Island vicinity (WRC, 1995). This some 3 - 4 times faster than that calculated by the tritium dating of Grant-Taylor and Taylor (1967) and Morgenstern (1998, pers. comm.).

At IBM \#1 (also called UWA 1) in the western side of the valley near the foreshore (see Figure 7.4.6.2 for location), the water is 21 years old in the Waiwhetu Artesian Aquifer and 50 years old in the Moera Gravel Aquifer (pers comm. Uwe Morgenstern, GNS, 1998).

The above values imply that the water travels very fast in the central and eastern part of the Waiwhetu Artesian Aquifer, but much slower in the western side of the valley. The reason for this is probably attributable to two main factors. Most importantly is the overall tilt of the sediments within the valley. Being in a highly tectonic region, and lying within a fault angle depression, the sediments are subjected to shortening in the north-south axis, and tilting to the west in the west-east axis. With the water within the aquifers being under pressure, they will tend to flow towards the region of least pressure which, in the absence of any breaches in the confining beds, will be up dip towards the east. The second controlling factor in the difference of seepage rates throughout the valley will be due to preferential flowpaths, (present as relic channels), and the connection of these pathways of higher transmissivity with the recharge zone.

The age of the water sampled at Somes Island (sourced from the Waiwhetu Artesian Aquifer) gave an age of 20 years (pers comm. Uwe Morgenstern, GNS, 1998). With a travel time of 3.5 years to the Hutt Park region, the 20 year old water recorded at Somes Island is unusually old. This is likely to be attributable to the large decrease in pressure and hydraulic head within the Waiwhetu Artesian Aquifer around the zones of abstraction (see Figure 7.4.7.2). However, it also possible that this large difference in travel times could be attributable to a secondary loss of pressure via submarine spring leakage in the vicinity between the Petone Foreshore and Somes Island. Uwe Morgenstern supported this hypothesis, saying that he too had considered this as a reasoning behind the much older water found at the Somes Island bore.

The age of the water in the Moera Gravel Aquifer is also quite surprising given that previous chemical analyses of this water implied that it would be of a similar age to the Waiwhetu Artesian Aquifer water (WRC, 1995; WRC 1998). However, the high degree of certainty within the tritium dates as previously pointed out and the evidence of low transmissivities in the Moera Gravel Aquifer as provided by pump tests (WRC, 1995; WRC, 1998) do suggest that this 50year age is correct. 
The Moera Gravel Aquifer 50 year travel time from recharge zone to the IBM\#1 bore, combined with the extremely low hydraulic gradient (Hutton, 1965), and the high piezometric head within this aquifer, implies that there is no major leakage from the Moera Gravel Aquifer to the Waiwhetu Artesian Aquifer. Furthermore, it also suggests that the flow of water through this aquifer is very slow. As such, it is likely that there is no significant connection of this aquifer with the harbour. It also implies that the majority of the water in the recharge zone replenishes the Waiwhetu Artesian Aquifer. 


\section{Chapter Eight}

\section{EXTENT AND CHARACTER OF THE SUB HARBOUR WAIWHETU ARTESIAN AQUIFER}

\subsection{Introduction}

Before addressing the problem of defining the extent of the sub harbour Waiwhetu Artesian Aquifer, we must remember that an aquifer can only be artesian when it is covered by a confining unit. Therefore we must identify not only the extent of the Waiwhetu Artesian Aquifer deposits, but also the extent of the overlying aquiclude, the Petone Marine Beds.

The best methods for identifying sub-surface deposits are directly, through coring (boreholes), and indirectly, through seismic interpretation. While boreholes are common on land, in the Lower Hutt Valley and along the Petone Foreshore, very little coring has been performed in the sub-harbour basin. The only exceptions to this are the Somes Island water supply bore (just east of the northern tip of Somes Island), plus a number of shallow offshore bores in the northern portion of the harbour.

These were drilled by the Engineering Consultancy Bricknell, Moss, Rankine and Hill at Korokoro (Report S420, 1968) and at Pt Howard (Reports S490, 1970 and S693, 1971). Due to the shallow nature of these bores, very little useful information concerning the artesian gravels can be obtained from them, apart from the depth at which they were encountered. They do, however, provide some information on the thickness and nature of the confining Petone Marine Beds formation.

One further bore, drilled just to the west of Ward Island, was drilled by Alpine Geophysical Associates Inc. in 1970. Unfortunately, information relating to this bore (and the sediments it cored) could not be located during the course of this research.

However, many seismic surveys have been undertaken in Wellington Harbour, from which a great deal of information can be obtained. It is the data collected from these seismic surveys that forms the basis of the following chapter. 


\subsection{Seismic surveys undertaken in Wellington Harbour}

The aim of a seismic survey is to obtain sub-surface information of the geological structure of an area. In the most basic terms, seismic investigations work by sending an energy pulse (in the form of sound) at the surface which then radiates out and down through the underlying lithology. Where changes in density occur, a proportion of the signal is returned to the surface (essentially "bounced back") to be recorded on a string of 'receivers' at the surface, while the remainder of the energy continues deeper. The amount of signal returned is relative to the amount of density contrast within the sediments. The larger the density contrast, the stronger the returned signal. As different rock types or sedimentary layers have different densities, the strength of the returned signal can be used to identify changes in the type of geology encountered, or changes in the fluid or gas content within the geological units (hence their widespread use in the petroleum industry). The recorded signals are then processed to remove 'noise' to make the output readable.

The sound frequency is critical in determining the depth of seismic penetration. In general, the lower the frequency - the deeper the penetration. However this gain in depth is accompanied by a loss of resolution.

A number of seismic surveys have been performed in Wellington Harbour with varying success. Two of these, Hochstein and Davey (1974) and Wood and Davy (1992) targeted the basement structure, while other focused on localised areas such as the Wellington fault (Lewis, 1989), and the harbour entrance (Lewis et al, 1987; and Wood et al, 1989).

Three major seismic surveys, targeting the shallow sedimentary units beneath Wellington Harbour, have also been carried out over the last 30 years. The surveys in question were undertaken by Alpine Geophysical Associates Inc. in 1970, Reyners and Christoffel (Victoria University of Wellington) in 1972/3, and Davy and Wood (institute of Geological and Nuclear Sciences) in 1993. The reports accompanying these surveys were completed in 1971,1973 , and 1993 respectively.

The purpose of Alpine's survey was to identify the top of the artesian gravels. It consisted of ten lines across the harbour in various directions. Reyners and Christoffel's work built on Alpine's initial findings with the aim of determining the nature of the sediments under the floor of Wellington Harbour with particular reference given to the depth of the subsurface artesian gravels. Both of these surveys used a 'sparker' system as an energy source. This technique produces a usable sonic bandwidth of $50-1600 \mathrm{~Hz}$ (Reyners and Christoffel, 1973).

While these surveys provided some good information on the depth to the top of the Waiwhetu Artesian Aquifer in the north-east quadrant of the harbour, the remainder of the 


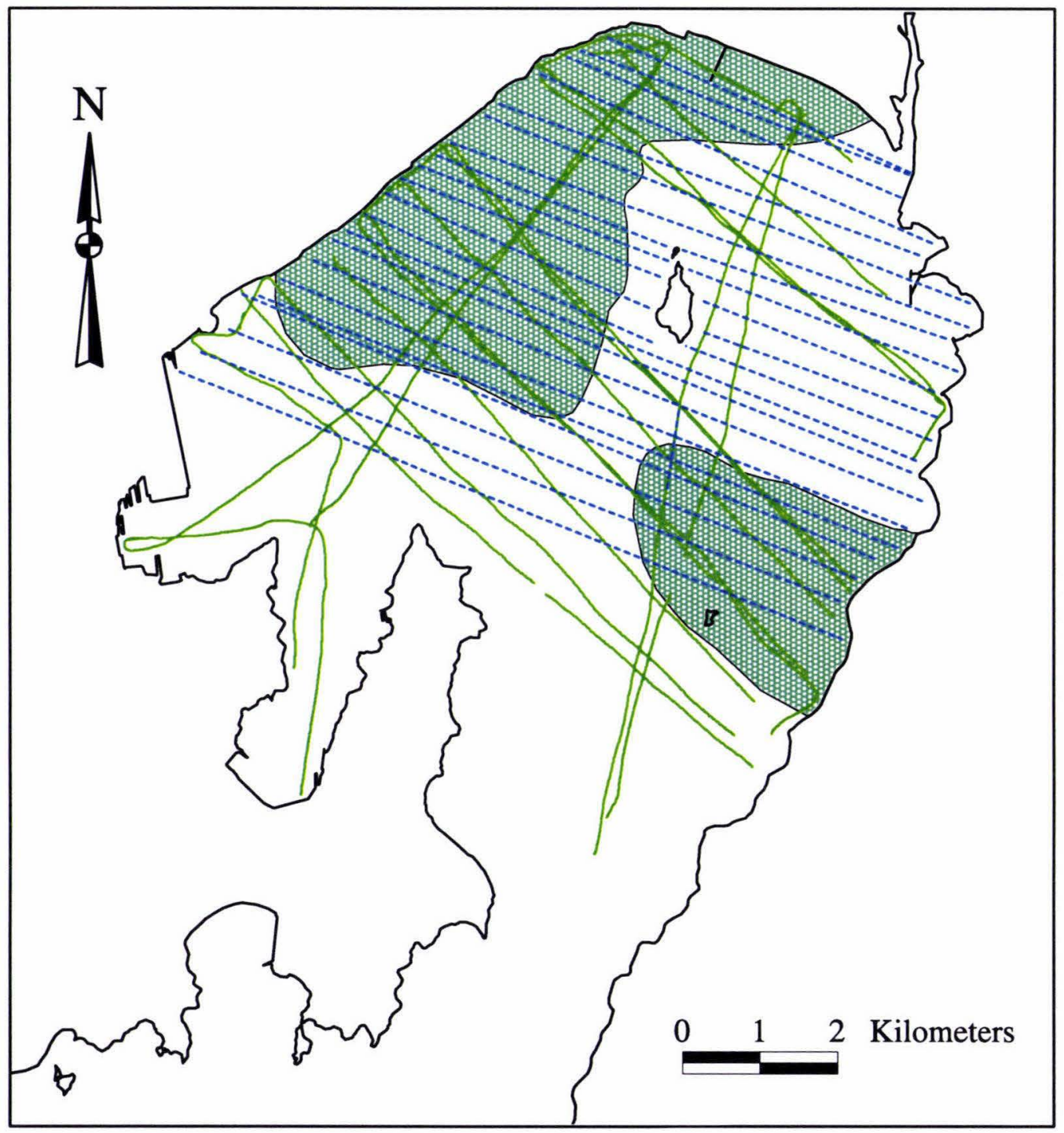

Figure 8.2.1 The 'interference' region as mapped by Davy and Wood (1993). Data from Reyners and Christoffel (1973) was used to improve the definition of the interference extent around Somes Island. The seismic lines of the respective surveys from which the interference region was mapped are shown (Reyners and Christoffel in Blue, Davy and Wood in green). The aquifer and aquiclude thickness' and extent were also derived from these seismic surveys. 
area surveyed provided very little sub-surface information. This was due to a lack of seismic penetration caused by the attenuation of energy within a shallow layer lying in the upper few metres of sediment beneath the harbour floor. These areas were simply named the 'interference' or 'scattering' regions.

The purpose of Davy and Wood's survey was once again to "obtain information about the Waiwhetu Artesian Aquifer beneath Wellington harbour to assist the Wellington Regional Council manage groundwater resources" (Davy and Wood, 1993). It was hoped that advances in seismic investigation over the 20 year period between the surveys (particularly those concerning the type of energy source and the way in which the seismic lines were to be processed) would improve the quality of data obtained, particularly in the interference regions.

The survey carried out by Davy and Wood used two types of energy generating devices uniboom and airgun. The Uniboom is an electro-acoustic sound converter producing a broad frequency band $(200$ to $4,000 \mathrm{~Hz}$ ). Airguns often have more power, but output a lower frequency of $20-1000 \mathrm{~Hz}$ (Davy and Wood, 1993). Given the higher frequencies, Uniboom is useful for the collection of shallow data, whereas the airgun is better for depth penetration. A number of the seismic lines in Davy and Wood's survey were run twice once using an uniboom energy source and the other using an airgun. This was done to obtain the best possible data from beneath the shallow interference layer.

Unfortunately, neither of these new energy sources were strong enough to greatly improve on the earlier 'sparker' surveys and the sedimentary units beneath the shallow energyabsorbing layer present in much of the harbour still only exhibited very weak signals at best. Figure 8.2.1 shows the extent of the 'interference' regions as mapped by Davy and Wood (1993). The locations of the seismic lines from both Reyners and Christoffel's survey in 1972/3 and Davy and Wood's survey in 1993 are over-plotted.

The 'interference' region as mapped by Davy and Wood (1993) is essentially identical to that mapped by Reyners and Christoffel (1973) except that Reyners and Christoffel map the interference region as extending across the entire width of the harbour over their five southern-most seismic lines. The reasons for this discrepancy are unclear, especially given that an examination of the seismic lines collected by Davy and Wood (1993) show that the quality of data in the southern part of the harbour is little better than beneath the interference regions. As such, it is probably an improvement in the processing techniques available at the time of this latter survey that allow for interpretation of the data in this southern region rather that a spatial change in the phenomenon that causes the interference. 
The causes of this interference to seismic penetration will be discussed in section 8.5 . However at this point it is important to note that the subsurface stratigraphy beneath these interference regions cannot be mapped with as much confidence as elsewhere in the harbour.

\subsection{Characteristics of the sub harbour Waiwhetu Artesian Aquifer based on Seismic Information}

With regards to the sub-harbour sediments, the most significant information obtained was the depths and spatial distribution of the various sedimentary units within the basin. Interpretation of the data gathered from the shallow seismic surveys performed in Wellington Harbour make it possible to compile contour maps of all of the recognised formations down to and including the Wilford Shell Beds.

Using the information they collected, Davy and Wood (1993) were able to map the various units across much of the harbour. They then used a computer model to draw contour maps of the various stratigraphic units. While this worked reasonably well in areas where good data was plentiful, errors were caused at the extremities of the seismic line coverage where the computer model extrapolated the picks poorly, giving erroneous depths to the tops of the various horizons. Davy and Wood (1993) acknowledged this, stating that while their computer model contoured the entire harbour area, the "confidence in their [the contours] accuracy declines away from the seismic tracks".

Furthermore, it was found that not only were the aquifer extremities poorly extrapolated, but there were also areas where the contour map of the top of Waiwhetu Artesian Aquifer did not match up with known borehole depths of the aquifer. One such discrepancy was a six metre mismatch of the top of the Waiwhetu Artesian Aquifer with the depth at which it is encountered at the Somes Island well bore. Another mismatch was also noted off the Korokoro Stream at the western end of Petone Foreshore. Here, a number of shallow bores drilled by Bricknell, Moss, Rankine and Hill Consulting Engineers in 1968 encountered the Waiwhetu Artesian Aquifer five metres shallower than that shown on Davy and Wood's contour map.

As a result of these errors, it was deemed necessary to compile new contour maps of the various stratigraphic members pertinent to this research. Using the seismic lines interpreted by Davy and Wood (1993), new contour maps of the depth to the base and top of the Waiwhetu Artesian Aquifer were compiled by re-calculating the two-way travel time into depth below sea level. Reyners and Christoffel (1973), had used a seismic velocity of $1500 \mathrm{~m} / \mathrm{s}$ for both the water and the sediments. While this figure is correct for the water, it is very low for the sediments (something they actually conceded in their report). Davy and Wood (1993) used a velocity of $1500 \mathrm{~m} / \mathrm{s}$ for the water, but $2000 \mathrm{~m} / \mathrm{s}$ for the sediments. 
This value seems a little on the high side. Indeed, other reports that collected and analysed inner harbour seismic data such as Davy and Wood (1987), Lewis et al (1987), Wood et al (1989) and Wood and Davy (1992), used seismic velocities ranging between 1700 and $1900 \mathrm{~m} / \mathrm{s}$ for the shallow sediments.

As such, when the maps were re-calculated, $1500 \mathrm{~m} / \mathrm{s}$ was used for the travel time through the water, and $1800 \mathrm{~m} / \mathrm{s}$ was adopted as the seismic velocity through the sediments down to and including the Waiwhetu Artesian Aquifer.

The resulting re-calculated maps are thus essentially the same as Davy and Wood's computer drawn contour maps, except that the stratigraphic units are, on average, about five metres shallower (which is due to the lower seismic velocity used for the sediments in the re-calculated maps). This meant that the new contour map for the top of the Waiwhetu Artesian Aquifer correlated extremely well with the depths at which is was encountered at the Korokoro and Somes Island bores. From this evidence alone, it would appear that the chosen velocity of $1800 \mathrm{~m} / \mathrm{s}$ for the shallow harbour basin sediments is correct.

The new contour maps are also more accurate at the extremities of the seismic line coverage, especially around the harbour shoreline and around Somes Island and Ward Island where horizon picks were extrapolated logically, as opposed to the method used by the computer programme Davy and Wood employed. Data from Wood et al (1989) was also incorporated into the model to enable the extrapolation of the aquifer thickness through the harbour entrance.

While such contour maps themselves can reveal a great deal about a given formation, the real benefit of contour maps comes in the ability to generate isopach, or thickness, maps from them. These can be used to highlight the areas where a sedimentary unit may be unusually thick or thin. This knowledge can subsequently be used to develop a sedimentation history of how the unit was deposited.

Such isopach maps can be generated by obtaining the difference between the depths of the upper and lower limits of the unit in question. For instance, the difference between the top of the Waiwhetu Artesian Aquifer, and the top of the Wilford Shell Beds (the formation immediately beneath the Waiwhetu Artesian Aquifer) gives us an isopach map of the Waiwhetu Artesian Aquifer. This very function was performed in GIS (Geographic Information System) computer application Arcinfo.

To this end, the re-calculated contour maps for the top and bottom of the Waiwhetu Artesian Aquifer were digitised in Arcinfo. Each digitised contour map was then transformed into a "TIN" (Triangulation Information Network), which extrapolates the values between the digitised contours and thus generates a depth value for any given point 


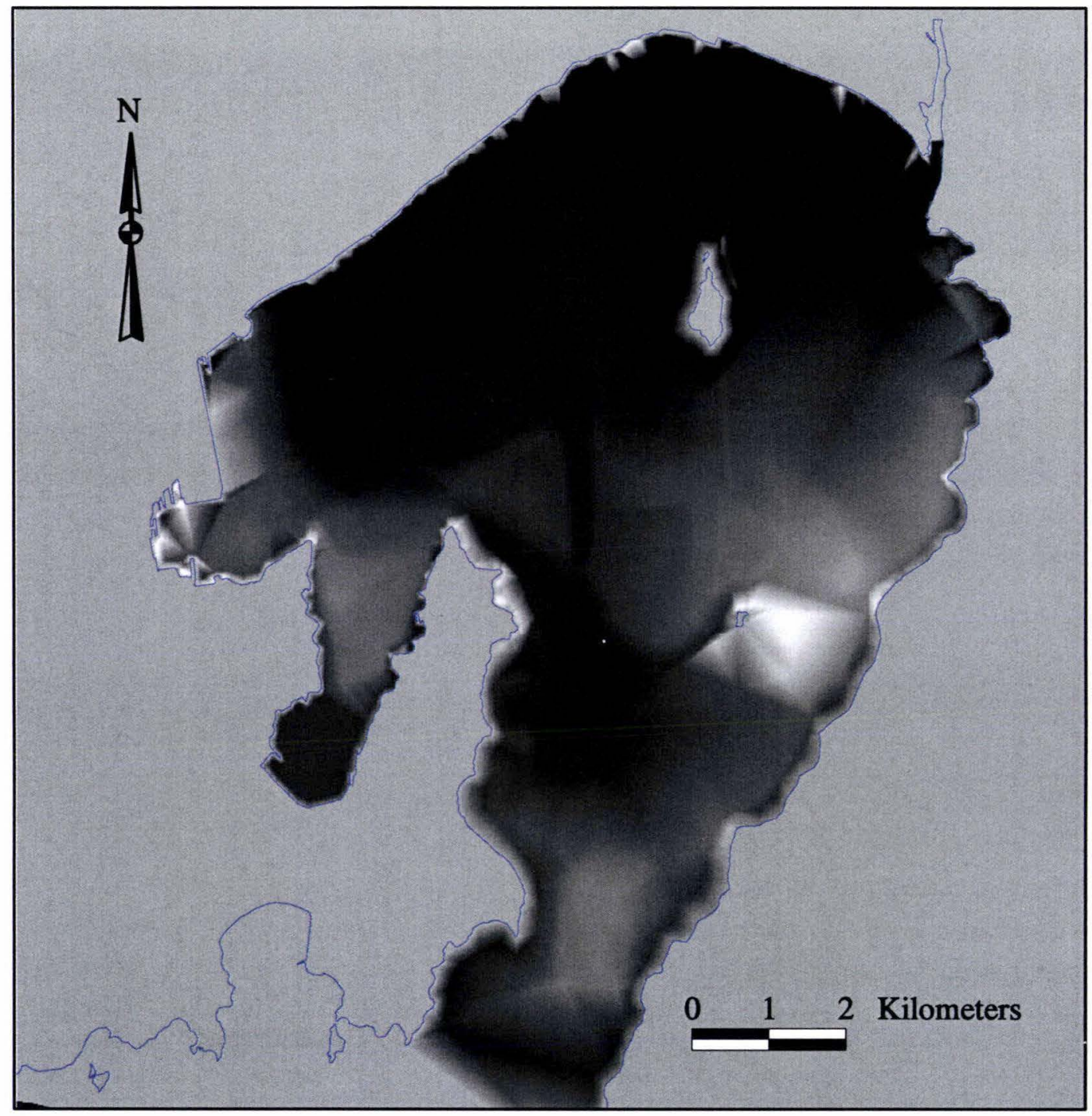

Figure 8.3.1 Isopach image of the Waiwhetu Aquifer based on seismic data collected by Davy and Wood (1993). Thickness is relative to shading (the darker the shading, the thicker the aquifer). The darkest areas are in the order of around 70 metres thick, grading to about 20 metres thick in the lightest areas.

Note: There are a few errors in this image due to the way the TIN image is created in ArcInfo (explained in text). One error can be seen in southern Evans Bay where the aquifer apparently thickens. This is not valid - in reality the aquifer continues to thin to the south. The light area between Ward Island and Eastbourne is also incorrectly extrapolated. This portion of the aquifer probably grades in thickness between that shown to the north and south of it. 
within the modelled coverage. The TIN of the bottom of the Waiwhetu Artesian Aquifer was then subtracted from the TIN of the top of the aquifer to produce an isopach image of the Waiwhetu Artesian Aquifer which is displayed in Figure 8.3.1. Note that it is the relative, rather than the absolute, thickness that is shown - hence the absence of a scale.

The image can be interpreted on the shading. In this case, the darker the area - the thicker the aquifer. Errors exist in this image as apparent around the extremities of the modelled area. A more notable error can be seen in Evans Bay where it appears that the aquifer gravels thicken markedly from north to south. This is not the case, and in fact the aquifer gravels are extremely thin here, as demonstrated by Lewis and Mildenhall (1985). This error arose because the Waiwhetu Artesian Aquifer could not be mapped any further south into Evans Bay because of its extreme thinness on the seismic record. This region of the harbour is described in more detail in Chapter 8.6.3.

A second prominent error is evident to the east of Ward Island where it appears that the aquifer is unusually thin. This is almost certainly incorrect and highlights the problems that can occur when the contour data used in the model is coarse (no seismic lines ran through this side of Ward Island). While the aquifer is likely to be thin in this region, it is unlikely to be as thin as the image depicts. In reality, the aquifer is probably of a similar thickness to that shown to the north and south of this region.

Despite these obvious errors, a good idea of the relative thickness of the aquifer can be derived from the majority of the modelled area. The thickness of the aquifer varies across the harbour, being thicker in the north and west, but shallower in the south and east. This can be explained by the complex tectonic nature of the region which gives a westerly dip to the Wellington block and a fault angle depression alongside the Wellington Fault into which a great thickness of sediment has been deposited (see Chapter Five, section 5.2). The thickening of gravels near Falcon Shoals, at the northern end of the harbour entrance, could similarly reflect an accumulation of gravel alongside the down-thrown side of the Seatoun Fault.

The areal extent of Somes Island in Figure 8.3.1 is correctly shown as being larger than at present due to the fact that the sea level was much lower during the deposition of the Waiwhetu Artesian Aquifer, thus exposing a greater area of basement rock.

In terms of absolute thickness, the Waiwhetu Artesian Aquifer is around 20 metres thick on the eastern side of the harbour, thickening to as much as 70 metres thick alongside the Wellington Fault on the western side. These values are slightly lower (i.e. thinner deposits) than those proposed by Davy and Wood (1993). The differences are due to the slower seismic velocity used in the two-way travel time to depth conversion employed in this study. 


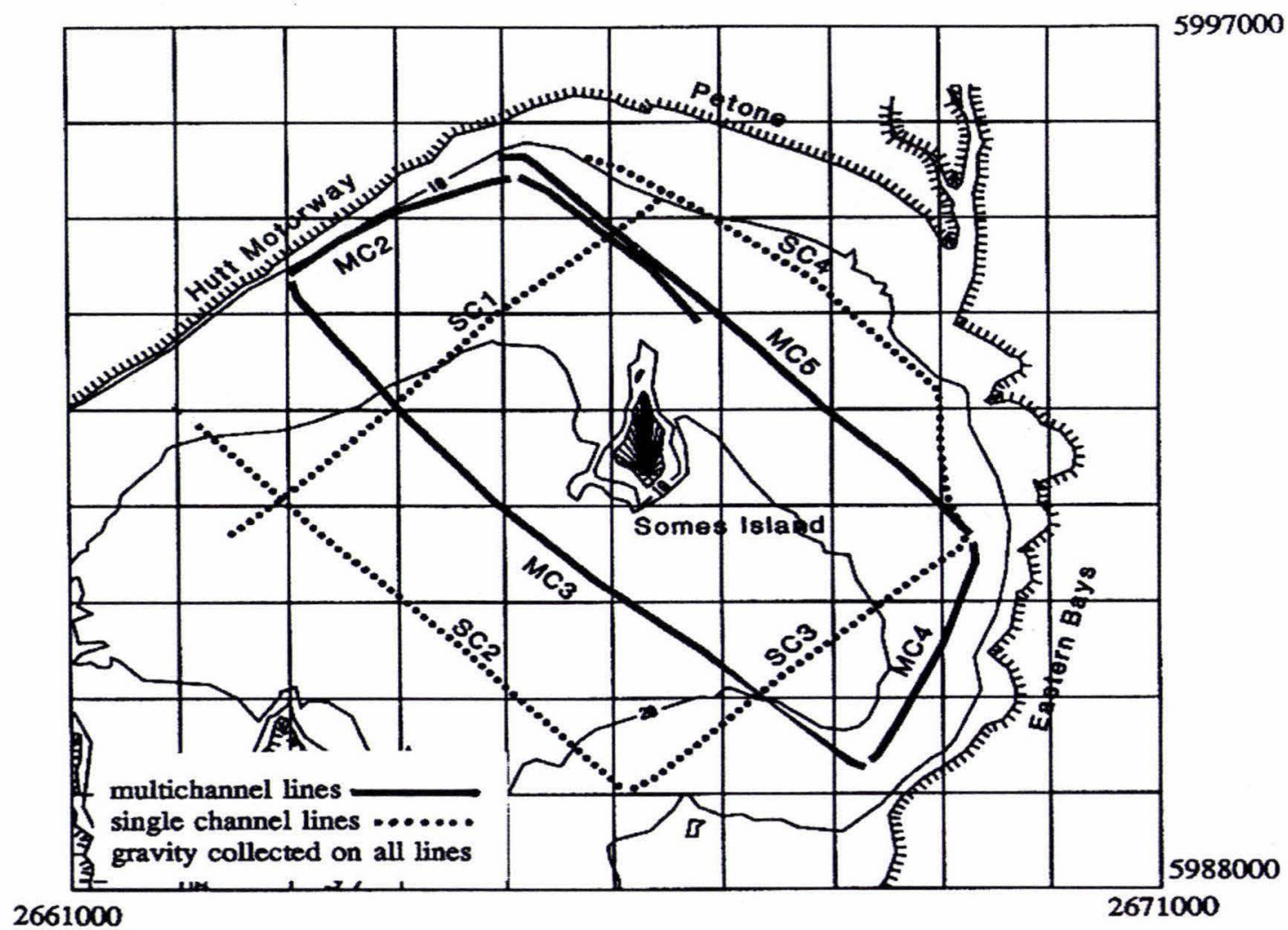

Figure 8.3.2a Location of the seismic lines that were run in the 1991 survey (from Wood and Davy, 1992). Although the purpose of this survey was to define the basement structure, some interesting features of the shallow sediments were revealed (see Figure 8.3.2b).

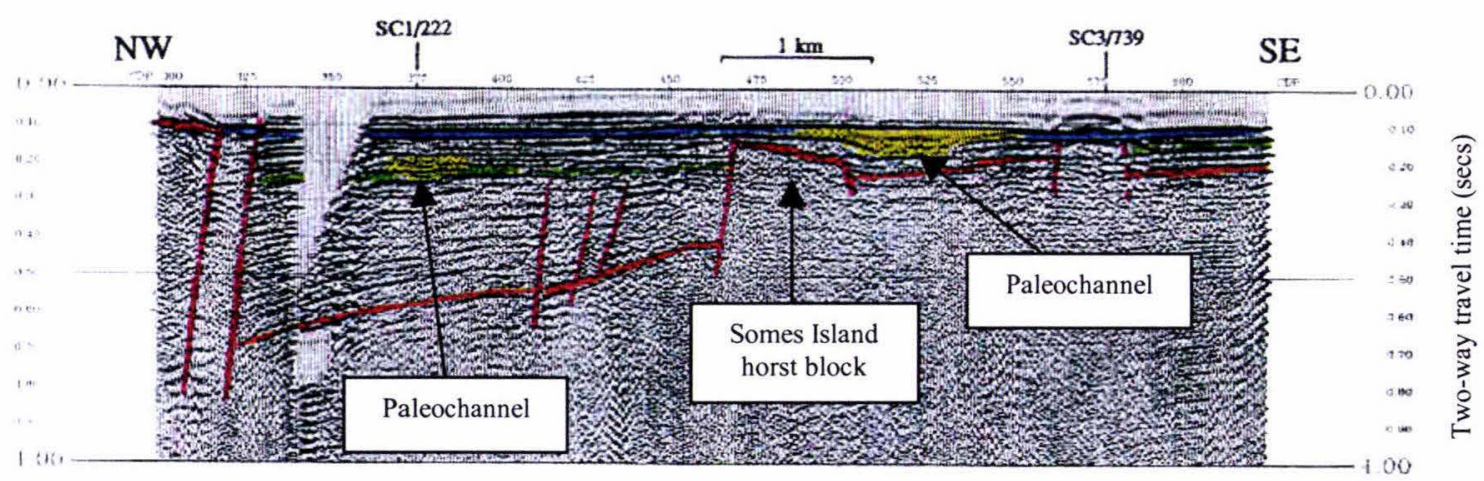

Figure 8.3.2b Seismic Line MC3 (Multi-Channel 3) from Wood and Davy (1992). This line runs approximately from Ngauranga Gorge on the western side of the harbour, to Eastbourne on the eastern side (see Figure 8.3.2a for location). The vertical scale is two-way-travel time (full scale is 1 second). The basic basement structure is marked in orange, with faults in red. The impressive offset at the Wellington fault zone can be seen on the western side of this line. The top of the Waiwhetu Artesian Gravels member is shown in blue. Of particular interest are the two yellow areas, believed to be paleochannels lying within the Waiwhetu Artesian Gravels member (as mapped by Wood and Davy, 1992). 
Of particular interest is the dark 'tongue' extending south from the main part of the harbour towards the harbour entrance, in a north-south lineation. This seismic lines that cross this area of the harbour clearly show a well-defined paleochannel which most likely represents the course of the Hutt River at the beginning of the last glacial period. It is proposed that, following the drop in sea level at the onset of the last glaciation, the Hutt river cut a channel into the newly exposed Wilford Shell Beds which was subsequently in-filled with gravel transported down the valley and deposited as part of the Waiwhetu Artesian Aquifer formation.

Another paleochannel evident in the seismic record can also be mapped running northsouth just to the east of Somes Island. This relic channel lies within the upper layers of the Waiwhetu Artesian Aquifer, and is of considerable width (probably a braided channel). As this channel lies within the Waiwhetu Artesian Aquifer formation, it does not increase the overall thickness and thus cannot be seen on the isopach image shown in Figure 8.3.1. It can however be seen in the seismic lines that cross it. This channel was also detected during an earlier seismic survey that targeted the basement structure of the basin (Wood and Davy, 1992).

An example of one of the seismic lines from this survey (multi-channel line MC3) is shown in Figure 8.3.2b. As can be seen, two paleochannels have been mapped by Wood and Davy (1992). The deeper one on the western side of the harbour is probably the course of the Hutt River at the onset of the last glaciation. The shallower one, to the east of the Somes Island horst block, could similarly represent the position of the Hutt River later on, towards the end of the last glaciation.

A picture of the sub-harbour sedimentation history of the Waiwhetu Artesian Aquifer can be formed from this information. In the early stages of the deposition of the Waiwhetu Artesian Aquifer member, the Hutt River flowed alongside the western side of the Hutt Valley and into the present day harbour, close to the Wellington Fault. The thickness of the aquifer deposits in this vicinity indicates that the main river channel remained on this side of the harbour for quite some time.

We can assume that the main river was on this side of the harbour due to the presence of a paleochannel that can be seen cutting into the Wilford Shell Beds on many of the seismic lines that cross this side of the harbour. This paleochannel runs from the western side of the harbour near the Ngauranga area towards the harbour entrance (as shown by the "dark tongue' visible in Figure 8.3.1). Thus is appears that the Hutt River initially followed the Wellington fault, then changed its course near Ngauranga to flow between Somes Island and the Miramar peninsular and out through the harbour entrance in this early stage of the deposition of the Waiwhetu Artesian Aquifer. 
At some point in time, the main channel migrated to the other side of Somes Island, possibly in response to a choking up of the main channel, or due to a catastrophic change brought about by a flood or tectonic event. This main channel is large and well-defined, and thus probably remained here for quite some time until the flandrian sea incursion flooded the valley and the confining Petone Marine Beds were deposited.

As such, the evidence obtained from the seismic surveys undertaken in the harbour indicates that the Evans Bay - Lyall Bay corridor was not cut, or used by the Hutt River during the Holocene. This is in contrast to the sedimentation history of the harbour as made popular by Stevens $(1955,1956$, and 1974) who proposed that this corridor was cut by the Hutt River during the deposition of the Waiwhetu Artesian Aquifer. Other evidence reinforcing this statement is detailed and elaborated on in section 8.6.3.

Davy and Wood (1993) noted strong reflectors within the seismic record in much of the Waiwhetu Artesian Aquifer member. The reflectors lie parallel to the sedimentary layers within the aquifer member, and often along the contact between these layers. They are characterised by having a strong initial negative response which indicates a change from high velocity to low velocity i.e. change from high density to low density sediments (pers comm. Brian Davy, GNS, 1998).

The reflectors, while being strong, do not appear to affect the signal continuing deeper, which indicates that whatever is causing the effect is not attenuating the seismic energy a great deal. The negative reflectors generally increase in amplitude up dip (indicating a greater change in density), and often 'step' across sedimentary units via migration through fault contacts. This phenomenon can be mapped as moving towards the paleochannels, particularly the major paleochannel running to the east of Somes Island in the upper levels of the Waiwhetu Artesian Aquifer. The reflectors typically terminate within this paleochannel a small distance beneath the harbour floor (possibly at the aquifer/aquiclude boundary). They also appear to terminate at the contact with basement rock (particularly on the eastern side of Somes Island). Davy and Wood (1993) postulate these reflectors as being caused by artesian water migrating from deeper in the aquifer.

However, while it is possible that fluid migration does occur upwards through the aquifer, it is more likely to be the presence of gas that causes the prominent response in the seismic record, as water-charged sediments do not cause such a distinctive seismic response (pers. comm. Les Singh, VUW, 1998). The anaerobic break-down of organic material (producing hydrogen sulphide, methane and carbon dioxide), deep within the aquifer layers, and possibly from the formations beneath the Waiwhetu Artesian Aquifer are likely to be the origin of the migrating gas. Reyners and Christoffel (1973) note that the presence of gas is certainly likely to cause a distinctive change in seismic velocities. 
Evidence for the presence of escaping water (and gas) is provided by Lewis (1989), who hypothesised that regions of seismic disturbance observed on the seismic record he recorded represented "migrating artesian water, using the fault as a means of escape to the sea". As described in Chapter Six, this theory can certainly be endorsed by the evidence of vertical plumes of disturbance emerging from the harbour floor as seen on boat echosounders.

As detailed previously, plumes of disturbance were even observed on the echosounder of the Wellington Harbour Board boat used to survey the bathymetry of the harbour in 1982 (pers comm. Roger Carter, 1996). At one location near the offshore trace of the Wellington Fault, SCUBA divers obtained samples of low salinity water from the harbour floor (pers comm Roger Carter, 1996).

In summary, we can say that the main characteristics of the Waiwhetu Artesian Aquifer derived from the seismic record is that this member is widespread across the entire harbour and likely continues some way into the harbour entrance. The lack of significant amounts of gravel deposits beneath Evans Bay indicates that the main river did not flow south into this bay. As such, it is proposed that the Evans Bay - Lyall Bay corridor was not cut or used by the Hutt River during the Holocene.

We can also propose that the Waiwhetu Artesian Aquifer deposits are characterised as having a number of prominent paleochannels where the sediments are likely to be wellsorted and the 'cleanest' in terms of being relatively free of fine grained overbank deposits. These paleochannels are likely to be the highest water-bearing areas of the Waiwhetu Artesian Aquifer member as shown by the presence of migrating water and gas towards these areas from regions both adjacent to and deeper within the aquifer.

\subsection{Characteristics of the Petone Marine Beds (upper aquiclude) based on Seismic Information}

As with the Waiwhetu Artesian Aquifer, the difference between two contour maps can be used to derive an isopach map of the Petone Marine Beds. In this case, it is the difference between the present day harbour floor and the top of the Waiwhetu Artesian Aquifer that provides us with the Petone Marine Beds isopach map.

Creating a contour map of the bathymetry of the harbour was generated by digitising Hydrographic Chart NZ4633 in Arcinfo. A spot depth coverage was also created of the harbour floor in areas where greater attention to detail was required (in and around the harbour floor depressions). To this end, echosounder images and divers' observations of the investigated harbour floor depressions were used. 


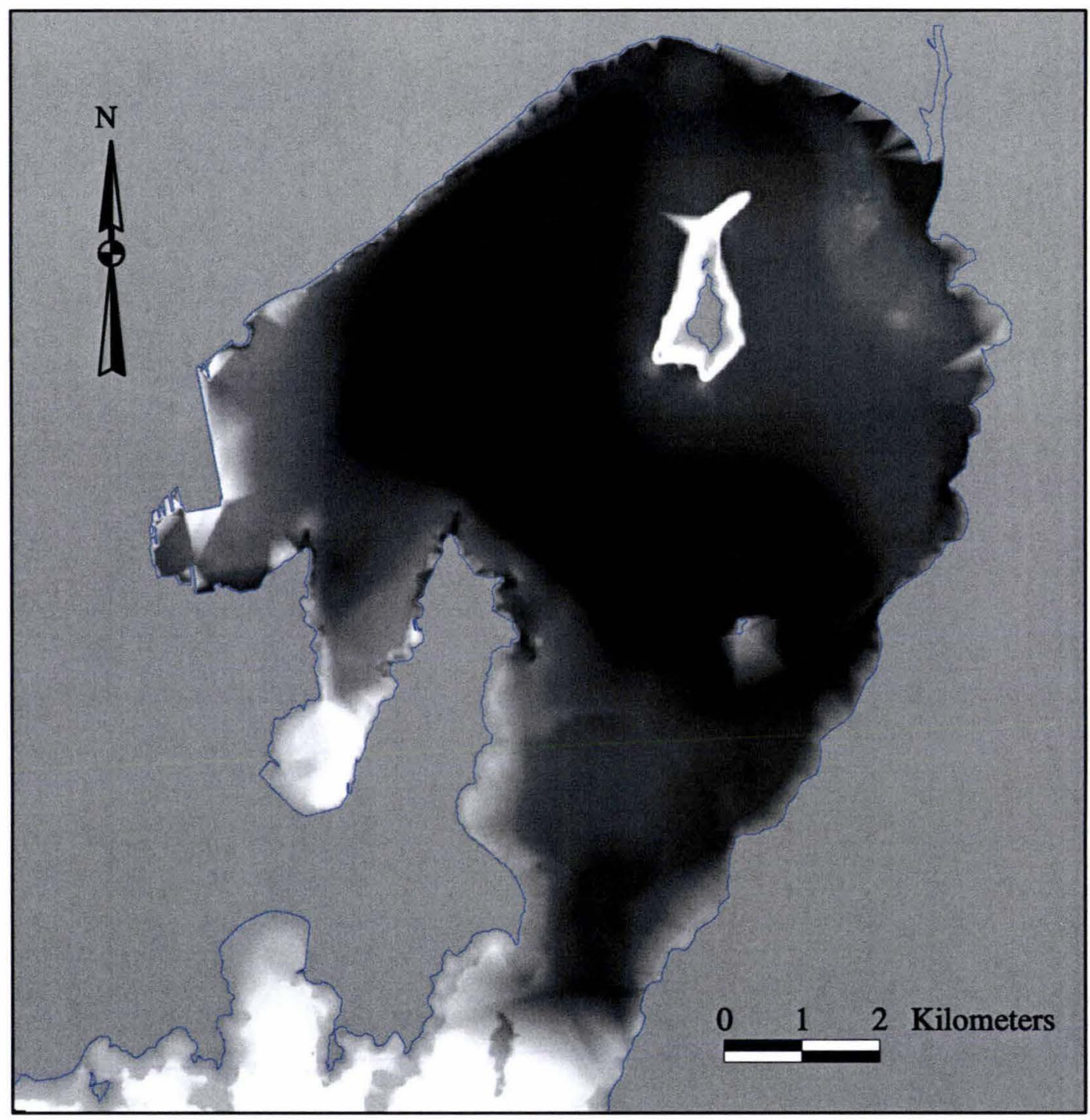

Figure 8.4.1 Isopach image of the Petone Marine Beds (upper aquiclude) based on seismic data collected by Davy and Wood (1993). Thickness is relative to the shading (the darker the shading, the thicker the aquifer). The darkest areas are in the order of around 30 metres thick, grading to about 10 metres thick in the lightest areas.

Note: There are a few errors in this image due to the way the TIN image is created in ArcInfo (explained in text). One such error is the small patch of apparent thinner aquiclude to the southeast of Ward Island. In reality the aquiclude here has the same thickness as that to the west of the island. The very thin patch in the northeast of the harbour is valid, with the light spots representing harbour floor depressions. 
The coastline and harbour islands (Somes, Mokopuna and Ward) were digitised separately as a polygon coverage. These coverages were then used to generate a TIN of the harbour floor.

The top of the Waiwhetu Artesian Aquifer had already been digitised and transformed into a TIN file (as described in the previous section), so it wasn't necessary to repeat this process. The isopach image of the Petone Maine Beds was thus created by subtracting the top of the aquifer TIN from the harbour bathymetric TIN. This image is shown in Figure 8.4.1. Once again, the darker the shading, the thicker the formation.

While the isopach image in Figure 8.4.1 does not provide the absolute aquiclude thickness, the contour maps produced from seismic line interpretations in Davy and Wood (1993) indicate that the confining sediment is between 10-12 metres thick in the north-eastern quadrant of the harbour. It is thicker, perhaps up to 30 metres thick, in the majority of the rest of the inner harbour (the very dark shading in Figure 8.4.1). Once again, these values are slightly lower (i.e. thinner deposits) than those proposed by Davy and Wood (1993) due to the lower seismic velocity used in the two-way travel time to depth conversion for these deposits.

Therefore, the confining beds are significantly thinner in the north-eastern quadrant of the harbour. This region coincides with the region of good seismic penetration as described in section 8.2. It also coincides with the region where most of the inner harbour artesian leakage occurs (detailed in Chapter Nine). The reason for the thinness can perhaps be explained by the sedimentation history.

With the Hutt River having migrated to flow down the eastern side of Somes Island in the latter stages of the deposition of the Waiwhetu Artesian Aquifer member (section 8.3), the river would have had a pronounced effect of sedimentation in the north-eastern quadrant of the harbour. As detailed previously, the size of the paleochannel, clearly visible in the seismic record, indicates that the Hutt River remained as a stable channel in the northeastern quadrant of the harbour for a good proportion of the latter stages of the Waiwhetu Artesian Aquifer deposition.

While the gradual flooding of the harbour took place during the flandrian sea incursion, deltaic deposition at the ancient Hutt River mouth would have kept the north-eastern portion of the harbour largely fluvial, or at least estuarine, for an extended period. Furthermore, the western side of the harbour is likely to have been slightly deeper due to the westerly dip of the harbour block. Thus the pattern of sedimentation during this very early stage of the Petone Marine Beds would have been coarse sediment around the river mouth (i.e. the north-eastern quarter), and fine sediment in the rest of the inner harbour. 


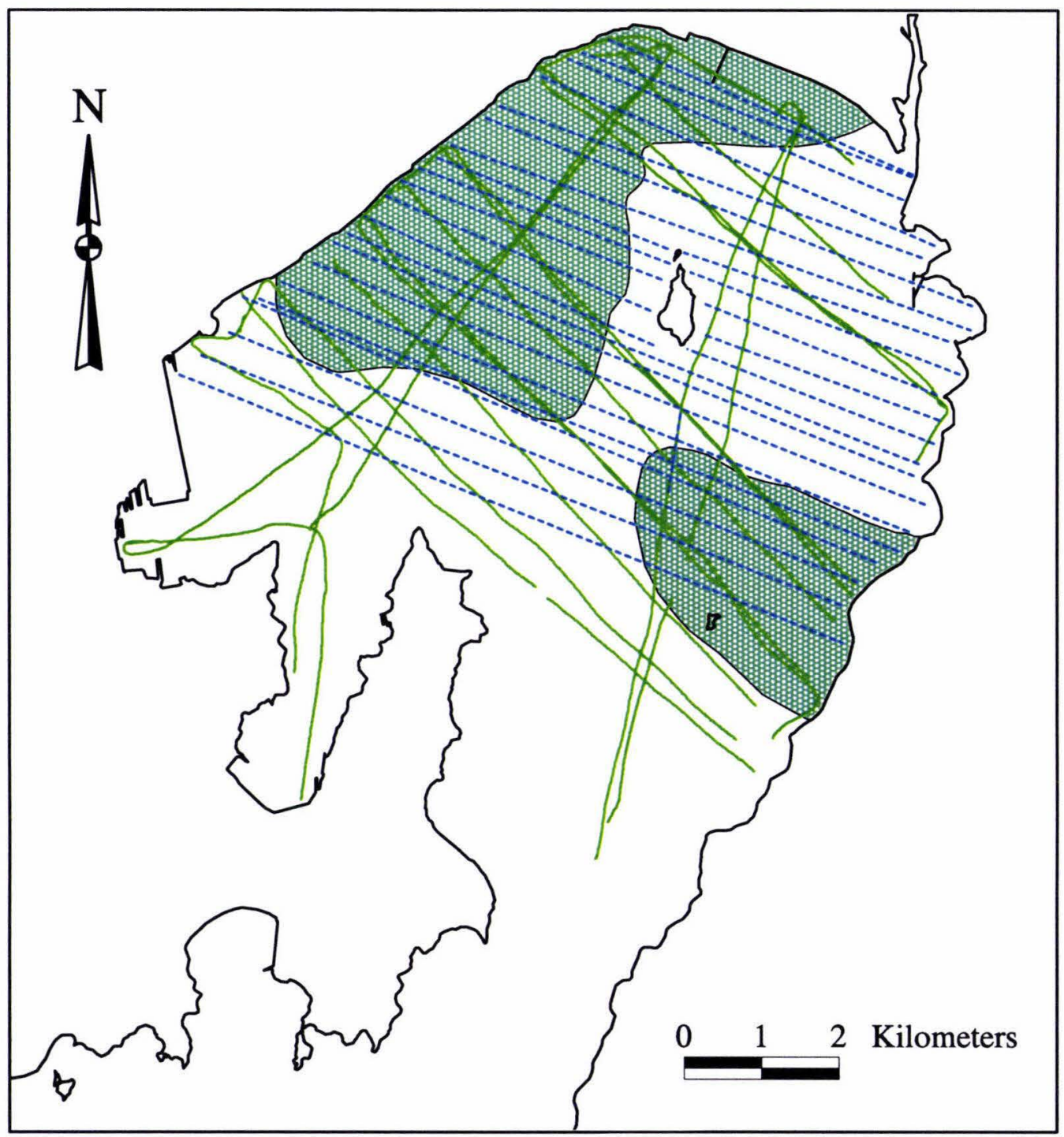

Figure 8.5.1 The 'interference' region as mapped by Davy and Wood (1993). This figure is identical to figure 8.2.1 but shown again here for reader convenience. Data from Reyners and Christoffel (1973) was used to improve the definition of the interference extent around Somes Island. The seismic lines of the respective surveys from which the interference region was mapped are shown (Reyners and Christoffel in Blue, Davy and Wood in green). 
This pattern of sedimentation would have remained for some time until the Hutt delta was finally overwhelmed by the rising sea level, perhaps assisted by a waning of material brought down by the Hutt River.

Thus, in summary, due to the deposition history of the Petone Marine Beds, the area of thinnest aquiclude overlies the region of the Waiwhetu Artesian Aquifer which contains the largest and most prolific paleochannel. We must keep in mind that this relic channel is likely to contain the cleanest gravels and thus is a region where above average transmissivities exist within the aquifer.

This paleochannel has also been shown to be a receptacle for water migrating from elsewhere within the aquifer member. This evidence will be used to explain the spatial distribution of the submarine springs (Chapter Nine).

The presence of sea floor depressions in the region of thin aquiclude means that in some locations the aquiclude may be as thin as two metres. Indeed, it has been postulated by Donaldson and Campbell (1977) that the aquiclude may even be absent beneath the two deep depressions south of Somes Island. They base this hypothesis on the depth of the depressions (32 metres) and the depth at which the aquifer is encountered at the Somes Island production bores to the northeast of the island ( 32 metres below sea level). Although this assumption doesn't take into account the dip on the aquifer, the dip is only very slight beneath this central portion of the harbour. As such, the depth to the top of the aquifer at the southern end of Somes Island is probably similar to that at which is encountered at the bores to the northeast of the island.

\subsection{The Interference Region}

The fact that much of the harbour is blanketed by something that causes an 'interference' to seismic energy penetration is certainly an interesting phenomenon. Perhaps more interesting is the fact that the north-east quadrant of the harbour, where this seismic scattering layer is absent, is also the region where many sea floor depressions exhibiting artesian leakage are located. This poses an interesting question: Is there a correlation between artesian leakage and the absence of the interference producing phenomenon?

We can deduce from the seismic survey information already collected that the distribution of the interference region is;

- Almost certainly not due to faulting as the boundary between the regions is not linear, as shown in figure 8.5.1 
- Within the aquiclude member, rather than at the aquifer/aquiclude contact. The calculated thickness of the Petone Marine Beds is between 10 to 15 metres thick in the northeast quadrant of the harbour and between 20 to 30 metres thick over the rest of the harbour (see previous section). Given that the shallow lying interference region lies "about 5 metres below the harbour floor" (Davy and Wood, 1993) and "in the upper few metres of the harbour floor" (Reyners and Christoffel, 1973), it clearly does not lie at the aquifer/aquiclude contact.

Based on this evidence, Alpine (1970) interpreted the interference as due to high-level gravels and suggests that the region of good seismic penetration (north-eastern quadrant) to consist of sediment deposited in an embayment in the gravels. Certainly, shallow gravels can cause such a distinctive response in the seismic record as demonstrated by Wood et al (1989). Their survey showed that a similar highly reflected layer in the harbour entrance was caused by a shallow boulder bank. However, with regard to the inner harbour, it is highly unlikely that gravels could be deposited across an area as widespread as the interference region, given the depositional history of the Petone Marine Beds previously described.

Further evidence is provided by a number of shallow bores sunk off Korokoro (western end of Petone Foreshore) in 1968 by Bricknell, Moss, Rankine and Hill (BMRH). These bores revealed a 'silty clay' in the upper layers of the Petone Marine Beds, which "has an organic smell and contains random broken shell" (BMRH, 1968). A similarly described "silty clay' layer was also encountered in the "upper $20 \mathrm{ft}$ " $(6 \mathrm{~m})$ of a bore drilled just to the south-west of Ward Island by Alpine Geophysical Inc., in 1971. None of these bores encountered any gravels, or coarse material of any type.

In addition to the bores drilled in the interference region, another set of bores drilled off $\mathrm{Pt}$ Howard, at the north-eastern corner of the harbour (in the region of good seismic penetration) also revealed a "silty clay" "identical to that off Korokoro" (BMRH, 1970). Furthermore, the first sediment layer encountered in the two Somes Island production bores is described as "sea mud" affording easy penetration (Reyners and Christoffel, 1973). Similarly, none of these bores located any gravels until the Waiwhetu Artesian Aquifer member was reached.

As such, the shallow gravel theory can be discarded. However, the evidence from the bores drilled in the harbour show that the sediment pattern is fairly consistent at each site drilled. Given the widespread spatial distribution of the bores, it is thus reasonable to expect that a fairly continuous layer of silty clay/mud exists immediately below the seabed across the majority of the central harbour. As Reyners and Christoffel (1973) note, "such a sediment distribution is in line with the distribution of surficial sea-bed sediments sampled 
by Van der Linden (1966)". Van der Linden's description was that the "central harbour seabed consists essentially of poorly sorted silty muds with an average carbonate content of $10 \% "$. This can certainly be endorsed by observations made by SCUBA divers as part of this research, as well as during previous studies (e.g. Dunbar, 1994).

Reyners and Christoffel (1973) offered an alternative hypothesis stating that it is the "rapid attenuation and/or scattering of acoustical energy in the silty clay layer" that causes the interference. However, they concluded that it is not the silty clay/mud layer itself that is not responsible for the attenuation of seismic energy since:

- It caps regions of good seismic penetration as well as the interference region.

- $\quad$ Silty clay and mud have a low measured attenuation of sound except where large amounts of organic material in the form of plant fragments, worms, molluses and varied organisms exist (Reyners and Christoffel, 1973).

As it is not the sediment itself, it follows that it must be something within the sediment that causes the attenuation of the acoustic energy. From their survey, Reyner and Chistoffel (1973) found that the interference causing phenomenon was at a constant depth within the aquiclude. As such, they suggest that it is either shell beds or gas bubbles that are the cause.

With regards to shell beds, the reasoning proposed by Reyners and Christoffel (1973) is that overlapping beds of flat shells would form an efficient scattering layer for a wide range of frequencies. The absence of this shell bed layer in the region of good seismic penetration was explained by the location of the Hutt River mouth and that "fresh water from the Hutt River would produce conditions adverse to the growth of marine organisms on the eastern side of the harbour" (Reyners and Christoffel, 1973).

However, it is hard to imagine that the typical discharge of water from the Hutt River (median flow $15 \mathrm{~m}^{3} / \mathrm{s}$ ) into the harbour could dilute the salinity of the harbour water enough to 'produce conditions adverse to the growth of marine organisms'.

Perhaps the only exception to this would be in the area immediately adjacent to the mouth of the river, or during large flood events, when a greater volume of the harbour water would be 'diluted' by the flow from the Hutt river. This would render the harbour water in this vicinity as having lower salinity that 'normal' sea water. But even this would only be a temporary inconvenience to any marine life given the tidally-induced movement of water around the harbour and the twice daily tidal exchange of harbour water with water from outside the harbour. 
Furthermore, fresh water and salt water do not mix readily (due to a difference in density) and it is quite common for a layer of low density fresh water to sit on top of salt water. This is certainly the case in Wellington Harbour, and fieldwork for this research has shown that during calm conditions this lower salinity layer can extend from the river mouth across the full width or length of the harbour (depending on the wind direction) before full mixing has occurred. The distance before full mixing occurs is dependent on the condition of the sea (quicker under rough conditions). As such, the water underneath the fresh-water lens (close to the harbour floor), has virtually the same salinity as that for 'normal' sea water. Salinity measurements taken as part of this research confirm this.

It would thus appear that the proximity to a surface fresh water source would not impact greatly on the abundance or growth of bottom-dwelling marine organisms from a reduction in salinity point of view. Perhaps the only reason that could account for less marine organisms near the Hutt River mouth would be due to a reduction in their food source.

There is a certain degree of light absorption in the interface between fresh and salt water caused by the different light refractive indices of waters of varying density. This reduction in light penetration through the water column would reduce the amount of photosynthesis that could occur at depth. This in turn would hinder the growth of microscopic marine flora on which many of the shell-inhabiting marine organisms feed on. While this may be a possible reason for the inability of these organisms to grow in prolific numbers, it would, once again, probably be limited to the very close proximity to the Hutt River mouth where the light penetration would be most affected. As such, it could not reasonably be the cause for the absence of hypothesised shell bed in the entire northeast quadrant of the harbour.

In addition to all of the aforementioned evidence, the fact that a shell bed layer was not encountered in any of the bores drilled in the harbour is perhaps the most conclusive evidence that the interference to seismic penetration is not caused by a layer of shells.

The gas bubble theory, however, does have some merit. Indeed, Andreeva (1964), cited by Reyners and Christoffel (1973) showed sound waves of frequency around $1 \mathrm{khz}$ are scattered by the buoyancy bags in small pelagic fish. The bags are around $1 \mathrm{~mm}$ in diameter and scatter the sound because it resonates in it. The same may happen in a layer of gas bubbles within a sedimentary unit.

The evidence for the scattering phenomenon being caused by gas bubbles are;

- There are no obvious layers within any of the bores drilled in the interference region that could account for the seismic disturbance. Gas is certainly one medium that would pass unnoticed to the eye. 
- The bores drilled offshore near Korokoro were noted as having an "organic smell" in the shallow silty clay layer.

The seismic survey performed by Davy and Wood (1993) found that the interference causing layer is characterised by "a strong negative reflection". They suggest that such a response could be caused by a gas or water saturated layer. They also noted that the amplitude of the negative response decreases away from faults which indicates that the cause of the interference (be it water or gas), could be using fault traces to migrate from deeper lying sediments. They also state that the interference layer "is not at a constant depth, but appears to be an imbricated series of reflectors" (Davy and Wood, 1993).

Note that it is unlikely that the interference layer has changed in the interval between this, and the previous seismic surveys. As such, we can assume that it is the more advanced processing techniques employed by Davy and Wood (1993) that enable such a slight variation in the nature of the interference layer to be noticed, rather than the layer not being imbricated at the time of the earlier survey.

Davy and Wood (1993) go on to state that "beach deposits in a progradational sequence could exhibit such an imbricated character, and could provide suitably porous sands in a mud/silt matrix to trap fluid or gas". A widespread, slightly coarser layer could possibly be caused by a sudden change in depositional environment during the deposition of this unit. A shallowing of the water depth as the result of tectonic uplift could be responsible for such a change. Not only would such a change in depositional environment produce a slightly coarser sediment size to be deposited, but it would also explain the widespread spatial distribution and relatively constant depth at which this phenomenon occurs. The presence of a slightly coarser layer may also be subtle enough for it not to be noticed in the bores cored in the harbour.

As detailed in section 8.3, the presence of water charged sediments does little to the passage of seismic energy through sediment (pers comm, Les Singh, VUW, 1998). Therefore, it is concluded that accumulated gas, and not water, is the cause of the interference. With regard to a source of this gas, Dunbar (1994) noted that the Petone Marine Beds formation contains "much organic matter". The decomposition of organic matter produces gas - mainly methane, carbon dioxide and hydrogen sulphide (in anaerobic conditions). Gas bubbles may form and migrate upwards through the Petone Marine Beds to accumulate within a slightly coarser layer within this member, spreading out and filling the voids in the sand/silt/clay matrix. Active fault traces may offer pathways for gas to migrate from deeper sedimentary units beneath the Petone Marine Beds as suggested by Davy and Wood (1993). 
If we accept the above hypothesis - that the seismic disturbance is in fact due to the accumulation of gas bubbles within a slightly coarser layer of the aquiclude, we must still provide reasons as to the spatial distribution of this phenomenon. We can assume that the change in depositional environment (responsible for the coarser sediment layer) would have affected the entire harbour. Certainly, there is nothing to suggest that the aquiclude material is any different in the regions of good seismic penetration than it is in the 'interference' regions - the similar stratigraphy described in the bores cored at Point Howard, Somes Island and off Korokoro confirm this.

However, if we compare figures 8.4.1 and 8.5.1, we can see that the interference region has virtually the same spatial distribution as the very thick areas of the aquiclude. This would certainly be the case if we used the interference region as mapped by Reyners and Christoffel (1973) which extends across the entire harbour width to the south of Somes Island. Thus it appears there is a relationship between aquiclude thickness and the presence of accumulated gas bubbles within the aquiclude.

Given that nothing suggests otherwise, we must assume that a shallow gas layer was also once present in the region of thin aquiclude in the northeast quadrant of the harbour. As such, some event must have occurred to release the accumulated gas in these regions. Liquefaction of the aquiclude during large tectonic events may provide the necessary mechanism.

Liquefaction is a process whereby water saturated, loosely packed sediments (typically sand), compact and decrease in volume by attempting to find the closest possible packing when subjected to ground vibrations such as cyclic earthquake shocks. Provided that the pore fluid cannot escape, or does so very slowly, an increase in the pore-water pressure increases to a level where it approaches the overburden pressure, then the sediment loses all strength and liquefies. While liquefaction is well-known to occur in water saturated sands, it can also occur in fine clay and mud sediments. Liquefaction in clay sediment also results from cyclic stresses causing closer particle packing, but the process is more complex than in sands (Leeder, 1982).

Freshly deposited marine muds often show a flocculated (random) structure with many edge to face contacts between clay particles. This open structure is also enhanced by quartz silt particles in the clay framework (Smalley, 1971, cited by Leeder, 1982). The potential for liquefaction to occur results from increased pore pressure brought about by the change from an open, flocculated clay structure with high porosity and water content, to a denser dispersed clay structure.

The highly tectonic nature of the Wellington Region provides many opportunities for liquefaction to occur in the soft harbour floor sediments. As such, the proposed hypothesis 
is that during large tectonic events, liquefaction of the aquiclude occurs. The temporary loss of the cohesiveness of the sediment as a result of the intense shaking enables the accumulated gas to leak out through the aquiclude to the harbour floor. However, liquefaction is restricted to where the aquiclude is thin enough and where it is of a suitably flocculated nature i.e. where it has less strength. It is proposed that the sediments forming the Petone Marine Beds are not only thinner, but were also more flocculated upon deposition in the northeast quadrant of the harbour than elsewhere.

The factors controlling sedimentation of this unit are likely to be responsible for these characteristics. As stated previously, it is probable that the interference layer, or the sediments in which the interference layer is held, was deposited at a shallower depth than the rest of the Petone Marine Beds. We can assume this because Davy and Wood (1993) noted that the interference layer was in places, imbricated, and as such probably represented "beach deposits in a progradational sequence". This was likely to be caused by a reduction in local sea level brought about by a tectonic uplift and allows for a slightly coarser substrate to be deposited which provides the necessary sedimentary matrix to trap gas bubbles.

Given the westerly tilt of the harbour, the western side of the harbour has probably always been slightly deeper than the eastern side. Furthermore, the northeastern quadrant of the harbour is likely to been made even shallower by the build up of deltaic deposits extending from the Hutt River mouth in this region. As such, the western side of the harbour and the entire width of the harbour immediately south of Somes Island would have had a deeper, and thus 'quieter' depositional environment than the northeastern quadrant for perhaps the entire time the Petone Marine Beds were being deposited.

This difference in depositional environment would also have been exacerbated by the shape of the harbour, and in particular, the harbour entrance. It is well-known that southerly swells can propogate relatively unhindered up through the harbour entrance and along the eastern side of the harbour. The western side of the harbour is sheltered from the affect of these southerly swells by the Miramar Peninsular, and to a lesser extent by Somes Island. There is nothing to suggest that this scenario has changed over the recent past, and certainly not during the Holocene when the Petone Marine Beds were being deposited. Even when the Rongotai Isthmus was submerged (from at least the time of the thermal maximum 6.500 years ago to about 500 years ago) and the harbour had two entrances, the energy from southerly storms would have been dissipated by the shallowness of the channel through this area.

As such, while the fine clay particles could settle orderly and compact naturally over time in the deeper and sheltered depositional regions of the harbour, the shallowness of the 
northeast quadrant and the disruptive nature of southerly swells would render this portion of the aquiclude deposits more flocculated in structure.

Therefore, subsequent to the deposition of the Petone Marine Beds, the thicker and more compact aquiclude sediments in the west and south of the inner harbour would be more resilient to liquefaction than the flocculated, thinner deposits in the northeast quadrant of the harbour. The failure of the aquiclude in this region of the harbour would allow any accumulated gas to escape, thus rendering this area free of the seismic scattering phenomenon. Note that liquefaction is a non-reversible process and as such, once it has occurred, it is unlikely to happen again. This hypothesis of earthquake shaking causing the loss of structure in the aquiclude will be elaborated on in Chapter Nine as a possible cause of submarine spring inception.

\subsection{The southerly extent of the aquifer}

\subsubsection{Introduction}

Over the years, many researchers have proposed various hypotheses concerning the geological history of the Wellington region including the Hutt Valley - Wellington Harbour basin. Given that it has already been shown that the Waiwhetu Artesian Aquifer extends over the main part of the harbour, we must look further south, through the harbour entrance and through the Evans Bay - Lyall Bay corridor (the Rongotai Isthmus) to determine exactly where the aquifer terminates.

As we already know, the Hutt River is the main supplier of material to the Hutt Valley Port Nicholson basin. As a consequence, the course of the Hutt River is very important in determining where the aquifer extends. There is however, much debate as to which path the Hutt River took during periods of lowered sea level when exiting the basin - through the Rongotai Isthmus, or through the present day harbour entrance.

It is well known from scientific studies and through the Maori verbal history of the area that the Miramar Peninsular used to be an island and thus there were two entrances to Wellington harbour - the present one and a second one through the Rongotai Isthmus (Cotton, 1912; Best, 1923). The peninsular was finally linked to the mainland by a tectonic movement that uplifted the region around 1460 AD leaving only a shallow ford which was soon completely blocked by sand (Best, 1923).

Crawford (1873) was the first to propose that the Evans Bay - Lyall Bay corridor marked an early course of the Hutt River. Cotton (1912) on the other hand, was astute in proposing that the geomorphology of the region suggests the drowning of two youthful streams, one flowing north into Evans Bay, and the other flowing south into Lyall Bay. 


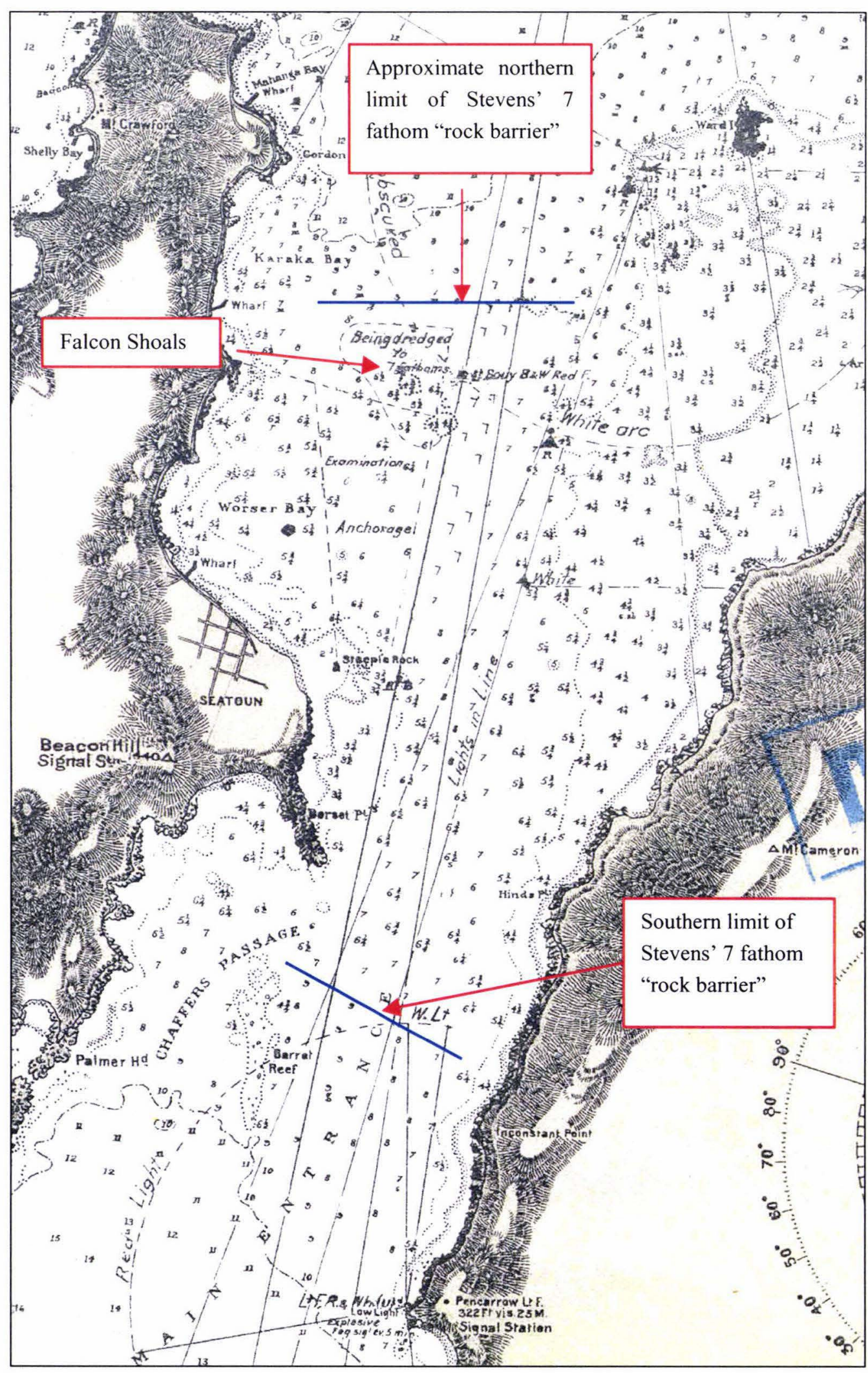

Figure 8.6.2.1 A scanned portion of bathymetric chart NZ 23, surveyed in 1950. Depths are in fathoms ( 1 fathom $=6$ feet or 1.83 metres). Approximate extremities of Stevens' 7 fathom (13 metre) deep "rock barrier" are shown. 
It was Stevens who did the first thorough research into the geological history of the Hutt Valley and sub-harbour regions, including the extent of the Waiwhetu Artesian Aquifer. Stevens (1955, 1956, and 1974) concluded that the Evans Bay - Lyall Bay corridor was, until recently, the harbour exit as used by the Hutt River. He proposed that the Rongotai Isthmus was first eroded by the ancient Hutt River and then in-filled with sediment during glacial and peri-glacial periods. He believes this continued until a choking of the channel as a result of sediment build up, combined with a fault movement, prompted the Hutt River to change its course and flow through the present harbour entrance.

This view was the preferred opinion among most geologists at the time, and research carried out by Adkin (1956) reinforces this. He states that a displacement on the Seatoun Fault, coupled with post glacial rise of sea level were critical in the formation of the present harbour entrance.

However Stevens reasoning, plus those around him, was based almost entirely on two pieces of incorrect assumptions - the depth of basement through the harbour entrance and through the Rongotai Isthmus. These two factors largely control the course of the ancient Hutt River and thus the likely extent of the Waiwhetu Artesian Aquifer. They will be examined in detail separately.

\subsubsection{The Harbour entrance}

Stevens (1955) incorrectly identified a 7 fathom (13 metre) deep area of sea floor through the harbour entrance as the depth to basement rock. His source for this information is a 1:25000 Bathymetric map titled "Wellington Harbour Isobaths from Chart NZ 23" surveyed in 1950 by the HMNNZ 'Lachlan' for the NZ Oceanographic Institute (see Figure 8.6.2.1). This chart does show an area of sea floor of 7 fathoms depth through the harbour entrance. It extends from the Falcon Shoals vicinity in the north, to the northern end of Barretts Reef in the south, where it ends abruptly in a west-east lineation across the harbour entrance. Given that this chart shows the bathymetry of the sea floor, it is not understood why Stevens assumed this area to represent basement rock. There is certainly nothing to suggest this on the chart.

The only possible answer is that Stevens noted that the sea floor was deeper to the north and south of this shallow area through the harbour entrance and concluded that this was because of a shallowing of the basement rock. This is likely to be his reasoning as Stevens (1974, p78) makes reference to the bathymetric chart, citing the morphology of the sea floor as the reason behind his way of thinking. He says "... The map also shows the marked shallowing at the harbour entrance, probably related to a buried rocky ridge linking Miramar Peninsular and the Pencarrow coast." 
However, it is peculiar that by 1974 Stevens still maintains that this shallow rock barrier exists. Previously, Garrick (1959) showed in a three profile refraction survey of the Wellington Harbour entrance that on no occasion did he encounter bedrock. Given that the maximum penetration of his survey was 60 feet (18 metres), we could say, based on Garricks work alone, that bedrock is at least 18 metres deep through the entrance.

A more recent seismic survey was performed in the harbour entrance in 1987 (Lewis et al, 1987). This survey, commissioned by the Wellington City Council, was to be a reconnaissance study to establish if a proposed sewerage pipeline could be constructed across the sea floor between Point Dorset and Hinds Point. The main concern of the council was the depth to basement rock.

The survey revealed a reflection horizon at depths up to 40 metres below sea level. Lewis et al (1987) interpreted this as the base of a possible erosional channel in greywacke basement. However, the seismic record was not of a high quality. Sea-floor multiple signals and airgun bubble pulses which didn't implode cleanly dominated the seismic reflection record. This made the reflector difficult to pick, and deeper horizons virtually impossible to recognise (Davy and Wood, 1987).

Upon receiving this report, the Wellington City Council contracted the Geophysics Department to perform a refraction survey over the same area (Point Dorset to Hinds Point) as a follow-up to this reconnaissance survey. The aim was to "further investigate the observed reflector and to identify any deeper lithologic layers" (Davy and Wood, 1987).

The findings of this survey suggest that the entrance can be divided into four parts. Moving from west to east between Point Dorset and Hinds Point, the basement quickly drops to 90 metres below sea level. This depth remains constant for about 450 metres whereupon the basement is dropped another 15 metres by a normal fault. This fault is most probably the Point Dorset Fault as recognised by Bell (1909), and Huber (1992).

The basement then continues, dipping at about 5 degrees to the southeast for a further 650 metres to be displaced again by another normal fault. This fault displacement is much greater and a throw of at least 200 metres offsets the basement to a depth of about 380 metres. The basement then continues to dip at about 5 degrees to the east, deepening from 380 metres to about 450 metres near the eastern coast. This refraction survey falls short of the eastern coastline by about 150 metres. However it is logical to assume that another fault must be present within this gap which offsets the basement to the surface on the eastern coastline. Davy and Wood (1987) prefer this reasoning, but acknowledge that a steep erosional scarp is possible. 


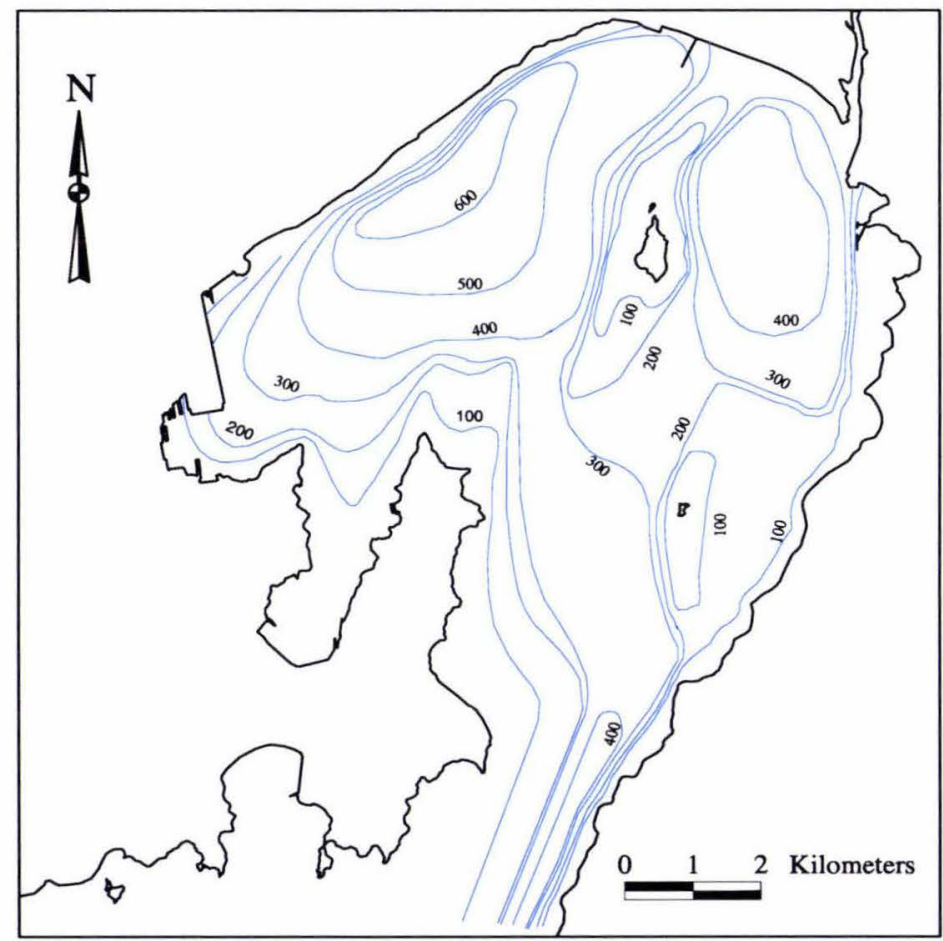

Figure 8.6.2.2a Map showing contours of depth to basement (in metres below sea level) for Wellington Harbour, based largely on Wood and Davy (1992). Note the two deep basins separated by the Somes Island ridge and the deep channel running through the harbour entrance. Note that this is the same image as depicted in Figure 5.2.3a.

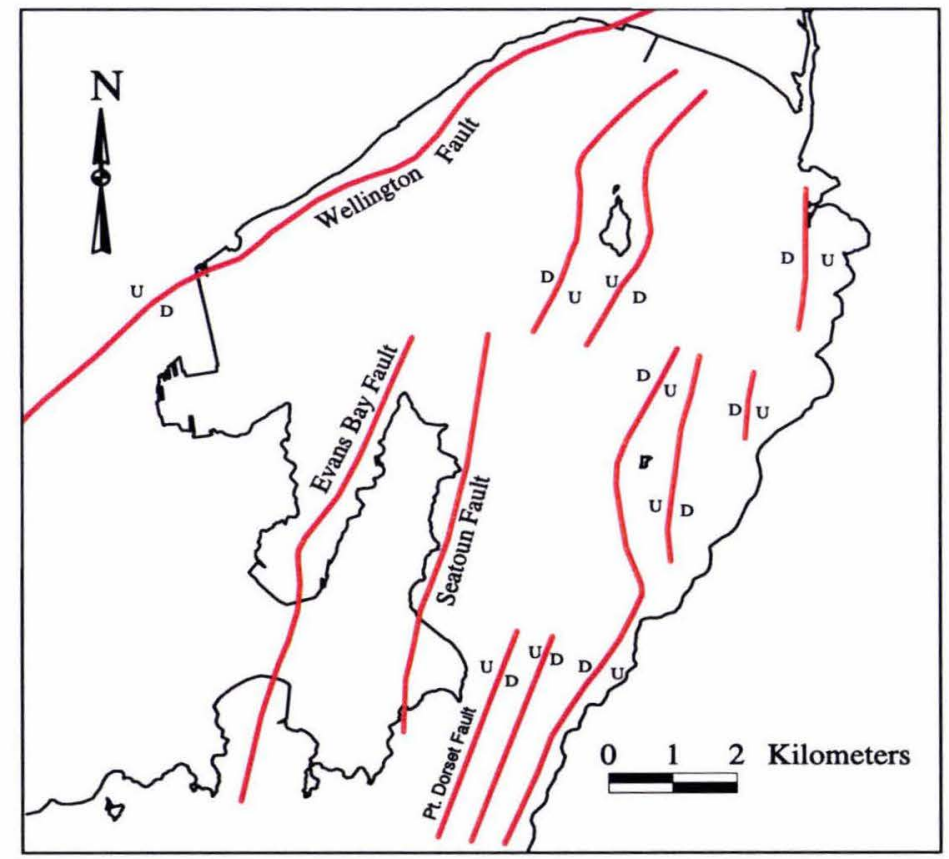

Figure 8.6.2.2b The major active faults in Wellington Harbour as identified by Wood and Davy (1992), Davy and Wood (1987), and Huber (1992), amongst others. Note that this is the same image as depicted in Figure 5.2.3b 
While this report provided much information about the depth to basement and the tectonic structure of the harbour entrance, it didn't help in identifying the reflector previously observed by Lewis et al (1987). However, this channel was later confirmed by Wood et al (1989), who performed a seismic reflection survey of the harbour entrance. The channel recognised by Lewis et al (1987) at a maximum depth of 40 metres below sea level, was found in this survey to lie at a maximum depth of 35 metres below sea level. This new data are of higher quality than the previous lines, and indicate that the channel is part of a channel and bar system and not an erosional surface of the basement rock which was suggested by the earlier work. This fits in with the findings of Davy and Wood (1987).

A fault mapped by Wood and Davy (1992) which raises the block which Ward Island is a part of, could be the northern extension of this missing fault through the harbour entrance. Wood and Davy map this fault as running just offshore and parallel to the eastern coastline down towards the harbour entrance. For the purposes of this study, this fault has been continued through the harbour entrance and is incorporated into the harbour entrance tectonic model. The basement contour map and the major faults within Wellington harbour and entrance have already been displayed in Figures 5.2.3a and 5.2.3b respectively, but are reproduced on the facing page for the reader's convenience.

Davy and Wood's model indicates that beneath 90 metres depth, the material down to basement greywacke is either compacted sediment or weathered greywacke. It is certainly of a distinctly higher velocity than the upper 90 metres of material. It is therefore possible that a substantial thickness of this channel is filled with weathered greywacke locally derived from the sides and deposited as part of the Moera Basal Gravels.

The depth of the harbour entrance channel suggests that it was open to the sea at the time when the Wilford Shell Beds were deposited. Whether any remnant of them is still there is not known. It is certainly not apparent on the seismic record. Given that this is a very confined channel, it is likely that tidal flows would have been too great to allow the deposition of any fine material there. However, it does mean that the Hutt River would have been able to use this channel to exit the harbour during the subsequent and final glaciation.

Other studies looking directly at the surface sediments by Carter (1977), Matthews, (1980) and Wear and Anderlini (1993) prove via sampling, and through direct observations (diving) that it is coarse sediment and not basement rock on the sea floor in this area. Carter (1977) gives good evidence to suggest that the build up of sediment through the harbour entrance is due to a pulse of coarse sediment (derived from the Orongorongo River) that is being transported from the south coast up into the harbour entrance by strong southerly swells. 
Carter and Mitchell (1988), carried out a side-scan sonar survey of the harbour entrance for the Wellington City Council to determine the sea floor substrate (also to help with the construction of the proposed sewerage scheme). Once again, their report detailed no evidence of basement rock through the entrance apart from Barretts Reef, to the south of Miramar Peninsular.

\section{Previous Evidence for Aquifer Leakage in the harbour entrance vicinity}

There exists a great deal of evidence concerning possible areas of aquifer leakage in the harbour entrance. This evidence can be accumulated to provide an idea of the aquifer extent through the region. While Stevens (1974) bases the extent of his aquifer model on his harbour entrance 'rock barrier' theory which has been proven to be incorrect, he does make a few statements regarding evidence of aquifer leakage in the harbour entrance that deserve some attention.

With no reference to previous work Stevens (1974) states that "individual gravel beds tend to thin and rise towards this rock barrier, until they peter out completely". He goes on to say that because of tidal scour, the capping of sea-bottom mud (i.e. the aquiclude material) also thin towards the rock barrier. From these premises, Steven's concludes that "artesian water flows under the harbour and rises towards the surface just to the north of Barrett's Reef. Here the pressure of the rising water has punched numerous holes in the sea floor muds and enlarged them by scouring. Such holes are quite numerous around Falcon Shoal, just off Seatoun; divers have descended into some of them and obtained samples of quite potable water".

As Stevens does not reference where he obtained his evidence from, it is hard to determine which of his claims are based on fact, and which are speculation. Certainly, research as part of this study has shown no evidence of 'holes' (which are more correctly termed 'depressions') in the Falcon Shoals vicinity. This area was extensively dived on and echosounded. No depressions were found, but the entire area was observed to be covered in large low-lying mounds.

The current hydrographic chart NZ4633, surveyed in the early 1980's, also shows mounds and not depressions. In fact, even the 1950 bathymetric survey (Chart NZ 23) shows mounds and not depressions in the Falcon Shoals region - and these appear identical in shape and form to those on chart NZ4633. These mounds are irregular in shape, and are raised up to a metre above the surrounding sea floor. Given that Stevens used this chart in his earlier work (Stevens, 1955) it is possible that he incorrectly interpreted these mounds as depressions. 
However, the description of divers descending into a depression and obtaining samples of 'quite potable water' is noteworthy. It is possible that the 'holes' Stevens talks about were referenced from an earlier report and had infilled with sediment by the time of the 1950 bathymetric survey. Stevens (1955) does reference an early report by McKillop (1931) (although incorrectly referenced as 1935 in Stevens (1955)) who gave an address to the Wellington Philosophical Society in 1931 on "The underground flow of the Hutt River as a source of water supply". In his talk, which was later transcribed, he discussed 'a clearing of the Falcon Shoals area off Seatoun' that resulted in an 'unusually high percentage of dead marine organisms' found in the dredgings".

The exact time that this dredging took place is not mentioned, but he goes on to say that "The Harbour Engineer at the time, Mr Ferguson, considered that such mortality might be related to the close proximity of an outflow - a salinity decrease thus occurring". Given that a Mr W R Ferguson was employed as an Engineer (among other positions) by the Wellington Harbour Board between 1884 to 1908 (Johnston, 1996), we can assume that it was during this period that this dredging took place. However, McKillop makes no mention of divers obtaining samples of potable water in the Falcon Shoals area something that surely would have been attached to the dredging report had it occurred.

McKillop also makes no mention of any 'holes' discovered, and it is likely that there were none as the dredging was carried out to deepen the area - something more indicative of the presence of mounds and not holes. However, in the same paper, McKillop discusses an occasion (in 1929) when a diver descended into a 'hole' in the harbour floor caused during construction of the Pt Howard wharf whereupon he obtained a sample of water that was 'quite fresh and potable'.

It is feasible that Stevens (1974) obtained his information about Falcon Shoals from McKillop's report as the entire transcript appears in the appendices of his earlier work (Stevens, 1955). It is therefore possible that he got his facts mixed up when writing "Rugged Landscape" and combined the presence of dead marine organisms found at Falcon Shoals (hypothesised to indicate artesian leakage), with the story of a diver who descended into a 'hole' obtaining potable water.

Brodie (1958), detected low salinity water in the harbour entrance between the tip of the Miramar Peninsula and Ward Island. Salinity values as low as 22 ppt (parts per thousand) were detected. However, low salinity water was not always present, and there was no relationship with the height of the tide. Brodie hypothesised this low salinity band to represent artesian leakage at the termination of the Waiwhetu Artesian Aquifer.

Side-scan sonar work carried out by Carter and Mitchell (1988) in the harbour entrance actually detected what they thought was a submarine spring discharge. It appeared as a 
plume of disturbance rising from the sea floor not far from Pt Dorset on the western side of the constricted harbour entrance. While this is certainly good evidence of artesian leakage, it is probably not Waiwhetu Artesian Aquifer water as it is extremely unlikely that any fine sediment beds were ever deposited through the confined harbour entrance to cap the Waiwhetu Artesian Aquifer due to the strong tidal currents in this region.

\subsubsection{The Rongotai Isthmus (Evans Bay - Lyall Bay corridor)}

While it has been shown that the harbour entrance was almost certainly open during the entire deposition of the Hutt Formation sediments, it does not mean that the Rongotai Isthmus was closed. Many researchers have studied various aspects of the geology of this corridor, and thus there is a great deal of evidence to draw on.

From a purely logical perspective, it can be argued that the erosion of the Evans Bay Lyall Bay corridor was probably of fluviatile origin, since waves do not easily erode a deep embayment at right angles to the coast (Huber, 1992). In fact, there is little argument as to whether the channel is of fluviatile erosion or of marine erosion. Rather, there is some debate as to what sort of fluviatile erosion took place.

Stevens (1955) states that during the last glacial maximum, the Evans Bay - Lyall Bay corridor was cut down to glacial sea level by the Hutt River. It is unclear what evidence he bases this on, but he does acknowledge that this alternate harbour entrance was first recognised by Crawford (1973). In the following year, Stevens (1956), goes into more detail saying that Crawford's alternative harbour entrance theory had been confirmed by test drilling for the Rongotai Aerodrome. The bores drilled in the Rongotai vicinity traced basement to a depth of $200 \mathrm{ft}$ ( $\sim 60$ metres) below sea level. Unfortunately, the exact whereabouts of these bores are not made clear (Stevens quotes the information about the bores as being made available by $\mathrm{Mr}$ M C Pick). However, he doesn't say which organisation this person is affiliated with.

Stevens (1956) goes on to say that basement "probably continues deeper indicating that a passage had been deepened by erosion down to the low glacial sea-level." He later states that basement must actually be deeper than this - as much as 83 metres deep to allow for the deposition of the Wilford Shell Beds (due to the fact that the Wilford Shell Beds are a marine unit, presently lying at a depth of between 70 to 83 metres deep along the Petone Foreshore). This unit is the aquiclude to the Moera Gravel Aquifer and separates the Moera from the Waiwhetu aquifers. It is believed to extend across the entire extent of the harbour with no down-valley tilt that is characteristic of fluvially deposited sediments.

Stevens makes this assumption as he believes that the Rongotai Isthmus is the preferred course for the Hutt River at this time and that the present harbour entrance is closed due to shallow basement rock. Given that the Waiwhetu Artesian Aquifer gravels were deposited 


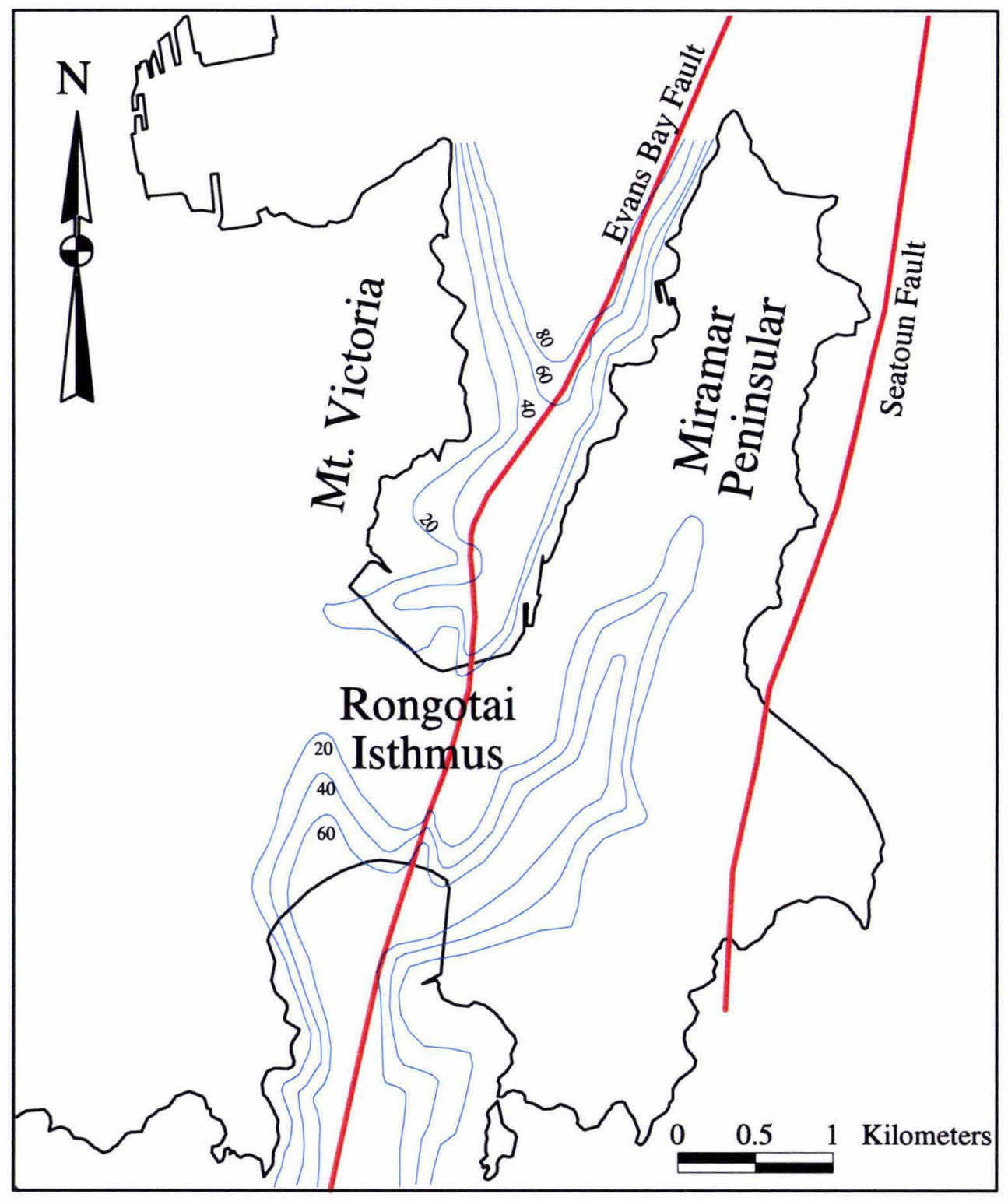

Figure 8.6.3.1 Basement contour map of the Rongotai Isthmus (after Huber, 1992 and Lewis and Mildenhall, 1985). Contour interval is 20 metres (depth below sea level). 
on top of the Wilford Shell Beds as part of an uninterrupted sequence, it is implied that the Hutt river used this passageway after the Wilford Shell Beds were deposited

Extrapolation of the Waiwhetu Artesian Aquifer top, as picked by Reyners and Christoffel (1973), imply depth of gravels below MLW (mean low water) of approximately $210 \mathrm{ft}$ $(64 \mathrm{~m})$ if they were deposited in this region. Rogers (1968) carried out a gravity survey in the Rongotai-Miramar region and showed a channel running along the hills to the west of Evans Bay that was initially thought to represent a former course of the Hutt River. However, this gravity data indicates that the channel in the greywacke is roughly $140 \mathrm{ft}$ $(43 \mathrm{~m})$ below MLW at its shallowest point. This is $25 \mathrm{~m}$ shallower than that necessary to allow the deposition of the Waiwhetu Artesian Aquifer as indicated by Reyners and Christoffel (1973), and 40m shallower than the depth required to allow the deposition of the Wilford Shell Beds as stated by Stevens (1956)

Lewis and Carter (1976) suggest that the Evans Bay - Lyall Bay corridor was initially eroded and used by the Hutt River but continued subsidence of the basin to the east of the Miramar Peninsula caused the river to migrate to a "more permanent exit through the present harbour entrance". They do not state how long ago "initially' means, but they do go on to recognise that subsequent to this event the bays either side of the Rongotai Isthmus were then cut by two streams - one flowing north into the harbour, and the other flowing south towards Cook Strait.

Later, Lewis and Mildenhall (1985) and Huber (1992), provide evidence to support the theory that Evans Bay was cut by a river flowing north from the Hataitai hills on the western side of Rongotai Isthmus, while Lyall Bay was cut by a river flowing southward from the Miramar Peninsular. The depth to basement contour map after Huber (1992) and Lewis and Carter (1976) certainly endorses as two clearly defined channels cut into the basement rock can be seen, separated by a basement high of just over 5 metres depth beneath Rongotai. A contour map of the depth to basement is shown in Figure 8.6.3.1. The depth to basement in the southern section (Lyall Bay) is supported by geophysical investigations carried out by Davey (1971).

Furthermore, the presence of a channel cut by the Hutt river in the Wilford Shell Beds as described in section 8.3 and shown in Figure 8.3.1 indicates that the river certainly flowed through the harbour entrance and not the Rongotai Isthmus during the initial stages of the deposition of the Waiwhetu Artesian Aquifer.

Regardless, of whether the Hutt River ever flowed through the Rongotai Isthmus, it certainly didn't do so during the Holocene, and so the Waiwhetu Artesian Aquifer gravels were never deposited in the Rongotai Isthmus vicinity. It is, however, possible that the river flowing northwards from the Hataitai/Mt Victoria region into the harbour deposited 
coarse sediment of its own in Evans Bay which join the Waiwhetu Artesian Aquifer gravels in the inner harbour. This may theoretically extend the Waiwhetu Artesian Aquifer into Evans Bay, but this cannot be proven, even with the seismic data available as only two seismic lines extend into Evans Bay, and these are of poor quality.

\section{Previous Evidence for Aquifer Leakage in Evans Bay}

The only piece of information suggesting possible artesian leakage in Evans Bay, (seafloor depressions aside), is offered by Calhaem (1968) who measured geothermal heat flow in Wellington Harbour. He found a spot in Evans Bay, just out from Miramar Wharf, where anomalous heat flow was recorded. Reyners and Christoffel (1973) suggest that it could have been caused by a constant temperature source of $14^{\circ} \mathrm{C}, 15 \mathrm{~m}$ below the sea floor, which they attribute to a leak in from the Hutt Valley Groundwater system. While possibly a groundwater leak, given the preceding evidence of sedimentation of the Waiwhetu Artesian Aquifer, it is perhaps more likely to be derived from a local aquifer deposited by the north flowing stream that eroded Evans Bay. 


\section{Chapter Nine}

\section{SUBMARINE SPRINGS IN WELLINGTON HARBOUR}

\subsection{Introduction}

This chapter describes the locations where submarine spring discharges are found in Wellington Harbour. It provides reasons as to their spatial distribution and relates the distribution of the springs to the mechanisms of spring inception.

\subsection{Background Information}

Before investigating the spatial distribution of the springs, it is timely to give a summary of the information that already existed on submarine spring discharge into Wellington Harbour before this research was undertaken.

Various authorities, each with an interest in the Lower Hutt Groundwater Zone or its leakage into Wellington Harbour have existed over the years. Many of these organisations now cease as they are amalgamated into bigger and bigger organisations. For example, the Hutt Valley Underwater Authority (HVUWA) was an organisation formed in 1959, solely concerned with the management and development of the underground water resource beneath the Lower Hutt Valley. It became incorporated into the newly-formed Wellington Regional Water Board in 1973. This regional water board then became part of the Wellington Regional Council in 1980, which in turn was redefined in 1989.

Much of the early records from these now defunct organisations are 'archived' in boxes. While this material is not lost, it does require a lot of time to search through for relevant information. When the Wellington Harbour Board was amalgamated into the newly reformed Wellington Regional Council in 1989, many of the WHB employees were made redundant, with their offices locked up and left untouched. As a result, the 'archived' Wellington Harbour Board records are largely in disarray. Finding useful material was often a case of intensive searching through all the records, with the occasional 'find' coming from the most unlikely of areas. However, after many weeks spent searching through the old Harbour Board Offices, I believe that the records gathered for this study represent as near a complete set of archived information relating to submarine spring investigations in Wellington Harbour as you could possibly get. Note that the Wellington Harbour Board records are presently being catalogued by the WRC. 
The information gathered from the Harbour Board records was supplemented with communication with many of the ex-Harbour Board employees such as the once Chief Engineer Karl Renner, and retired Boatmasters Commander Johnson and Roger Carter. $\mathrm{Mr}$ F. de Jong of the old Wellington Regional Water Board and the HVUWA before that, was also contacted. All provided useful information. I cannot stress enough how much useful information was obtained from personal communication with these retired employees of the various organisations previously interested in aquifer leakage into Wellington Harbour.

While no major study of the springs was ever undertaken in the past, by piecing together what information does exist, an idea of the discovery and prolificness of the various springs can be obtained. The salient unpublished archived material is summarised below (chronologically ordered), however the entire collection of this material is set out in Appendix One.

Late 1920's; While the Wellington Harbour Board dredges were dredging off the Hutt River mouth for the Thorndon reclamation, a Mr Daniells from the Gear Meat Company (on the Petone Foreshore), noted a lowering of piezometric head in their wells. The recovery of head took a "long time". The Gear Meat company was sited near the UWA 1 bore in the western side of Petone, not far from the Petone Foreshore. The exact timing of this event is not clear, but it is referred to in unpublished reports of McKillop (1931) and again in a correspondence between the city engineer, $\mathrm{Mr} \mathrm{K}$ Carmichael and a $\mathrm{Mr}$ Swinburne on the $25^{\text {th }}$ January 1937 . We must keep in mind that although a dredge was operating at the time of the noticed drop in piezometric level, these events may be coincidental and not directly related to each other.

July 1929; During construction of the Point Howard Oil Jetty, investigative borings using a 3 inch pipe $(7.6 \mathrm{~cm})$ made into the soft harbour floor muds penetrated through the aquiclude and reached the artesian gravels. Upon completion of the borings, a distinct sea surface disturbance was noticed at one location (No. 6 bore), caused by an upwelling of fresh water. A diver was sent down and he estimated that the diameter of the hole was about $4 \mathrm{ft}$ 6inches (1.4metres). The outflow was so great that he could not inspect the hole any further. "Some days later" a second inspection was made and this time the diver found that the flow was "considerably reduced." He was able to descend to the bottom of the hole which gradually tapered to a minimum of $3 \mathrm{ft}(91 \mathrm{~cm})$ diameter at the gravel strata. The hole then continued $5 \mathrm{ft}$ ( 1.5 metres) into the gravel bed. He noted that "the gravel strata was composed of water worn boulders up to about 8 inches $(20 \mathrm{~cm})$ in diameter" and that "the flow of water came from the sides of the gravel strata rather than from the bottom of the hole." The sample of water taken by the diver was slightly brackish.

January 1937; While dredging the Hutt River mouth a loss of 18 inches $(46 \mathrm{~cm})$ in piezometric head was observed at Gear Island bores, as well as other bores in the Gear Island vicinity. The area being dredged was Scaby Island - a shallow river-mouth build up 
of sediment. Scaby Island was being dredged to improve the hydraulic efficiency of the river channel and thus reduce the effect and duration of flooding. The area where Scaby Island once stood now forms part of the Seaview reclamation.

At the time the dragline dredge was operating, the WHB stated that the upper drag was digging at $26 \mathrm{ft}$ ( 8 metres) below water level, and it was thought that "the Lower Drag may have been deeper." However, once the drop in pressure was noted, the dragline dredge was stopped and the cut in the river bed was investigated and found to be $50 \mathrm{ft}(15 \mathrm{~m})$ below low water for the upper drag, and $60 \mathrm{ft}(18 \mathrm{~m})$ deep for the lower drag. The lower drag line of the dredge had encountered "successive layers of sand and pug and finally had picked up beach boulders." It is unknown whether these 'beach boulders' were in fact that, or were actually aquifer gravels.

A diver was sent down to investigate, but found no evidence of discharging aquifer water. However, it must be noted that it would have been hard to distinguish aquifer leakage in a river environment (fresh water discharging into fresh water). Despite this the diver did note that not even the fine suspended sediment in the water column above the river bed was being moved. He also noted that the walls and base of the pit consisted entirely of hard silt formation. No evidence of gravels were found, which is unusual given that the dragline apparently picked up some.

Most wells in this vicinity draw their water from $80-90 \mathrm{ft}(24-27$ metres) below low water, in the high water yielding upper portion of the Waiwhetu Artesian Aquifer. This is significantly deeper than the depth to which the dragline cut to.

Due to the localised effect of this event, it was never proven whether an aquifer blowout had occurred, or whether it was simply the result of an extended drought period combined with heavy abstractions at the Gear Island pumping station (demand was high at the time).

After this event, the dragline was restricted to operate to within $30 \mathrm{ft}$ below low water. Piezometric pressures gradually recovered and were only 9 inches $(23 \mathrm{~cm})$ below normal by April, and were at normal levels by the end of May, 1937. The dredge was still operating during this period, and continued right through till the end of November 1937.

November 1937; Further head losses experienced, but this time across the entire valley. Not as pronounced as the localised drop of Jan 1937, but still between $6-12$ inches (15$30 \mathrm{~cm}$ ) in most places. While many instantly blamed the dredge's operation again, it is possible that it was due to an extremely dry spell. The dredging operation was abandoned after this second head loss.

August 1969; While surveying the harbour floor between Somes Island and Petone Foreshore (near the Hutt river mouth), three new depressions not shown on the existing bathymetric chart were found by a team of divers. Salinity readings were taken and 
artesian leakage was proven, as well as being visible in some places. Echosounder strips (held within the WRC archives show the form of these depressions).

November 1970; An infra-red camera (spectrometer) was used at Pt Howard to search for artesian leakage in the Petone Foreshore and Pt Howard Wharf area. IR radiation (essentially heat) is emitted from all objects in varying amounts, relative to the heat of the object. No differences in sea surface were detected during these investigations. However, a few important points must be noted;

- The survey was carried out in a time of year when the inner harbour sea temperature would have been practically identical to the temperature of the artesian water. Harbour water temperature at this time of year is $\sim 14^{\circ} \mathrm{C}$ (Booth, 1975). The Waiwhetu Artesian Aquifer water is $\sim 13.9^{\circ} \mathrm{C}$ throughout the entire year (pers comm, Brydon Hughes, WRC, 1997). Thus even if massive amounts of artesian leakage was occurring, no significant difference would have been observed in the surface water temperatures above a submarine spring, and certainly not enough to be detected by an IR spectrometer.

- The IR equipment was set up on a hill at Pt Howard and was viewing the harbour from an angle of around 30 degrees. As the amount of IR radiation detected by a spectrometer is directly proportional to the angle from the object being studied, this acute angle would have meant that very little of the total amount of IR radiation emitted from the sea surface would have been registered by the spectrometer.

July 1972; Salinity measurements were taken over one of the two deep depressions south of Somes Island, by VUW, the Oceanographic Institute and the DSIR. Unfortunately, the salinity probe was lost (the cable was severed by the boat propellers) and could not be retrieved. As such, no data was obtained from this survey. The depression investigated was probably the larger of the two near Somes Rock (a submerged rock pinnacle to the south-west of Somes Island) as the other depression had not been charted at this stage.

September 1972; An infra-red aerial survey of Wellington Harbour was undertaken to detect differences in sea surface temperature. Unfortunately a thin layer of cloud at $4000 \mathrm{ft}$ $(\sim 1200 \mathrm{~m})$ which was not visible from the ground, would have absorbed any infra-red radiation from the sea surface. Weather conditions did not permit a second run over the next few weeks and so the mapping was abandoned.

September 1972 - January 1973; Sometime during this period divers investigated "likely leakage areas" in the harbour. The divers' investigations found no present day evidence of artesian leakage which led the HVUWA to surmise that "it is unlikely that any artesian water outflows from the deep depression south of Somes Island, into the harbour." They go on to state that "outflows probably occur over moderately large areas and at very low 
velocities much closer to the shore (Petone Foreshore) and mainly in the north-eastern corner of the harbour. Once again, it is likely that the "deep depression south of Somes Island' they investigated was the one near Somes Rock.

January 1973; Personal communication with the now retired Mr F. de Jong (formerly of the now defunct HVUWA) in May 1998, revealed an investigation he was involved in as part of the investigation into the depression near Somes Rock. Apparently a large funnel made of steel was constructed and lowered upside down over the deepest part of the Somes Rock depression in order to collect some fresh water where the divers had failed. The operation was not a success and no 'freshened' water was collected or even detected.

\subsection{The causes of Submarine Spring inception in Wellington Harbour}

Kohout had little trouble in explaining the inception of submarine springs in the literature he reviewed as most of it dealt with springs issuing from karstic or volcanic aquifers. The most common way for springs to form from these aquifers would be via the collapse of material through the roof of a subterranean cavern causing a breach in the confining layers.

The collapse of material would form a depression in the sea floor (regardless of the substrate) and the resulting discharge from the aquifer could be quite prolific due to the high transmissivities that are typically found in karstic aquifers. However, unlike karstic or volcanic aquifers, unconsolidated rock aquifers contain no large cavernous spaces through which the collapse of material can lead to a rupturing of the aquiclude. Thus some other process or event is necessary to compromise the aquiclude's ability to withstand the pressure of the artesian water beneath.

Given that an aquiclude's ability to constrain artesian water is dependent on the competency and strength of the formation, a process or event that leads to submarine spring inception must in some way act to alter one of these two properties. What is meant here is that something must happen that weakens the aquiclude, or raises the piezometric pressures within the aquifer to a level which the aquiclude cannot withstand.

A knowledge of how and why aquifer leakage initiates is useful information as it enables us to get an idea of why some areas of the harbour may exhibit artesian leakage while others areas may not. It may also reveal the reasons as to why some of the significantly large sea floor depressions exhibit no signs of present day groundwater leakage.

Given that this research is concerned with artesian leakage from the Waiwhetu Artesian Aquifer into Wellington Harbour, the mechanisms discussed in the following section are those that are hypothesised to be the likely cause of artesian leakage in the Wellington 
Harbour environment. These mechanisms may certainly be applicable to other artesian aquifer systems around the world (particularly unconsolidated gravel aquifers like the Waiwhetu Artesian Aquifer), but it must be noted that the following are purely written with the sub-Wellington Harbour groundwater system in mind.

\subsubsection{Tidal Scour}

The only commonly recognised process that can weaken a shallow marine aquiclude is Tidal Scour. This process acts to reduce the thickness of a confining bed to a critically thin level. With regards to the formation of submarine spring discharges, Tidal scour operates either by keeping an area free of fine sediment while the confining beds are being deposited. Alternatively, some event occurs after the deposition of the confining beds that alters a particular coastal area, with the resulting new tidal regime stronger and more erosive in places.

Basic sedimentological properties state that the faster the current, the larger the grain size it can erode and transport (the theory relative to Hjilstrom's curve). This statement is a little crude, as other factors such as the density and cohesiveness of the grains and the depth of water do have an effect on the curve's applicability (Hjilstom based his findings on experiments undertaken in just one metre depth of water). However, for the purposes of promoting this process as a possible mechanism for aquiclude weakening, we'll assume these factors are redundant for now.

In general, tidal currents are faster through constricted passageways where the water has to speed up to drain or fill a large body of water, and around headlands or rocky outcrops where the flow of water is forced to take a longer route (around an outcrop). Therefore, these are the more likely areas where tidal scour could be strong enough to erode sea floor sediment and create a depression. However, it would be expected that any depression formed in such a way would have a characteristic form - probably reasonably large in surface area and with gently sloping sides. An oval type feature rather than a circular one would be more likely due to the fact that tidal currents generally operate in one direction during the flood and in the opposite direction during the ebb. This would generate an elongated feature rather than a well defined circular one.

With regards to an event that may alter the tidal flow regime, a large tectonic event may be enough to cause a change, particularly in the case of Wellington Harbour. Movements on the Wellington Fault tend to uplift the ends of the Lower Hutt Valley/Port Nicholson basin (Taita Gorge and the harbour entrance), while deepening the main harbour relative to the basin highs (the result of compression - see Chapter Five). The outcome of this is an increase in the harbour's volume resulting in a greater volume of water that must pass 
through the constricted harbour entrance in the same six and a quarter hour ebb or flood period. This results in faster tidal velocities, especially through the confines of the harbour entrance.

While this process may thin the confining bed, the development of a prominent submarine spring following the reduction of the confining aquiclude is dependent on the hydrological properties of the aquifer beneath.

\subsubsection{Gas Blowout}

Gas escape as an erosive medium of fine sediment is recognised by Hovland and Judd (1988) as a means of creating small 'pockmarks' on the seabed. While their work concentrated on gas escape from hydrocarbon deposits, gases such as carbon dioxide, methane and hydrogen sulphide would certainly be produced in the sub-harbour sediments via the biogenic break-down of organic material. However, the gas escape features noted by Hovland and Judd (1988) are typically less than one metre in depth (relative to the sea floor) and are thus much smaller than the depressions found in Wellington Harbour.

However, a catastrophic release of gas could possibly produce enough energy to remove a large amount of sediment. These events are termed 'gas blowouts' by Hovland and Judd (1988). The Petone Marine Beds aquiclude are known to contain significant amounts of organic matter as described by Dunbar (1994). The decomposition of this material produces the gases previously mentioned which can then accumulate until a point is reached when the sediment above can no longer withstand the pressure provided by the buoyancy of the growing gas pocket. The result is a massive outpouring of gas, which ruptures the aquiclude and re-suspends the displaced sediment in the water column. Any resultant discharge of fresh water from the aquifer will then prevent the sediment from settling back down in the newly created crater, thus leaving behind a sea floor depression.

Thus the scenario proposed here is that a catastrophic event such as a gas blowout is first needed to remove a large proportion of the confining bed, upon which time water from the aquifer would find an easy route through to the sea floor. Once again, the prolificness of any SGWD would be dependent on the hydrological properties of the aquifer beneath.

\subsubsection{Tectonism}

It is hardly surprising to discover that the effects of intense shaking may detrimentally affect a groundwater regime, especially concerning artesian aquifers where the confining bed above needs to be competent enough to withstand the pressures of artesian water beneath. Anyone who has seen, or who comprehends the basic physics behind the liquefaction process will know how unconsolidated sediments (especially water saturated 
ones) behave in an earthquake. This process has been briefly described in the previous chapter. This is but one of three processes that are assumed to be possible causes of SGWD and the subsequent development of a submarine spring.

\section{Direct fault rupture}

The most obvious way in which tectonism affects an artesian aquifer is through direct fault rupture. This can lead to the development of pathways of weakness through the confining bed between the aquifer and the marine environment. The discharge of groundwater as a result of this process is dependent on the hydrological properties of the aquifer (especially the piezometric head) and the amount of vertical offset that the fault movement provided. This is important, as the amount of offset will determine how much confining bed the water has to pass through before it reaches the sea floor. Wellington fault is a classic example of this type of process and aquifer leakages along the sub-harbour fault trace have been identified in a couple of studies prior to this one (Lewis, 1989. Truebridge et al, 1978).

\section{Different seismic velocities}

Earthquake wave propagation is dependent on a number of factors, with perhaps the medium through which they travel being the most influential. Consolidated rock and unconsolidated sediments have different seismic velocities and as such earthquake waves behave differently in them (different frequency). Where consolidated bedrock borders an artesian system, the variation in shaking frequencies can lead to a rupturing of the formations (during shaking) and subsequent rupture of seal provided by the confining beds. Artesian water will exploit this temporary condition and leak out along the bedrock contact to emerge at the sea floor. The release of the artesian water may remove large amounts of the fine confining sediment forming a depression. Reyners and Christoffel (1973) provide similar reasoning as to the formation of the sea floor depressions south of Somes Island.

The amount of water that will initially escape as a result of the earthquake is probably dependent on the severity and duration of shaking, the hydrological properties of the aquifer and the extent to which liquefaction within the aquifer occurs (see next section). Whether a submarine spring is present after the shaking has ceased will be dependent on how much of the confining beds were removed by the action of the leaking water and whether the pressures within the aquifer are still high enough to overcome the remaining confining bed (if any is present).

\section{Liquefaction/Aquifer Blowout}

Although not a previously recognised mechanism of submarine spring formation, it is possible that liquefaction may occur within the confining aquiclude as a result of the 
intense shaking that accompanies earthquakes. Liquefaction is a process whereby a saturated unconsolidated unit loses its structure and essentially turns into a fluid. As described briefly in the previous chapter, the effect of shaking an unconsolidated unit is to cause settling between the grains, thus reducing the pore spaces. Pore water pressures rapidly become extreme as water is a non-compressible medium. As there is now not enough room for the water to fit within the adjusted matrix structure, it is forced out of the unit, towards an area of lower pressure. In an unconfined scenario, this is towards the surface. On land, such a phenomenon is manifested as sand 'volcanoes' in areas where liquefaction has occurred.

With regards to a confined aquifer, liquefaction of the confining beds would mean the loss of ability to confine the artesian water in the aquifer beneath. If the piezometric pressures within the aquifer were high enough, water would escape through the weakened aquiclude and an aquifer 'blowout' would occur.

Due to the highly tectonic nature of the Wellington region, there has certainly been the opportunity in the past for liquefaction of the aquiclude to have occurred. The intense shaking associated with the 1855 Wellington Earthquake alone would have probably been sufficient to cause liquefaction if it hadn't had occurred prior to this time.

As detailed in Chapter Eight, liquefaction of the confining aquiclude may be restricted to isolated areas where the geologic conditions allow. What is meant here is that the aquiclude itself is, for the main part, quite hard and consolidated, and thus unlikely to liquefy (pers comm. B. Brabhaharan, Opus International Consultants, 1999). However, there exist some areas, most notably between Somes Island and the Hutt River mouth, where the aquiclude is notably thin and not as competent as elsewhere in the harbour (see Figure 8.4.1). Note that the aquifer underneath this area is underlain by a paleochannel that is likely to contain much higher transmissivities than elsewhere in the aquifer, and thus the high piezometric pressures in the aquifer here would certainly exploit any breach in the aquiclude.

The resulting feature left behind would almost certainly be a sea floor depression, and it is also reasonable to assume that artesian water would continue to escape through this newly formed pathway for as long as the hydrogeologic conditions permit.

Furthermore, Parker and Stringfield (1950) provide accounts of earthquakes causing water levels in bores penetrating gravel aquifers to fluctuate. They also observed the same effect when trains passed over the aquifer. While neither the effect of earthquake shaking nor passing trains has been observed on piezometric wells recording the pressure in the Waiwhetu Artesian Aquifer, fluctuations in piezometric head have been recorded under a changing load. Both tidal and atmospheric changes place a load on aquifer, with the 


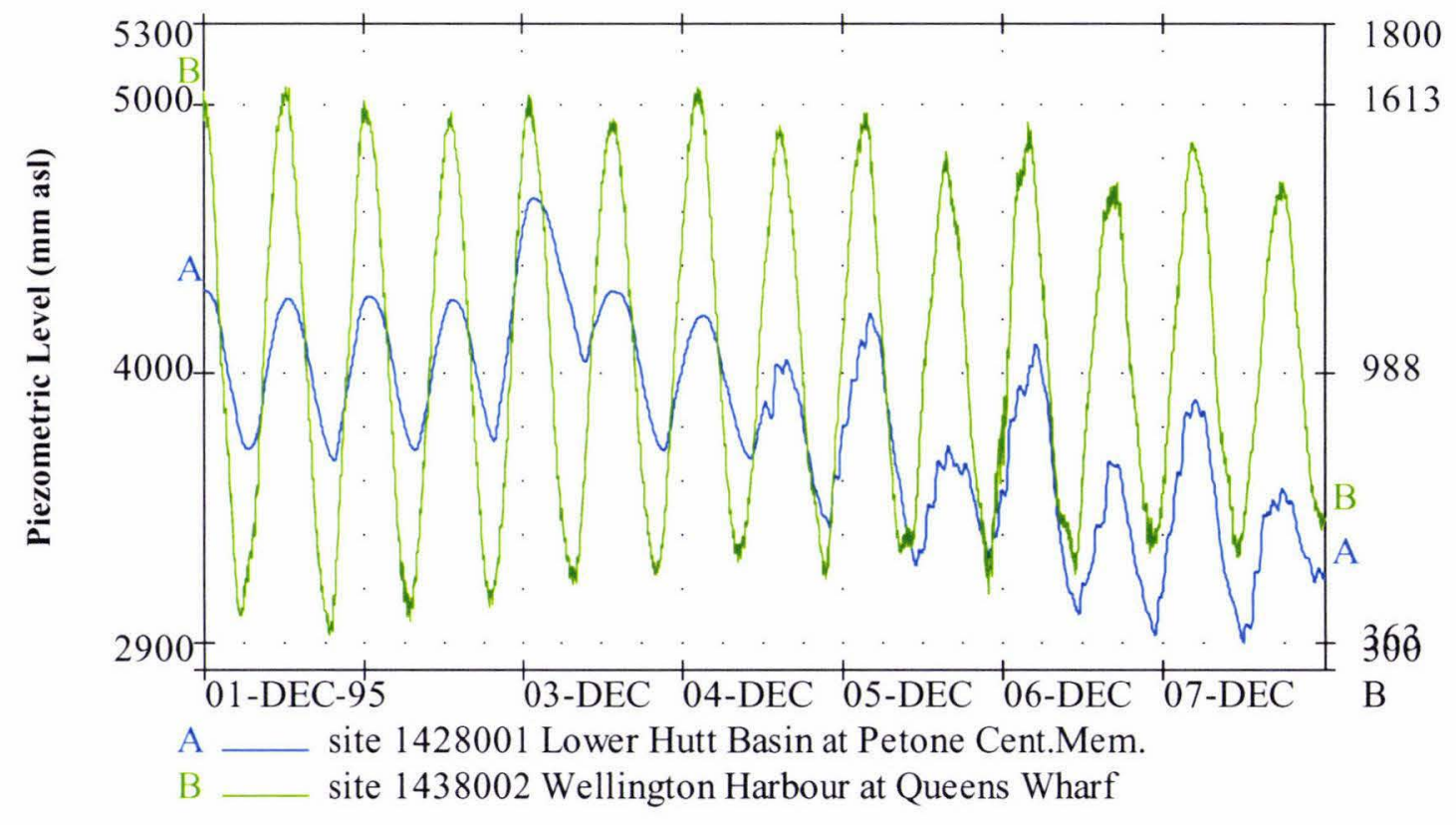

E

Figure 9.3.3.1 Example of how the changing load of the tides affects the piezometric pressure in the Waiwhetu Artesian Aquifer as measured at the Petone Centennial Memorial piezometric level recorder. The blue line (A) is the piezometric pressure at the PCM bore, and corresponds to the left axis. The green line (B) is the height of the tide above the Lowest Astronomical Tide (LAT), and corresponds to the right axis. 
associated fluctuation in piezometric head plainly obvious in well records within the Lower Hutt Valley.

Figure 9.3.3.1 shows the response of the Petone Centenial Memorial observation well to the changing tide. As can be seen, the fluctuating piezometric head within the aquifer corresponds to the diurnal tidal cycle. The deviations from this trend are caused by the influence of groundwater abstraction from nearby wells.

The effect of the tides on an artesian bore drilled for investigation purposes at the Point Howard Wharf was described in January 1936. The report states that "at low water on the $10 / 1 / 36$ the flow observed was 1,650 gallons per hour. At high water on the 15/1/36 the observed flow was 2,300 gallons per hour."

This evidence demonstrates that piezometric pressures within the Waiwhetu Artesian Aquifer are temporarily increased under loading. Given that Parker and Stringfield (1950) observed similar patterns during earthquake shaking and passing trains, the effect of intense shaking during a large earthquake may possibly temporarily raise the piezometric pressure within the aquifer to a level that could not be contained by the confining aquiclude. If the aquiclude structure is also weakened via liquefaction, the potential for aquifer blowout to occur is greatly increased.

\section{Anthropogenic Influences}

Dredging, shipping movements and wharf construction are all possible ways of removing or redistributing sediment from the harbour floor. Dredging has certainly been identified in the past as a possible cause of artesian leakage in Wellington Harbour, and the construction of the Point Howard Wharf is a good example of the way in which man can detrimentally affect his environment by acting in an unscientific or poorly-informed manner.

Shipping movements are probably not as much of a risk to the competency of the confining member, but it has been noted recently that the Lynx, a fast inter-island ferry vessel, cuts a two metre deep channel through the shallow portion of the harbour entrance around Falcon Shoals (pers comm. Jim Mykos, Wellington Fishing Club, 1998). Furthermore, according to Jim Mykos, after the ferry has passed, an 'oiliness' appearance to the water occurs.

As described previously, an 'oiliness' or 'blurriness' in the water is one of the ways in which divers investigating submarine spring sites can detect artesian leakage. This is due to the different light refractive indices between fresh and salt water. It is possible that each time the Lynx passes over the shallow Falcon Shoals area, the disturbance of the already thin aquiclude in this region enables leakage from the Waiwhetu Artesian Aquifer to occur. 


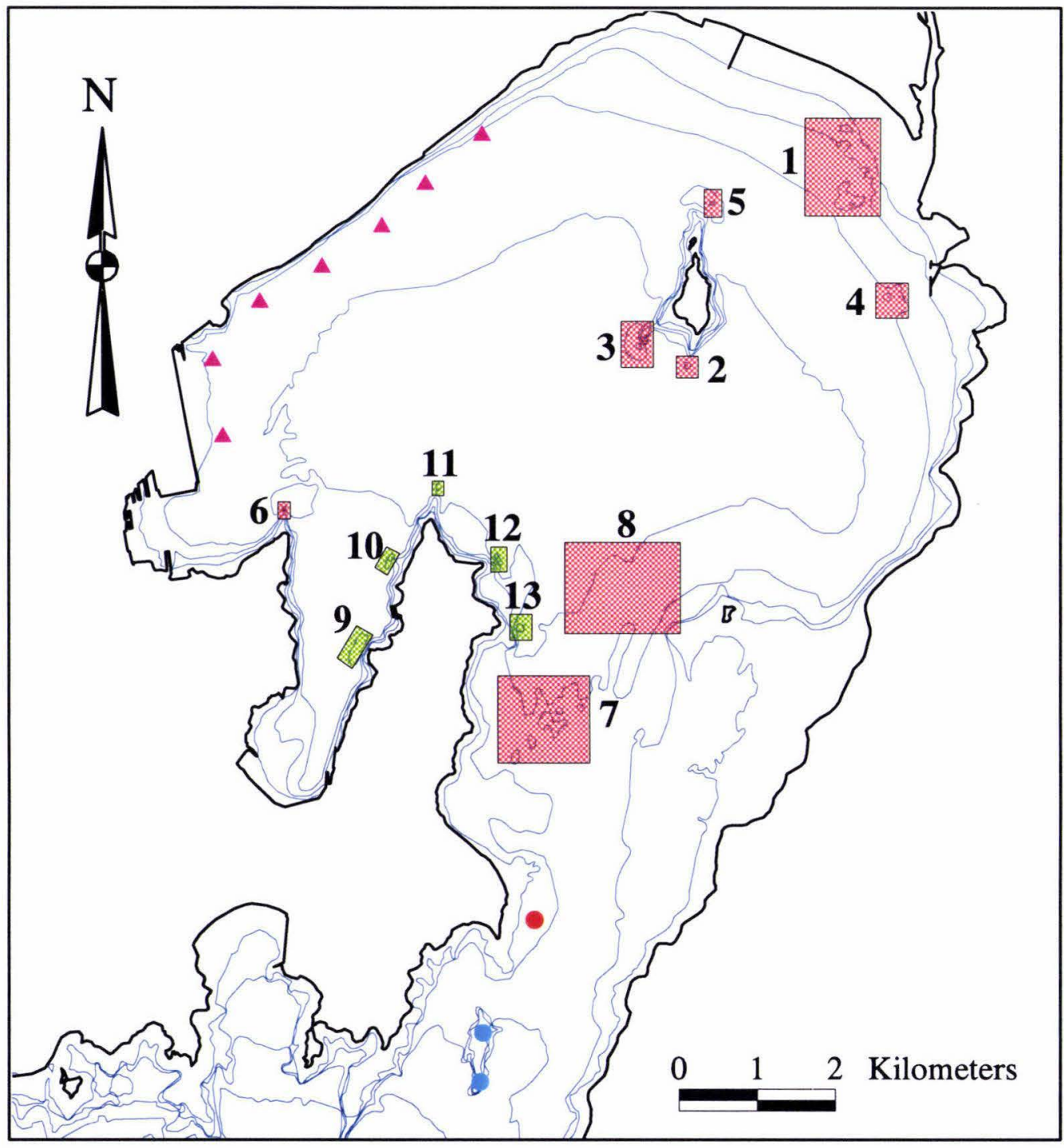

Figure 9.4.1.1 Location map of the areas investigated for submarine spring discharge as part of this research. The red regions represent areas that exhibited signs of present day artesian leakage. The green regions represent other areas investigated, based on the fact that they contained sea floor depressions, but were found to have no signs of artesian leakage. The pink triangles show those locations that have been identified in the past as having artesian leakage, but were not investigated due to there being no sea floor depression present on which to base investigations. The blue dots represent areas around Barrett's Reef where SCUBA divers have noted disturbance in the water that fit the description of artesian leakage, but were not investigated due to the leakage being almost certainly unrelated to the Waiwhetu Aquifer. The dark red dot represents a suspected submarine spring discharge as detected by NIWA using side scan sonar during an unrelated study in 1987. High resolution bathymetric surveys were undertaken in Zones $1-6$. Bathymetric contour lines are shown in blue (5m interval). 


\subsection{Sites of Active Leakage}

\subsubsection{Introduction}

Thirteen zones were selected for investigation into their potential as sites for present day artesian leakage. Eleven of these sites were chosen based on them being significant depressions in the harbour floor. The other two zones (zones 7 and 8), in the northern part of the harbour entrance, were chosen because of the reported low salinity water from them in the past (Brodie, (1958) for Zone 8; Stevens, (1955, 1956, and 1974) for Zone 7).

Prior evidence existed for the presence of artesian leakage along the Wellington Fault (Lewis, 1989; Truebridge et al, 1978), off Point Dorset (Carter, 1988) and at Barrett's Reef (divers' observations). However, these were not investigated due to the fact that no sea floor depressions are associated with them, and as such, are difficult to locate. Figure 9.4.1.1 shows the locations of these areas, including the zones investigated.

Up to 20 salinity values were recorded with a portable conductivity/temperature meter at the thirteen zones. This was performed at both low and high tide so as to detect the nature of artesian leakage under a changing load. These results are set out in Appendix Two. The highly localised nature of artesian leakage indicted that random sampling with the conductivity probe was perhaps not the best method for identifying leakage, especially when it was realised that leakage only occurred at discrete vents. However, this was the only cost effective means of investigating all of the harbour floor depressions.

Five of the zones exhibited artesian leakage to a significant degree, and in some cases a discernible trend with tide is apparent (Zones 1, 4, 5, 7 and 8). Interestingly, Zones 2 and 3 , the two sites were once considered to be the main outlets for artesian water into the harbour (Donaldson and Campbell, 1977; Stevens, 1974), showed very little evidence of leakage. This discovery supports information detailed in an unpublished Wellington Harbour Board report of divers finding no evidence of artesian leakage in these areas during a survey conducted sometime between September 1972 to January 1973 (as described in section 9.2).

Zone 6, near Pt Jerningham, exhibited a small amount of leakage, which cannot really be called significant. However, on one occasion while mapping the depressions in the harbour, noticeable sea floor disturbances were noted on the echosounder at this site. Unfortunately the conductivity probe had been lost at this point and thus salinity measurements could not be taken to confirm leakage. However, based on the echosounder signal, this site must be considered to be at least a periodic site of SGWD, when artesian pressures are high. 
Zones 1 to 6 were dived on and their depression characteristics noted. Their bathymetric form was also mapped using the Kiwitech program Chartplotter. While slightly 'freshened' water was occasionally detected at the other five depressions (all around the Miramar Peninsular), they were omitted from any further investigation due to their low importance to the research aims, as well as time and financial constraints.

All sites were noted for being void of any marine flora, but this is not specific to the depression regions - other researchers (Dunbar, 1994; pers. comm. J. Goff, 1996) noted an absence of marine vegetation in the majority of the inner harbour region.

\section{General Depression Dimensions}

The morphological shape and dimensions of the sites is an effective way of comparing the depressions. Table 9.4.1.1 summarises the depression dimensions of the sites that were fully investigated. As can be seen, the depressions exhibit a wide range of geomorphic form and slope angle. Some depressions are circular in shape, but where they are elongated, the length of the longest and shorted axes (and their rough orientation) are provided. The locations given for each depression correspond to the deepest point in each depression floor and have been adjusted to correlate with the Hydrographic Chart NZ4633 (i.e. 0.1 minutes southwards have been added to the satellite positioning obtained for them).

\begin{tabular}{|c|c|c|c|c|c|c|}
\hline & Latitude & Longitude & \multicolumn{4}{|c|}{ Depression Dimensions } \\
\hline Zone/No. & (dec. deg.) & (dec. deg.) & Top & Base & Max depth & Max slope \\
\hline $1 / 1$ & -41.23942 & 174.88774 & $97 \mathrm{~m}(\mathrm{~W}-\mathrm{E}), 72 \mathrm{~m}(\mathrm{~N}-\mathrm{S})$ & $35 \mathrm{~m}$ (circular) & $13.3 \mathrm{~m}$ & 7.1 degrees \\
\hline $1 / 2$ & -41.24225 & 174.88626 & $53 \mathrm{~m}(\mathrm{~W}-\mathrm{E}), 88 \mathrm{~m}(\mathrm{~N}-\mathrm{S})$ & $14 \mathrm{~m}$ (circular) & $15.2 \mathrm{~m}$ & 11.3 degrees \\
\hline $1 / 3$ & -41.24428 & 174.88620 & $62 \mathrm{~m}(\mathrm{~W}-\mathrm{E}), 110 \mathrm{~m}(\mathrm{~N}-\mathrm{S})$ & $22 \mathrm{~m}(\mathrm{~W}-\mathrm{E}), 32 \mathrm{~m}(\mathrm{~N}-\mathrm{S})$ & $15.1 \mathrm{~m}$ & 7.5 degrees \\
\hline $1 / 4$ & -41.24374 & 174.88921 & $82 \mathrm{~m}(\mathrm{~W}-\mathrm{E}), 115 \mathrm{~m}(\mathrm{~N}-\mathrm{S})$ & $23 \mathrm{~m}(\mathrm{~W}-\mathrm{E}), 34 \mathrm{~m}(\mathrm{~N}-\mathrm{S})$ & $16.4 \mathrm{~m}$ & 9.8 degrees \\
\hline $1 / 5$ & -41.24632 & 174.88782 & $126 \mathrm{~m}(\mathrm{~W}-\mathrm{E}), 94 \mathrm{~m}(\mathrm{~N}-\mathrm{S})$ & $30 \mathrm{~m}$ (circular) & $16.5 \mathrm{~m}$ & 9.6 degrees \\
\hline $1 / 6$ & -41.24784 & 174.88774 & $78 \mathrm{~m}(\mathrm{~W}-\mathrm{E}), 98 \mathrm{~m}(\mathrm{~N}-\mathrm{S})$ & $16 \mathrm{~m}(\mathrm{~W}-\mathrm{E}) .24 \mathrm{~m}(\mathrm{~N}-\mathrm{S})$ & $19.4 \mathrm{~m}$ & 17.3 degrees \\
\hline 2 & -41.26709 & 174.86477 & $154 \mathrm{~m}(\mathrm{~W}-\mathrm{E}), 129 \mathrm{~m}(\mathrm{~N}-\mathrm{S})$ & $21 \mathrm{~m}(\mathrm{~W}-\mathrm{E}), 48 \mathrm{~m}(\mathrm{~N}-\mathrm{S})$ & $31.3 \mathrm{~m}$ & 14 degrees \\
\hline 3 & -41.26533 & 174.85700 & $314(\mathrm{~W}-\mathrm{E}), 369 \mathrm{~m}(\mathrm{~N}-\mathrm{S})$ & $69 \mathrm{~m}(\mathrm{~W}-\mathrm{E}), 46 \mathrm{~m}(\mathrm{~N}-\mathrm{S})$ & $31.0 \mathrm{~m}$ & 3 degrees \\
\hline 4 & -41.25883 & 174.89433 & $92 \mathrm{~m}(\mathrm{~W}-\mathrm{E}), 172 \mathrm{~m}(\mathrm{~N}-\mathrm{S})$ & $12 \mathrm{~m}(\mathrm{~W}-\mathrm{E}), 10 \mathrm{~m}(\mathrm{~N}-\mathrm{S})$ & $20.1 \mathrm{~m}$ & 12 degrees \\
\hline 5 & -41.24817 & 174.86733 & $60 \mathrm{~m}(\mathrm{~W}-\mathrm{E}), 130 \mathrm{~m}(\mathrm{~N}-\mathrm{S})$ & $14 \mathrm{~m}$ (circular) & $25.4 \mathrm{~m}$ & 7.5 degrees \\
\hline 6 & -41.28517 & 174.80338 & $210 \mathrm{~m}(\mathrm{~W}-\mathrm{E}), 82 \mathrm{~m}(\mathrm{~N}-\mathrm{S})$ & $160 \mathrm{~m}(\mathrm{~W}-\mathrm{E}), 40 \mathrm{~m}(\mathrm{~N}-\mathrm{S})$ & $24.9 \mathrm{~m}$ & 8.5 degrees \\
\hline
\end{tabular}

Table 9.4.1.1 Dimensions, and locations of depressions exhibiting artesian leakage. As indicated, six depressions within Zone 1 were investigated.

Each zone detailed in Table 9.4.1.1 is described fully in the following chapter. However, a number of general comments can be made about the submarine spring sites as a whole.

\section{Character of Leakage}

All of the sites exhibiting present day artesian leakage display the same characteristics. All depressions, while varied in their geomorphology, are conical features with sloping sides that extend from the relatively flat harbour floor down to a flat base. Three of the 


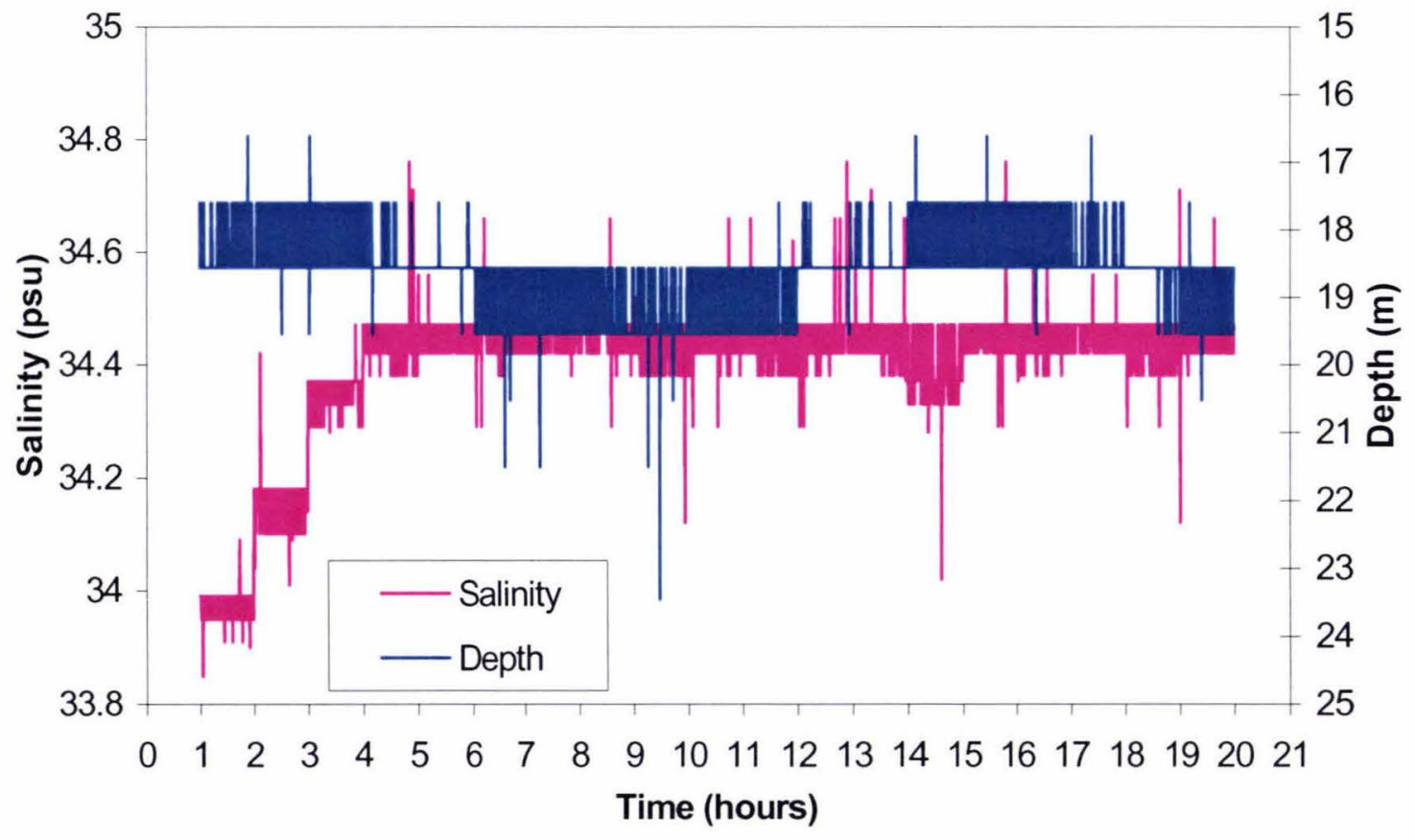

Figure 9.4.1.2 Observed increase in salinity on depression floor (not over spring vent). The slow but steady increase in salinity over time shows that while known leakage from a spring vent is occurring within this depression (demonstrated by the lower salinity water upon deployment), the area of the depression floor where the S4 was placed does not show any signs or artesian leakage. Thus the increase in salinity over time is caused by the slow mixing of the water within the S4 housing unit with 'normal' sea water from above. The spikes in the salinity record show evidence of some minor leakage, but overall the trend is that this particular area of the harbour floor is absent of significant leakage. The spikes in the depth record are likely to be caused by passing waves or boat wake. 
individual depressions in Zone 1 were found, upon diving, to contain submarine spring vents. These are depressions 1, 4 and 6 in Zone 1 (see Figure 9.4.2.1). Exactly how many vents occur in any one depression is unknown because of the difficulty in locating them. It is likely that other depressions within Zone 1 also contain similar spring vents, but with the visibility being so poor in these depressions, finding them is effectively by chance.

The vents themselves are usually one to two metres in diameter and form mini depressions within the base of the main depression. They are extremely soft in nature, and as described previously, offer little resistance to objects pushed into them. Whether these vents extend all the way to the aquifer is unknown, but it is envisaged that they certainly provide an easy pathway for water to migrate from the aquifer to the harbour.

The discharge from the vents almost certainly depends on the hydrological conditions that exist within the aquifer. As the hydrological conditions of the aquifer changes constantly as a result of the variable piezometric head (dependent primarily on the amount of recharge, abstraction rate on land, and changing load (tidal fluctuations)), the discharge from the vents also varies.

It is reasonable to assume that during high piezometric head, the aquifer beneath the harbour will have a steepened hydraulic gradient and thus the areas close to the Petone Foreshore will have higher piezometric pressures than areas further away from the recharge zone. During these conditions, spring sites close to Petone Foreshore should have greater discharge than those further from Petone Foreshore.

However, during a drought or extended periods of high abstraction, this trend may reverse and the submarine spring discharges closest to the Petone Foreshore will be affected to a greater extent than those areas further away. In extreme drought conditions, the hydraulic gradient may reverse and piezometric pressures may fall to a low enough level that the submarine springs closest to the Petone Foreshore may reverse and become sites of saltwater intrusion. This will be elaborated on in Chapter Ten.

In the past, it was believed that artesian leakage occurred as a widespread leakage across the entire harbour floor. Data obtained during this research indicates that this is not very likely, or at least isn't the case where submarine spring discharges are nearby. This was discovered within the Petone Foreshore depression cluster when the S4 current meter was set-up on a depression floor (Depression 5, Zone 1), but not over a spring vent, to see if there was any widespread seepage of fresh water through the depression floor. Figure 9.4.1.2 shows the recorded salinity of the water as it changes over time. As can be seen, the salinity was around 33.95 psu (slightly lower than normal sea water) at the time the S4 set-up was placed on the harbour floor. 
The S4 (inside its 44 gallon drum housing unit - see Chapter Six) was set to record for two minutes every hour between $1.20 \mathrm{pm}$ on the $29^{\text {th }}$ May 1997 to 11.20 am the following day upon which time the set-up was retrieved, hence the 'steps' in the record.

The 44 gallon drum housing unit is the perfect means of detecting SGWD from a discrete region of the depression floor as it only allows the S4 to record the salinity, temperature and current speed of water in the vertical plane. Thus, the results of this experiment could not be affected by the movement of water in the horizontal plane from the surrounding areas of the depression floor. As such, any discharge of artesian water from nearby spring vents would not be detected.

The data shows a constant increase in salinity over time via 'steps' in the chart. The increase in salinity rises in 'steps' because of the sampling interval applied ( 2 minutes every hour). This continues until the salinity of 'normal' sea water for Wellington Harbour is reached (34.5 psu). After this time, the salinity of the water does not vary to any appreciable amount, despite a changing load on the aquifer caused by tidal changes. A few lower salinity 'spikes' are evident in the data, and the salinity of water between hours 14 and 15 indicates that some minor leakage may have occurred during this period. However, these 'spikes' in the data cannot be called significant as the change in salinity recorded by them is very small.

An examination of the rainfall, river flow and aquifer abstraction records showed that no significant change to river or rain recharge, or in the amount abstracted from the aquifer occurred during this period or in the preceding few days which could have had an affect on the sub-harbour discharge regime.

The results indicate that on a 'typical' day, the leakage of artesian water is restricted to the vent sites only and doesn't occur as a widespread leakage through the entire harbour floor depression. This is despite the fact that the aquiclude is very thin beneath this depression floor.

However, it must be remembered that this is just one 'snapshot' in time of the leakage regime in these depressions. It is possible that during periods of high piezometric head (e.g. after floods, or extended periods of low abstraction) a much larger area of the depression floor may exhibit artesian leakage.

The long period sinusoidal pattern evident in the depth data reflects the effect of the tidal changes. The short period, rapidly fluctuating nature of the depth record reflects the slight changes in depth caused by fluctuating sea swell. The more prominent spikes in the depth record are likely to represent passing waves or boat wake. 


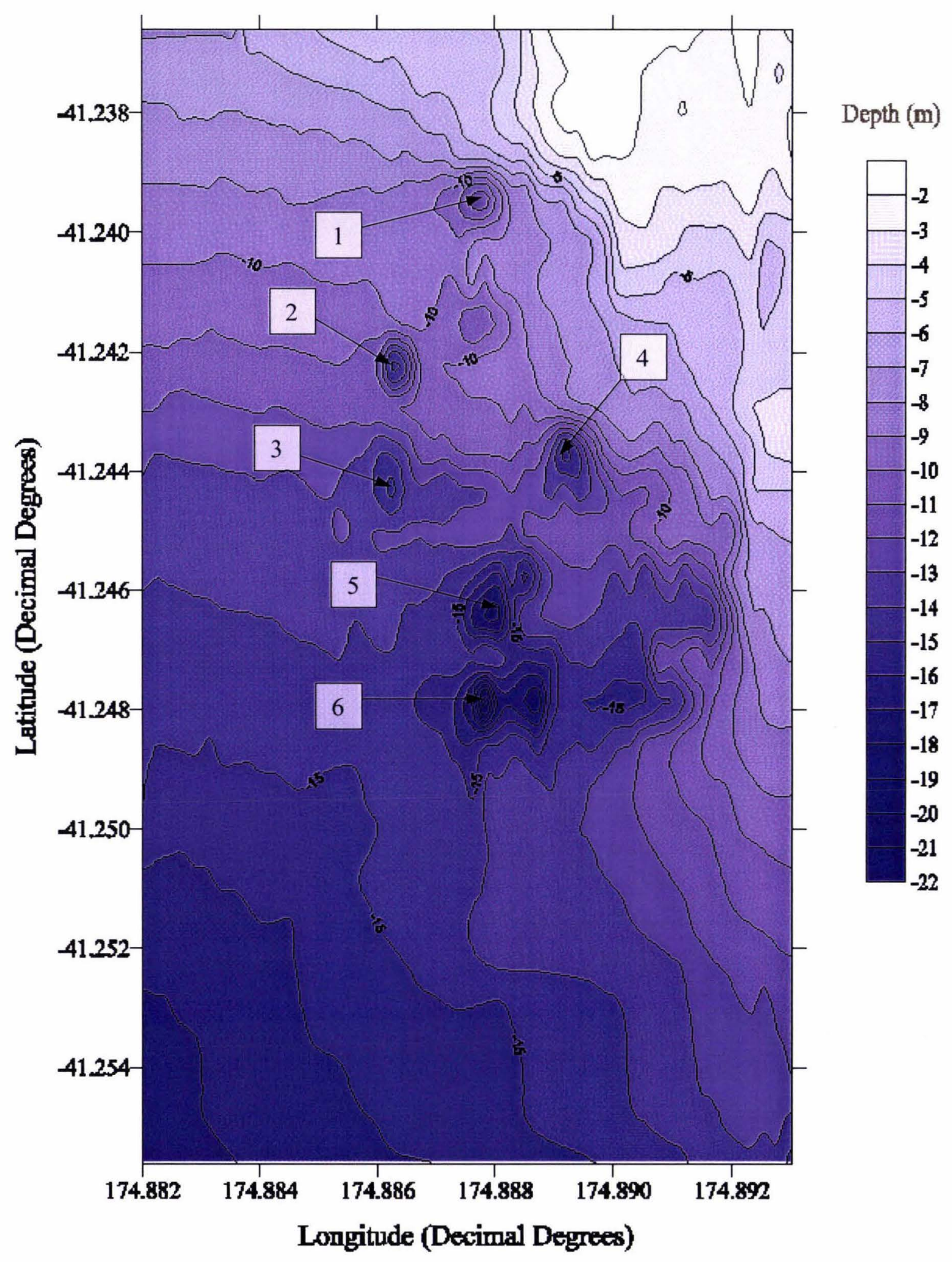

Figure 9.4.2.1 Bathymetry of the Zone 1 sea floor depressions as surveyed in January 1999 using the Kiwitech navigational program Chartplotter. The six depression sites investigated fully are indicated. Contour lines are in one metre increments (annotated at 5,10 and 15 metres depth below sea level).

Note that the co-ordinates have been adjusted to fit with Hydrographic Chart NZ4633. To correlate with GPS positioning, latitude values must be moved 0.10 minutes North. 


\subsubsection{Zone 1 (Petone Foreshore/Hutt River mouth springs)}

\section{Description}

- An area approximately $1 \mathrm{~km}^{2}$ in size containing a cluster of at least 10 individual sea floor depressions.

- Six of the ten depressions within this cluster were investigated fully, by diving and through taking salinity measurements. These are noted on Figure 9.4.2.1.

- The closest depression is roughly 550 metres from Petone Foreshore (Depression 1, Figure 9.4.2.1).

- Spring vents were observed in three of the depressions (1, 4, and 6)

The contoured bathymetry of Zone 1, as shown in Figure 9.4.2.1, was generated from data collected in January 1999 during a bathymetric survey of this area. The survey was performed with the Chartplotter software package and provides an accurate map of the sea floor bathymetry in this region. The exact locations of the recorded depths of this survey (from which the bathymetric contours were generated) are shown in Appendix Five.

This zone was surveyed via a series of north-south survey lines using a one second sampling rate, travelling at 3 Knots (i.e. ground speed of 1.5 metres per second). Survey lines were run every hundredth of a nautical mile (i.e. 18.5 metre spacing in the east - west orientation). Thus the data resolution is 1.5 metres in the longitude, and 18.5 metres in the latitude. However, a number of east-west orientated lines were also surveyed to tie the north-south lines together. Harbour floor depressions were targeted during these cross lines and thus the depressions form and dimensions can be considered particularly accurate.

As can be seen in Figure 9.4.2.1 and in Table 9.4.2.1, the depressions range in both size and depth, with the most prominent depression being Depression 6 and the closest to the zone of abstraction being Depression 1 .

\section{Salinity values}

\begin{tabular}{|c|c|c|}
\hline & \multicolumn{2}{|c|}{ Average Salinity Values } \\
\hline Depression Site & High Tide & Low Tide \\
\hline 1 & 30.70 & 31.65 \\
\hline 2 & 31.35 & 31.80 \\
\hline 3 & 32.60 & 33.30 \\
\hline 4 & 31.40 & 32.80 \\
\hline 5 & 31.15 & 31.60 \\
\hline 6 & 30.28 & 30.78 \\
\hline
\end{tabular}

Table 9.4.2.1 Average salinity values for the sites in the Petone Foreshore cluster (Zone 1). See Appendix Two for full list of values 
All of the six depressions investigated in this region exhibited some form of artesian leakage. It is thus reasonable to assume that the other depressions within this cluster that were not investigated also discharge artesian water. A trend is observed within these data, with high tide values being slightly less saline overall than the values recorded at low tide. This trend demonstrates an apparent increase in leakage with an increase in tidal load.

\section{Formation Mechanism}

The formation mechanism for this cluster of depressions is the hardest to determine for all the depressions in Wellington Harbour. Due to their lineation (see Figure 9.4.2.1), the immediate theory would be one of weakening of the aquiclude via fault movements with the consequent migration of water from the aquifer through the aquiclude to the sea. However, interpretation of seismic lines in this area indicates that there are neither active nor inactive faults in this region. As such, there is not the option of fault rupture of the confining aquiclude beds. The basement greywacke is also very deep (about $400 \mathrm{~m}$ ) and as such the theory of different seismic shaking velocities causing a breaking apart at a bedrock/sediment interface cannot be applied.

Given the proximity to Petone Foreshore and the previous historical evidence of piezometric pressure drops coinciding with periods of dredging in the foreshore area (Stevens, 1955; see also Historic Notes, Appendix One), we must consider the option of these depressions being caused by dredging activity.

\section{Dredging}

Large amounts of material was dredged offshore from the Petone Foreshore area during the late 1920's and early 30's to be used as fill for the construction of the Thorndon Container Terminal as detailed in the Wellington Harbour Board Annual Reports, 1925 - 1933. Unfortunately, the exact locations of where the dredging took place is not referred to, although it is stated in the 1927 report that much of the dredging was concentrated "at the mouth of the Hutt River" (WHB, 1927). Exactly how far from the Hutt River mouth this dredging occurred is not clear, but some of the depressions in Zone 1 are reasonably close to the mouth of the Hutt River.

Whether the dredges 'Kaione' or the larger 'Whakarire' that were operating at the time could cut to the depths of the depressions in this region is quite possible, at least for the shallowest depression. Indeed, in a letter from the Napier Harbour board (from whom the 'Whakarire' was loaned) in March 1971, it is stated that the Whakarire dredge could cut to a maximum depth of 45 feet (13.8metres) below water level (see Historic Notes, Appendix One). The northernmost and shallowest depression within this cluster is presently just over $13 \mathrm{~m}$ deep. 


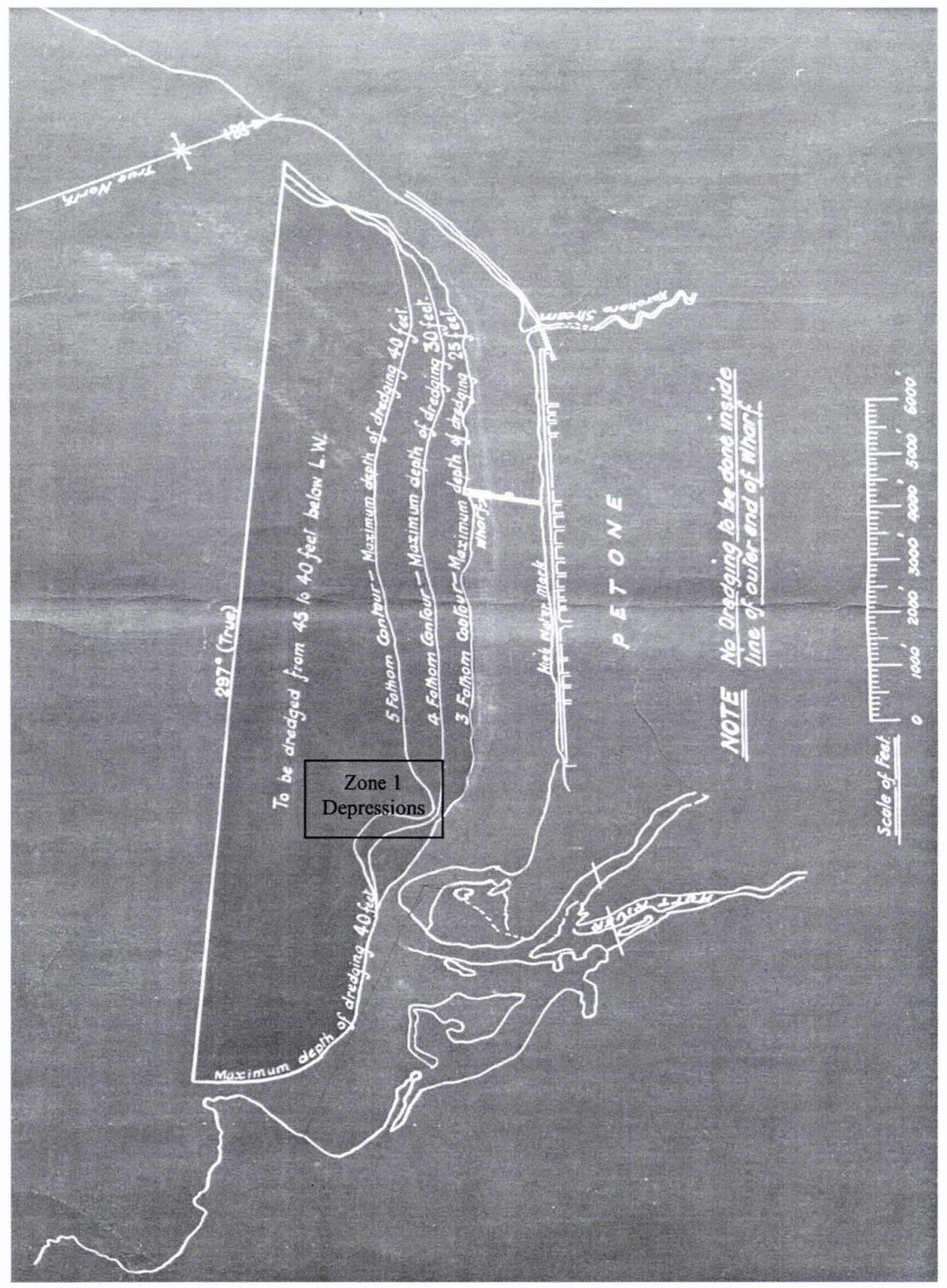

Figure 9.4.2.2 Dredging plan for the dredging carried out in the late 1920's and early 1930's off Petone Foreshore. The material dredged was used as fill for the Thorndon Container Terminal reclamation. The region of the depression cluster in Zone 1 is shown. 
Figure 9.4.2.2 shows the original plan for allowed dredging depths off the Petone Foreshore. As can be seen, the region of Zone 1 depressions lies within the area that was permitted for dredging. The northernmost and shallowest depression (Depression 1) lies just within the area that could be dredged to the maximum of $45 \mathrm{ft}(13.8 \mathrm{~m})$, slightly deeper than the present depression depth of 13.3 metres.

Whether or not this depression, or others in Zone 1 could have been caused by dredging remains a mystery, especially as there are no precise records concerning the exact locations of dredging. However, even earlier records suggest that at least a couple of the Zone 1 depressions were present before dredging of this region began.

Figure 9.4.2.3 shows a very early bathymetric survey of the northeastern quadrant of the harbour as surveyed in 1849 (prior to the 1855 Wellington earthquake) and 1904. Two areas have been circled - these representing depressions 1 and 4 in the Petone Foreshore submarine springs cluster, Zone 1. A depth of 10 fathoms (18.3 metres) is evident in the vicinity of depression 1 . This is the pre 1855 earthquake depth and thus can be translated to a current depth of $\sim 16.5$ metres. Although depression 1 is only about $13 \mathrm{~m}$ in depth at present, subsequent deposition of sediment here may have reduced this depression to this depth. Regardless, it is clear that a depression of significant size was present in this spot prior to dredging operations in this vicinity.

Depression 4 also shows up in these early bathymetric records. The reported depth here was 10 fathoms in 1904 (i.e. 18.3 metres). Once again, Depression 4 is currently not as deep as this $(16 \mathrm{~m})$, but sedimentation since this time may have reduced the depth of this depression.

This evidence suggests that dredging during the 1920's and 30's were not responsible for the formation of these depressions within Zone 1. Following from this, it is unlikely that the other depressions within Zone 1 were formed as a result of dredging, especially considering that all are deeper that the maximum allowed dredging depth. The bathymetric evidence also suggests that depressions 1 and 4 were once deeper than at present and thus it is likely that their leakage regime is not great enough at present to prevent sedimentation occurring. This may be a fairly recent factor - due to a reduction in the amount of water that flows in the aquifer under the harbour as a result of abstraction of water on land during the last century.

In view of the aforementioned evidence, the preferred reasoning for the formation of these depressions with associated submarine spring development is the result of an aquifer blowout associated with the liquefaction of the aquiclude above during an earthquake. 


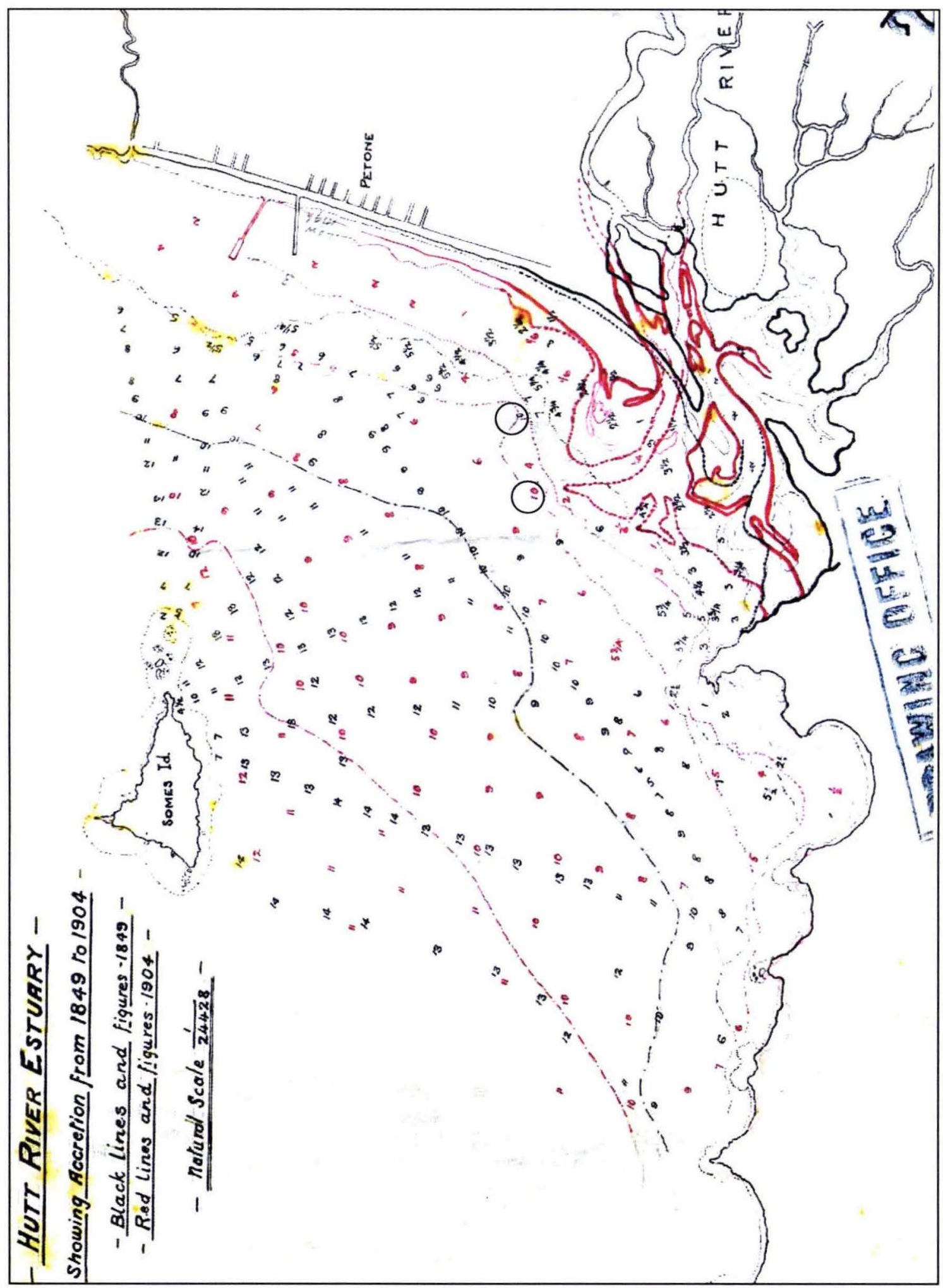

Figure 9.4.2.3 Bathymetry of the northeastern quadrant of the harbour as surveyed in 1849 (black values), and 1904 (red values). Hence this map shows the bathymetry pre and post the 1855 Wellington Earthquake uplift event. Two of the present day submarine spring sites in Zone 1 are shown (black circles). Depths are in fathoms below sea level $(1 \mathrm{fathom}=6 \mathrm{ft}$ or $1.83 \mathrm{~m})$. 


\section{Liquefaction/Aquifer Blowout}

As described previously, an aquifer blowout could occur as the result of the raising of piezometric pressures within the aquifer and the reduction in cohesiveness strength of the aquiclude via liquefaction during a large earthquake.

The aquiclude has already been noted for being very thin in the northeastern quadrant of the harbour (Chapter Eight), with liquefaction of this region being responsible for the absence of the shallow energy-absorbing layer that causes interference to seismic energy penetration in the remainder of the harbour. Furthermore, a large relic river channel (paleochannel) has been identified in the upper layers of the Waiwhetu Artesian Aquifer beneath this cluster of depressions (Chapter Eight). The combination of an area of aquiclude having high transmissivities beneath an area of thin aquiclude certainly gives weight to the aquifer blowout hypothesis.

A gas blowout may also be a possibility in this region of the harbour. The upper units within the Lower Hutt Groundwater Zone all dip to the west due to the tilting caused by tectonic movements on the Wairarapa Fault. As such, gas, generated by the biogenic decomposition of organic matter within the aquiclude, may make its way up-dip to accumulate in this region of the harbour. A gas blowout would occur when the pressure of the buoyancy of the gas within the aquiclude becomes too great for the already thin aquiclude to withstand.

However, due to the nature of such an event, it is envisaged that if gas blowout did occur, it would create one large depression and not a cluster of small independent ones. As such, the preferred mechanism of depression/spring formation in this Petone Foreshore cluster is from aquifer blowout during liquefaction of the aquiclude. 


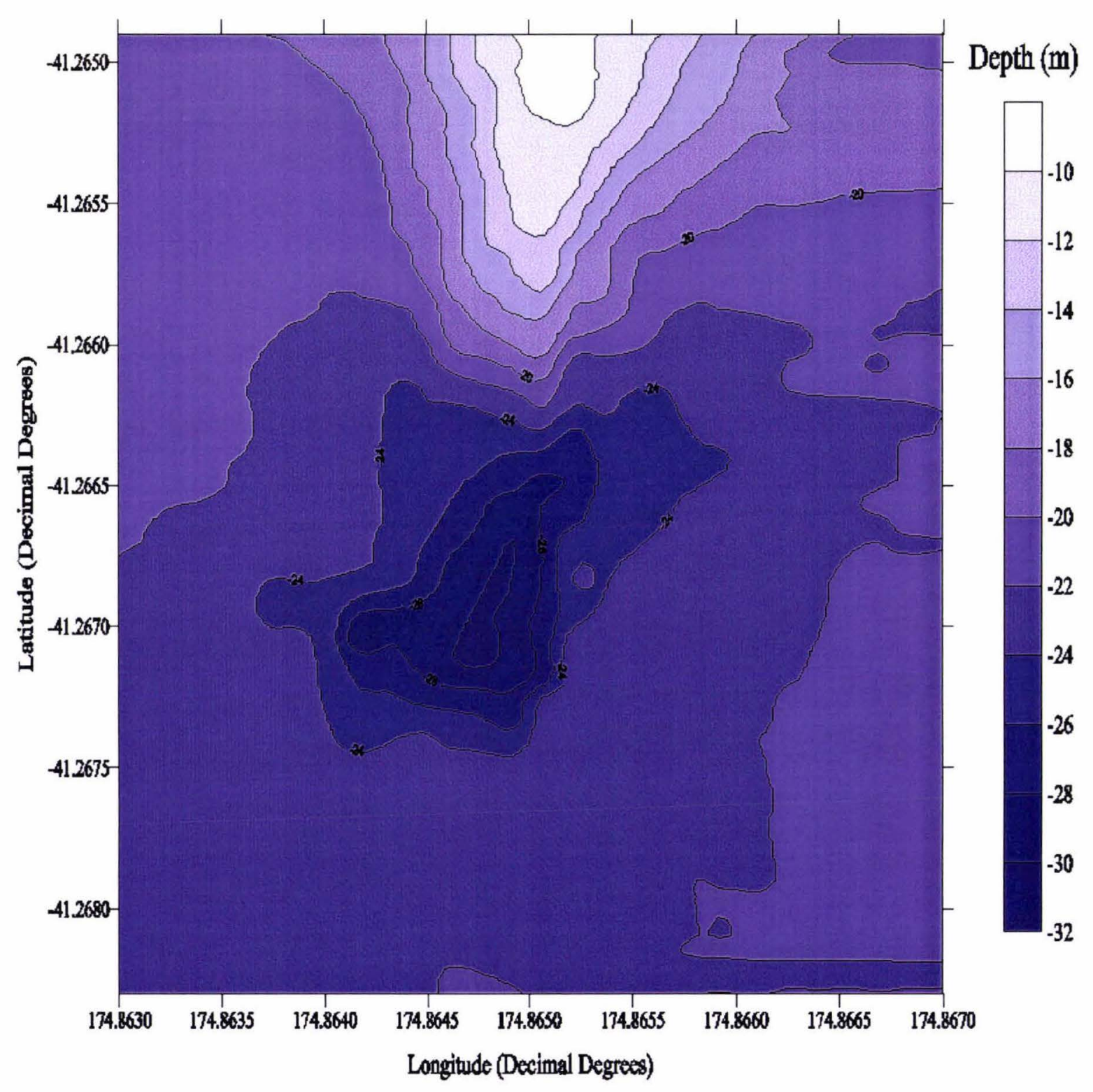

Figure 9.4.3.1 Bathymetry of the Zone 2 sea floor depression as surveyed in January 1999 using the Kiwitech navigational program Chartplotter. This site is just to the south of Somes Island, and contains the deepest depth found in Wellington Harbour (31.3 metres below sea level). Contour lines are in two metre increments (annotated at 20, 24 and 28 metres depth).

Note that the co-ordinates have been adjusted to fit with Hydrographic Chart NZ4633. To correlate with GPS positioning, latitude values must be moved 0.10 minutes North. 


\subsubsection{Zone 2 (South of Somes Island)}

\section{Description}

- A small steep sided depression just to the south of Somes Island (see Figure 9.4.3.1).

- This depression contains the deepest point in the harbour floor at approximately $32 \mathrm{~m}$ below sea level.

- Very little leakage was detected from this site during the course of the fieldwork (see Appendix Two).

- No spring vents were found upon diving.

The area surveyed in Figure 9.4.3.1 followed the same methodology as described for the Zone 1 depressions. Thus, in general, the data resolution is 1.5 metres in the latitude, and 18.5 metres in the longitude. The exact locations of the recorded depths of this survey (from which the bathymetric contours were generated) are shown in Appendix Five.

\section{Salinity values}

\begin{tabular}{|c|c|c|}
\hline & \multicolumn{2}{|c|}{ Average Salinity Values } \\
\hline Depression Site & High Tide & Low Tide \\
\hline Zone 2 & 34.10 & 33.65 \\
\hline
\end{tabular}

Table 9.4.3.1 Average salinity values for the Somes Island site (Zone 2). See Appendix Two for full list of values

\section{Formation Mechanism}

The formation of this depression is almost certainly due to a shaking apart of the aquifer from the bedrock on which it rests during a tectonic event, thus allowing large quantities of water to escape thereby eroding the aquiclude material in the process. This scenario, initially proposed by Reyners and Christoffel (1973) is based on the understanding that different rock types have different seismic shaking velocities. Where bedrock and unconsolidated sediments meet, the effect of a large earthquake is to make them move at different frequencies and thus rupture apart. This allows water to escape, and if prolific enough, can erode enough of the aquiclude to ensure that artesian leakage will continue in the future.

This is likely to have been the case initially, but the reduction in water flowing under the harbour as a result of abstractions from the aquifer has led to the demise of this spring discharge. There was certainly little evidence of leakage when the salinity measurements were taken. It is possible that this site may exhibit artesian leakage during times of high piezometric head (e.g. after a flood event), but this cannot be proven without the collection of much more data, particularly during conditions of high piezometric head. 


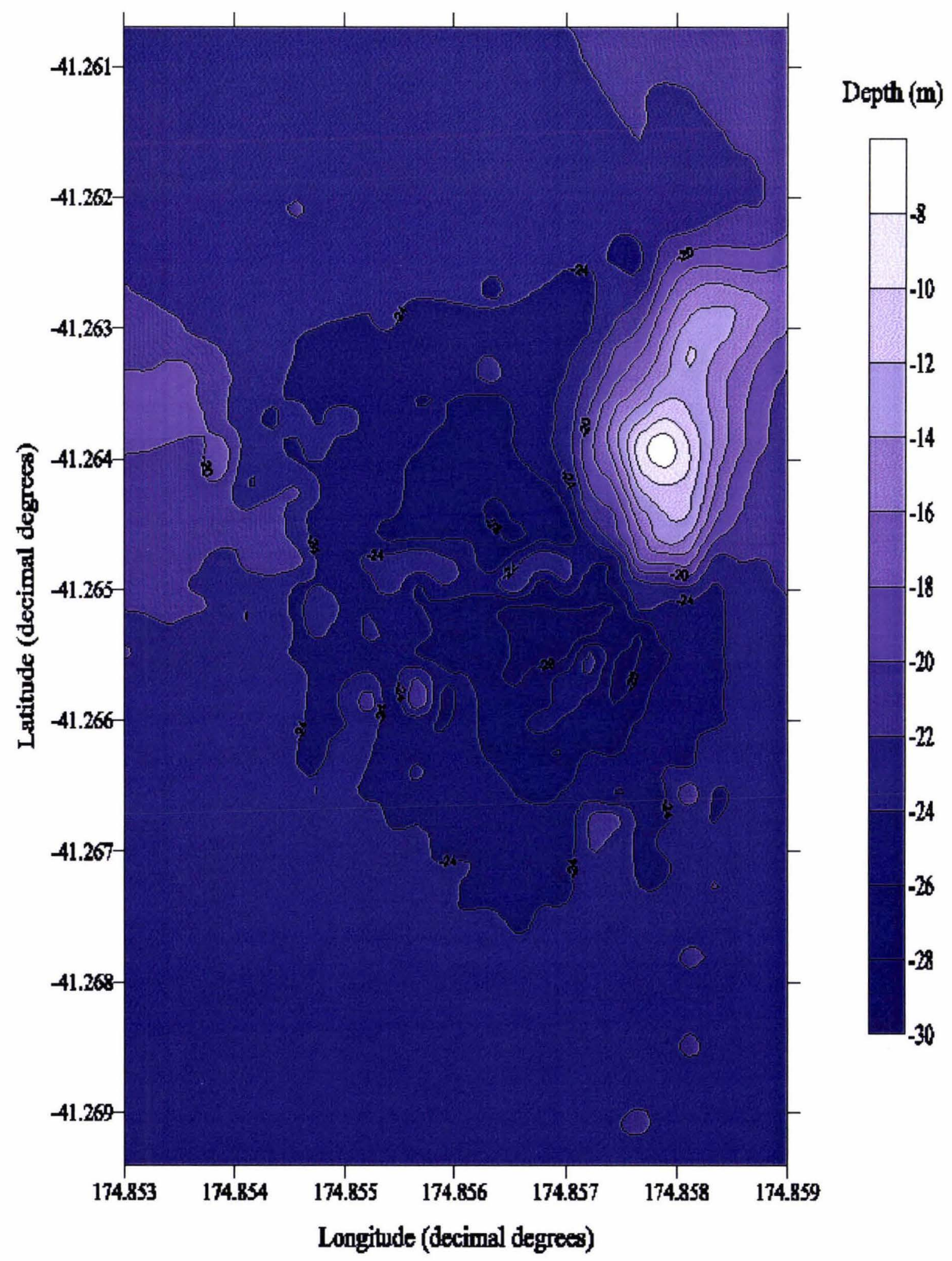

Figure 9.4.4.1 Bathymetry of the Zone 3 sea floor depression as surveyed in January 1999 using the Kiwitech navigational program Chartplotter. Contour lines are in two metre increments (annotated at 20, 24 and 28 metres depth). The submerged rock pinnacle (Somes Rock) can be seen as a white peak in the middle right of the diagram .

Note that the co-ordinates have been adjusted to fit with Hydrographic Chart NZ4633. To correlate with GPS positioning, latitude values must be moved 0.10 minutes North. 


\subsubsection{Zone 3 (Southwest of Somes Island, near Somes Rock))}

\section{Description}

- A large, gently-sloping depression, just to the southwest of Somes Island (see Figure 9.4.4.1).

- Little, if any, evidence of present day artesian leakage.

- No spring vents were found upon diving.

- The 'lumpy' nature of the harbour floor in this depression reflects the various bits of rubbish that have been dumped here. This site was used as a dumping ground for many years (particularly during the 1960's and 70's) to get rid of unwanted items both large and small. The types of things that can be encountered include steel cable, various steel structures (such as old lighthouse fittings), and Police confiscated ammunitions.

This site was considered by Donaldson and Campbell (1977) and Hutton (1965) to be the most likely source of artesian leakage in the harbour and was hypothesised by them to be the most likely source of salt-water intrusion (if conditions permitted).

The area surveyed in Figure 9.4.4.1 followed the same methodology as described for the Zone 1 depressions. Thus, in general, the data resolution is 1.5 metres in the latitude, and 18.5 metres in the longitude. The exact locations of the recorded depths of this survey (from which the bathymetric contours were generated) are shown in Appendix Five.

\section{Salinity values}

\begin{tabular}{|c|c|c|}
\hline & \multicolumn{2}{|c|}{ Average Salinity Values } \\
\hline Depression Site & High Tide & Low Tide \\
\hline Zone 3 & 33.55 & 33.15 \\
\hline
\end{tabular}

Table 9.4.4.1 Average salinity values for the Somes Rock site (Zone 3). See Appendix Two for full list of values

\section{Formation Mechanism}

This is another depression situated close to a basement outcrop (Somes Rock). Thus once again it is likely that this depression was formed as a result of artesian water escaping through the harbour floor sediments during an earthquake, removing the confining aquiclude. However, the large, flat, and gently sloping sides of this depression implies that a more subtle process caused this depression form. It is possible that tidal scour around Somes Island, perhaps in times gone past, when sea level was lower, eroded the harbour floor sediment in this region and formed the depression. Whether any significant leakage used to occur or will occur in the future is not something we can answer right now given the information available. 


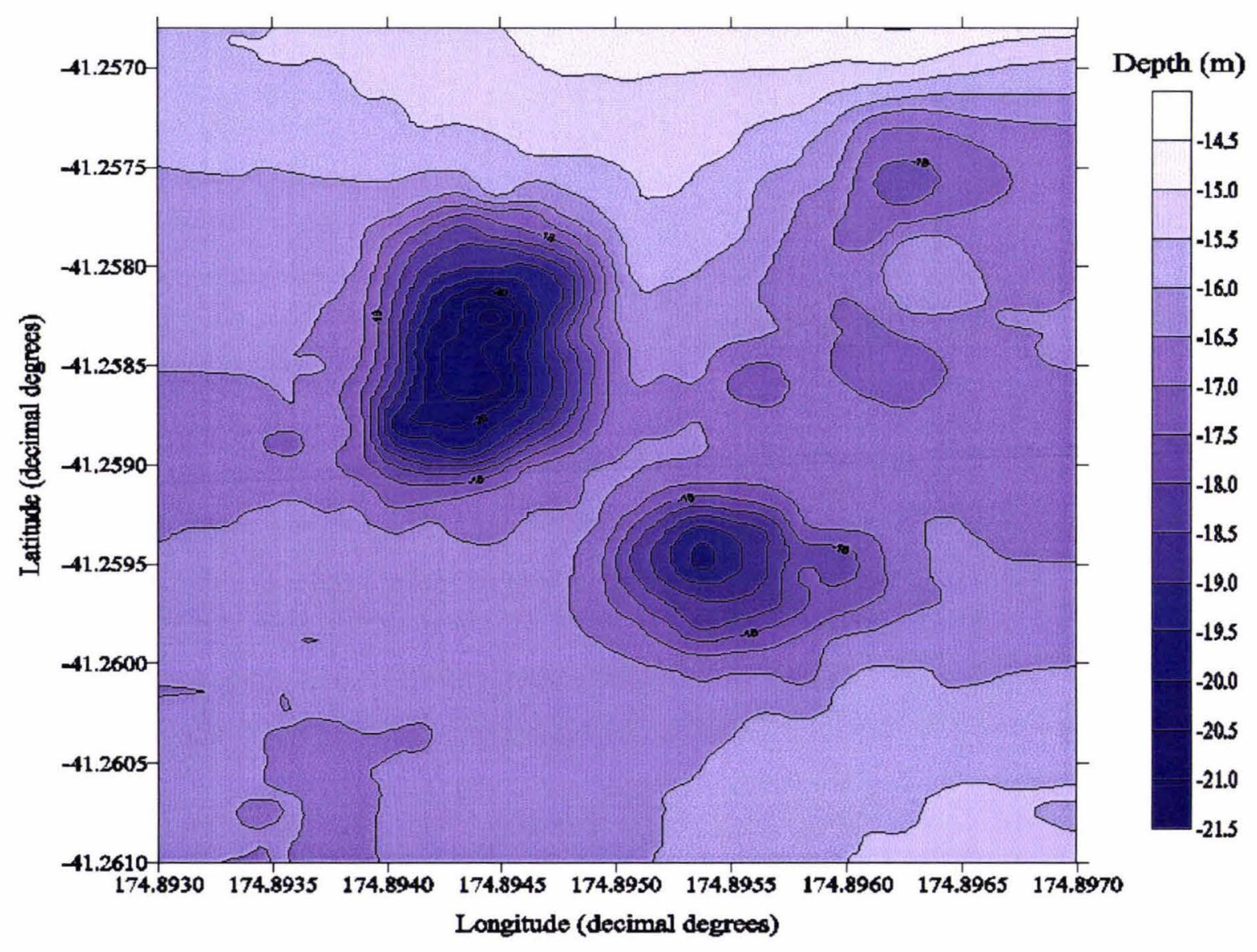

Figure 9.4.5.1 Bathymetry of the Zone 4 sea floor depressions (near Seaview Wharf) as surveyed in March 1999 using the Kiwitech navigational program Chartplotter. Contour lines are in half-metre increments (annotated at 15 and 20 metres depth).

Note that the co-ordinates have been adjusted to fit with Hydrographic Chart NZ4633. To correlate with GPS positioning, latitude values must be moved 0.10 minutes North. 


\subsubsection{Zone 4 (near Seaview Wharf)}

\section{Description}

- One large, and one smaller depression are evident in this zone.

- The larger of the two depressions was investigated, two spring vents found upon diving.

Figure 9.4.5.1 shows the bathymetry of the area containing these depressions. The area surveyed in Figure 9.4.5.1 followed the same methodology as described for the Zone 1 depressions. Thus, in general, the data resolution is 1.5 metres in the latitude, and 18.5 metres in the longitude. Note that the contour interval is 0.5 metres. The exact locations of the recorded depths of this survey (from which the bathymetric contours were generated) are shown in Appendix Five.

\section{Salinity values}

\begin{tabular}{|c|c|c|}
\hline & \multicolumn{2}{|c|}{ Average Salinity Values } \\
\hline Depression Site & High Tide & Low Tide \\
\hline Zone 4 & 31.40 & 32.80 \\
\hline
\end{tabular}

Table 9.4.5.1 Average salinity values for the Seaview Wharf site (Zone 4). See Appendix Two for full list of values

The full range of salinity values (Appendix Two) show one value reaching only 26psu salinity. This is extremely low given that a certain degree of mixing would take place with the sea water before being recorded. The values recorded at the tidal extremes do indicate that leakage here is affected by the load on the aquifer.

\section{Formation Mechanism}

This depression is situated close to a basement outcrop (upon which Seaview Wharf is built out to). Thus once again it is likely that this depression was formed as a result of artesian water escaping through the aquiclude as a result of rupture from basement during a tectonic event. The well-defined conical form of these depressions precludes the notion of a tidally eroded feature, and also implies that the depression is relatively active. The salinity meter measurements certainly support this implication. 


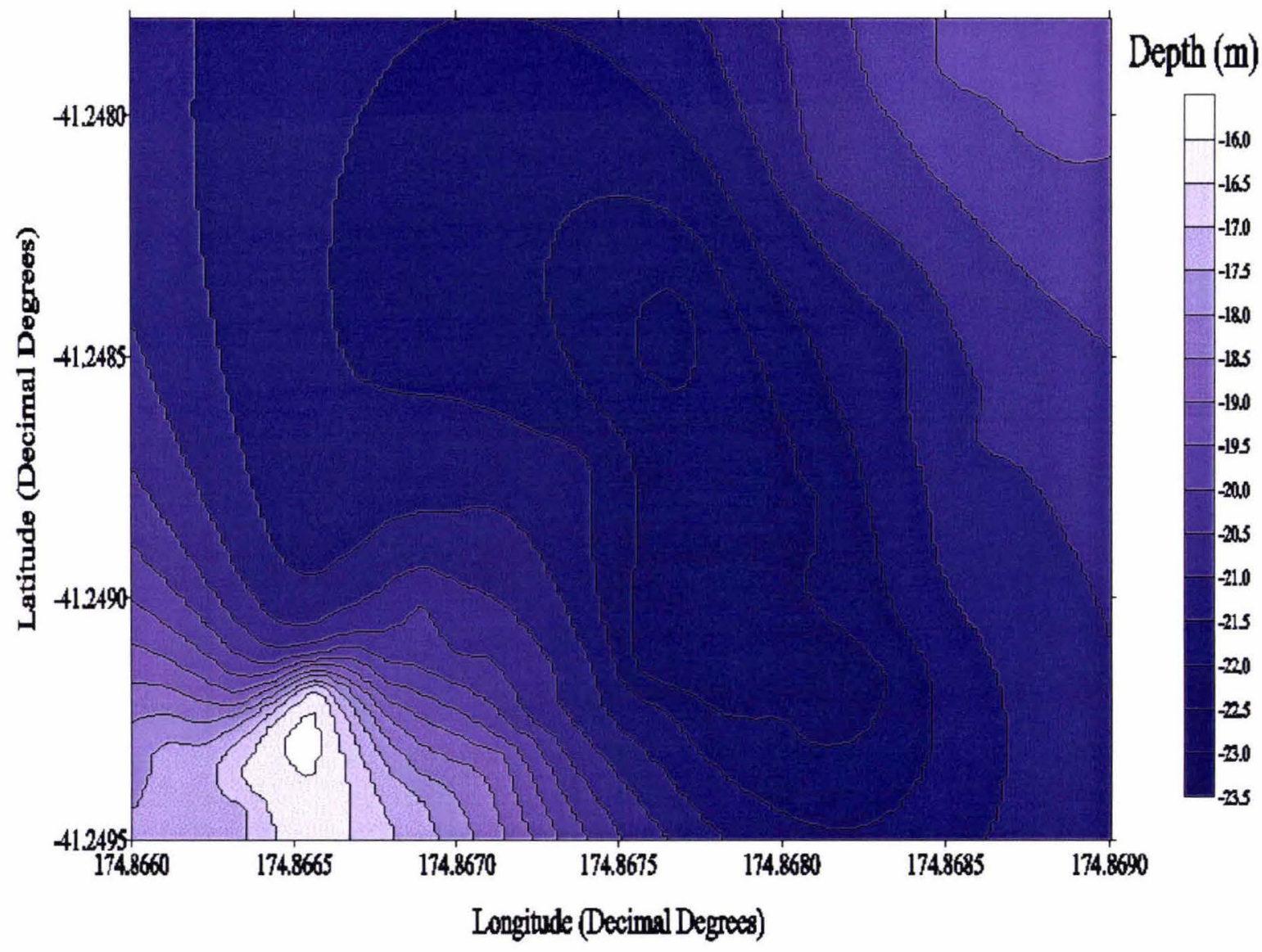

Figure 9.4.6.1 Bathymetry of the Zone 5 sea floor depression as surveyed in January 1999 using the Kiwitech navigational program Chartplotter. This site is just to the northeast of Mokopuna Island, to the north of Somes Island. Contour lines are in halfmetre increments (not annotated).

Note that the co-ordinates have been adjusted to fit with Hydrographic Chart NZ4633. To correlate with GPS positioning, latitude values must be moved 0.10 minutes North. 


\subsubsection{Zone 5 (North of Somes Island)}

\section{Description}

- A small depression just to the northeast of Somes Island (see Figure 9.4.6.1).

- Some present day artesian leakage detected, but no spring vents found upon diving.

The area surveyed in Figure 9.4.6.1 was performed randomly covering the area in a small space of time. No set pattern of surveying was adhered to, and as a result, the bathymetry of the area depicted may not be totally accurate. Mapping this area involved making a number of 'passes' over the deepest part of the depression to determine the maximum depth. The exact locations of the recorded depths of this survey (from which the bathymetric contours were generated) are shown in Appendix Five. The depression is elongated and its sides are of a relatively low gradient.

\section{Salinity values}

\begin{tabular}{|c|c|c|}
\hline & \multicolumn{2}{|c|}{ Average Salinity Values } \\
\hline Depression Site & High Tide & Low Tide \\
\hline Zone 5 & 31.65 & 31.40 \\
\hline
\end{tabular}

Table 9.4.6.1 Average salinity values for the northern Somes Island site (Zone 5). See Appendix Two for full list of values

\section{Formation Mechanism}

This is another depression situated close to a basement outcrop (Mokopuna Island). Thus once again it is likely that this depression was formed as a result of artesian water escaping through the harbour floor sediments during an earthquake. However, two major faults run through this region as identified by Davy and Wood (1993), thus this depression could be associated with leakage up through the fault trace. The other possibility is tidal scour, as the depression is an elongated feature near to a basement rock outcrop. However, it is hard to imagine that the tidal currents were significantly stronger at this location in the past than they are at present. 


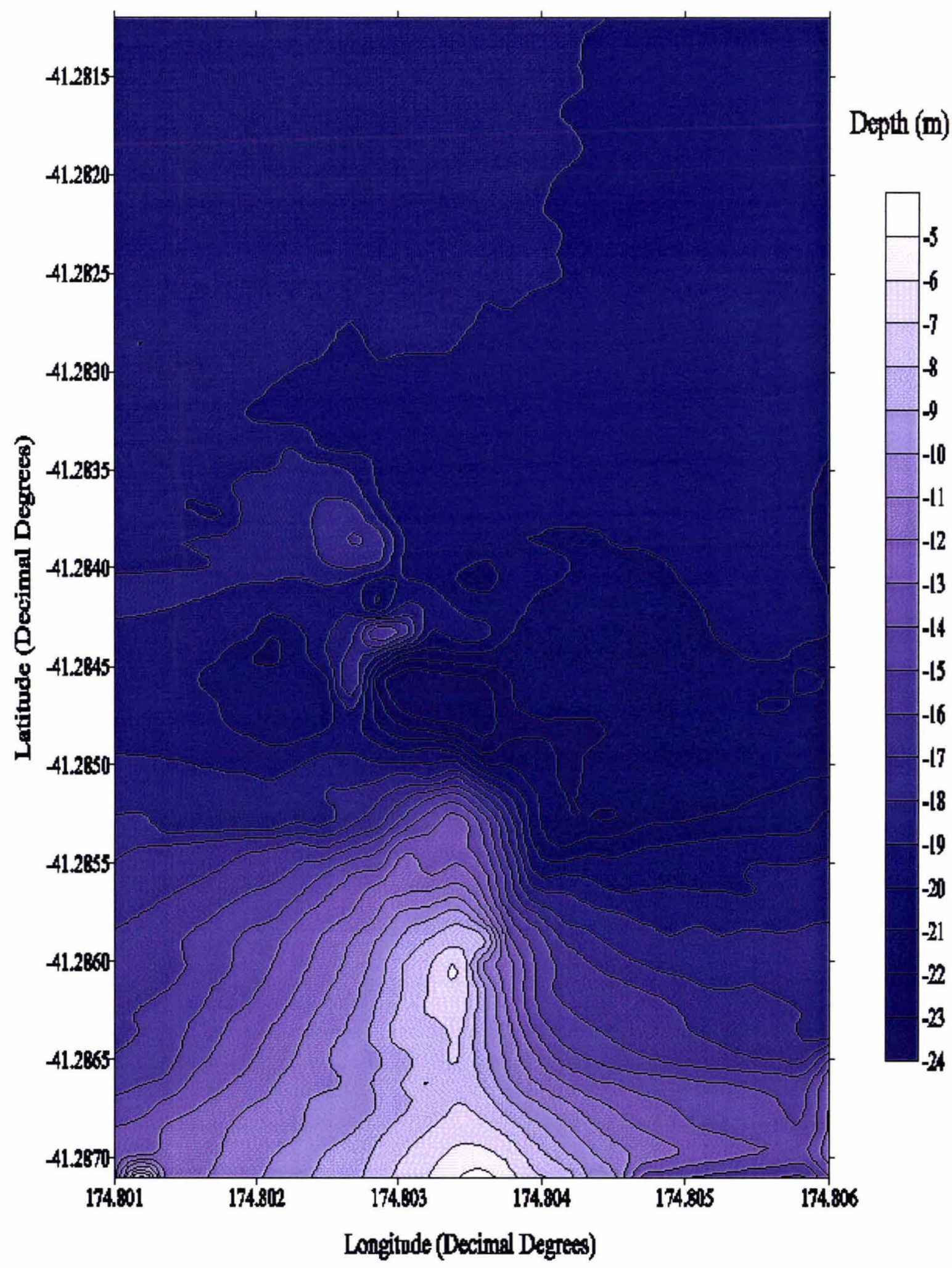

Figure 9.4.7.1 Bathymetry of the Zone 6 sea floor depression as surveyed in January 1999 using the Kiwitech navigational program Chartplotter. This site is just to the north of Point Jerningham at the northern tip of Mt Victoria. Contour lines are in one metre increments (not annotated).

Note that the co-ordinates have been adjusted to fit with Hydrographic Chart NZ4633. To correlate with GPS positioning, latitude values must be moved 0.10 minutes North. 


\subsubsection{Zone 6 (Pt Jerningham)}

\section{Description}

- Another depression associated with a rocky headland.

- A reasonably deep ( $25 \mathrm{~m}$ ) depression, with fairly steep sides and a flat base.

- No significant leakage was detected, but the water did have salinity values lower than normal seawater and prominent sea floor disturbances were observed on the echosounder while mapping this depression.

- No spring vents found upon diving.

The method of surveying the depression in Figure 9.4.7.1 was similar to that employed at Zone 5 - i.e. no navigational pattern was followed. As a result, the bathymetry of the area depicted may not be totally accurate. However, the central depression area should be of reasonable quality and accuracy as many data points were collected here. The exact locations of the recorded depths of this survey (from which the bathymetric contours were generated) are shown in Appendix Five.

\section{Salinity values}

\begin{tabular}{|c|c|}
\hline & Average Salinity Values \\
\hline Depression Site & Mid Tide \\
\hline Zone 6 & 33.00 \\
\hline
\end{tabular}

Table 9.4.7.1 Average salinity values for the Pt Jerningham site (Zone 6). See Appendix Two for full list of values

The salinity values shown in Appendix Two do indicate a certain degree of leakage in places. This site was only surveyed once, (at mid-tide) due to the salinity meter being lost before another survey could be undertaken The site was dived but no visible evidence of leakage was found.

\section{Formation Mechanism}

This is another depression situated close to a basement outcrop (Pt Jerningham). The most likely mechanism for formation of this depression is the escape of water up through the basement/unconsolidated sediment contact during a tectonic event. 


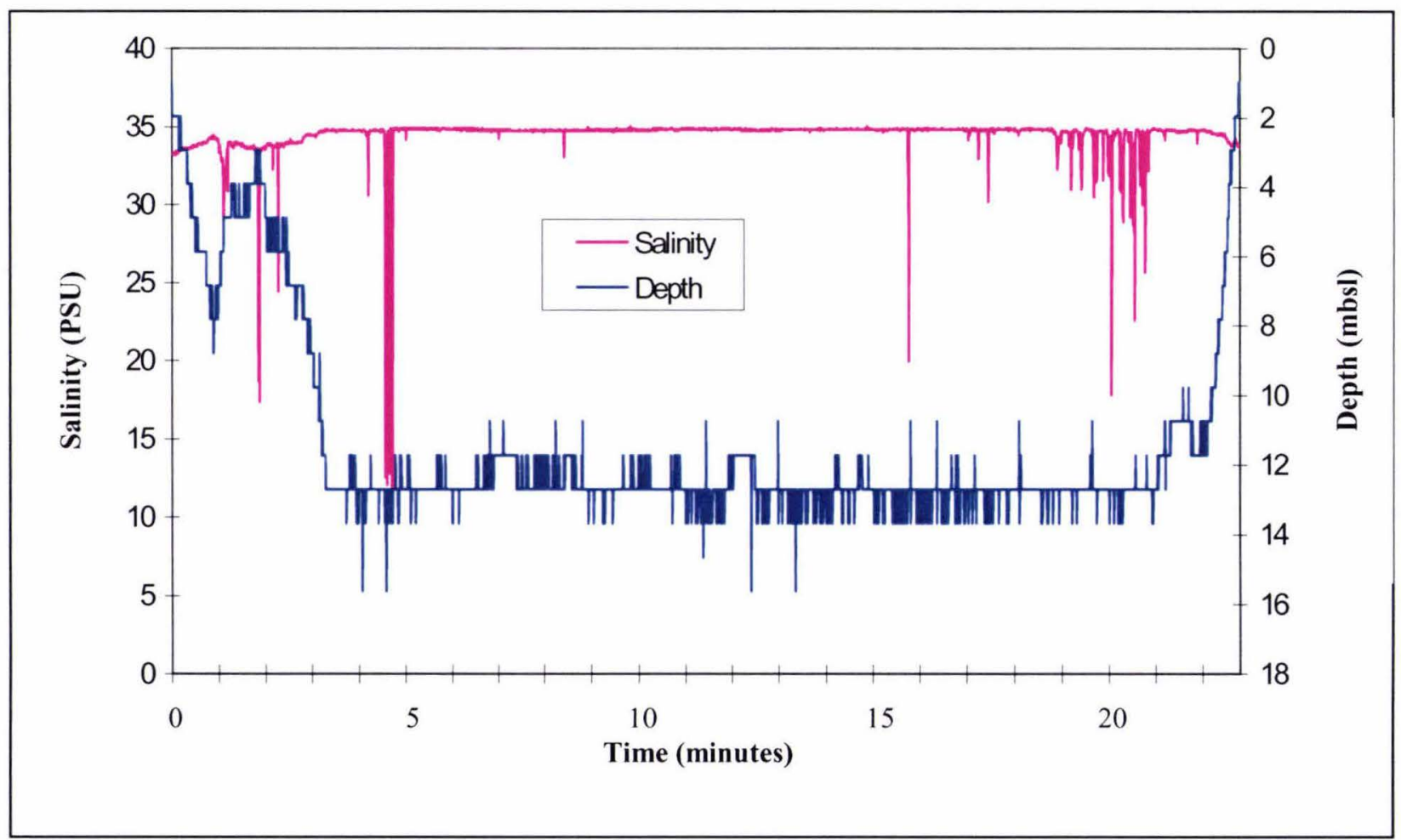

Figure 9.4.8.1 Salinity v Depth in the Falcon Shoals region, as recorded by the S4 Current meter in 1997. No sea floor depressions are present in this vicinity, but evidence of widespread leakage is apparent by the presence of the many 'spikes' in the recorded salinity. 


\subsubsection{Zone 7 (Falcon Shoals) and Zone 8 (Harbour Entrance)}

\section{Description}

Zones 7 and 8 represent a particularly important regions as it is likely that the results from them may help to define the southern extent of the Waiwhetu Artesian aquifer.

- Previous evidence of low salinity water in these regions of the harbour entrance are provided by Brodie (1958) and Stevens (1955).

- These areas are not characterised by any sea floor depressions or any other such geomorphologic feature that could aid the positioning process. These are relatively flat areas of the sea bed that, in the case of the Falcon Shoals, are characterised by low lying mounds and not depressions. These mounds (only about 0.5 metres in height) have been hypothesised in the past as being caused by the pressure of the artesian water in the aquifer pushing up the confining beds where they weaken and thin towards the harbour entrance (Stevens, 1974).

\section{Salinity Values}

\begin{tabular}{|c|c|c|}
\hline & \multicolumn{2}{|c|}{ Average Salinity Values } \\
\hline Site & High Tide & Low Tide \\
\hline Zone 7 & 30.08 & 30.10 \\
\hline Zone 8 & 29.68 & 31.08 \\
\hline
\end{tabular}

Table 9.4.8.1 Average salinity values for Zones 7 and 8. See Appendix Two for full list of values

The exact locations of where the salinity values were recorded was not possible due to the fact that DGPS was not available at this time. However, the salinity values were consistently low at most places where the probe was lowered thus indicating widespread leakage within these zones. Similar low salinity areas were also recorded with the S4 current meter during a dive in September 1997.

Figure 9.4.8.1 depicts some salinity data recorded by the $\mathrm{S} 4$ current meter while diving in the Falcon Shoals region. A wide search of the area was performed with the S4 continuously recording data while the dive was in progress. The area surveyed is essentially flat, and although low salinity water was recorded by the $\mathrm{S4}$, there was no visible evidence of leakage. This is probably attributable to a combination of widespread seepage in this region (as highlighted by the 'spiky' nature of the record).

The substrate in this region is medium sized sand. Whether any aquiclude material underlies this sand is not known, but given the strong tidal flow rates through this area, it is unlikely that any such fine sediment has been deposited in this vicinity while the present tidal regime has existed. 
Zone 8 to the north was also dived, but the $\mathrm{S} 4$ was not taken due to the difficulty in moving around while holding the S4. The substrate in this zone was fine sand, but there was still no evidence of the fine silt that is characteristic of the aquiclude in the inner harbour.

\subsubsection{Other sites}

\section{Zones 9 to 13 (Miramar Peninsular)}

The other sites investigated during this study such as zones $9-13$ can all be classified as relic possibly episodic submarine spring discharge sites. The depressions are all in close proximity to shallow bedrock and thus the formation of them is once again considered to be due to tectonic events rupturing the seal between the unconsolidated sediments and the bedrock resulting in large discharges of artesian water that eroded the aquiclude. Whether these sites then continued to exhibit artesian leakage is unknown, especially given their distance from the recharge zone. However, once again it must be noted that these sites were only visited once and thus may have been sampled on a day when the leakage potential was low.

\section{The Wellington Fault Leakages}

As described previously, artesian leakage along the submarine trace of the Wellington Fault has been identified in the past by various researchers (Lewis, 1989, Truebridge et al, 1974). The reasons for the existence of these springs can be put down to simple breaching of the aquiclude due to fault movement and the subsequent formation of a flow path between aquifer and sea floor. These leakages were not investigated during the course of this study because no significant features mark the spring sites thus making locating the leakages very time-consuming.

\section{Point Dorset}

Carter and Mitchell (1988) performed a side-scan sonar survey of the Wellington Harbour entrance, looking at the sea floor substrate in this region. One of their images showed a sea floor disturbance on the western side of the harbour entrance near Point Dorset (see Figure 9.4.1.1). They attributed this disturbance to be a site of artesian leakage. This site was not investigated during this research so cannot be verified as such.

\section{Barretts Reef}

Divers have noted a 'blurriness' in the water around Barretts Reef (pers comm. J. Goff, 1997; pers comm. R. Williamson, 1997). As described earlier, a 'blurriness' in the water is exhibited at sites of artesian leakage where the mixing of waters of different light refractive 
indices causes such an effect. This site was not investigated as part of this research, but remains a possible source of artesian leakage. However, given the likely petering out of the confining aquiclude through the harbour entrance, if any leakage does occur around Barrett's Reef, it is more likely associated with discharge from the deeper Moera Gravel Aquifer. 


\section{Chapter Ten}

\section{SALT-WATER INTRUSION AT SUBMARINE SPRING SITES}

\subsection{Introduction}

As outlined in Chapter One, the water consents granted in August 1998 allow the WRC to abstract more water from the Waiwhetu Artesian Aquifer than ever before, with extremely high volume abstraction rates allowable during the summer months, December to February. While current scientific knowledge of the aquifer's characteristics were considered in the granting of these new consents, the lack of knowledge of the characteristics of the subharbour portion of the aquifer arises some concerns with regards to the possibility of saltwater intrusion at the submarine spring sites.

\subsection{Piezometric pressures within the sub-harbour Waiwhetu Artesian Aquifer}

Underlying the consents granted, a fail-safe piezometric head value of 1.4 masl at the McEwan Park observation well on the Petone Foreshore is the level below which groundwater abstraction must cease. This level was calculated by Donaldson and Campbell (1977), to be the piezometric head level at the McEwan Park Observation Well below which salt-water incursion would occur at the deep depression near Somes Rock, south of Somes Island. In the absence of any discharge data from the Somes Rock deep depression, the relationship they formulated was based on the relative piezometric head levels at the McEwan Park and Somes Island observation wells (which represented the piezometric conditions in the aquifer beneath the deep depression near Somes Rock).

The method they used was to "plot the 24 hour average head difference between McEwan Park (site 1428009) and Somes Island (site 1428003) against the 24 hour average head at McEwan Park for noon and midnight each day between January 25 and March 6, 1973" (page 35; Donaldson and Campbell, 1977). They used a 24 hour average to "eliminate the tidal effect and the non-uniform withdrawal characteristics that could obscure the true picture" (Donaldson and Campbell, 1977). The chosen time period (January - March, 1973 ) is noted for being an extended drought period, and thus a period when the aquifer was under great stress. The straight-line relationship they applied to this data was extrapolated to give a zero head difference (between McEwan Park and Somes Island) corresponding to a piezometric head of 1.4masl at the McEwan Park bore. 


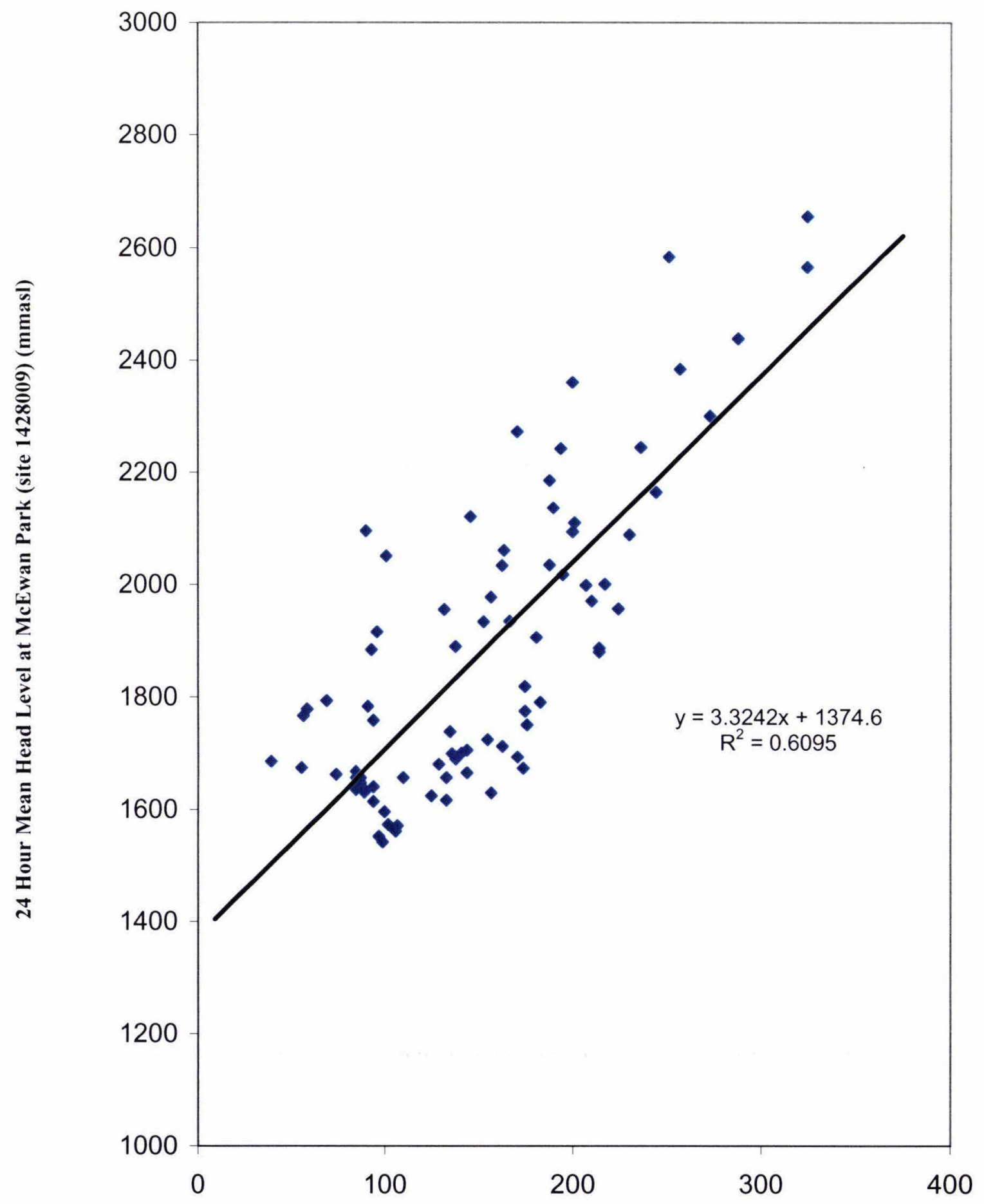

24 Hour Mean Head Difference; McEwan Park - Somes Island (mm)

Figure 10.2.1 Plot showing the relationship between the 24 hour mean difference in piezometric head levels between McEwan Park and Somes Island observation wells, and the 24 hour mean groundwater level at McEwan Park for the period of data January $25^{\text {th }}$ and March $6^{\text {th }}, 1973$ (after Donaldson and Campbell, 1977). 
The correlation coefficient they obtained for this relationship is stated as being 0.9 . Figure 10.2.1 shows a recreation of the plot shown in Donaldson and Campbell (1977). It uses the same data and is identical in appearance to that shown in their report (page 35). However, the correlation coefficient obtained from this recreation is 0.61 , and not 0.9 as stated in Donaldson and Campbell (1977). Regardless of this discrepancy, the trend of the data does indicate (based on this data), that the zero head difference between McEwan Park and Somes Island corresponds to a piezometric head of 1.4masl at McEwan Park.

In 1993, the Somes Island monitoring bore (site 1428003) was found to be leaking at the harbour floor (WRC, 1995). It was not clear how long this bore had been leaking, but given that the fail-safe minimum Petone Foreshore piezometric head level as determined by Donaldson and Campbell (1977) uses data from this bore, the WRC decided it was imperative to review this relationship. As such, WRC followed the same procedure outlined by Donaldson and Campbell (1977) on data collected between May 1993 and June 1994, after the Somes Island bore had been repaired. The relationship based on this data gave a zero head difference of 2.8 metres above sea level (page 159; WRC, 1995).

This higher Petone Foreshore fail-safe limit would restrict the amount of water that the WRC could abstract from the Waiwhetu Artesian Aquifer. A probability distribution of the post 1981 data, after the abstraction focus was shifted $3 \mathrm{~km}$ inland to the Waterloo Well Field, shows that the piezometric head level is below $2.8 \mathrm{masl}$ for $3.5 \%$ of the time (Appendix Seven).

The difference in values calculated by Donaldson and Campbell (1977) and WRC (1995) was reasoned by WRC (1995) to be the result of the leaking Somes Island bore over the period of data that Donaldson and Campbell (1977) used in their calculation (i.e. during the summer of 1972/73). However, a leaking bore would record lower piezometric head values than the true pressure, and thus differences between McEwan Park and Somes Island piezometric pressures would be erroneously high. Thus if the Somes Island bore had been leaking over the period when Donaldson and Campbell (1977) derived their minimum foreshore value (i.e. between January to March 1973) the value they obtained (1.4masl) would have also been erroneously high. As such, although the Somes Island bore was found to be leaking in 1993, it can be concluded that it was not leaking between January to March 1973. Thus, a leaking bore can not be the reason why the value obtained by Donaldson and Campbell (1977) is lower than that calculated by WRC (1995).

It is therefore proposed that the discrepancy between the foreshore fail-safe minimum water level values obtained between these reports is due to the change in abstraction focus that occurred in 1980. This can be shown to have affected the sub-harbour and foreshore piezometric levels. 


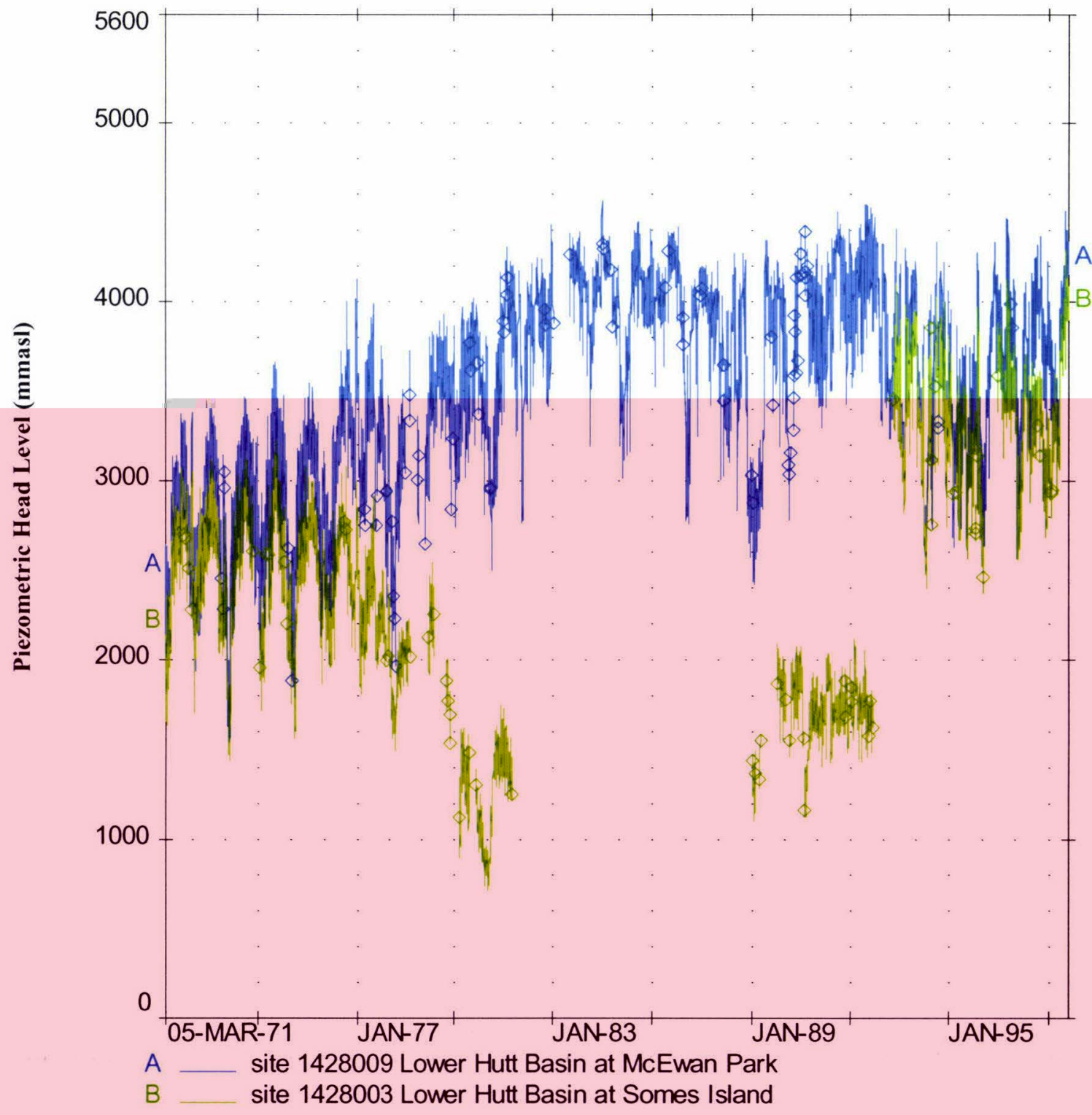

Figure 10.3.1 Piezometric Head Level as recorded at the McEwan Park and Somes Island Observation wells between March 1971 and August 1998. Note that large gaps are apparent in the Somes Island record (green). It is proposed that the sudden drop in head level in the Somes Island bore in 1977 is due to a leak in the bore at the harbour floor. As such, all Somes Island data between 1977 and when the leaking bore was detected and fixed in May 1993 can be considered erroneous. The rise in piezometric head in the McEwan Park Observation bore between 1980 to 1982 is attributed to the relocation of the abstraction focus $3 \mathrm{~km}$ inland to the Waterloo Wellfield. The seasonal fluctuation of groundwater levels is clearly visible.

Note: Data has been transformed to a 24 hour average to eliminate the effect of the tides. 


\subsection{Effect of Changing Abstraction Focus}

A plot of piezometric head level as recorded at Somes Island and McEwan Park for March 1971 to August 1998 is shown in Figure 10.3.1. As can be seen, the McEwan Park record shows a marked increase in piezometric head between 1980 and 1982. This increase is almost certainly due to the shift in abstraction focus from the foreshore vicinity to the Waterloo Well Field, 3km inland. This abstraction regime occurred in 1980 and was accompanied by the closure of the Hutt Park Well Field (near bore UWA 3) and the reduction in the amount of abstraction from the Gear Island Well Field (see Figure 7.4.6.2 for locations of these well fields). The result of this change has allowed piezometric foreshore levels to recover somewhat in the foreshore and sub-harbour Waiwhetu Artesian Aquifer.

The Somes Island record is unfortunately partly absent because of gaps in the data. However, prior to the first major gap in the record, a sharp drop in piezometric pressure occurs around $78 / 79$, and continues dropping over the space of the next few years. It is proposed that this initial drop in pressure represents the initiation of the leak in the Somes Island bore. The fall in pressure continues until equilibrium is reached about three years later. The following few years of record are absent because of a gap in the record, however the very low head levels are still apparent in the patch of record between late 1989 to mid 1992. The repair to the leaking bore is clearly evident by the 'normal' head values recorded after May 1993. The period after May 1993 shows that the relative position of the Somes Island piezometric head level to the McEwan Park head level is similar to the period of record prior to 1978, except that now they both fluctuate at a higher head level. Only a small difference in piezometric head is apparent between these sites when both records are accurate (i.e. pre 1978 and post May 1993).

Thus the Donaldson and Campbell (1977) calculated piezometric head level for salt-water intrusion (1.4masl) was based on a period when the overall piezometric head within this portion of the aquifer was much lower than at present - due to the closer proximity of the main abstraction well fields at the time. The WRC (1995) calculated figure of 2.8 masl was based on data taken well after the abstraction focus had shifted $3 \mathrm{~km}$ inland from the foreshore region.

This provides additional evidence to support the claim that the Somes Island bore was in fact not leaking during 1973. It also shows that the piezometric head values in the foreshore and sub-harbour regions of the Waiwhetu Artesian Aquifer have both risen since the early 1980's, this being attributable to the commissioning of the Waterloo Wellfield in 1980, and the consequent closure of the Hutt Park pumping station. The overall effect of this abstraction regime change is that the aquifer beneath the harbour (and Petone Foreshore) is now 'healthier' than it was before the shift in abstraction focus. 


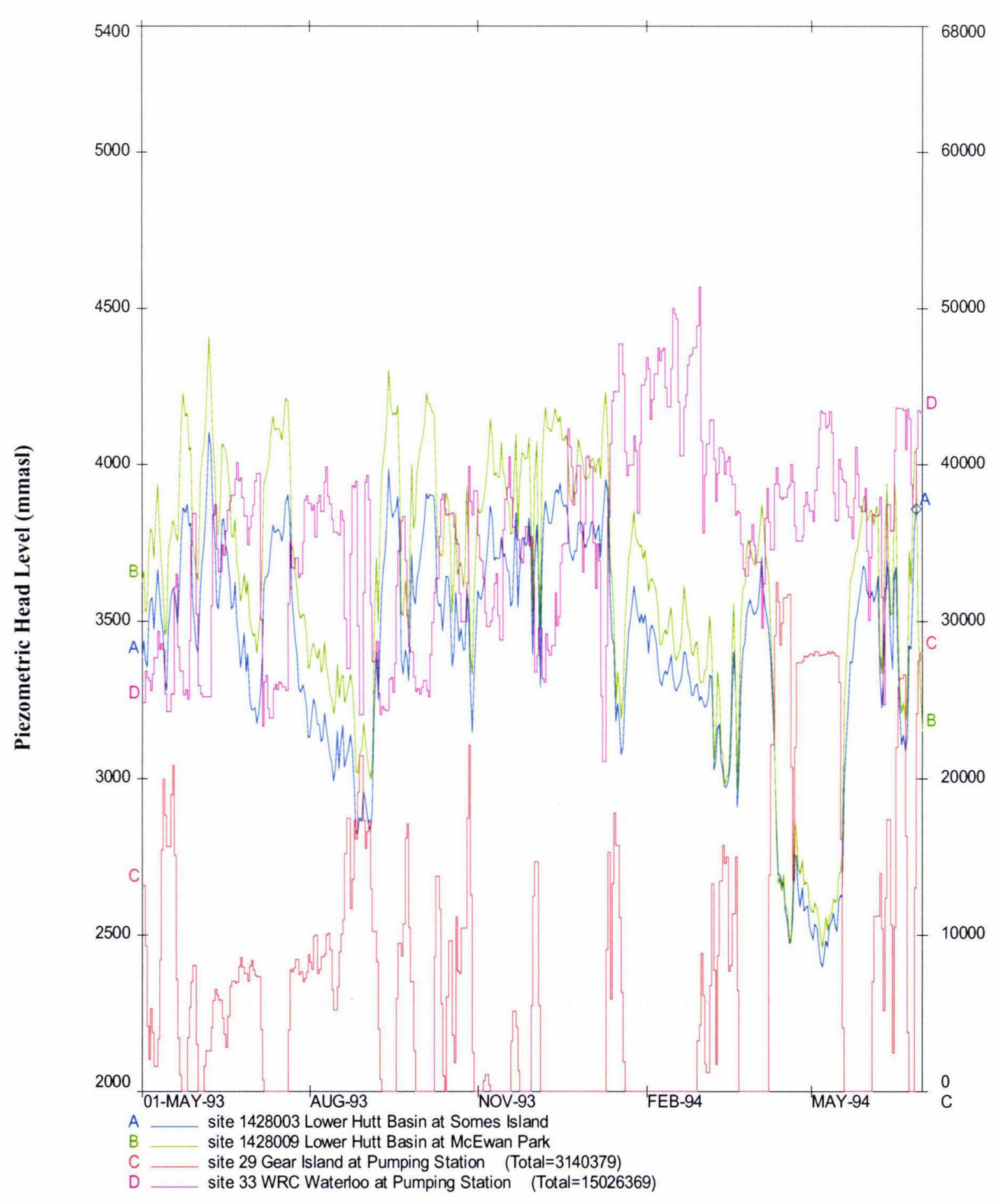

Figure 10.4.1 Plot showing the relationship between groundwater abstractions at the Waterloo and Gear Island well fields and the piezometric head levels recorded at McEwan Park and Somes Island for the period May 1993 to June 1994. 


\subsection{The present day potential for salt-water incursion at the deep depressions south of Somes Island}

Given that piezometric pressures within the sub-harbour aquifer indicate that it is now 'healthier' than it was prior to 1980, it is unusual that WRC (1995) calculated that saltwater intrusion would occur at a higher piezometric head level than that calculated by Donaldson and Campbell (1977). Indeed, this implies that salt-water intrusion is a greater threat at present than it was before. However, this is clearly not the case, and the real reason for this discrepancy in values can be explained relatively easily.

The minimum foreshore level as calculated by Donaldson and Campbell (1977) and WRC (1995) is essentially just an indicator of when the hydraulic gradient between the Petone Foreshore and Somes Island changes from positive to negative. Above the calculated minimum foreshore level, the hydraulic gradient beneath the harbour is positive and the flow of artesian water is away from the abstraction well fields towards Somes Island. However, because the hydraulic gradient between the Petone Foreshore and Somes Island is remarkably low (as shown by the similar piezometric values recorded at these sites), it does not require a great change at either site to reverse it.

This can be demonstrated by comparing the piezometric head at Somes Island and McEwan Park over time. Figure 10.4.1 is a plot of these piezometric head records with the daily abstraction volumes of Waterloo and Gear Island well fields overplotted (for the period May 1993 to June 1994). This period was that used by WRC (1995) to obtain their minimum foreshore value of 2.8 masl.

As can be seen, for the majority of the record, the pressure at McEwan Park is greater than that at Somes Island. However, when the Gear Island pumping station is 'switched on', piezometric head levels at McEwan Park and Somes Island fall dramatically. In fact, the drawdown is so rapid that on occasion the piezometric head at McEwan Park temporarily drops below that of Somes Island. This is due to the time it takes for the change in piezometric pressure to travel through the aquifer to be registered at the Somes Island bore. During these occasions, the head difference between the bores is negative and thus the hydraulic gradient will reverse. This effect is only temporary and when the pressure drop has reached the Somes Island bore (less than 24 hours later), the gradient is made positive again.

However, a reversal in the hydraulic gradient from positive to negative does not necessarily mean that salt-water incursion will occur at depressions in the harbour floor. While it implies that the flow of water may be from beneath the harbour towards the foreshore, the pressure within the aquifer may still be sufficient to sustain artesian leakage out of these deep depression sites. 


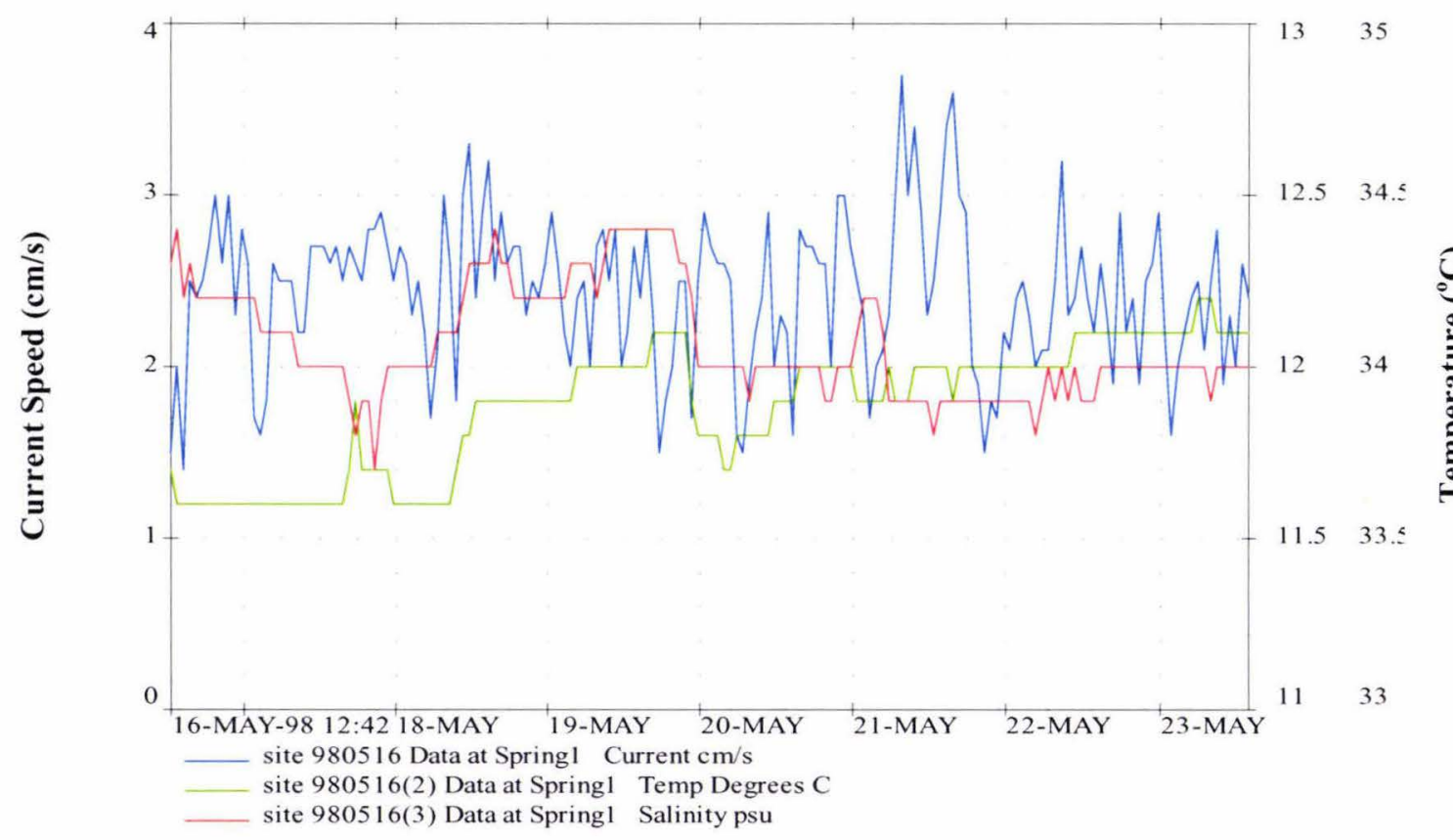

Figure 10.5.2.1 Recorded discharge from a submarine vent within Depression 1, Zone 1. The left hand vertical scale corresponds to current speed; the first vertical scale on the right hand side corresponds to temperature $\left({ }^{0} \mathrm{C}\right)$ and the second vertical scale on the right corresponds to salinity (PSU).

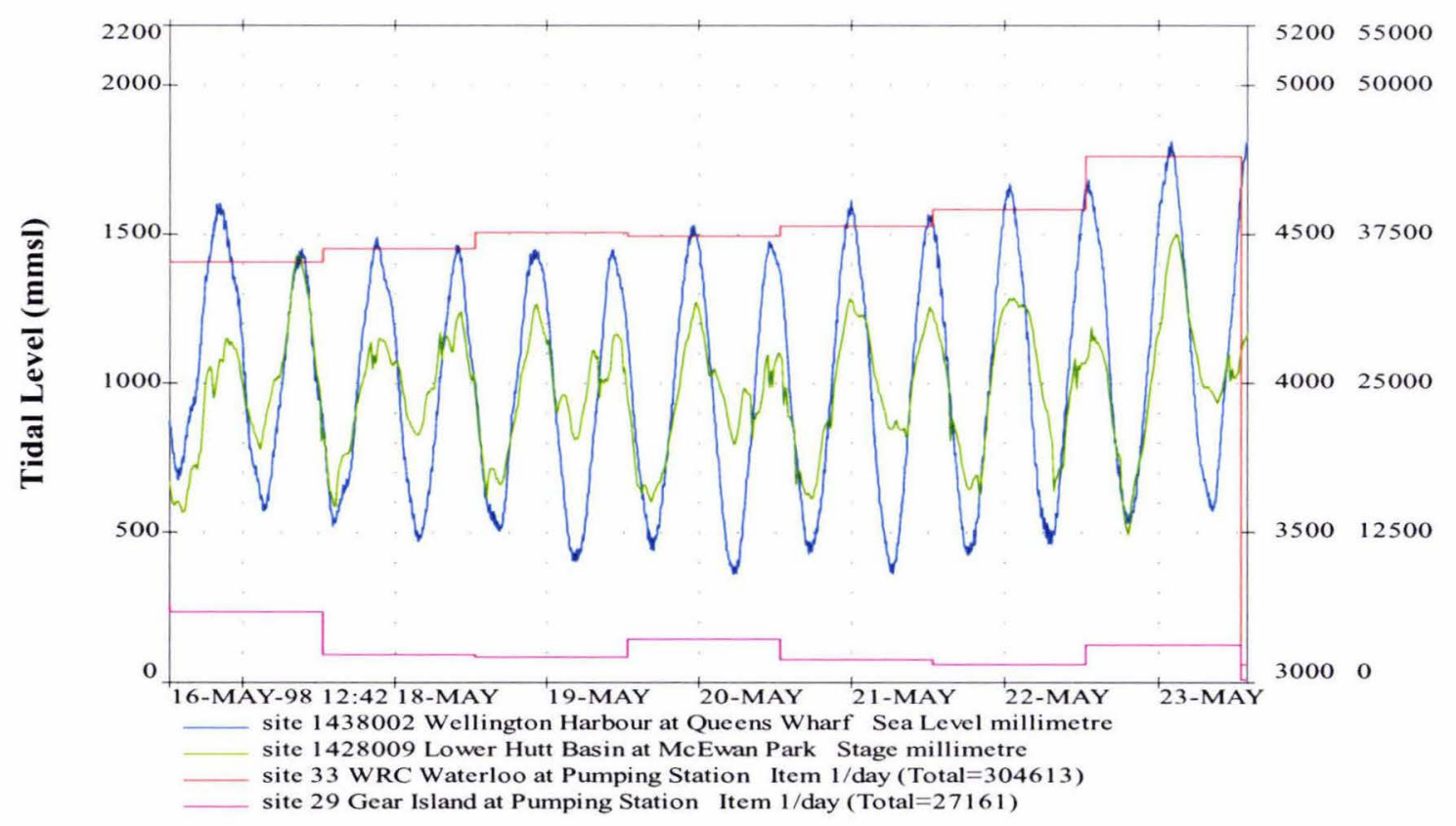

Figure 10.5.2.2 The hydrological conditions within the aquifer at the time of S4 deployment. As can be seen, Gear island (pink line) was hardly used over this period. The first vertical scale on the right corresponds to the Piezometric Head at McEwan Park, the second vertical scale on the right corresponds to Daily Groundwater abstractions (in $\mathrm{m}^{3}$ /Day). 
Seawater has a density of 1.025 times that of fresh water. Applying this density difference to the depth of seawater above the deep depressions $(31.3 \mathrm{~m})$, it follows that to counter the pressure of seawater at the deep depression sites, the piezometric head within the aquifer must be greater than 0.7825 masl $(31.3 * 1.025-31.3)$. Reynolds (1993) recognises this fact, and correctly suggests that there is no threat of saline intrusion at these deep depression sites south of Somes Island until the piezometric level in their vicinity falls below $0.8 \mathrm{masl}$. To maintain differential between the foreshore and the deep depressions, Reynolds (1993) suggests that the minimum Petone Foreshore piezometric head level could be reduced to a safe 1.0 masl.

The piezometric head level at both McEwan Park and Somes Island, has never been below 0.8 masl for the period of record available ( 1971 to present). In fact, the lowest value ever recorded at McEwan Park was 1.187 masl (during the 1973 drought). Since 1981, the lowest value recorded was 2.063 masl (in January 1996). As such, the only envisaged scenario in which the pressure at either bore could drop below 0.8 masl would be from a combination of an extended drought and sustained high volume abstractions from the Gear Island well field. In such a scenario, the 'cone of depression' from the Gear Island well field may extend far enough into the sub harbour aquifer to reach the deep depressions south of Somes Island.

However, for the piezometric pressures to drop below 0.8 masl beneath these depression sites, not only would the drought and abstractions need to be extreme, but the present failsafe minimum foreshore level would have to be exceeded, which, as stated in the consent requirements, cannot be allowed to happen. Furthermore, the Gear Island pumping station is presently only used when the demand cannot be met by Waterloo alone. Thus it is unlikely that it will ever again be used for the abstraction of large volumes of water for extended periods. Prior to the change in abstraction focus when sub-harbour piezometric pressures were lower, the possibility of salt-water intrusion at the deep depression sites was greater. However, under the present regime, we can safely say that the deep depressions south of Somes Island can be discarded as potential sites of salt-water intrusion.

In conclusion, it is clear that the method of plotting the 24 hour difference in piezometric head between Somes Island and McEwan Park against the 24hour mean piezometric head at McEwan Park is not suitable for determining the minimum foreshore level below which salt-water intrusion occurs. It can only be used as an indicator of the hydraulic gradient within the sub-harbour aquifer.

It can also be concluded that the higher piezometric pressure in the sub-harbour Waiwhetu Artesian Aquifer since 1981 not only implies that the possibility of salt-water intrusion has decreased since the shift in abstraction focus, but the amount of SGWD may have possibly increased. 


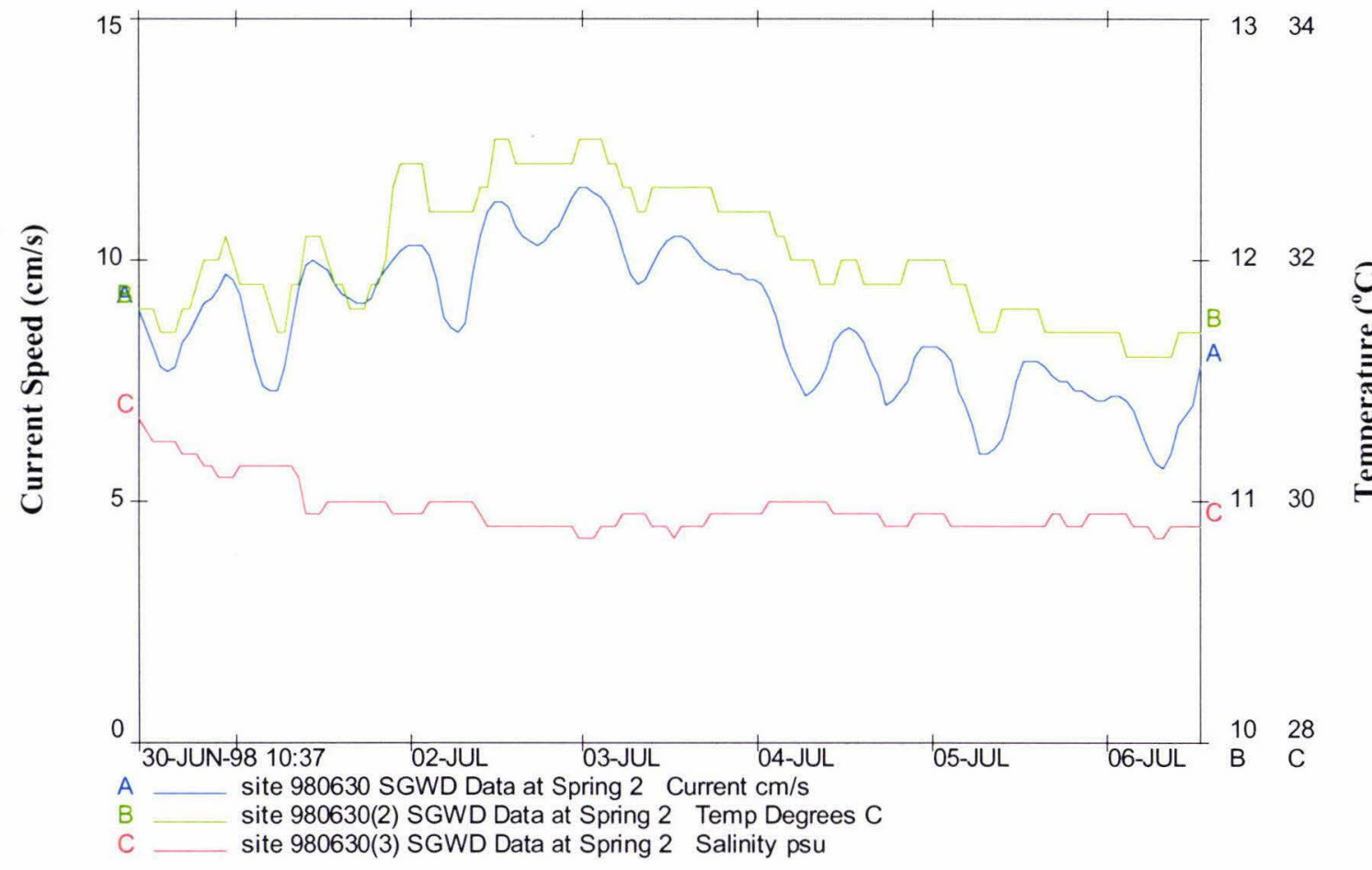

Figure 10.5.3.1 Plot of the data recorded at Depression 6, Zone 1. The left hand vertical scale corresponds to current speed; the first vertical scale on the right hand side corresponds to temperature $\left({ }^{\circ} \mathrm{C}\right)$ and the second vertical scale on the right corresponds to salinity (PSU).

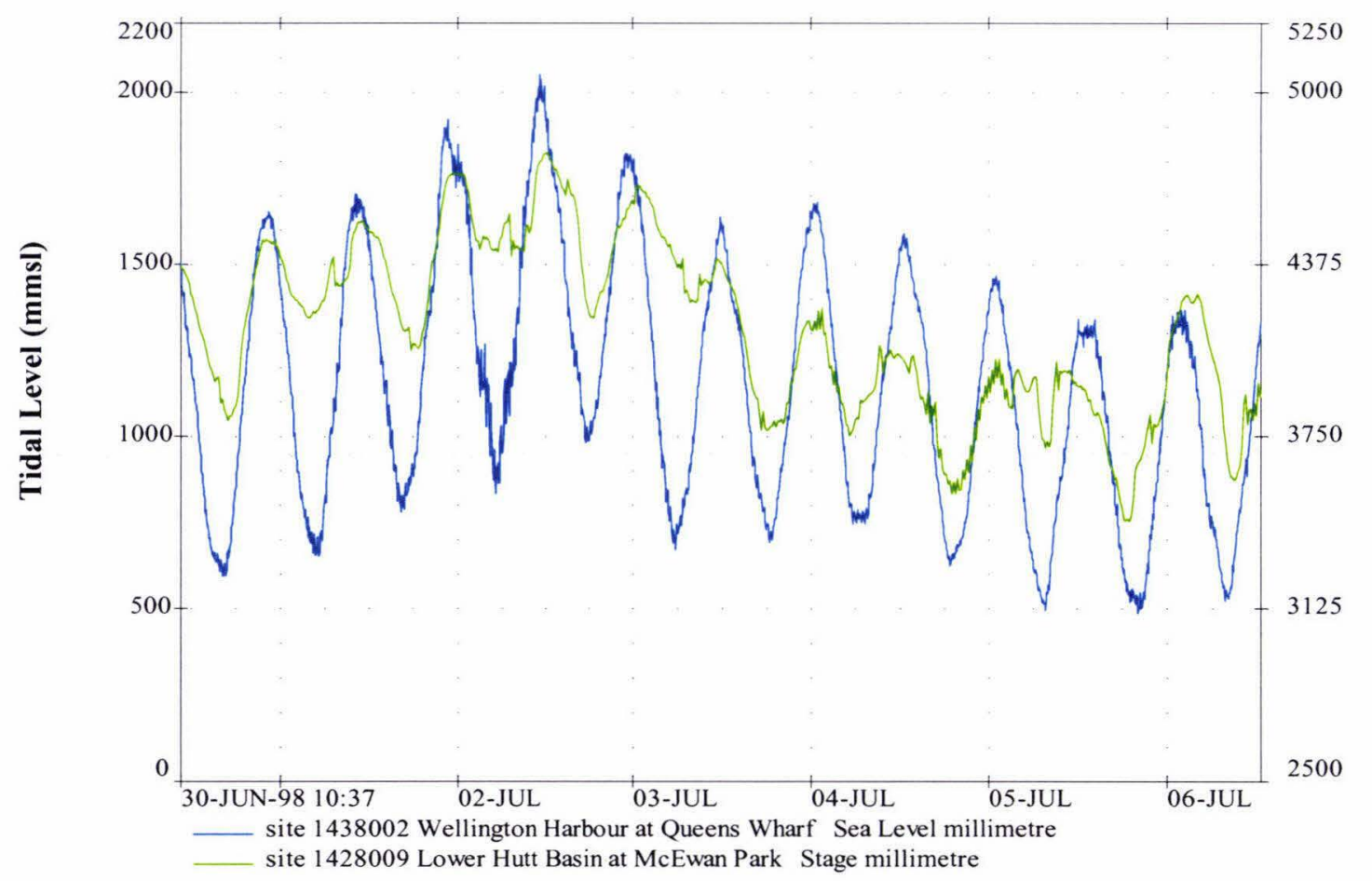

Figure 10.5.3.2 The tide (recorded at Queens Wharf) and the piezometric level as recorded at McEwan Park on the Petone Foreshore. No abstraction data was available for this period. 


\subsection{Recorded Submarine Spring Discharges in Zone 1}

\subsubsection{Introduction}

The presence of the depression cluster off the Hutt River mouth, as mapped and described in this research, allows a possible alternative site of salt-water intrusion. This zone of submarine spring leakage (referred to as the Zone 1 leakages in Chapter Nine), is much closer to the Petone Foreshore, and has been shown to lie above a paleochannel within the Waiwhetu Artesian Aquifer (see Chapter Eight). Given that the potential exists for paleochannels to have much higher transmissivities than the 'average' aquifer, an investigation into the relationship of piezometric head at these sites compared to the McEwan Park observation well would be extremely useful.

Spring vents were found in three of the depressions in Zone 1. These are Depressions 1, 4 and 6 (see Figure 9.4.2.1). As stated in Chapter Nine, this does not imply that there are no vents in the other depressions, it merely reflects the difficulty in locating the vents which tended to be by chance rather than for any scientific reasons.

\subsubsection{Results from Depression 1, Zone 1}

It was decided to measure the discharge from a vent in Depression 1 of Zone 1 first as this site is closest to Petone Foreshore and thus closest to the zone of abstraction.

Following the set-up procedure as stated in the methodology (Chapter Six), the S4 was bolted in its purpose built end-less 44 gallon drum housing unit and taken to the depression floor where it was set up over the selected vent. The vent has a diameter of approximately $1.1 \mathrm{~m}$ at the depression floor, tapering to roughly $60 \mathrm{~cm}$ across, one metre beneath the depression floor. The $\mathrm{S} 4$ was set to record twice a second for one minute every hour, thus 120 values would be recorded in a one minute burst every hour. As depth was going to be constant (apart from minor changes caused by tidal fluctuations), only two channels were set to record - conductivity and temperature (current is automatically recorded). Very little discharge was observed issuing from the vent upon deployment.

This set-up was left for one week whereupon it was retrieved and the data downloaded and analysed. For compatibility with recorded piezometric data from the Lower Hutt Valley, the raw S4 data was transformed into a TIDEDA format file and listed into TIDEDA. In doing this, the 120 values recorded in one minute every hour were averaged to give one value per hour.

A graphical representation of these results is shown in Figure 10.5.2.1, with the corresponding tidal, McEwan park piezometric record and abstraction data shown in Figure 10.5.2.2. 


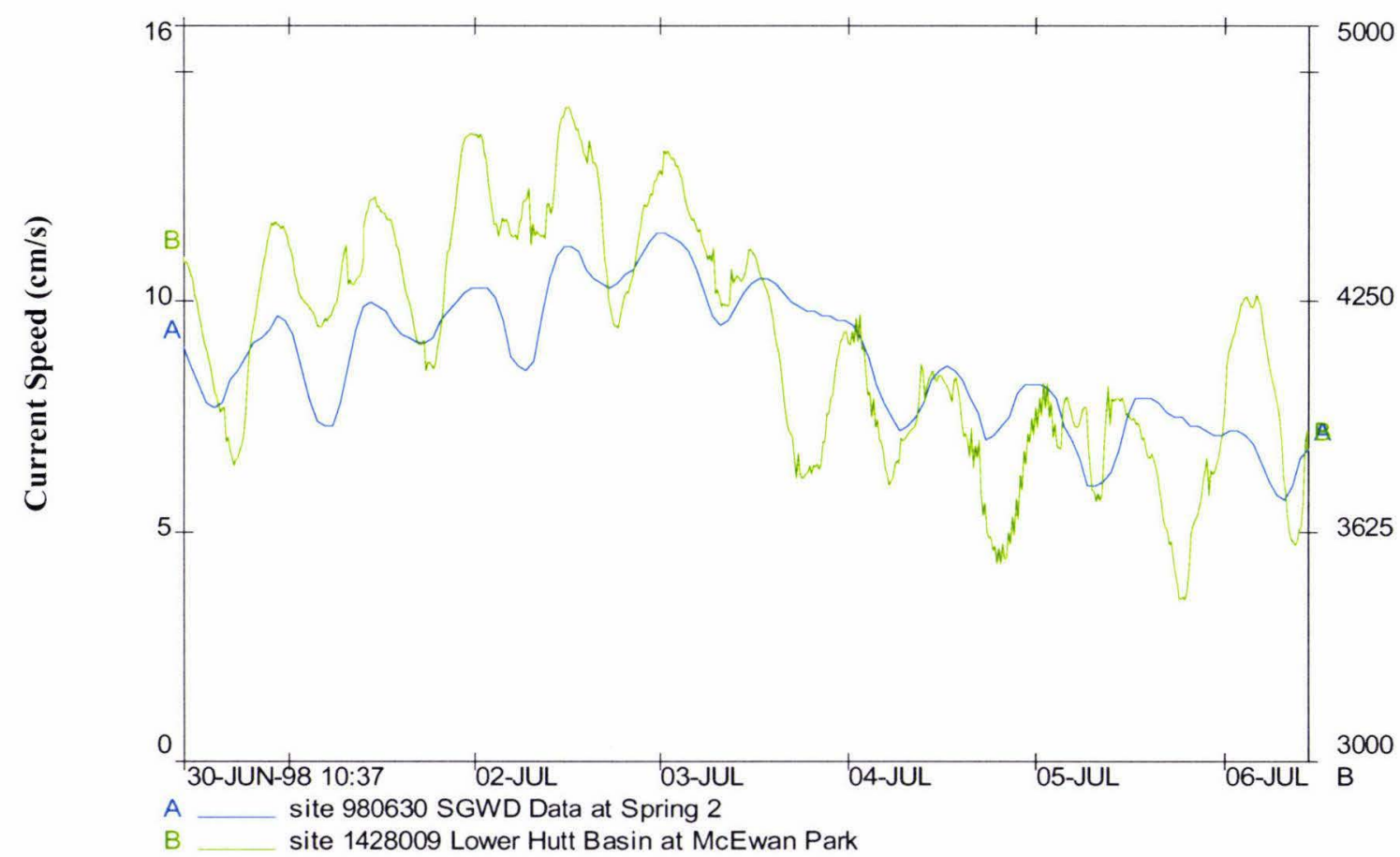

Figure 10.5.3.3 Plot showing the relationship between current speed as recorded at Depression 6, Zone 1, and Piezometric Head Level as recorded at McEwan Park from $30^{\text {th }}$ June to $6^{\text {th }}$ July 1998.

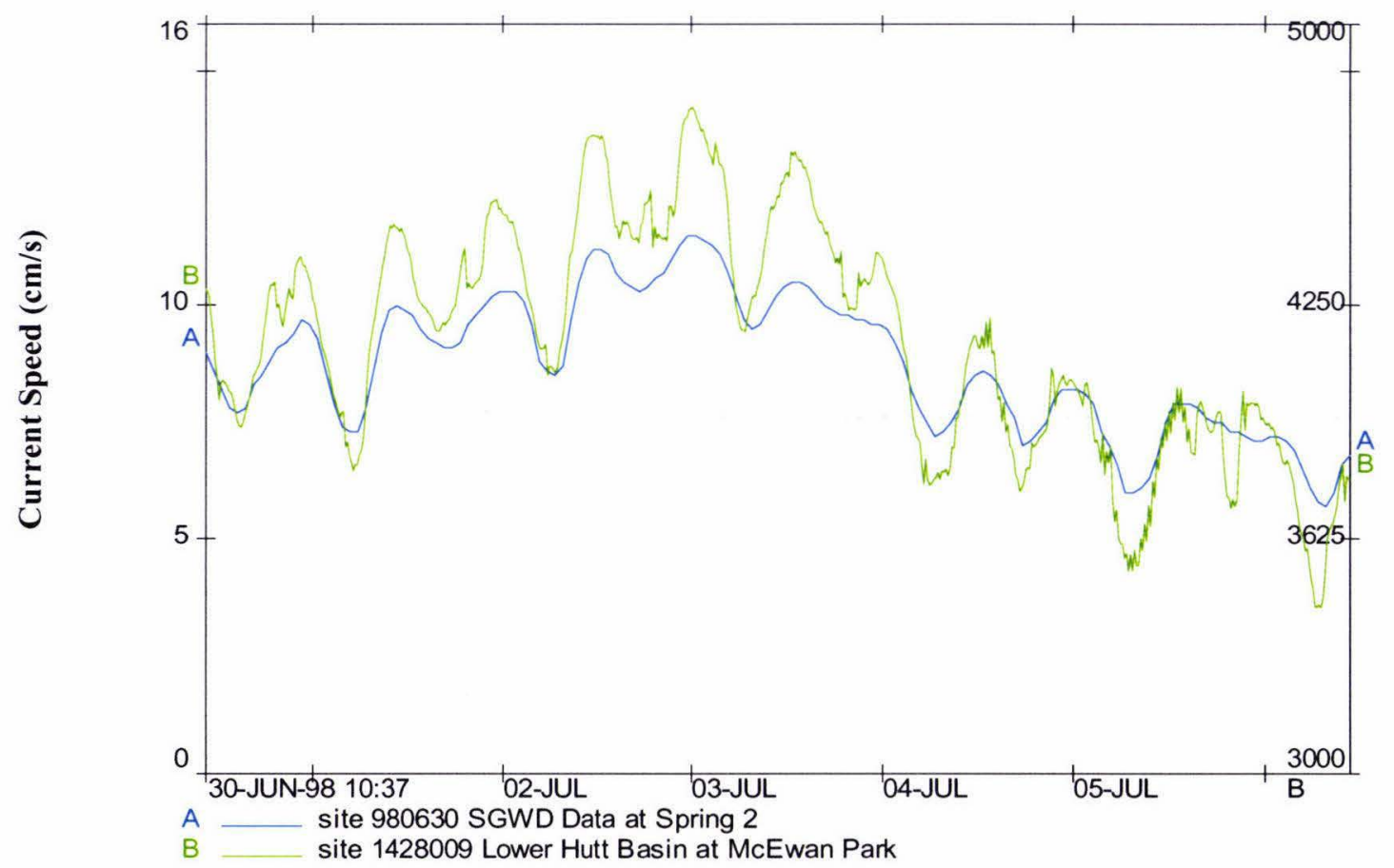

वิ

Figure 10.5.3.4 Same plot as above except that the McEwan Park head water level has had a 12 hour lag applied to it. As can be seen, a strong correlation between spring discharge and the lagged piezometric head at McEwan Park is apparent. 
As can be seen in the graphs, there is no correlation whatsoever between the spring discharge and either salinity or temperature, except for just before the $18^{\text {th }}$ of May when a peak in the discharge correlates with a trough in the salinity values and a peak in the temperature. This is what we would expect to see as the greater the discharge the more 'freshened' the water (i.e. lower salinity).

There is no apparent correlation with the tidal fluctuations and the current velocities are very erratic. It is likely that the submarine vent selected was not discharging any significant quantities of water during the seven day period of this test. Indeed, neither the river flow nor the abstractions changed significantly over the week of recording. This is reflected in the consistent trend of the piezometric level at McEwan Park. The slight fluctuation on the McEwan park record is probably due to localised abstractions.

It is possible that in Depression 1, the flow from the selected vent was so weak during this period that it was not great enough to create a smooth flow around the S4 current meter. The result of this would be to affect some of the current sensors but not others. This could be responsible for the poor data recorded.

\subsubsection{Results from Depression 6, Zone 1}

A second site was chosen to perform the same test again to try and obtain some useful data. This time a spring in Depression 6 of Zone 1 was selected. This spring vent has a diameter of approximately $1.4 \mathrm{~m}$ at the depression floor, tapering to roughly $1.1 \mathrm{~m}$ across, one metre beneath the depression floor. This time the S4 was set to internally average the flow, conductivity and temperature data it recorded for a two minute burst, every hour. A strong discharge, estimated at approximately $30 \mathrm{~cm} / \mathrm{s}$ was noticeable upon deployment.

This set-up was once again left for one week, whereupon it was retrieved and the data downloaded and transformed into a TIDEDA format file and listed into TIDEDA.

Figure 10.5.3.1 shows this data, with the corresponding tidal record at Queens Wharf and McEwan Park piezometric record plotted in Figure 10.5.3.2. As can be seen, the spring discharge record is a lot smoother than that obtained from Depression 1. This is likely to be the result of a more consistent and larger flow of water around the S4, giving more accurate readings.

The salinity at this site is fairly constant at just under 30 PSU. Temperature fluctuates relative to current speed, which reflects the fact that the artesian water is warmer than the harbour waters at this time of year (June/July) and thus the greater the spring discharge, the greater the 'dilution' of the sea water with warmer groundwater. 


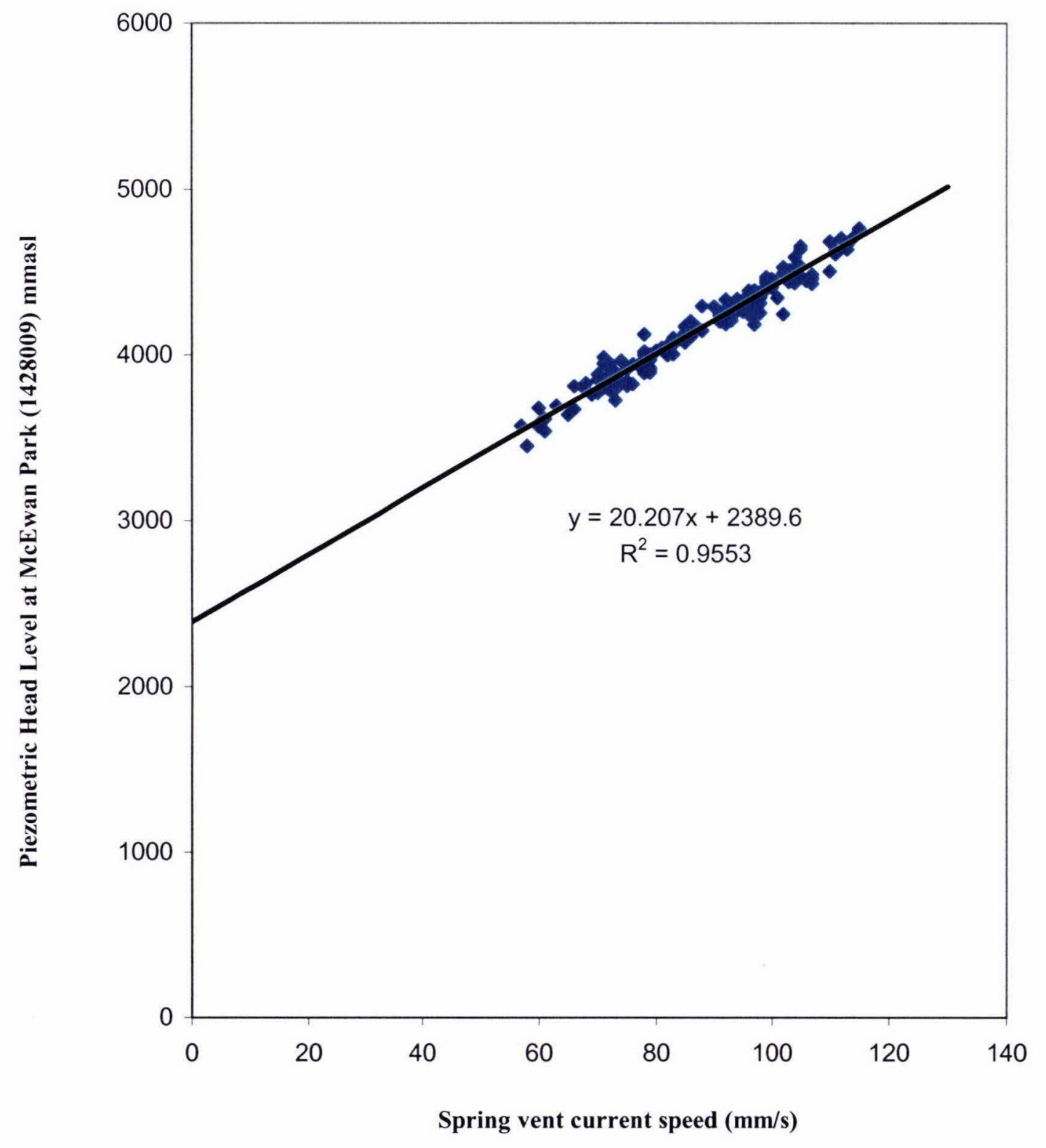

Figure 10.6.1 Relationship of spring discharge (at Depression 6, Zone 1) to piezometric head as recorded at the McEwan Park observation well. 
The discharge data does not correlate well to the piezometric head data as shown in Figure 10.5.3.3. However, as described previously, we can expect a time lag between the pressure changes at McEwan Park being mirrored at the spring discharge site due to the time it takes for the pressure to travel through the aquifer.

As such, various lag times were applied to the McEwan Park record to see which lag fitted best to the spring discharge data. It was decided that a lag of approximately 12 hours was the best fit. Figure 10.5.3.4 shows the two records overplotted with the 12hour lag applied to the McEwan Park data. The correlation with this lag applied to the McEwan Park observation well data looks very good (see Figure 10.5.3.4).

\subsection{Minimum Petone Foreshore level based on Spring Discharge}

Having obtained some useful submarine spring discharge data, there exists a unique opportunity to derive the relationship between piezometric head at Petone Foreshore with actual submarine spring discharge from the sub-harbour Waiwhetu Artesian Aquifer, rather than hypothesising it from a nearby observation well.

Figure 10.6.1 shows the hourly discharge data recorded at the spring vent correlated with hourly instantaneous data measured at the McEwan Park Observation Well on the Petone Foreshore. A 12 hour lag has been applied to the McEwan Park data as was determined previously to be the correct time lag in piezometric pressures between these sites.

The relationship is very strong with a correlation coefficient of 0.955 . The extrapolation of this relationship shows that spring flow will cease when the piezometric level at McEwan Park falls below approximately 2.4 masl. Note this value represents the McEwan Park piezometric level below which salt-water intrusion is likely to occur at this depression site, and not the level at which the hydraulic gradient will reverse. We must remember that by recording the spring discharge, the pressure of the seawater above the spring is already taken into account, and reflected in the amount of artesian leakage. Thus, by extrapolating the relationship of spring discharge versus piezometric head to the point where spring discharge ceases, we are establishing the level at which salt-water incursion may occur if pressure drops further.

This indicates that the hydraulic conditions within this region of the aquifer are vastly different from those hypothesised beneath the deep depressions south of Somes Island. Indeed, if we apply the formula mentioned previously, (as used by Reynolds, 1993), we obtain a piezometric head of 0.485 masl $\left(19.4 m^{*} 1.025-19.4 \mathrm{~m}\right)$ as being the pressure required to withstand the weight of water above this spring site. Note that this is the depth to the main depression floor, rather than the spring vent, as it is unknown how deep the spring vent continues into the sediment. 
This implies that when the piezometric head within the Waiwhetu Artesian Aquifer is 2.4 masl at McEwan Park, it is in the order of 0.5 masl within the aquifer beneath this depression site (Depression 6 in Zone 1). Dividing the difference in head between these sites $(2.4 \mathrm{~m}-0.5 \mathrm{~m}=1.9 \mathrm{~m})$, by the distance between the sites (approximately $1700 \mathrm{~m}$ ), we obtain a hydraulic gradient of approximately 0.001 . This gradient is approximately two orders of magnitude steeper than that inferred at present.

While this hydraulic gradient is extremely steep, we must not forget that a paleochannel is observed to dominate the region of the Waiwhetu Artesian Aquifer beneath the Zone 1 depressions, as apparent on the seismic record. The presently accepted sub-harbour hydraulic gradient is based on piezometric data between Somes Island and McEwan Park. The aquifer characteristics may be quite different at Somes Island than that beneath the Zone 1 depressions. As such, the hydraulic gradient calculated between McEwan Park and Depression 6 in Zone 1 may be valid. It follows that the associated minimum foreshore piezometric level calculated on these data may also be valid.

However, there are a couple of points that raise doubts as to the validity of these calculated values. Firstly, the spring flow at the time of $\mathrm{S} 4$ deployment was estimated at being approximately $30 \mathrm{~cm} / \mathrm{s}$ (diver observation). Data recorded by the $\mathrm{S} 4$ indicates that the flow was initially in the order of $9 \mathrm{~cm} / \mathrm{s}$, and was never greater than $11.5 \mathrm{~cm} / \mathrm{s}$ for the entire duration of its deployment. Although estimating current speed underwater is difficult, it is hard to imagine the current flow being estimated that poorly. Given that the $\mathrm{S} 4$ is designed to be used to detect the movement of large currents, such as tidal currents or wave surge, it is possible that the $\mathrm{S} 4$ did not record this small current flow that accurately. Recording low volume currents was seen to be a problem at the spring vent in Depression 1 and so current flow rates may in fact be under-stated at the Depression 6 spring vent. Higher spring flow velocities would change the relationship with the McEwan park data, which, depending on the shift in trend line, could result in a much lower extrapolated minimum foreshore level.

The second point regards the relationship used to extrapolate the data. It must be noted that the relationship shown in Figure 10.6.1 was extrapolated to zero spring flow with a straight line. However, the relationship may be more complex than this. Spring discharge may in fact exponentially decrease as piezometric pressures drop towards the limit of salt-water intrusion. Without the luxury of having data collected over a wide range of piezometric head values, we can only speculate at what the true relationship is.

Although this fail-safe minimum foreshore level represents a significant reduction in the theoretical amount of water able to be abstracted from the aquifer, a probability distribution of the McEwan Park data shows that the piezometric water level has only been below 2.4masl less than $1 \%$ of the time, for the period 1/1/82 to 9/9/98 (see Appendix Seven). 


\title{
Chapter Eleven
}

\section{CONCLUSIONS}

\author{
Sub-harbour extent and characteristics of the Waiwhetu Artesian Aquifer and Petone
} Marine Beds

The sub-harbour extent of the Waiwhetu Artesian Aquifer has been mapped, with data obtained from previous seismic survey investigations, as extending across the entire width of Wellington Harbour to the harbour entrance vicinity. The extent of the aquifer deposits through the harbour entrance cannot be extrapolated with any confidence although the nature of sedimentation implies that the Hutt River certainly used this corridor during the entire period of deposition of this unit.

The extent of the upper confining aquiclude to the Waiwhetu Artesian Gravels (the Petone Marine Beds) has similarly been mapped as covering the aquifer deposits across the entire inner harbour area to the northern extent of the harbour entrance, petering out in the Falcon Shoals region. It is not envisaged that the Petone Marine Beds extend any further through the harbour entrance due to the nature of the strong tidal currents through this corridor which prevent the settling of the fine material characteristic of this aquiclude.

Seismic information reveals the presence of a number of paleochannels within the Waiwhetu Artesian Aquifer. These paleochannels have been used to aid in the interpretation of the deposition of the aquifer deposits. One such paleochannel, in the upper level of the Waiwhetu Artesian Aquifer, is over $300 \mathrm{~m}$ in width and can be mapped to the east of Somes Island, extending southwards.

Another paleochannel, apparent at the base of the Waiwhetu Artesian Aquifer member, can be mapped as an incision into the Wilford Shell Beds beneath the Waiwhetu Artesian Aquifer, and thus likely represents the course of the ancient Hutt River at the onset of the last glaciation. This paleochannel runs between the Ngauranga Gorge vicinity and the present day harbour entrance. As such, this precludes the hypothesis made by previous researchers that the Hutt River used the Evans Bay - Lyall Bay corridor during the initial stages of the last glaciation.

Furthermore, the depositional history of the units beneath the Waiwhetu Artesian Aquifer implies that the Hutt River never used the Evans Bay - Lyall Bay corridor as a former exit from the harbour. It is believed, as suggested by Cotton (1912), that Evans Bay was cut by a north flowing stream and Lyall Bay cut by a south flowing stream, originating from the 
Miramar Peninsular. However, this corridor did represent a second harbour entrance for a long period during the deposition of the Petone Marine Beds, finally being closed by tectonic uplift around 1460AD. The depth to basement through the present harbour entrance was found to be much deeper than earlier studies previously hypothesised. This evidence further supports the premise that the ancient Hutt River always used the present harbour entrance as an exit during glaciation periods.

As such, it is believed that the Waiwhetu Artesian Aquifer deposits do not extend a great distance into Evans Bay. However, it is possible that sediments deposited by the north flowing stream that cut Evans Bay are present as a thin layer beneath this bay, and perhaps interdigitate with the Waiwhetu Artesian Gravels. A hydraulic connection is possible.

Seismic evidence reveals that the Waiwhetu Artesian Aquifer deposits vary in thickness across the harbour. In general they are close to $70 \mathrm{~m}$ thick against the Wellington Fault, thinning to about $20 \mathrm{~m}$ thick against the eastern harbour margin. A westerly dip is apparent in this unit, reflecting the tectonically active nature of the Wellington Region coeval with the deposition of this member.

Data on recharge rates and throughflows were used in Chapter Seven to show that groundwater recharge has not been constant over time, and processes such as gravel abstraction have reduced the day-to-day recharge rate. Pump tests carried out on the Waiwhetu Artesian Aquifer in the early 1990's show a huge variation in transmissivity values, ranging from 10,900 to $69,450 \mathrm{~m}^{2} /$ day.

Travel times and transmissivity values throughout the aquifer were used to show how heterogeneous the aquifer material is, and in particular, the presence of paleochannels within the Waiwhetu Artesian Aquifer. These paleochannels are able to supply large amounts of water to localised areas, and as such, the most prolific spring discharges are likely to have paleochannels of high transmissivity nearby.

The Petone Marine Beds (upper aquiclude) also vary in thickness across the harbour, ranging from roughly $30 \mathrm{~m}$ thick against the western side of the harbour, to around $12 \mathrm{~m}$ thick against the eastern coastline. This variation in thickness can also be explained by the ongoing tectonic adjustment of the Wellington Region during the deposition of this unit. The thinness of the aquiclude in the northeast quadrant of the harbour (where most of the artesian leakage occurs) is attributed to the sedimentation history of the aquiclude. In particular, the lack of protection from southerly swells propagating northwards through the harbour entrance, and the position of the Hutt River delta during the deposition of this unit is reasoned to be largely responsible. 
A highly energy absorbing layer in the upper few metres of the Petone Marine Beds aquiclude renders much of the inner harbour seismic record void of any detail below this layer. The region covered by this seismically opaque layer is known as the 'interference' region. It has been hypothesised in this research to be caused by a shallow layer of accumulated gas bubbles, generated within the aquiclude deposits by the biogenic breakdown of organic matter over time.

The absence of the interference region in the northeast quadrant of the harbour is proposed as being due to the release of the accumulated gas in this region as a result of liquefaction of the aquiclude during a tectonic event. The localised nature of liquefaction is hypothesised as being due to thinness of the sediments in this region and the flocculated (random) nature in which they were deposited.

\section{Submarine Spring Discharge in Wellington Harbour}

Thirteen zones within Wellington harbour were selected for investigation as part of this research. These included eleven harbour floor depression zones, plus two seepage zones. Depressions were chosen as they represent areas where the aquiclude is thinner than usual and as such are less able to withstand the pressure of artesian water beneath. The reason for leakage at the two seepage zones in the harbour entrance (Zones 7 and 8) is simply due to the fact that the confining aquiclude is thin in this vicinity, where the strong tidal flows have restricted their deposition. As such Submarine Groundwater Discharge in the harbour entrance occurs as widespread seepage rather than from prominent harbour floor depressions.

Ten of the eleven depression zones investigated are located close to basement rock outcrops. The depression formation mechanism for such sites is attributed to the effect of intense shaking associated with a tectonic event. Due to the different shaking velocities observed between sedimentary deposits and basement rock, unconsolidated deposits tend to shake apart from the basement rock during earthquakes. The rupturing of the seal provided by the aquiclude allows the artesian water beneath to escape. Furthermore, if the earthquake is large enough to cause some settling of the aquifer deposits, then the piezometric pressures within the aquifer will become temporarily artificially raised, thus enabling artesian leakage to occur with greater force. It is the strength of this initial outpouring that largely determines the shape and form of a harbour floor depression.

The depressions not in close proximity to basement rock - the Zone 1 depressions off the Hutt River mouth, were found to be a cluster of 10 distinct depressions, six of which were investigated and found to exhibit artesian leakage (to varying degrees). In the absence of nearby basement rock or major faults, the formation mechanism proposed here is 
liquefaction of the aquiclude during tectonic events. Dredging was considered as a possible formation mechanism, but later dismissed when two of the shallower depressions were located on bathymetric charts surveyed prior to any dredging operations in their vicinity.

Liquefaction of the upper aquiclude (the Petone Marine Beds), while easy enough to understand as a process, is harder to understand when restricted to a localised portion of the aquiclude as is the case with the Zone 1 depressions. Isopach (thickness) maps of the aquiclude show that the aquiclude within the region of Zone 1 depressions is unusually thin. This thinness, combined with the flocculated nature of the deposited sediments (due largely to the disturbing nature of southerly swells during deposition) renders this region of the aquiclude particularly well-suited to liquefaction. Furthermore, evidence of a paleochannel running underneath this region of the harbour provides the means of generating high piezometric head within the aquifer underlying this thin confining bed. As such, it is proposed that the depressions in Zone 1 were formed by liquefaction of the aquiclude combined with aquifer blowout due to extreme piezometric pressures generated during a large tectonic event.

With regards to continued artesian leakage after the formation of a sea floor depression, it is quite clear that it is the characteristics of the aquifer adjacent to a depression that determines how much leakage will occur post depression formation. Where aquifer transmissivities and throughflow are high beneath the harbour floor depressions, artesian leakage is likely to continue after the initial formation of the depression.

All of the depression zones ( $1-6$ and 9 - 13) plus both the seepage zones ( 7 and 8 ) in the harbour entrance were found to be exhibiting present day artesian leakage to varying degrees, as recorded by conductivity measurements. The amount of artesian leakage was found to vary widely not only between the zones, but also within each zone. With regards to the depression zones, this was due to the fact that leakage was found to occur from spring vents within the depression, rather than from the entire depression floor.

Only zones $1,4,5,6,7$ and 8 exhibited artesian leakage of an appreciable amount, but it is noted that this is possibly due to the random nature of conductivity sampling. However, up to 20 values were taken at each depression site to reduce this possible source of error. Zones 9 to 13 were omitted from any further part in the research, partly due to the minor evidence of artesian leakage, and partly because of their great distance from the abstraction zone, and thus of lesser importance to this study.

Interestingly, the depressions previously considered to be the major sources of artesian leakage from the aquifer to the harbour (Zones 2 and 3), exhibited little evidence of artesian leakage. This supports evidence of a Wellington Harbour Board report in which 
divers found no evidence of artesian leakage during a survey of these sites sometime between September 1972 to January 1973

Zones 1 to 6 were charted and dived on extensively. Submarine Spring vents were found in three of the depressions within Zone 1, although more are hypothesised to exist in other depressions in this zone, and possibly in Zone 4 also. It is proposed that the day to day discharge of artesian leakage occurs from these vents within the depressions. However, during periods of high piezometric head, it is hypothesised that leakage may be more widespread from the depression floor, enabling the depressions to maintain their geomorphic form.

Spring vent discharges were recorded at two of the depressions in Zone 1. The currents recorded indicate that there are pathways of high hydraulic gradient beneath the harbour in this region. It was also revealed that the method used in the past to calculate the minimum foreshore level before salt-water intrusion occurs is illogical, and it would be better to base the relationship on actual submarine spring discharges. This was performed with spring data collected from one of the depression vents. The extrapolated foreshore level at which spring flow ceases is 2.4 masl at McEwan Park.

While this is much higher than the previously calculated Donaldson and Campbell (1977) value of 1.4 masl, we must keep in mind that their calculation was based on erroneous data. When the methodology used by Donaldson and Campbell (1977) was used on accurate data, a value of 2.8 masl was obtained (WRC, 1995). However, it has also been noted that the submarine spring discharge to Petone foreshore piezometric head relationship as detailed in this thesis needed to be extrapolated to such an extent that the confidence with which we can accept the 2.4 masl value is lessened. Obtaining more submarine spring data on which to improve the present relationship would be a great step forward in understanding the hydrodynamics of the sub-harbour Waiwhetu Artesian Aquifer.

As such, further research needs to be carried out on these submarine springs, with data collected during both drought and 'flood' conditions so that a complete picture of spring discharge in relationship to piezometric head can be obtained. Only then can conclusions regarding the relationship of spring discharge to piezometric head be made with any degree of certainty. 


\section{References}

Alpine Geophysical Associates Inc. 1971. Continuous seismic reflection survey of Wellington Harbour, New Zealand. Job 1099

Bell, J.M. 1910. The Physiography of Wellington Harbour. Transactions NZ Institute vol 44 pp 208-213

Berryman, K. 1990. Late Quaternary movement on the Wellington Fault in the Upper Hutt area, New Zealand. New Zealand Journal of Geology and Geophysics vol 33 pp 257-270

Best, E. 1923. Miramar and its history: How Motu-kairangi was discovered and settled by Polynesians and how in times long past it became Miramar Peninsula. Transactions and proceedings of the New Zealand Institute vol 54 pp $779-791$

Bokuniewicz, H. 1980. Groundwater Seepage into Great South Bay, New York. Estuarine \& Coastal Marine Science vol $10 \mathrm{pp} 437-444$

Booth, J.D. 1975. Seasonal and Tidal variations in the hydrology of Wellington Harbour. New Zealand Journal of Marine and Freshwater Science vol 9 no 3 pp333-354

Bricknell, Moss, Rankine and Hill Consulting Engineers. 1968. Korokoro Bores Report $\$ 420$

Bricknell, Moss, Rankine and Hill Consulting Engineers. 1970. Pt Howard Bores Report $\$ 490$

Bricknell, Moss, Rankine and Hill Consulting Engineers. 1971. Pt Howard Bores Job Number 5693

Brodie, J.W. 1958. A note on tidal circulation in Port Nicholson, New Zealand. New Zealand Joumal of Geology and Geophysics vol 1 no 4

Brooks, H.K. 1961. The Submarine spring off Crescent Beach, Florida. Quarterly Journal of the Florida Academy of Sciences. Vol 24 pp 122-134

Calhaem,I.M. 1968. The Design and Operation of heat flow probe for use in shallow water. Unpublished M.Sc thesis, Victoria University of Wellington, New Zealand.

Carter, L. 1977. Sand Transport, Wellington Harbour Entrance, New Zealand. New Zealand Journal of Geology and Geophysics (20). pp 335-351

Carter, L. \& Mitchell, J.S. 1988. Side-scan sonar survey, Wellington Harbour Entrance. Contract report NZOI 1988/20 for Wellington City Council

Clarke, G. D. 1988. Hutt River Flood Control Scheme Review. Interim Report Hutt River Mouth Sedimentation Study. Rivers Control Department, Wellington Regional Council

Cowan, M. \& Hatherton, T. 1968. Gravity Surveys in Wellington and Hutt Valley. New Zealand Journal of Geology and Geophysics. Vol 11 (I) pp 1-15

Crawford, J.C. 1874. Did the great Cook Strait River flow to the North-west or to the South-east? Transactions-Geology:

Davey, F.J. 1971. Seismic surveys in Wellington Harbour. Geophysics Division Report no 70 DSIR.

Davy, B. and Wood, R. 1987. Refraction Survey of Wellington Harbour Entrance. Contract Report No. 35 Prepared for the Wellington City Council Geophysics Division, DSIR, Wellington, New Zealand 
Davy, B. and Wood, R. 1993. Seismic Reflection Surveying in Wellington Harbour. Prepared for Wellington City Council, Wellington. Client Report 553904 IGNS, Wellington, New Zealand

Davis, W.M. 1911. Notes on the description of land forms, iv. Wellington Harbour, New Zealand Bulletin American Geographical Society 43 pp $190-194$

Donaldson, I.G. 1974. Underground waters of the Lower Hutt Valley - a model study. Journal of Hydrology (New Zealand) 1974. Vol 13 no 2

Donaldson, I.G. and Campbell, D.G. 1977. Groundwaters of the Hutt Valley - Port Nicholson Alluvial Basin; A Resource Evaluation. DSIR Information Series No. 124

Dunbar, G. B. 1994. Seismic and cultural influences on the sedimentary record, Wellington Harbour, New Zealand. Unpublished M.Sc thesis, Victoria University of Wellington, New Zealand

Easther, J. 1991. The Hutt River (Te-Awa-kai-rangi); A Modern History 1840 - 1990 Compiled and Typeset by Catchment Engineering of NZ Ltd.

Fetter, C. 1994. Applied Hydrogeology. Prentice Hall

Foster, M.W. 1988. Wellington Tidal Patterns: an essay on Wellington tides. Unpublished Wellington Harbour board report

Freeze, R.A.\& Cherry, J.A. 1979. Groundwater. Prentice Hall

Hay, A. 1984. Remote acoustic imaging of the plume from a submarine spring in an Arctic Fjord. Science Vol 225 pp $1154-1156$

Heath, R.A. 1976. Circulation and hydrology of Wellington Harbour. Report done for the Wellington Harbour Board: Report of Hydrographic sub-committee of harbour survey.

Heath, R.A. 1971. Hydrology and Circulation in central and southern Cook Strait, New Zealand. New Zealand Journal of Marine and Freshwater Science. Vol 5(1) pp 178-199

Hochstein, M.P. and Davey. F.J. 1974. Seismic measurements in Wellington Harbour. Journal of the Royal Society of New Zealand. Vol 4 no 2 pp 123-140

Hovland \& Judd 1988. Seabed Pockmarks and Seepages: Impact on geology, biology and the marine environment. Graham \& Trotman.

Huber, P.H. 1992. Late Quaternary Stratigraphy and Neotectonics of Miramar Peninsular and Rongotai Isthmus, Wellington, New Zealand. Unpublished M.Sc thesis, Victoria University of Wellington Library.

Hutton, P.R. 1965. Report on the Hydrology of the Lower Hutt Valley. Unpublished Hutt Valley Underwater Authority Report

Ian R Brown Associates 1995. An investigation of latest displacement events on the Wellington Fault in the Lower Hutt area. Earthquake Commission Research Project 93/128.

Irwin. S.L. 1993. Modern Sedimentary Processes and Distribution Trends in the Petone Foreshore Area, Wellington Harbour, New Zealand. Unpublished B.Sc. Honours project. Victoria University of Wellington Library. $85 p$

Jankowska, H. et al. 1994. Salinity variations as an effect of groundwater seepage through the seabed (Puck Bay, Poland). Oceandogia. Vol 36(i) pp 33-46 
Johannes, R.E. \& Hearn, C.J. 1985. The effect of submarine groundwater discharge on nutrient and salinity regimes in a coastal lagoon off Perth, Western Australia. Estuarine, Coastal and Shelf Science. Vol 21 pp $789-800$

Johnson, G.B.W. 1988. Wellington Harbour and Approaches: Tidal streams and currents. Unpublished report for Wellington Harbour Board.

Kohout, F.A. 1966. Submarine Springs: A neglected phenomenon of coastal hydrology in: Hydrology and Water Resources Development - Symposium C.E.N.T.O Ankara 5-12 February, 1966. pp 391-413

Lauder, W.R. 1962. Port Nicholson and the "Plough" mechanism in transcurrent faulting. New Zealand Journal of Geology and Geophysics. Vol 5 pp 189-191

Lee, D.R. 1977. A device for measuring seepage flux in lakes and estuaries. Limnology and Oceanography. Vol $22(1)$ pp 140-147

Leeder, M.R. 1982. Sedimentology; Process and Product. George Allen \& Unwin

Legrand, H.E. \& Stringfield, V.T. 1973. Karst hydrology - a review. Journal of Hydrology. Vol 20 pp 97 120

Lewis, K.B. 1989. A reversal of throw and change of trend on the Wellington Fault in Wellington Harbour. New Zealand Joumal of Geology and Geophysics. Vol 32 pp 293-298

Lewis, K.B. and Carter, L. 1976. Depths, Sediments and Faulting on each side of the Rongotai Isthmus, Wellington. New Zealand Oceanographic Institute Summary no. II

Lewis, K.B. \& Mildenhall, D.C. 1985. The late quaternary seismic, sedimentary and palynological stratigraphy beneath Evans Bay, Wellington Harbour. New Zealand Journal of Geology and Geophysics. Vol 28 pp $129-152$

Lewis, K.B., Davy, B.W., Mitchell, J.S., Shakespeare, B.S. 1987. Reconnaissance seismic survey of the entrance to Wellington Harbour. Contract report for the Wellington City Council.

Matthews, E. R. 1980. Observations of Beach Gravel Transport, Wellington Harbour Entrance, New Zealand. New Zealand Journal of Geology and Geophysics. Vol. 23 pp $209-222$

Meinzer, O.S. 1927. Compressibility and elasticity of artesian aquifers.

Parker, G.G. \& Stringfield, V.T. 1950. Effects of earthquakes, trains, tides, winds

Pedersen, L. 1974. Bibliography of Scientific studies of Wellington Harbour. Miscellaneous Publication 56 New Zealand Oceanographic Institute DSIR.

Reyners, M. \& Chistoffel, D. 1973. A continuous seismic reflection of part of Wellington Harbour. Report Phys $17 / 73$ Part 1 and 2. Physics Department, Victoria University of Wellington, New Zealand.

Roxburgh, I.S. 1985. Thermal infrared detection of submarine springs associated with the Plymouth iimestone. Hydrological Sciences - Joumal-des Sciences hydrologiques. Vol 30 no 2

Sadler \& Searson. 1980. An unusual polynya in an Artic Fjord. Fjord Oceanography.

Schneider, H.; Thiele, R. \& Wille, P. 1985. Measurement of sound absorption in low salinity water of the Baltic Sea. Journal of the Acoustic Society of America. Vol 77 (4) pp $1409-1412$ 
Stevens, G.R. 1955. The Late Tertiary and Quaternary Geological History of the Hutt Valley. Unpublished M.Sc thesis (2 volumes), Victoria University of Wellington Library, New Zealand.

Stevens, G.R. 1956a. Earth movements in the Wellington Area. New Zealand Geographer (13) pp 189. 194

Stevens, G.R. 1956b. Stratigraphy of the Hutt Valley, New Zealand. New Zealand Journal of Science and technology Series B Vol 38 pp $201-235$

Stevens, G. R. 1974. Rugged Landscape: The Geology of central New Zealand. A.H. and A. W. Reed, Wellington

Stirling, M.W. 1992. Late Holocene beach ridges displaced by the Wellington Fault in the Lower Hutt area, New Zealand. New Zealand Journal of Geology and Geophysics Vol 35 pp 447-453

Stringfield \& Cooper 1951. Geologic and Hydrologic features of an artesian submarine spring east of Florida. Florida Geological Survey: Report of investigations. Vol 7 pp $57-92$

Suggate R.P.; Stevens, G.R.; Te Punga, M.T. (Eds) 1978. The Geology of New Zealand Government Printer, Wellington. 2 Vols, $820 p$

Thorpe, H. 1992. Groundwater - The Hidden Resource; in Waters of New Zealand, Ed. Mosley, M.P

Todd, D.K. 1959. Groundwater Hydrology. John Wiley \& Sons

Truebridge, Callender, Beach \& Co. 1978. The Kaiwharawhara Development. Environmental Impact and Feasibility Study. Prepared for the Wellington Harbour Board.

Van der Linden, W.J.M. 1966. Wellington Harbour Sediments. 1:63,360 NZ Oceanographic Institute Chart. Miscellaneous Series No. 14

Van der Linden, W.J.M. 1967. A Textural Analysis of Wellington Harbour sediments. New Zealand Journal of Marine and Freshwater Research (1). pp $26-37$

Van Dissen et al. 1992. Paleoseismicity of the Wellington - Hutt Valley segment of the Wellington Fault, North Island, New Zealand. New Zealand Journal of Geology and Geophysics. Vol 35 pp 165-176

Van Dissen \& Berryman 1996. Surface rupture earthquakes over the last 1000 years in the Wellington region, New Zealand, and implications for ground shaking hazard. Journal of Geophysical Research (B3). Vol 101 pp 5999-6019

Vanek, V. \& Lee, D.R. 1991. Mapping submarine groundwater discharge areas - an example from Laholm Bay, southwest Sweden. Limnology and Oceanography. Vol 36 pp 1250-1262

Wellington Harbour Board 1925 - 1933. Various unpublished Wellington Harbour Board Annual Reports $1925-1933$.

Wellington Regional Council (WRC). 1995. Hydrology of the Hutt Catchment; Volume 2 Groundwater. Hydrological Services Group, Wellington Regional Council.

Wellington Regional Council (WRC). 1998. Moera Aquifer Investigation. Prepared by Brydon Hughes, Resource Investigations Department. Publication No. WRC/RINV-T-98/13

Wood, R. and Davy, B. 1992. Interpretation of Geophysical Data Collected in Wellington Harbour. Client report no. 1992/78. Prepared for Wellington Regional Council. IGNS, Wellington, New Zealand 
Wood, R., Davy, B., \& Cook, D. 1989. Seismic Reflection Survey of the Entrance to Wellington Harbour, 1989. Contract Report no. 113. Prepared for Wellington City Council. DSIR, Wellington New Zealand

Zektzer, I.S., Ivanov, V.A. \& Meskheteli, A.V. 1973. The problem of direct groundwater discharge to the sea. Journal of Hydrology. Vol 20 pp 1-36

Zuber, A. 1970. Method for determining leakage velocities through the bottom of reservoirs in: Isotope Hydrology IAEA. Pp 761-771 
Appendix One

Historic Notes; Unpublished reports/information found in the Wellington Harbour Board and Wellington Regional Council Archives 
Wellington, c.i, N.z., 26tis Feoruary, 1937.

\title{
HUTT RIVES ESTUERE: AEIEGSD ISOSITC OE ARTESTAT MANQR.
}

\author{
The City Engineer, \\ Tom Fall, \\ TELIINETOI.
}

\section{Dear Sir,}

With reference to the abore-noted matte: and conrespondence that has been received oy the Jepentment from the Tom EaIi, I wish to advise rou that $a$ careful examination has been made by a citren ol those deeo dredge holes minich have been suguested as tie cause of the alleged loss of artesian head. The divel reponts that he found no trace at all of any disturiance on inzom of rater, the water in both pits being quite celm, the particles of silt izghted up oj his torch act shoming any movement. He aiso reports he ojid zind ac trece of porous on graveliy seañ, the mazis of the zit apean

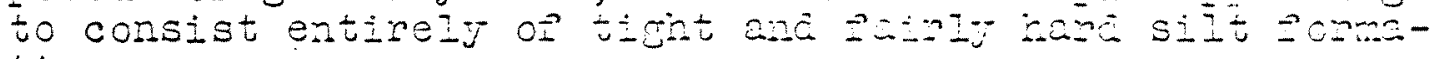
tion.

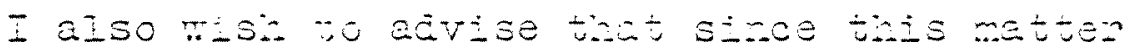

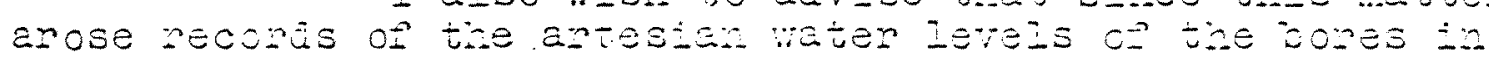

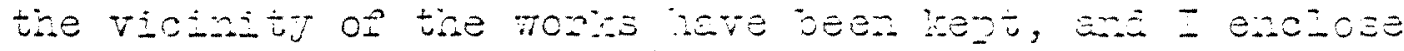

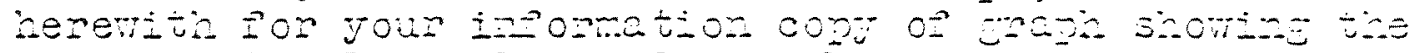
antesian ievels at jor tice as diservec à tis bore at

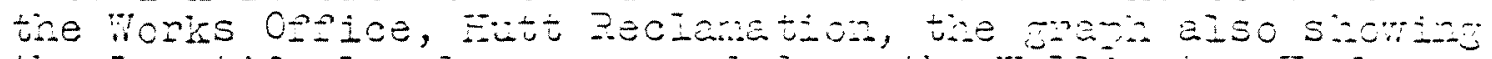

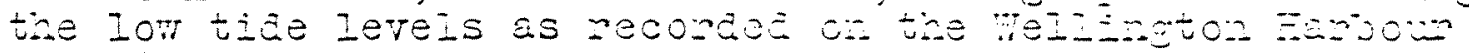
3oard's chants. Gre obsepretiona have bean maje at Iow

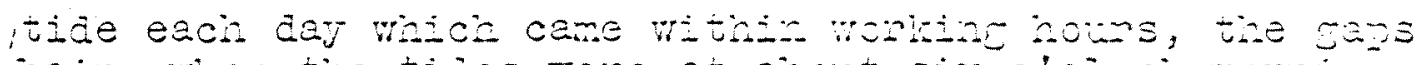

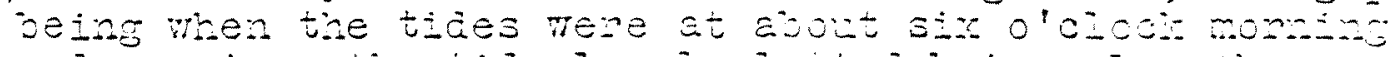

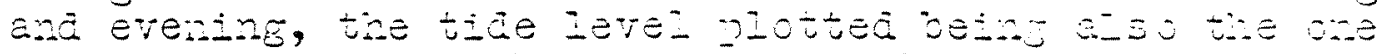

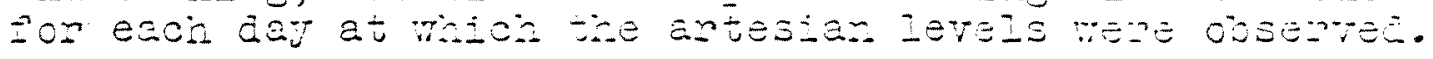

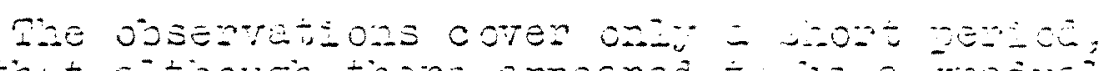

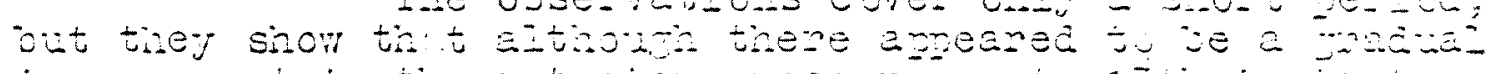

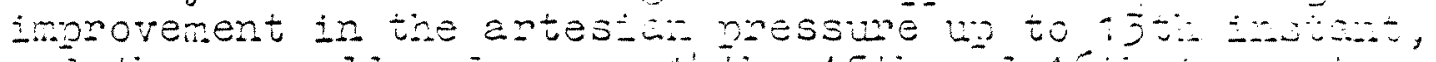

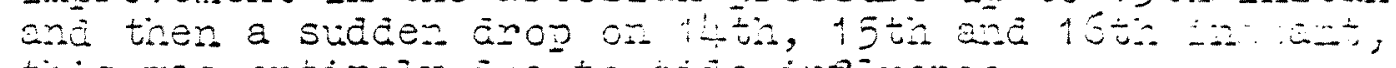
this was entireit sue to jide infuence.

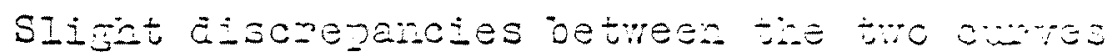

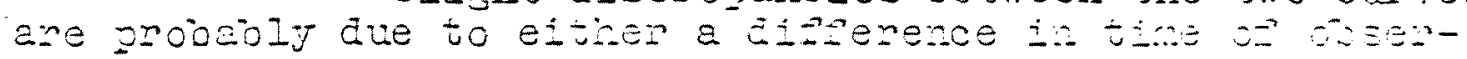

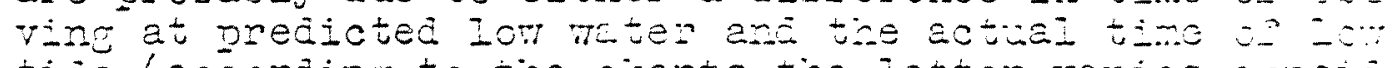
tide (according to the chants the latten vazies conjoenabiy, in some cases the tide being less tian iz a.......

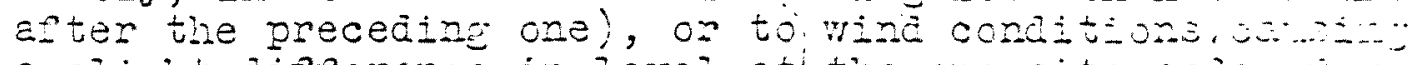
a sifont difference in Level at the opposite ends $\ldots . .$. Earbour.

These ojsenvations cleariy show th- $\quad \because \mathrm{i}$ to which variations in the artesian mater leveis to tidal influence, tine level also varying curing in: in step with the vaniation in tide levels. 



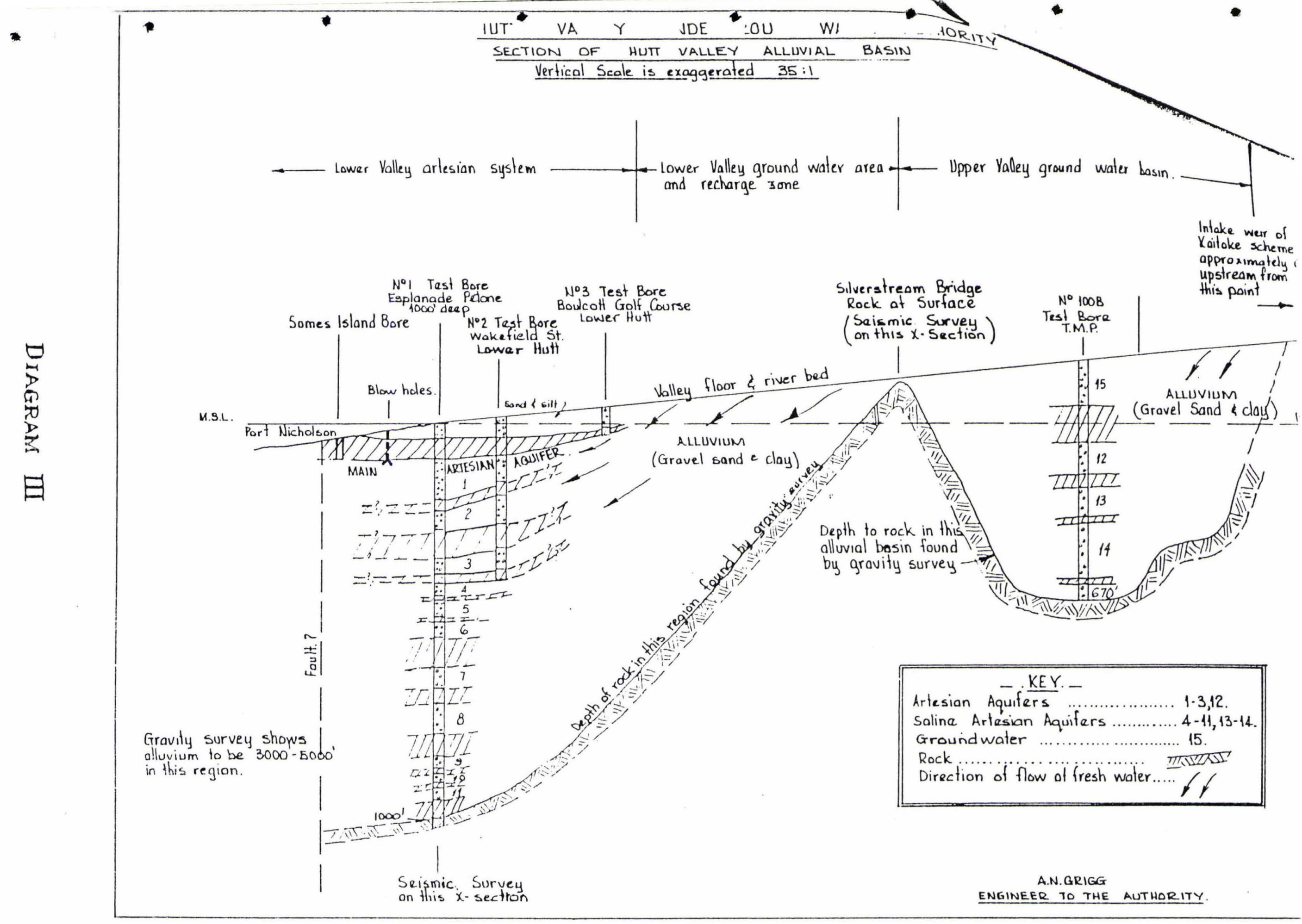


5th March, 1937.

To the Engineer-1n-onlaes and

Under-3ecretary,

Eublic Horks Departront,

HELETaTO: OI.

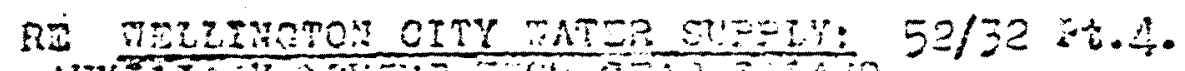

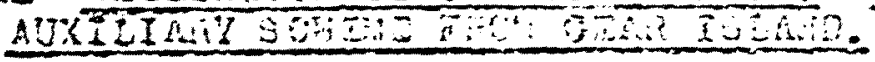

Dear S15;

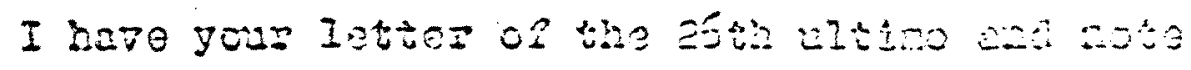

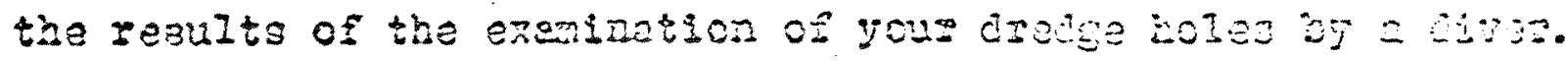

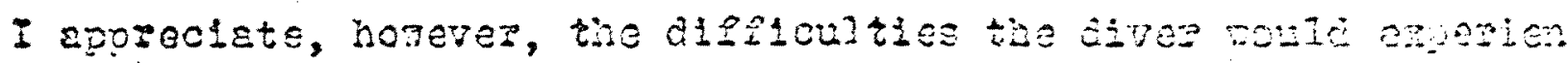

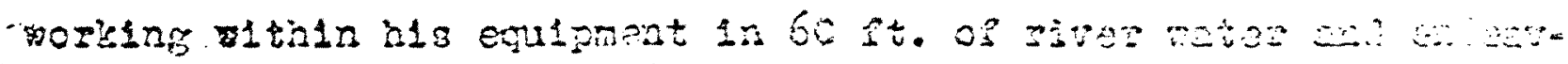

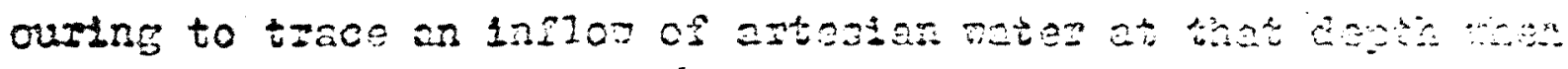

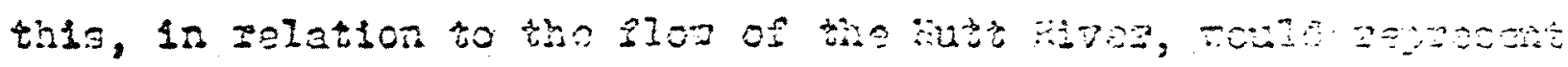

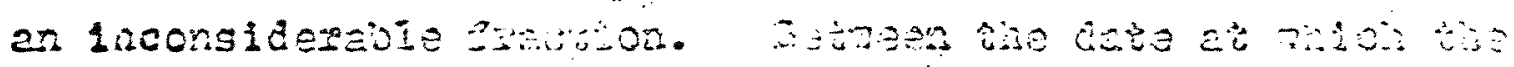

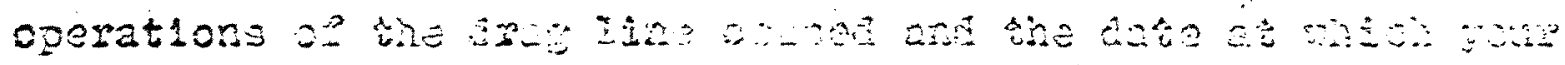

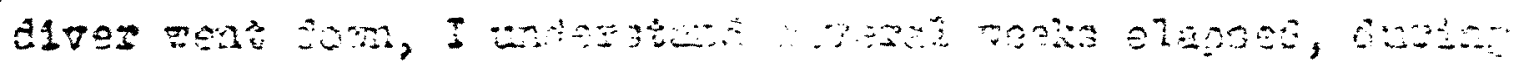

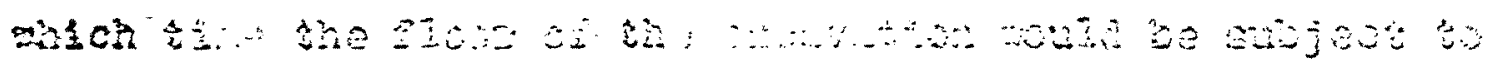

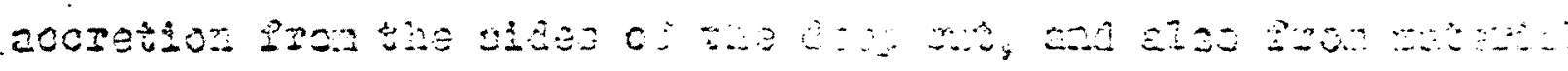

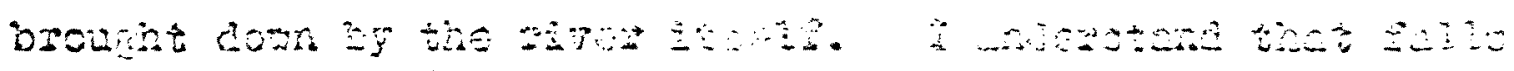

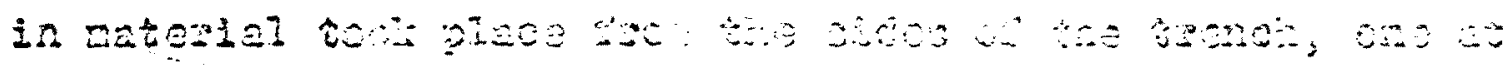

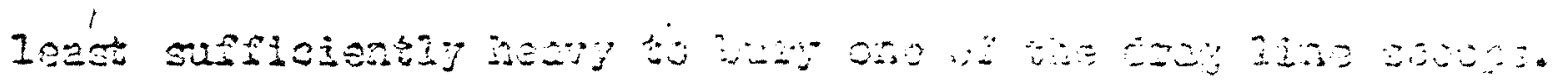

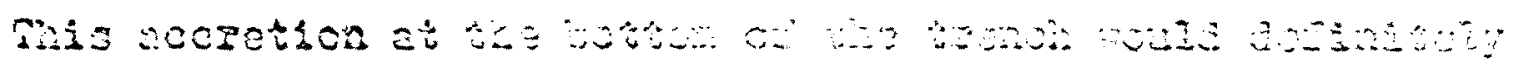

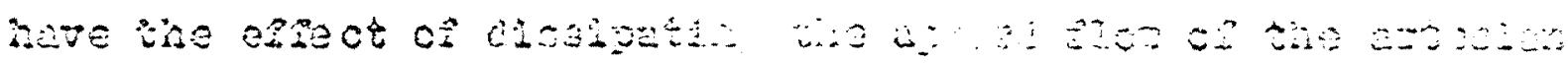

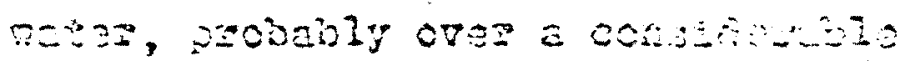

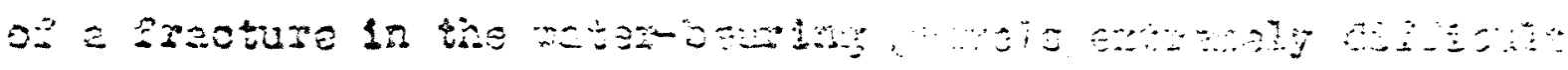
¿̊sect.

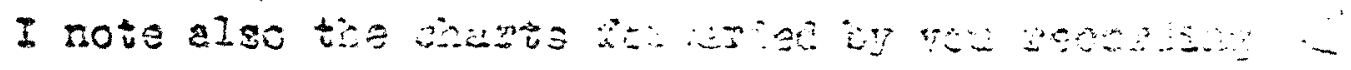

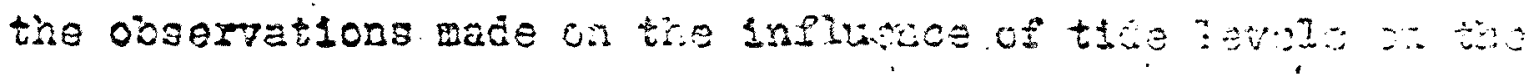
plezometrie head. I ish to advige, in this obmectic. 
orer the last three or four gears and bave not been confined to the lower end of Gear Island, but have been riated to vells spread orer the jhole artesian area. None of cur records shor the sudeen drop which as noted on tis ezuge at the Gear Isiand Punplng station on the l2th January last. I should al so like

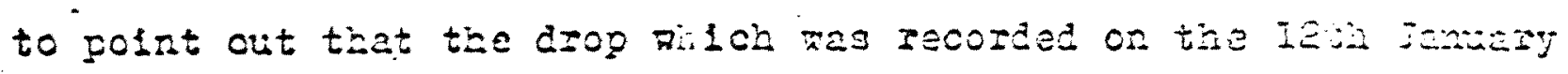

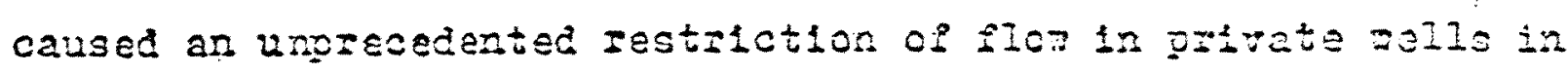
areas contigious to Gear Isiand. If the drop in level nas, as you imply, the natural sequance of tile epfect, than sureiy this

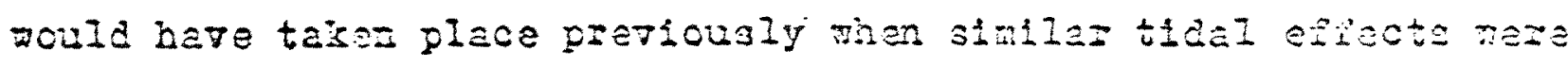
experienced.

\section{Eefore cecting or a derelognext of an artesian} supply in the Futt $\nabla$ a Iey, the Otty Corporation cartisi att

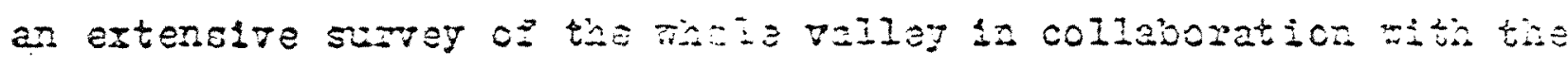

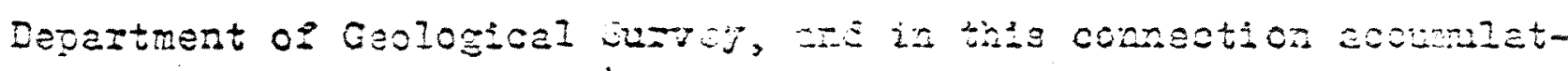

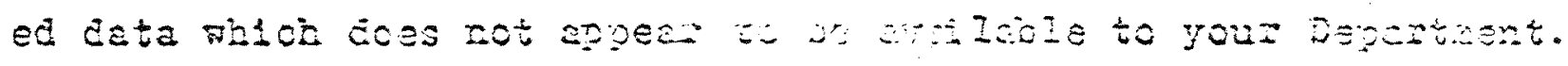

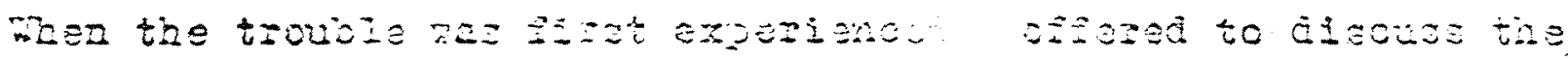

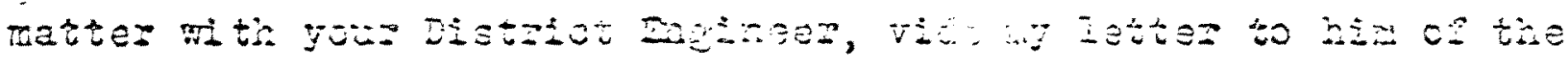

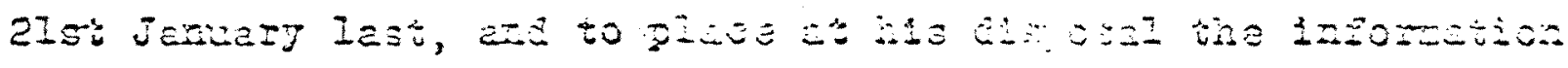

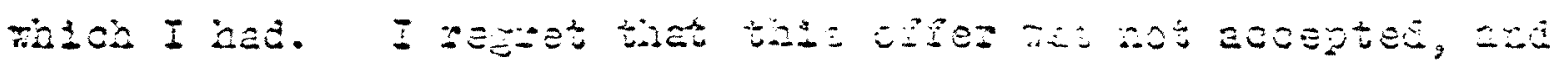

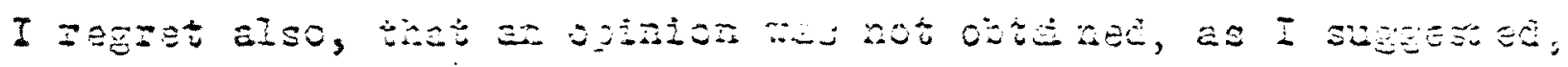

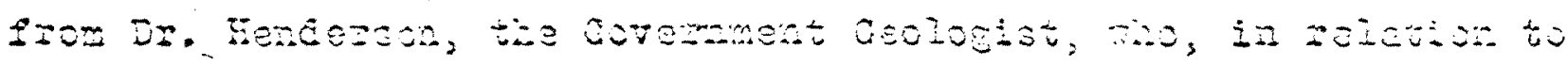

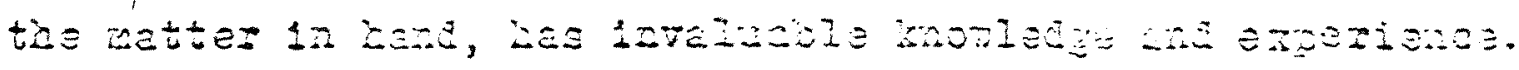

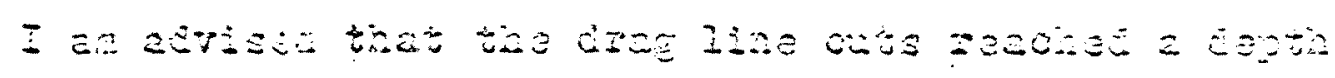

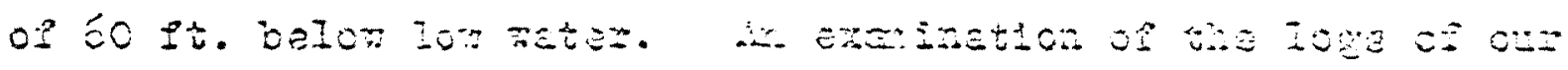

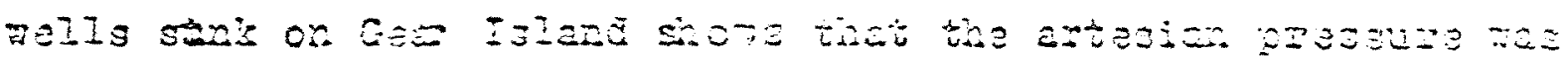

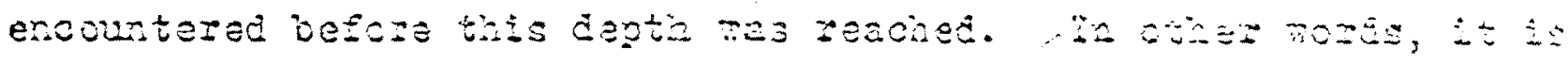

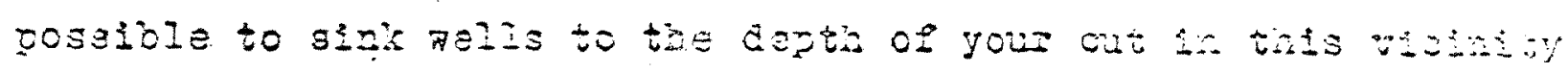

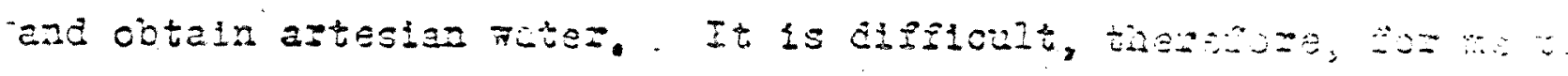

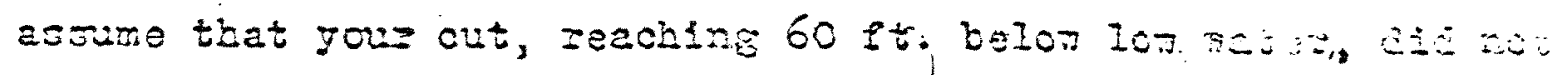

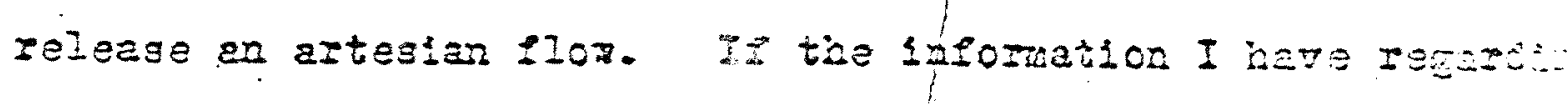

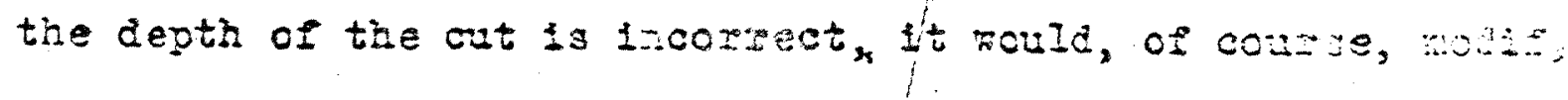

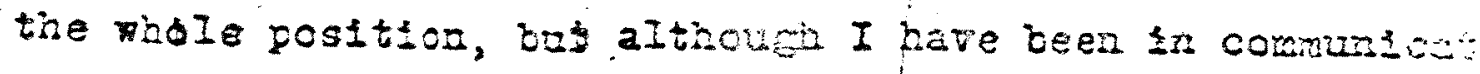




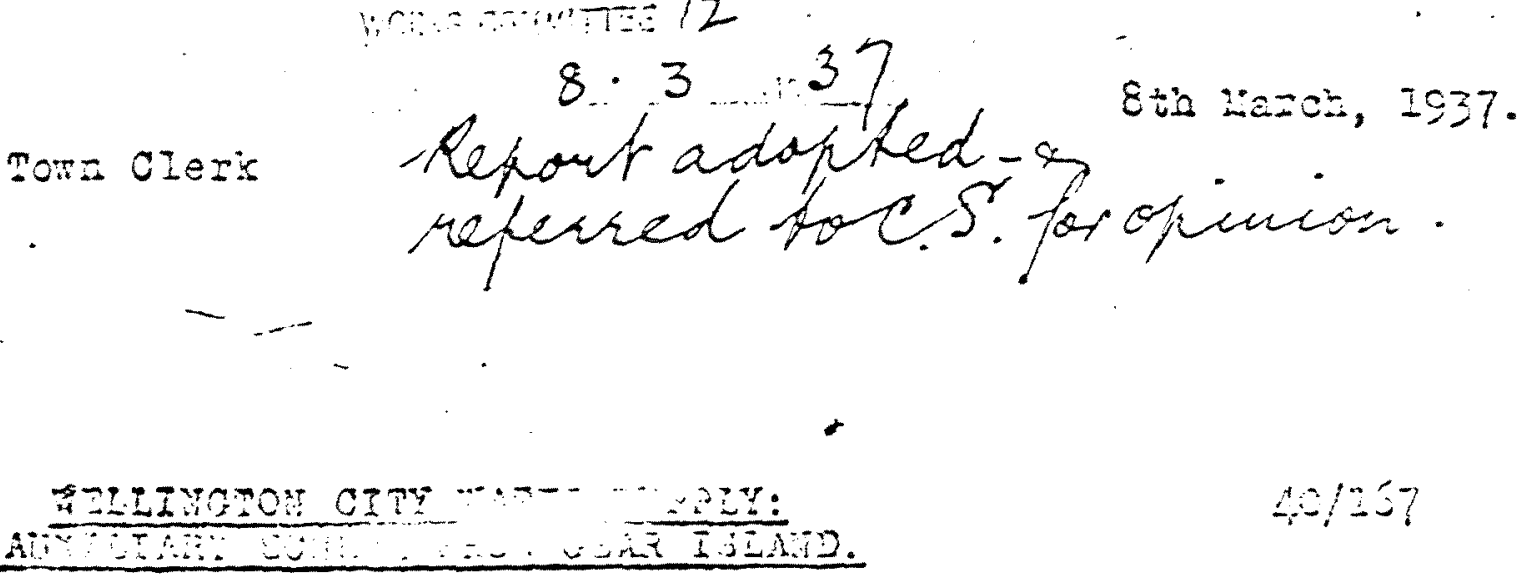

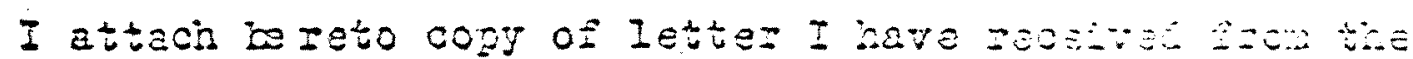

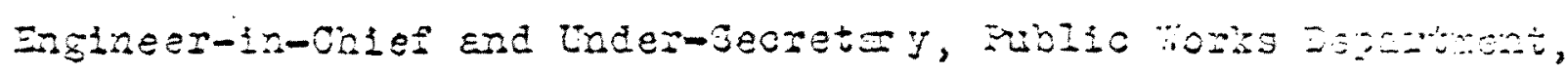
dated 26ti ultimo, and a copy of my reyly to hix. E:-

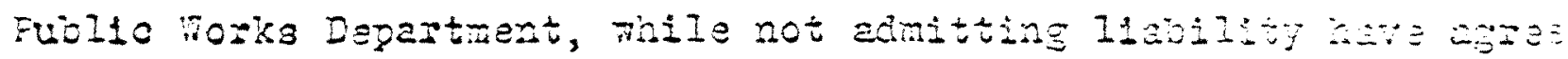
to restrict the operations of the drag Iine ca soato 20 ind

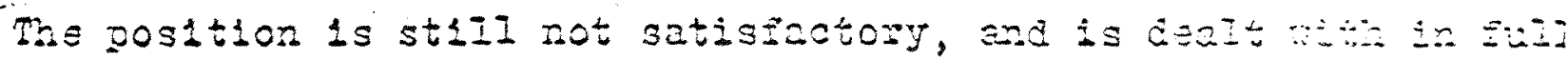
In wy repiy to the Engineez-1n-oniez.

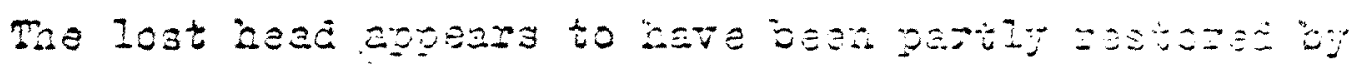

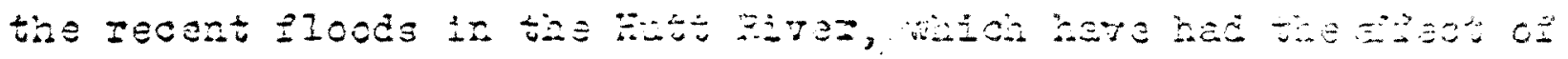

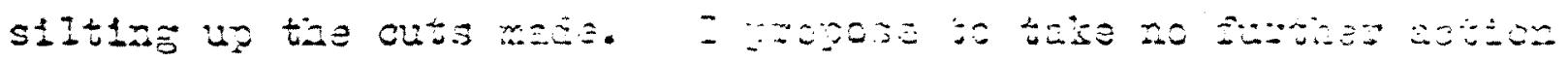

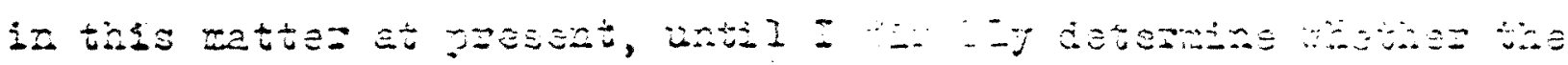

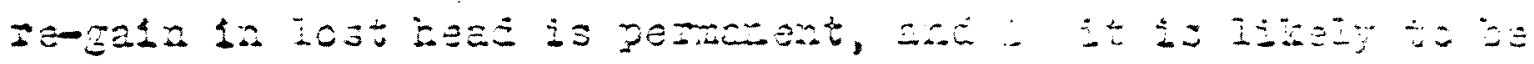
cumulatร7?.

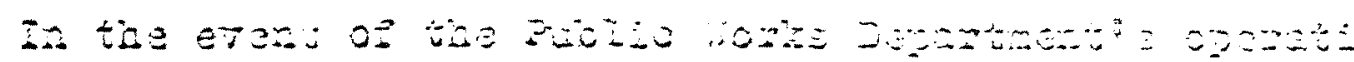

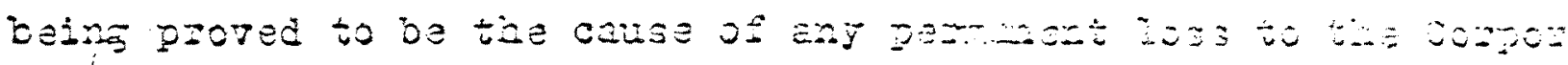

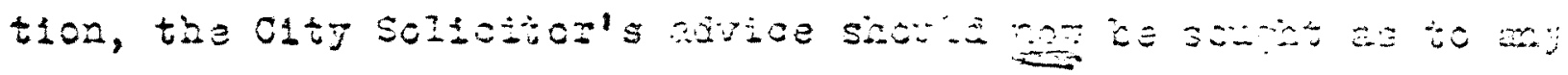

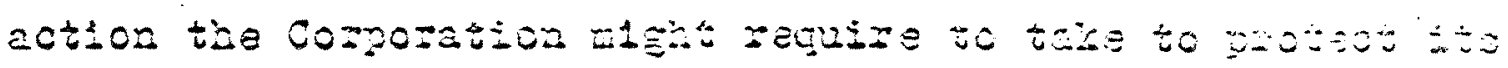
1nterests. 
Memorandur for

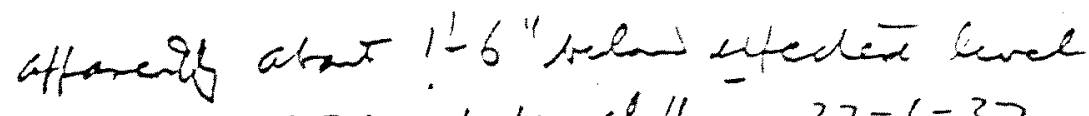

ux. Siniburne.

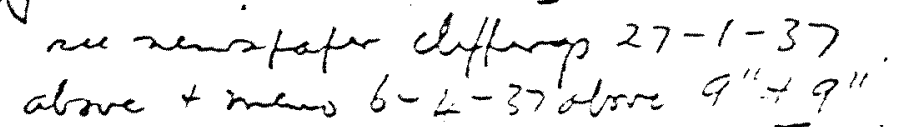

RE LOSS OF PAESSURE: GEAR ISLAND ARTESIAN SUPPIY. JaW $5-2-68$

on suesdey the 12th 1nstant, a casual obsezvation

of the static gauge reading at the Gear Ioland Pumsta

Station appeared to indicate a lop reading when congared with the state of tide. Actual tide helght not observed.

on Thursday tre 14tis ingtant, a complaint wes

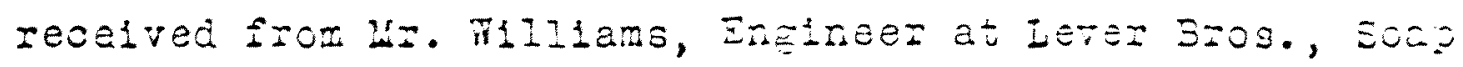
Torks, re lot pressure.

on Friday the 15th Anstant, 7 ith its. Fromaz

visited the Puplag Station and checked stutto sause ankinst tide readires, be1ne gauge 50.14 C.D., tide 37.00 .

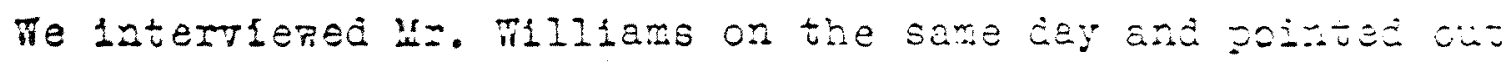
that the drop ras not ceused by any operations of tas T. S. o.

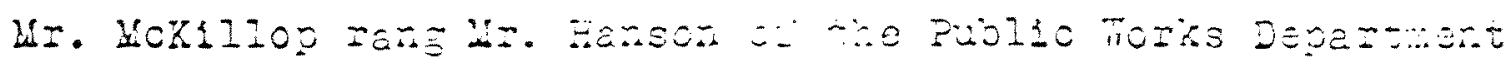

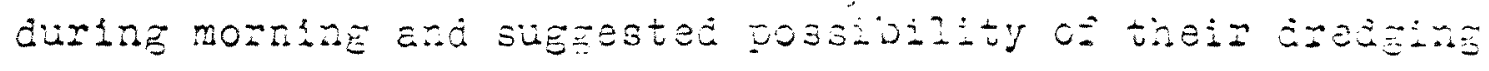
operations caustig the trouble.

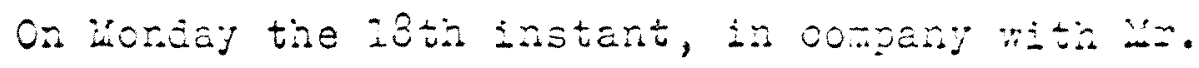

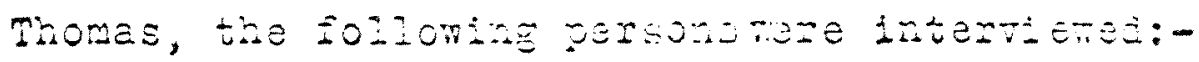

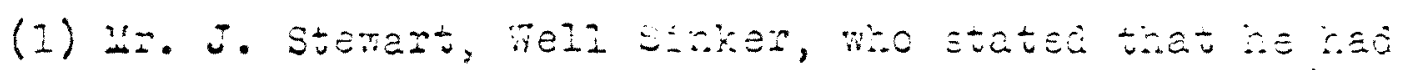

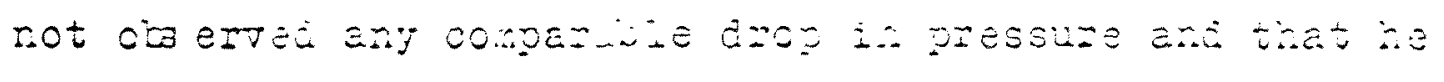

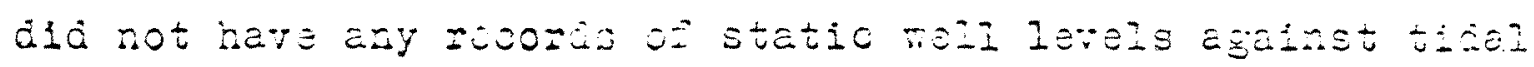
Lย约施.

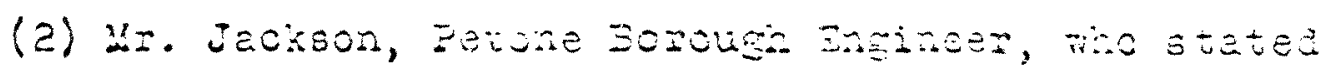

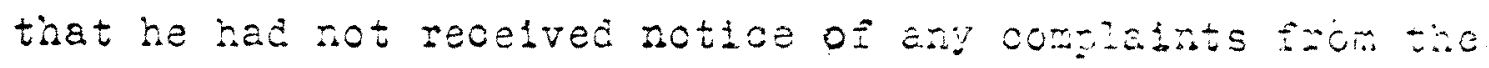

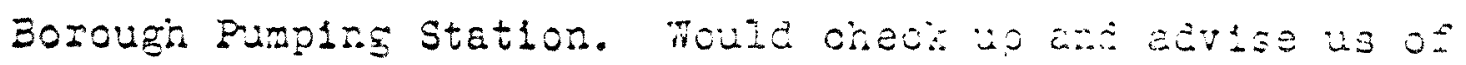
results.

(3) Mr. Danielis, Inzineer to the Gean lleat irons, who has not exere of ary iocel effect.

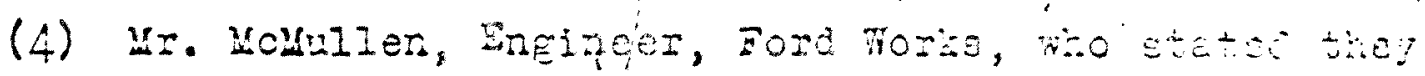
had no wells, but proposed sirking one and mould be : to record any data requilea. 
Harbour Board, who showed us sourdings off mouth of intt River. Thege revealed low water soundingup to $63 \mathrm{ft}$, one such depth belng off Pt. Howard Fiarf and too or three others some distance off sinore to the west of mouth of river

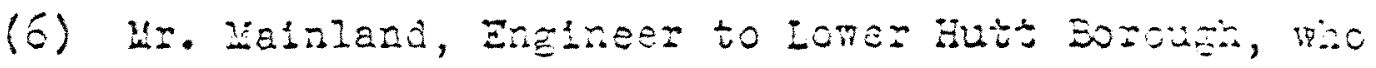
had no knowledge of any trouble, but rould advise us futthe after checking.

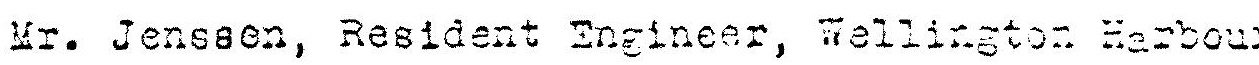
Board (per telephone) was quite agreeable to the Zu.

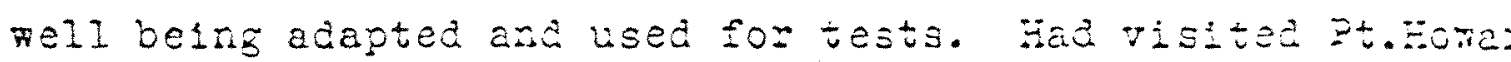

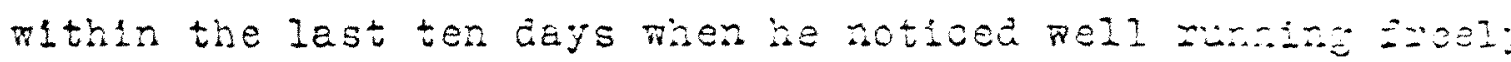

Tie risited site of Ava test pore, ?.i. Z. zezianat. noris, Acetone Company's bujloing end Gean IGIans zunsinz

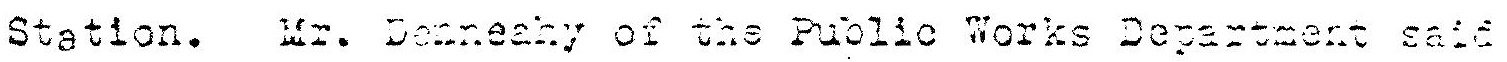

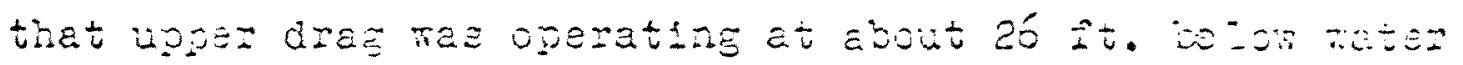

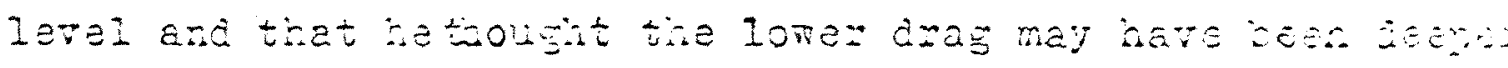

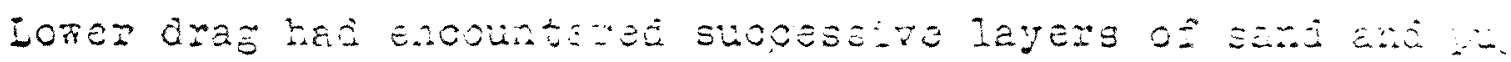

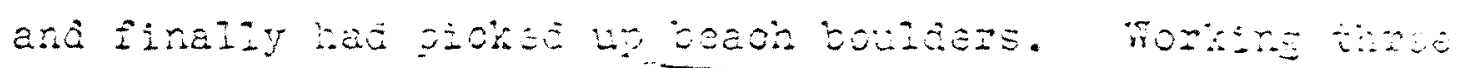

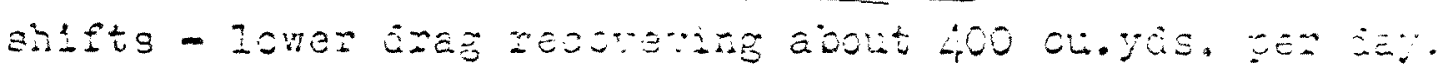

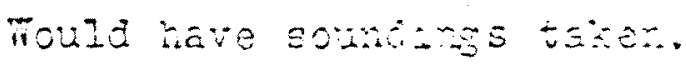

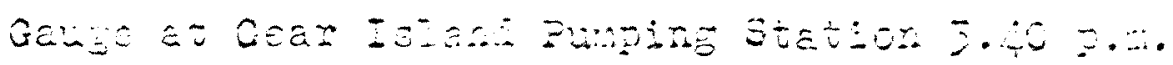
49.60 0.0. Iice 36. इ0 C.2.

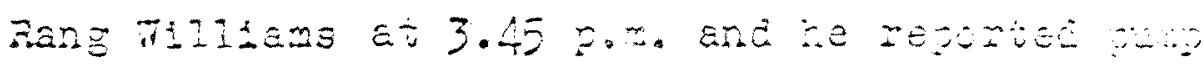
on condensers subirine Ėz.

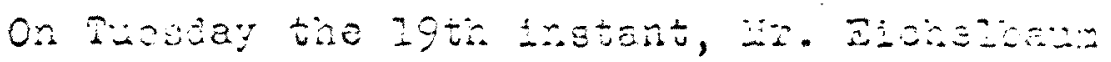

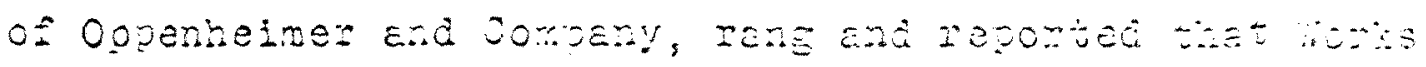

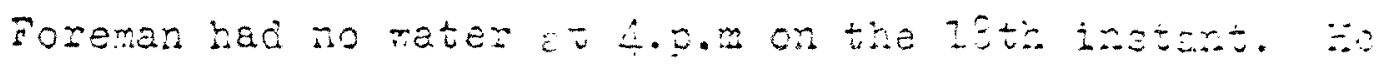

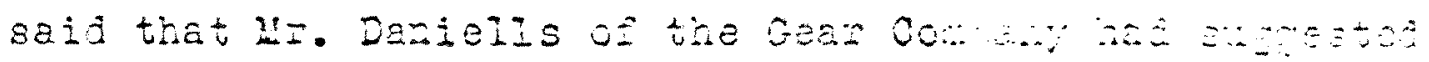

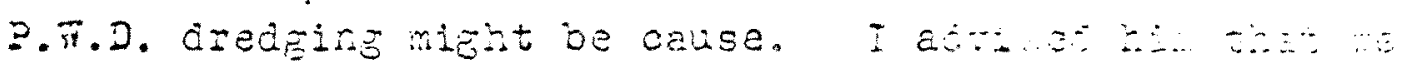

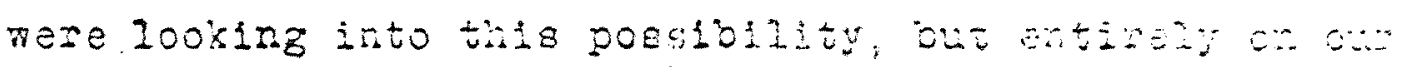

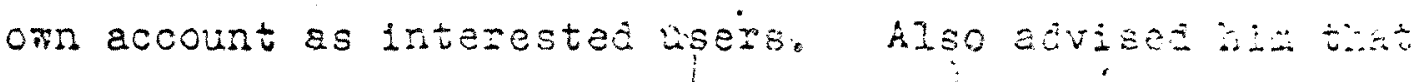
wells had been shut dom fof from 6 weeks to 2 montas.

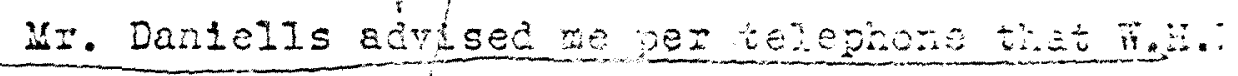

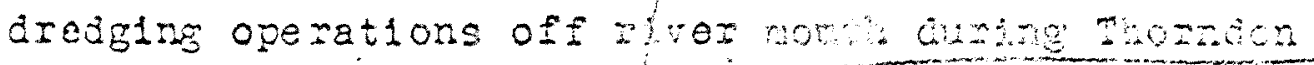


Reclametion had regulted in lowering of head at theis mells, a long time being taken over its recovery.

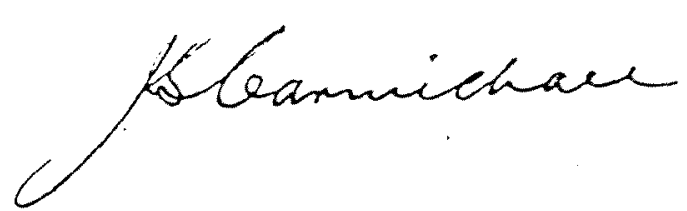


*

A trench has -been formed some little distance up

the river from where they are at present working,

and this proved to be $45 f t$.

$(45 \pm t)$

Still further up, where work was carried out in

January of this year, a trench was found to be $45 f t$. (145tt)

deep. It was while work was in progress at this

point, that the sudden drop in the height of rater

in the Artesian Hell took place.

We took measurements from high water mark, and con-

aidered that the tide would rise another five feet;

this rise mould add still another five feet on to

the measurements already given.

A. Rance l

Yours faithfully, 


\section{AFTESIAY BORE STME AT FO $G A R D$ DOINT OIT BERTH JANOARY 1936.}

An ortaslen bore was sunk in the position marlied on plan 3.T. $316 \cdot($ alas S.T,343)

A $3^{\prime \prime}$ diameter iron plpe vas sunk to a depth of 47 foot belon city Detum. The top of tho pipe is at 43 reat. ebovo elty Datuen.

A. Lo Weter on loth Januers 1936 the flow observed we 1.650 za 110 as por hour. At 71 gh water on 25 th Jenuary 1936 tha flow coservod wa 2 30 gallons pas hour 


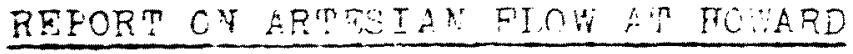

YOINI.

In July 1920, during the construction of Howard Foint 011 Jetty borings were thken to eacentein the reture of the hottom and the dopth cf the rervel bed. rhe borings ware tekon by mefins

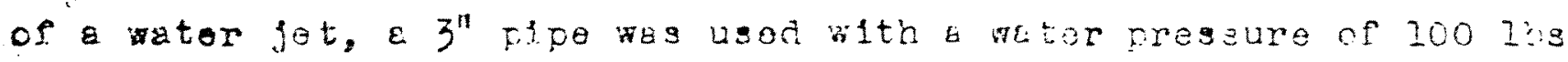
per square 1neh.

The bottor xas founa to consist of a single bed crerlaid

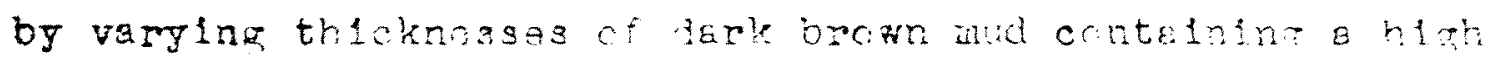
percentage of deceylng oreanic matter, which hec a stron cicur or Sulphupetted Pydroren. The borint ploe wa carried dow in - ach ease to the fraval bed and the cepth recorded. Pre mud offered very I Itte resistance, but 1t ras found affloult to penotrate into the ersel strate.

After the howhos rad hean completed e distinct disturbance was noticed on the surface of the water at the spot where No. 6 bore hed bean taken (sae plsn). Mila disturbance indicetad a strong upare flor of reter from the bot of the herocur enz spread over en ares of aprroximately 20 feet in diametar ch the surface.

A civer weg gent dom to investicate ond the folicyin: 1s a copy of his report:-

"Tro lnspations of this flow wero mad m mo. Cn the

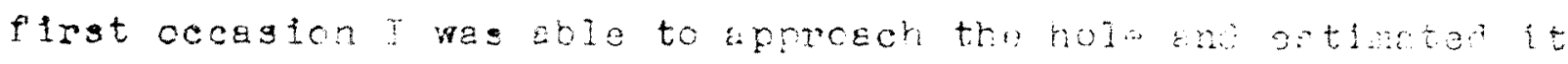

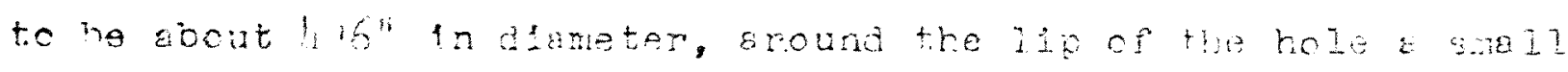
mound ubout : root in beltht had been buslt. The cutflow mas

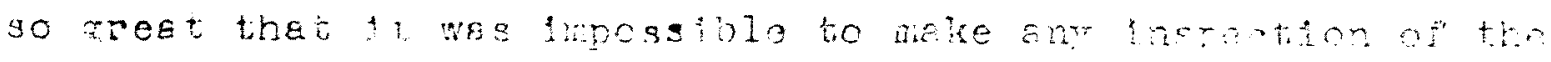
nole. 
Level, or at 38 feet below c1ty Detum. Some days afterwards I made a second inspoction. On this occasion a plpo was lowered Into the hole by the plie driver to ssist me to inspect the Plow and sample the flow. On descendirs to the bottom I found the flow considerebly reduced; the size and position of the hole had not changed. I lowered myelf into the hole and round that 1t gradueliy tepered to a minimum of 3 ' diameter at tho gravel strata some 361 below the around level, or at 33 feet below City Datum.

The bole continued about $5^{\prime}$ into the gravel bed and increxsed somowhat in diameter. This arovel strata was composed of water worn boulders up to about gn $^{n}$ in alze. The rlo of Fater seemed to come from the sides of the gravel strate rethar than from the bottom. I bottled samples of the vater from the bottom of the hole.

$$
\begin{aligned}
& \text { (SLgned) D. McLaan. } \\
& \text { D17er. }
\end{aligned}
$$

- The samplo of mater procured by the dires wa alightiy brackith

Aftar tho completion of the harf the holo was plugged by mogs of dumping spoli until the flow weg stopged and the hole fliled up to the orlainal depth at that spot. 
Lendictrat,

City. Fagineer optor

WEILINGTON.

Dear Sir,

As requested by you, I an forwarding the depth's of different channele ricich now exist in the Hutt River. These channels have been formed owitag to the Fublic Torks Dept dredging.

I took soundings at $10-30.2$ m., on satundey jovenben 6th, in the Futt River, wisere the Fublic Torks Dept have been working, and stili are pixking. I had with me my asoistant Engineer, in webley, together mith a man to use the sounding line, and also two nen to row the boat. We found the depti of the trenci were the drag is orkine neareat the sea, to be 35 ti desow rater.
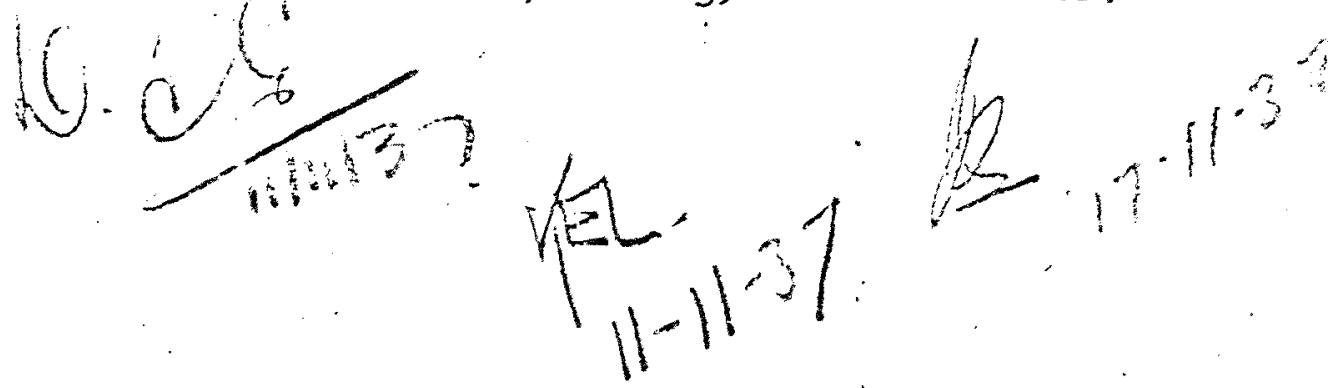


\section{2th Horember, 1937 .}

The Deputg City Inglneer.

RE ARTESIAT SUPPLT: GEAR ISLATI. O.E. 52/3? (Pt.4).

The folloning is a report on the position of the

artesian aupply at Gear Islend covertig the period when troubles nere experlenced onlng to nork carried out at scabef Island by the Public Moris Department:June, 1936 :

After the completion of the ertestan purping schom, a test run was made on the $4 / 6 / 36$, Fith all pumps maning for a pertod of at leest three hours. The puips at Gear IaZs=L

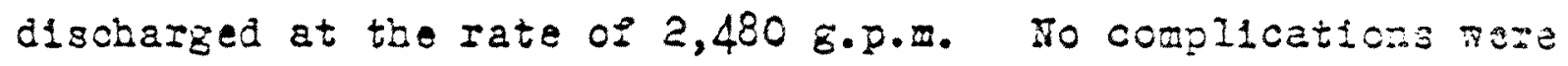
orident at the time ot this test. JuII, $1936:$

From the $9 / 7 / 36$ to $14 / 7 / 36$, the nelle neae leat

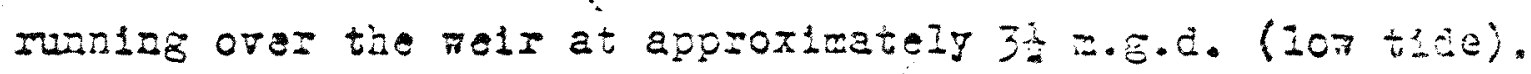

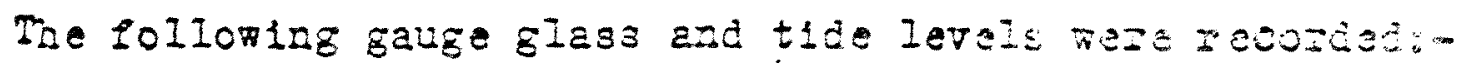

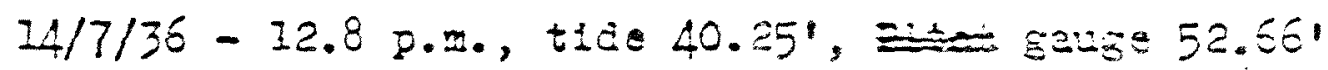

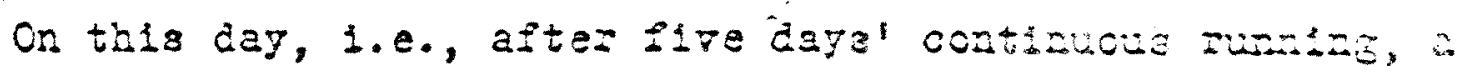
complatut ras zocelved from di. Batlend, Foultzy Gazaaz.

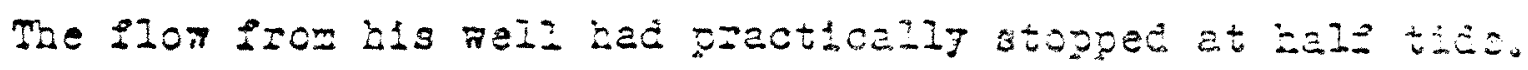

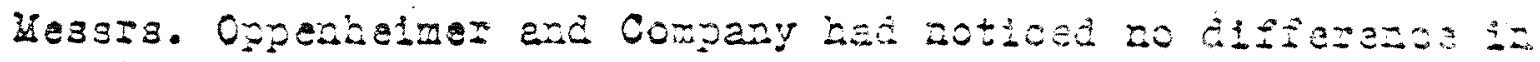
flow and pere not anaze that our rella had bas opezatins. Decenicas, $1925:$

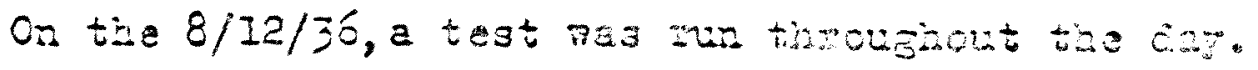

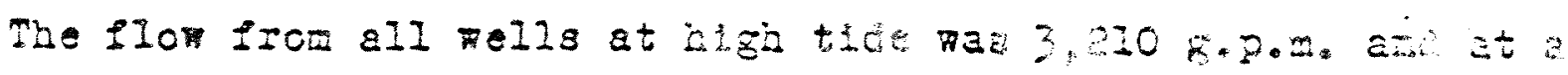
Ifttle belot half tide 2,930 g.p.a.

January, $1937:$

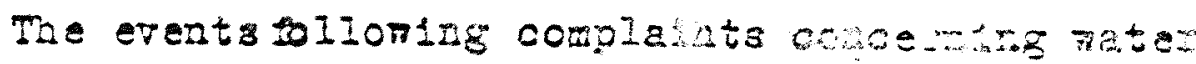
shortage by vartous local usom ot.

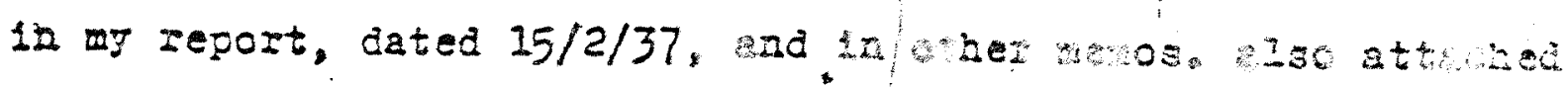
to file $52 / 32(8+.4)$. 


\section{IEgurta:-}

\begin{tabular}{|c|c|c|c|c|}
\hline ine. & $\frac{\text { Eutt RITeI }}{\text { Ilde. }}$ & $\frac{\text { R.B.B. }}{\text { I.de }}$ & Gauze. & $\frac{\text { Plon in }}{\text { G.P.L. }}$ \\
\hline $12.50 \mathrm{p} .2$. & $37.00^{\circ}$ & $36.20^{\prime}$ & $50.14^{\prime}$ & $\cdot 2,480$ \\
\hline $7.10 \mathrm{p.m.}$ & $39.20^{\circ}$ & & 51.281 & 2,71 \\
\hline
\end{tabular}

Frequent readings of bead and tice lepel folloriag tisto date are recorded on file 52/32 (Pt.4).
A comparison o
these
readings
os wis the 1953

racords as shonn on Chatt 3, Follo R. 165, indicated that the plezometric readiags on 18/1/37 wer $18^{\prime \prime}$ to $20^{\prime \prime}$ belor tis

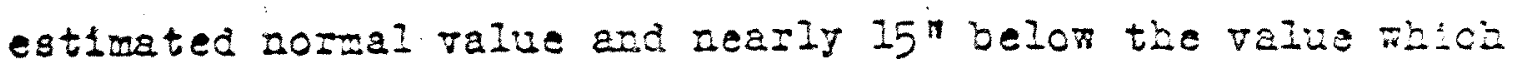
It was estinated fould be reached under drought conditions. The dimintion in Plon orer the nelr corresponding -to the above Ieduction in plezotetrlo pressura nould exount to approxiately I6\% of the high tide reading taken on 8/12/36, and eren tins leading eppeared to be lom and to indicate tias 2. dinfuntion of proseuzerad aIzeady commenced.

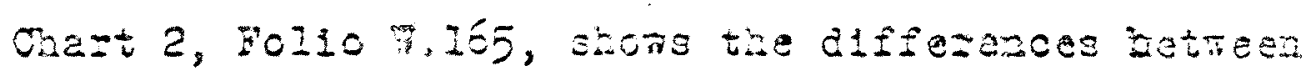

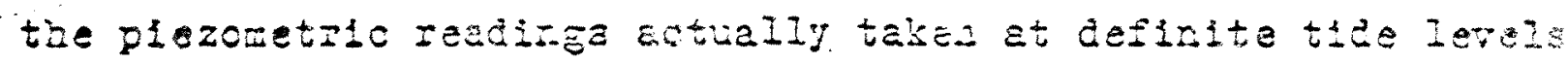
and the ralueg rifich rould be erpected for siailar tide Ievele teken from the 1953 recoras.

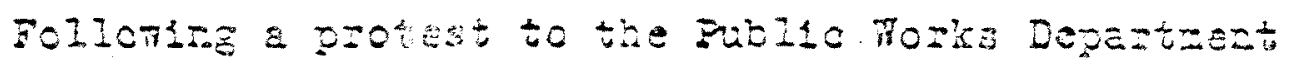

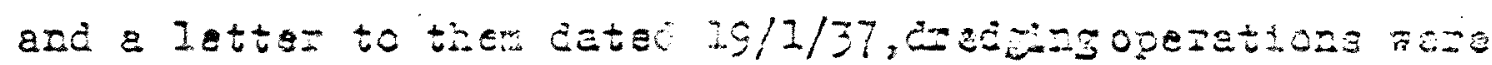

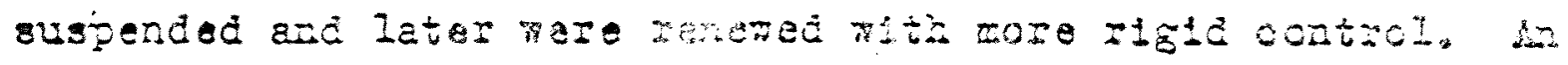

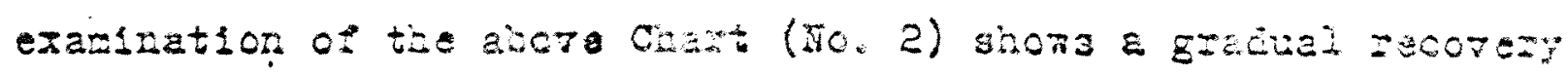

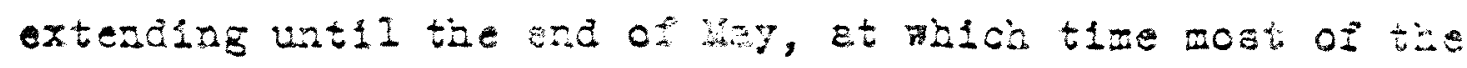
pressuze had boen rectored boording to gauge glase reactngs.

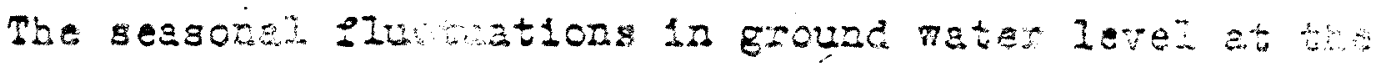

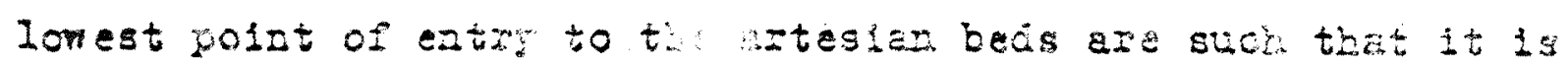

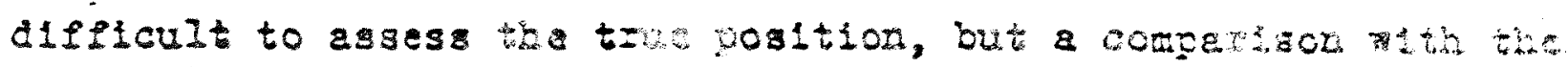

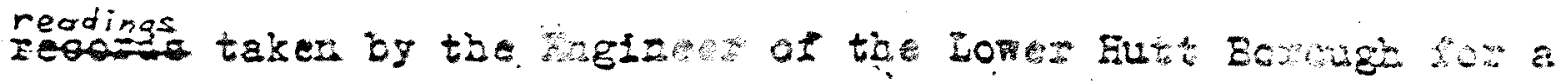


Deiz at Materioo Road Indicates that the plezonet-so pressurc at this mell was 6 abore normal at th1s date, obviously due to heary rains (soe Chart I0. I, J0110 M. 165) Taking th18 Into account, It 18 probeble that a 1088 in prossure of $4^{*}$ to 6*. stil_ezlated at Gear Island. June, $1937:$

In June and July, I937, this pressure loss was appreciably greater and the Pull10 Borks Department rere esked, per telephone, to check their soundiags. October, $1937:$

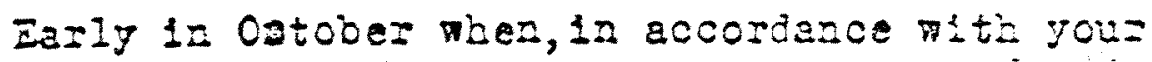
instriction, dated $25 / 8 / 37$, a furthor ciect on gavge ietels end Ilons was made, the bigh tide llon reading was 3,000 E.p.D. and the pressuro 1083 appeared to be approxinately $6 "$. Nore-rics, $1937:$

On the lgt Noremier, complatnts of rater shoptes were again recelved from local users of this artestar supply

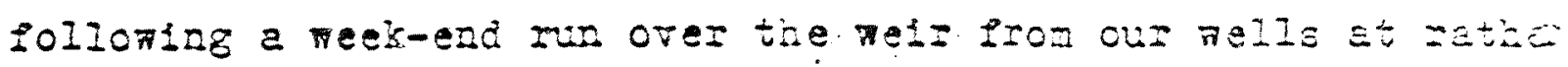

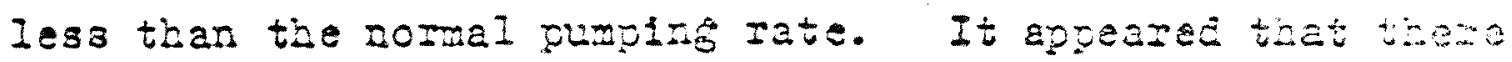
Lad been a considarable dzop in presaure a1zoe the 8/10/3i:

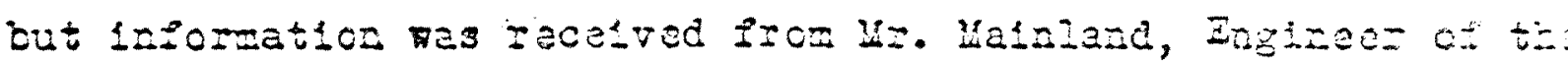
Lorer Futt Eorougia, that a drop of $6^{\prime \prime}$ had occurred at tise

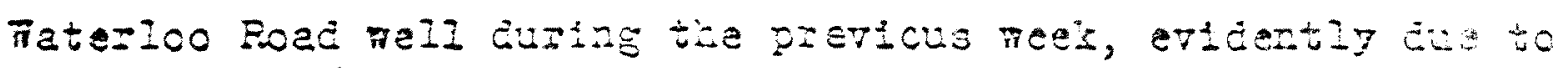
the ezceptionaly diy syell, axd tats rould account for nost of tie drop at ous rella.

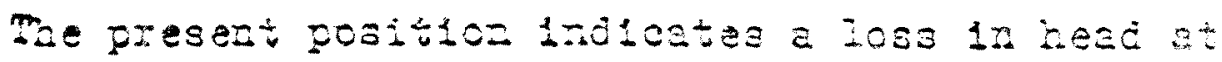

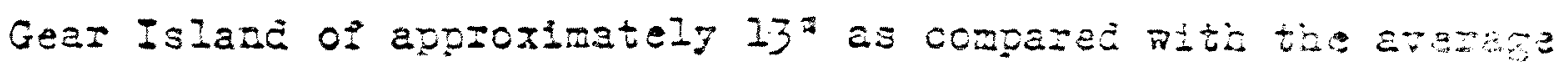

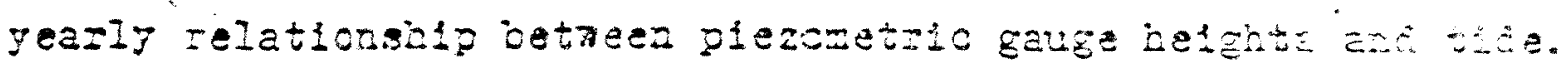

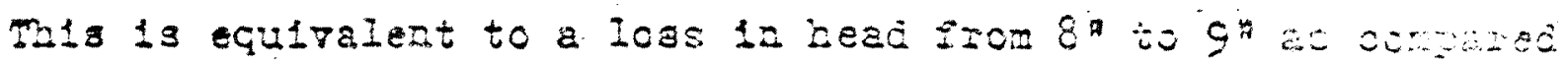
Wth the estinatec head uncer eroeptionally cig conc:

Using a value of $10^{\prime \prime}$ as zopresenting the Ioss riotof might be expected under dry neather conditions, such as a

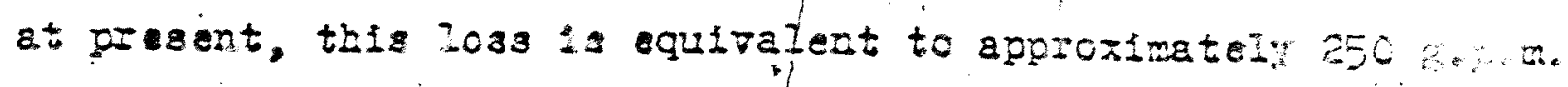
or the flow from one $4^{*}$ weII. 


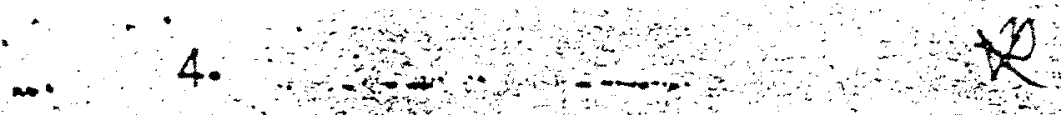

To1s pressure Ioss $\left(13^{n}\right)$, as compared with the relationships establisied by a largo number of readings taken in 1933 and 1934 , 1a largely due to the operation of the Publ10 Horks Department's drag-11nez, probably not wore than $3^{n}$ or $4^{*}$ being attributable to the present dry reather cond1t10ns.

$$
\text { giB Jhomas. }
$$




\section{Hon. MInstar of PuDile Vorks,}

In eferonce to $70:=$

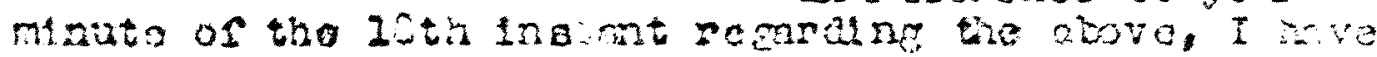

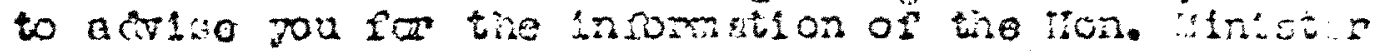

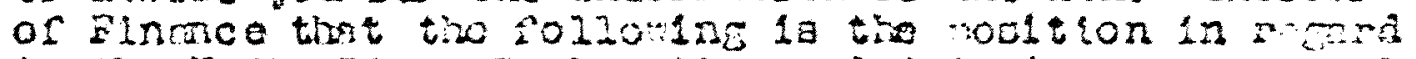

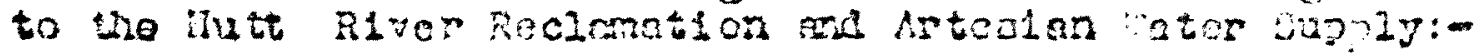

It 10 clasmed by tho

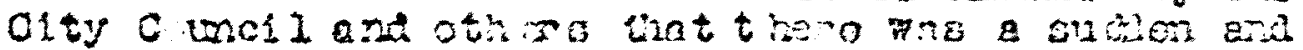

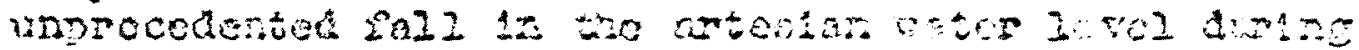

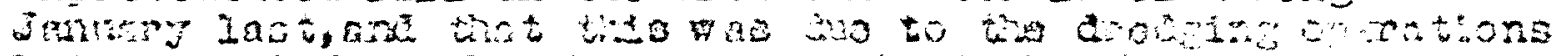

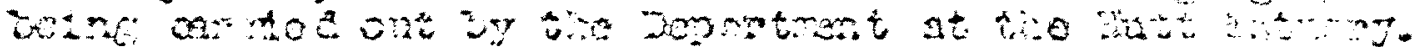

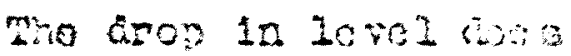

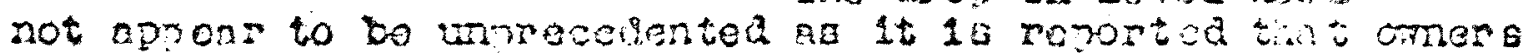

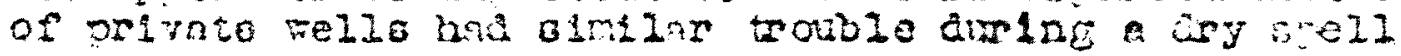
come joaro sgo.

\section{I bave no record of}

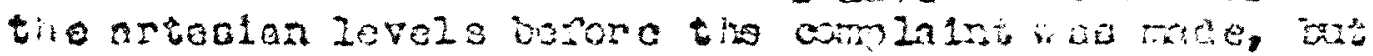

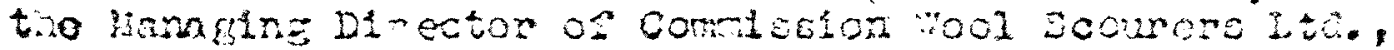

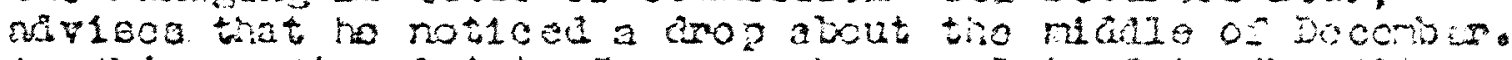

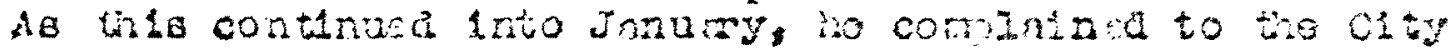

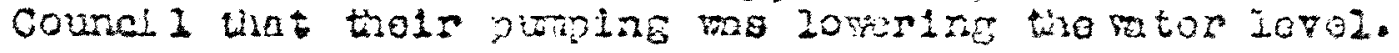

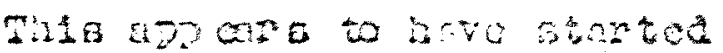

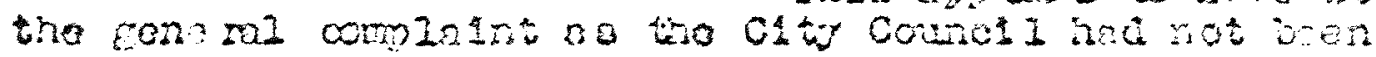

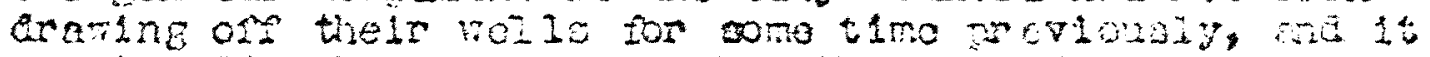

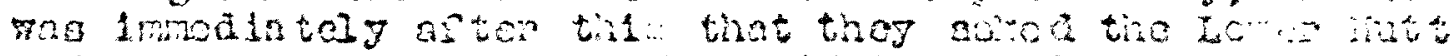

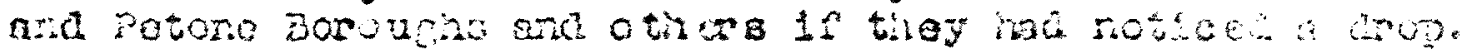

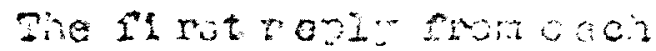

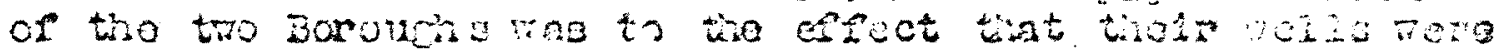

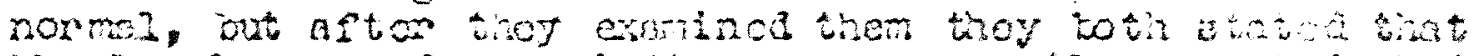

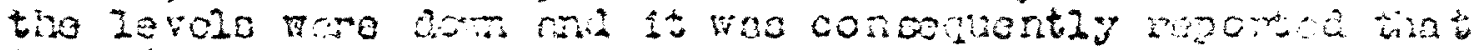

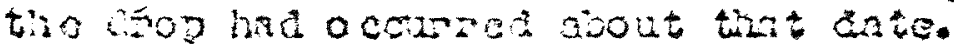

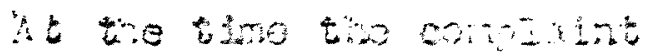

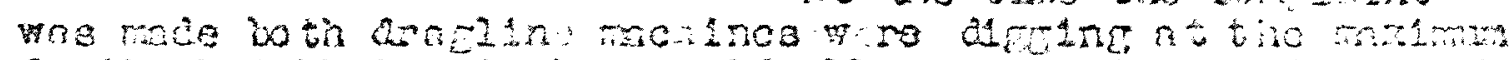

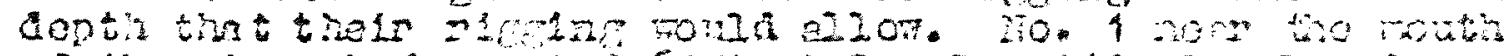

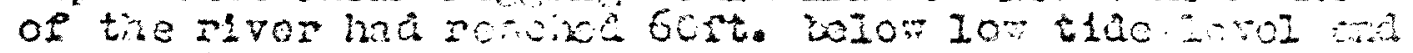

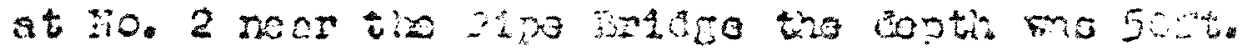

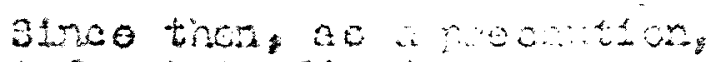

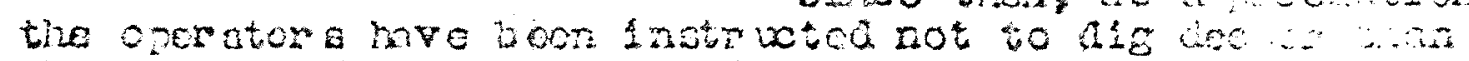

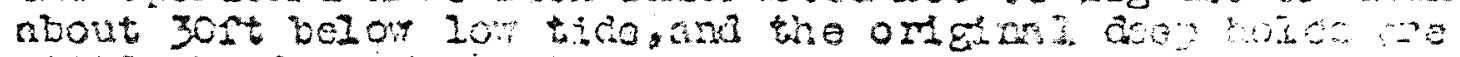
at121 the deepest is the river.

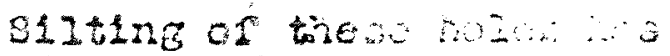

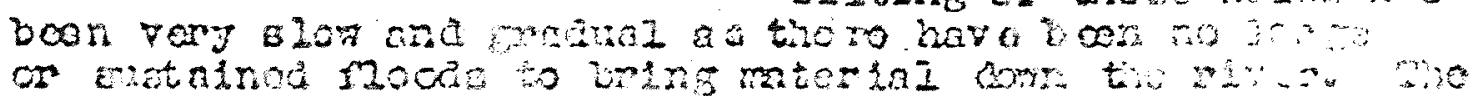

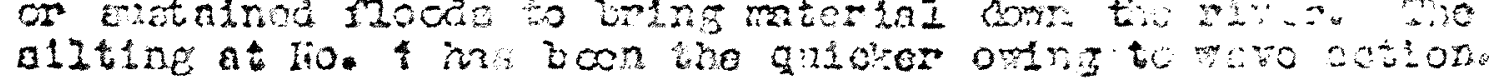

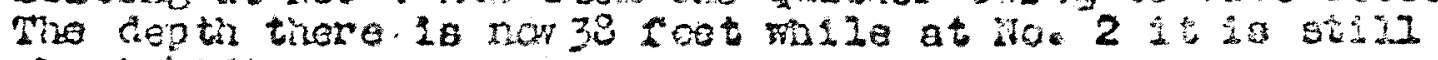
about 40 st.

$$
\text { The C1t }
$$

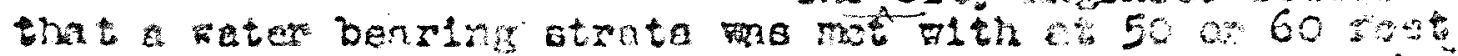

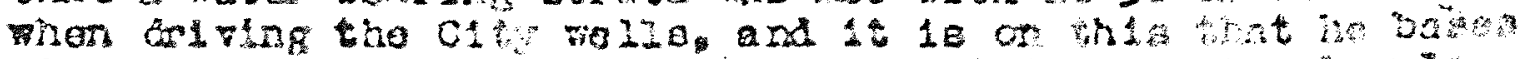

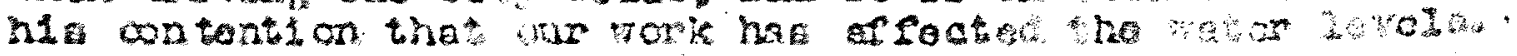


I do not inor of any welis in the 20 wer end of tho Valloy whore rator is dram from auch a dinilon dopth. Host of them are betwen 30 and 90 fect and gomo aro aeeper.

(2) Brom our orn rell 87 st. doep critren noar ro. 1

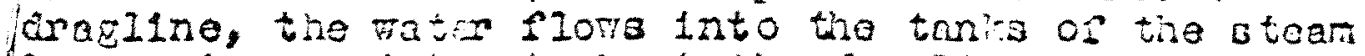
locomotives and tha tanis at tho anagling. If to para to cat the mater barlng otrata within a fot chains or 1t, one roizid expect that tisia would bo the first rell to pall. The only time have had and troulo $\nabla 1$ th 1t, however, wa mas the Clty Council ras testing the flon of thelp pella with the valves fuld o.on.

(3) rho rafntail has a conaderabio expet os tro arteslan water lovela. Levelo ricorded at oun roll

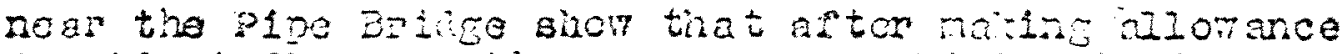

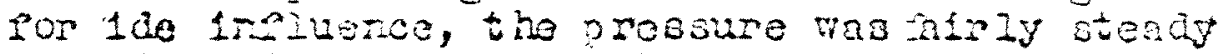
from the tirno of the complatnt to Fourking 25 til, 1937.

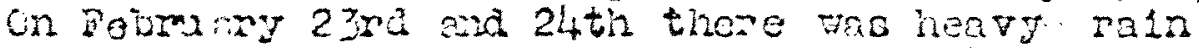
what caupea a Plood in the rivor on 24th. Tho artesian lavela st the lower ad os tive valiey respond

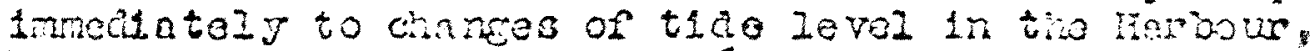
but the riven I crei of 5 to 6 foet, exovo nomal at

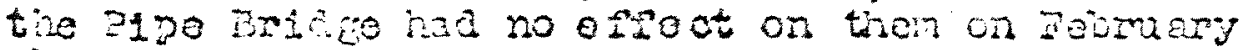

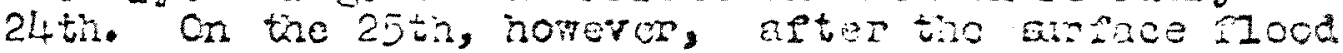

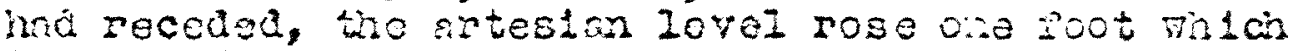
lnd cot ed that wee mo no free connocticn. between the river nen fto moutin and the noteetan moter, and that the level of the latter only roto when the adeftit a uncer foura mater had timo to reach that far.

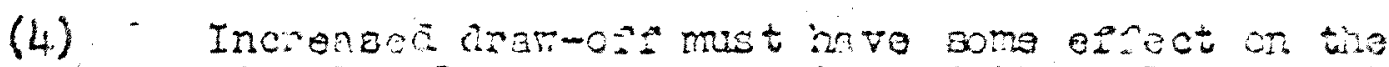
wher level. If the opchisg of the valves of the

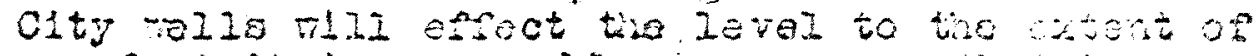
one root it is reschable to suprose tint tiso

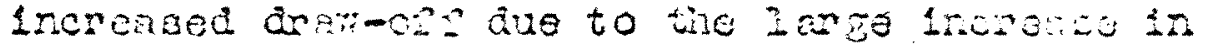
population of tower rut and Jetche ching the sast

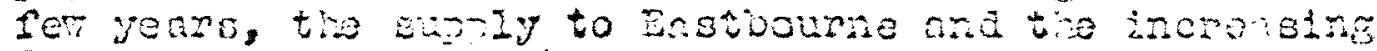

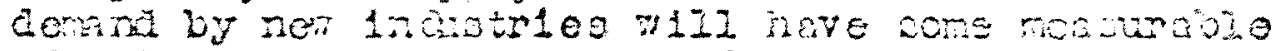

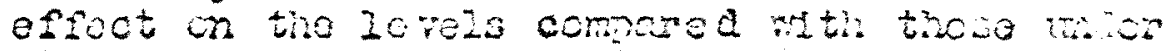

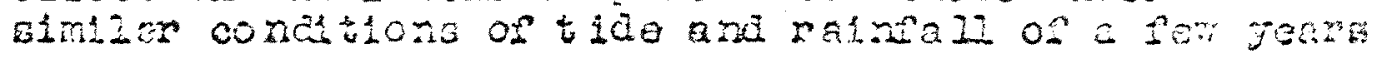
ago.

(5) In cotro cases vare peonlo have compazikd on

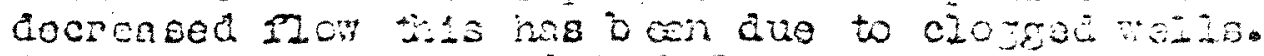
In the letter refernod to below the $20 \%, 0$......

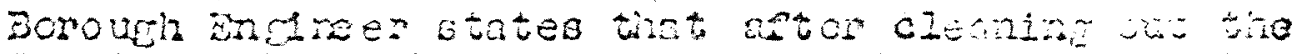

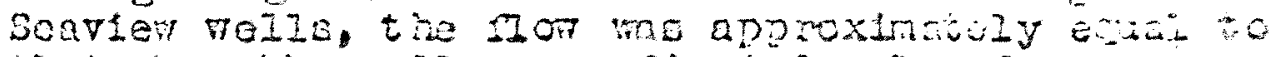
that then the "eila wero first deycloped.

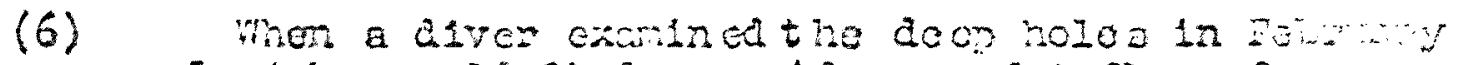

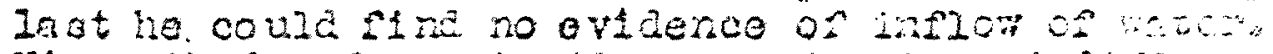

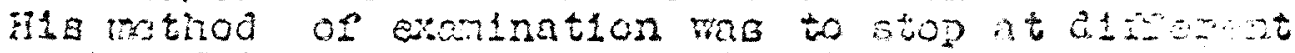
parto of the excavation, hola a torch at arca - wath and rateh for moveront of the axspended mats $\therefore$...

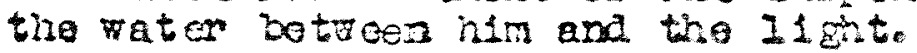

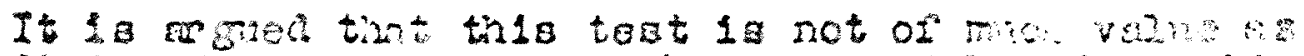

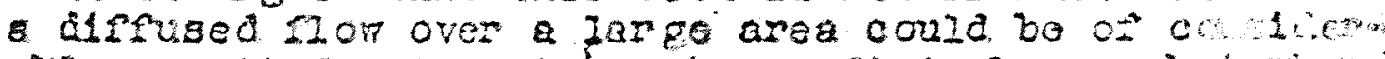

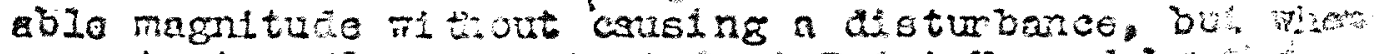
en arteglar thor was atartec at polnt horrard by

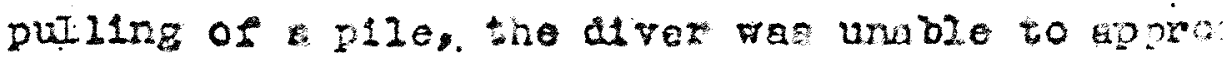


of this I coraidor that li thor ma a riow from tho czcavationa surflclent to cause the drop in prossure complainod of, tho alver would at loabt have boen oane morcment in tho water.

\section{During tire Winter montho the artegian}

level at low tide remie ined filrly constent at sbout $56^{\prime} 3^{\prime \prime}$ above City datum untiI torards the end of octoocr, alter

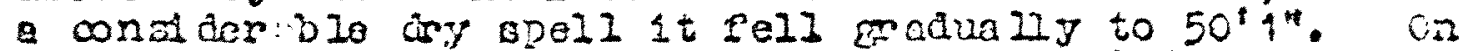
Trovember lot end and tirere ma a drop to $49^{\prime} 2^{\prime \prime}$, but this was found to be due to the valvea of tho Clty Councli vello solng

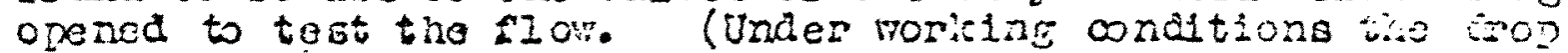
wo uia not be so Ereat as the purpine plent ino tailed could not icel जith the amount of vater that is avalinele frow the

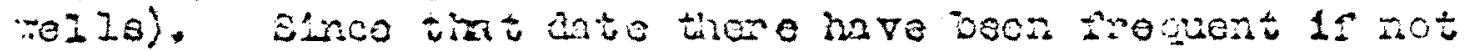

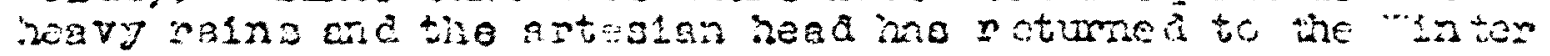
3evel.

Theop ante June 72 th the 1.0\%er rust

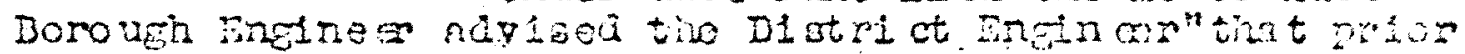
to Janung of this yon the avorace level os artesian isead at tho siain Puming Station, Fililama street, in temis os

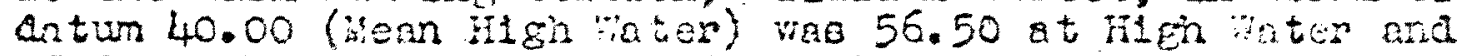
55.20 at Low rater. Poadineb talen in jonumy shor a arop in hond, out rom the meale of Februery to prosent dito an improvenont $1 \mathrm{n}$ hend is recorcied."

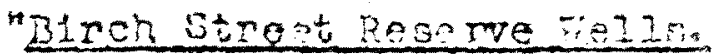

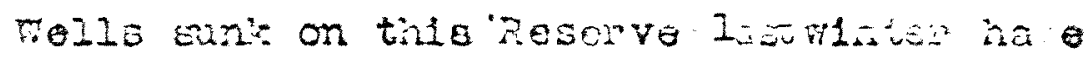
been kept under observition from Docomider last to date. Theoe rella are furthes to tho north than the lleirs ining Station teila.

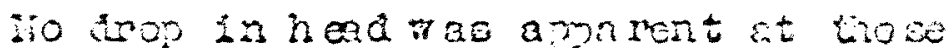
Fello in January Iast, bit it to knova that tho miorioning Btrata into which they hrve bsan siven 13 very compat. pheeo vella are cefinitely affected by ralnali."

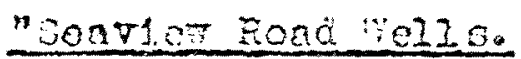

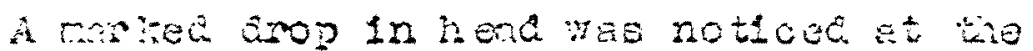

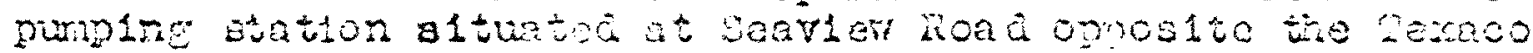

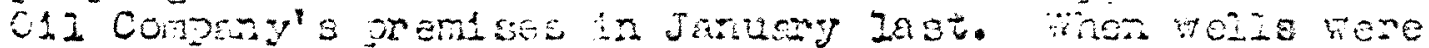

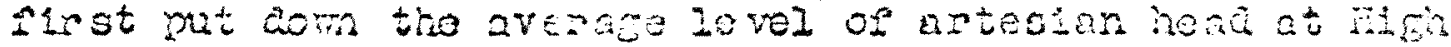
Water was 53.50, but on tire 27 th January a det tirs had ialien to 49.50 .

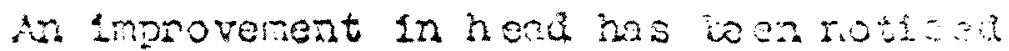

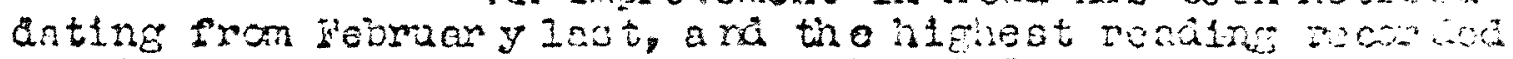
nt high water since wasuriry in at 1952.50 .

These relle have boon cloane aut acemity

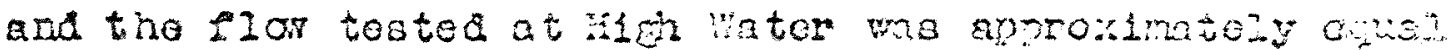
to that pien tive rolis moe frot ceveloped.

Fron tho abovo recoma th is aperont that the raduotion in hord has been almost fulit restoreds.

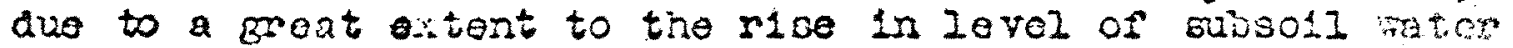
Which naturally almays occurs during tho wintor nontise.

It has beers atablished that the artentan

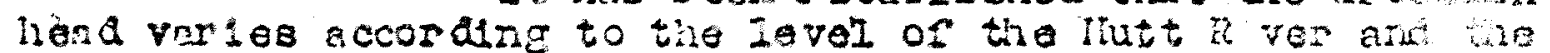
rainfa21. Grapha recentiy prepared show tho rise aid ith ot antegian hord in relation to riter level and the rainfas. rocordod in the Borouet." 
In a recent $18 s u 0$ of the "iventing post" there appeard a repont of a discussion of the potone jorougit counc1 1 rogarding a proposal ror a deputation to eprroncit tho Hon. "xash regarding the allogod tapplng of tho azesian rats by this Departmont's pperationo. In it tiro liagos is report ed to ha vo stated that ho rould bo culte plecsod to bo assoclatod with tho coputation, although as fes as petono was concernda tho pressure and roluto had been rogalnod.

To aum up, it appers to mo that any ructuations

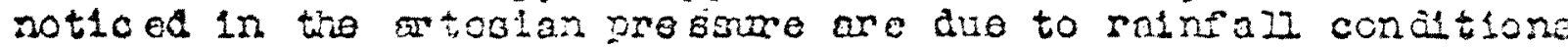
and to increasod crar-osf. and have not bien caused by tire Department's operations.

23. 2. 30. 
IN THE LATPER of the Hutt Valley Undorground Wator Authority Bopowering BiIl, 1963.

\section{EVTDENCE OF KENNTTH STANLEY ODLIN}

My name is Konneth Stanley Odlin, and I am a Senior staff Engineer on Wir. Bach's stafis.

The Hutt Valloy, which goologically speaking includes Hellington Harbour, was formod mainly as tho rosult of movements on a faut lino on the western side of the valloy. Streems flowing into the resultant falt anglo depression carried dom gravel and other material and gradually fillod in the dopression to produce the alluvial filats that we have today.

This diagran stows, in the form of a eneralised longitudinal section, our present komledge of tho geology of tho area. It will be noted thet :

1. The base of the faut angle depression is not unitom so that a number of basins wore fomed, the most important onos being tho Uppor Futt Basto and the Fvans Bay-Tatta Gorgo Basth.

2. Until tests now boing carried out by tho Goological surroy aro completo, a reliable ostimate of the date of tho formation of the valley is not available. It is thought that the infiling or tho valley in the potono foreshoro aroa began ebout halj a milison yeans aso.

3. The lower valoy's infiling is complisod principany of altomating beds of gravel end silt dipping gentiy towneds the horbour. It is considerod by the geologists that the gravel beds were laid dom during poriods of norid uido glaciation when the sed lorel wes much lower then at presont, the olincte in this ave res mueh colder and tho vegortion was sparso. Those conditions ol cimate and

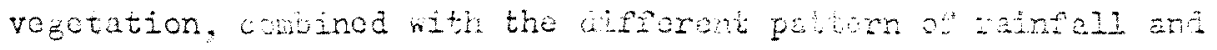
rivor flow, onblod this relatively sall river to form the thick

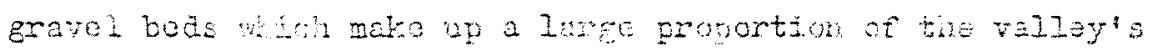
inftusing. 
Separating each glacial period was a poriod of warm climate similar to the present. Sea level rose and flooded the lower part of the river plain, and dense forest covered the surrounding hills. Erosion was much roduced, resulting in deposits of a silty or peaty nature.

4. The information shom on the diagram has been obtained from geophysical and geological studies, from bore logs, and in particular from the Authority's No. 1 Test Bore which is by far the deepest bore in the area and the first to penetrate through the alluvial infilling to the basement rock. It was sunk at a cost of abont. $£ 8,000$ and has provided valuable data which I will shortly describe in moro detail.

Some of the strata on the diagram aro shom with dashed Iines and represent the probable extension of particular strata found in test bores.

5. The gravels strate are generally porous encugh to pormit the passage of watar. Thege streta aro therefore temed aquifors. The ailt, clay or peat layors are elmost completely impervious to water and are therefore tormez agiloludes.

Whe Futt Rivon can be regarded as flowing both in its open channel as sunfece netor, and through the gravel aquitiors, as underground wator. It has beon found that at the upper end of the Upper Hutt Basin about 10 niliton gellons of water leaves the rivez each bay to flow trucugh tho gravels and reppear to join the river some constaenable time later at Silvorstream. Agein, at tho Southem end of raita gorgo about 30 milion gallons of nater per day leaves the river, flows under Lower Hutt un Petome and ultinately, many years later, jotns the sea to tha South hi Bomos Istard, we thint somethore near tho Harboum mowh.

Whit is the reascr wy, koth in tho wper and lome basks of the Hutt inIfy, weseround water can bo cbtaind. At the southon end

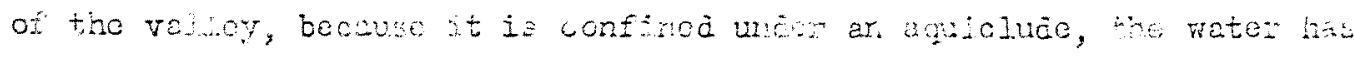

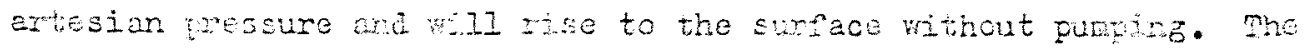

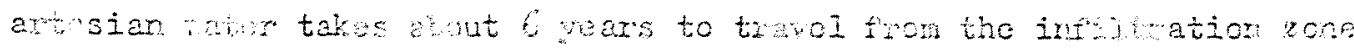

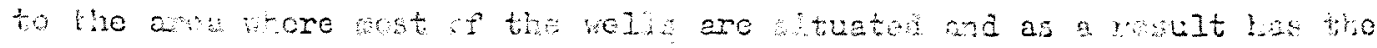


highost bactoriological purity. Tho non-ertosian undorgound water, which ve refor to as ground wator, is liablo to pollution from the surface as it is not protectod by an aquicludo.

The level to wich wator wil riso up a bore is tomed the piczonotric pressure or lovel, and is a moasure of tho artesian pressure of the aquifer tappod by the bore. It is desirable for the piezometric lovel to be kept as high as possible because :-

(i) If the piezomotric lovel is below ground level, polluted surfaco water may flow through leaks in the aquiclude to pollute the artesion wator with consoquent denger to public health. Such loaks may be natural, or may be mon-made such as abandoncd bores, or damago by piling or drodging or loakago around the outside of poonly dosigned boros.

(ii) If the piezomotric level falls too close to soa lovel, the dircction of wator flow may roverse and sea water anter the equifors. Due to tho greator donsity of soa water, this reversal will cocur oven though tho piezonctric level is abcro sea levol, and evon whore some fresh whter still fiows out to sco.

(iti)Jon piozonotric lovols can couso pumps to pail due to priming difficuitiss.

The piezometric lovel in ow artosian system deponds ot:

(a) Soa Ievel.

(b) River or grounduator lovel in tho lowor ond of tho infiltration zono.

(c) Draw-off; tho groator the amcunt of water thas is axtracted from tho artusian sysiom, the lower the piezometis.. prosuro. Pumping easts carrice out in 4957 , the rosults of whes wero

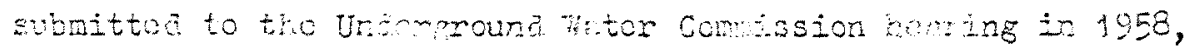
showed cloariy that waw-ofi from any w tosian woll affocts or Enterfomes with, to loast some degen, the pionomotrio pressure it oin othe rais. 
Ovorseas, there are numerous examples more over-usage has lowored the piozometric pressure to such or oxtont that soa-water has invaded the aquifors to considorible distances inland. Nuncrous countrics havo soctions of their coasts which are subjoct to sea water contamination as evidenccd by roports from the Unitod Kingdon, Gomeny, the Notherlands, Japan and tho Unitod States of Amorica. In the lattor country the cxtensive Californian coastline has boen subject to an unusual anount of intrusion rosulting from vator neods accompanying a iarge influx of population into coastal aroas. Investigations by tho state of california revolod thet soa water had encroached into thintecn coastal aquifers occupying a total area of 90,000 cors. Seven cthors are fmodiately throatenod ond 60 othors aro potentially throatened.

It is essential, theroforo, if we aro to propont such a disaster fwon occurring hore, to linit usogo to sato values. I would stross that in this respect there is a vitcl difforonco betwoon a wiver intake weter supply such as the Kaitoke schemo, and an artostan systom. In the former case, an attempt to draw more water than tho rivor can eupply wi11 feil, but no harm will bo done to tho piver or to the schene. Tf, dud to cromsage or othor causcs, an artosian syston booones invaded with sea wator, it is nocessary to rostrict on cven pronibit usago for a considerablo period.

The first estimate of the sefe capocity of the antesian aystem vas

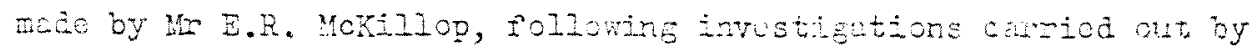
Wolington City Council in 1929. Fumbow invostigations and estinatos

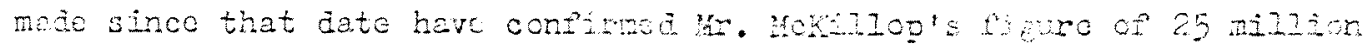
guilons per day. The capactty ruet dopond on :

1. Minimum rivor flow. Tho folowing is a guototes from tho report of the Underground Wator ommats ston:

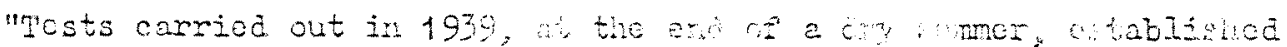

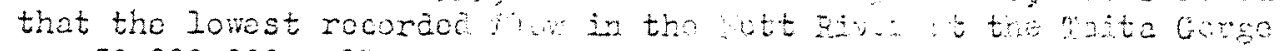
was $50,000,000$ gations for.

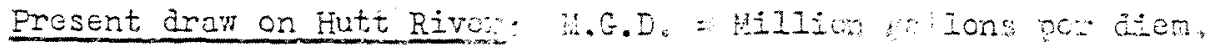

Tho Wator Board

Lower Hutt City anc Foton

Industry in the Aroa

Minimun flow requirea in wh River below Bolmont 


\section{$\mathrm{B} / \mathrm{f} \quad 39 \mathrm{~m} \cdot \mathrm{g} \cdot \mathrm{a}$.}

Minimu flow in aquifor to mantain a pock of artosian vater in tho soa and provont ertry of salt water Goar Island pumping station

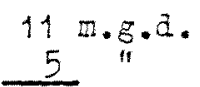

55

Those figures indicate that the prosint domand is $5 \mathrm{~m} \cdot \mathrm{g} \cdot$. . over tho lowest rccorded Plow in tho Hutt Rivor. It is suggosted that thoso figures alone justify the constitution of an underground water area for this district."

2. Tho capacity must also depond on rivar lovel at the lower end of the infiltration zone. For a givon flow of wator from this zone to tho artosian well zono, thore must be a cortain difforonce in piezonctric pressure betiven the two points.

3. Safo capacity can also be roucca by unvise specing of rells. For example if two largo welis wore spacod close together near the shoroline, the risk of drawing scawatur back would be greater than if the same wolls wore located furthor inland or further apart. This aafe capacity of 25 militon gallons per day represonts an estimate of tho safe paximu continuous sunron draw-off. It may be possible to increase this in wintor, and it is hoped that it acr bo furthor incmased for short poriods, provided these are followed by poriods when draw-off is rouced to a very low value on is stopped entirely. This latter is tumed "overdrat pumping" as frosh rater in the aquifen to tho scaward sido of tho bore is "borrowod" and replacod by soe wator which mut later be vashod out by an increasod flow of srosh water. Swoh a method car onjy bo uscd where there is striet control of usage from artesiar wells. Most, if not all of the ovidoroo I hwo ghon, was known pricm to the stant of the Authority's investigations. Our work hes consinged provious studios in most rospects, wut it has also rotolod a muner of distroing fucts.

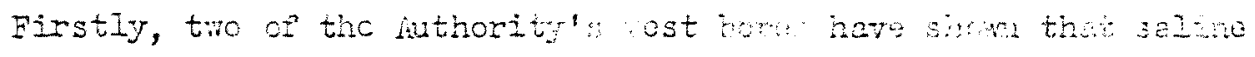
water pollution of somo equifors tas arcad occurred ard probably extends

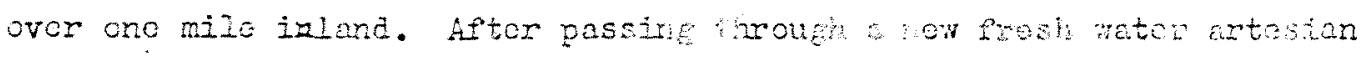

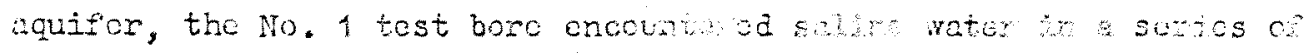


uifors extendine from $400 \mathrm{ft}$. below ground lovel to besomont rock at 1,000 ft. The No. 2 borc, a mile inland, confirmod this when it found salino water with a losser concontration at tho same depth. 1roreover, It was found that, initielly, the concontration of salt increasod with dopth. Although this trend was rovorsod bolom 612 foot thare is a markod similarity to tho known soe water intrusions on the californian coast of the unitod states.

Socondly, it is non realised that on adocuate flow of wator in the rivor bolow the infiltration zone is osschtial to provont sea water entoring tho artesian systom at lowor and of tho infiltration zone.

Thirdly, thore has beon a consiacrablo and continuing drop in piezometric levels since the survey carricd out by Mr. Hckillop. It appeors cortain thet this is duo not only to increasod consunption but also to the lowering of the rivor bed in the infiltration zone by the operations of tho Hutt River Boord.

Fourthiy, at the dato thet tho futhority was constituted, the capacity of oxisting wolls was et least 40 militon gellons per day. Average sumper lusego was of the ordow of sovonteon million gollons per day. Lest sumer usage was aporoxintely tronty two ni2lion gallons per day.

Pifthly, during the last sumer wator supply in the aroa was close to crisis point. Eoth Eotore Borough and Wollington City Councils had to moko urgont altowations to thoir punping stationsto mantain supgly; Petono had to ask Tolington on a number of oconsions to shut dom tho Gear Island station winle the petone puwes noro roprimed Lower Huti had, for a fow days, no rosowe capanily at al; and a number of indutrics

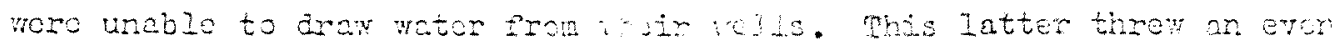
greator load on the municipalities conramod.

To sum up:

(1) Dhoro are valuable underzound resotros in tho Fut Tatroy.

(2) The safo capacity of the Antes

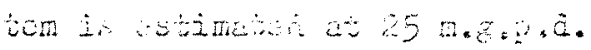

(3) Thore is evidenco that its caps is deceocing.

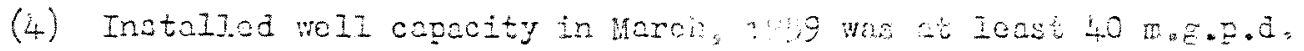

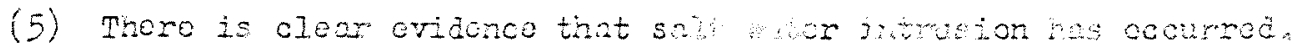

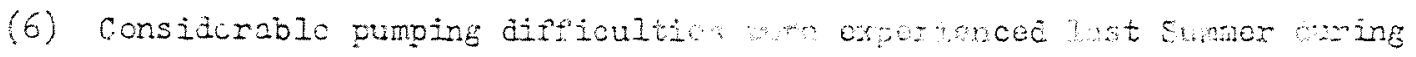
a poriod of incroasca drail off'. 


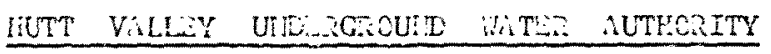

AND ARTESIAN PNESSUNE IN TIE LOWER IIUTT VALLEY

\section{Description of the Artesian System:}

The artesian system in tire loner lfutt Valley is an alluvial basin comprised of alternate becis of silt and gravel. Mater from the liut Rive: soaks into these gravels between Taita Gorge and the liutt Golf Coursc, becomes trapped below the various silt becs, and, after flowing bencath Lower iutt and petone, eventualiy fims its way into the harbour somewhere to the south of Somes IElanc. Driliing near the Petone foreshore has shom that water bearing gravel beus exist to a depth of almost 1,000 feet and that the water in the upper 400 feet of these is of high quality and low mineral content.

Below 400 fect, the water has a relatively high mireral content and is not considered acceptable for normal industrial or muricipal use.

Over a period of 80 years, wells have been surk in lic lower valley to tap this artesian supply, and at the prosent time it provides approximately $45 \%$ of the water used by industry and local bodics in the greatar Hellington arca.

When first tapped ticre was sufficient pressume in meny parts of the artcsion systom to lift ater into tians situated in roots of houacs. In terms of Ciby datum this would be about an $\mathrm{R}$. 2 . of $56-60$ at the lower cnd of the valiey. (Mean itigh lioter level is R.L.40). Tocay, the artesion pressure is norwajly at or below ground level during the sumaer monclis anc regularly falls te $2 . L, 43$ in the vicinity of the petone Esplanade. The carlicst records of artesian head were made in 1931 and since that tine there has becn a total fall in artesien pressure of approximately 9 fect.

\section{Rcosons for the fall in artesian piessure:}

It has always been known that the artesian basin wes river charged and that the level of the river would have sone bearing on ertestan pressure. Ilowcrer, until approximately aightacn ronths ago, it mas considered that the decline in artesian pressurcs was aimost entirely due to the increase that hed taken place in usage and thet other ractors subh as an increase

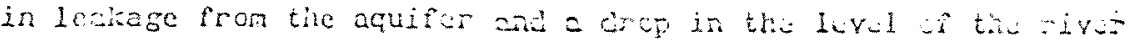
were of much less importance.

However, study of data collcctod by the duthority shors that for the same rate of pumping and at the sane state of the tide, artesian levels in 1964 are on the everage 4 feet icyer than in 195\%. This mears that there are some other factors besice itucased usagt contributing to the fall in the artesian pressures.

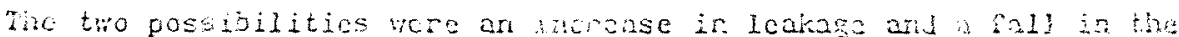
level of the river.

Loss Co Head due to incrase in Natwa Leakage:

It was realised that, with the whocas in the ruber as weins wath bricge piles penetrating to tike arteston syster and with denper river dredging activities, that 3 mo incrase in loakgge was butat to have taker

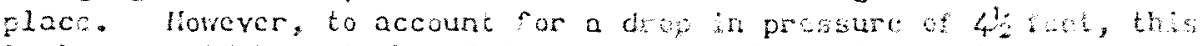

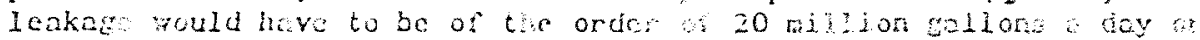

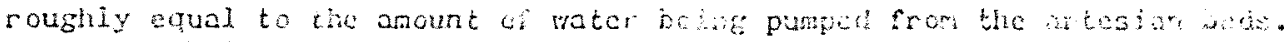

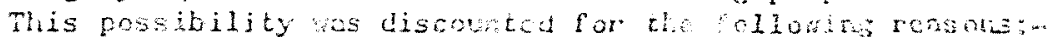


(i) River gauging has shown that roughly 25 million zallons per day of water lcaves the river and enters the artesian gravels. Howcver, to satisfy both pumping and leakage about $40-45 \mathrm{~m} . \mathrm{g} . \mathrm{p} . \mathrm{d}$. would have to soak into the gravels, leaving a residual flow in the river of $13 \frac{1}{2}$ m.g.p.d. during periods of sumer low $\mathrm{flow}$. In actual fact the minimum residual flow measured by the iuthority, has been $47 \mathrm{~m} . \mathrm{g} \cdot \mathrm{p} . \mathrm{d}$.

(ii) A leakage of this size would probably form a very large natural. spring, or a scrics of springs, which vould be very noticeable on the land and could not escape notice by River Board's staff if it occurred in the siver. As a leakage of this magnitude has never becn obscrved, attention was directed at the fall that has taken place in river level.

\section{Loss of Head due to lowering of the River Bed:}

In the first place diagrams were made showing the fall that had taken place in artesian level and in river level during the period 1931 to 1964. These graphs showed remarkable similarity which indicated that further tests should be made to determine the exact relationship wich existed between river level and artesian pressure. The first of these was to show the relationship which exists betwecr river level anc the level of the nonartesian ground water in the Taita/Avalon/Naenac area. Tro level recorders wore installed on the river to determine the pattern of river rise arid fall. fit the same time fiftecn wells vere bored to observe the rise and fall that takes place in the non-artesian ground water level. This survey produced the following results:

(i) That the level of the ground-water was controlled by the level of the river.

(ii) That the level of the ground-water reached its maximum approximately two days after the peak of a flood.

(iii) That the risc in level of the groundwater was shortived.

(iv) That the pattern of $r$ ise and fall at all recorders is alnost identical showing that the wholc of the Taita/Wacnee/Avaion area is hydraulically interconnccted.

(v) That the zone of greatest infiltration of rivar water into the ground is north of Mabey Road.

Having shown that the river level controlied ground-water level, it was then necessary to demonstrate that $r i s c$ and fill in the level of the ground-water in the Taita/ivalon/Nacnac area offects artesian pressures. Thiz was done by exanining the effect of the rise in ground-water levels on the levela at the nine recorders already installed in the artesian arca. The influence of ground-woter lovels is very clear on the recorders at both the lut lospital and Birch street, but further south than this the effect is masked due to (i) tidal vasiation. (ii) rise in artesian level caused by the reduction in pumping during wet periods, and (iii) the short duration af the rise of the gronini-water levels.

The deco that his been collectud is at presentheing cxarined by $\mathrm{a}$

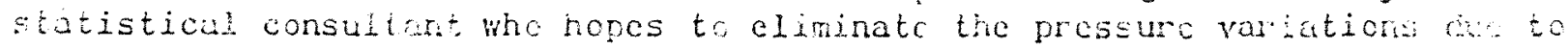
puming, tide, etc., and by si doing fird the mathematical relationship between river lcvel and artesian pressure in the lower part of the yalley. 
As a final check, it was decided to find out how far up the valley the artesian system extended and determine the nature of the physical connection between the non-artesian ground-water basin and the artesian system. This was done by means of a series of bores at approximately to mile intervals from lielling Bridge to Mabcy Road.

In each of these bores it was found that the water in the upper gravels was approximately at river level and that its level was rapidly affected by changes in the level of the river. When drilling was continued, it was found that a silt bed scparated these gravels from the artesian gravels below. South of Stellin Strect, the artesian weter rose to a higher level than ground-iwater, was affected by pumping, tide, etc., but was not influenced rapidly by changes in river level. The difference in level between ground-rater and artesian level become less the further up the valley drilling proceded. North of stellin street, it was found that drilling through successive clay beds did not produce any difference in the water levels and that at all depths the level of the water in the gravels was approximately that of the river.

To recapitulate, therefore, it was shown:-

1. That historically the fall in artesian pressire has cuincided with the fall in river level.

2. That river level controls ground-water level.

3. That there hes been a very marked drop in river levels, ground-water leveis and artesian pressures between 1957 and 1964.

4. That all the ground-water in the Taita/Naenac/Avalon area is hydraulically interconncted.

5. That the ground-water level influences artesian pressures.

6. That the cntire artesian basin is hydraulicaliy intercannected.

7. That the artesian system cxtends as far north as a line across the valley at Stellin Street.

8. That there is physical continuity between the groundmivier basin and the artesian systcm.

From these factors, it is concluded that the fall that has taken plate in the level of the river, particularly since 1957, is responsibie for the grcatcr part of the total fall that has taken place in artesian pressures.

Significanre of fall in Artesian Pressure:

The importance of the fall that has taken plece in siver lowi and artesian pressure is four-fold:-

1. It has reduced the capacity of the system.

2. It has reduced water storage.

3. It has incrcased the risk of contanifution of arkesiab water.

4. It has led to consicrable expenditure in mockpring pusteng installations.

A. Effect on the Copacity of tho syster

As the aricsian system is connected to the son, it is not posotile to lower artesian pressurces permanently below san level withou .... ing the contomination of the whole wate supply system ats sed 70 .

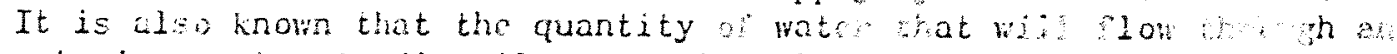
artesian syster is directiy proportinal to he hea wailat o force the wer through the gravels (narcy"s aw). 
This means that the capacity of the system is determined by the iifference in level between sea level and the level of the ground water at the northern end of the artesian system. The present level of the river is acicquate to allow approximately $25 \mathrm{~m} . \mathrm{g} . \mathrm{p} . \mathrm{d}$. to be extracted from the system without lowering artesian levels below sea level. Howcver, any extension in pumping beyond that figure could lead to saline intrusion in the upper artesian beds. Under its original conditions of pressure and river level, it would probably have been possible to extract $40-45 \mathrm{~m} . \mathrm{g} . \mathrm{p} . \mathrm{d}$. , assuming always that this amount of water was available in the river.

B. Effect on Water Storage:

The storage of the system has been affected in two ways. The ground water storage in the Nocnac/Taita/Avalon area has becn greatly reduced. This lost capacity can no longer be called on to supply the artesian system nor can it be utilised to feed wells situated in this area.

Secondly, the drop in pressurc has reduced clastic storage in the artesian system.

C. Risk of Contamination:

Reduction in artesian pressure has meant that in recent years it has become necessary to apply suciion pressure to most artesian bores in order to maintain water output. This means that any leakage which exists in wells or collecting mains con permit the inflow of contaminated ground-rater. A recovery of artesian. pressure would eliminate this dangerous condition.

D. Effect on Existing Fumping Installations:

Almost all existing punping installations were designed for frositive artesian pressure. Wher installes they cperated with little or no suction on the wells and as the artesian level was above the top of the pumps no difficulty was cxperienced with priming. However, es artesian levels have fallen it has becn necessary to apply an incrasing amount of suction to the vells in order to maintain capacity. This has not only increased pumping costs but has led to priming difficulties which have teen remedied only by extensive modifications to the pumping installations.

\section{CONCLUSIOY:}

It is considered that some recovery of artesian przssure and water storage could be achicved by means of a linited lifting of the river leval. It is suggested that we should experiment firstly on the lengti of river between Boulcott Golf Course and Mabey road. The exact siza, design and location of the vejrs shoule be to the approval of the Board's Enginecr.

It is therefore asked that the lutt River Sonnd give considerntion to the acceptability of such at programme.

gen June, 1964 . 


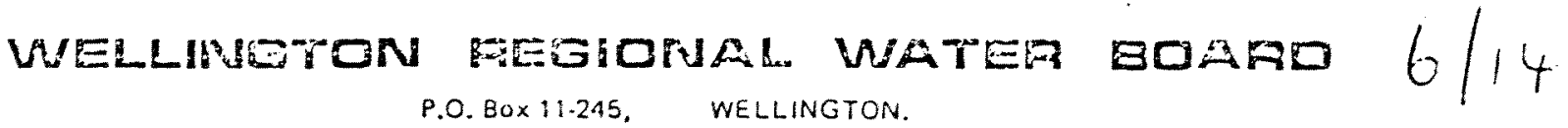

GROUHDWATERS OF THE HUTT VALIEY-PORT NICHOLSON

ALLUVIAL BASTH

The Hutt Valley-Port richolson groundwater basin is one of the major sources of water in the velington Region. velis tapping the aquifer of this basin suppiy the municipal needs of Lower Hutt, Petone and Eastbourne and supplement the supply to Hellington City. other wells slipply the needs of many of the major industries of the Lower Hutt Valley.

The basin consists of the lower Hutt Valloy and Port licholson. The area concerned is shom on the attached Fig.2.1. The basin is associated with the velington fault and vas formed by a longitudinal vanping about an axis nomal to this fault during the middle to late pleistocene period. The groundvaten basin itself is defined physically by the narrowing of the Taita Gorge towards Silverstream in the north, by the eastern Hutt hills to the east and by the vellington fault to the vest. To the south a bounding stmature is not so clearly defined but Fig. 2.3 from papers by stevens illustrates the groundwater structures extending to the present harbour entrance. Fig. ?.4 shows a transverse section of the basin at the petone foreshone.

According to geologists, during the last glacial feriod in New zealand, the sea probably whthow from the basin and tho ancestral Hutt River would have cut the Rongotai harboul entrance, i.e. Evans Bay, Lyall Bay, dorn towards the giacial sea level. In the immediate post-glacial peniod the Fut Delta vould have extended southwands from tatta conge into the lower Hutt-Pont Nicholson basin and the vilfond shell bed wonda have formed as the sea level rose vith the initiai incursion of the sea. After this initial incursion, deltaic scamertation would have occumed setting up the vivhetu artesian gravels and this would have kept pace with the rising sea lever until about 6000 - 7000 years ago. At this time the sea flooded the lover pontion of the deIta and deposited the petone nanine beds which form the aquiclude (sealing dayen). This high ses level period occurned ebout 4000 yeare do and since thet tire the sea lavel has fallen to its presont leve? and the deltadr development of the basin has continued uth the rivon cutting ney channels fron tine to time in various sedimentary beds. depositing the uppor layers of grovel over most of the basin surface. The raita al thiun rould have been deposited during this perioc.

The lower velley can be broady ivider into wo regionethe non artesian aid the artesian. mhae areas are shoun on Fig. 2.5. These are loosely referned to as the fiata Gravels. The raita gravals consist largety of bum on gney-brom gravel

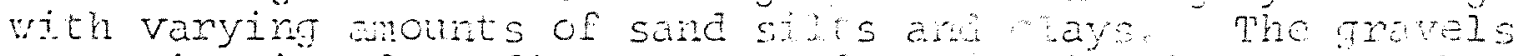

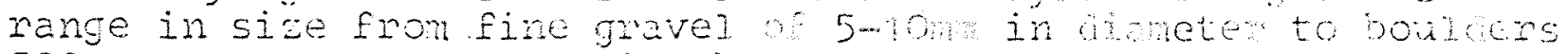

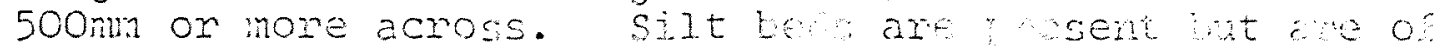
linited lateral extent. In nos pars the ogion the grays 
sc and othor alluvium are covered by $2-3$ metres of surface - soils and silts. Almost all the water that occurs in the gravels in this region is hon-artesian and the permanent water table is about 3-10 metres below the ground surface and relates closely to the river level in the vicinity.

At the Taita Gorge almost all of the water flowing down-valley appears in the open channel of the river as bedrock rises to the surface. As the underlying gravel Formations thicken to the south, however, a considerable proportion of riven vater soaks into the alluvium and into the gromdwater systen. vater entering the groundyater system in this non-actesian region mainly flows south beneath the various capping layers of the artesian region to the vells tapping this region or to the sea in the harbour. A small amount of vater does, hovever, return to the riven at the Boulcott Hutt Golf course area.

In the antesian region, there are two distinct aquifers which are exploited for water. These are the main

aquifer lying immediately below the main aquiclude which caps the entire antesian section and the second aquifer which consists mainly of the uppon section of the deeper horizons.

Most of the water drawn comes from the main aquifen winch consists of material langing from coarse open gravels to ciays, with a wide range of sande, sand and claypacked gravols and sizts.

The second aquifer has only about seven bores into it and the artesian pressure in this aquifer is generally it to 2 metres above that in the upper aquifers. The gravels in the deeper aquifers are found to be much more veatheres than those in the main aquifer and have an overall lower perneability.

As has baen said before, the source of water for the system is the Hutt Riven and in fact gangings of the Hutt Riven were done as long ago as 1939 which indicated the genenal area of lose from tho riven. In the drought of Jamary/pebruary 1973, Boand staff did stepuse gaugings gom the Hutt piven and pinpotinted the area of tufiltrotion as being from the Taita Rock to Belmont School.

In 1939 when the river we at a simiany low love it was observed that the not loss mon the riven to this system vas about 4.9 ill por hou (26 mgd) In midecomany ig73, horever, tho nott infi].tration to the system ras miy 2.1 MI per hour (11 ngd). This apparen faliofe, the ratc of infiltration is at wouted to major mivernonk such as the ctraightoning and grave romoval which cavsod

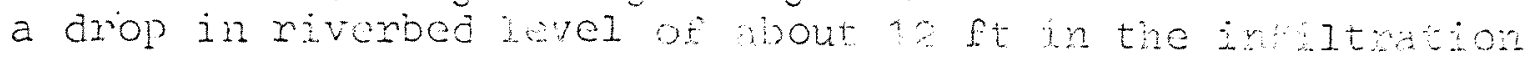
zone. 
It was also considored that in 1973 the dischange of fine material from quarry washwaters contributed to a clogging of the riverbed during the sumner and adversely affected the system.

The system is veII monitored with analogue to digital vaten level recorders being installed on vells in both the non-artesian and artesian regions. The position of the major water level recording stations is shown in Fig. 2.5. River levels are measured at Silverstream, at The Rock, Taita, at Baulcott and at the river mouth, also using analogue to digital recoriens recording the levels every 15 minutes. During the summer, when the river becomes 10v, a regular gauging at Taita Gorge and Boulcott is undertaken every meek to moniton the low flow recession and rate of nett infiltration into the acuifer.

From the usage point of view, all major users of artesian water have water meters fitted to thein bores and these are read every morning at about 9.00 o'clock and the readings sant in monthly to the Board.

The Board has let a contract which is nearly completed for the installation of water level sensing and transnitting equipment in its foreshore vells. This equipment is connectad by the means of undorground cabies to a central reconaing at the Gean Island Fumping station where a mini computen wi... record the differences between crtesian level and sea leven. This equipment is capable of telephone interrogation and is programmed to dial out should various critical phases be reached. While not in cperation yet, this equipment wil certainly be commissioned before next summer.

In 1977, as a result of several years of investigation and analysis of years of histonical data on water usage arid antesian water levels, a publication entitled "Groundutens of the Hute Valley - Pont richolson Alluvial basin - A Resounce Evaluation" by Drs. I.G. Donaldson and D.G. Camphed, was published by D.S.I.R. This publication apart from cantining a description of the geology of the district, its hydrology and the hydrological structures involved investigates severa simplo explanatory mathematical models of the system and dovelops and comparcs two major tro dimensionel transient modols. Thoir malysis indicatod the limits that must be set cn the syster to cnsure that sit water wil not enten the aquifers during severe drought. This publication has formct the basis of a Venagenent Plan for the rutt vajuey artestan syster and cor be nade available on request:

The attached figurss have been taken enon the above prbitcatsu. 


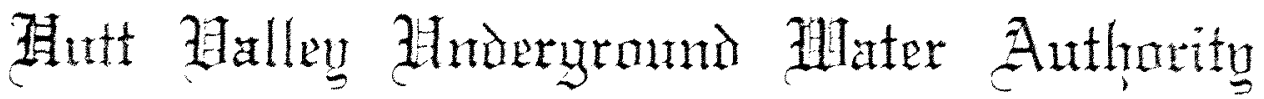

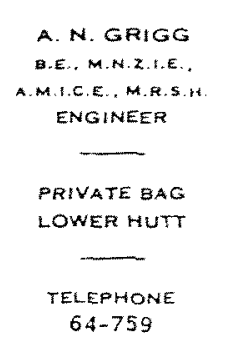

MEMORAHDUSI --

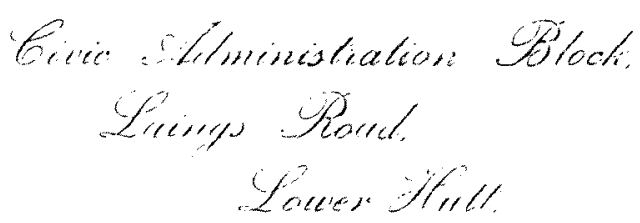

20th. July, 1960.

\author{
TIE EIGIIEER, \\ HUPP VALIEY UIDERGROUID WATER AUTHOKIIY,
}

\section{Artesian Outrall Investigations:}

On Friday, 15th. July, a meeting was held at the oceanographic Institute to discuss possible methoos of locating the artesian outiall(s) and areas of local lealcage. Present were Dr. Gamer and other technical officers of the Institute, and Mr. De Jonge and Wr. Mansfield of the Authority's staif. The Director of the Institute, Mr. Brodie, was unable to stay for the meeting, but expressed his willingness to help the Autrority if possible.

The general characteristics of the harbour were discussed, including sediment depths, tidal movements, river entry, distribution of marine life, and the geography and geology or the harbour floor.

Some previous reports were discussed, and the present knowledge of the harbour floor and the artesien outfall enumerated. The early report on dredging in the Falcon shos area was not known to the Institute, but the mexine blologist present considered that it was uniliely that the evidence was conw clusive. Fork done by the Institute had not showr that any mark ed changes in distribution occur in this area. A cony is bing forwarded to the Institute for further study.

The Institute lnew of a seismic sivey in the vicinity of ialcon shoais carried out by the Geophysise Division of D.S.I.K. (lieliy); this report; was not inom to the Autholity's staff, but an approach will be made to the Gophysion Divisior for a copy.

A report on sedinent distribution and graring is under preparation, and a copy wili be forwerded to he Authority when completed.

hethods of detemining the outs is) an arent

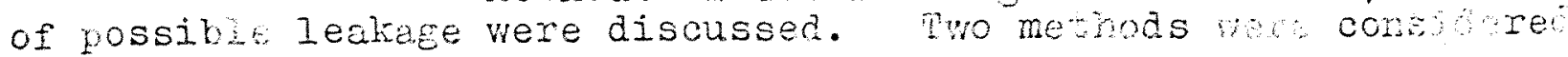
practicable: 


\section{(i) Salinity/Temperature Readings:}

Apparatus is available for constantly monitoring the salinity and temperature at the sea floor. A small (12ft.) boet is required for this, the major necessity being that it will travel sufficiently slowly to allow readings to be taken. The Institute is prepared to make this apparatus, and an operitor, available to the Authority if a suitable vessel cin be supplied. In the meantime Dr. Gamer is prepared to take salinity readings in suggested areas during the course of his other work.

Several areas of possible leakage are kown as well as possible sites of the outlet(s). These sites will be given to the Institute for preliminary investigation. It may be necessary, at a later date, to do a "box" search of the harboux to look for other leakeges or outfalls.

\section{(ii) Seismic Probe:}

The Institute is develocine a seismic mrove which should be suficicitly accunte to aistinguish a sejiment/gravel interfuce, a gravel/grivel silt, clay intercace or a gravel/ rock interfice. Develowent tests will be carried out in the harwour and the Institute is prepared to carry these out in eress specified by the tutrority. A lange vessel is required, dúe to the eeneratine equiphent necessary, so that clase inshore work may not be possivle.

\section{The question of sealing leakages or minor out-} lets was aiscussed, but no examples were loom, nor were any methods sugesested except in vury genoral terus.

\section{At present a chart of the harbour is beins marked} to pass on to the Institute for prelininary survey during tho course of other work. This vili be confinat to the deep water aress, as in the vicinity of Soanes Island, as the ressel used by the Institute is unsuitable for insiore work.

After these prelininary tests consderation could be frven to the hiring of a swall boat for jamore investigetins.

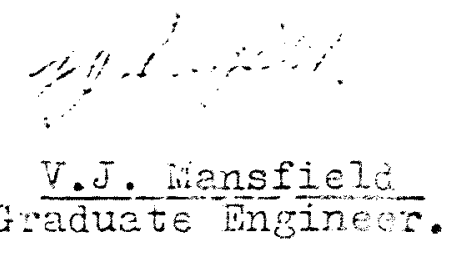




\section{UEFAKIIVIEIVI UF VYURAD ALVL ILRLYIYIY}

WELLINGTON - NEW ZEALAND

Citr cuanez:

J. 8. Roterens.

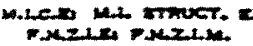
amitic.

REPLY TO CITY ENGINEER:

ATTENTION MR...... 71 IIZZazor

TELEPHONE NO. 45-040 EXT. .753

The Engireer,

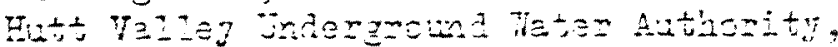

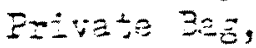

IOT: ITtm.

Iesi Sin,
MUNICIPAL OFFICE BUILDING, MERCER STREET. P.O. BOX 2199, WELLINGTON, C.1.

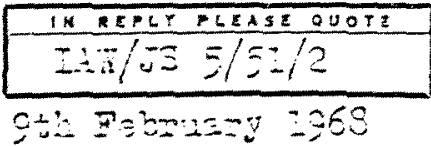

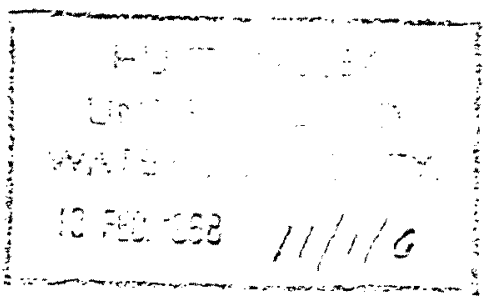

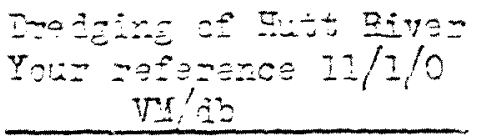

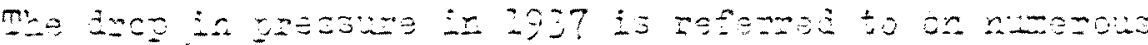

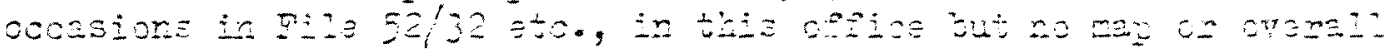

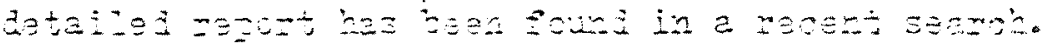

Buey, the rsoordo show the folloning :-

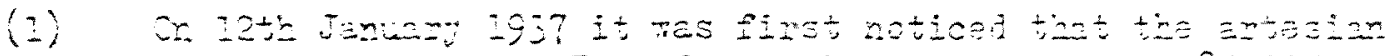

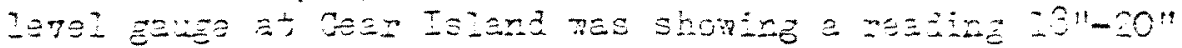

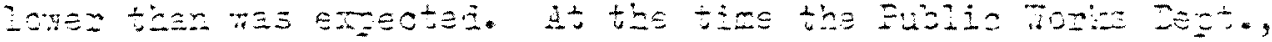

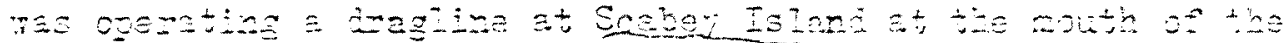

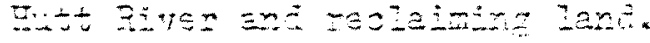

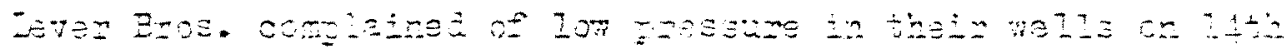

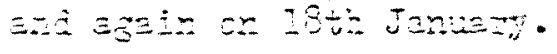

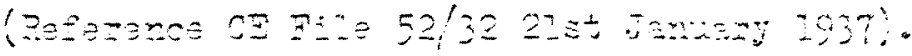

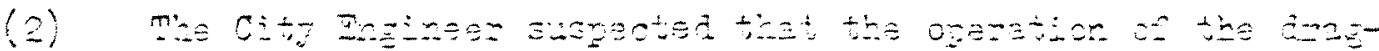

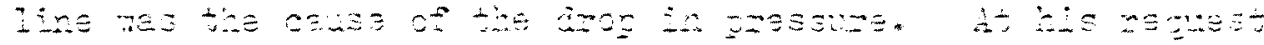

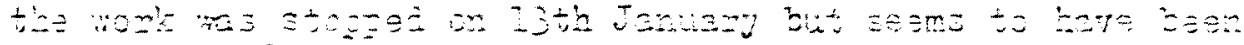
rezunez

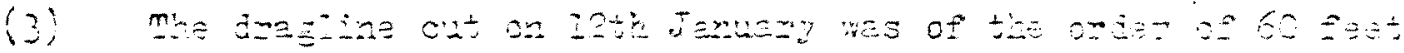

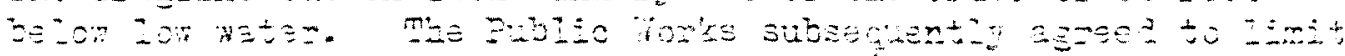

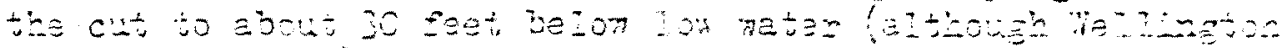

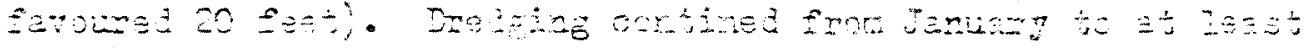
Tovemis: 2937.

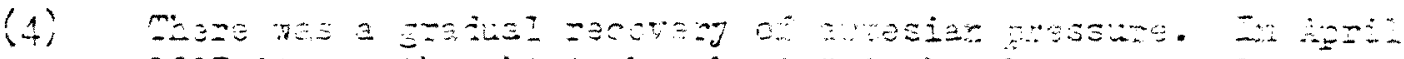

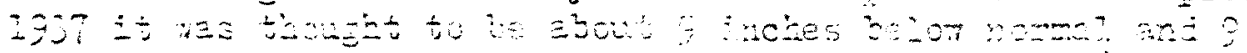

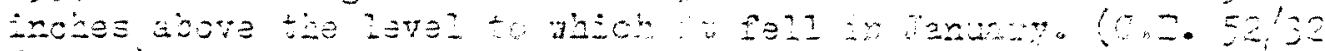
$5.4 .37)$.

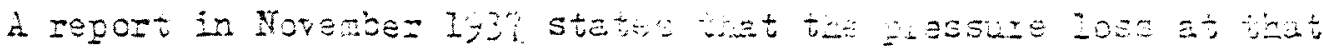

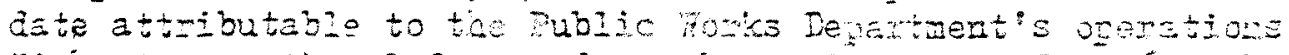
"is not more thar I foot nd way he as 1 ththe as from 6 inches

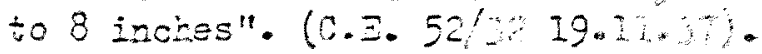

In ingust 1938 the Citu gine in bead due to the dreen "set: but that it ould be difle out? nsidered that rone reduction

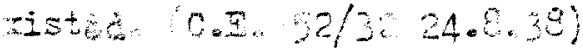
cove ox ate of 5 . 
Copies of some of the zore important cocuments are exclosed. Tou are relcome to insfect the remainder in this office if you nish. Fours faithouly,
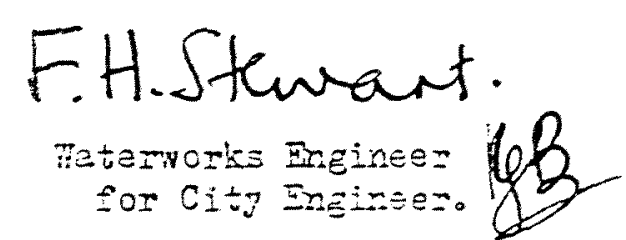

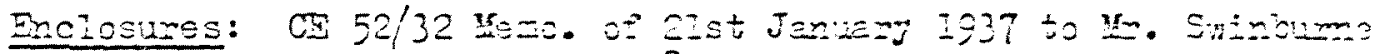

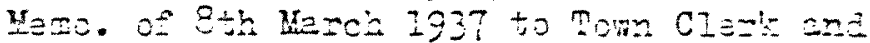
coptes of the tinc letters zeferaed to.

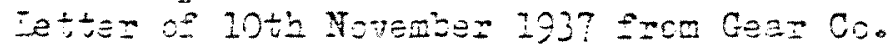

reac. of I2th Noredber 1937 to Deputy City

Engiver.

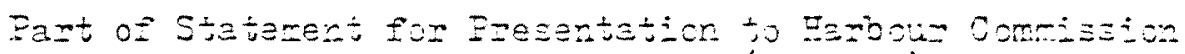

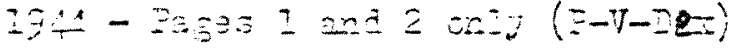




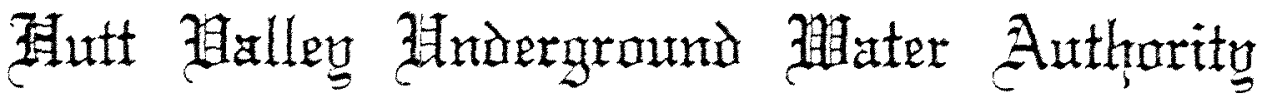

A. N. GRIGG

B.E. M.N.Z.L.E.

A.M.T.C.E., M.R.S.H.

ENGINEER

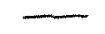

PRIVATE BAG

LOWER HUTT

TELEPHONE

$64-759$
Berre Stiministiation $\mathscr{B}$ lock

Luings Rasid.

Lower

8th Narch, 1968

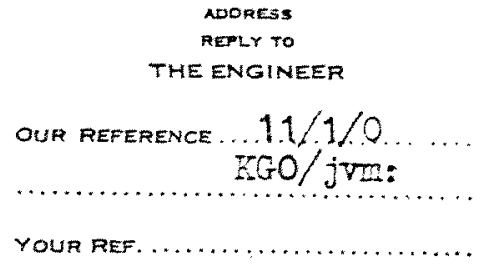

ADOREST HE ENGINEEF KGO/jum:

NEWO: ENGINEER TO TEE AUTHORITY

$$
r e \frac{\text { Weeting with Mr H.F. Bennett }}{\text { Damage to Aquiclude, } 1937}
$$

On Exiday, 1st Warch, Wr Oman and ryself met wir $\%$. F. Bennett a rotired Ministry of Works Engineer who had been in charge of the dred 5 inf and reclamation in jamary, 1937 when the alleged damage took place. He has lived at 143 Gracelield Road since 1926.

Mr Bennett, whose memory appeared to be very reliable, gave the following information.

1. Two excavetors were used for the work both beirg set up on Scobie Island. These were relatively large, steem rimenchines and operating over a 30 to 45 degree segrent. The booms leing sufficiently long to reach, approximately to the middle of the present river chamel.

2. Although the excavators were designed to be manoeuvrable it $\pi s$ in fact a mejor operetion and in effect, the excavetors aithoupt on szids, were fixed, relyins on the river to keep them suppliod with grevel.

3. The sumer was perticularly ary and the supply of gravel dut to miver action failed. The southemost excavator was to some cutent, supolied with sand etc by and tice action but the northempost excavator was outside the range of were action and materiaI $\%$ available only by deepening the hole.

4. Initially excavation was through grevels, but, as suppig frum the rive: decreased, the northem excavator entered a pug, described Wr Bemett as being very difficult to excavate. At the twre the truble was first noticed the excaration was at a mawn deph ef approximately 50 feet, below water leve.

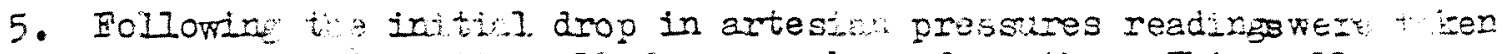
at a nearb, homestiv well for a mube of rortho. This weI at the Tork Offos aear Cropt Grove. During thid tine arem. Iev increase of apprisinately 1 foot. 
6. A Earbour Board diver inspected the excavation imediately following the drop in artesian pressures He did not observe any movement indicative of an upwards flow of water, nor did he notice a temperature change.

7. Mr Bennett was, and still is, certain that the drop in artesian pressures was not due to the excavation but that it was due to the particulariy dry sumer.

8. Two small (probably 2") artesian bores were put down to supply the boilers with feed water.

On impacting the area in Bennett fixed the approvimate positions of the two excavators as follows : -

1. The southemost opposite the southermost boundary of B.I.(N.Z.) Iimited, the river bank being in the vicinity of the present footpath in post Road.

2. The northemmost opposite the last oil tank in B.F.'s property, Egain on the line of the present footpath.

An old plan of the area, in the City Council files, shows what may be Scobie Island. Details from this plan superimposed on a wore upto date plan shows, that, in fact, the position of the excavators would be east os Eort Road. The deepest pert of the northemmost excavation would be urier or adjacent to Port koad, prssibly some of the excavation would be uider the present river.

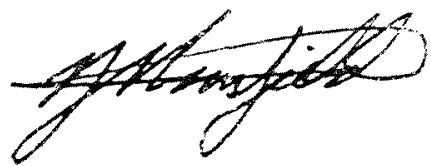




\section{$20 / 2$}

\section{MINISTRY OF WORKS}

MEFTTEIM

Telephone: 85119 Upper Eutt
691106 TeIlington

P.O. $80 x$

12 Harch 1968

The Engineer,

Futt Vallej Underground Tater Authority Private Ras

IOHER EUTT

Dear Sir,

\section{DPEDGE OE EUTT PIVER}

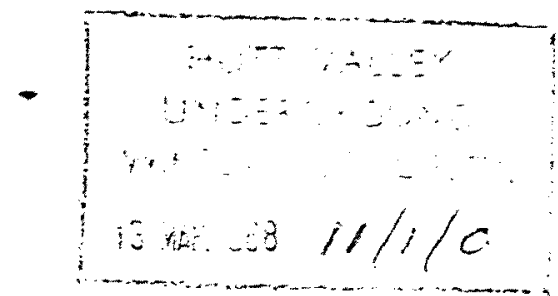

Please refer to rour $11 / 1 / \mathrm{C}$ dated 15 Decenoer 1958

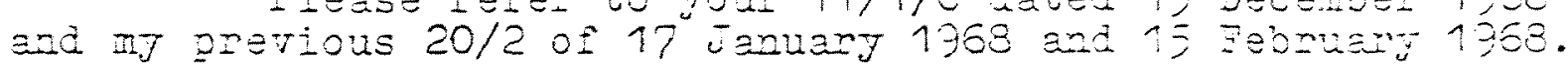

I an able to acrise tiset we now hare some information

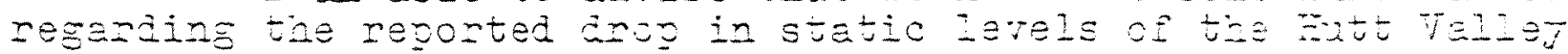
artesian sustem.

The drop occurned in Jexuary 1937 end it wes the suoject of representation naje to the then Haister of Einarce,

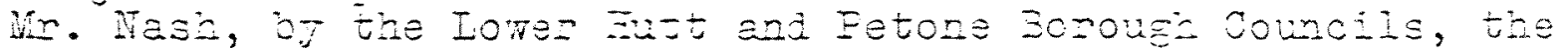
Hutt County Council and Pire industrial usere. The tetter

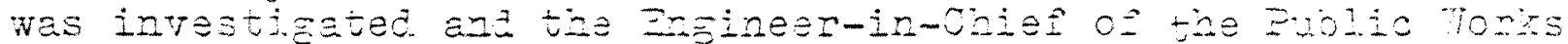

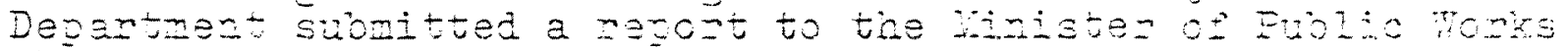
who in turn formanded a cong to in. Nash.

$\therefore$ oopy of this pezont is enclosed fon yow infompetson. You Will notice that tas canolusion oz the negont was that the

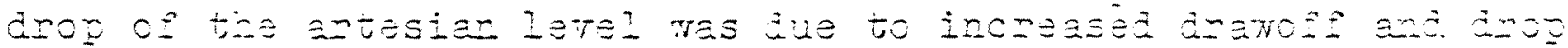
in rainela juning the geziod uniez discussion. It mas in no way causez by the Depantaznt's recieration ogenations.

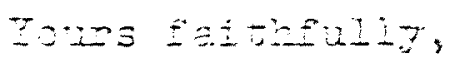

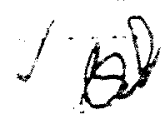

Encl.

Z.J.MctongazI

Besident ingineg

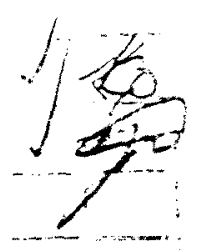

zen:

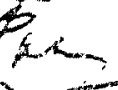

C.7. $i$ 


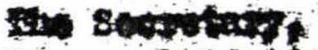

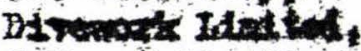 1 zanat atosict. etarizat}

\section{oth As tos}

\section{Dow ger.}

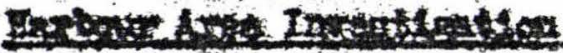

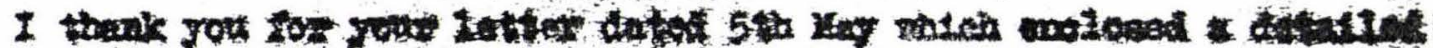

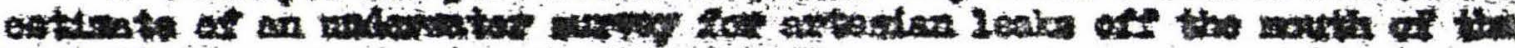
Bat etrot.

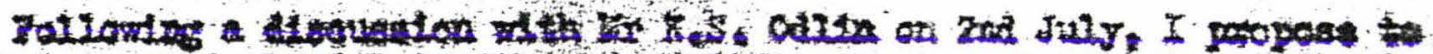

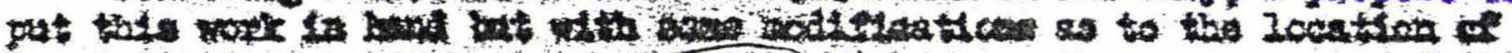

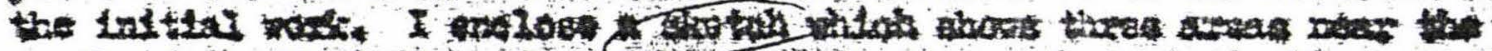

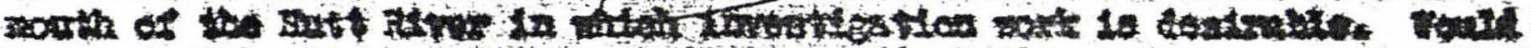

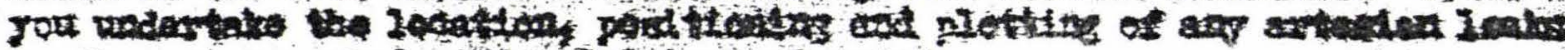

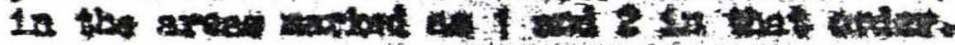

20.1

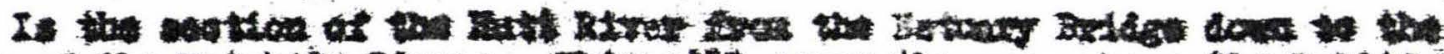

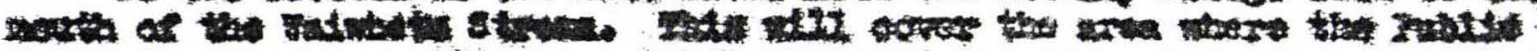

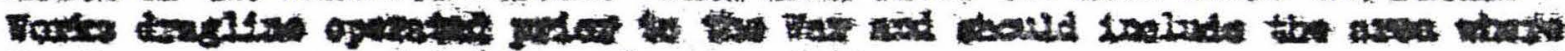

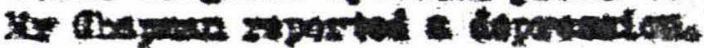

\section{Ax: 3}

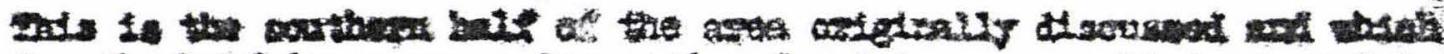

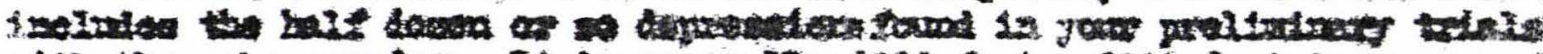

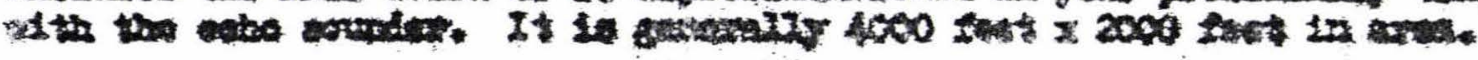

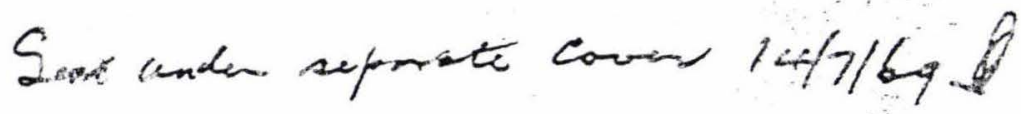




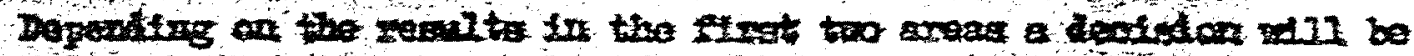

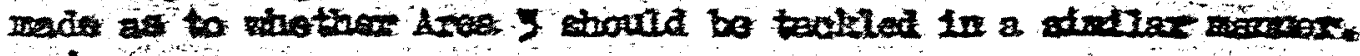

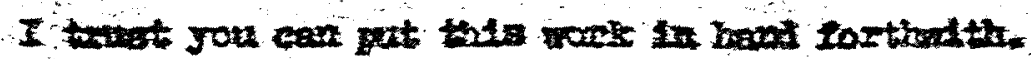

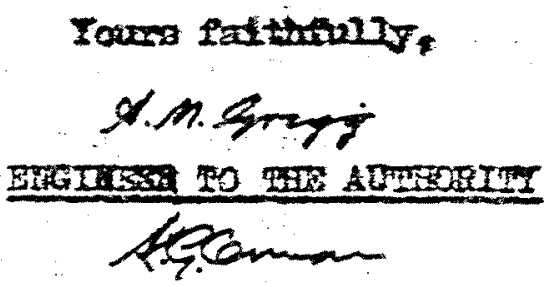




\section{DIVE WORK LIMITED}

$I$ TAWAI STREET, TRENTHAM NEW ZEALAND

TELEPHONE 84-560 UPPER HUTT

4th August, 1969.

\section{REPORT ON DEPRESSIONS OFF PETONE BEACH}

\section{SHOWING SIGNS OF ARTESIAN LEAKAGE.}

$023^{\circ}$ magnetic from the old wharf at Somes Island we discovered off Petone beach in the area between 1000 yards and 500 yards below high tide mark 3 deep depressions.

An echo-sounder strip of this area is enclosed and we would draw your attention to the 20 to 1 horizontal. to vertical scale of this strip.

Salinity readings were taken in the area and were found to be marisedly lower than normal sea-water which gives a reading of 8000 on our salinometer. The surface readings taken in this area varied between 3925 and 4175 , the readings taken near the sea floor were also low, ranging from 5150 to 5680 . Fresh water gives a reading of 1585 on our meter. Following these salinity tests it was considered advisable to dire on these holes to determine their nature more exactly.

The holes are simjlar in size and general conformation, variations in depth being the mejor difference. They have a top diameter of approximately 60 yards and the flat saucer-like fioor is about 20 yards across. The slopes of the sides vary from 1 in to steeper than 1 in 1.5. The bottoms are composed o? the normal harbour floor mud but contain a number of extremely soft patches some of which display risible eridence of artesian leakage.

Core samples of the materials have not been taken nor have shear values been established, both these tests can be carried out if required. 


\section{DIVEWORK LIMITED}

I TAWAI STREET, TRENTHAM NEW ZEALAND · TELEPEONE 84-560 UPPER HUTT

29 th August, 1969.

Hutt Valley Underground Fater Authority, Private Bag, LOWER HUTT.

Attention Mr. K. G. Orman.

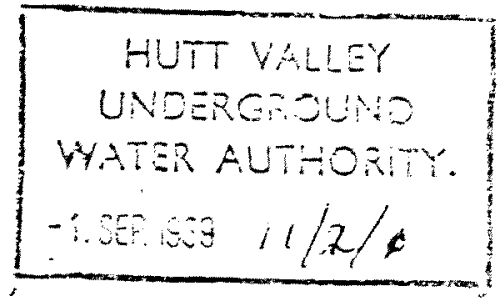

Dear Sir,

We thank you for your letter of August 20 th.

We will shortly complete a chart showing the exact

locations of artesian formed depressions in the Harbour, in the area off the Petone foreshore occupied by the proposed Ministry of works cable route to Somes Island. Completion of this chart has been delayed by the discovery of inaccuracies in the present Land and Survey Department map of the Petone foreshore. New information from Land and Survey is now being processed and on completion a copy of this chart will be forwarded to you.

PJS: sir.
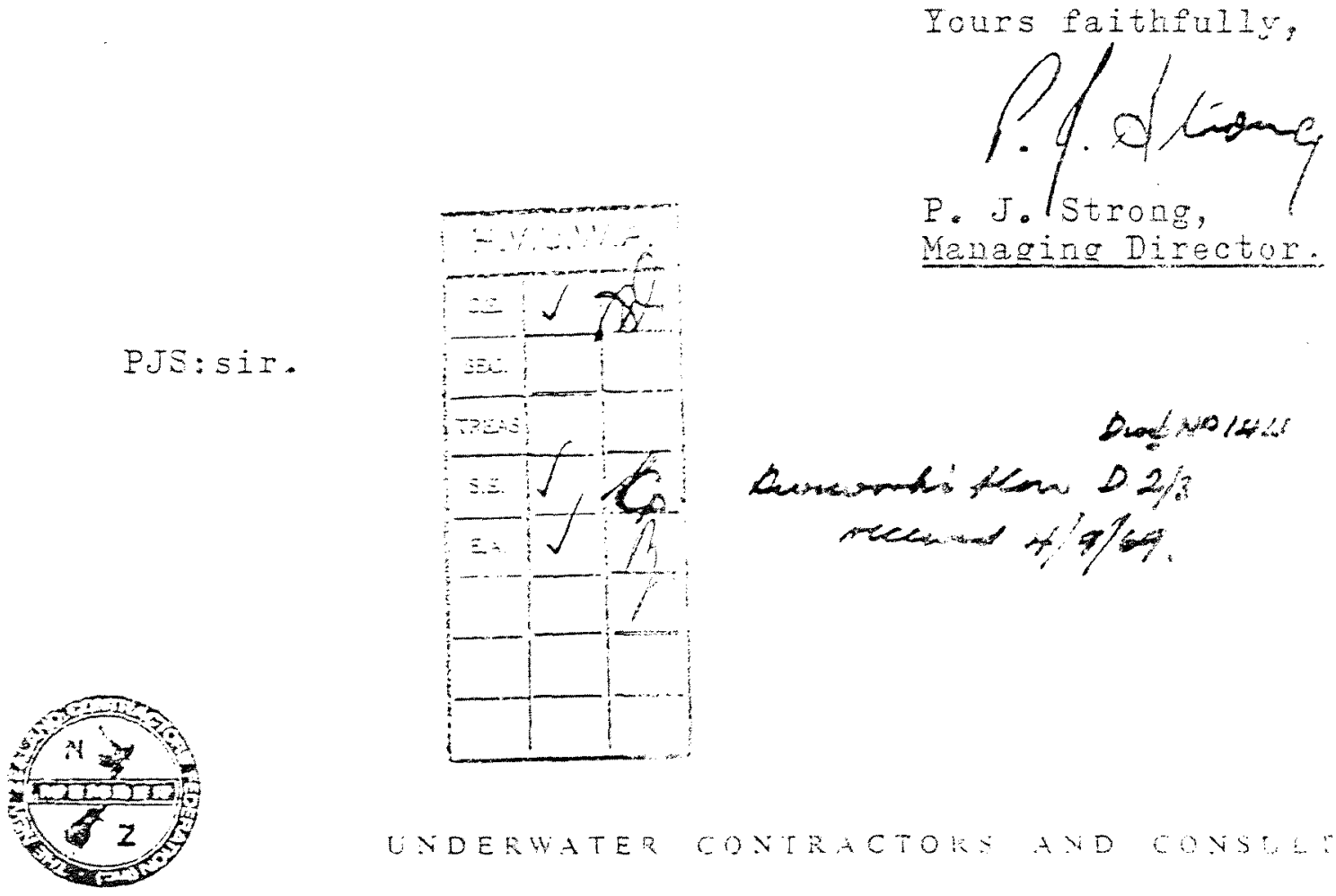

UNDERWATER GONTRACTOKE AWD OONSTE: VI 


\section{DIVEWORK LIMITED}

I TAWAI STREET, TRENTHAM NEW ZEALAND - TELEPHONE 84-560 UPPER HUTT

20th October, 1969.

The Engineer,

Hutt Valley Underground Water Authority, Private Bag,

LOWER HUTT.

Attention Mr. K. G. Orman.

Dear Sir,

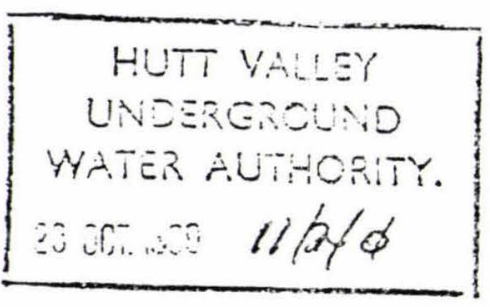

HARBOUR SURVEY.

We enclose our drawing No. UGA $69 / 5$ showing the location of depression areas and a number of spot depths on which contour lines have not yet been charted.

To enable us to cover the area thoroughly and as quickly as possible we did our sounding runs on sextant arcs and established the positions of holes by cross sights as the echo sounder recorded each depression. This method, though well suited to the task of finding holes, does not give a patteri. from which contours can be drawn.

We would be pleased to discuss our echo sounder strips and plottings with you to assist in deciding what detail is required.

PJS:sir.

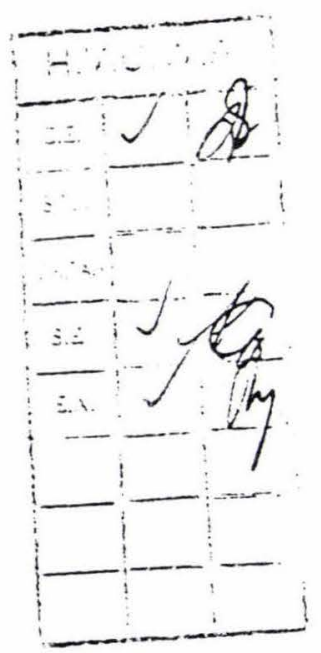

Yours faithfully,

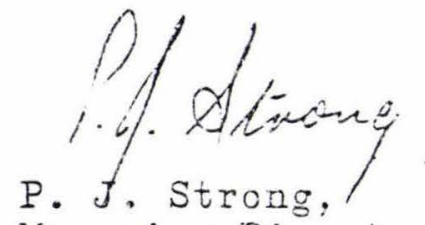

Managing Director.

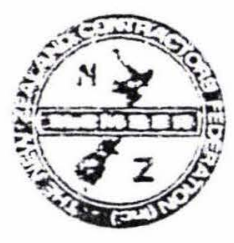

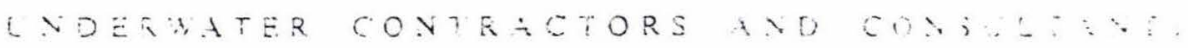


The Engineer,

Hutt Valley Underground Water Authority, Private Bag,

LOWER HUTT.

Attention Mr. K. G. Orman.

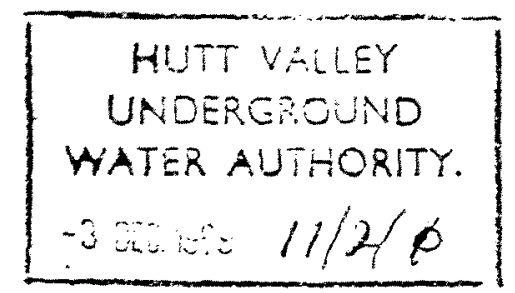

Dear Sir,

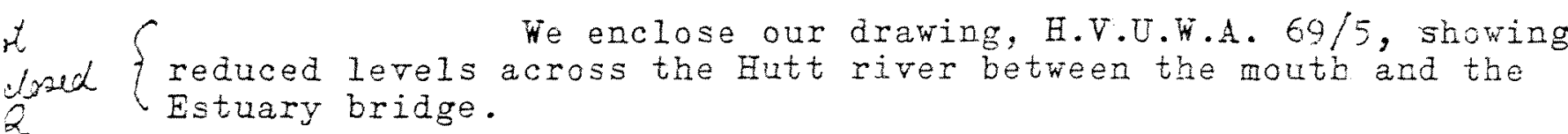

This survey did not locate the hole, near the mouth of the Waiwhetu stream, reported in Jure by Mr. Chapnan. We have echo-sounded over the indicated area un a very close pattern and this also has been unsuccessful. We would suggest that, as this hole is reputed to be deep but of very small diameter, it would be possible to pass very close ovex it without discovering it. Therefore, we feel that the most economical method in the long run could well be to do an underwater grid search over the area. We expect that such a search would occupy a 3 man diving tean for 2 to 4 days, the cost being between. $\$ 360.00$ and $\$ 720.00$ for such a period.

The grid search over the old dreg trenoh is now second on our list and it is expected that this will be completed before Christmas.

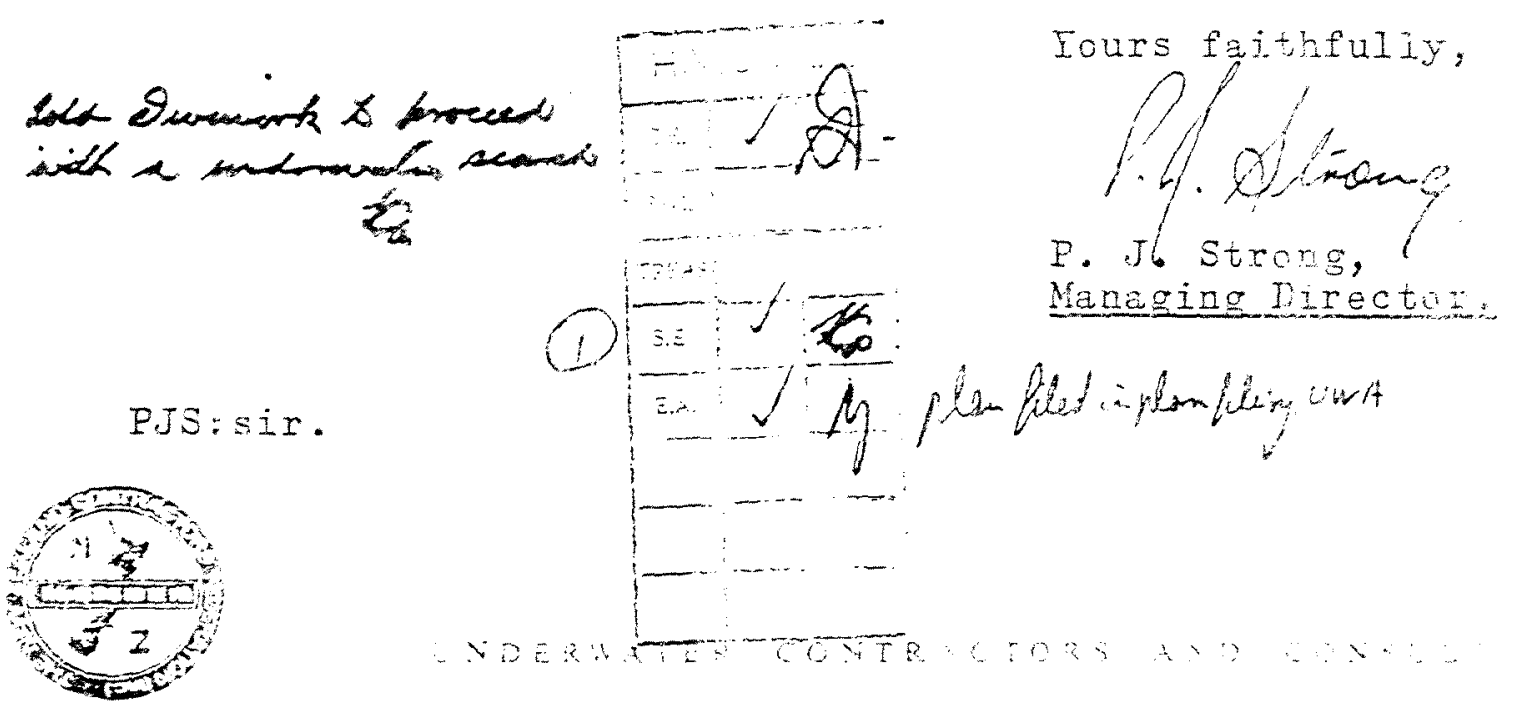




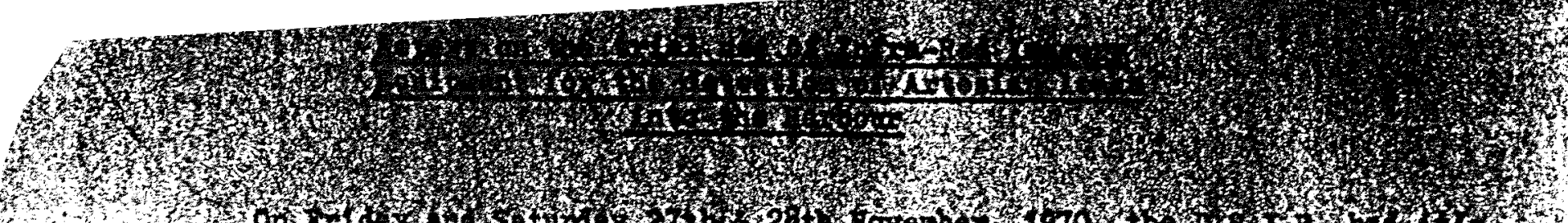
f b)

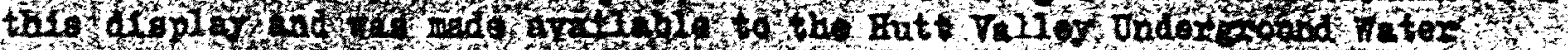

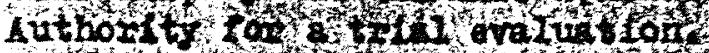

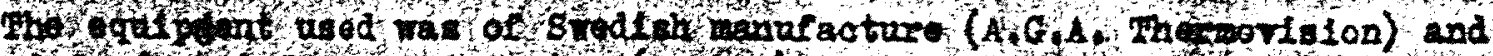

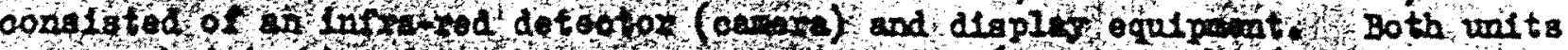

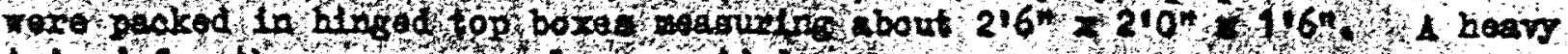

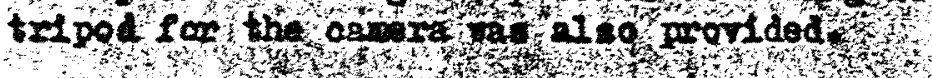

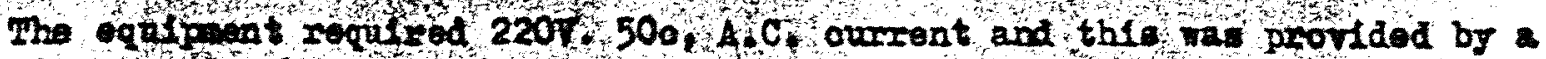

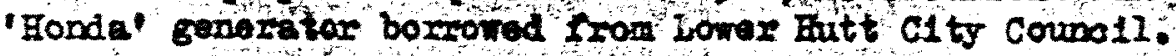

The equipent inoludine the gonorator fitted asily into the back of a Holden Station Trson.

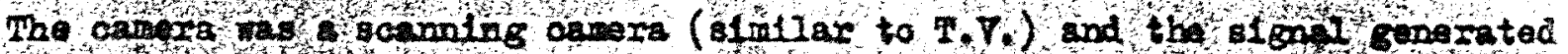
wa tranaramed by pans or a cable to the seperate alsplas unt whtog contalnod

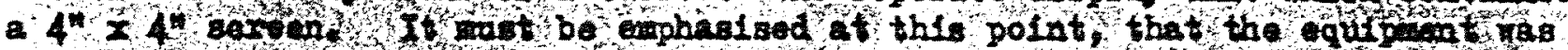

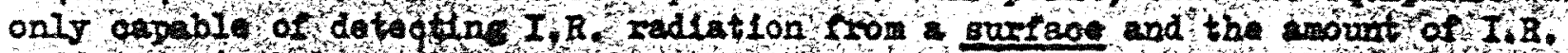

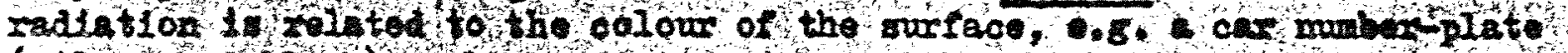

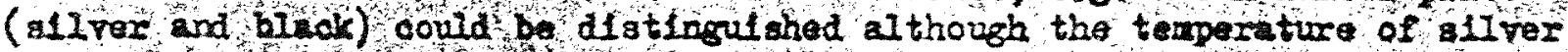
and black agotlons was the same.

The oqu'ponent was used on llonday, 30th Hovenber, 1970, at the end of

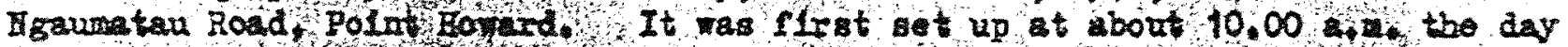

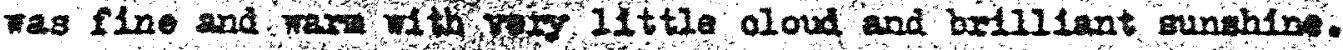

Iand asses could be ldentffied easily and the defferences in I.R. radiation of the rldges and ralley oould be distingulahed and black bl himen nat topped roof's could easliy be etected.

When the canera was tralned on the water no distioction in the amount of I.R. could be observed, The platble harbour espeolelly the closer areas aroure Polnt Howard harl $10 \mathrm{re}$ thoroughly scanned and no evldence of temperstures difference were lound.

It mas be recognlsed that the camera vas viewlag the harbour from an angle of about $30^{\circ}$

As no reeulto were obtalned it was doclded to dismantlo the equipoent and

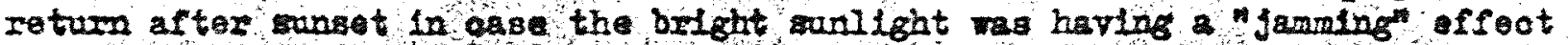

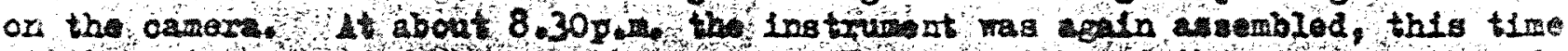

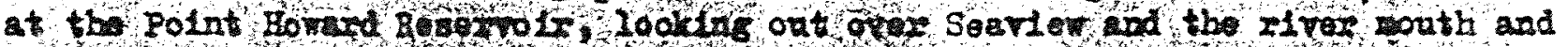

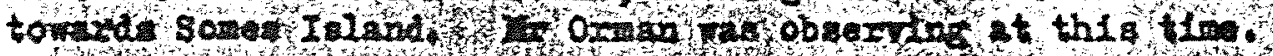

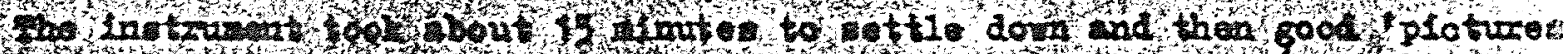

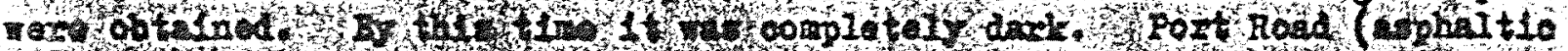

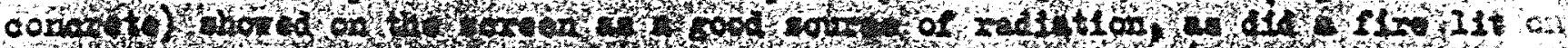

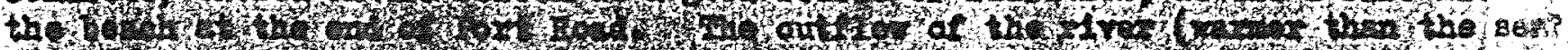

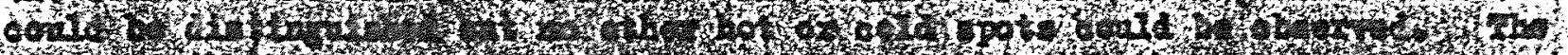

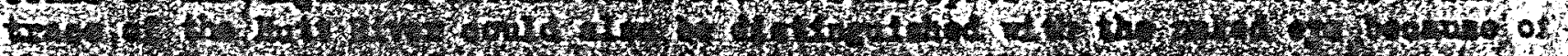

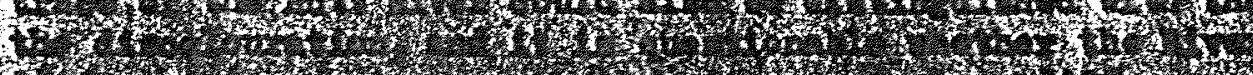




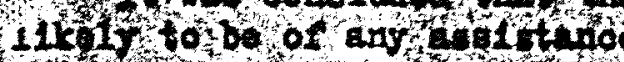

$u=$

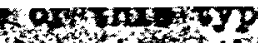

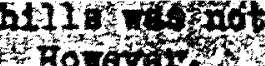

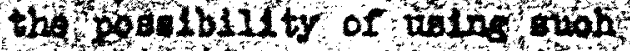

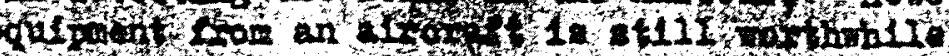

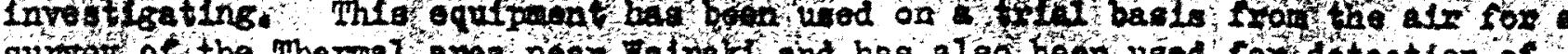
under sea springs in Hama.

It is intended that a full aerial survey be done of Falraki area In April, 1971.

It is recommended, however, that before any attempts are made to use this equipment in an aircraft for Underground Water Authority, that more literature on it's use in similar situations be studied in order to evaluate the optima conditions or use and likely outcome.

J.A. Jones,

ENC INFER HYDROLOGY

Temperature deferencis of batapen 0.5 a $1^{\circ} \mathrm{C}$

cant be detested with confluence

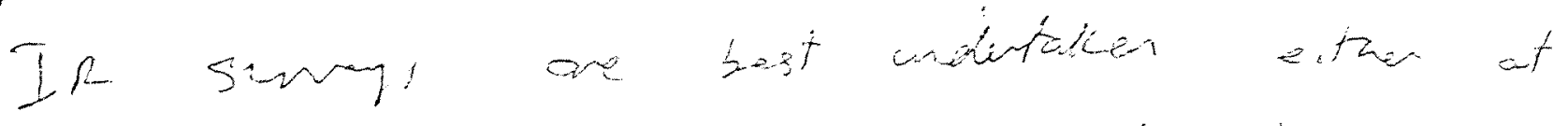

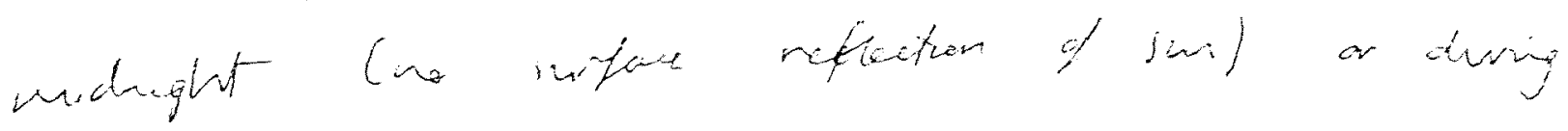

periods

prolonged

overcast

cowotitions

notate winds. 
10.0.

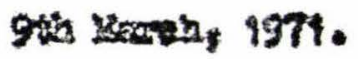

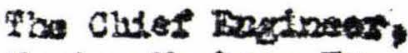

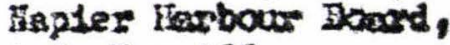

3.0. $\mathrm{B} 0 \mathrm{0} 166$,

IISTER.

Dest 512 .

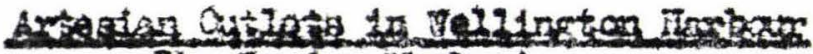

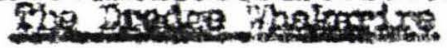

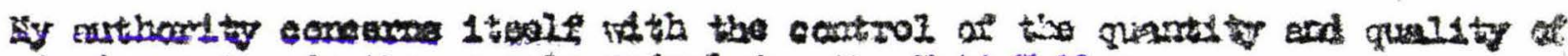

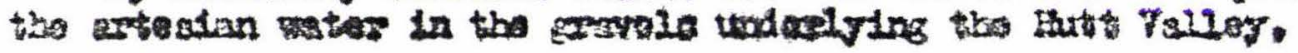

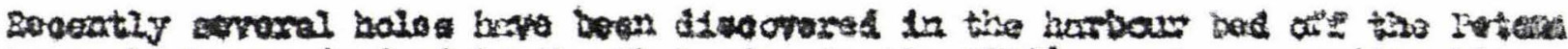

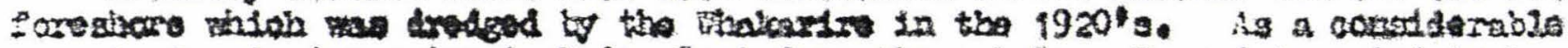

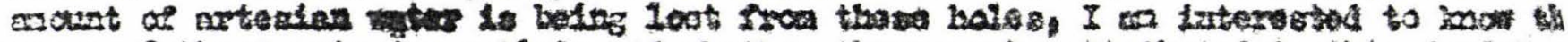

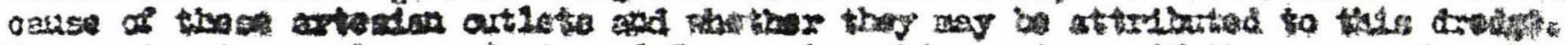

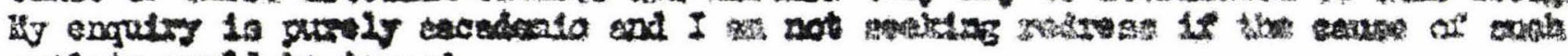
cutilets oorald be troud.

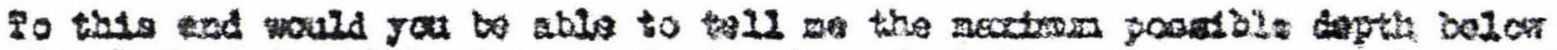

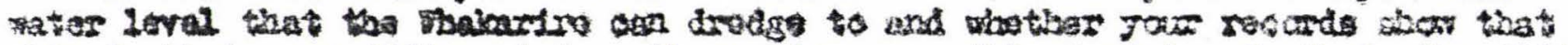

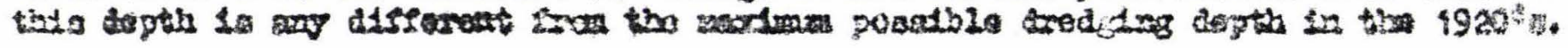

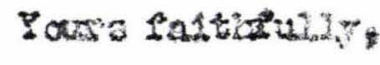

$$
\text { sis enray }
$$

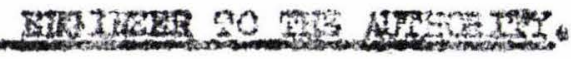

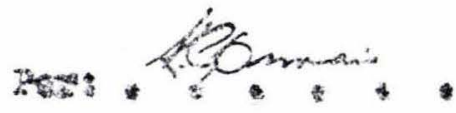


Magier Hartioum Poand

Enginecrs Office,

Brativiator,

Napier, N.Z.

P.O. $80 \times 166$ NAPIER

TELEHONE NO.

8684
17 vacch, 197?

Pino Encinas?

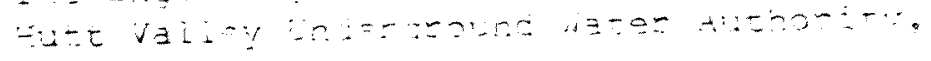

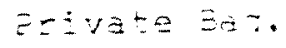

OSits

$19401971 \% ; 6$

Your

Jeョะ

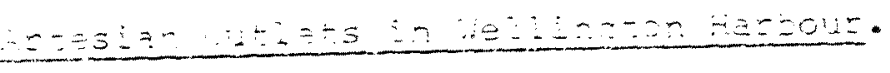

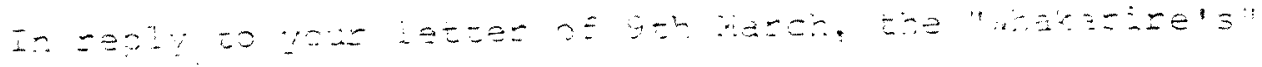

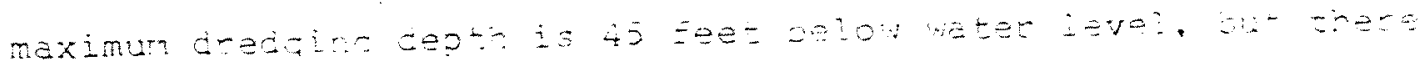

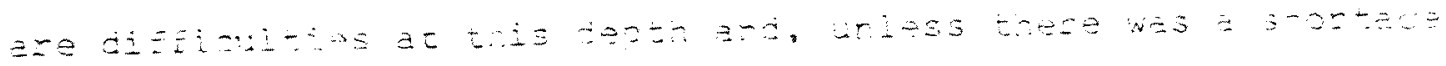

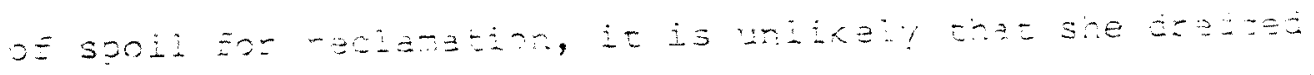

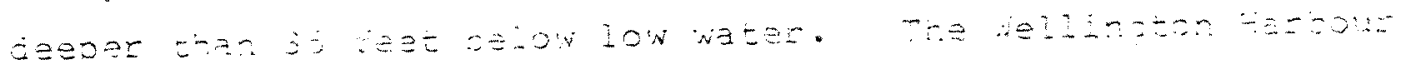

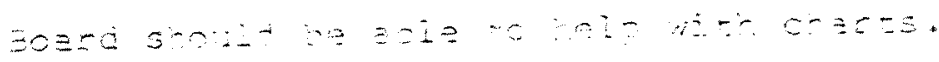
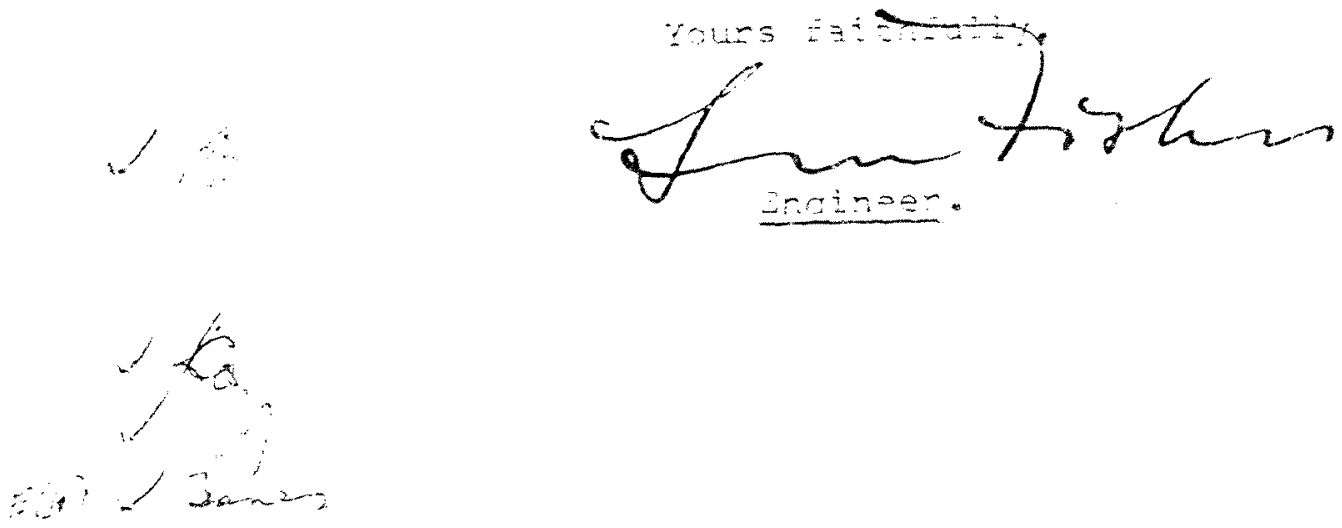


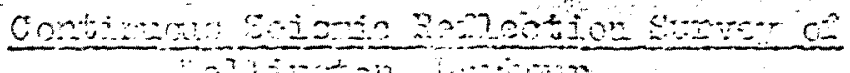

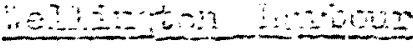

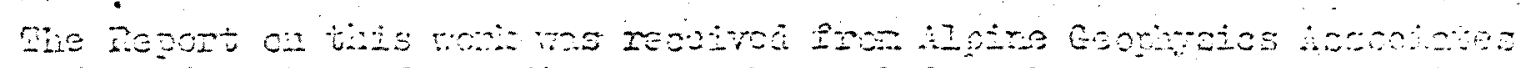

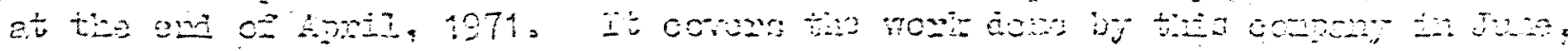

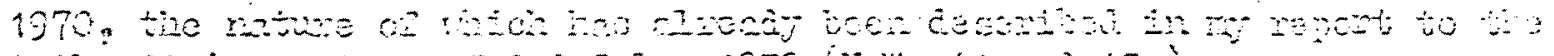

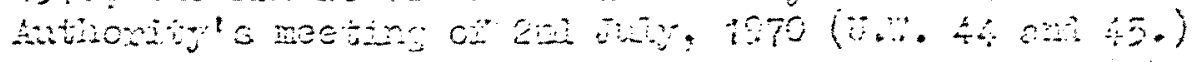

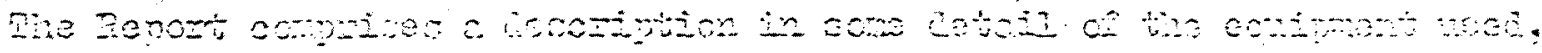

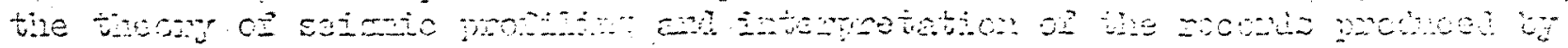

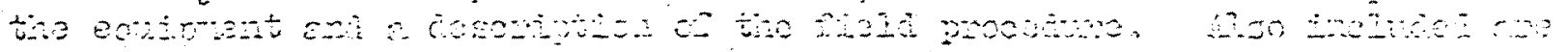

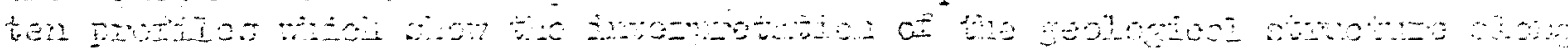

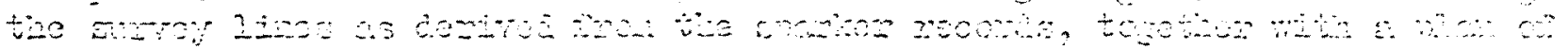

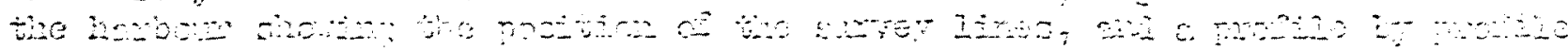

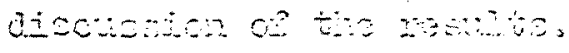

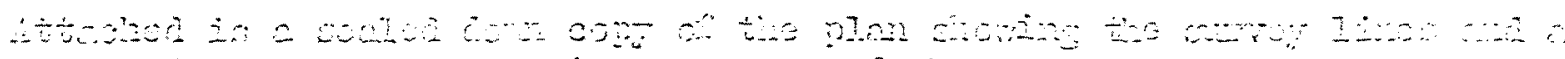

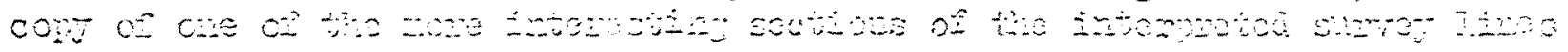

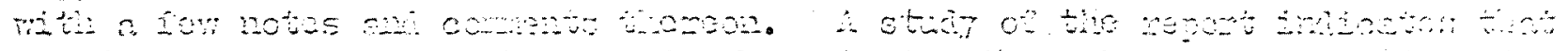

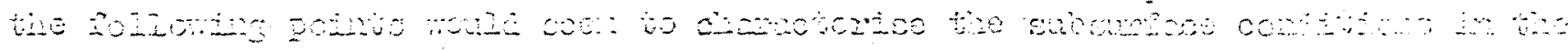
$12=0 \mathrm{an}$.

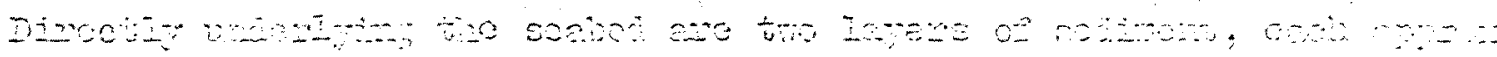

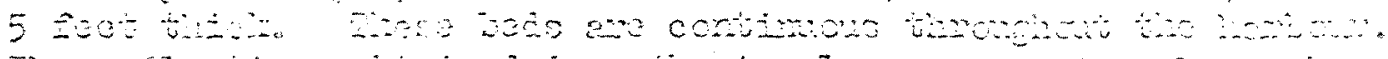

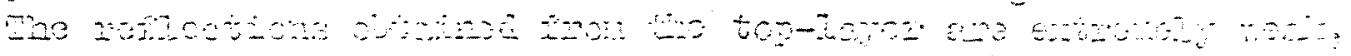

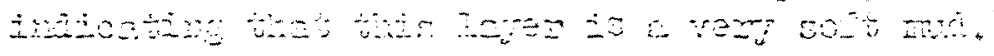

$(2)$ Then

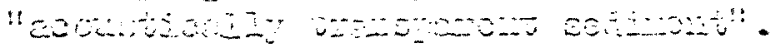

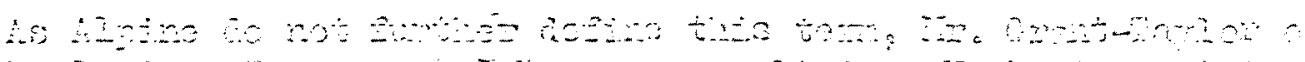

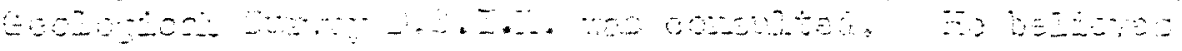

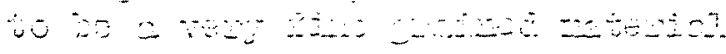

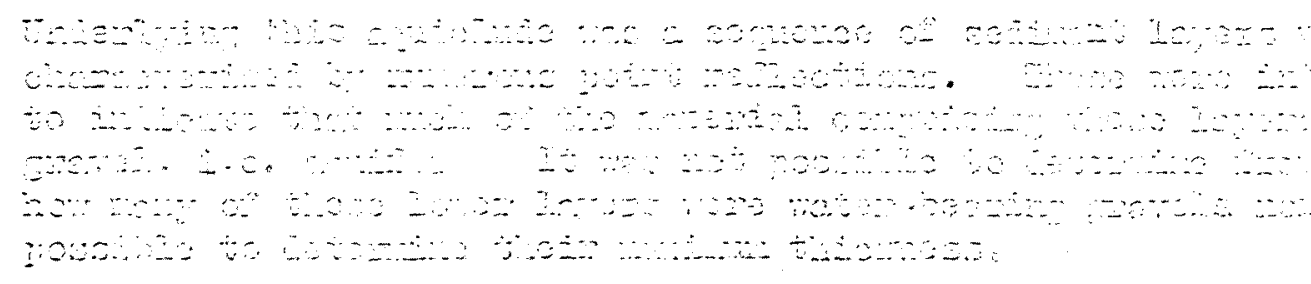

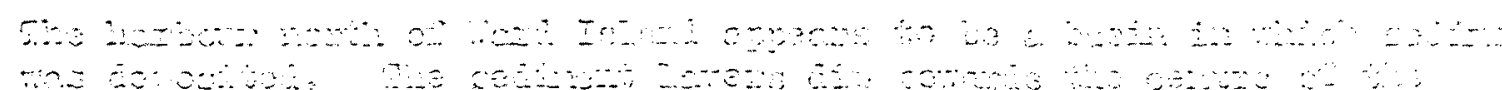

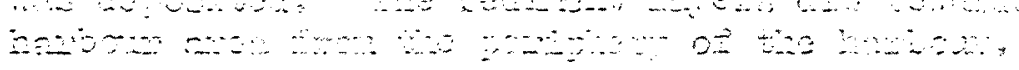

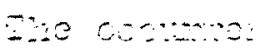

$+500,0$

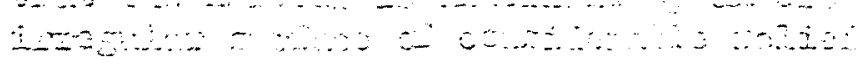

$\therefore-\cdots$

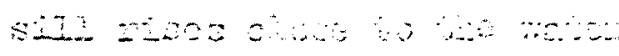

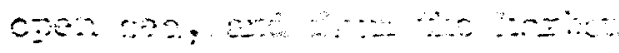

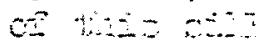

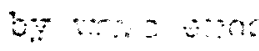

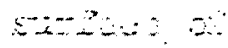




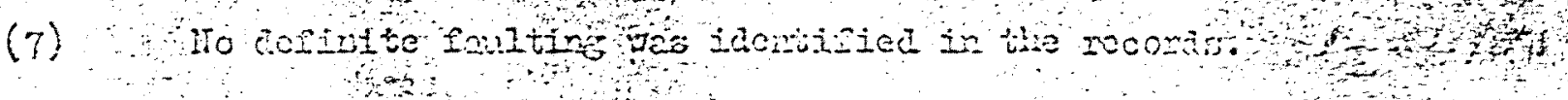

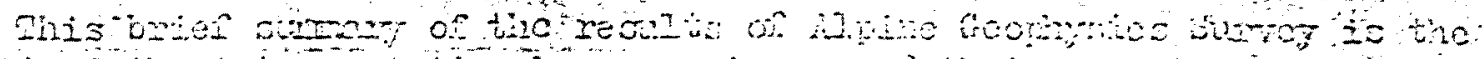

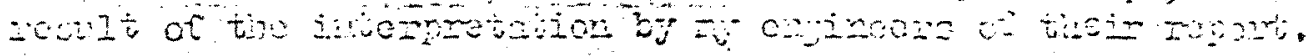

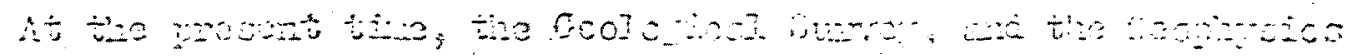

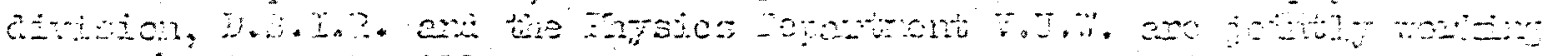

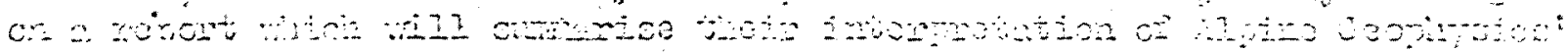

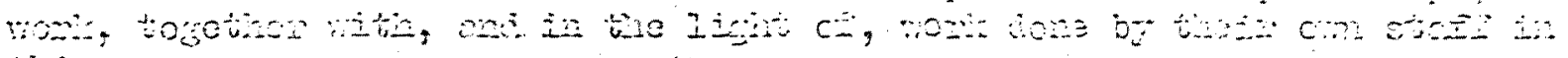
tisis asos.

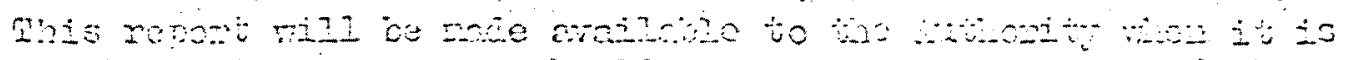

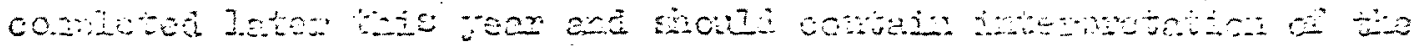

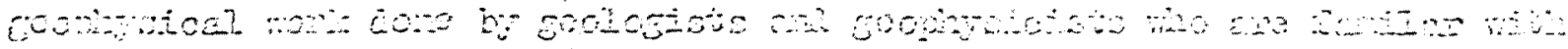

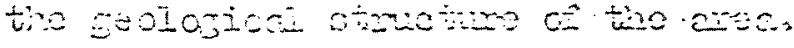

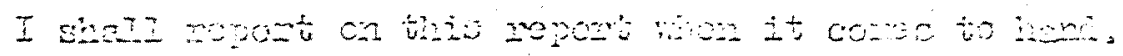

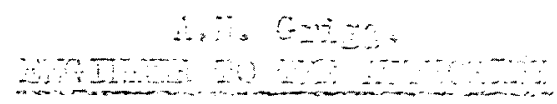

$\operatorname{Ixp} 2$

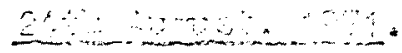




\section{DIVEWORK LIMITED}

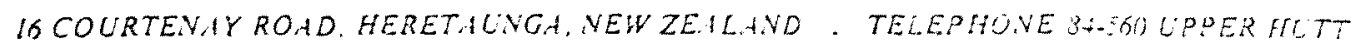

25 th July, 1972 .

The Engineer,

Hutt Valley Underground water Authority,

Private Bag,

LOWER HUTT.

Attention Mr. K.G. Orman.

27. 1072 ift 197

Dear Sir,

\section{HARBOUR STRVEY.}

As requested we have examined your requirements ard, against the figures quoted in our letter of Way 22nd. we estimate as follows.

Depending upon how far west the Survey goes, ?rom 80 to 110 runs will be needed. At ar average of $T \times 1$ mile runs per 10 hour day 12 to 16 days of field work will be required, this could rary if bad reather causes a significant percentace of part days.

Our Consulting Engineer estimates $\$ 500.00$ - $\$ 600.00$ for shore survey and, as best we can calculate, the E.C.B. cherges should be $\$ 200.00-\$ 220.00$

As we are not now required to produce a chart, cur office Work will be greatly reduced.

The estimate therefore cajoulates on 2 baves, f for go runs. E for 110 runs.

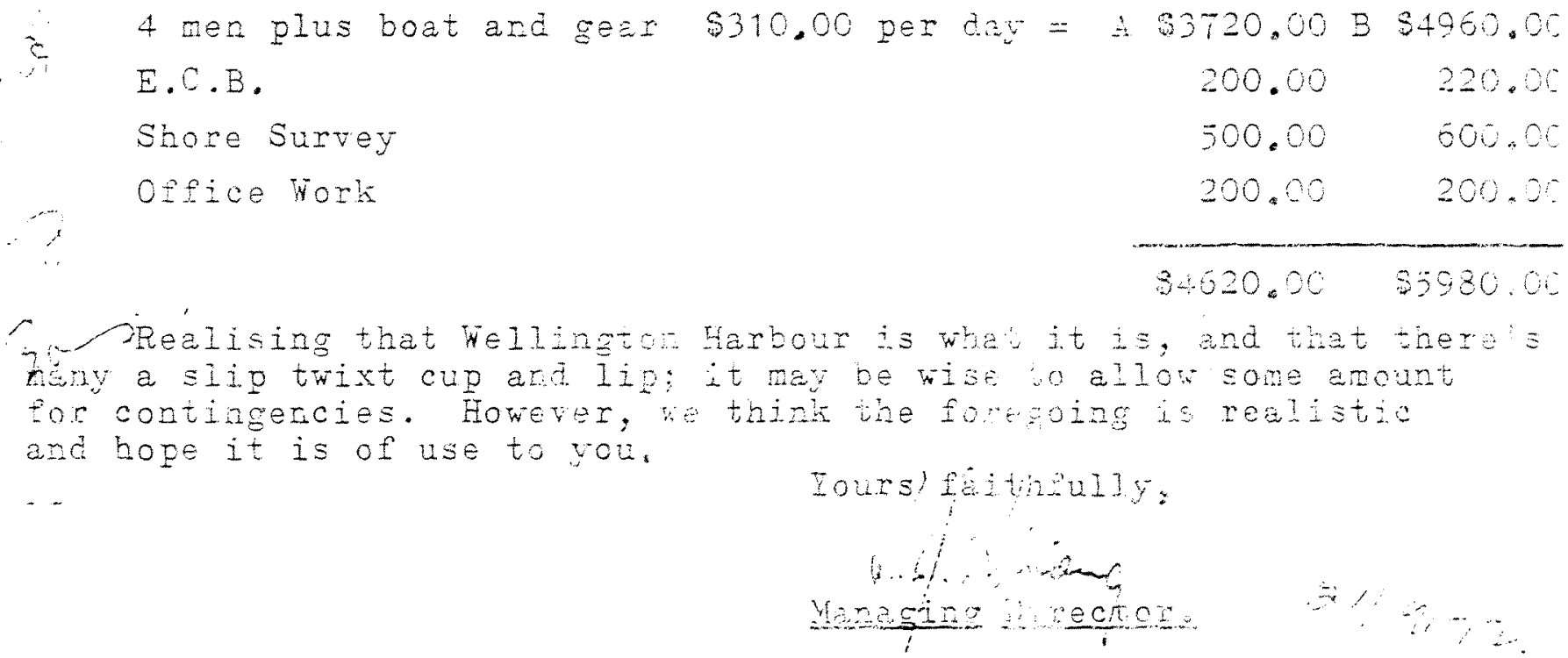




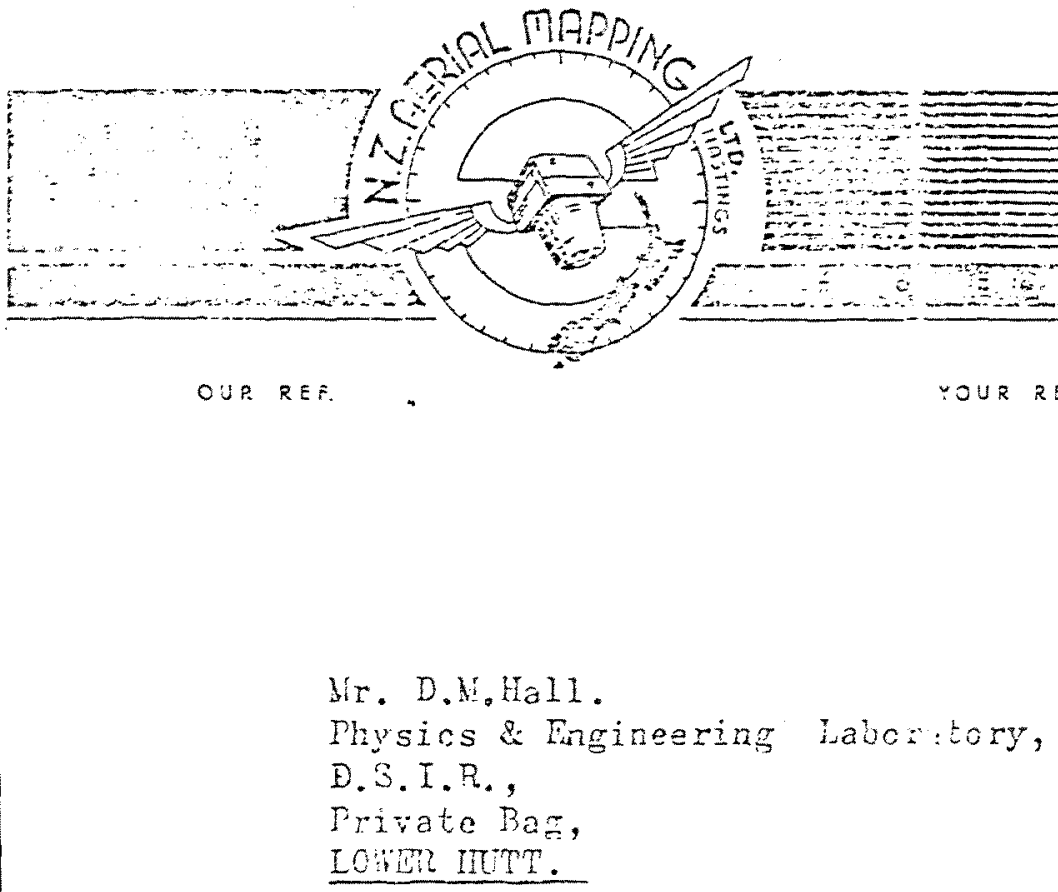

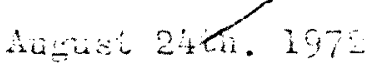

Jir. D. Mi.Hall.

Physios \& Fangineering Laboz:tory,

B. S.I.R.,

Cat?

IOHTR ITTT.

Dear Sir:

Conftrang oar conterention on the tojerbone this rorning, the costing for the Infra Fed imgery o: the Heiliroton Farbour, woula be at be por lina mile, which yndudes the roting

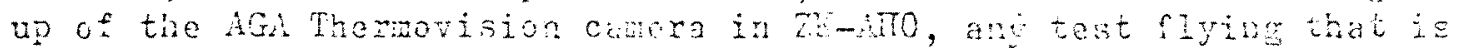
necossary, the positinning of the aiverat at llelington, nnd standby until the job is complete, with a maximu of $C$ deys, ard retum to Fastiness.

An apropination of the number of exposinas requiren

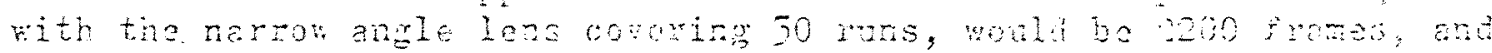

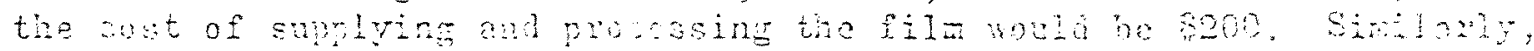
for the wide ande lerse the moner of pames woud be 750 and the

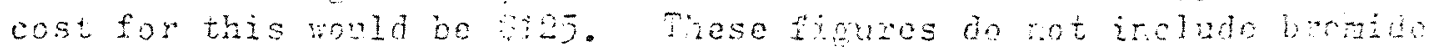

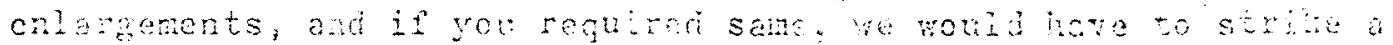

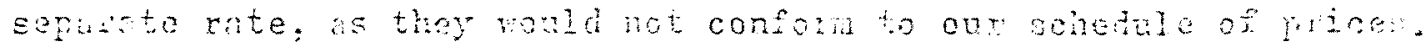

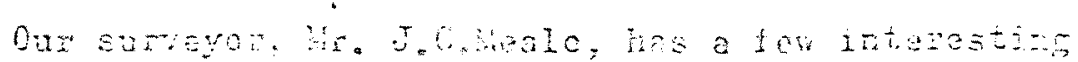

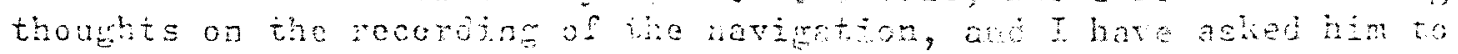

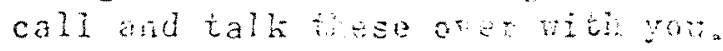

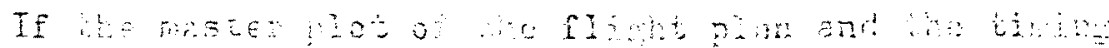

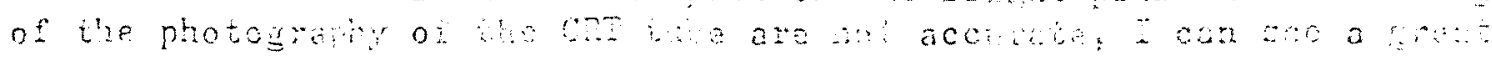

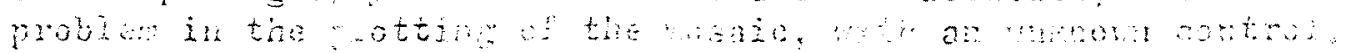

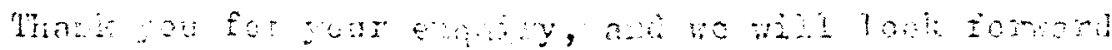

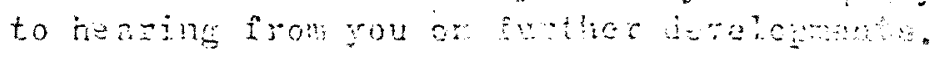

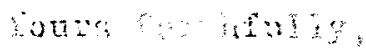




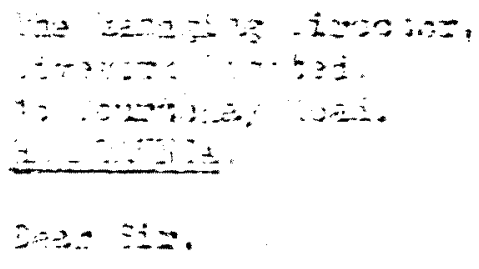

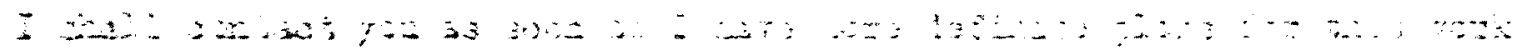

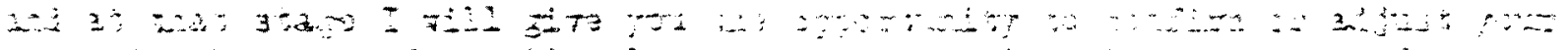

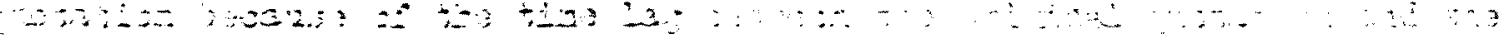

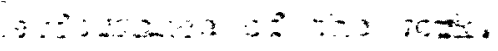

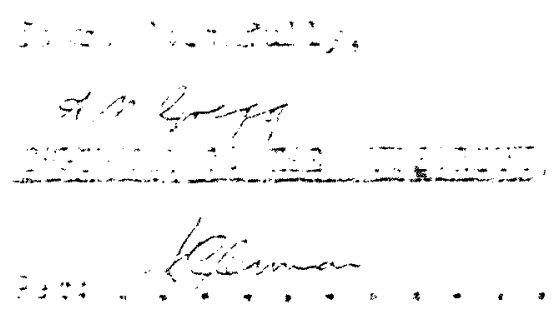




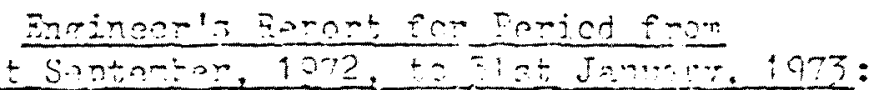

\section{Sering of Bores:}

An old donestic bore was áiscowered sfier o house ras demolished edjoctet to the Petone Eorling Club. The sito is reguired for the lavins of a third green for the club. This bore has been extented and reamed and. should bo Erouted shontly.

A futher bore was discovered in the couse of riverdank clcaring works neer lfelling Brizge by the Hutt River Jonra. This has been extended and reamed and will be srouted shonily.

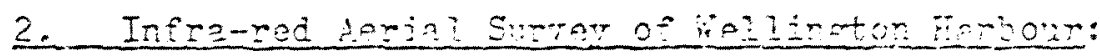

An attempt ras rese early in Yonday moming, 11 th Septender, 1972, to cotcot likely leabare aroas in the rerbour by detectire the tempenatuo differences between the fresh aguifer whet and tha sos notor. Unfortunately, a thin cioud layer at 4000 foet, phim nas net tisidic

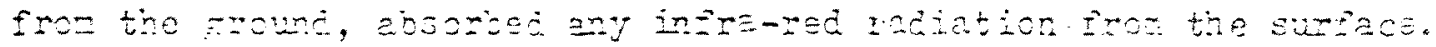

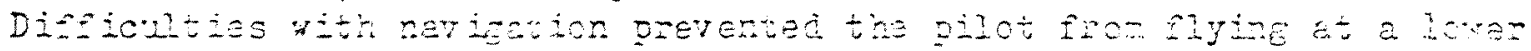
o.ltitude Elong set lires.

Suiteble tidel conditions existed for the revalmion of that moln

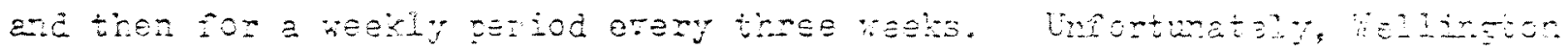

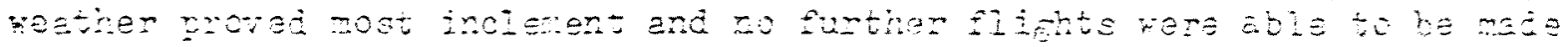
cue to the uncuitcieintig of the reather conditions.

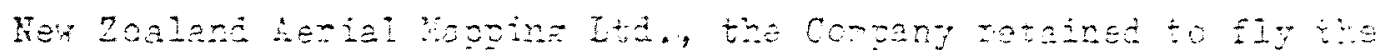

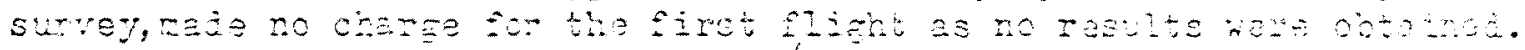

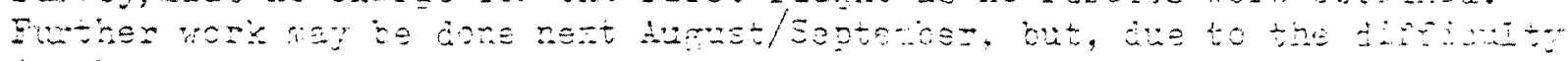

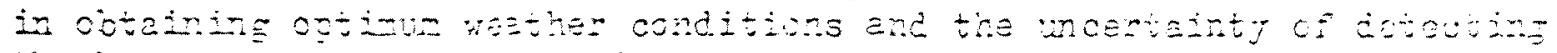

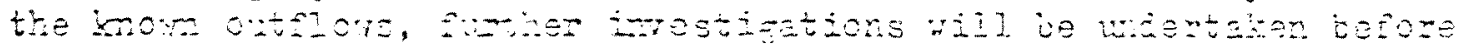
further eszial rik is tona.

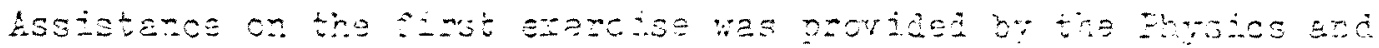

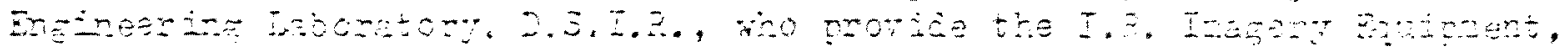

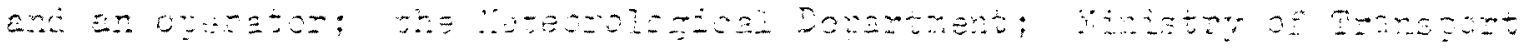

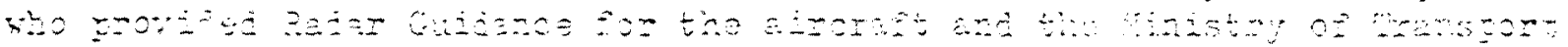

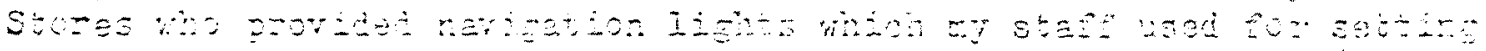
cut the ratht ines.

z-

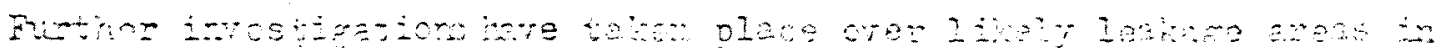

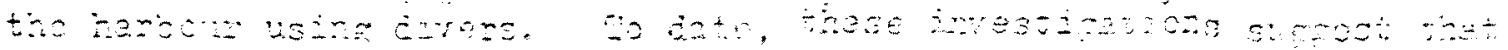

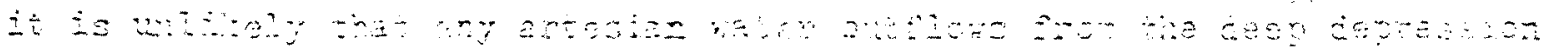

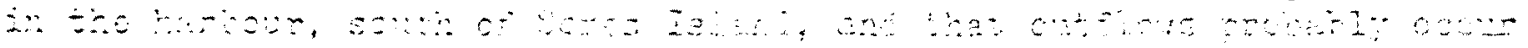

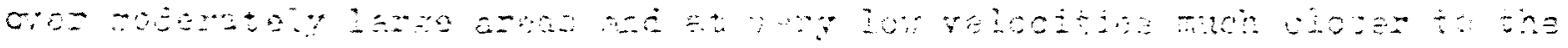

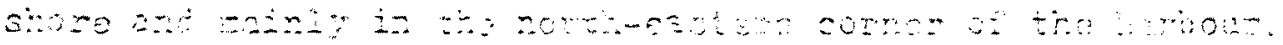

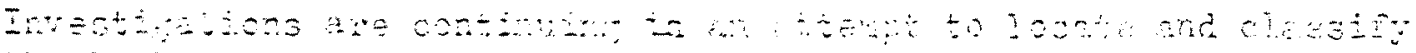
the loritre areas. 
DGPS locations and line of sight positioning of sites investigated 


\section{Appendix Two \\ (Location of Sites Investigated)}

\begin{tabular}{|c|c|c|c|c|c|}
\hline \multirow[t]{2}{*}{ Zone } & \multirow[t]{2}{*}{ Name } & Latitude & Longitude & \multirow{2}{*}{$\begin{array}{l}\text { Maximum Depth } \\
\text { (mbsi) }\end{array}$} & \multirow{2}{*}{$\begin{array}{l}\text { Line of Sight Positioning } \\
\text { (Bearing, magnetic) }\end{array}$} \\
\hline & & \multicolumn{2}{|c|}{ (decimal degrees) } & & \\
\hline 1 & Petone 1 & -41.23942 & 174.88774 & 13.3 & $\begin{array}{l}\text { North tip Somes Island (228) } \\
\text { Pt Howard Lighthouse }(120) \\
\text { Seaview container }(048)\end{array}$ \\
\hline 1 & Petone 2 & -41.24225 & 174.88626 & 15.2 & $\begin{array}{l}\text { Pt Howard Lighthouse (120) } \\
\text { North tip Mokopuna Island (217) } \\
\text { Petone Wharf (287) }\end{array}$ \\
\hline 1 & Petone 3 & -41.24428 & 174.88620 & 15.1 & $\begin{array}{l}\text { Petone Wharf (292) } \\
\text { North end Pt Howard Wharf (112) } \\
\text { North tip Mokopuna Island (221) }\end{array}$ \\
\hline 1 & Petone 4 & -41.24374 & 174.88921 & 16.4 & $\begin{array}{l}\text { North tip Mokopuna Island (221) } \\
\text { Petone Wharf (287) } \\
\text { Marina Light (072) }\end{array}$ \\
\hline 1 & Petone 5 & -41.24632 & 174.88782 & 16.5 & $\begin{array}{l}\text { Pt Howard Lighthouse (120) } \\
\text { North tip Mokopuna Island (224) } \\
\text { South tip Somes Island (200) }\end{array}$ \\
\hline 1 & Petone 6 & -41.24784 & 174.88774 & 19.4 & $\begin{array}{l}\text { North tip Mokopuna Island (211) } \\
\text { Pt Howard Lighthouse (127) } \\
\text { Pt Dorset (180) }\end{array}$ \\
\hline 2 & Somes Hole & -41.26709 & 174.86477 & 31.3 & $\begin{array}{l}\text { Somes Lighthouse (332) } \\
\text { Mt Crawford Satellite Dish (200) } \\
\text { Seaview Wharf (052) }\end{array}$ \\
\hline 3 & Somes Rock & -41.26533 & 174.85700 & 31.0 & $\begin{array}{l}\text { Somes Lighthouse (035) } \\
\text { Mt Crawtord Satellite Dish (191) } \\
\text { Mokopuna Island (002) }\end{array}$ \\
\hline 4 & Seaview Wharf & -41.25883 & 174.89433 & 20.1 & $\begin{array}{l}\text { Seaview Wharf (084) } \\
\text { Pt Howard Lighthouse (032) } \\
\text { Mt Crawford Satellite Dish (210) }\end{array}$ \\
\hline 5 & North Somes & -41.24817 & 174.86733 & 25.4 & $\begin{array}{l}\text { Seaview Wharf (094) } \\
\text { Petone Wharf (344) } \\
\text { Mokopuna Island (183) }\end{array}$ \\
\hline 6 & Pt. Jerningham & -41.28517 & 174.80338 & 24.9 & Pt Jerningham Lighthouse (170) \\
\hline 7 & Falcon Shoals & & & $\begin{array}{c}\text { NA } \\
\text { (not a depression) }\end{array}$ & \\
\hline 8 & Zone 8 & & & $\begin{array}{c}\text { NA } \\
\text { (not a depression) }\end{array}$ & \\
\hline 9 & Evans Bay 1 & -41.30334 & 174.81498 & 23.1 & \\
\hline 10 & Evans Bay 2 & -41.29033 & 174.82012 & 22.4 & \\
\hline 11 & Pt Halswell & -41.28192 & 174.82617 & 24.7 & \\
\hline 12 & Kau Pt & -41.29004 & 174.83667 & 25.3 & \\
\hline 13 & Pt Gordon & -41.29752 & 174.83983 & 29.6 & \\
\hline
\end{tabular}

* The Latitude and Longitude values are adjusted so the they correlate to Hydrographic Chart NZ4633.

To correlate with satellite positioning, Latitide values must be moved 0.16666 decimal degrees North. 
Salinity values recorded at sites during July, August and October 1997 


\section{Appendix Three \\ (Salinity values of depression sites)}

\begin{tabular}{|c|c|c|c|c|c|c|c|c|c|c|c|c|c|c|}
\hline \multirow{5}{*}{$\frac{\text { Zone }}{1}$} & \multirow{5}{*}{\begin{tabular}{|l} 
Name \\
Petone 1
\end{tabular}} & \multirow{3}{*}{$\frac{\text { Date/Time }}{\text { 9/7/97, 8am }}$} & \multirow{3}{*}{$\frac{\text { Tide }}{\text { High }}$} & \multicolumn{10}{|c|}{ Salinity values (PSU) } & \multirow{3}{*}{$\frac{\text { Mean }}{33.08}$} \\
\hline & & & & 31.5 & 32.0 & 32.0 & 32.0 & 32.5 & 32.5 & 32.5 & 33.0 & 33.0 & 33.0 & \\
\hline & & & & 33.5 & 33.5 & 33.5 & 33.5 & 33.5 & 33.5 & 34.0 & 34.0 & 34.0 & 34.5 & \\
\hline & & \multirow[t]{2}{*}{$9 / 7 / 97,12 \mathrm{pm}$} & \multirow[t]{2}{*}{ Low } & 32.0 & 32.5 & 33.0 & 33.0 & 33.0 & 33.5 & 33.5 & 33.5 & 33.5 & 33.5 & \multirow[t]{2}{*}{33.58} \\
\hline & & & & 33.5 & 33.5 & 34.0 & 34.0 & 34.0 & 34.0 & 34.0 & 34.5 & 34.5 & 34.5 & \\
\hline \multirow[t]{4}{*}{1} & \multirow[t]{4}{*}{ Petone 2} & \multirow[t]{2}{*}{$9 / 7 / 97,9 \mathrm{am}$} & \multirow[t]{2}{*}{ High } & 29.5 & 29.5 & 29.5 & 30.0 & 30.0 & 30.0 & 30.0 & 30.5 & 30.5 & 31.0 & \multirow{2}{*}{31.50} \\
\hline & & & & 31.5 & 32.0 & 33.0 & 33.0 & 33.0 & 33.0 & 33.0 & 33.5 & 33.5 & 34.0 & \\
\hline & & $9 / 7 / 97,1 \mathrm{pm}$ & Low & 31.5 & 31.5 & 32.0 & 32.0 & 32.5 & 32.5 & 33.0 & 33.0 & 33.0 & 33.5 & 33.15 \\
\hline & & & & 33.5 & 33.5 & 33.5 & 33.5 & 33.5 & 34.0 & 34.0 & 34.0 & 34.5 & 34.5 & \\
\hline 1 & Petone 3 & $9 / 7 / 97,9.30 \mathrm{am}$ & High & 31.5 & 31.5 & 32.0 & 32.0 & 32.0 & 32.0 & 32.0 & 32.5 & 32.5 & 32.5 & 32.85 \\
\hline & & & & 33.0 & 33.5 & 33.5 & 33.5 & 33.5 & 33.5 & 34.0 & 34.0 & 34.0 & 34.0 & \\
\hline & & 9/7/97, 1pm & Low & 32.0 & 32.0 & 32.0 & 32.5 & 32.5 & 32.5 & 33.0 & 33.0 & 33.5 & 33.5 & 33.33 \\
\hline & & & & 33.5 & 33.5 & 33.5 & 33.5 & 34.0 & 34.0 & 34.5 & 34.5 & 34.5 & 34.5 & \\
\hline 1 & Petone 4 & $13 / 7 / 97,11 \mathrm{am}$ & High & 29.0 & 29.0 & 29.5 & 29.5 & 29.5 & 30.0 & 30.0 & 30.0 & 30.0 & 31.0 & 30.95 \\
\hline & & & & 31.0 & 31.5 & 31.5 & 31.5 & 32.0 & 32.5 & 32.5 & 33.0 & 33.0 & 33.0 & \\
\hline & & $13 / 7 / 97,4 \mathrm{pm}$ & Low & 29.5 & 30.5 & 31.5 & 31.5 & 32.0 & 32.0 & 32.0 & 32.0 & 32.5 & 32.5 & 32.58 \\
\hline & & & & 33.0 & 33.0 & 33.5 & 33.5 & 33.5 & 33.5 & 33.5 & 34.0 & 34.0 & 34.0 & \\
\hline 1 & Petone 5 & $15 / 7 / 97,12 p m$ & High & 29.0 & 29.5 & 30.0 & 30.0 & 30.5 & 31.0 & 31.0 & 31.0 & 31.0 & 31.5 & 31.53 \\
\hline & & & & 31.5 & 32.0 & 32.0 & 32.5 & 32.5 & 32.5 & 33.0 & 33.0 & 33.5 & 33.5 & \\
\hline & & $13 / 7 / 97,5 \mathrm{pm}$ & Low & 30.0 & 30.0 & 30.5 & 30.5 & 30.5 & 31.0 & 31.0 & 31.5 & 31.5 & 31.5 & 32.05 \\
\hline & & & & 32.0 & 32.5 & 32.5 & 33.0 & 33.5 & 33.5 & 34.0 & 34.0 & 34.0 & 34.0 & \\
\hline 1 & Petone 6 & $15 / 7 / 97,1 \mathrm{pm}$ & High & 27.5 & 28.0 & 28.5 & 29.5 & 30.0 & 30.5 & 31.0 & 31.0 & 31.5 & 31.5 & 31.23 \\
\hline & & & & 32.0 & 32.0 & 32.0 & 32.5 & 32.5 & 32.5 & 32.5 & 33.0 & 33.0 & 33.5 & \\
\hline & & 16/7/97, 8am & Low & 29.0 & 29.5 & 29.5 & 30.0 & 30.0 & 30.0 & 30.5 & 31.0 & 31.0 & 31.5 & 31.55 \\
\hline & & & & 32.0 & 32.0 & 32.0 & 32.5 & 33.0 & 33.5 & 33.5 & 33.5 & 33.5 & 33.5 & \\
\hline 2 & Somes Hole & $8 / 7 / 1997,8 \mathrm{am}$ & High & 33.5 & 33.5 & 34.0 & 34.0 & 34.0 & 34.0 & 34.0 & 34.0 & 34.5 & 34.5 & 34.17 \\
\hline & & & & 34.5 & 34.5 & 34.5 & 34.5 & 34.5 & & & & & & \\
\hline & & $8 / 7 / 1997,2 \mathrm{pm}$ & Low & 33.5 & 34.0 & 34.0 & 34.0 & 34.0 & 34.0 & 34.0 & 34.5 & 34.5 & 34.5 & 34.23 \\
\hline & & & & 34.5 & 34.5 & 34.5 & 34.5 & 34.5 & & & & & & \\
\hline 3 & Somes Rock & $8 / 7 / 97,8.30 \mathrm{am}$ & High & 33.0 & 33.0 & 33.0 & 33.0 & 33.0 & 33.5 & 33.5 & 33.5 & 33.5 & 34.0 & 33.60 \\
\hline & & & & 34.0 & 34.0 & 34.0 & \begin{tabular}{|l|}
34.5 \\
\end{tabular} & 34.5 & & & & & & \\
\hline & & 8/7/97, 3pm & Low & 33.0 & 33.0 & 33.0 & 33.5 & 33.5 & 33.5 & 33.5 & 34.0 & 34.0 & 34.0 & 33.77 \\
\hline & & & & 34.0 & 34.0 & 34.5 & 34.5 & 34.5 & & & & & & \\
\hline 4 & Seaview Wharf & $16 / 7 / 97,1 \mathrm{pm}$ & High & 28.0 & 28.0 & 28.5 & 29.0 & 29.5 & 30.0 & 30.0 & 31.0 & 31.0 & 31.0 & 31.08 \\
\hline & & & & 31.5 & 32.0 & 32.5 & 32.5 & 32.5 & 32.5 & 33.0 & 33.0 & 33.0 & 33.0 & \\
\hline & & 16/7/97, 9am & Low & 28.0 & 28.5 & 29.0 & 29.5 & 29.5 & 30.0 & 30.5 & 30.5 & 31.0 & 32.0 & 31.33 \\
\hline & & & & 32.0 & 32.0 & 32.5 & \begin{tabular}{|l|}
32.5 \\
\end{tabular} & 33.0 & 33.0 & 33.0 & 33.0 & 33.5 & 33.5 & \\
\hline 5 & North Somes & $8 / 7 / 97,9.30 \mathrm{am}$ & High & 29.0 & 29.5 & 29.5 & 30.0 & 31.0 & 31.0 & 31.0 & 31.0 & 31.5 & 31.5 & 31.83 \\
\hline & & & & 32.0 & 32.5 & 33.0 & 33.0 & 33.0 & 33.5 & 33.5 & 33.5 & 33.5 & 34.0 & \\
\hline & & $17 / 7 / 97,8 \mathrm{am}$ & Low & 31.5 & 31.5 & 32.0 & 32.0 & 32.0 & 32.5 & 32.5 & 32.5 & 33.0 & 33.0 & 33.05 \\
\hline & & & & 33.5 & 33.5 & 33.5 & 33.5 & 33.5 & 34.0 & 34.0 & 34.0 & 34.5 & 34.5 & \\
\hline 6 & Pt. Jerningham & $17 / 7 / 97,11.30$ & Mid & 31.0 & 31.5 & 32.0 & 33.0 & 33.5 & 33.5 & 33.5 & 33.5 & 34.0 & 34.0 & 33.38 \\
\hline 7 & Falcon Shoals & $8 / 8 / 97,12 \mathrm{pm}$ & High & 28.0 & 28.5 & 29.5 & 30.0 & 30.5 & 30.5 & 31.0 & 31.0 & 31.0 & 31.5 & 31.75 \\
\hline & & & & 32.0 & 32.0 & 32.5 & 33.0 & 33.5 & 33.5 & 34.0 & 34.0 & 34.5 & 34.5 & \\
\hline & & $10 / 8 / 97,4 \mathrm{pm}$ & Low & 28.0 & 29.0 & 29.0 & 29.5 & 30.5 & 30.5 & 31.0 & 31.0 & 31.0 & 31.5 & 31.88 \\
\hline & & & & 32.0 & 32.5 & 33.0 & 33.5 & 34.0 & 34.0 & 34.0 & 34.5 & 34.5 & 34.5 & \\
\hline 8 & Zone 8 & $8 / 8 / 97,2 \mathrm{pm}$ & High & 29.0 & 30.5 & 30.5 & 31.0 & 31.5 & 31.5 & 31.5 & 32.0 & 32.0 & 32.5 & 32.40 \\
\hline & & & & 33.0 & 33.0 & 33.0 & 33.5 & 33.5 & 33.5 & 33.5 & 34.0 & 34.5 & 34.5 & \\
\hline & & $10 / 8 / 97,5 \mathrm{pm}$ & Low & 30.0 & 30.5 & 31.0 & 31.0 & 31.5 & 31.5 & 32.0 & 32.0 & 32.5 & 32.5 & \begin{tabular}{|l|}
32.68 \\
\end{tabular} \\
\hline & & & & 33.0 & 33.0 & 33.5 & 34.0 & 34.0 & 34.0 & 34.0 & 34.5 & 34.5 & 34.5 & \\
\hline 9 & Evans Bay 1 & $1 / 10 / 97,10 \mathrm{am}$ & Low & 33.5 & 33.5 & 34.0 & 34.0 & 34.0 & 34.5 & 34.5 & 34.5 & 34.5 & 34.5 & 34.15 \\
\hline 10 & Evans Bay 2 & $1 / 10 / 97,11 \mathrm{am}$ & Low & 34.0 & 34.0 & 34.0 & 34.0 & 34.5 & 34.5 & 34.5 & 34.5 & 34.5 & 34.5 & 34.30 \\
\hline 11 & Pt Halswell & $1 / 10 / 97,1 \mathrm{pm}$ & Mid & 33.5 & 34.0 & 34.0 & 34.0 & 34.5 & 34.5 & 34.5 & 34.5 & 34.5 & 34.5 & 34.25 \\
\hline 12 & Kau Pt & $1 / 10 / 97,4 \mathrm{pm}$ & High & 33.0 & 33.5 & 33.5 & 34.0 & 34.0 & 34.0 & 34.0 & 34.0 & 34.5 & 34.5 & 33.90 \\
\hline 13 & Pt Gordon & $1 / 10 / 97,5 \mathrm{pm}$ & High & 33.0 & 33.5 & 33.5 & 33.5 & 34.0 & 34.0 & 34.5 & 34.5 & 34.5 & 34.5 & 33.95 \\
\hline
\end{tabular}

${ }^{\star}$ PSU stands for Practical Salinity Units (normal seawater $=34.5$ PSU; fresh water $=0$ PSU) 


\section{Appendix Four}

\section{PSim routines used to correct the Bathymetric data to lowest astronomical sea level (to correlate with Hydrographic Chart NZ4633)}

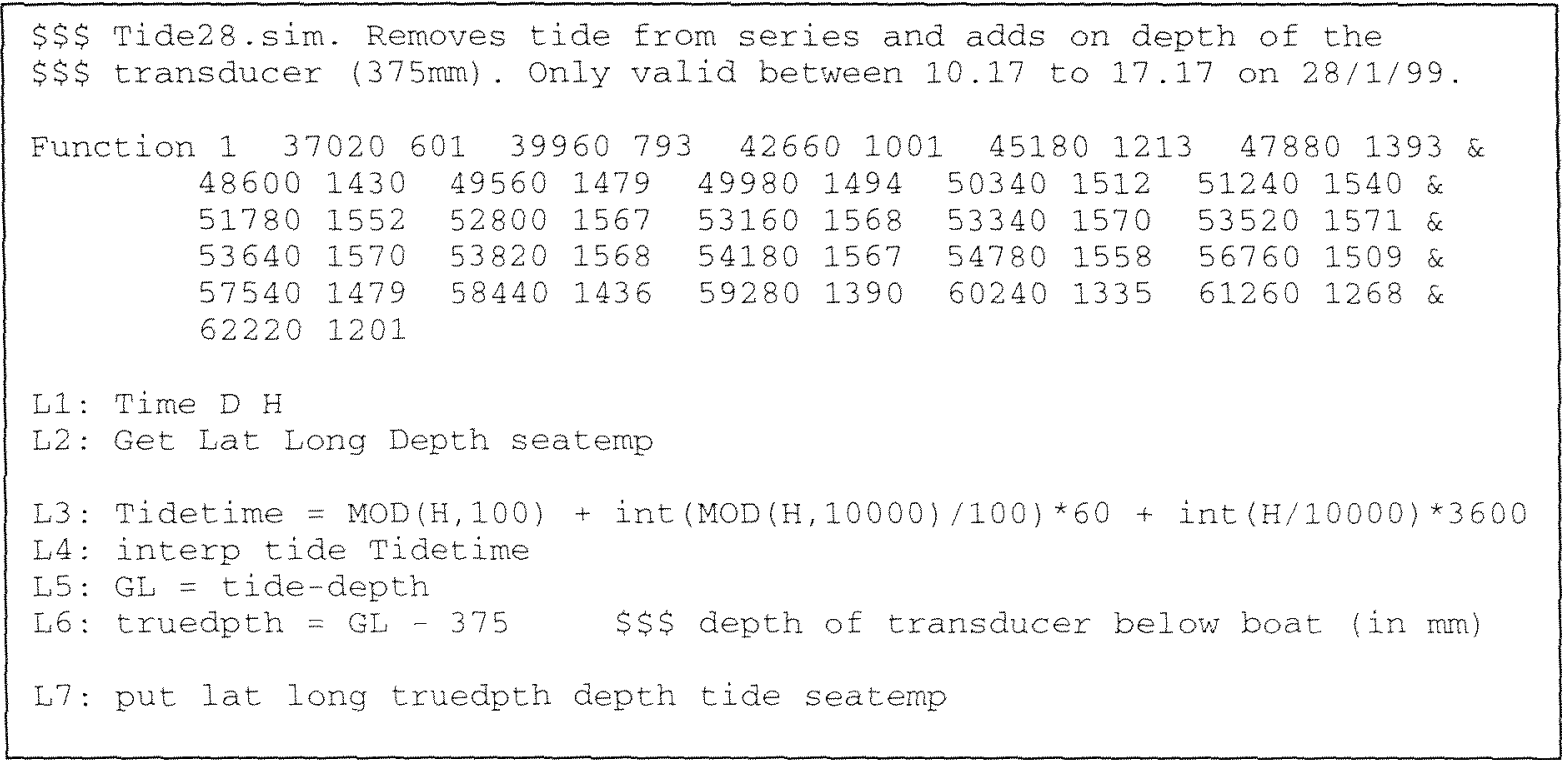

Line 1: Assigns Date and Time to $D$ and $H$ respectively

Line 2: Assigns 'Lat' to the first item, 'Long' to the second item etc

Line 3: Reduces the time to seconds ( 86400 seconds in a day; midnight $=0$ ) using the equation described in Line 3 (see general maths text, or Excel Help, for explanation of MOD and INT functions) and calls it 'Tidetime'

Line 4: Takes the time (Tidetime, in seconds) and uses Function 1 to interpolate what the tide level would have been at that particular time. The values obtained in the function were read off tide tables for the particular day and assigning the correct heights above the Lowest Astronomical Tide (i.e. Chart Datum). Tide heights are interpolated between these values using a straight-line function. This introduces a slight error as tides are typically sinusoidal in nature. However, this error was reduced to a minimum by incorporating many values into the function, particularly at the areas of greatest change of slope with time i.e. around the slack waters of high and low tide.

Line 5: GL equals the difference in the height of water above the Lowest Astronomical Tide (Tide) and the depth recorded by the echosounder (Depth). Thus, GL will be a negative number (depth below Lowest Astronomical Tide).

Line 6: Truedpth equals GL, as calculated above, minus the depth of the echosounder transducer below the water $(375 \mathrm{~mm})$. As the depth of the water must be incorporated into the truedpth, subtracting it from the negative GL is correct.

Line 7: The data is then written to a new file (as specified before running the Psim). This new file will have six items, with truedpth and tide being the only newly created data.

NB. Before using this Psim, the data was first corrected from satellite positioning to Hydrographic Chart NZ4633 positioning by subtracting 0.16666 decimal degrees $(0.1$ minutes) from all latitude values. This was done in Excel as TIDEDA only recognises integers. This altered data was then listed to a TIDEDA file following the TList process as described on page 48 of the TIDEDA reference manual (Rodgers and Thompson, 1992). The Psim was then run on this newly created Tideda file. 


\section{Appendix Five}

Bathymetric survey data plots (Recorded 28/1/99, 30/1/99 and 5/3/99 using Kiwitech Chartplotter programme) 


\section{Appendix Five (1)}

Bathymetry of Zone 1 showing the locations of the data on which the contours were compiled. The data was collected in January 1999 using the Kiwitech programme Chartplotter.

(This image was created in the programme 'Surfer')

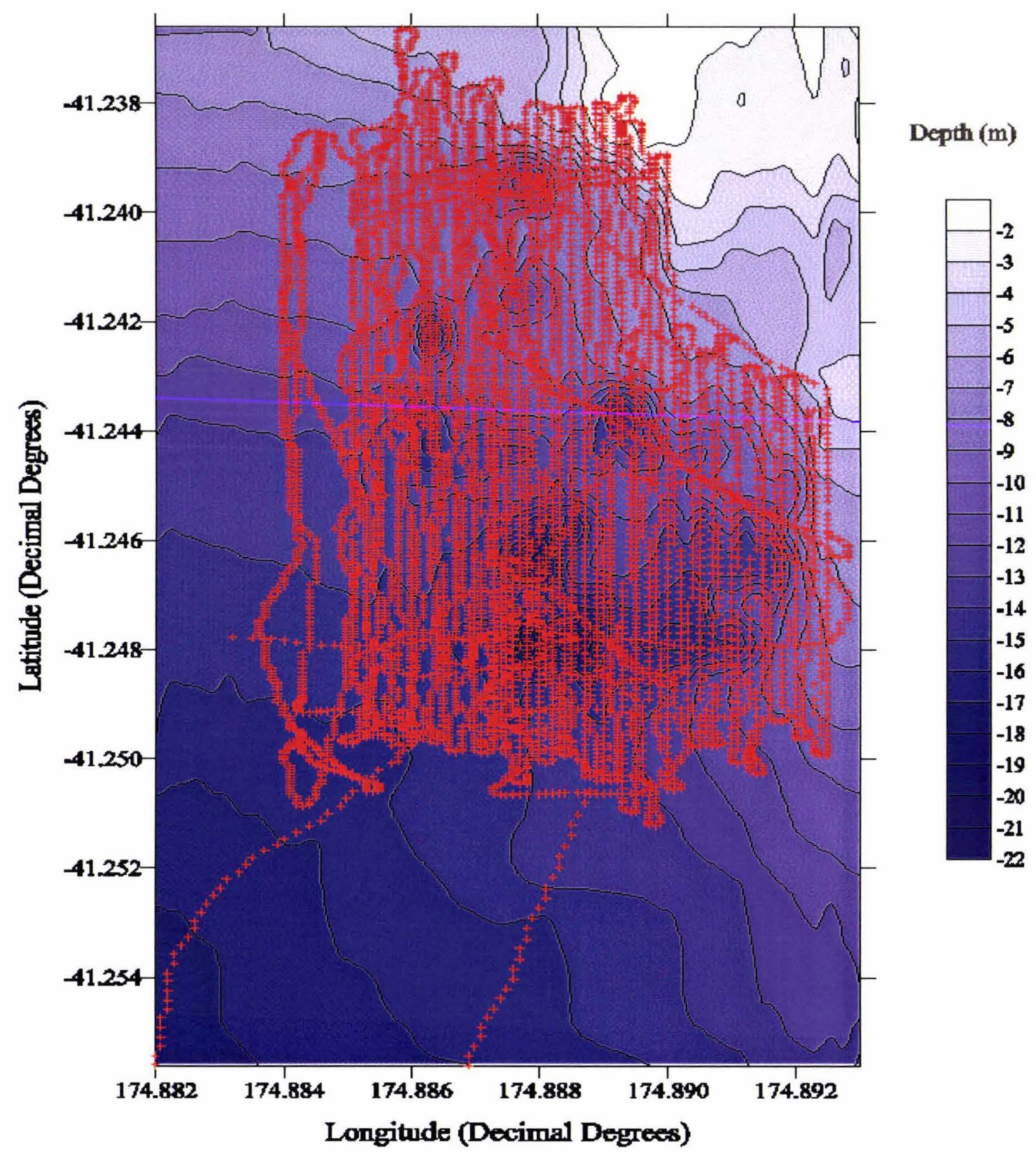




\section{Appendix Five (2)}

Bathymetry of Zone 2 showing the locations of the data on which the contours were compiled. The data was collected in January 1999 using the Kiwitech programme Chartplotter.

(This image was created in the programme 'Surfer')

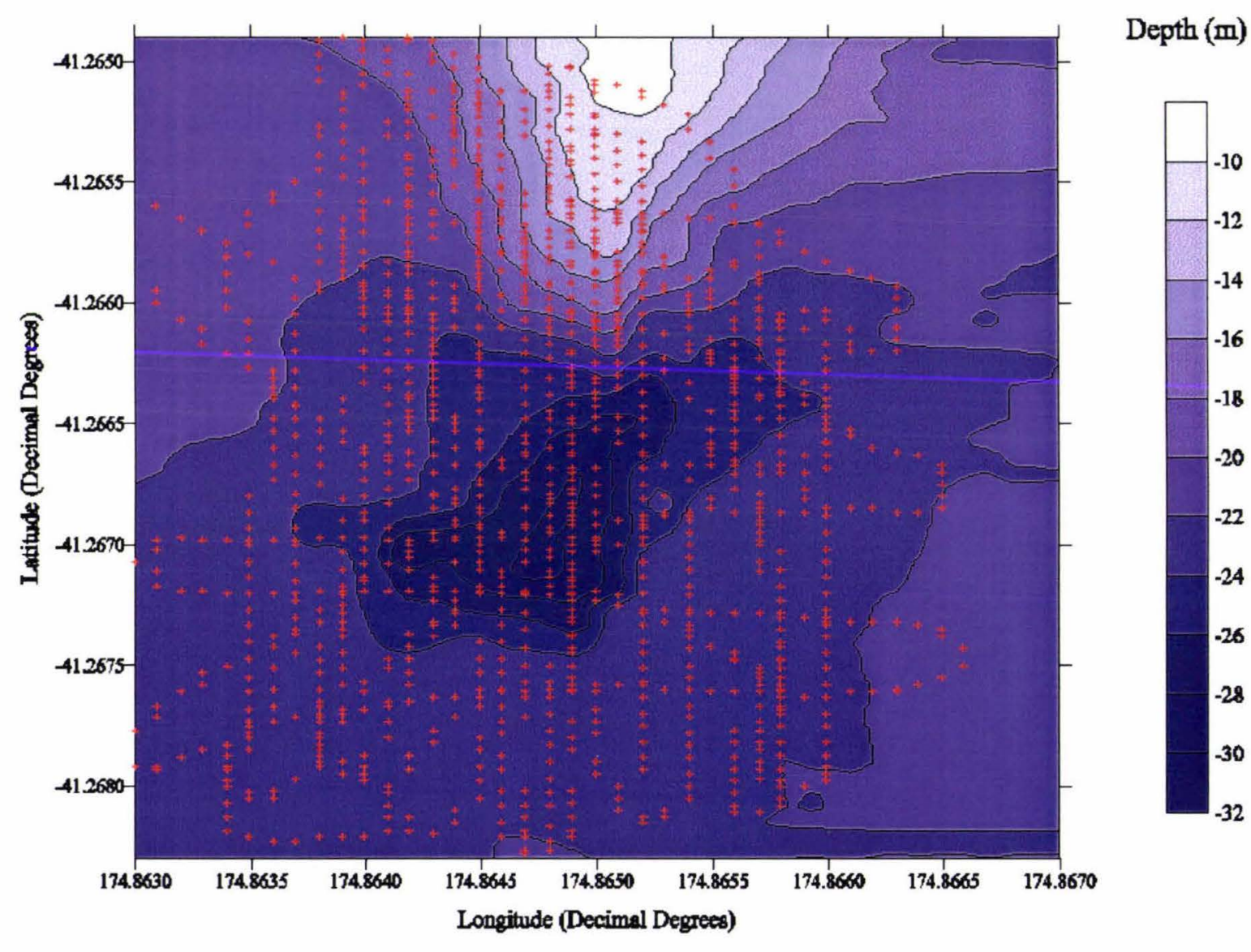




\section{Appendix Five (3)}

Bathymetry of Zone 3 showing the locations of the data on which the contours were compiled. The data was collected in January 1999 using the Kiwitech programme Chartplotter.

(This image was created in the programme 'Surfer')

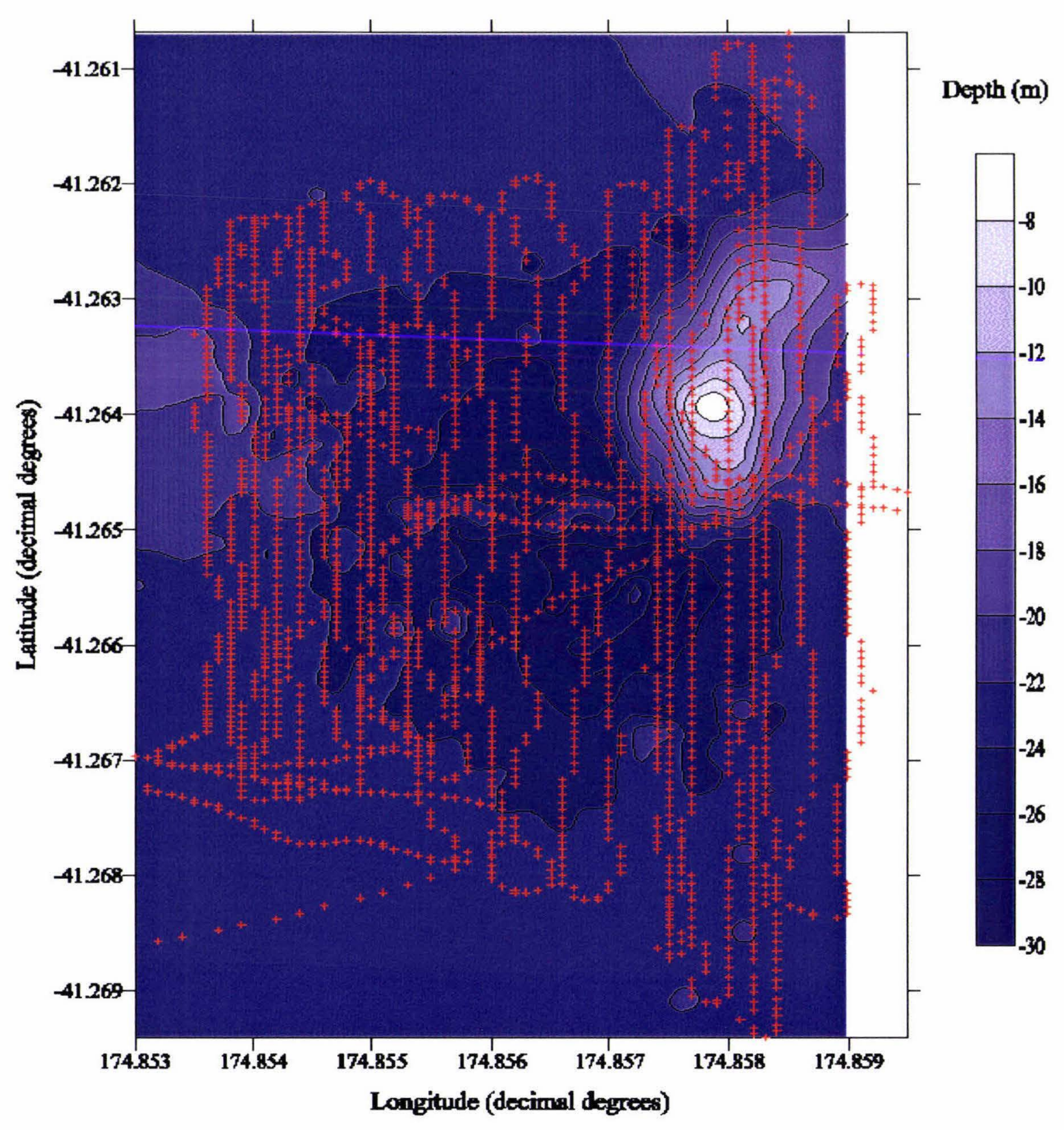




\section{Appendix Five (4)}

Bathymetry of Zone 4 showing the locations of the data on which the contours were compiled. The data was collected in March 1999 using the Kiwitech programme Chartplotter.

(This image was created in the programme 'Surfer')

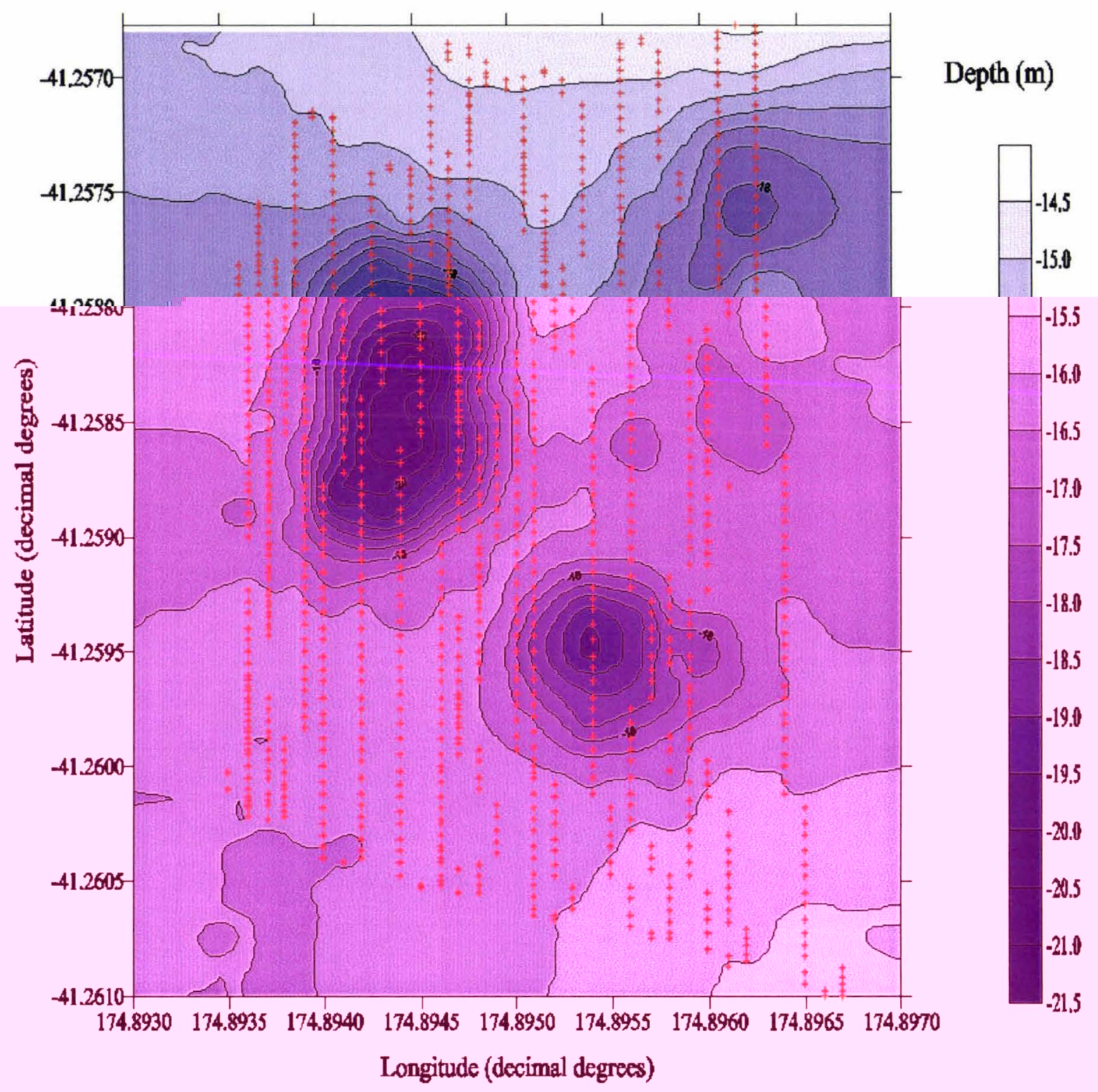




\section{Appendix Five (5)}

Bathymetry of Zone 5 showing the locations of the data on which the contours were compiled. The data was collected in January 1999 using the Kiwitech programme Chartplotter.

(This image was created in the programme 'Surfer')

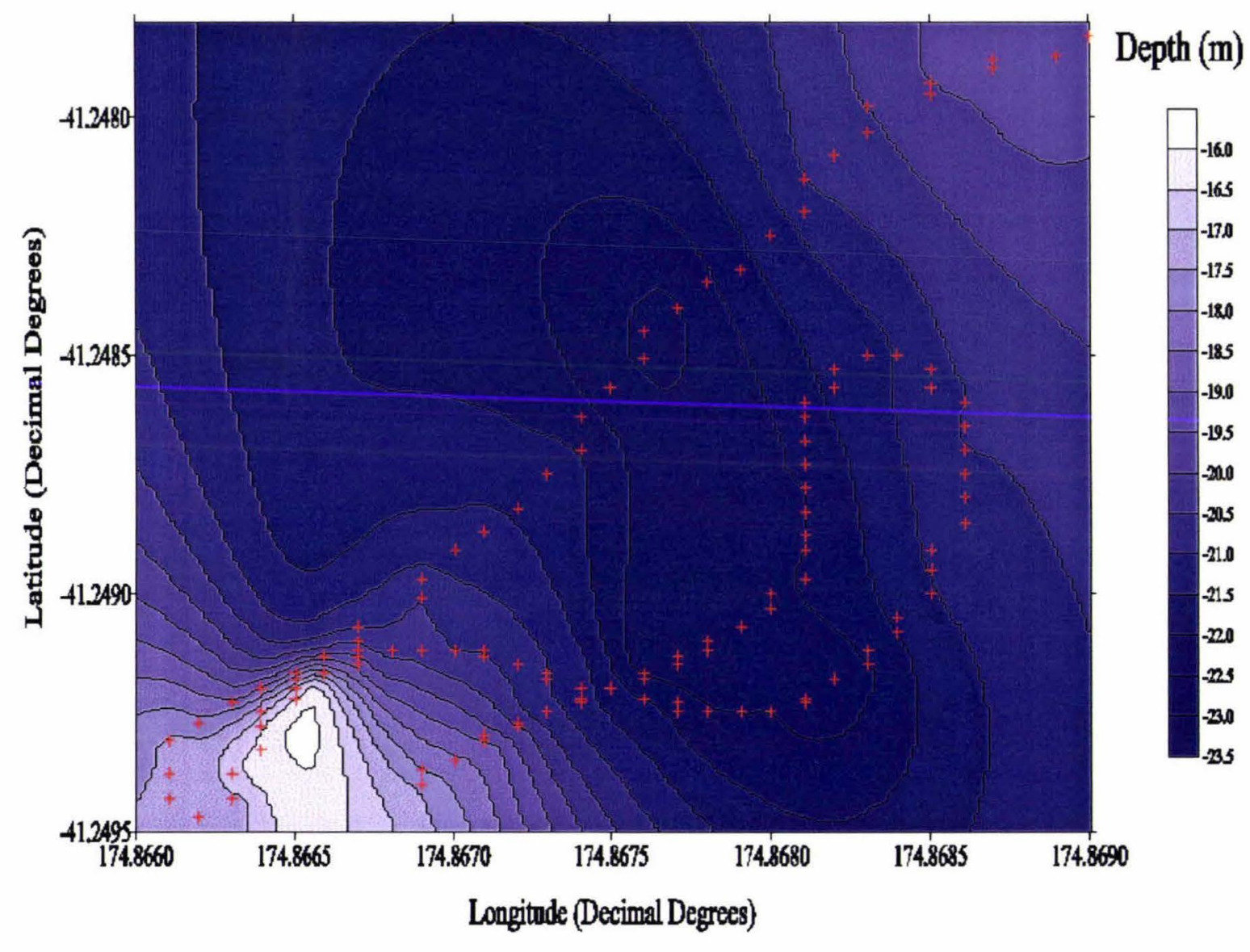




\section{Appendix Five (6)}

Bathymetry of Zone 6 showing the locations of the data on which the contours were compiled. The data was collected in January 1999 using the Kiwitech programme Chartplotter.

(This image was created in the programme 'Surfer')

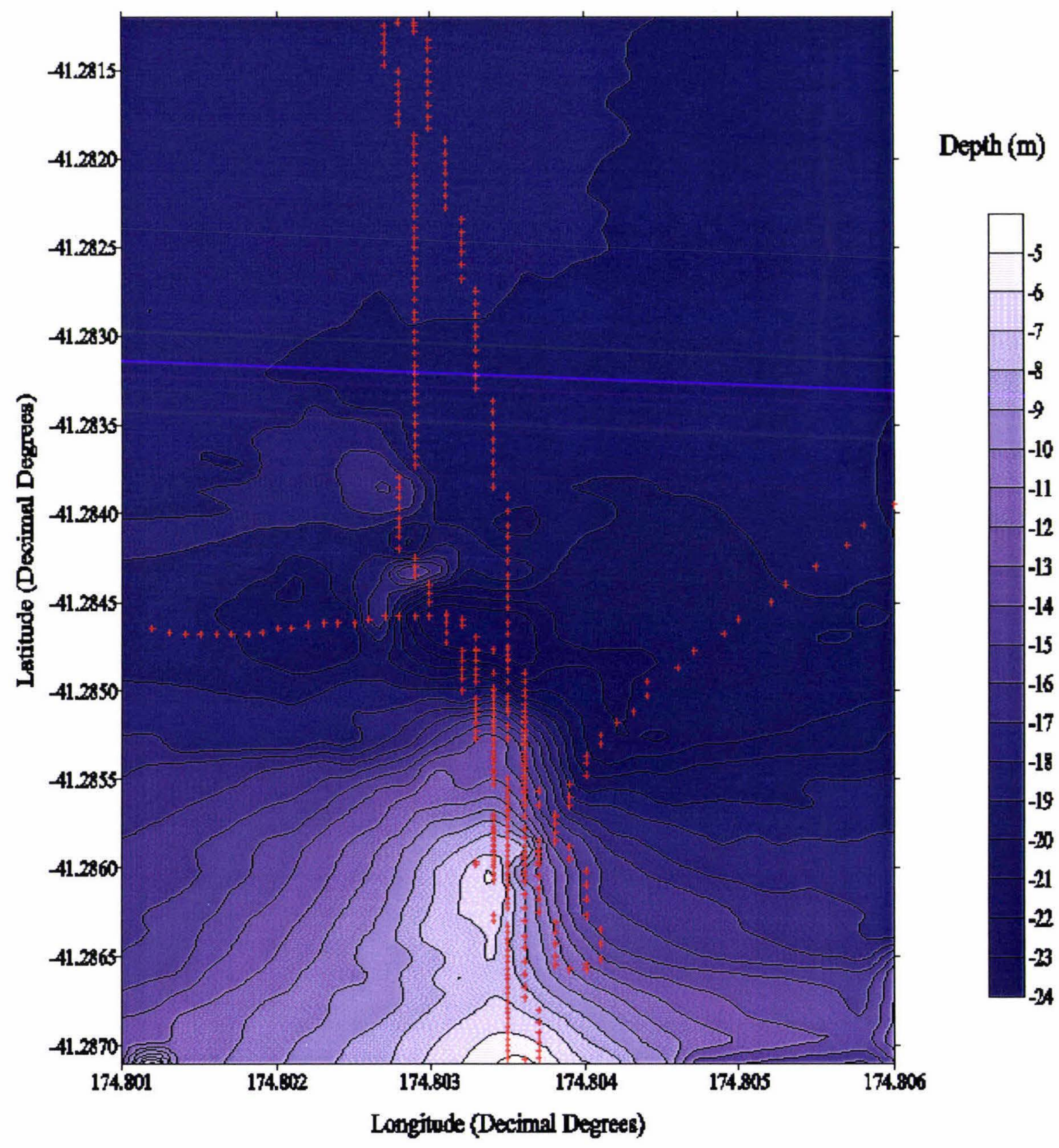


Appendix Six

Pump Test Data 


\begin{tabular}{|c|c|c|c|c|c|c|}
\hline \multicolumn{7}{|c|}{ Pumptest Data from pump tests conducted on the Waiwhetu Aquifer (after WRC, 1995) } \\
\hline Pump Test & Year & Site & $\begin{array}{c}\text { Distance to Pumping } \\
\text { Locus (m) }\end{array}$ & \begin{tabular}{|c|} 
Well \\
Depth $(m)$ \\
\end{tabular} & $\begin{array}{c}\text { Mean Transmissivity } \\
\left(\mathrm{m}^{2} / \text { day }\right)\end{array}$ & $\begin{array}{c}\text { Mean } \\
\text { Storativity }\end{array}$ \\
\hline \multirow{3}{*}{ Wellington Meat Export Company } & 1933 & WMEC & NA & NA & 1.444 & NA \\
\hline & & WMEC & NA & NA & 217 & NA \\
\hline & & WMEC & NA & NA & 1,237 & NA \\
\hline & & & & & & \\
\hline \multirow[t]{9}{*}{ Gear Island } & 1957 & Gear Island & NA & NA & 25,229 & NA \\
\hline & & Gear Meat Co & NA & NA & 24,883 & NA \\
\hline & & Buick St & NA & NA & NA & NA \\
\hline & & Hutt Park & NA & NA & 27,302 & NA \\
\hline & & Nelson St & NA & NA & NA & NA \\
\hline & & Seaview 4" & NA & NA & NA & NA \\
\hline & & Seaview 8" & NA & NA & 20,736 & NA \\
\hline & & \begin{tabular}{|l|} 
Petone Tech. \\
\end{tabular} & NA & NA & NA & NA \\
\hline & & Waione St & NA & NA & NA & NA \\
\hline \multirow[t]{9}{*}{ Gear Island } & 1967 & Gear Island & NA & NA & 22,810 & NA \\
\hline & & Gear Meat Co & NA & NA & 36,461 & NA \\
\hline & & Buick St & NA & NA & 9,504 & NA \\
\hline & & Hutt Park & NA & NA & 13,824 & NA \\
\hline & & Nelson St & NA & NA & 13,824 & NA \\
\hline & & Seaview 4" & NA & NA & 17,971 & NA \\
\hline & & Seaview 8" & NA & NA & 18,835 & NA \\
\hline & & Petone Tech. & NA & NA & 17,971 & NA \\
\hline & & Waione St & NA & NA & 20,995 & NA \\
\hline & & & & & & \\
\hline \multirow[t]{4}{*}{ Hutt Park } & 1974 & Pumped Bore & $\overline{N A}$ & $\overline{N A}$ & 1,296 & NA \\
\hline & & Bore 1 & NA & NA & 17,280 & $3.5 \times 10^{-2}$ \\
\hline & & Bore 2 & NA & NA & 18,144 & $7.8 \times 10^{-3}$ \\
\hline & & & & & & \\
\hline
\end{tabular}




\begin{tabular}{|c|c|c|c|c|c|c|}
\hline \multicolumn{7}{|c|}{ Pumptest Data from pump tests conducted on the Waiwhetu Aquifer (after WRC, 1995) } \\
\hline Pump Test & Year & Site & $\begin{array}{c}\text { Distance to Pumping } \\
\text { Locus (m) }\end{array}$ & $\begin{array}{c}\text { Well } \\
\text { Depth }(m)\end{array}$ & $\begin{array}{c}\text { Mean Transmissivity } \\
\left(\mathrm{m}^{2} / \mathrm{day}\right)\end{array}$ & $\begin{array}{c}\text { Mean } \\
\text { Storativity }\end{array}$ \\
\hline \multirow[t]{17}{*}{ Gear Island } & 1991 & Tennyson St & 453 & NA & 25,700 & $8.5 \times 10^{-4}$ \\
\hline & & Shandon Golf Club Bore & 185.5 & NA & 28,300 & $1.4 \times 10^{-4}$ \\
\hline & & Hutt Park & 987 & NA & 14,800 & $1.0 \times 10^{-3}$ \\
\hline & & IBM Well 2 & 1766 & NA & 14,600 & $7.6 \times 10^{-4}$ \\
\hline & & Wellington Newspapers & 1291 & NA & 13,500 & $8.0 \times 10^{-4}$ \\
\hline & & Gear Island Artesian & 550 & NA & 23,200 & $9.2 \times 10^{-4}$ \\
\hline & & Ajax Factory & 1534 & NA & 19,700 & $4.1 \times 10^{-4}$ \\
\hline & & Shandon Golf Observation & 16.9 & NA & 20,400 & $3.0 \times 10^{-2}$ \\
\hline & & Randwick & 1122 & 51.8 & 19,800 & $3.8 \times 10^{-4}$ \\
\hline & & McEwan Park & 586 & 29.6 & 20,350 & $1.5 \times 10^{-3}$ \\
\hline & & PCM & 1159 & 24.4 & 16,000 & $1.2 \times 10^{-3}$ \\
\hline & & Bell Park & 1689 & 23.5 & 10,900 & $9.1 \times 10^{-4}$ \\
\hline & & Hutt Recreation Ground & 1805 & 33.8 & 20,600 & $3.0 \times 10^{-4}$ \\
\hline & & HVMTC & 798 & 23.2 & 19,500 & $1.3 \times 10^{-3}$ \\
\hline & & Port Road & 1159 & 33.5 & 17,200 & $1.0 \times 10^{-3}$ \\
\hline & & Port Road & 1159 & 33.5 & 15,900 & $1.1 \times 10^{-3}$ \\
\hline & & Somes Island Artesian & 3705 & 26.2 & 33,700 & $2.3 \times 10^{-4}$ \\
\hline \multirow[t]{8}{*}{ Waterloo } & 1993 & Bloomfield Terrace & 580 & 39.8 & 32,360 & $3.5 \times 10^{-4}$ \\
\hline & & Colin Grove & 420 & 38.9 & 33,140 & $5.4 \times 10^{-4}$ \\
\hline & & Hautana Street & 280 & 39.4 & 34,240 & $8.5 \times 10^{-4}$ \\
\hline & & Penrose Street & 200 & 39.0 & 35,280 & $1.7 \times 10^{-3}$ \\
\hline & & Willoughby Street & 180 & 39.1 & 36,060 & $2.0 \times 10^{-3}$ \\
\hline & & Mahoe Street & 320 & 38.0 & 36,600 & $8.6 \times 10^{-4}$ \\
\hline & & Willoughby Street (new) & 90 & 39.0 & 36,000 & NA \\
\hline & & Pentose Street (new) & 90 & 39.0 & 35,975 & NA \\
\hline Waterloo cont & 1993 & Birch Lane & 720 & 33.8 & 69,450 & $3.3 \times 10^{-2}$ \\
\hline
\end{tabular}


Appendix Seven

Probability Distributions for the Hutt River Flow and PCM and McEwan Park Groundwater Observation Wells 


\section{Hutt River at Taita Gorge (site 29809)}

\section{(over period $16 / 3 / 79$ to $18 / 8 / 99$ )}

\begin{tabular}{|l|c|c|c|c|c|c|c|c|c|c|}
\hline $\begin{array}{l}\text { Percent } \\
\text { Greater }\end{array}$ & $\mathbf{0}$ & $\mathbf{1}$ & $\mathbf{2}$ & $\mathbf{3}$ & $\mathbf{4}$ & $\mathbf{5}$ & $\mathbf{6}$ & $\mathbf{7}$ & $\mathbf{8}$ & $\mathbf{9}$ \\
\hline $\mathbf{0}$ & 1540.2 & 190.0 & 133.1 & $\mathbf{1 0 5 . 2}$ & 87.0 & 75.7 & 67.0 & 60.3 & 55.1 & 51.0 \\
\hline $\mathbf{1 0}$ & 47.7 & 44.8 & 42.4 & 40.3 & 38.4 & 36.6 & 35.0 & 33.6 & 32.3 & 31.2 \\
\hline $\mathbf{2 0}$ & 30.2 & 29.3 & 28.4 & 27.6 & 26.9 & 26.2 & 25.5 & 24.8 & 24.2 & 23.6 \\
\hline $\mathbf{3 0}$ & 23.1 & 22.5 & 220 & 21.5 & 21.0 & 20.5 & 20.0 & 19.6 & 19.1 & 18.7 \\
\hline $\mathbf{4 0}$ & 18.2 & 17.8 & 17.4 & 17.1 & 16.7 & 16.4 & 16.0 & 15.7 & 15.4 & 15.1 \\
\hline 50 & 14.8 & 14.5 & 14.2 & 13.9 & 13.6 & 13.4 & 13.1 & 12.8 & 12.5 & 12.3 \\
\hline 60 & 12.0 & 11.7 & 11.5 & 11.3 & 11.0 & 10.8 & 10.6 & 10.4 & 10.2 & 10.0 \\
\hline 70 & 9.7 & 9.5 & 9.3 & 9.1 & 8.9 & 8.7 & 8.5 & 8.3 & 8.1 & 7.9 \\
\hline 80 & 7.6 & 7.4 & 7.2 & 7.0 & 6.7 & 6.5 & 6.3 & 6.1 & 5.9 & 5.6 \\
\hline 90 & 5.4 & 5.2 & 5.0 & 4.7 & 4.5 & 4.1 & 3.8 & 3.4 & 3.0 & 2.5 \\
\hline $\mathbf{1 0 0}$ & 1.6 & & & & & & & & & \\
\hline
\end{tabular}

How to read this table The onlues in the left column and the top row are added together to give the excedance percentile for the flow in the intersecting cell e.g. for $33 \%$ of the time the flow is greater than $21.5 \mathrm{~m} / \mathrm{s}$.

NB. Mean $=25^{3} \mathrm{~m} 3 / \mathrm{s}$

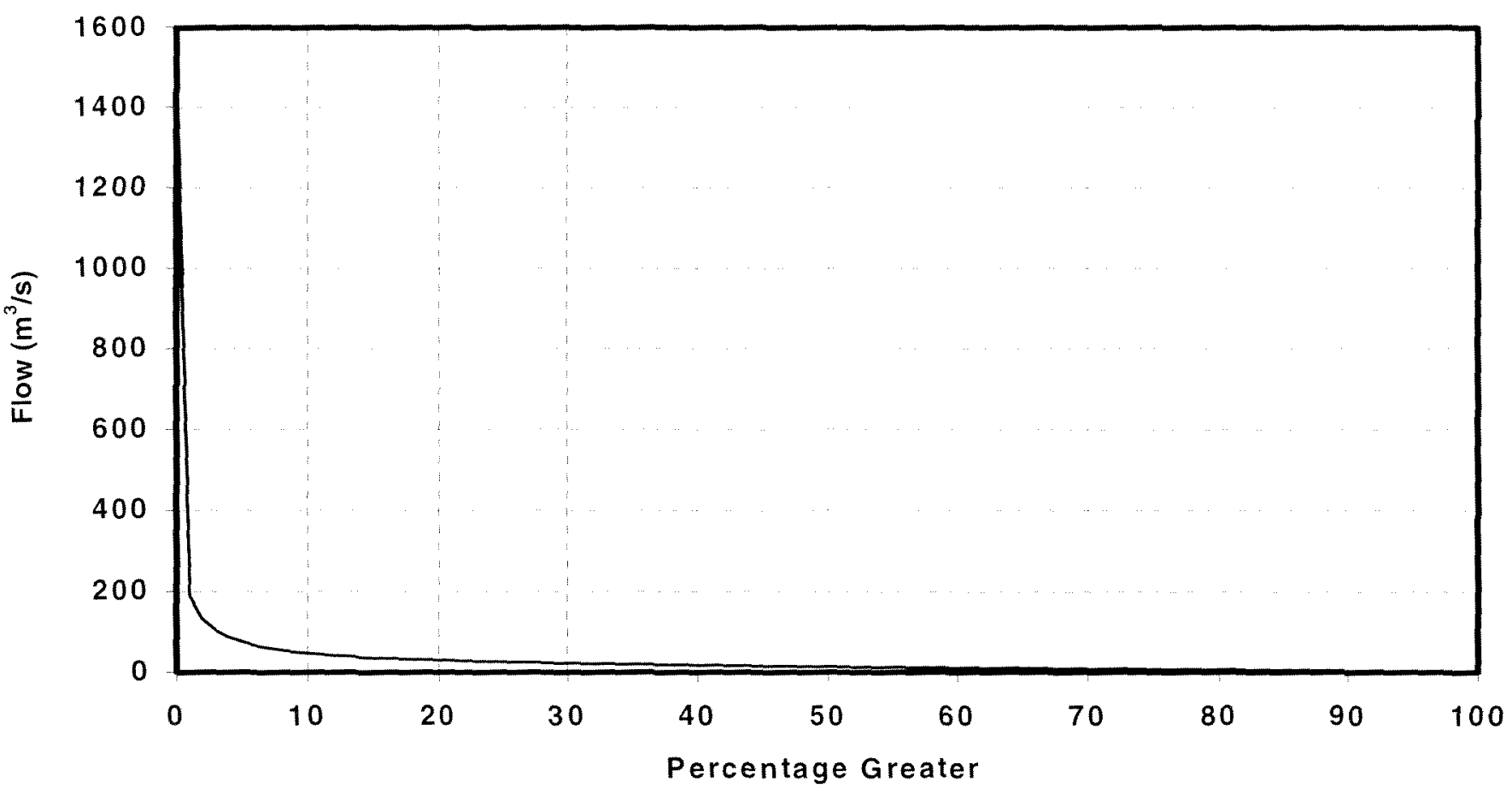




\section{Waiwhetu Artesian Aquifer at McEwan Park}

(site 1428009)

\section{(over period $3 / 3 / 71$ to $9 / 9 / 98$ )}

\begin{tabular}{|l|c|c|c|c|c|c|c|c|c|c|}
\hline $\begin{array}{l}\text { Percent } \\
\text { Greater }\end{array}$ & $\mathbf{0}$ & $\mathbf{1}$ & $\mathbf{2}$ & $\mathbf{3}$ & $\mathbf{4}$ & $\mathbf{5}$ & $\mathbf{6}$ & $\mathbf{7}$ & $\mathbf{8}$ & $\mathbf{9}$ \\
\hline $\mathbf{0}$ & 4941 & 4552 & 4482 & $\mathbf{4 4 3 4}$ & 4395 & 4362 & 4333 & 4307 & 4283 & 4260 \\
\hline $\mathbf{1 0}$ & 4239 & 4219 & 4199 & 4181 & 4163 & 4146 & 4129 & 4112 & 4096 & 4081 \\
\hline $\mathbf{2 0}$ & 4065 & 4049 & 4034 & 4019 & 4004 & 3989 & 3974 & 3959 & 3945 & 3930 \\
\hline $\mathbf{3 0}$ & 3916 & 3901 & 3887 & 3872 & 3857 & 3842 & 3826 & 3811 & 3795 & 3779 \\
\hline $\mathbf{4 0}$ & 3763 & 3747 & 3730 & 3714 & 3697 & 3680 & 3662 & 3644 & 3626 & 3607 \\
\hline 50 & 3589 & 3570 & 3551 & 3532 & 3513 & 3494 & 3474 & 3455 & 3435 & 3415 \\
\hline $\mathbf{6 0}$ & 3396 & 3376 & 3356 & 3336 & 3315 & 3295 & 3274 & 3253 & 3232 & 3211 \\
\hline $\mathbf{7 0}$ & 3189 & 3168 & 3145 & 3123 & 3100 & 3078 & 3055 & 3031 & 3006 & 2982 \\
\hline 80 & 2957 & 2930 & 2904 & 2876 & 2846 & 2817 & 2787 & 2756 & 2724 & 2690 \\
\hline 90 & 2653 & 2613 & 2572 & 2526 & 2474 & 2414 & 2344 & 2259 & 2148 & 1978 \\
\hline $\mathbf{1 0 0}$ & 1187 & & & & & & & & & \\
\hline
\end{tabular}

How to read this table The values in the left column and the top row are added together to give the excedance percentile for the flow in the intersecting cell e.g. for $33 \%$ of the time the piezometric head level is greater than $3872 \mathrm{mmas}$.
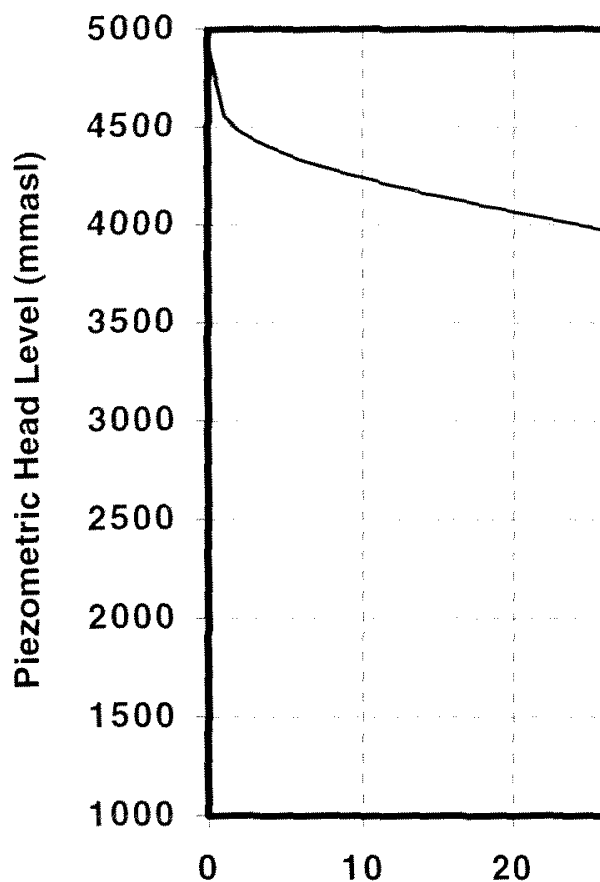


\section{Waiwhetu Artesian Aquifer at McEwan Park}

(site 1428009)

\section{(over period $1 / 1 / 82$ to $9 / 9 / 98$ )}

\begin{tabular}{|l|c|c|c|c|c|c|c|c|c|c|}
\hline $\begin{array}{l}\text { Percent } \\
\text { Greater }\end{array}$ & $\mathbf{0}$ & $\mathbf{1}$ & $\mathbf{2}$ & $\mathbf{3}$ & $\mathbf{4}$ & $\mathbf{5}$ & $\mathbf{6}$ & $\mathbf{7}$ & $\mathbf{8}$ & $\mathbf{9}$ \\
\hline $\mathbf{0}$ & 4941 & 4595 & 4532 & 4491 & 4458 & 4430 & 4405 & 4383 & 4363 & 4344 \\
\hline $\mathbf{1 0}$ & 4326 & 4310 & 4294 & 4279 & 4265 & 4251 & 4237 & 4224 & 4212 & 4199 \\
\hline $\mathbf{2 0}$ & 4187 & 4175 & 4163 & 4152 & 4140 & 4129 & 4118 & 4108 & 4097 & 4086 \\
\hline $\mathbf{3 0}$ & 4076 & 4065 & 4054 & 4044 & 4034 & 4023 & 4013 & 4003 & 3992 & 3982 \\
\hline 40 & 3972 & 3962 & 3952 & 3941 & 3931 & 3921 & 3911 & 3901 & 3890 & 3880 \\
\hline 50 & 3869 & 3858 & 3847 & 3836 & 3825 & 3813 & 3801 & 3790 & 3778 & 3765 \\
\hline 60 & 3753 & 3740 & 3727 & 3713 & 3700 & 3685 & 3671 & 3655 & 3640 & 3624 \\
\hline 70 & 3608 & 3591 & 3573 & 3556 & 3537 & 3518 & 3499 & 3478 & 3457 & 3436 \\
\hline 80 & 3414 & 3391 & 3368 & 3344 & 3318 & 3292 & 3264 & 3235 & 3204 & 3171 \\
\hline 90 & 3136 & 3099 & 3059 & 3016 & 2968 & 2914 & 2850 & 2775 & 2688 & 2559 \\
\hline 100 & 2063 & & & & & & & & & \\
\hline
\end{tabular}

How to read this table The values in the left column and the top row are added together to give the exceedance percentile for the flow in the intersecting cell e.g. for $33 \%$ of the time the piezometric head level is greater than $4044 \mathrm{mmasi}$.

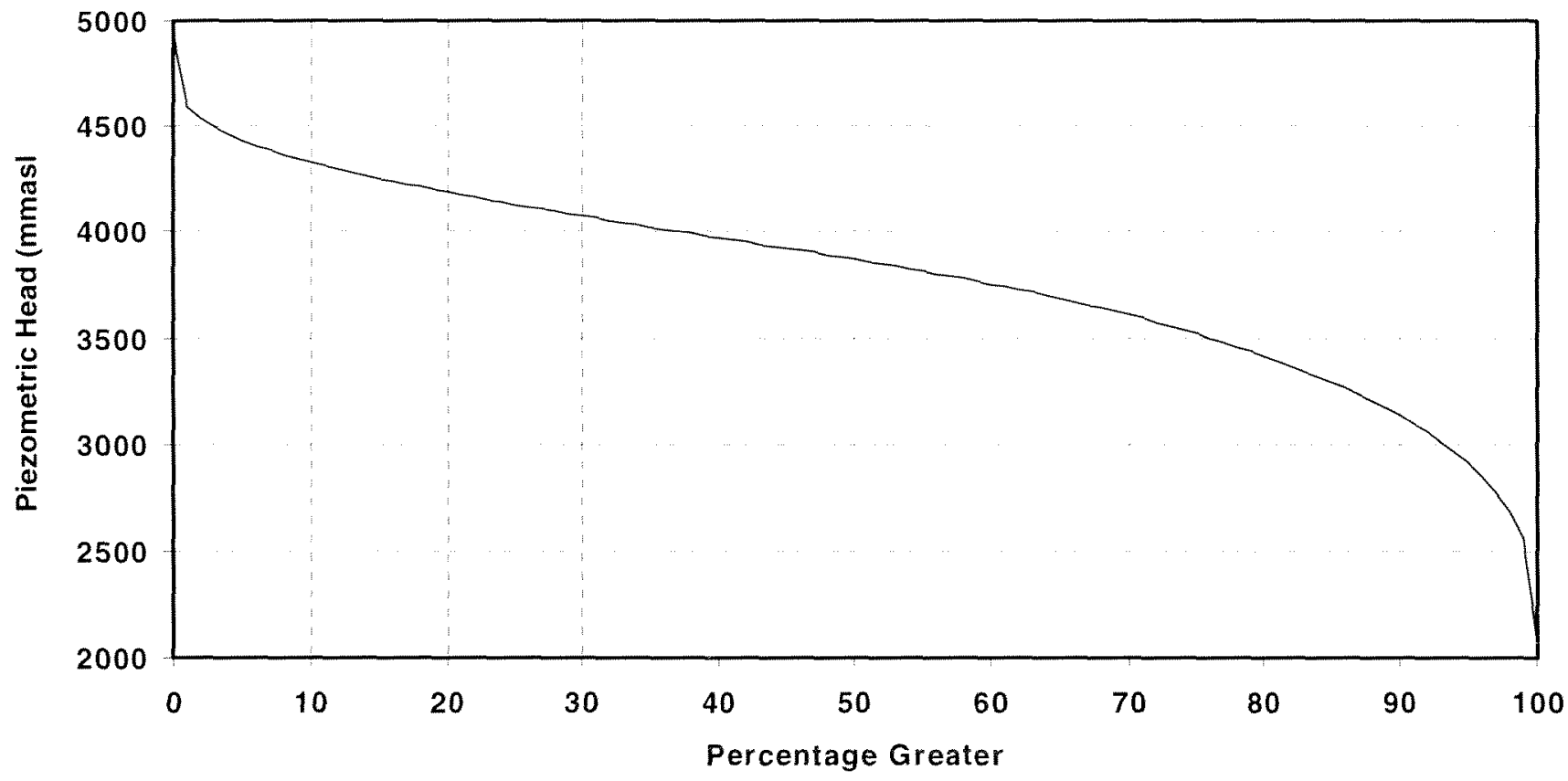




\section{Waiwhetu Artesian Aquifer at Petone Centenial Memorial (site 1428001)}

(over period $24 / 9 / 69$ to $29 / 5 / 96$ )

\begin{tabular}{|l|c|c|c|c|c|c|c|c|c|c|}
\hline $\begin{array}{l}\text { Percent } \\
\text { Greater }\end{array}$ & $\mathbf{0}$ & $\mathbf{1}$ & $\mathbf{2}$ & $\mathbf{3}$ & $\mathbf{4}$ & $\mathbf{5}$ & $\mathbf{6}$ & $\mathbf{7}$ & $\mathbf{8}$ & $\mathbf{9}$ \\
\hline $\mathbf{0}$ & 4950 & 4514 & 4442 & 4392 & 4352 & 4319 & 4289 & 4262 & 4237 & 4214 \\
\hline $\mathbf{1 0}$ & 4193 & 4172 & 4151 & 4131 & 4112 & 4093 & 4075 & 4057 & 4039 & 4022 \\
\hline $\mathbf{2 0}$ & 4005 & 3988 & 3972 & 3955 & 3939 & 3922 & 3905 & 3889 & 3872 & 3855 \\
\hline $\mathbf{3 0}$ & 3838 & 3821 & 3803 & 3786 & 3767 & 3749 & 3730 & 3710 & 3690 & 3670 \\
\hline $\mathbf{4 0}$ & 3649 & 3627 & 3605 & 3582 & 3559 & 3536 & 3513 & 3488 & 3463 & 3438 \\
\hline $\mathbf{5 0}$ & 3412 & 3387 & 3361 & 3335 & 3309 & 3284 & 3258 & 3232 & 3207 & 3182 \\
\hline $\mathbf{6 0}$ & 3157 & 3131 & 3106 & 3081 & 3057 & 3032 & 3007 & 2982 & 2957 & 2932 \\
\hline $\mathbf{7 0}$ & 2906 & 2881 & 2856 & 2830 & 2805 & 2779 & 2753 & 2727 & 2700 & 2673 \\
\hline $\mathbf{8 0}$ & 2646 & 2618 & 2590 & 2561 & 2532 & 2501 & 2469 & 2434 & 2398 & 2360 \\
\hline $\mathbf{9 0}$ & 2320 & 2278 & 2232 & 2181 & 2127 & 2064 & 1994 & 1911 & 1806 & 1642 \\
\hline $\mathbf{1 0 0}$ & 926 & & & & & & & & & \\
\hline
\end{tabular}

How to read this table The values in the left column and the top row are added together to give the exceedance percentile for the flow in the intersecting cell e.g. for $33 \%$ of the time the piezometric head level is greater than 3786 mmasl.

5000

1000

0

10

20

30

40

50

60

70

80

$90 \quad 100$

Percentage Greater 